University of Louisville

ThinkIR: The University of Louisville's Institutional Repository

Electronic Theses and Dissertations

$5-2012$

\title{
Cationic aminooxy lipids : synthesis, liposome stabilization and applications.
}

Xuan Huang

University of Louisville

Follow this and additional works at: https://ir.library.louisville.edu/etd

\section{Recommended Citation}

Huang, Xuan, "Cationic aminooxy lipids : synthesis, liposome stabilization and applications." (2012). Electronic Theses and Dissertations. Paper 646.

https://doi.org/10.18297/etd/646

This Doctoral Dissertation is brought to you for free and open access by ThinkIR: The University of Louisville's Institutional Repository. It has been accepted for inclusion in Electronic Theses and Dissertations by an authorized administrator of ThinkIR: The University of Louisville's Institutional Repository. This title appears here courtesy of the author, who has retained all other copyrights. For more information, please contact thinkir@louisville.edu. 


\title{
CATIONIC AMINOOXY LIPIDS: \\ SYNTHESIS, LIPOSOME STABILIZATION AND APPLICATIONS
}

\author{
By \\ Xuan Huang \\ A Dissertation \\ Submitted to the Faculty of the \\ College of Arts and Sciences of the University of Louisville \\ in Partial Fulfillment of the Requirements \\ for the Degree of \\ Doctor of Philosophy \\ Department of Chemistry \\ University of Louisville \\ Louisville, Kentucky
}

May 2012 


\title{
CATIONIC AMINOOXY LIPIDS: \\ SYNTHESIS, LIPOSOME STABILIZATION AND APPLICATIONS
}

\author{
By \\ Xuan Huang
}

A Dissertation Approved on

May 2012

by the following Dissertation Committee:

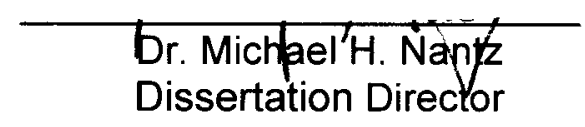

Dr. Christopher T. Burns

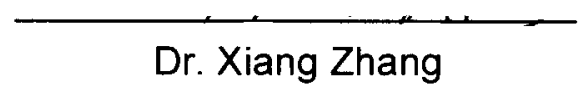

Dr. Geoffrey J. Clark 


\section{ACKNOWLEDGEMENTS}

I am always very grateful to Dr. Michael $\mathrm{H}$. Nantz for serving as my research advisor and supporting my research in the past six years.

I would also like to thank the following faculty members for reading this thesis and sitting on my defense committee: Dr. Christopher T. Burns, Dr. Geoffrey J. Clark, and Dr. Xiang Zhang. Many thanks to Dr. Neal Stolowich, Dr. Bill Richmond, Dr. Bogdan Bogdanov and Dr. Mark Mashuta who have been very helpful in solving problems on departmental facilities. I also need to give special thanks to Laura E. Gordon who prepared cells for my gene transfection experiments.

Also I feel fortunate to have been a member of the terrific group of highly dedicated scientists. I am grateful to the past and present group members of the Nantz lab over the years: Dr. Bhaskar Poola, Dr. Archna Massey, Dr. Souvik, Bisvas, Wesley R. Badger, Joseph D. Moore, Ryan Hendrix, Clay Peace, Sebastien Laulhe, Stephanie Mattingly, Ralph Knipp and Sadakatali Gori. People come and go, but their cooperation and friendship remain etched in my memory.

I am deeply appreciative of my wife, my son and my family members for their unconditional love and support. Words cannot express my gratitude for the love, patience, and support they gave to me during my graduate studies. 


\section{ABSTRACT}

\section{CATIONIC AMINOOXY LIPIDS: \\ SYNTHESIS, LIPOSOME STABILIZATION AND APPLICATIONS}

Xuan Huang

May 3rd 2012

This dissertation describes research focused on the synthesis, polymerization and applications of cationic aminooxy lipids. An efficient and convenient method was developed to stabilize liposomes using 'click chemistry'. The 'click stabilized liposomes' are fortified via covalent crosslinks generated between aldehyde and aminooxy functionalities in the lipid bilayers. Compared to untreated liposomes (i.e., no lipid-lipid bonding), the 'click' stabilized liposomes are considerably more stable against surfactant-mediated liposome disruption or serum-mediated liposome aggregation. Stabilized liposomes also can react with 'clickable' targeted ligands on the liposome surface for specific organ (e.g. breast cancer cells or liver) targeting. In this thesis, I have explored the feasibility of using the click stabilized liposomes in three different applications: i) colonic targeted delivery ii) gene vector iii) enzyme nanoreactor. 
This dissertation is divided into six chapters. Chapter 1 gives a review of liposomes and liposome stabilization. Chapter 2 describes the synthesis and characterization of cationic aminooxy compounds 2.1 and 2.2 as the headgroup domains of prototype lipids. Chapter 3 describes the synthesis, characterization and hydrolysis of cationic aminooxy enol ether lipids 3.1 and 3.2. The liposomes formulated from lipid 3.2 were stabilized using a pH-triggered lipid polymerization strategy. Chapter 4 describes the synthesis and characterization of a variety of aminooxy lipids and dextran polyaldehydes (DPAs). The liposomes formulated from lipids 4.1 were stabilized by simply mixing with DPAs. The resultant 'click' stabilized liposomes have potential applications such as drug carriers for colonic targeted delivery and as nano-reactors. Chapter 5 focuses on applying 'click' stabilized liposomes as gene carriers. The initial results of in vitro gene transfection revealed that the stabilized lipoplexes formulated from lipid 4.1 successfully transfected MFC-7 cells, but with lower transfection potency. A liver-targeted ligand $\mathbf{5 . 2}$ based on lactose was synthesized for future in vivo gene transfection applications. Chapter 6 details all experimental procedures and approaches used for compound characterizations. 


\section{TABLE OF CONTENTS}

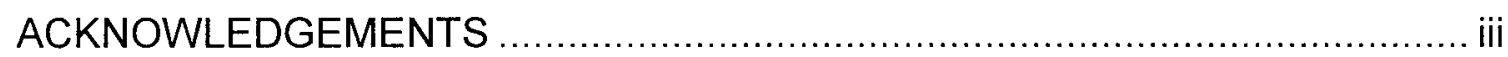

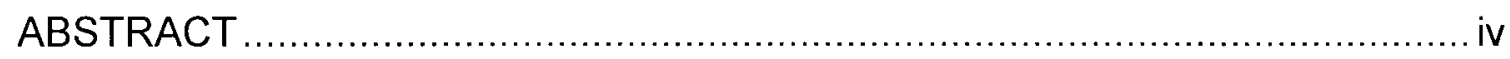

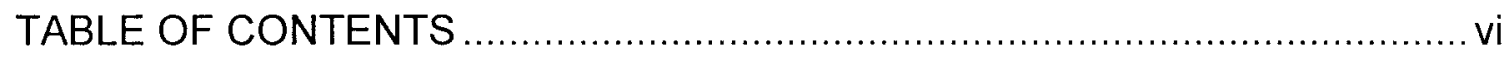

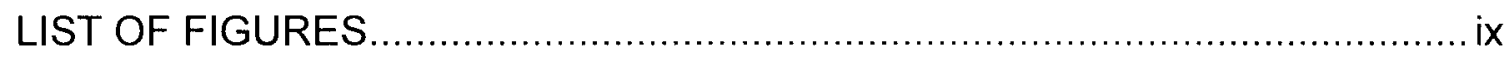

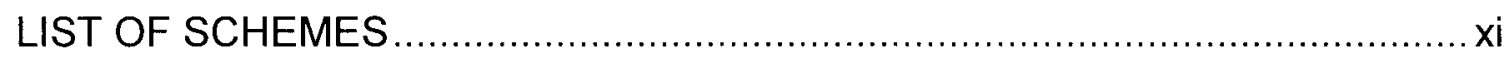

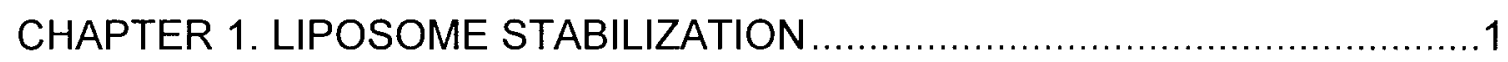

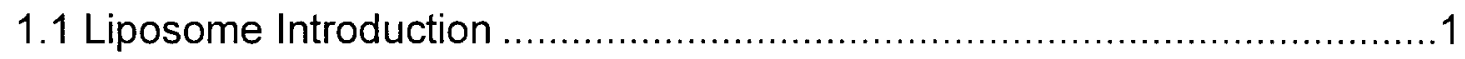

1.2 Cationic Liposomes as Gene Carriers ...................................................... 3

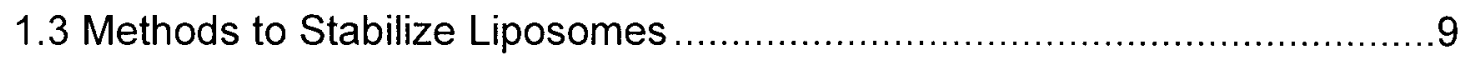

1.4 New Strategies to Stabilize Liposomes ................................................15

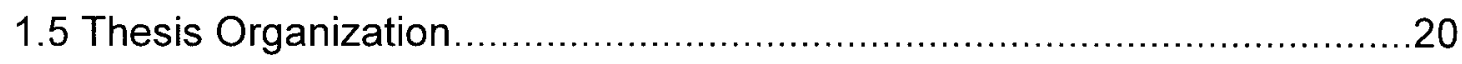

CHAPTER 2. CATIONIC AMINOOXY REAGENTS ......................................21

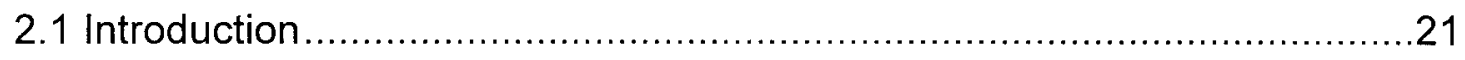

2.2 Cationic Aminooxy Reagent Synthesis ..............................................23

2.2.1 Synthesis of Cationic Aminooxy Reagent 2.1 …............................23

2.2.2 Synthesis of Cationic Aminooxy Reagent 2.2 ….............................26

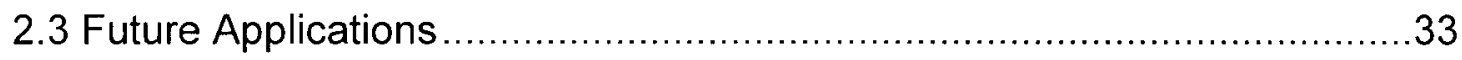

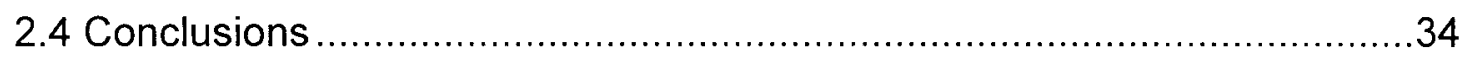

CHAPTER 3. CATIONIC AMINOOXY LIPIDS FOR pH-TRIGGERED LIPOSOME POLYMERIZATION--FIRST GENERATION CONCEPT ....................................36

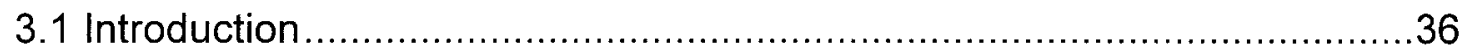

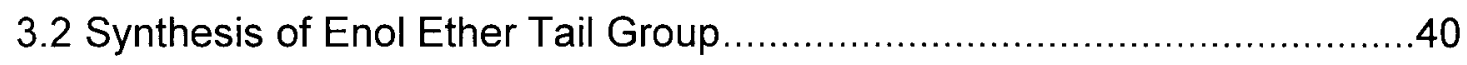

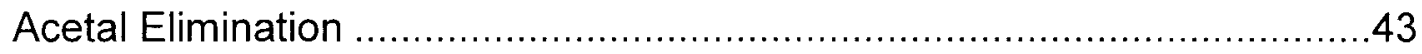

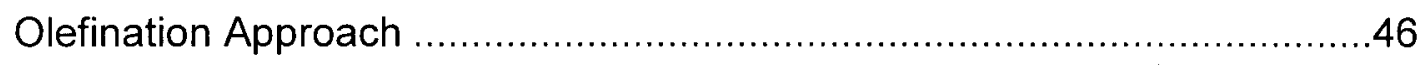




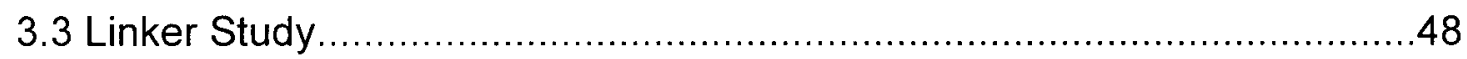

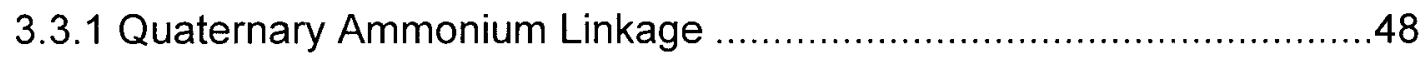

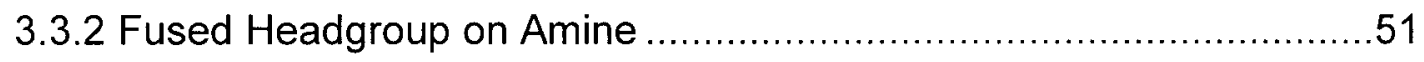

3.3.3 Fused Headgroup via Epoxide Opening ......................................53

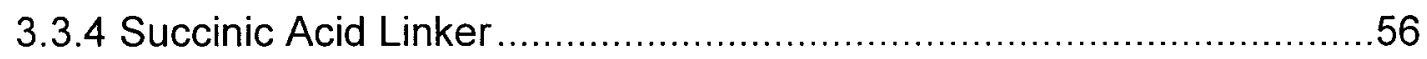

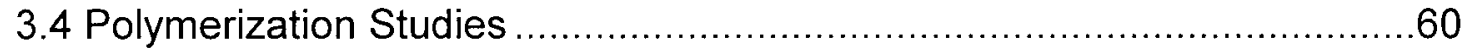

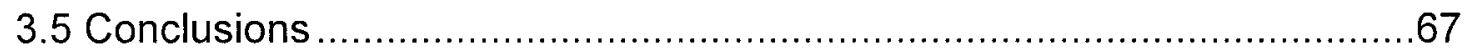

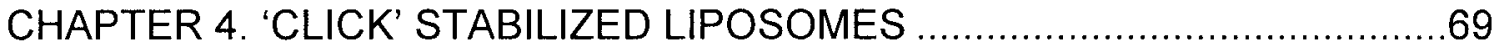

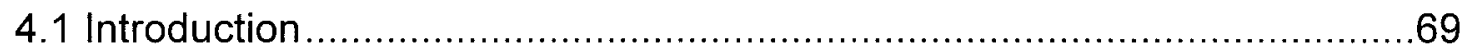

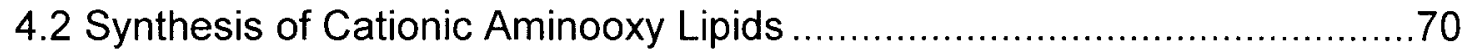

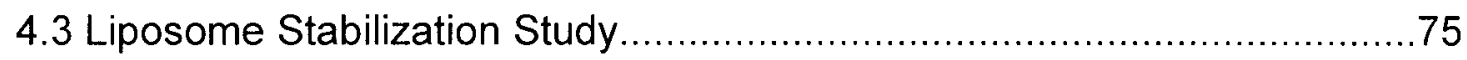

4.3.1 Liposome Formulation and Bis-aldehyde Stabilization Attempts.........75

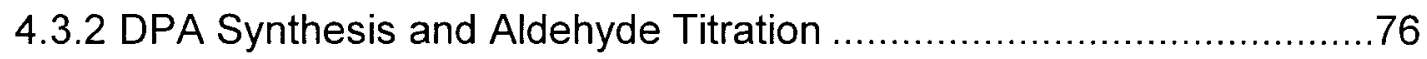

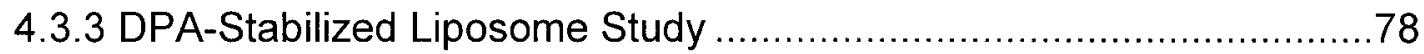

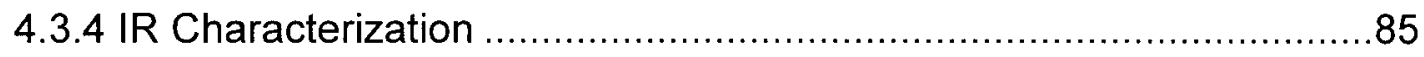

4.4 Permeability Study of 'Click' Stabilized Liposomes.................................87

4.5 'Click' Stabilized Liposomes as Nano-reactors .........................................91

4.6 Aminooxy Lipids as 'Clickable' Co-lipids ..............................................93

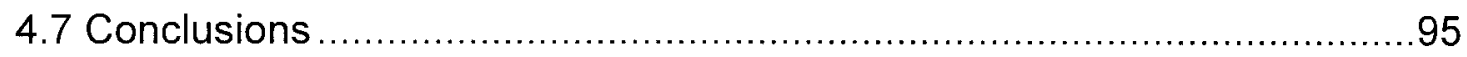

CHAPTER 5. 'CLICK' STABILIZED LIPOSOMES FOR GENE TRANSFECTION

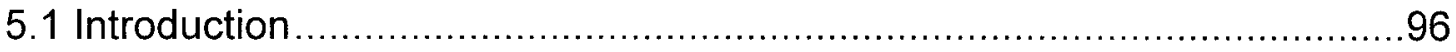

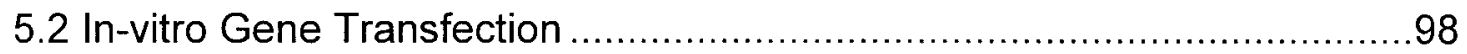

5.3 Synthesis of Aminooxy Functionalized Lactose ....................................101

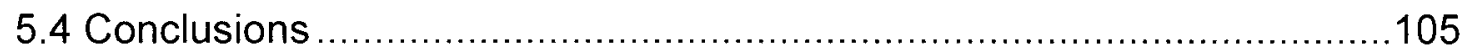

CHAPTER 6. EXPERIMENTAL PROCEDURES, NMR SPECTROSCOPY ....106

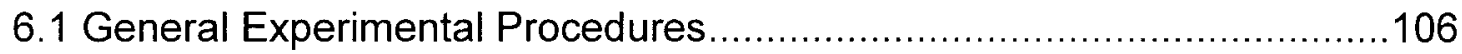

6.2 Chapter 2. Cationic Aminooxy Reagent...............................................107

6.3 Chapter 3. Cationic Aminooxy Lipids for pH-Triggered Liposome Polymerization--First Generation Concept. 
6.4 Chapter 4. 'Click' Stabilized Liposomes...........................................174

6.5 Chapter 5. 'Click' Stabilized Liposomes for Gene Transfection ...............222

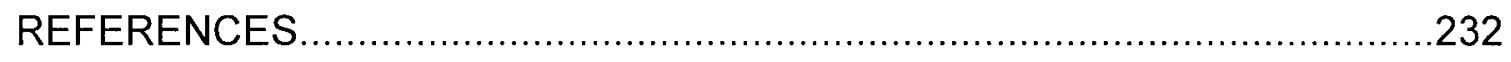

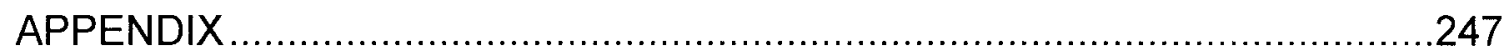

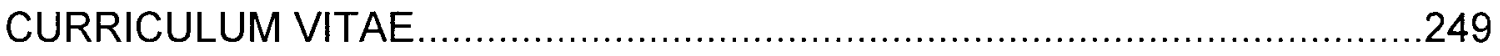




\section{LIST OF FIGURES}

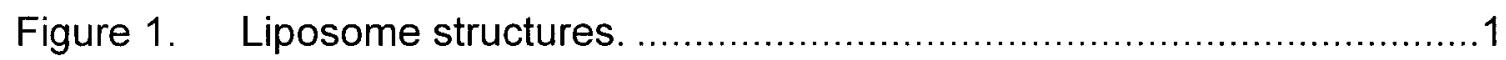

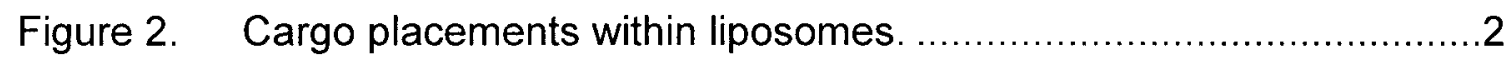

Figure 3. Structures of cationic lipids for gene transfer.............................. 5

Figure 4. Cationic liposome mediated gene delivery. .................................. 8

Figure 5. Liposome destabilization processes........................................10

Figure 6. Methods to stabilize liposomes.............................................11

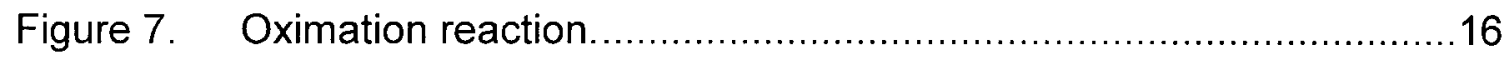

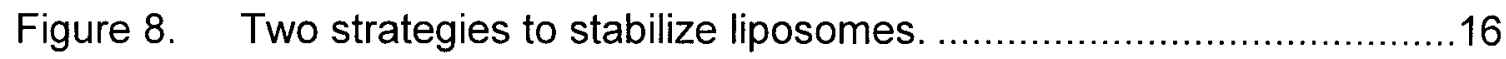

Figure 9. $\mathrm{pH}$-triggered intermolecular polymerization. ..............................18

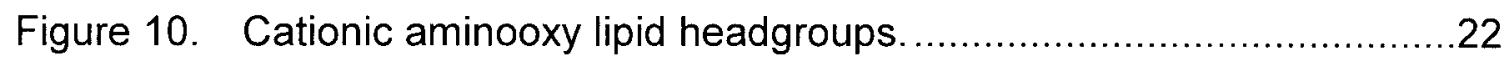

Figure 11. Cationization reagents and cationic aminooxy compounds ...........22

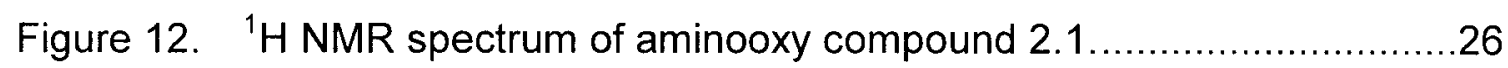

Figure 13. ${ }^{1} \mathrm{H}$ NMR and COSY spectra of aminooxy compound 2.2 ...............32

Figure 14. Proposed multifunctional magnetic nanoparticle for drug delivery...34

Figure 15. Examples of polymerizable groups for liposome polymerization. ....37

Figure 16. $\mathrm{pH}$-Triggered liposome polymerization via oximation reaction. .......39

Figure 17. Structures of prototype lipids for $\mathrm{pH}$-triggered lipid polymerization..39

Figure 18. Lipids with enol ether functionality.............................................41

Figure 19. ${ }^{1} \mathrm{H}-\mathrm{NMR}\left(\mathrm{CDCl}_{3}, 500 \mathrm{MHz}\right)$ spectrum of $3.9(\mathrm{Z}: \mathrm{E}=5: 1) \ldots \ldots \ldots \ldots \ldots . . . .44$

Figure 20. Concept aminooxy enol ether lipid with quaternary ammonium. .....48

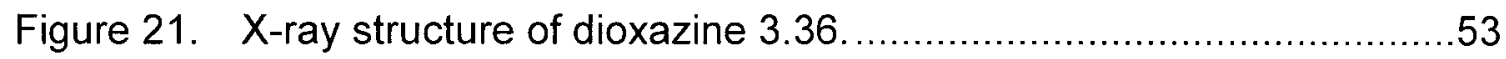

Figure 22. ${ }^{1} \mathrm{H}$ and COSY NMR spectra of lipid (Z)-3.2. ..............................59

Figure 23. Polymerized liposome from enol ether lipid 3.2 .......................60

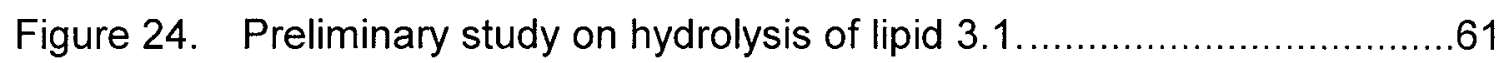


Figure 25. ${ }^{1} \mathrm{H}$ NMR analysis of the acid-triggered polymerization...................62

Figure 26. ${ }^{1} \mathrm{H}$ NMR spectra of lipid 3.1 under acid-triggered polymerization. ...62

Figure 27. ${ }^{1} \mathrm{H}$ NMR spectra of lipid 3.2 before and after acid hydrolysis..........65

Figure 28. Acid triggered liposome polymerization..................................66

Figure 29. 'Click' stabilized liposomes -- revised strategy ...............................69

Figure 30. Structure of TransFast ${ }^{\top \mathrm{M}}$ and cationic aminooxy lipid mimics.........71

Figure 31. ${ }^{1} \mathrm{H}$ NMR spectrum of cationic aminooxy lipid 4.1 .........................73

Figure 32. Effect of glutaric dialdehyde on liposome stabilization....................75

Figure 33. Structure of dextran and dextran polyaldehyde...........................77

Figure 34. Results of liposomes treated with Triton X-100 .........................79

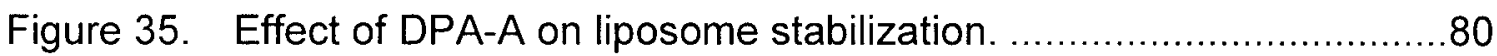

Figure 36. Effect of incubation time on liposome stabilization. ......................81

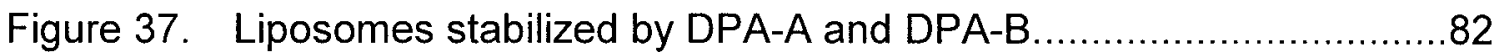

Figure 38. Liposomes stabilized by polyaldehyde compounds.......................83

Figure 39. Aggregation behavior of liposomes and DPA stabilized liposomes. 84

Figure 40. IR spectra of the lipid 4.1 and corresponding liposome.................86

Figure 41. IR spectra of the cationic aminooxy liposome during reaction and integrated IR absorbance around $1650 \mathrm{~cm}^{-1}$ as a function of time...................87

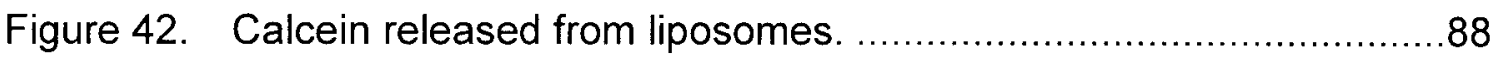

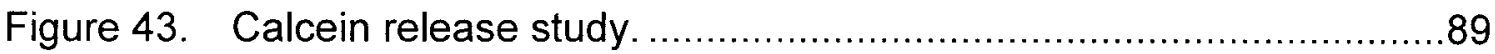

Figure 44. Calcein released from DPA-B stabilized liposomes.......................90

Figure 45. The activity of phosphatase encapsulated within liposomes. .........92

Figure 46. Antibody conjugated with aminoxy-lipid.......................................94

Figure 47. Pre- and Post-modification formulation.......................................

Figure 48. Transfection of MCF-7 cells using lipoplexes from lipid 4.1 ...........99

Figure 49. Transfection of MCF-7 cells using stabilized lipoplexes. .............100

Figure 50. Aminooxy functionalized D-lactose ........................................102

Figure 51. ${ }^{1} \mathrm{H}$ NMR spectrum of aminooxy functionalized D-lactose 5.2 .......104 


\section{LIST OF SCHEMES}

Scheme 1. Strategies to introduce aminooxy functionality...........................23

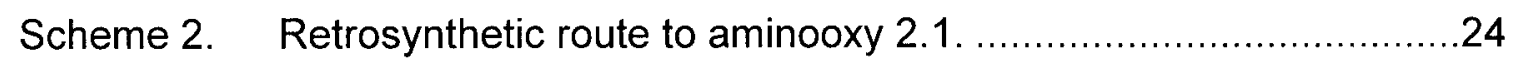

Scheme 3. Synthesis of cationic aminooxy compound $2.1 \ldots \ldots \ldots \ldots \ldots \ldots \ldots \ldots \ldots . .24$

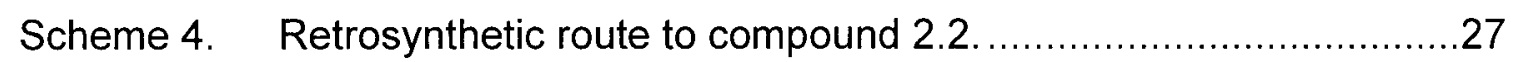

Scheme 5. First attempt to synthesize cationic aminooxy $2.2 \ldots \ldots \ldots \ldots \ldots \ldots \ldots . .28$

Scheme 6. Second attempt to synthesize cationic aminooxy 2.2 ...............28

Scheme 7. Synthesis of Boc-protected bis-aminooxy amine 2.26 ................29

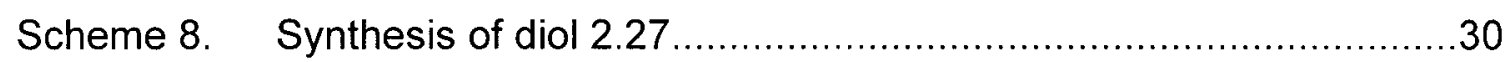

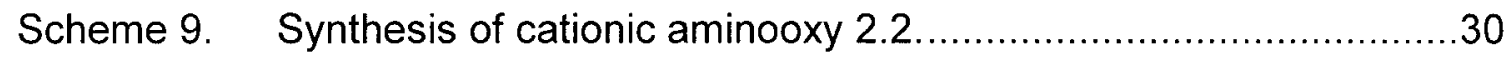

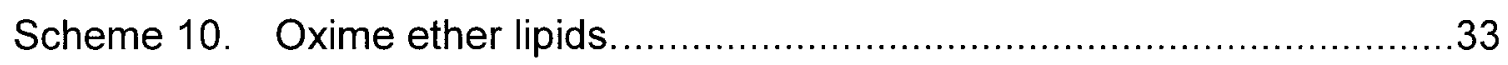

Scheme 11. Initial examples of lipid polymerization via oxime ether formation.

Scheme 12. Methods to incorporate an enol ether into a lipid sidechain.........42

Scheme 13. A shift of enol ether group in the prototype lipid. .......................42

Scheme 14. Synthesis of enol ethers via TESOTf-induced elimination............43

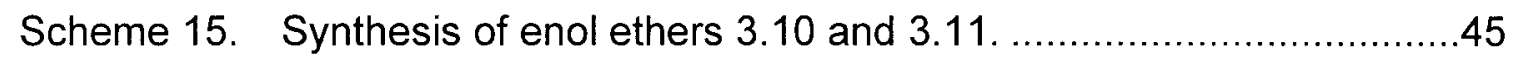

Scheme 16. Synthesis of enol ether tail 3.15. ..............................................46

Scheme 17. Synthesis of enol ether tail 3.20 .........................................4

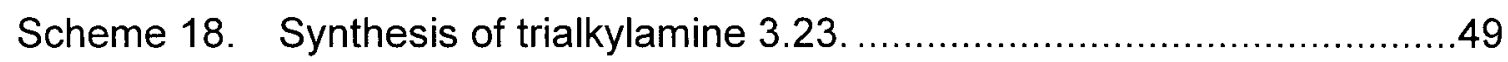

Scheme 19. Synthesis of iodoalkyl enol ether 3.26 ....................................50

Scheme 20. Synthesis of enol ether ammonium 3.27 ..................................50

Scheme 21. Attempts to quaternize headgroup amine .................................51

Scheme 22. Fused protected aminooxy headgroup on the amine ...................52

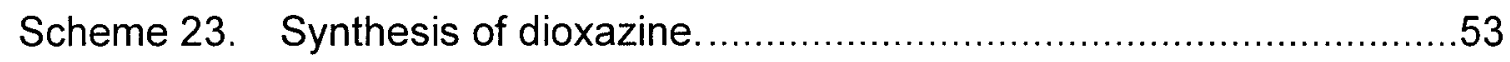


Scheme 24. Plan for synthesis of aminooxy enol ether lipid $3.42 \ldots \ldots \ldots \ldots \ldots . . .54$

Scheme 25. Plan for synthesis of lipid 3.43 using ether linkage approaches. ..54

Scheme 26. Synthesis of cationic enol ether lipid 3.49...............................55

Scheme 27. Synthesis of cationic enol ether lipids 3.1 and $3.2 \ldots \ldots \ldots \ldots \ldots \ldots . .57$

Scheme 28. Synthesis of cationic aminooxy lipid 4.1 .................................

Scheme 29. Synthesis of cationic aminooxy lipid 4.2 …............................72

Scheme 30. Synthesis of aminooxy lipid 4.3. and 4.17 ................................74

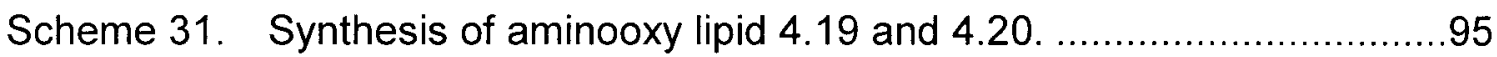

Scheme 32. Synthesis aminooxy functionalized D-lactose $5.2 \ldots \ldots \ldots \ldots \ldots \ldots \ldots . . . . .103$ 


\section{CHAPTER 1. \\ LIPOSOME STABILIZATION}

\subsection{Liposome Introduction}

Liposomes, first introduced by Bangham et al. in $1965,{ }^{1}$ have an aqueous core domain surrounded by unilamellar or multilamellar lipid bilayers with diameters from $20 \mathrm{~nm}$ to $100 \mu \mathrm{m}$ (Figure 1). Liposomes have attracted considerable attention since Bangham's report and over 40,000 papers related to the study of liposomes have been published. ${ }^{2}$ Due to their biocompatibility, biodegradability and ease of preparation, liposomes are widely applied as universal carriers in drug/gene delivery systems as well as other applications including artificial cell models, biosensors, nanoreactors and cosmetic products. ${ }^{3,4}$ Many commercial products apply liposomes to fulfill various jobs, such as to improve drug solubility (AmBisome ${ }^{T M}$, Visudvne ${ }^{T M}$ ), reduce drug toxicity (Doxil ${ }^{\mathrm{TM}}$, Myocet ${ }^{\mathrm{TM}}$ ), increase the response to vaccines (Epaxal ${ }^{\mathrm{TM}}$, Inflexal $^{T M}$ ) or increase gene delivery efficiency (Lipofectamine ${ }^{T M}$, Transfast $^{T M}$ ). ${ }^{5,6}$

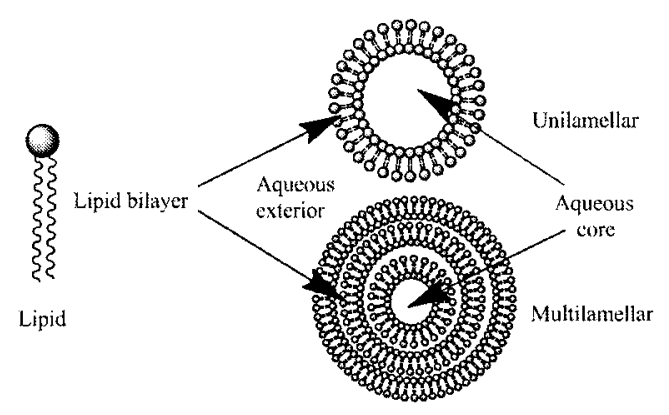

Figure 1. Liposome structures. 
The unique structure of liposomes allows hydrophilic cargo to be encapsulated in aqueous core domain whereas the hydrophobic cargo can be bound in the lipid bilayer. For the charged cargo, liposomes can carry small molecules via association on the lipid surface, and charged macromolecules can be packaged via complexes into the lipid bilayer (Figure 2). For example, cationic liposomes may complex negatively charged DNA to form compacted, charge affinity complexes called lipoplexes, which tend to form as mutilamellar vesicles. ${ }^{7,8}$ The lipid bilayer offers protection by separating the cargo from the surrounding environment which makes liposomes ideal carriers.

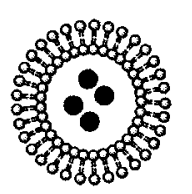

A

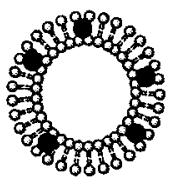

B

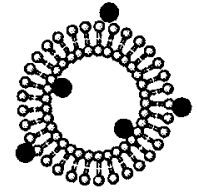

C

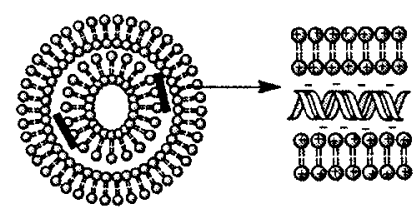

D

Figure 2. Cargo placements within liposomes.

The black dots and bars in the figure represent cargo molecules: A. Hydrophilic cargo; B. Hydrophobic cargo; C. Charged cargo; D. Charged macromolecules (e.g. plasmid DNA).

According to their different size and morphology, liposomes can be classified as various vesicles: the Small Unilamellar Vesicles (SUVS) refer to single-shelled vesicles with diameters ranged from 25 to $50 \mathrm{~nm}$; the Large Unilamellar Vesicles (LUVs) ranged from 50 to $500 \mathrm{~nm}$; the Multilamellar Vesicles (MLVs) have "onion-like" structure and usually range from $100 \mathrm{~nm}$ to $10 \mu \mathrm{m}$ (Figure 1); and the Giant Vesicles (GVs) with very large size range from 10 to $100 \mu \mathrm{m}$ which can be either unilamellar or multilamellar. ${ }^{9,10}$ The size of the liposomal vesicles significantly influences their biodistribution. Usually, SUVs and MLVs with diameters less than $200 \mathrm{~nm}$ are applied 
as systemic drug/gene delivery vehicles because they can pass through the capillary veins without clogging after intravenous injection administration.

\subsection{Cationic Liposomes as Gene Carriers}

Broadly speaking, gene therapy seeks to use genetic material as a drug to treat genetic or acquired diseases. In the past three decades, the meaning of gene therapy expanded from gene replacement through addition of recombinant plasmid DNA ( $p D N A)$ to regulation of a particular gene via RNA interference (RNAi). ${ }^{11}$ To date, increasing numbers of biological studies and clinical trials have attempted to use gene therapy to treat cancers, chronic inflammatory diseases, severe combined immunodeficiency, cardiovascular diseases etc. ${ }^{12}$ Despite the great potential of $p$ DNA and siRNA-based (small interference RNA) gene therapy, there have been few successful outcomes in early clinical trials, and no gene therapy products have been approved by the FDA so far. One important reason is the difficulty in delivering $p D N A$ or siRNA into targeted cells.

The simplest gene delivery strategy is injection/inhalation of 'naked' (uncomplexed) nucleic acids (e.g. pDNA, siRNA). However, the direct injection of 'naked' nucleic acids into tissue or blood is ineffective and limited to a few tissues due to the following reasons: first, nucleic acids generally undergo rapid enzymatic degradation by nucleases in vivo; second, 'naked' nucleic acids cannot reach many organs by systemic injection because they are rapidly cleared by the liver (naked siRNA, due to its relatively smaller size, is cleared by the kidney and as a result, the half-life of RNA in plasma is less than 5 minutes while the half-life of DNA in serum is 10 
minutes. $\left.{ }^{13,14}\right)$; lastly, the net negative charge of a cellular membrane may repel negatively charged oligonucleotides or pDNA, which leads to low efficiency of cellular uptake. To overcome these limitations, it is necessary to develop gene delivery carriers to safely transport DNA/RNA into targeted cells.

The most successful gene delivery vector as chosen by nature is the virus. Viruses have evolved as a highly efficient way of encapsulating and delivering nucleic acids into human cells. Several viruses, such as the retrovirus, adenovirus, pox virus and adeno-associated virus have been reengineered as pDNA and siRNA delivery vectors to treat cancers, AIDS (acquired immune deficiency syndrome) and many other diseases in clinical trials.11,15 Although viral vectors are the most powerful tool for gene transfection due to their high efficiency, they are difficult to produce on large scale and hard to modify for desired tissue selectivity. Moreover, viral approaches have a variety of other potential problems, such as the potential for oncogenesis due to chromosomal integration, gene mutation, out-of-control immune response and inflammatory responses which may lead to the death of patients. Therefore, using non-viral delivery vectors, in principal, is a preferred approach due to safety issues.

Cationic liposomes are promising nonviral gene vectors because of various advantages besides the safety issues. First, the mutation-free synthesized compounds are compatible to mass production and quality control with relatively low cost. Second, nonviral vectors can acquire tissue specificity by conjugation to targeting groups such as ligands, peptides and antibodies. Third, nonviral vectors can deliver large genes (e.g. pDNA containing hundreds of $\mathrm{Kbp}$ ), whereas viruses have limited loading capacity (e.g. adeno-associated virus has $4.8 \mathrm{Kbp}$ genome limit). 
Fourth, the biodegradable design of vectors can achieve controllable release of pDNA/siRNA.

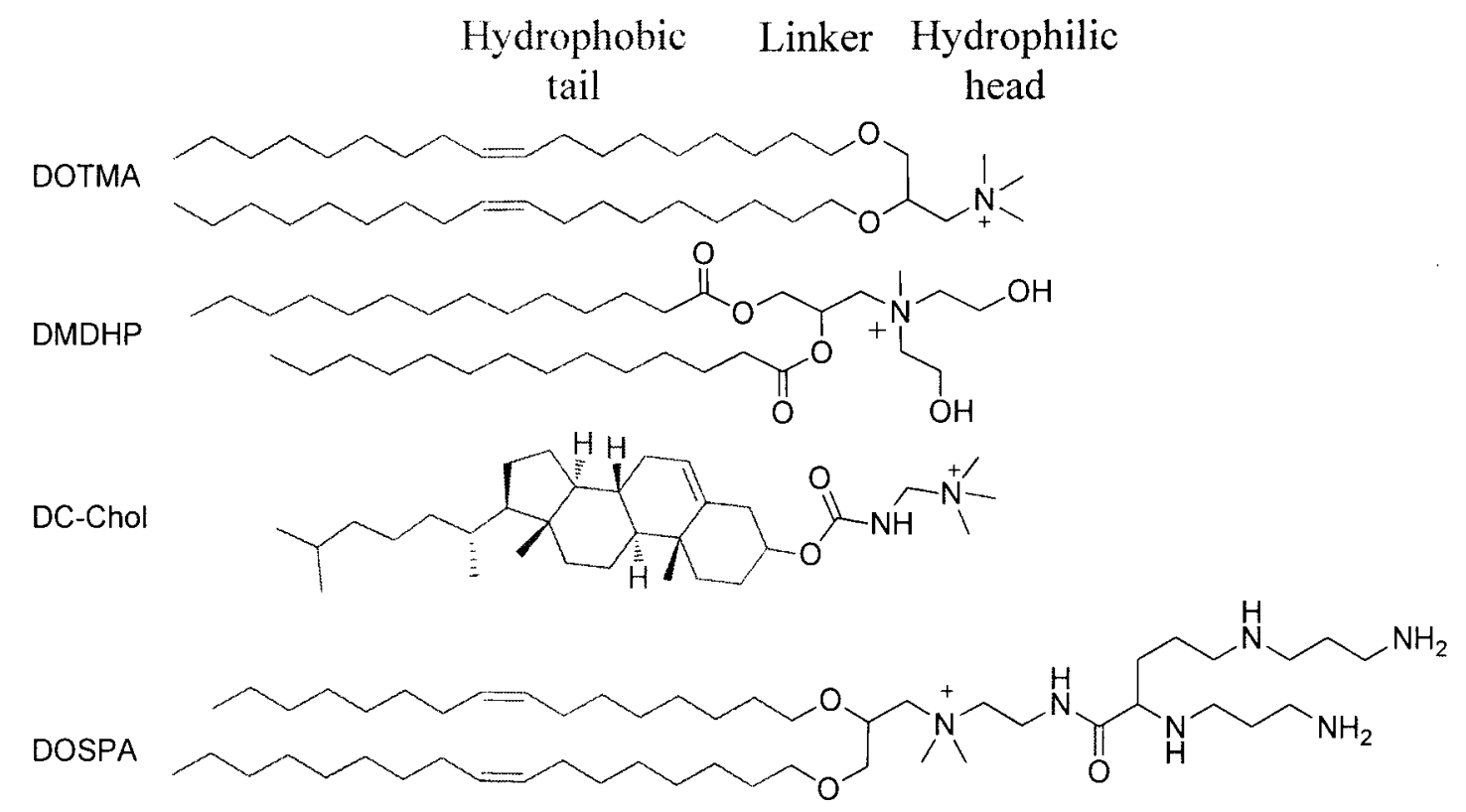

Figure 3. Structures of cationic lipids for gene transfer.

Since Felgner and colleagues applied DOTMA as gene delivery vector in 1987, hundreds of new cationic lipids including DMDHP, DC-Chol, DOSPA have been developed (Figure 3) ${ }^{16-18}$ Generally, cationic lipids are amphiphilic compounds with three domains: the hydrophilic head, the hydrophobic tail and the linker. The hydrophilic head, usually with positive charge in an aqueous environment, interacts with negatively charged nucleic acids. The hydrophobic tail, with one or two linear carbon chain tails or ring structures, such as a cholesterol group, help form the interior of the protective bilayer. The linker domain can be a variety of functional groups, such as ether, amide, ester, acetal, carbamate or oxime functionalities ${ }^{19-21}$, which serve to connect the hydrophobic tail to the hydrophilic head. 
The first step of cationic lipid mediated gene delivery is complex formation. Usually, nucleic acids are mixed with cationic liposomes in aqueous solution. Due to the electrostatic interactions between cationic lipids and negatively charged DNA, bilayer vesicular-like structures called lipoplexes are formed. ${ }^{7,8}$ Because of the time-dependent aggregation tendency, lipoplexes usually are administered shortly after their formation.

After administration via intravenous injection, lipoplexes must circulate through and/or diffuse intercellularly before arriving at the surface of a targeted cell. During this process, the lipids can protect the pDNA/siRNA against nuclease cleavage. For successful gene therapy, the final destination of siRNA is the cytoplasm of the target cells, while for pDNA it is the nucleus. This means both formulations have to pass through the cell membrane. Usually, lipoplexes bind to the cell surface via nonspecific interactions of the cationic lipids with anionic membrane components.

Theoretically, there are two different possible transmembrane mechanisms. The lipoplex can fuse with the membrane of the target cells, dumping its contents ( $p$ DNA or siRNA) into the cytoplasm. Alternatively, the lipoplex can enter cells through an endocytosis pathway. The actual process is thought to occur more often by the second mechanism, as verified by electron microscopy which shows that the vast majority of lipoplex complexes are localized within endosome-like compartments. ${ }^{22}$

Once the lipoplex has been trapped within an endosome, the nucleic acids may be released through different pathways. The cationic lipid forms ion pairs with the endosomal lipid which leads to the fusion of the lipoplex with endosomal membrane and release of the nucleic acids. Alternatively, the lipoplex may have a large amount of 
unprotonated amines that can induce the influx of protons, chloride ions and water into the endosome. Eventually the endosome bursts due to increased osmotic pressure. This so-called "proton sponge effect" enhances endosomal release of lipoplexes. The free lipoplex will disassemble to release nucleic acids in the cytoplasm. If the lipoplexes are disassembled in the endosome, the nucleic acids can be released in the endosome and then go to the cytoplasm. ${ }^{16,23}$ The mechanistic process is illustrated in

\section{Figure 4.}

However, liposome blood instability is one of the biggest problems in gene/drug delivery. Cationic lipoplexes are likely to aggregate with blood proteins due to charge interactions and consequently this disassembles the lipoplexes. The liposome-protein aggregation leads to a high rate of clearance by the reticuloendothelial system, which in turn prevents in vivo applications via intravenous administration. ${ }^{24}$ Liposomes also show chemical and physical instabilities in aqueous dispersions during long-term storage. For example, the phospholipids may be hydrolyzed or oxidized under aqueous conditions; the encapsulated cargoes may leak out due to liposome fusion; and liposomes may from precipitate due to aggregation. Although lyophilization is a good way to preserve many drugs, the ice crystals formed during lyophilization can

damage the integrity of lipid bilayer. ${ }^{25}$ Therefore, to realize the full potential of liposome applications, it is necessary to stabilize the liposomes. This strategy is the focus of my thesis research. 


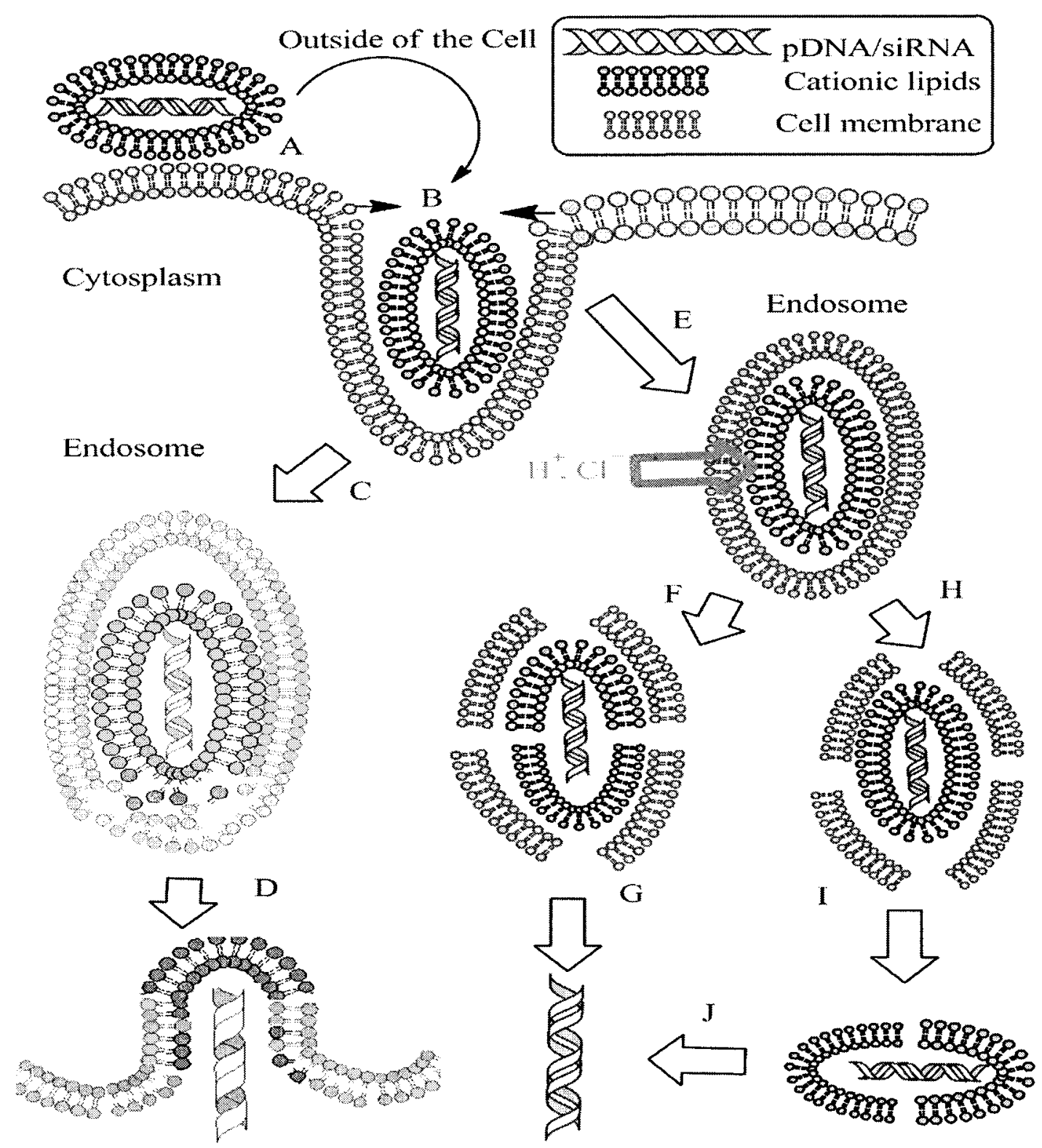

Figure 4. Cationic liposome mediated gene delivery.

A. The cationic lipoplex interacts with a cell membrane; B. Starting formation of endosome; C. The endosome is destabilized by lipids; D. G. I. Release of gene materials; E. Lipoplex containing molecules with buffer capacity in endosomal $\mathrm{pH}$ range which can trigger proton sponge effect; $F$. Lipoplex decomposes inside the endosome and releases genetic materials; H. Intact lipoplex escapes from the ruptured endosome; I. Lipoplex decomposes inside the cytoplasm and releases genetic materials. 


\subsection{Methods to Stabilize Liposomes}

Liposome stability is a complex issue. Many researchers have defined liposome stability differently based on their research interests. ${ }^{26-29}$ Because our lab's research interest centers on the applications of cationic liposomes as drug/gene carries, we focused on the liposome capability to maintain structural integrity (mechanical stability) and unimpeded suspension in serum (colloid stability).

Liposomes can be destabilized through fusion, aggregation or disassembly (Figure 5). The fusion of liposomes naturally happens when liposomes encounter each other. ${ }^{30}$ After they adhere, their lipid bilayers fuse together (e.g. lipid mixing). During the "open-and-fuse" process, bigger liposomes are formed. Liposome aggregation decreases the colloid stability and consequently leads to particle precipitation. Usually, charged liposomes aggregate due to electrostatic interactions in the presence of oppositely charged macromolecules or high salt conditions. ${ }^{31} \mathrm{~A}$ good example is that cationic liposomes precipitate in the presence of serum, which contains many negatively charged proteins. Disassembly of liposomes is the process whereby lipid bilayers break down to smaller ones and release contents. Usually liposomes can be disassembled by shear force, high temperature or exposure to surfactants. Some designed liposomes can be disassembled under certain conditions (acid, reduction conditions, light, ultrasound, etc) to achieve a controlled release effect.

Generally, there are two strategies to stabilize liposomes: (1) liposome surface modification and (2) lipid bilayer modification. The former strategy stabilizes liposomes mainly through changing liposome surface properties to generate electrostatic or 
steric barriers to discourage lipid interactions with other liposomes or molecules (e.g. serum proteins). The latter strategy stabilizes liposomes mainly through lipid composition modification or crosslinking lipid bilayers to prevent disassembly of liposomes. In some cases, the two strategies can be combined to stabilize liposomes.

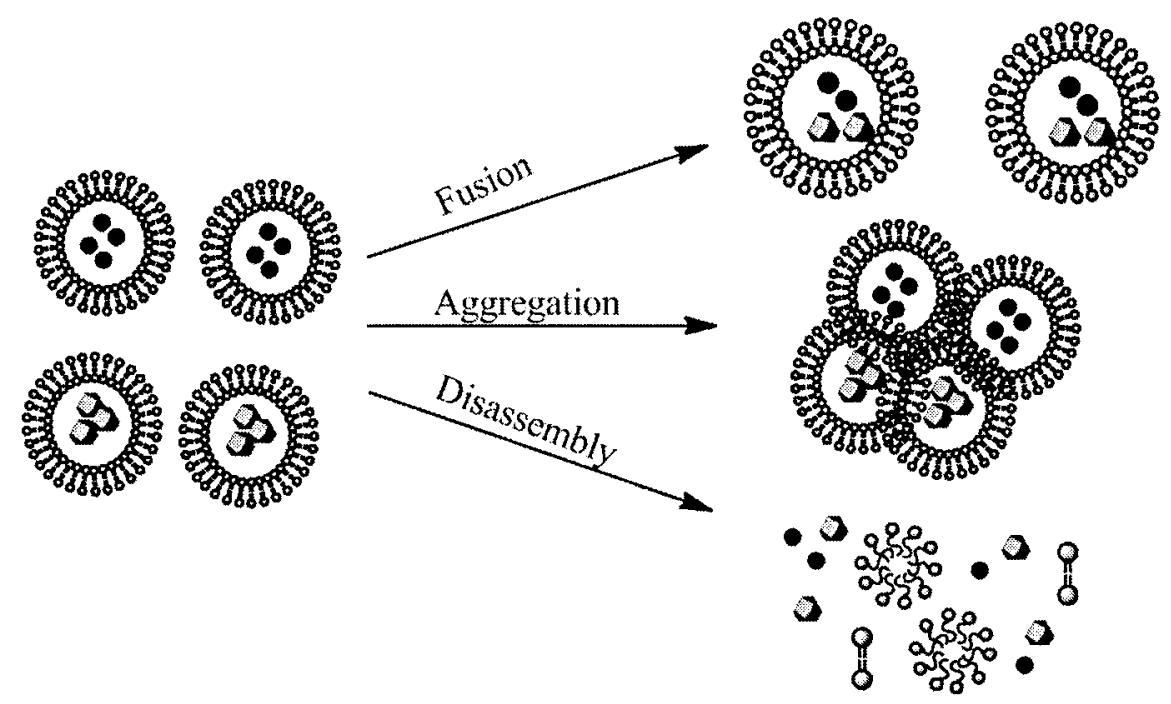

Figure 5. Liposome destabilization processes.

It is well appreciated that charged liposomes have better stability than neutral liposomes due to the electrostatic force discouraging liposomes approaching each other. Therefore, liposomes can be stabilized by adding charge to the surface to work as an electrostatic barrier (Figure 6 A). Zhang et al. reported that neutral phospholipid DLPC liposomes can be stabilized by absorbing charged nanoparticles at the surface ${ }^{26}$ The resultant liposomes were stable for more than 50 days, while the similar yet untreated liposomes lasted less than 4 days. The presence of the surface nanoparticles did not induce content leakage, as determined by fluorescence measurement. However, charged liposomes can not be stabilized using this method. 


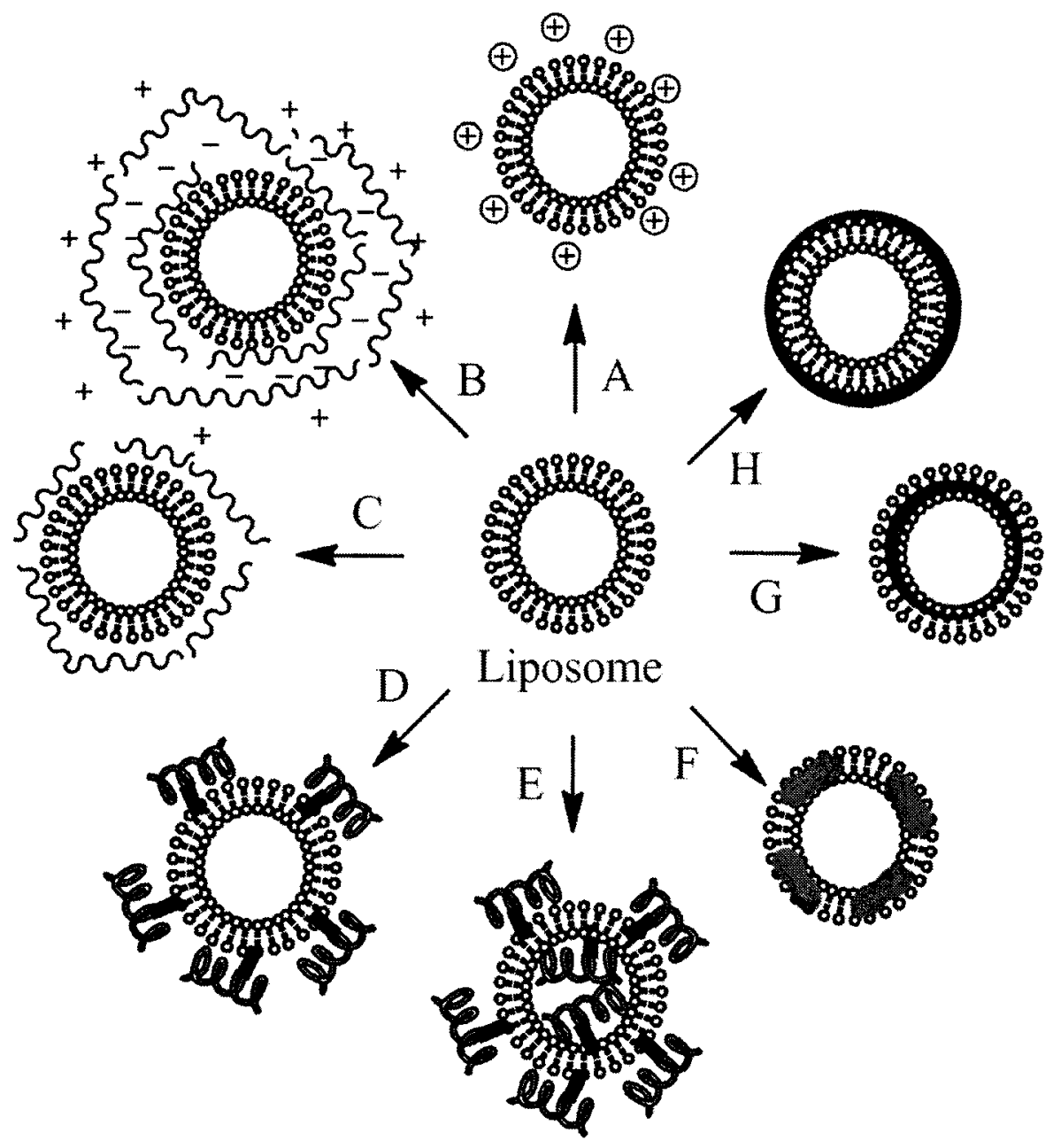

Figure 6. Methods to stabilize liposomes.

A. Addition of charged nanoparticles; B. Addition of an outer layer of charged polymers; C. Surface absorbed polymers; D. Anchored polymers; E. Anchored polymers in both sides of a lipid bilayer; F. Lipid/polymer layer stabilization; G. Lipid layer crosslinking; H. Surface crosslinking.

To stabilize charged liposomes, a layer-by-layer (LBL) strategy (Figure 6 B) can be applied. The LBL strategy involves fabricating multilayer films on the surface of targeted liposomes via sequential deposition of oppositely charged polyelectrolytes. ${ }^{32}$ 
The multilayer not only imparts a steric and electrostatic barrier, but also stabilizes lipids against disassembly due to electrostatic interactions between polyelectrolytes and oppositely charged lipids. Fukui et al. stabilized negatively charged liposomes by the LBL strategy using chitosan (a cationic polysaccharide) and anionic polymers (dextran sulfate or DNA). The four layer liposomes displayed a dramatic increase in stability against a surfactant (Triton X-100) treatment that completely disassembles bare liposomes. ${ }^{27,33}$ They also demonstrated that the encapsulated cargo release rate from the stabilized liposomes is slower than that from bare liposomes. However, this strategy has an intrinsic problem when applied to stabilize cationic liposomes. It is well known that liposomes change their aggregation morphology by collapse and fusion when they interact with oppositely charged polyelectrolytes. The collapse and fusion during the LBL deposition process will result in cargo leakage and decreased encapsulation efficiency. The detailed mechanism of DNA cargo release from cationic lipoplexes after adding anionic dextran sulfate has been well elaborated by $\mathrm{Xu}$ et al. ${ }^{22}$

Uncharged steric barriers can also be applied to stabilize liposomes. Usually, the steric barriers are made from hydrophilic molecules such as poly(vinyl alcohol) $)^{34,35}$, poly(ethylene glycol) (PEG) ${ }^{36,37}$, polysorbate $80^{38,39}$, and polysaccharides ${ }^{40-42}$. The hydrophilic layers can be introduced via absorption onto the liposome surface (Figure $6 \mathrm{C})$. However, the ease of dissociation of the adsorption compounds is a problem and leaves the liposomes unstable after dilution. To decrease the dissociation rate, anchored amphiphilic polymers have been developed. Those polymers, equipped with a hydrophobic domain that can insert into the lipid bilayer, can be immobilized on the liposome surface with less dissociation (Figure 6 D, E). 
There are two formulation procedures that can be applied to generate anchored polymers to stabilize liposomes. One is a premodification formulation process where stealth molecules mix with the lipids prior to liposome formulation by either dehydration-rehydration or reverse-phase evaporation procedures. The resultant stabilized liposomes have stealth molecules distributed on both sides of the lipid bilayer (Figure $6 \mathrm{E}$ ). However, the presence of stealth molecules in the inner leaflet of liposomes is not preferred because it remarkably reduces the interior volume (carrying capacity) of the liposomes and interferes with the interaction between cationic lipids and pDNA. ${ }^{43.44}$ Another is a postmodification formulation process where stealth molecules may be absorbed and anchored into the outer layer of liposomes (Figure 6 D). By simply mixing the liposomal suspension with the polymer solution, the polymers can be adsorbed and anchored on the liposomes surface. Although this strategy was successesful in applications of stealth liposomes for drug delivery, there have not been many reports using this approach for gene delivery. ${ }^{45}$ Alternatively, the postmodification can occur through chemical conjugation of stealth molecules onto the liposome surface. So far, variable success using amide, imine, hydrazone linking, thiol-maleimide coupling, azide-alkyne coupling as well as Staudinger ligation has been achieved. ${ }^{46-50}$

Besides surface modifications, changing the lipid bilayer composition can also stabilize liposomes. Initial research showed that changing the composition of lipids, such as adding co-lipids (cholesterol), can dramatically improve liposome stability. ${ }^{51}$ Considering that bigger molecules have lower mobility than smaller molecules, the incorporation of co-polymers into liposomes can lead to stabilization by reducing liposome fusion and aggregation. Ruyssaheert et al. reported that $A B A$ triblock 
copolymers can be inserted into liposomes via simple mixing. The resultant hybrid membrane had better stability against dehydration. ${ }^{28,52}$ However, this method may not provide suitable stability to protect liposomes against serum-induced aggregation.

Highly stable liposomes have been generated through polymerization techniques, either in the lipid bilayer or at the liposome surface (Figure 6 G, H). Most examples involved polymerization of acrylate $\left(\mathrm{CH}_{2}=\mathrm{CHCOO}-\right)$ domains. O'Brien et al. published a good review on this subject. ${ }^{53}$ Our group also developed polymerized lipids as gene carriers ${ }^{54,55}$ However, the free radicals produced during the polymerization process may react with cargo compounds or other resident functional groups (e.g. target ligands or $\mathrm{pH}$ liable groups). Although it is possible to first polymerize the liposomes and then incorporate a cargo and other functional groups to prevent side reaction from free radicals. However, polymers may adversely affect liposome preparation, cargo encapsulation as well as target ligand incorporation. Therefore, a better approach would be to conduct the polymerization after cargo encapsulation using radical-free method, such as a chemoselective polymerization.

Recently, many new strategies have been developed to stabilize liposomes via non-radical polymerization. For example, Ruysschaert and co-workers developed a method to stabilize liposomes through DNA polymerization. A 25-mer oligonucleotide was covalently immobilized on the surface of liposomes. Subsequent addition of an enzyme (terminal deoxynucleotidyl transferase) elongates the $25 \mathrm{bp}$ DNA to larger (300-500 bp) single-stranded DNA with random sequence. The elongated DNA hybridizes to create a random network with short segments of double-stranded DNA. The random network was then reinforced by more double-stranded DNA produced by DNA polymerase. The resultant DNA stabilized liposomes survived after surfactant 
treatment at a rate of $5-40 \% .^{56}$ Nguyen's group developed the polymer-caged liposomes based on chemical cross-linking between poly(acrylic acid) and bis(ethylamine) and applied the stabilized liposomes in drug delivery. ${ }^{29,57,58}$ However, the poly(acrylic acid) polymers usually contain negative charge under physiological conditions and this makes it unsuitable for packaging gene materials.

Considering the pros and cons of each method, we hypothesized that new strategies to stabilize liposomes should be explored. We considered two new approaches, both involving chemoselective crosslink formation via non-radical polymerization. In this thesis, we aimed to develop these strategies for stabilization of liposomes and lipoplexes, and to demonstrate their suitability for drug/gene delivery.

\subsection{New Strategies to Stabilize Liposomes}

Our liposome stabilization strategies are based on lipid crosslinking via oximation chemistry (a typical type of "click chemistry" ${ }^{59}$ ). Oximation is a chemospecific reaction between aminooxy groups and the carbonyl groups of aldehydes/ketones (Figure 7). Aminooxy groups react selectively with either aldehyde or ketone carbonyl groups to form oxime ethers $\left({ }^{1} \mathrm{R}-\mathrm{ON}=\mathrm{CH}_{-}{ }^{2} \mathrm{R}\right)$. The coupling process proceeds rapidly under aqueous conditions and thus is ideal for applications involving DNA or RNA, especially since these polynucleotides do not possess aldehyde or ketone functionalities. The resultant oxime ether linkages are robust and particularly stable to physiologic conditions. Importantly, aminooxy groups will not react with DNA/RNA functionality. Our group recently reported the attachment of a fluorescent aminooxy probe to a ketone-containing lipid (DMDK) by forming an oxime ether. ${ }^{60}$ We also showed that 
lipoplexes containing aminooxy and ketone functionalities are active in gene transfection applications. Therefore, if a cationic lipid were to contain both aldehyde and aminooxy functionality, then the reaction between these two functionalities on neighboring lipids potentially could form crosslinks.<smiles>[R7]ON=C([R1])[R]</smiles>

\section{Aminooxy Aldehyde/Ketone Oxime Ether}

Figure 7. Oximation reaction.

We designed two strategies to stabilize liposomes through generation of crosslinks: strategy $\mathrm{A}$ is a $\mathrm{pH}$-triggered lipid polymerization and the strategy $\mathrm{B}$ is an external reagent generated crosslinking (Figure 8).

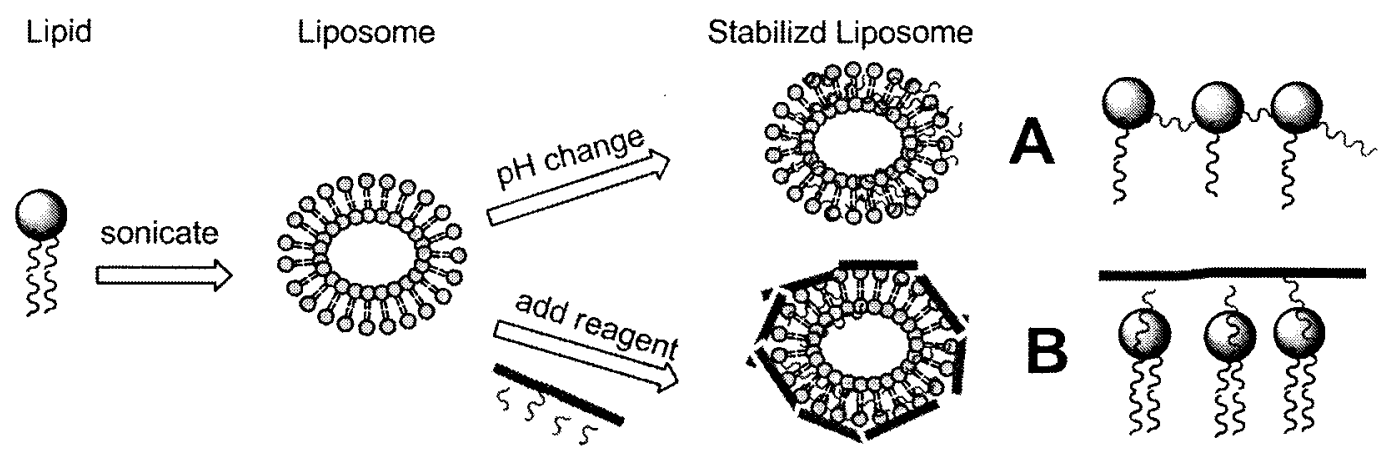

Figure 8. Two strategies to stabilize liposomes.

For strategy A, the lipid is fitted with both functional groups: aldehyde and aminooxy. To prevent spontaneous crosslinking, the aldehyde groups are masked as enol ethers, which are stable under neutral aqueous conditions but susceptible to 
aqueous acid-mediated hydrolysis. We envisioned actuating the process of 'pH-triggered lipid polymerization' in the following manner: After the polynucleotide is added to an aminooxy lipid formulation in water (with or without co-lipids/adjuvants) to generate a lipoplex, the $\mathrm{pH}$ can be lowered (ca. 3.0) to hydrolyze the enol ether sidechains and then 'incubated' for a given time to allow the aminooxy-aldehyde oximations to occur (step A). The fortified particles then can be (a) used directly after adjusting the $\mathrm{pH}$ or after purifying (e.g., extrusion), (b) labeled by direct addition of targeting elements (step B), or (c) passivated by addition of small ketone or aldehyde compounds (e.g., PEG-CHO). As a result of intermolecular oximation reactions, the lipoplex surface undergoes lipid-lipid polymerization to generate a more robust delivery vehicle. Furthermore, any unreacted aminooxy groups can be used to conveniently attach targeting elements by simple mixing with keto- or aldehyde-labeled components (step B). The extent of polymerization will be directly related to the percent of individual lipid molecules that undergo enol ether hydrolysis. The outer layer of the lipoplex formulation (outer leaflet of the bilayer coating) is most susceptible to the hydrolysis conditions; however, oximation may occur within the lipoplex interior (polar domains of inner leaflets) depending on reaction times and acid strength. The condensed polynucleotide within the lipoplex bilayers is largely shielded during the oximation phase. Intramolecular oximation may occur, but due to the large ring size formed in this event (e.g., a 21-membered ring, in the case of lipid 3.2), the likelihood that this side reaction will pose a problem is low. This process is illustrated in Figure 9. 


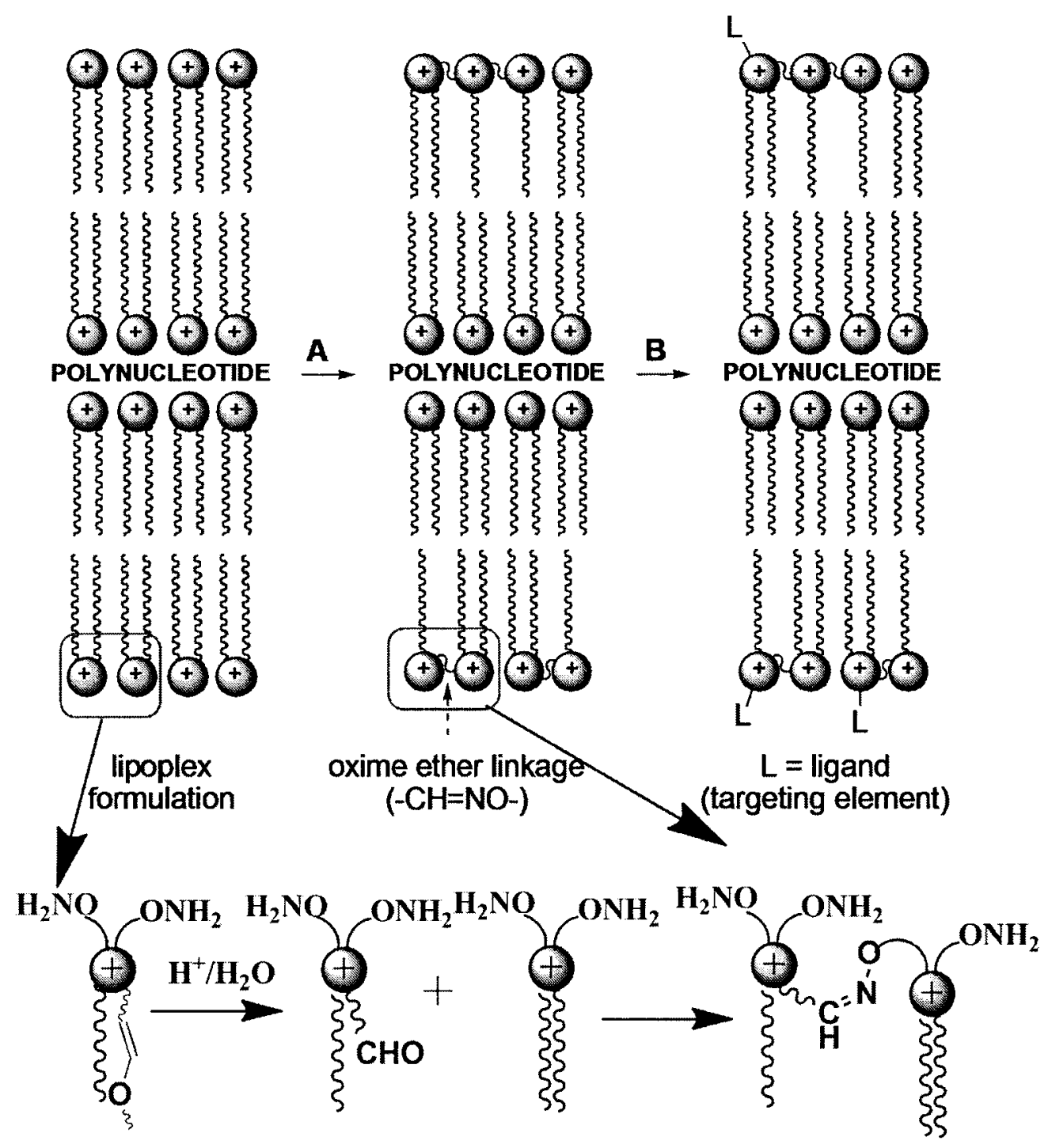

Figure 9. pH-triggered intermolecular polymerization.

For strategy $B$, each lipid was functionalized with two aminooxy groups for reaction with an external crosslink reagent that contains aldehyde functionality. This strategy not only avoids the use of acid as in strategy $A$, but also simplifies the prototype lipid structure and synthesis. We envisioned actuating the process of 'click' stabilization in the following manner: After cationic aminooxy lipid formulation or lipoplex formulation in water to generate liposomes, an external reagent containing bis-/multi-aldehyde 
functional groups can be added and incubated for a given time to allow aminooxy-aldehyde oximations. As a result of intermolecular oximation reactions, the liposome surface will undergo lipid-reagent polymerization to generate a stabilized liposome (Figure 8). Due to different equivalents of aldehyde added, the 'click' stabilized liposome surface may have available unreacted aminooxy or aldehyde functionality. Any unreacted aminooxy/aldehyde groups then can be used to conveniently attach targeting elements by simple mixing with keto-, aldehyde-or aminooxy-labeled components. The extent of polymerization will be directly related to the equivalents of aldehyde reagent/polymer added. 


\subsection{Thesis Organization}

The goal of my research is to discover new methods to stabilize liposomes or lipoplexes and to demonstrate their application in gene or drug delivery.

Chapter 2 describes the synthesis and characterization of novel cationic aminooxy compounds. These aminooxy compounds were designed to function as the headgroup domains of prototype lipids as well as for other potential applications.

Chapter 3 describes the liposome stabilization strategy $\mathrm{A}$ : $\mathrm{pH}$-triggered lipid polymerization. The prototype cationic aminooxy lipids were synthesized and characterizated and the hypothesis of strategy A was tested.

Chapter 4 describes the liposome stabilization strategy B: external reagent 'click' stabilization. The prototype cationic aminooxy lipids were synthesized and the hypothesis in strategy B was tested and confirmed. The 'click' stabilized liposomes were applied as a drug/enzyme carrier.

Chapter 5 deals with 'click' stabilized liposomes for gene transfection. The 'click' stabilized liposomes were applied in in vitro gene transfections. A liver-targeted ligand based on lactose was synthesized for future in vivo gene transfection applications.

Chapter 6 details all experimental procedures and compounds characterization. 


\section{CHAPTER 2. \\ CATIONIC AMINOOXY REAGENTS}

\subsection{Introduction}

As discussed in Chapter 1, the instability of liposomes is a fundamental obstacle that impedes liposome applications in gene/drug delivery. One promising approach to address this problem is liposome stabilization via a non-radical mediated lipid polymerization. In our proposed liposome stabilization strategies (Chapter 1.4), oximation was selected as an ideal polymerization reaction because it is a mild, selective and convenient procedure. To test the hypothesis of our proposed strategies, prototype cationic aminooxy lipids needed to be synthesized. The first step towards this type of lipid synthesis was to develop a synthesis route towards the hydrophilic headgroup, which contains the cationic aminooxy functionality. We designed the headgroup of the prototype lipid, as illustrated in Figure 10, to contain three functionalities: (1) an aminooxy moiety for subsequent polymerization; (2) a tetraalkylammonium ion to import a positive charge for DNA/RNA binding; and (3) a hydroxyethyl group for attachment to the hydrophobic domain of the lipid.

Besides being applied as headgroups of prototype aminooxy lipids, these designed cationic aminooxy compounds can also be used as a new type of nucleophilic cationization reagent. ${ }^{61}$ Cationization reagents, usually electrophilic 
quaternary ammonium reagents, have been widely applied to react with a variety of materials to equip them with positive charges. ${ }^{62-65}$ This derivatization process, also known as cationization, can impart described properties. For example, the cationization of proteins is performed to enhance their intracellular delivery via adsorptive-mediated endocytosis. ${ }^{66}$ The cationization of cellulose fibers (e.g., cotton) can improve the uptake of dyes in subsequent coloring operations. ${ }^{67}$ Some electrophilic cationization reagents $(2.3-2.7)$ are shown in Figure $11 .^{68-72}$

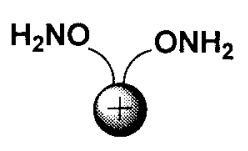

Headgroup

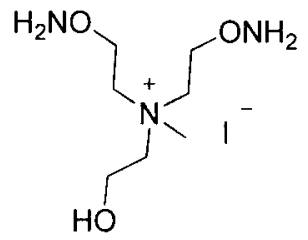

2.1

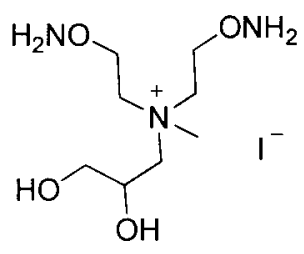

2.2

Figure 10. Cationic aminooxy lipid headgroups.

Given the ease of oximation and the robust nature of the oxime ether linkage, cationic aminooxy reagents are ideal nucleophilic counterpart to the current electrophilic reagents. Our interest in gene transfer materials led us to prepare a series of cationic aminooxy compounds (2.1, 2.2 in Figure 10 and 2.8, 2.9, 2.10 in Figure 11). The synthesis of 2.1 and 2.2 is described in this chapter.<smiles>C[N+](C)(CC1CO1)CC1CO1</smiles><smiles>C[N+](C)(C)CCCSS(C)(=O)=O</smiles>
2.3 2.4 2.5 2.6<smiles>C[N+](C)(C)CCON</smiles>

2.8<smiles>C[N+](C)(CCON)CCON</smiles>

2.9 2.7

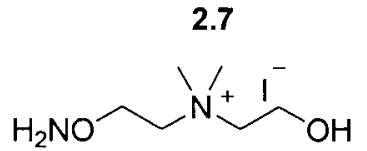

2.10

Figure 11. Cationization reagents and cationic aminooxy compounds. 


\subsection{Cationic Aminooxy Reagent Synthesis}

There are two common methods to introduce the aminooxy functionality (Scheme 1). One is introduction of an N-hydroxy imide into the molecule followed by cleavage with hydrazine to give the aminooxy. ${ }^{73}$ The other is to displace a halide using a Boc-protected hydroxylamine (tert-butyl N-hydroxycarbamate) followed by Boc-deprotection using acid to give the aminooxy. ${ }^{74}$ Previous work in our lab described the synthesis of a series of aminooxy reagents. ${ }^{75}$ In this work, a double halide displacement by tert-butyl N-hydroxycarbamate was troublesome; however, the $\mathrm{N}$-hydroxy imide route was successful. Based on this experience, I opted to use the $\mathrm{N}$-hydroxy imide route to synthesize the target cationic aminooxy compounds.

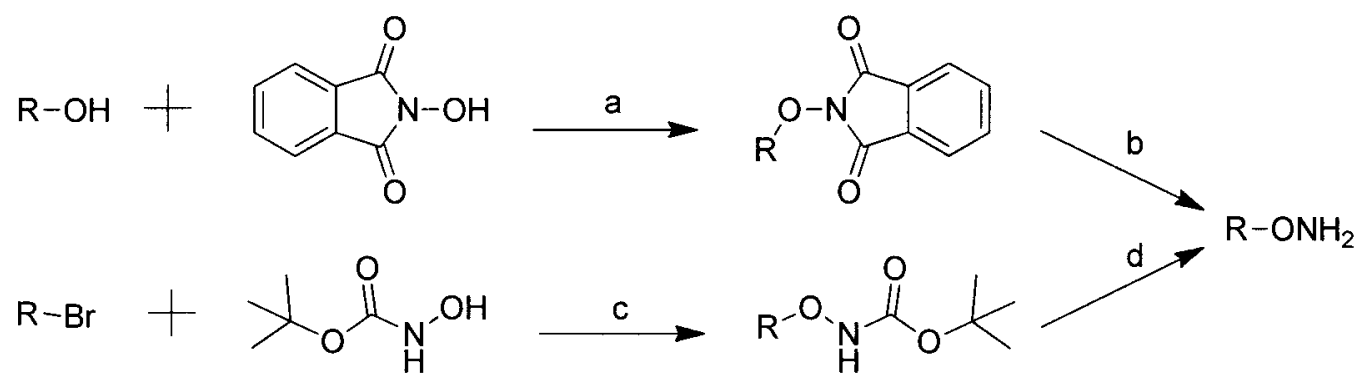

Scheme 1. Strategies to introduce aminooxy functionality.

Conditions: a) N-hydroxyphthalimide, $\mathrm{PPh}_{3}$, DIAD, THF, $0^{\circ} \mathrm{C}$ to rt.; b) $\mathrm{N}_{2} \mathrm{H}_{4} \cdot \mathrm{H}_{2} \mathrm{O}$, ethanol, rt.; c) HONHBoc, DBN, TBAI (cat.), $\mathrm{CH}_{3} \mathrm{CN}$, rt.; d) $\mathrm{TFA}, \mathrm{CH}_{2} \mathrm{Cl}_{2}, 0^{\circ} \mathrm{C}$ to it.

\subsubsection{Synthesis of Cationic Aminooxy Reagent 2.1}

Our retrosynthetic route to the cationic bisaminooxy compound $\mathbf{2 . 1}$ is shown in

Scheme 2. Commercially available reagent triethanolamine is used as starting 
material; no extra $\mathrm{C}-\mathrm{C}$ bonds need to be installed. The synthesis route relies only on functional group interconversions.

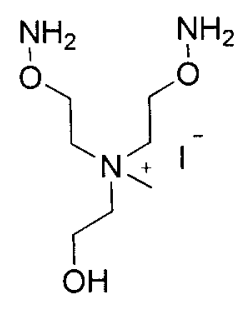

2.1

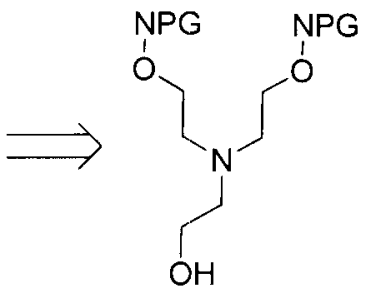

Scheme 2. Retrosynthetic route to aminooxy 2.1.

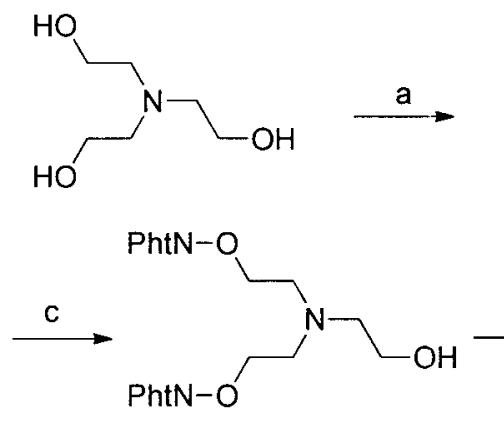

2.13

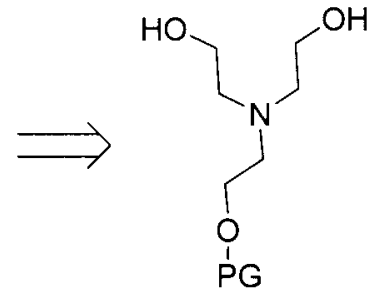

$$
\text { (PG = Protection Group) }
$$
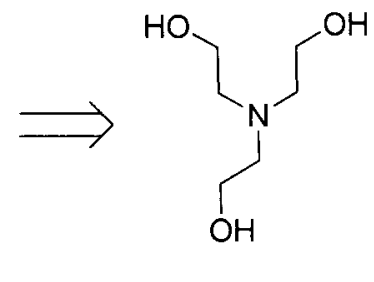

Triethanolamine

\section{Scheme 3. Synthesis of cationic aminooxy compound 2.1.}

Conditions: $\mathrm{Pht}=$ phthaloyl a) $\mathrm{TBSCl}, \mathrm{Et}_{3} \mathrm{~N}, \mathrm{CH}_{2} \mathrm{Cl}_{2}, 90 \%$; b) $\mathrm{N}$-hydroxyphthalimide, $\mathrm{PPh}_{3}, \mathrm{DIAD}$, THF, $0^{\circ} \mathrm{C}$ to rt., $12 \mathrm{~h}, 82 \%$; c) $48 \%$ aq. HF, THF, $0^{\circ} \mathrm{C}$ to rt., $12 \mathrm{~h}, 86 \%$; d) $\mathrm{CH}_{3} \mathrm{l}$, sealed tube, $60^{\circ} \mathrm{C}$, $2 \mathrm{~h}, 98 \%$; e) $\mathrm{N}_{2} \mathrm{H}_{4} \cdot \mathrm{H}_{2} \mathrm{O}$, ethanol, rt., $12 \mathrm{~h}, 70 \%$.

The synthesis route used to prepare compound 2.1 is shown in Scheme 3. Monosilylation of triethanolamine was accomplished by reaction of triethanolamine with 0.2 eq. of $\mathrm{TBSCl}$ as the limiting reagent. To favor the production of 
mono-protected product 2.11 (90\% yield based on TBSCI), the TBSCI was diluted $(0.2$ $M$ ) in dichloromethane before very slow addition (dropwise overnight). The resultant mono-protected triethanolamine $\mathbf{2 . 1 1}$ was then transformed to the corresponding bis- $N$-(2-hydroxyethyl)-functionalized aminooxy reagent 2.12 in $82 \%$ yield through Mitsunobu reaction conditions. ${ }^{73}$

The desilylation of compound 2.12 was problematic. Standard TBAF-mediated deprotection of 2.12 resulted in double $\mathrm{N}-\mathrm{O}$ cleavage, giving triethanolamine as the principal product. Other attempts (e.g., AcOH- or TsOH-mediated deprotections) were equally disappointing. We were gratified to find, however, that prolonged reaction with aqueous HF furnished the desired crude product. After recrystallization in ethyl acetate, compound 2.13 was obtained in $86 \%$ yield.

The amine quaternization was best accomplished by heating the amine 2.13 in methyl iodide. After evaporation of the unreacted methyl iodide in the fumehood, compound 2.14 was obtained in $98 \%$ yield. The resultant, crude ammonium iodide was treated directly with hydrazine in ethanol to cleave the phthaloyl groups. After work-up, the aminooxy product $\mathbf{2 . 1}$ was obtained in $70 \%$ yield by reverse phase HPLC purification. In the ${ }^{1} \mathrm{H}$ NMR spectrum $(500 \mathrm{MHz})$ of 2.1 (Figure 12), the broad signal at $6.28 \mathrm{ppm}$ and $5.26 \mathrm{ppm}$ corresponds with aminooxy proton and hydroxyl proton, respectively. The quaternized amine methyl group was observed at $3.16 \mathrm{ppm}$. 


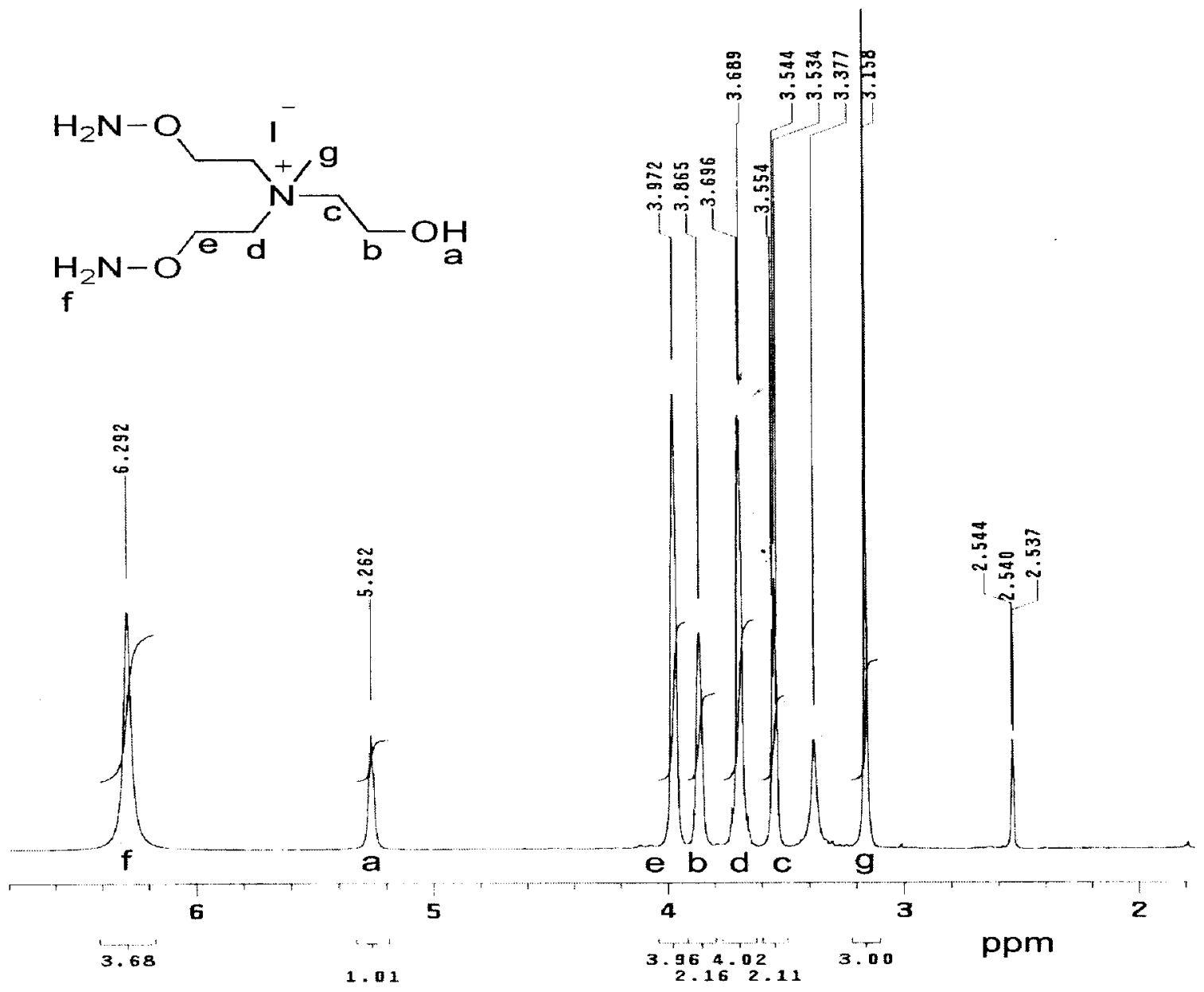

Figure 12. ${ }^{1} \mathrm{H}$ NMR spectrum of aminooxy compound 2.1.

\subsubsection{Synthesis of Cationic Aminooxy Reagent 2.2}

The synthesis of compound $\mathbf{2 . 2}$ requires extra work to generate a $\mathrm{C}-\mathrm{N}$ bond due to the lack of a template (which was available for compound 2.1.1). (Scheme 4). The glycidol epoxide- ring opening by amine is an ideal reaction for this purpose. The selection of protection group and the purification of the hydrophilic product are two major concerns that need to be addressed. 
<smiles>C=CC=CC(=O)NOCCNCCONC(=O)ONC(=O)ON=O</smiles>

Scheme 4. Retrosynthetic route to compound 2.2.

$$
(P G=\text { Protection Group) }
$$

The first attempt at constructing the target compound went smoothly up to the stage of the epoxide opening reaction (Scheme 5). Briefly, the alcohols of diethanolamine were first protected by TBS in $94 \%$ yield, and then amine functionality was Boc-protected in $79 \%$ yield. After silyl deprotection by TBAF, the diol 2.17 was treated with $N$-hydroxyphthalimide under Mitsunobu conditions to provide 2.18 in $51 \%$ yield. After TFA mediated cleavage of the Boc protection group, ammonium salt 2.19 was obtained in $99 \%$ yield. However, in subsequent chemistry, we observed that ammonium salt 2.19 failed to react with epoxide 1,2-epoxyhexadecane. Under base conditions, the reaction was very sluggish and many byproducts formed, presumably due to the sensitive phthalimide group. Therefore, we explored a different route to synthesize compound $\mathbf{2 . 2}$. 


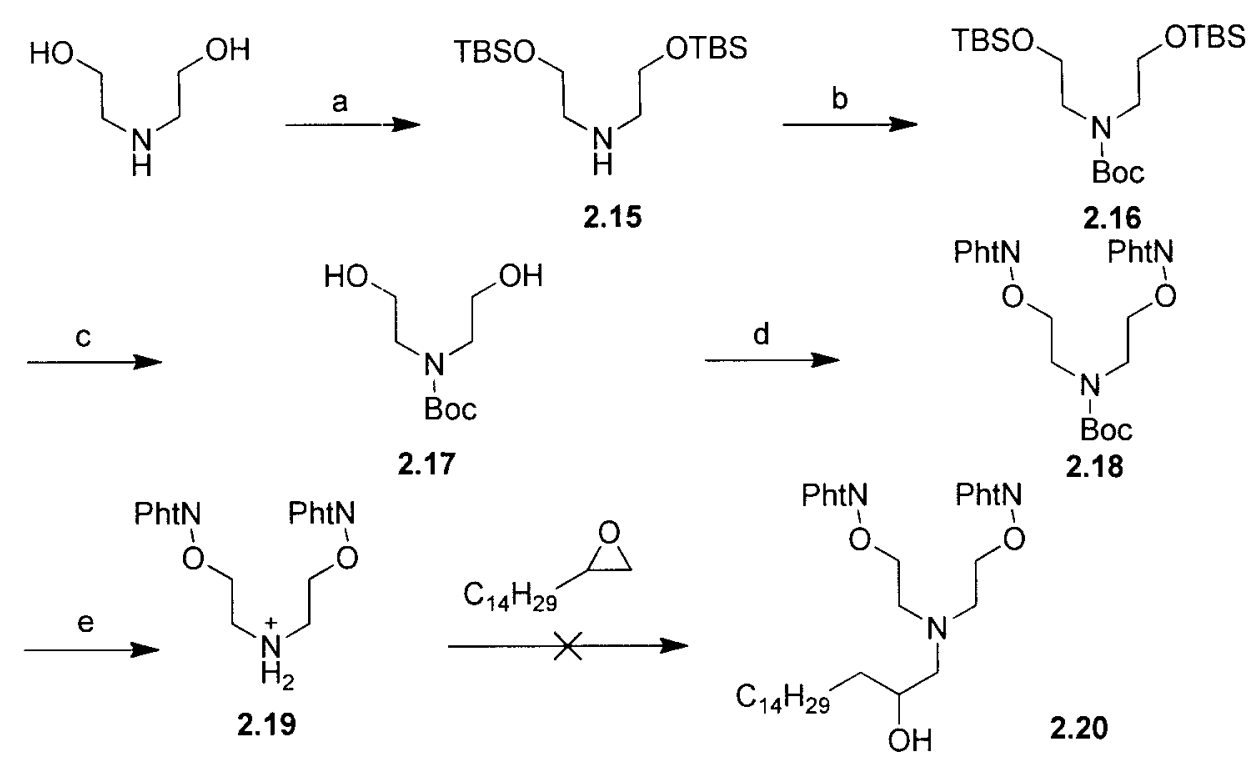

Scheme 5. First attempt to synthesize cationic aminooxy 2.2 .

Conditions: $P h t=$ phthaloyl a) $\mathrm{TBSCl}\left(2.2\right.$ eq.), $\mathrm{Et}_{3} \mathrm{~N}$ (2.4 eq.), $\mathrm{CH}_{2} \mathrm{Cl}_{2}, 12 \mathrm{~h}, 94 \% ;$ b) $(\mathrm{Boc})_{2} \mathrm{O}$, $\mathrm{Na}_{2} \mathrm{CO}_{3}, \mathrm{CH}_{2} \mathrm{Cl}_{2}$, rt., $13 \mathrm{~h}, 79 \%$; c) TBAF, THF, rt., $12 \mathrm{~h}, 100 \%$; d) $\mathrm{N}$-hydroxyphthalimide, $\mathrm{PPh}_{3}$, DIAD, THF, $0^{\circ} \mathrm{C}$ to rt., $12 \mathrm{~h}, 51 \%$; e) TFA, THF, rt., $12 \mathrm{~h}, 99 \%$.

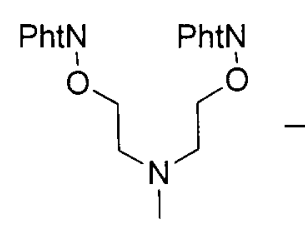

2.21

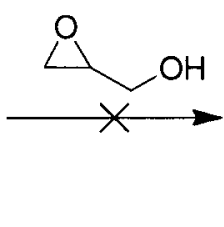

Pht $、$

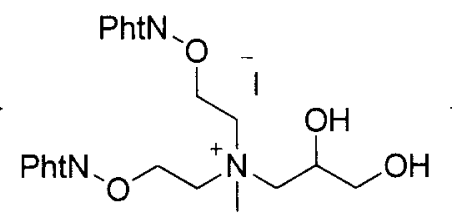

2.22<smiles>CC(C)(CO)[N+](C)(CCON)CCON</smiles>

2.2

Scheme 6. Second attempt to synthesize cationic aminooxy 2.2 .

Our second attempt involved using N,N-bis(2-phthalimidooxyethyl) -methylamine reacted with glycidol (Scheme 6). However, this reaction also failed, possibly due to steric hindrance issues. The phthalimide group is inconvenient to handle when the target is a hydrophilic compound. The phthalimide protecting group is readily 
decomposed on silica gel when the eluent contains methanol. Furthermore, the phthalimide protecting group is unstable in the presence of a secondary or tertiary amine (e.g. $E t_{3} N$ ) which is often used during silica chromatography of polar amines.
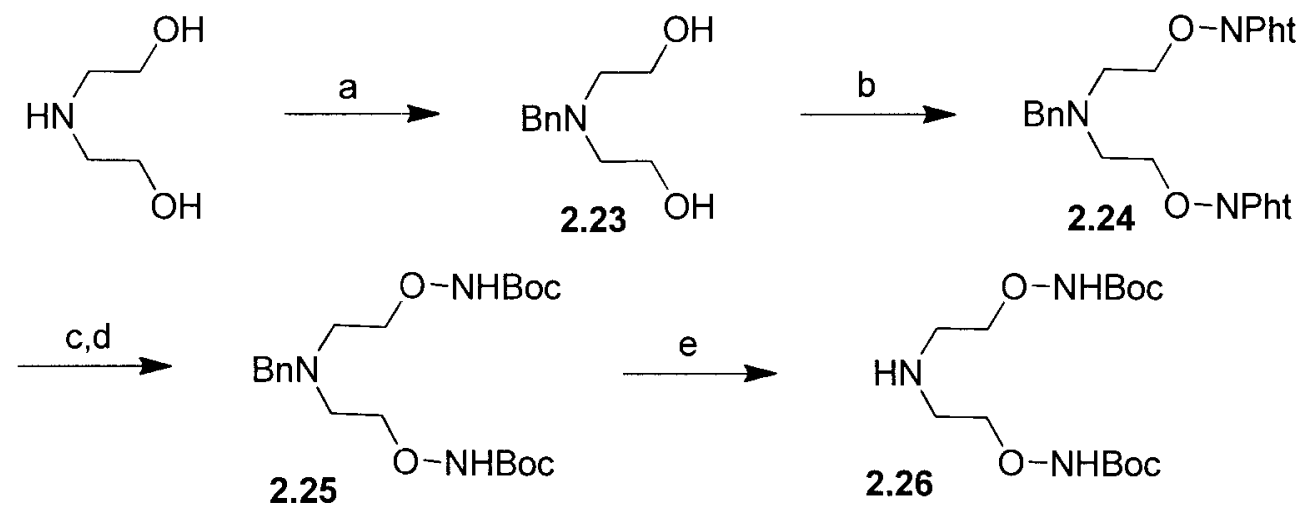

Scheme 7. Synthesis of Boc-protected bis-aminooxy amine 2.26.

Conditions: Pht = phthaloyl, $\mathrm{Bn}=$ Benzyl. a) Benzyl chloride, $\mathrm{CH}_{3} \mathrm{CN}, \mathrm{Na}_{2} \mathrm{CO}_{3}$, reflux, $17 \mathrm{~h}, 92 \% ;$ b) $\mathrm{N}$-hydroxyphthalimide, $\mathrm{PPh}_{3}, \mathrm{DIAD}, \mathrm{THF}, \mathrm{O}^{\circ} \mathrm{C}$ to $\mathrm{rt}, 12 \mathrm{~h}, 79 \%$; c) $\mathrm{N}_{2} \mathrm{H}_{4} \cdot \mathrm{H}_{2} \mathrm{O}$, ethanol, $\mathrm{CH}_{2} \mathrm{Cl}_{2} ; 15$ $\min$; d) (Boc) $)_{2} \mathrm{O}, \mathrm{NaHCO}_{3}, \mathrm{CH}_{2} \mathrm{Cl}_{2}$, rt. $17 \mathrm{~h}, 99 \%$ for two steps; e) $\mathrm{H}_{2}, \mathrm{Pd} / \mathrm{C}$, rt., $22 \mathrm{~h}, 60 \%$.

Due to the difficulty in handling bis-phthalimide compounds, we switched to using a bis-Boc protecting strategy (Scheme 7). The Boc-protected bisaminooxy amine compound 2.26 was synthesized according to the method described previously. ${ }^{75}$ Briefly, diethanolamine was first protected with benzyl chloride and then followed by Mitsunobu reaction using $N$-hydroxyphthalimide to incorporate the protected aminooxy functionalities. The protecting groups were exchanged through hydrazine cleavage followed by reaction with excess Boc-anhydride. Finally, the benzyl protecting group of compound $\mathbf{2 . 2 5}$ was cleaved by hydrogenolysis to generate the bis-Boc protected $\mathbf{2 . 2 6}$ in $43 \%$ overall yield. 
With the Boc-protected bisaminooxy amine 2.26 in hand, the $\mathrm{C}-\mathrm{N}$ bond of the target compound should be readily formed through glycidol ring opening reaction (Scheme 8). Unfortunately, reaction of 2.26 with glycidol in the presence of base generated 2.27 in low yield $(40 \%)$ with hard-to-separate byproducts (i.e. compound 2.28) which were observed by TLC using an $I_{2}$ stain. Presumably, intramolecular proton transfer from the initial expoxide cleavage adduct generates a primary oxyanion that competes with the starting amine for the remaining glycidol. ${ }^{76}$ Moreover, the purification of methylated product of 2.27 , a quaternary ammonium, was considerably problematic due to its polar nature.

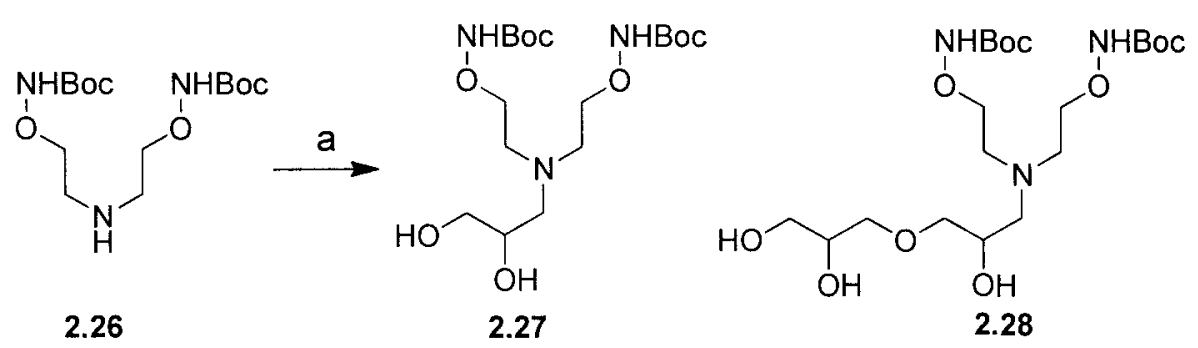

Scheme 8. Synthesis of diol 2.27.

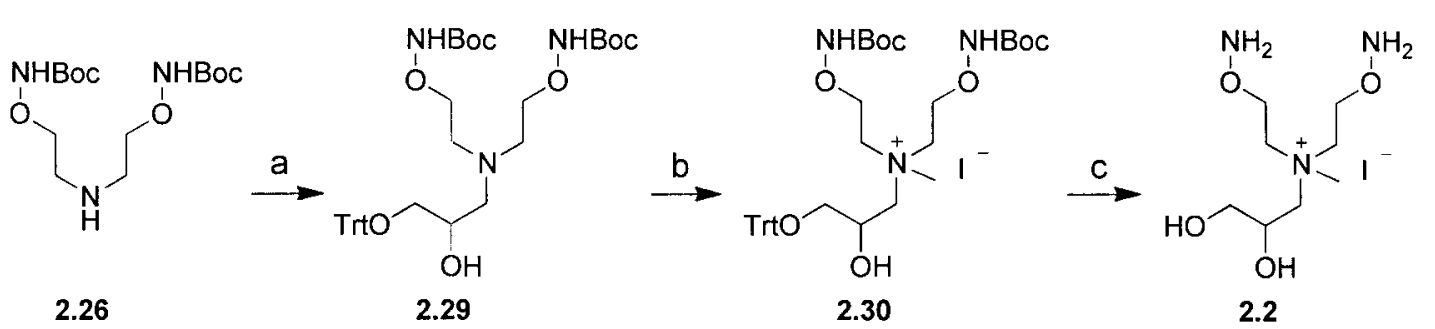

Scheme 9. Synthesis of cationic aminooxy 2.2.

Conditions: a) 2-(trityloxy)methyloxirane, $\mathrm{Na}_{2} \mathrm{CO}_{3}$, ethanol, $60{ }^{\circ} \mathrm{C}, 22 \mathrm{~h}, 64 \%$; b) $\mathrm{CH}_{3} \mathrm{l}_{,} \mathrm{CH}_{2} \mathrm{Cl}_{2}$, sealed tube, $60^{\circ} \mathrm{C}, 24 \mathrm{~h}, 80 \%$; c) TFA, $\mathrm{CH}_{2} \mathrm{Cl}_{2}$, triethylsilane, $0{ }^{\circ} \mathrm{C}$ to rt., $12 \mathrm{~h}, 38 \%$. 
To eliminate the side reactivity of the primary oxyanion, as well as to increase the hydrophobicity of the product, we protected glycidol using the bulky triphenylmethyl group. Therefore, 2-(trityloxy)methyloxirane was used as the reactant instead of glycidol and epoxide ring opening product 2.29 was obtained in $64 \%$ yield after $\mathrm{SiO}_{2}$ chromatographic purification. Subsequent amine quaternization was performed by heating 2.29 with methyl iodide in a sealed tube. The resultant crude material was chromatographed to give $\mathbf{2 . 3 0}$ in $\mathbf{8 0} \%$ yield. Finally, the Boc and trityl protecting groups were removed by treatment with TFA, and the target product 2.2 was obtained in $36 \%$ yield (Scheme 9). The low yield for the last step can be mainly attributed to two reverse phase chromatographic purification steps, and this still leaves room for overall synthesis improvement.

In the ${ }^{1} \mathrm{H}$ NMR spectrumof 2.2 in $\mathrm{CD}_{3} \mathrm{OD}$ (Figure 13), the broad signal at $\delta 5.08$ $\mathrm{ppm}$ corresponds to the aminooxy protons and the hydroxyl proton. Quaternized amine methyl group $\mathrm{NCH}_{3}$ was observed at $3.33 \mathrm{ppm}$. With the additional information from COSY spectrum, the signal at $\delta 4.43 \mathrm{ppm}$ to $\delta 4.52 \mathrm{ppm}$ can be assigned to $\mathrm{CH}_{2}-\mathrm{ONH}_{2}$ while the signals at $\delta 3.92 \mathrm{ppm}$ to $\delta 4.02 \mathrm{ppm}$ can be assigned to $\mathrm{NCH}_{2} \mathrm{CH}_{2} \mathrm{ONH}_{2}$. The signal of $\delta 4.23 \mathrm{ppm}$ corresponds to $1 \mathrm{H}$ from $\mathrm{NCH}_{2} \mathrm{CHOH}$. The signal from $\delta 3.45 \mathrm{ppm}$ to $\delta 3.75 \mathrm{ppm}$ corresponds to the proton from $\mathrm{NCH}_{2} \mathrm{CHOHCH}_{2} \mathrm{OH}$. The high resolution mass (HRMS) found $\mathrm{M}^{+}$at 224.1605 $\left(\mathrm{C}_{8} \mathrm{H}_{22} \mathrm{~N}_{3} \mathrm{O}_{4}{ }^{+}\right.$, calculated as 224.1605). 

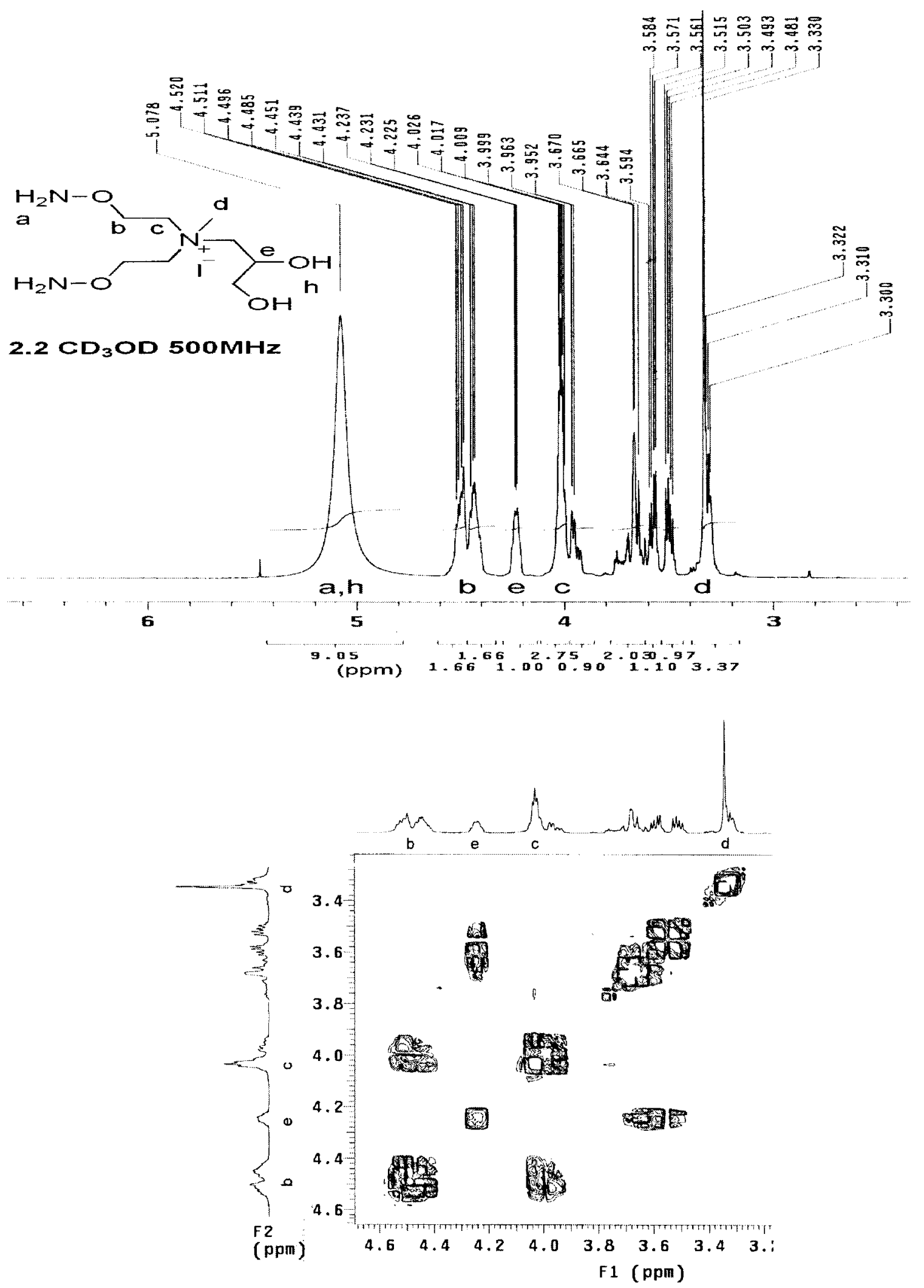

Figure 13. ${ }^{1} \mathrm{H}$ NMR and COSY spectra of aminooxy compound 2.2. 


\subsection{Future Applications}

Besides being applied as lipid headgroups for our proposed click polymerization, the cationic aminooxy reagents 2.1 and 2.2 may have other applications. One such application is for synthesis of cationic lipids for gene transfection using click chemistry ligation to attach hydrophobic (alkyl-chain) aldehydes (Scheme 10). Our lab already demonstrated that bis(oxime ether) lipid 2.31 , synthesized from compound 2.9 , is a good gene delivery lipid. ${ }^{61,77}$ Considering the benefit of hydroxyethylated polar domains in gene delivery, ${ }^{54,78}$ we believed that lipids 2.32 and 2.33 , assembled from the headgroup 2.1 and 2.2 via click chemistry, could be promising gene delivery lipids as well.

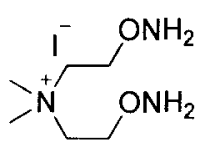

2.9<smiles>C[N+](CCO)(CCON)CCON</smiles>

2.1<smiles>[3H][N+](CCON)(CCON)CC(O)CO</smiles>

2.2

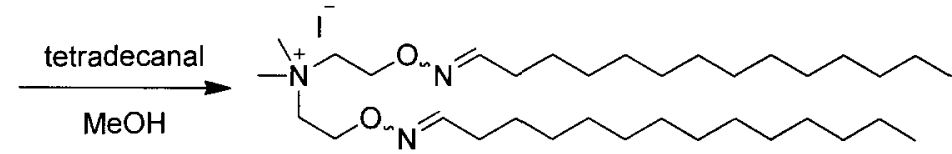

2.31

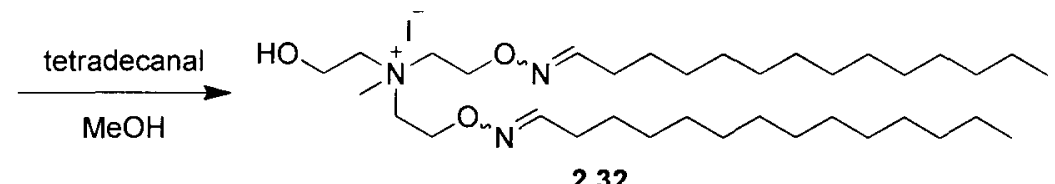

2.32

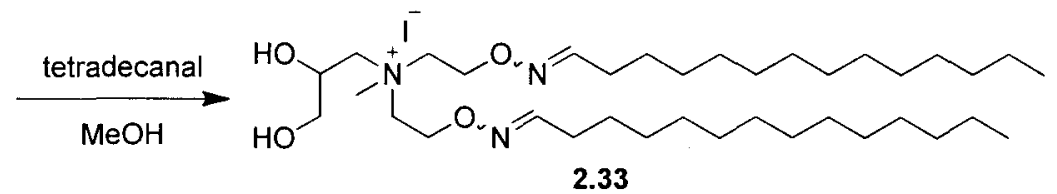

Scheme 10. Oxime ether lipids.

Another potential application of compound 2.2 is as a part of magnetic drug delivery system (Figure 14). Our lab has discovered that some cationic aminooxy regents can attach to magnetic iron oxide $\left(\mathrm{Fe}_{3} \mathrm{O}_{4}\right)$ nanoparticles and then dissociate from the particles when exposure to an alternating magnetic field due to induction 
heating. For example, one aminooxy moiety of 2.2 can be conjugated with an aldehyde-functionalized anti-tumor drug and the other one can be conjugated with aldehyde-functionalized tumor targeting agent. The diol portion as well as the cationic ammonium ion provides non-covalent binding to the iron oxide nanoparticles. We envisioned that the formulated drug-nanoparticle complex, once injected into the body, may concentrated around the tumor site due to targeting ligand as well as magnetic field. Once alternating magnetic fields applied near the tumor, the induced heating provides both thermotherapy (from heat) and chemotherapy (from drug) effect.

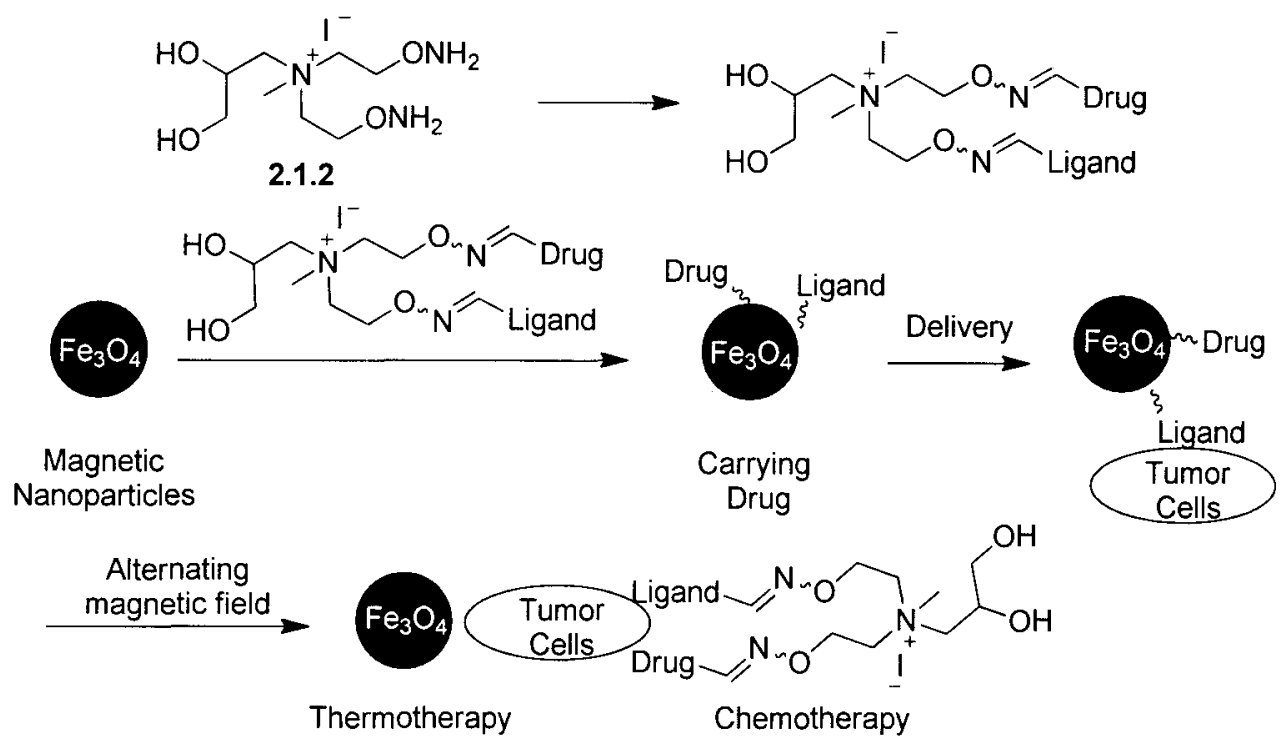

Figure 14. Proposed multifunctional magnetic nanoparticle for drug delivery.

\subsection{Conclusions}

In summary, this chapter presented the first synthesis of two cationic hydroxyethyl-functionalized bis-aminooxy reagents, 2.1 and 2.2 . The general synthesis route can be adapted to synthesis of other similar compounds. The two cationic aminooxy reagents constitute the headgroups of our target 
click-polymerizable lipids. Due to the ease of oximation and the robust nature of the oxime ether linkage, the cationic aminooxy reagents may have other applications including as headgroups of gene delivery lipids as well as coatings of magnetic nanoparticles for drug delivery. 


\section{CHAPTER 3.}

\section{CATIONIC AMINOOXY LIPIDS FOR pH-TRIGGERED LIPOSOME POLYMERIZATION --FIRST GENERATION CONCEPT}

\subsection{Introduction}

In the early 1980s, liposome polymerization was achieved by the Regen group using lipids that incorporated acrylate groups. ${ }^{79}$ Since then, an increasing number of lipids have been fitted with a great variety of polymerizable groups, such as styryl, vinyl, diacetylenyl, acryloyl, methacryloyl, butadienyl, isocyano, lipoyl and sorbyl (Figure 15). ${ }^{53}$ Most of these groups undergo polymerization by radical chain propagation except lipoyl, which uses a disulfide forming approach. ${ }^{80}$ Besides small molecule polymerizable groups, macromolecules, such as oligonucleotides, can be used as polymerizable groups once immobilized on liposome surface, ${ }^{56}$ While there is no question that such polymerizable molecules have been proven to be effective at improving liposome stability, next-generation polymerizable lipids need to be developed to fulfill various applications of liposomes.

Our lab's interest in liposomes for gene/drug delivery requires polymerizable lipids that have certain characteristics. First, the polymerizable lipids must be biocompatible 
and inert to various gene/drug functionalities. Next, the polymerization chemistry must occur in aqueous solution. Finally, the bonds generated from polymerization must be robust. For these reasons, we considered potential polymerizable motifs from the arsenal of "click chemistry" which provides many quick and reliable biocompatible reactions.

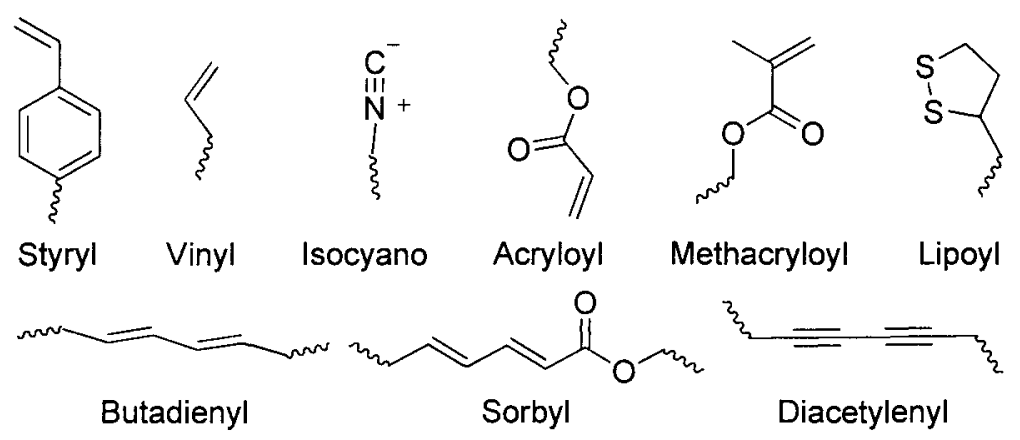

Figure 15. Examples of polymerizable groups for liposome polymerization.

Click chemistry, the philosophy promoted by K. B. Sharpless in 2001, describes a class of chemical reactions that are "modular, wide in scope, give very high yields, generate only inoffensive byproducts and be stereospecific" ${ }^{59}$ Although click chemistry reactions such as azide/alkyne and carbonyl/aminooxy have been widely used, only a few examples applied to polymerization have been reported. ${ }^{60,81-83} \mathrm{We}$ set out to achieve liposome polymerization via oxime ether formation instead of the more widely used azide/alkyne chemistry to avoid using $\mathrm{Cu}(\mathrm{I})$. In an early application, the Nantz group reported a bis-keto lipid, DMBDKE, that was polymerized by reaction with tetra-aminooxy linker TACL as well as bisaminooxy lipid BAL (Scheme 11). ${ }^{75}$ Although the prototype DMBDKE system successfully demonstrated that liposomes can be polymerized via an oximation reaction, there remained much room for improvement. For example, DMBDKE was hard to handle due to its low solubility in 
aqueous solution and somewhat sluggish reactivity. Additionally, the stabilized DMBDKE liposomes were vulnerable to aggregation by blood proteins after dilution. ${ }^{75}$

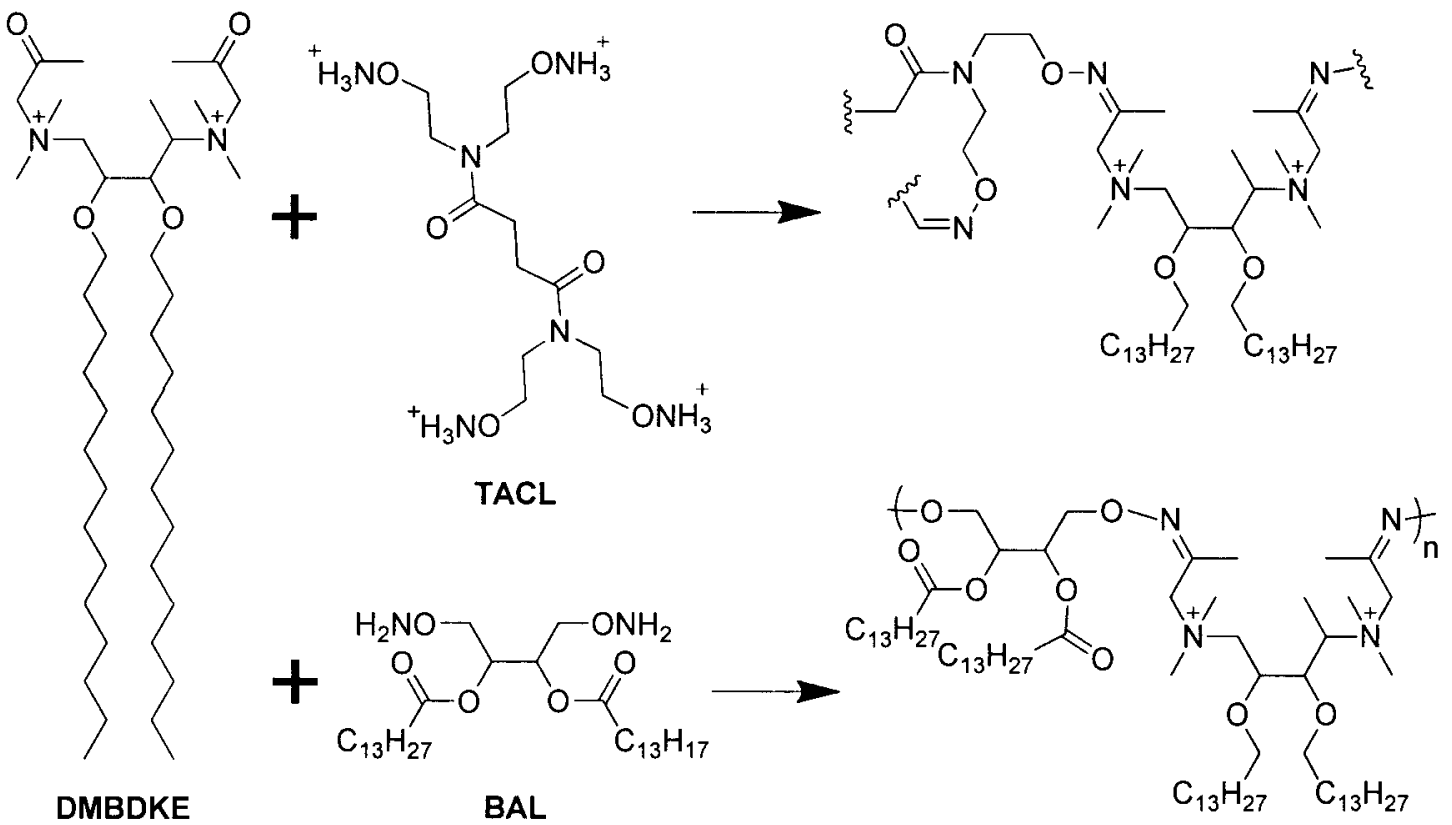

Scheme 11. Initial examples of lipid polymerization via oxime ether formation.

To improve our polymerizable liposome system for gene/drug delivery, my thesis work addressed a novel strategy for liposome stabilization: $\mathrm{pH}$-triggered liposome polymerization via oximation reaction (Figure 16). We postulated that aldehyde functionality can be masked as an enol ether group incorporated within the lipid hydrophobic domain. Under mild acid condition (ca. $\mathrm{pH}=3.0$ ), the enol ether sidechain would be hydrolyzed and release the aldehyde group. ${ }^{84,85}$ The free aldehyde group could then act as polymerizable group by reaction with an adjacent aminooxy group. 


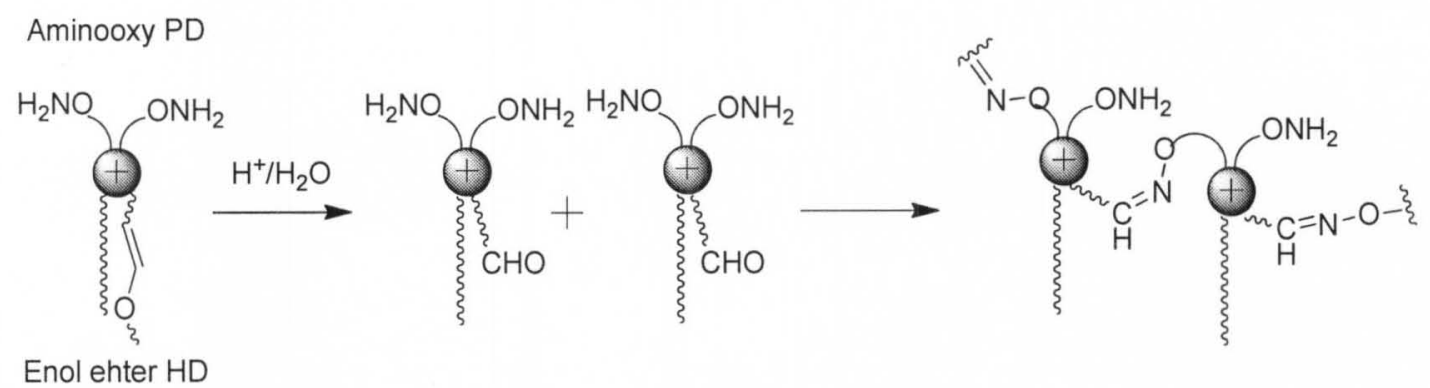

Figure 16. $\mathrm{pH}$-Triggered liposome polymerization via oximation reaction.

$\mathrm{PD}=$ Polar Domain; $\mathrm{HD}=$ hydrophobic Domain.

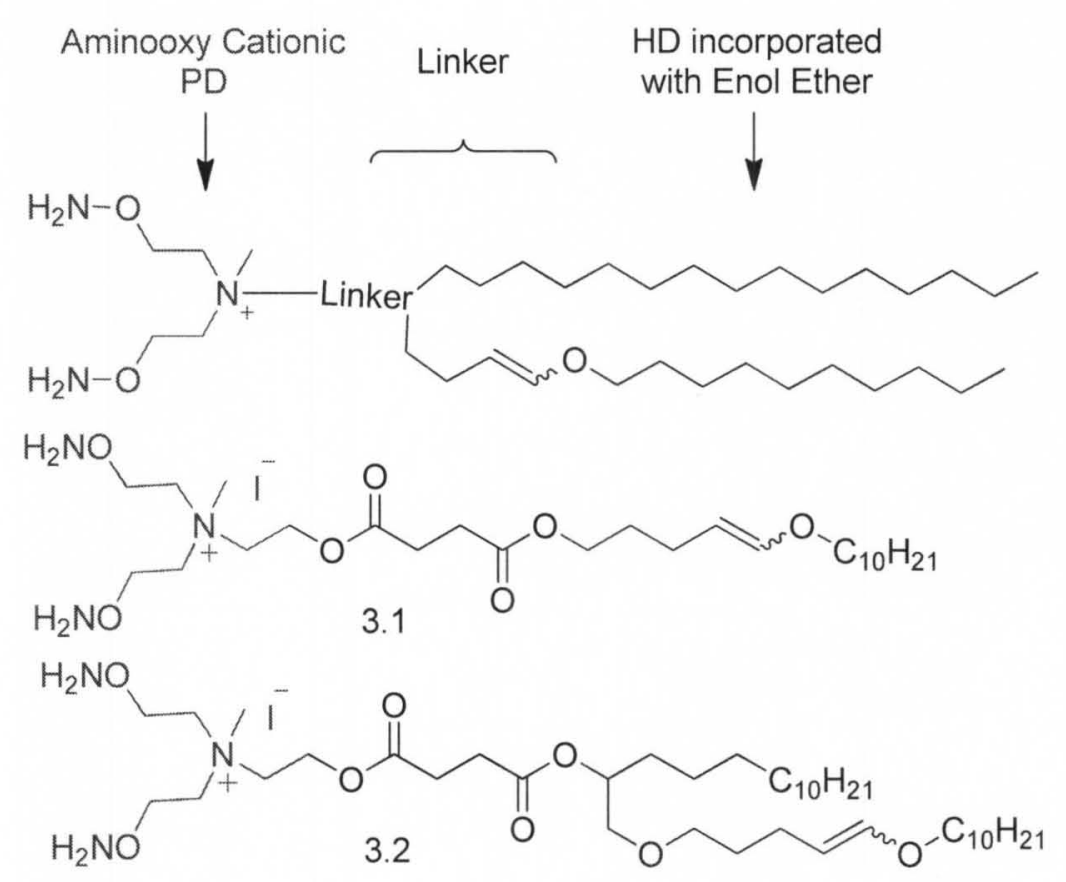

Figure 17. Structures of prototype lipids for pH-triggered lipid polymerization.

To achieve better water solubility as well as facilitate formation of a lipid bilayer, the prototype lipids were designed as shown in Figure 17. Like other typical cationic lipids (Figure 3), the prototype aminooxy lipid also has three parts: (1) a polar headgroup that contains two aminooxy moieties; (2) a hydrophobic domain that contains one or 
two linear carbon chains where at least one contains an enol ether moiety; and (3) linker used to join the polar (aminooxy) domain to the hydrophobic (enol ether) domain. Compared to the design of DMBDKE, the new prototype lipids have the following advantages: first, the bisaminooxy groups are more hydrophilic than bisketo groups which can enhance lipid aqueous solubility; second, the tetraalkylammonium headgroup is smaller than the bianteniary structure in DMBDKE which may facilitate lipid bilayer formation; third, a $\mathrm{pH}$-triggered release of aldehydes can provide control over the polymerization process; and last but not least, the released aldehyde group is more reactive than a ketone group. Based on these design considerations, compounds 3.1 and 3.2 were synthesized as prototype lipids to examine $\mathrm{pH}$-triggered lipid polymerization. Since various bis-aminooxy cationic compounds had already been synthesized (Chapter 2), this chapter will focus on the synthesis of the enol ether component and the linker.

\subsection{Synthesis of Enol Ether Tail Group}

The chemical principles behind $\mathrm{pH}$-triggered hydrolysis of a variety of functional groups have been reviewed by Cordes and Bull four decades ago ${ }^{84}$ Among the acid-cleavable functionalities, enol ethers are one of most studied acid labile functionalities in lipid chemistry. Thompson and associates reported several lipids (Figure 18) with acid-sensitive enol ether moieties. ${ }^{86-90}$ These mono- and bi-plasmenyl lipids have been widely used as acid labile drug/gene carriers that release encapsulated therapeutic agents once exposure to mildly acidic conditions (e.g. 5-6). ${ }^{86-90}$ 


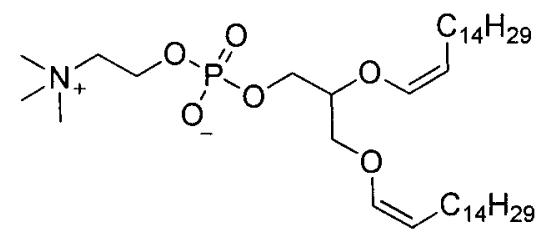

3.3<smiles>CCCCCCCCCCCCCCCCCCCCCCCCCCOP(=O)([O-])OCC[N+](C)(C)C</smiles>

3.4<smiles>COCCOCCOC(=O)C(=[Te])OCC/C=C\OCO</smiles>

3.5

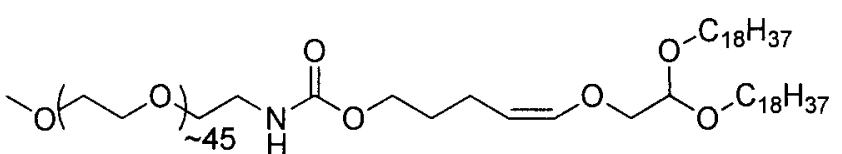

3.6

Figure 18. Lipids with enol ether functionality.

Incorporating enol ether functionality into lipids is challenging work because the enol ether bond is sensitive toward oxidants and acidic reagents. This places great limitations on the types of reagents and protective groups that can be employed in the synthetic route. The Thompson group published many methods for synthesis of plasmalogen type lipids, a class of naturally occurring phospholipids with an enol ether in the hydrophobic domain. ${ }^{88,91-93}$ For example, lipid 3.4 was synthesized via palladium(0)-catalyzed reduction of vinyl phosphates (Equation a, Scheme 12) or via Barbier-type reactions of vinyl acetal and alkyl halide in the lithium 4,4-di-tert-butylbiphenyl (LiDBB) solution. (Equation b, Scheme 12) ${ }^{88,91}$ Lipid 3.6 was synthesized via alkylation of TBS-protected 2-iodoethanol on allyl anion, but undesired a-coupling byproduct is a big problem. (Equation c, Scheme 12) ${ }^{89,92}$ The Buchwald group also reported a synthesis of vinyl ethers by using copper-catalyzed C-O coupling of alcohols with vinyl iodides.$^{94}$ However, this method cannot be used to prepare (Z)-vinyl ethers because the (Z)-vinyl iodides decomposed under the reported reaction conditions. (Equation d, Scheme 12) 

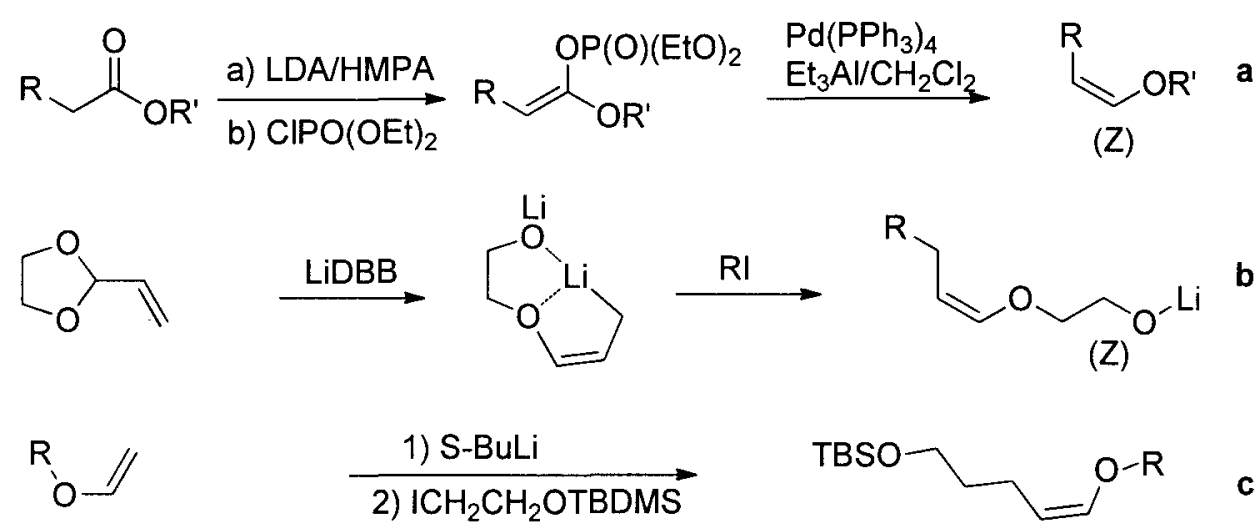

Cul,

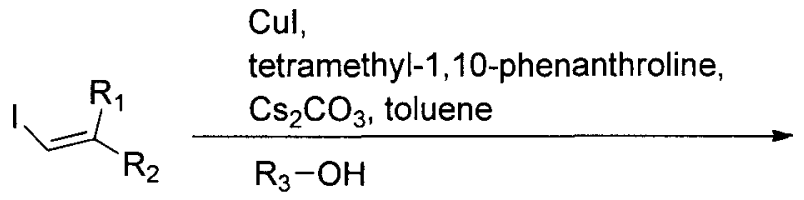<smiles>[R3]OC=C([R])[R]</smiles>

Scheme 12. Methods to incorporate an enol ether into a lipid sidechain.

In our prototype lipid design, the aldehyde group, not the alcohol group, remains attached to the lipid backbone after acid catalyzed hydrolysis (Scheme 13). Moreover, a secondary alcohol was chosen as linker functionality based on synthesis convenience. Those structural differences between the designed prototype lipids and plasmalogen type lipids required us to develop new methods for synthesis of the enol ether domain. The new method required incorporation of an enol ether, two hydrophobic chains and a secondary alcohol into one molecule. We developed three different strategies to prepare such enol ether tail compounds.

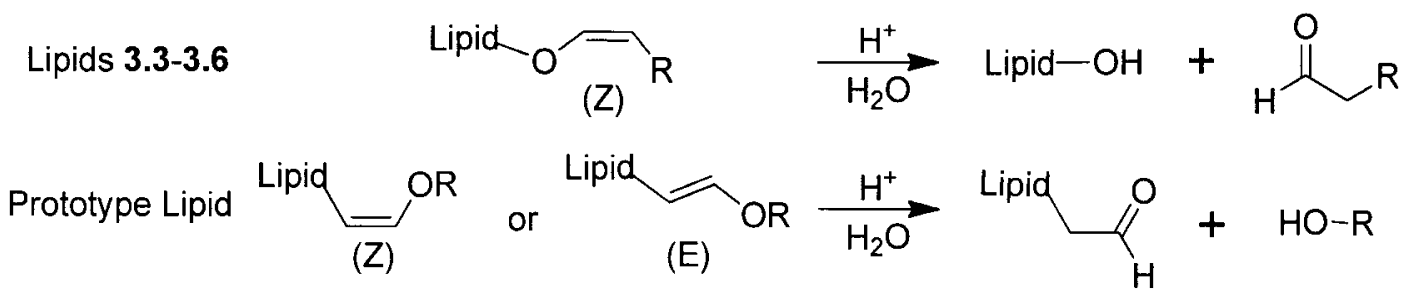

Scheme 13. A shift of enol ether group in the prototype lipid. 


\section{Acetal Elimination}

The first two strategies constructed the enol ether moiety through highly chemoselective deprotection of an acetal by using combinations of 2,6-lutidine--trimethylsilyltriflate (TMSOTf) or 2,6-lutidine--triethylsilyltriflate (TESOTf). ${ }^{95,96}$ The Kita group had applied this strategy to prepare enol ether 3.7 (Scheme 14). Considering the structural similarity of compound 3.7 and target lipid 3.9 , we believed that the enol ether of 3.9 could be synthesized via the same strategy by using acetal 3.8 as starting material.

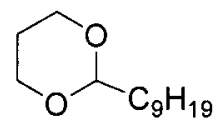

$\overbrace{\mathrm{O}^{-}}^{\mathrm{O}}-\mathrm{C}_{10} \mathrm{H}_{21}$

3.8
1) TESOTf, 2,6-lutidine

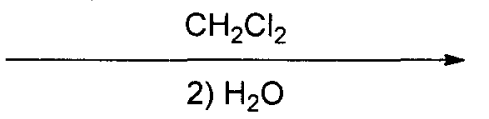

1) TESOTf, 2,6-lutidine<smiles>FS(F)(F)OCCCOC=CCc1ccccc1</smiles>

Kita

3.7

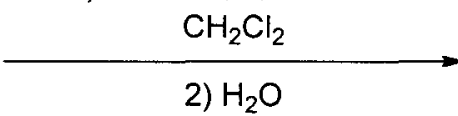

TESO

\section{9}

Scheme 14. Synthesis of enol ethers via TESOTf-induced elimination.

The dual chain enol ether tail group 3.11(Z) was synthesized from decanol in two parts (Scheme 15). The first involved generating an enol ether with a primary alcohol as linker; the second part involved conjugating to another chain. Decanol was first protected by reaction with dihydropyran under acid catalysis to obtain acetal $\mathbf{3 . 8}$ in $98 \%$ yield. $^{97}$ The resultant acetal was then treated with triethylsilyltriflate and 2,6-lutidine to obtain enol ether 3.9 in $91 \%$ yield. The Z:E ratio (5:1) was determined by the vinyl proton integrals. Distinction between the $E$ and $Z$ isomers was made by measuring the ${ }^{3} \mathrm{~J}$ coupling constants for vinyl protons (Figure 19). In the ${ }^{1} \mathrm{H}-\mathrm{NMR}$ 
spectrum, the $\mathrm{RCH}=\mathrm{CHOR}$ ' $(\delta 4.32 \mathrm{ppm})$ and $\mathrm{RCH}=\mathrm{CHOR}$ ' $\left(\delta 5.91 \mathrm{ppm}\right.$ ) have a ${ }^{3} \mathrm{~J}$ coupling constant of $6.5 \mathrm{~Hz}$ which is in the range expected for the $\mathrm{Z}$ isomer while the $\mathrm{RCH}=\mathrm{CHOR}$ ( $\delta 4.74 \mathrm{ppm}$ ) and $\mathrm{RCH}=\mathrm{CHOR}^{\prime}\left(\delta 6.22 \mathrm{ppm}\right.$ ) have a ${ }^{3} \mathrm{~J}$ coupling constant of $12.5 \mathrm{~Hz}$ which is in the range expected for the $E$ isomer.

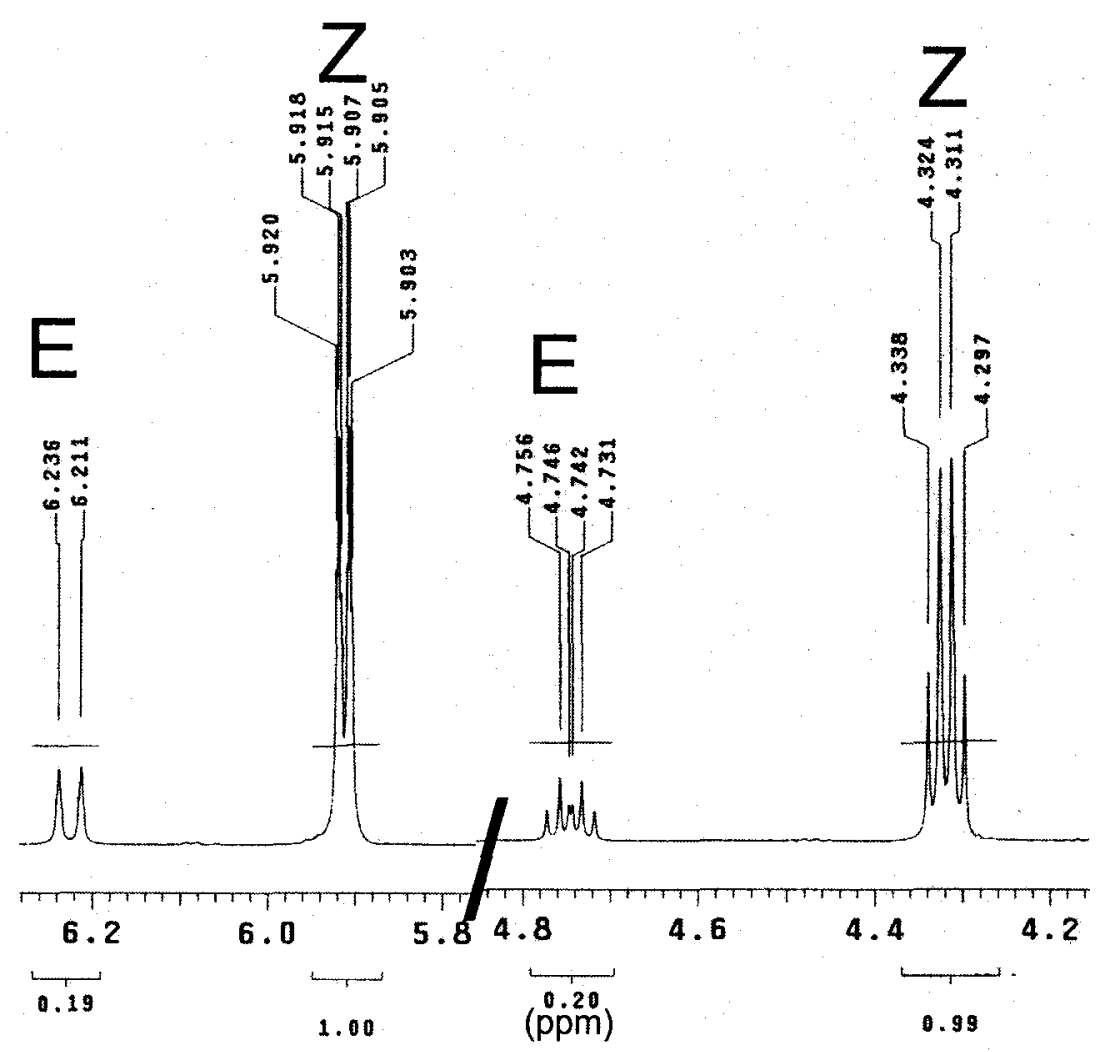

Figure 19. ${ }^{1} \mathrm{H}-\mathrm{NMR}\left(\mathrm{CDCl}_{3}, 500 \mathrm{MHz}\right)$ spectrum of 3.9 (Z: $\left.\mathrm{E}=5: 1\right)$.

The TES group was removed by reaction with TBAF to give the single chain compound 3.10. After seperation by $\mathrm{SiO}_{2}$ column chromatography, the $3.10(\mathrm{Z})$ and $3.10(E)$ isomers were obtained in $60 \%$ and $9 \%$ yield, respectively. After heating the sodium alcoholate of $3.10(\mathrm{Z})$ with 1,2-epoxyhexadecane, the dual chain tail $3.11(\mathrm{Z})$ was obtained in $83 \%$ yield (Scheme 15). It is noteworthy to mention that the commercially available 1,2-epoxyhexadecane (Sigma, 260215) is technical grade with 
$85 \%$ purity, and this reagent must be purified by $\mathrm{SiO}_{2}$ chromatography to minimize byproduct formation. Using same method, 3.11(E) was synthesized from 3.10(E). In summary, the dual chain $3.11(\mathrm{Z})$ has been obtained in 4 steps in $44 \%$ overall yield from decanol.

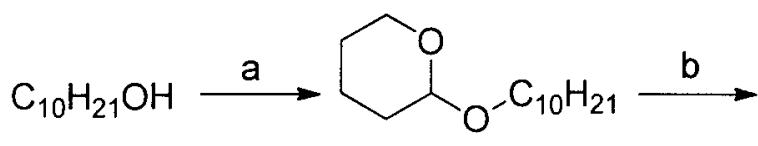

3.8

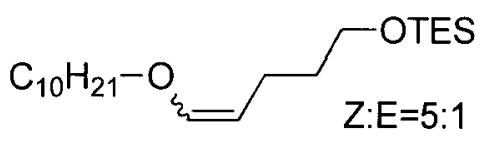

3.9

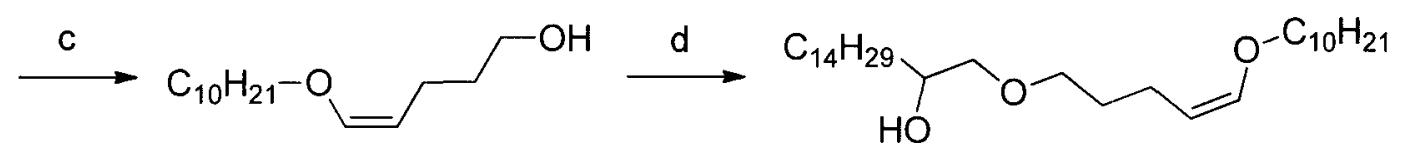

$3.10(Z)$

$3.11(Z)$

Scheme 15. Synthesis of enol ethers 3.10 and 3.11 .

Conditions: TES=Triethylsilyl a) 2,3-dihydropyran, $p-\mathrm{TsOH}, \mathrm{CH}_{2} \mathrm{Cl}_{2}, 0^{\circ} \mathrm{C}$ to rt. $12 \mathrm{~h}, 98 \%$; b) TESOTf, 2,6-lutidine, $\mathrm{CH}_{2} \mathrm{Cl}_{2}, 0^{\circ} \mathrm{C}$ to rt., $\left.12 \mathrm{~h}, 91 \%, \mathrm{Z}: \mathrm{E}=5: 1 ; \mathrm{c}\right)$ TBAF, THF, $0^{\circ} \mathrm{C}$ to $\mathrm{rt}, 24 \mathrm{~h},(\mathrm{Z}, 60 \%$, E $9 \%$, separated by $\mathrm{SiO}_{2}$ chromatography); d) i) $\mathrm{NaH}$, DMSO; ii) 1,2-epoxyhexadecane, $50^{\circ} \mathrm{C}$, $12 \mathrm{~h}, 83 \%$.

The second approach using this triflated-induced elimination strategy involves first preparing a two chain acetal and then generating the enol ether in similar manner using TMSOTf. As an example, enol ether 3.15 was synthesized by this method (Scheme 16). Firstly, the (3,4-dihydro-2H-pyran-2-yl)methanol was deprotonated by sodium hydride and then reacted with 1-bromododecane to generate 3.12 in $90 \%$ yield. Then, the compound $\mathbf{3 . 1 2}$ was reacted with 1-decanol under acid catalysis to give the dual chain acetal 3.13 . The resultant crude acetal 3.13 was treated with TMSOTf and 2,6-lutidine to generate enol ether 3.14 in $77 \%$ crude yield (two steps). 
Finally, the TMS group was removed by reaction with TBAF to give the dual chain enol ether $3.15(Z)$ after chromatography in $59 \%$ yield. In ${ }^{1} \mathrm{H}$ NMR spectrum, the RCHCHOR' ( $\delta 4.34 \mathrm{ppm}$ ) and RCHCHOR' ( $\delta 5.96 \mathrm{ppm}$ ) have a ${ }^{3} \mathrm{~J}$ coupling constant of $6.0 \mathrm{~Hz}$ which is in the range expected for the $\mathrm{Z}$ isomer. In a word, the dual chain tail 3.15 has been obtained in 4 steps in $41 \%$ overall yield from (3,4-dihydro-2H-pyran-2-yl)methanol.

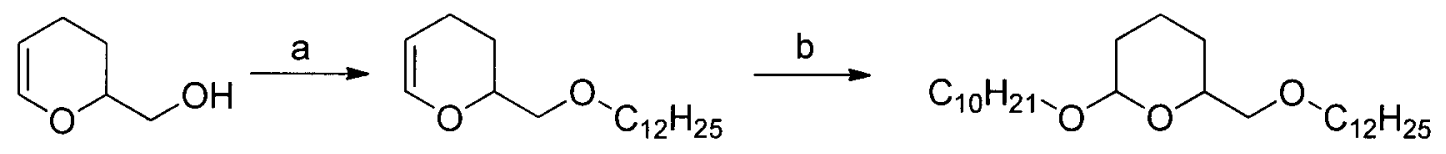

3.12

3.13

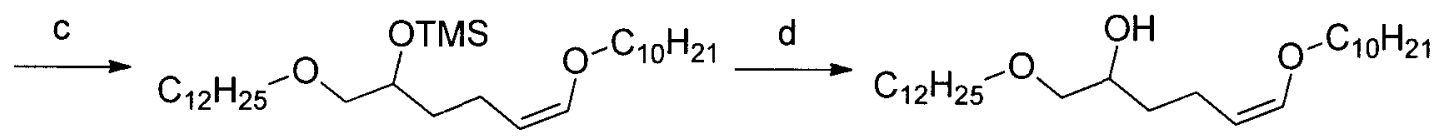

Scheme 16. Synthesis of enol ether tail 3.15.

Conditions: a) i) $\mathrm{NaH}, \mathrm{DMF}$, rt., $1 \mathrm{~h}$; ii) 1-bromododecane, rt., 24h, $90 \%$; b) p-TsOH, $\mathrm{CH}_{2} \mathrm{Cl}_{2}$, rt. 14h; c) TMSOTf, 2,6-lutidine, $\mathrm{CH}_{2} \mathrm{Cl}_{2}, 0^{\circ} \mathrm{C}$ to rt., $12 \mathrm{~h}, 77 \%$, two steps; d) TBAF, THF, $17 \mathrm{~h}, 59 \%$.

\section{Olefination Approach}

The third strategy used the Wittig reaction to generate the enol ether moiety. ${ }^{98} \mathrm{Mr}$. Wesley Badger, an undergraduate student working with me, synthesized enol ether 3.20 using a convergent synthesis route (Scheme 17). 


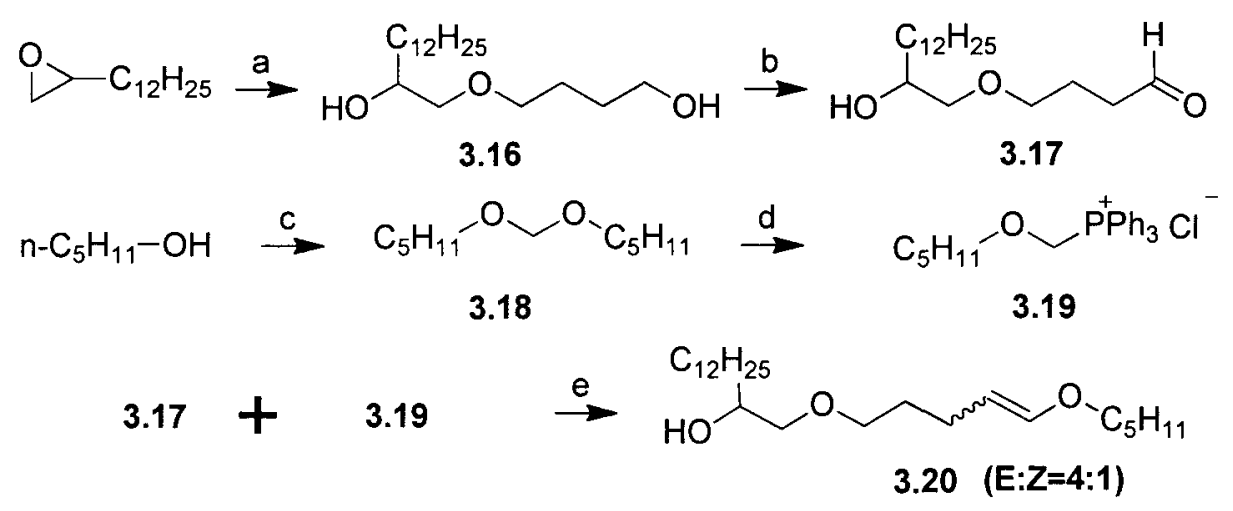

Scheme 17. Synthesis of enol ether tail 3.20.

Conditions: a) i) 1,4 butanediol, $\mathrm{NaH}$ in THF, $0.5 \mathrm{~h}$, rt; ii) 1,2 -epoxytetradecane, $55^{\circ} \mathrm{C}, 24 \mathrm{~h}, 97 \%$; b) 4-methoxy-TEMPO, $\mathrm{KBr}, \mathrm{NaOCl}, \mathrm{CH}_{2} \mathrm{Cl}_{2}, \mathrm{H}_{2} \mathrm{O}, 0^{\circ} \mathrm{C}, 8.5 \mathrm{~min}, 72 \%$; c) i) $\mathrm{NaOH}$, chlorobenzene, $\mathrm{H}_{2} \mathrm{O}$, $50^{\circ} \mathrm{C}, 1 \mathrm{~h}$; ii) $\mathrm{CH}_{2} \mathrm{Br}_{2}, \mathrm{TBAB}, 50^{\circ} \mathrm{C}, 4 \mathrm{~h}, 98 \%$; d) i) Octanoyl chloride, $\mathrm{ZnBr}_{2}, 4 \mathrm{~h}, 45^{\circ} \mathrm{C}$; ii) $\mathrm{PPh}_{3}$, toluene, $65^{\circ} \mathrm{C}, 12 \mathrm{~h}, 69 \%$; e) i) $3.19, \mathrm{KHMDS}, \mathrm{THF},-78^{\circ} \mathrm{C}$ to rt., $0.5 \mathrm{~h}$; ii) $3.17,-78^{\circ} \mathrm{C}$ to rt., $2.5 \mathrm{~h}, 93 \%$.

Firstly, 1,2 epoxy-tetradecane was cleaved by mono-alkoxide of 1,4-butanediol to give 3.16 in $97 \%$ yield. Then, the primary alcohol of 3.16 was selectively oxidized to aldehyde 3.17 in $72 \%$ yield by using radical catalyst 4-methoxy-2,2,6,6-tetramethyl-1 -piperidinyloxy (4-methoxy-TEMPO). ${ }^{99,100}$ The synthesis of Wittig reagent 3.19 from pentanol featured reaction of dibromomethane under the phase transfer catalyst (tetrabutylammonium bromide) to generate formaldehyde acetal 3.18 in $98 \%$ yield. ${ }^{101}$ The resultant formaldehyde acetal $\mathbf{3 . 1 8}$ was reacted with octanoyl chloride in the presence of $\mathrm{ZnBr}_{2}$ to form $\alpha$-halo ether, 1-(chloromethoxy)-pentane. Due to carcinogenic nature of $\alpha$-halo ether compound, the crude product wasn't isolated, rather it was directly reacted with triphenylphosphine in the same pot to generate Wittig reagent 3.19 in $69 \%$ (two steps) yield. Finally, the alcohol of 3.17 was deprotonated and then reacted with Wittig reagent 3.19 to generate enol ether 3.20 . 
The regioselectivity of the Wittig reaction was influenced by the base. For example, when using KHMDS the $E: Z$ ratio of product 3.20 was $4: 1$ while when using the $n-B u L i$, the $E: Z$ ratio was $1: 1$. This selectivity as well as the high yield obtained $(93 \%)$ are not unusual under these conditions. ${ }^{102,103}$ In summary, 3.20 was prepared in five steps in $65 \%$ yield from 1,2 epoxy-tetradecane with 3.20(E) as major isomer. This third method has the highest overall yield from commercially available starting material and represents a convergent synthetic route design.

\subsection{Linker Study}

After completing the syntheses of cationic aminooxy headgroups and enol ether sidechains, the next goal was to find a suitable linker to join these domains. In the course of these studies, we examined many linker strategies. Here we described some of the chemistry to prepare lipids 3.1 and $\mathbf{3 . 2}$.

\subsubsection{Quaternary Ammonium Linkage}

The first designed bis-aminooxy cationic lipid 3.21 has a quaternary ammonium nitrogen that has dual functionality: to serve as a cation and linker atom (Figure 20). The two hydrophobic tail chains, including one with enol ether, are directly attached to the ammonium ion.

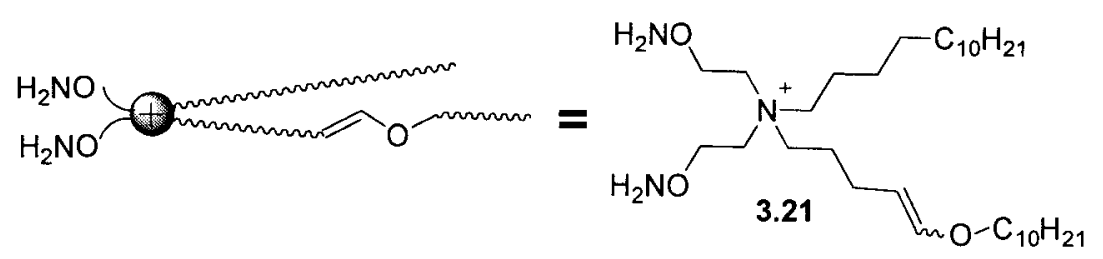

Figure 20. Concept aminooxy enol ether lipid with quaternary ammonium. 
To synthesize cationic lipid $\mathbf{3 . 2 1}$, a synthesis of the precursor trialkylamine $\mathbf{3 . 2 3}$ (Scheme 18) was developed. Considering that Mel may react with the aminooxy groups, the aminooxy groups were protected before the quaternization reaction. Firstly, diethanolamine was reacted with 1-bromotetradecane to form bis-alcohol 3.22 in $93 \%$ yield. Diol $\mathbf{3 . 2 2}$ was then transformed to the corresponding bis-protected aminooxy reagent 2.23 in $48 \%$ yield by treatment with $N$-hydroxyphthalimide under Mitsunobu reaction conditions. ${ }^{73}$

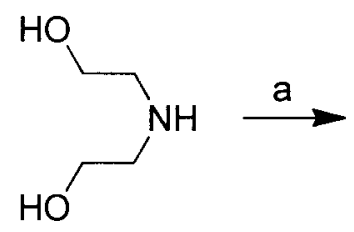

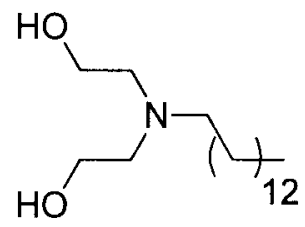

3.22

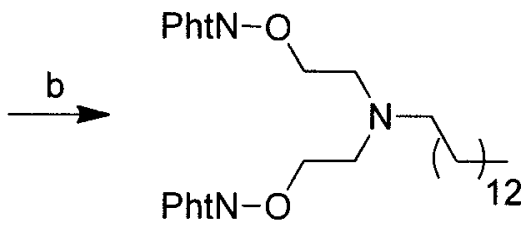

3.23

Scheme 18. Synthesis of trialkylamine 3.23 .

Conditions: Pht $=$ phthaloyl a) 1-bromotetradecane, $\mathrm{CH}_{3} \mathrm{CN}, \mathrm{Na}_{2} \mathrm{CO}_{3}$, reflux, $20 \mathrm{~h}, 93 \%$; b) $\mathrm{N}$-hydroxyphthalimide (2.2 eq.), $\mathrm{PPh}_{3}\left(2.2\right.$ eq.), DIAD (2.2 eq.), THF, $0^{\circ} \mathrm{C}$ to rt., $12 \mathrm{~h}, 48 \%$.

We planned to prepare the bromo-alkyl enol ether 3.24 from alcohol $3.10(\mathrm{Z})$ by reaction with triphenylphosphine and tetrabromomethane (Scheme 19). However, bromination of alcohol $3.10(Z)$ failed to deliver the bromo-alkyl product $\mathbf{3 . 2 4}$. Cyclization product 3.8 was instead obtained in $55 \%$ yield along with 1-bromodecane in $41 \%$ yield. Presumably, this is due to the decomposition of the enol ether starting material under the given reaction conditions. Fortunately, iodo-alkyl 3.26 was obtained in two steps without any problem. Alcohol $\mathbf{3 . 1 0 ( Z )}$ was converted to tosylated product 3.25 in $86 \%$ yield and then reacted with sodium iodide to give iodo-alkyl product 3.26 in $91 \%$ yield. 

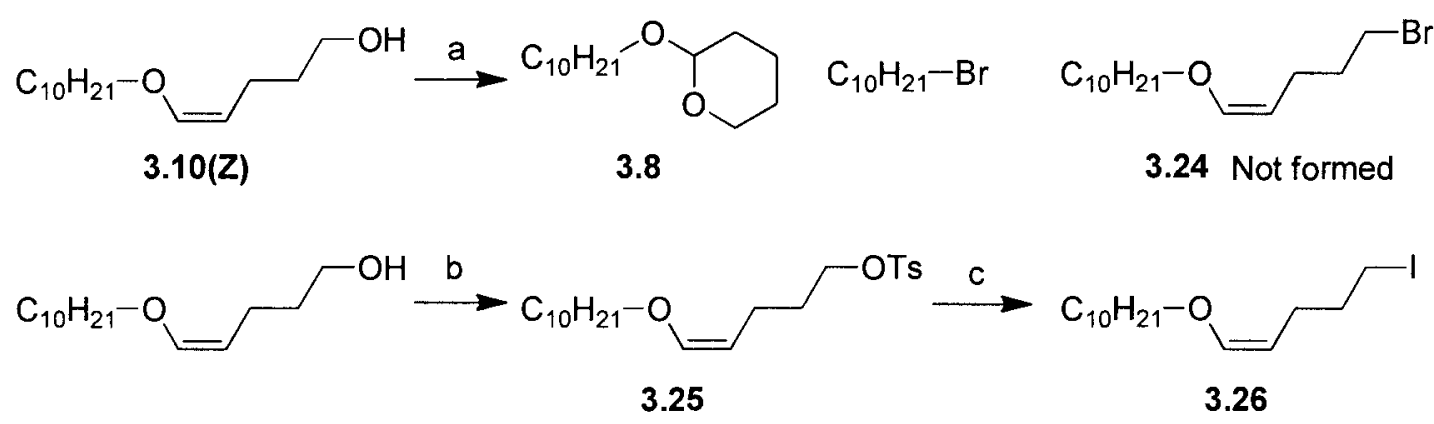

Scheme 19. Synthesis of iodoalkyl enol ether 3.26.

Conditions: a) $\mathrm{PPh}_{3}, \mathrm{CBr}_{4}, \mathrm{THF}$, rt., $12 \mathrm{~h}$; b) p-toluenesulfonyl chloride, $\mathrm{Et}_{3} \mathrm{~N}, \mathrm{CH}_{2} \mathrm{Cl}_{2}, \mathrm{rt}, 14 \mathrm{~h}, 86 \%$; c) Nal, acetone, $45^{\circ} \mathrm{C}, 12 \mathrm{~h}, 91 \%$.

With both iodo-alkyl 3.26 and trialkylamine 3.23 in hand, we examined the quaternization reaction (Scheme 20). Disappointingly, no amine alkylation accured since the phthalimide protection groups decomposed at the higher temperature needed for quaternization. The instability of phthalimide protection groups was also observed when attempting to measure the melting point of compound 2.14 .

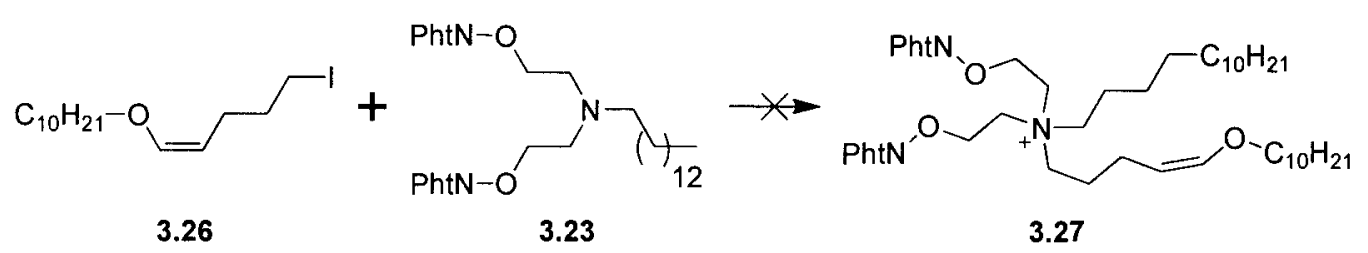

Scheme 20. Synthesis of enol ether ammonium 3.27.

Other quaternization attempts are described in Scheme 21. However, all reactions failed to produce desired products. For example, when compound 3.28 was reacted with 2-bromoethanol to produce the targeted product 3.29 , the salt 3.30 was formed instead. The other two reactions towards compound $\mathbf{3 . 3 3}$ also failed to generate 
ammonium ion before sluggish products was observed on TLC plate due to phthalimide protection group decomposition. Finally, the smallest alkyl halide, methyl iodide, was chosen because of its intrinsic high reactivity.

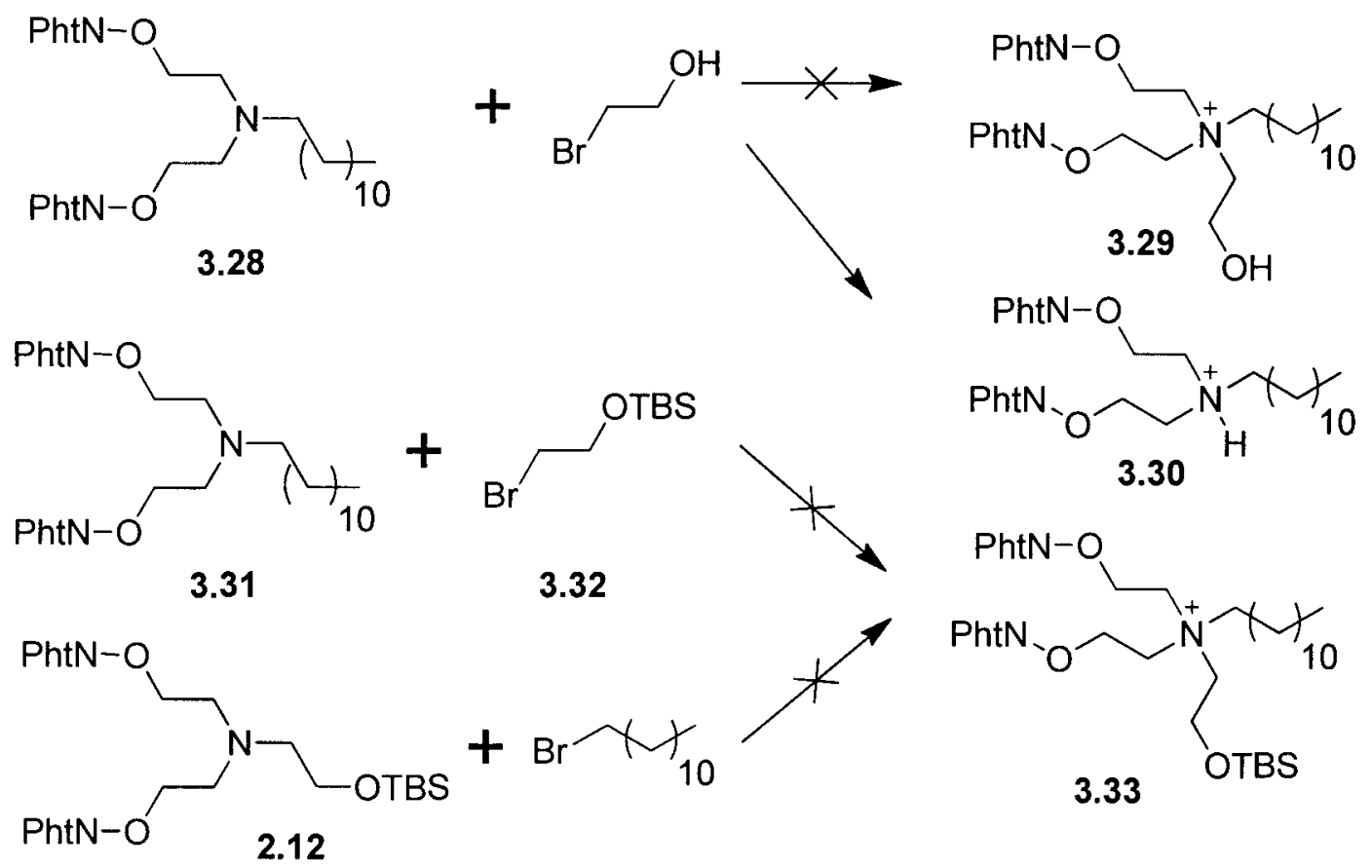

Scheme 21. Attempts to quaternize headgroup amine.

\subsubsection{Fused Headgroup on Amine}

The second method is based on building a protected aminooxy moiety on the amine, which works as a linker (Scheme 22). A similar strategy has been used to synthesized phospholipids with aminooxy functionality. ${ }^{104}$ Firstly, the enol ether tail fitted with a primary amine was synthesized; then the protected aminooxy moiety was directly conjugated on the amine group; finally, the target lipid will be obtained after methylation and deprotection. 


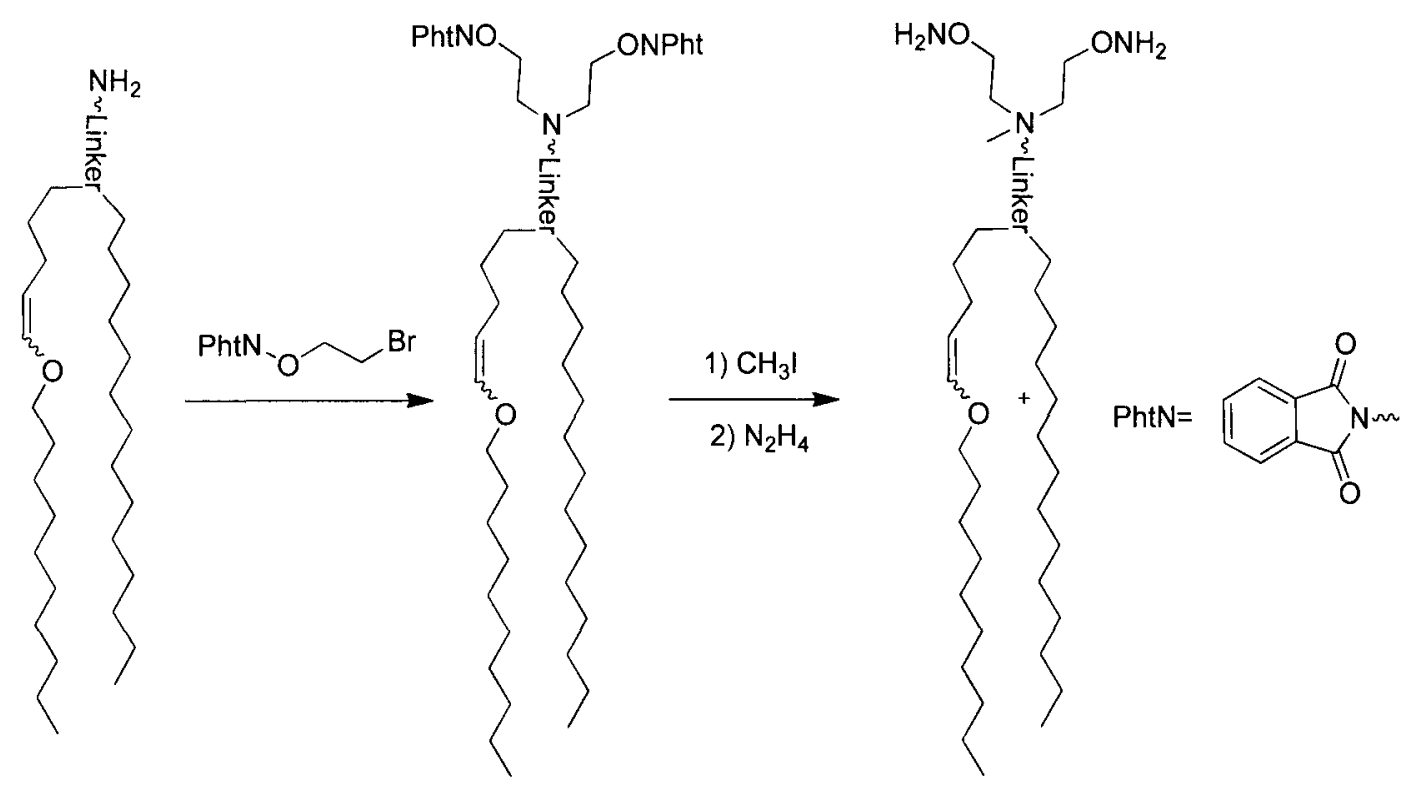

Scheme 22. Fused protected aminooxy headgroup on the amine.

To test this strategy, tetradecan-1-amine was used to mimic the enol ether component. First, 2-phthalimidooxyethyl bromide $\mathbf{3 . 3 4}$ was synthesized according to the reported methods (Scheme 23). ${ }^{105}$ Then tetradecan-1-amine was reacted with 3.34 in anhydrous $\mathrm{N}, \mathrm{N}$-dimethylformamide in the presence of triethylamine. After stirring overnight at room temperature, target compound $\mathbf{3 . 3 5}$ was not observed; however, the dioxazine compound 3.36 was isolated. From ${ }^{1} \mathrm{H}$ NMR, 4 protons $(\delta 4.19$ ppm (t, J=4.0 Hz, 2H), $\delta 4.44 \mathrm{ppm}(\mathrm{t}, J=4.0 \mathrm{~Hz}, 2 \mathrm{H}))$ were identified corresponding to the heterocyclic ring of a dioxazine. ${ }^{106-108}$ The dioxazine structure was confirmed by X-ray crystallographic analysis (Figure 21). Due to this surprising result, we gave up this method without resorting to synthesis of amine enol ether. 


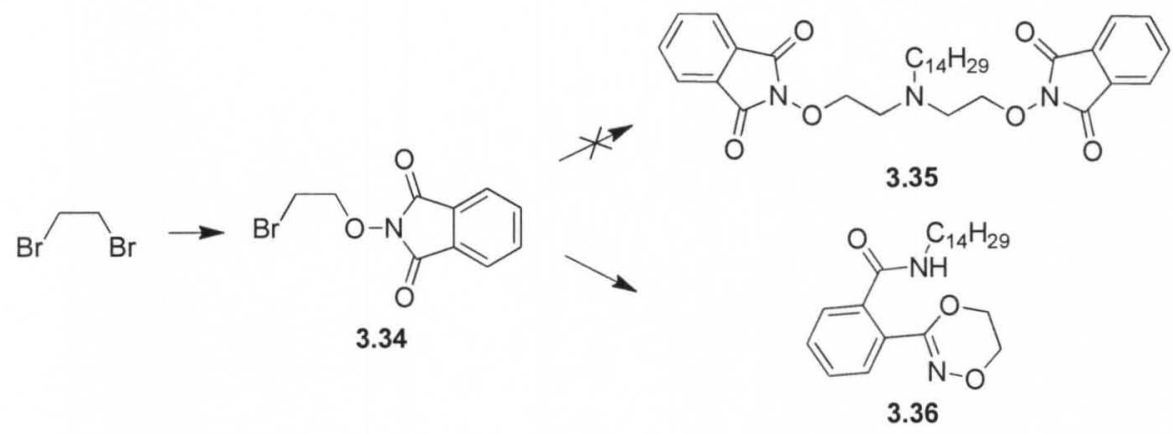

Scheme 23. Synthesis of dioxazine.

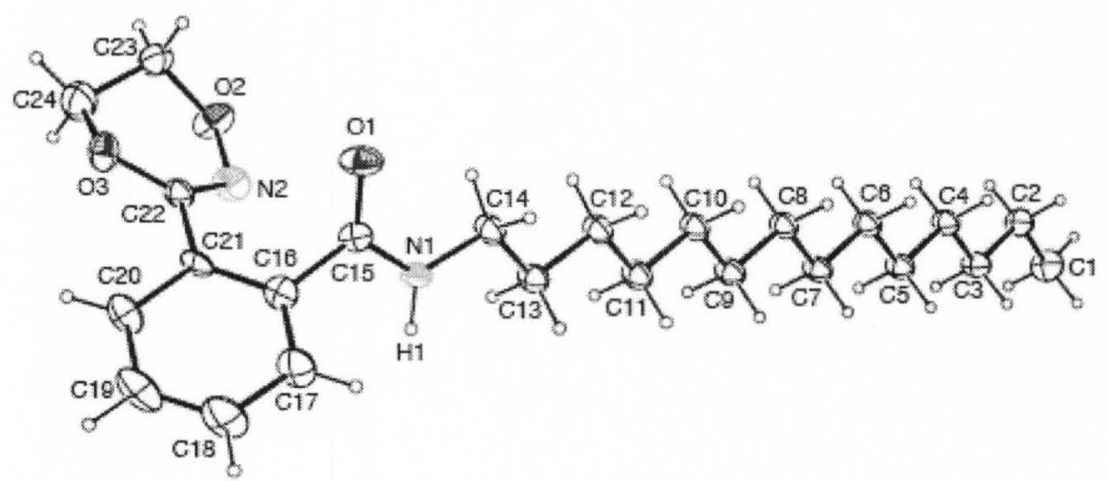

Figure 21. X-ray structure of dioxazine 3.36 .

\subsubsection{Fused Headgroup via Epoxide Opening}

We envisioned a third approach to prepare lipid 3.42 (Scheme 24). Reaction of bis-protected diethanolamine 2.15 with 2-dodecyloxirane can be expected to form 3.37. The addition of the three key components (enol ether, aminooxy and cationic ion) would be accomplished step by step. First, the enol ether chain would need to be added to the $2^{\circ}$ alcohol to form 3.38. After functional group interconversion (Scheme 24, steps c, d), the bis- protected aminooxy groups would be incorporated. The third step would generate the ammonium ion by methylation of the trialkylamine. Finally, the 
prototype lipid $\mathbf{3 . 4 2}$ can be obtained after hydrazine treatment to release the free aminooxy groups.
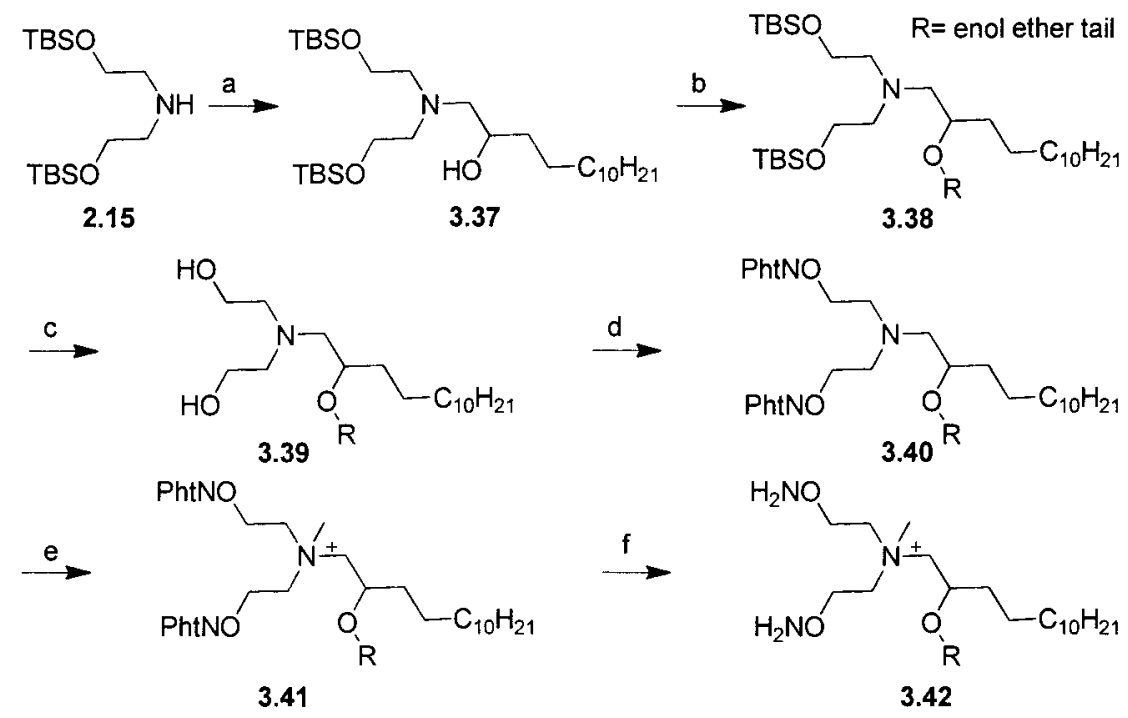

Scheme 24. Plan for synthesis of aminooxy enol ether lipid $\mathbf{3 . 4 2 .}$

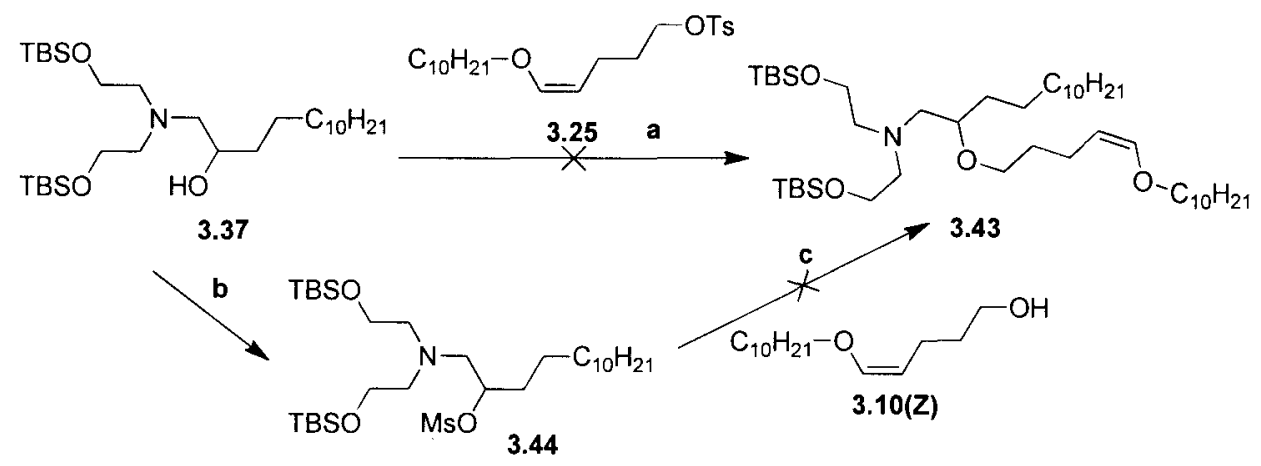

Scheme 25. Plan for synthesis of lipid 3.43 using ether linkage approaches.

Synthesis of $\mathbf{3 . 3 7}$ proceeded smoothly by reacting bis-protected diethanolamine 2.15 with 2-dodecyloxirane under catalysis of lithium perchlorate in $62 \%$ yield. However, to conjugate the enol ether chain onto the alcohol 3.37 via an ether bond was difficult. The tosylated enol ether chain 3.25 was reacted with the skeleton 
compound 3.37 but the reaction failed to produce conjugated product 3.43 . The mesylated skeleton $\mathbf{3 . 4 4}$ also failed to deliver 3.43 when reacted with $\mathbf{3 . 1 0}(\mathrm{Z})$. (Scheme 25)

After failing to establish the ether linkage, we turned to an ester linkage strategy. However, direct conversion of the alcohol to a carboxylic acid group requires harsh oxidation conditions, a big challenge in the presence of the fragile enol ether. Many oxidization attempts of $3.10(\mathrm{Z})$ ended up with enol ether decomposition and/or hydrolysis.

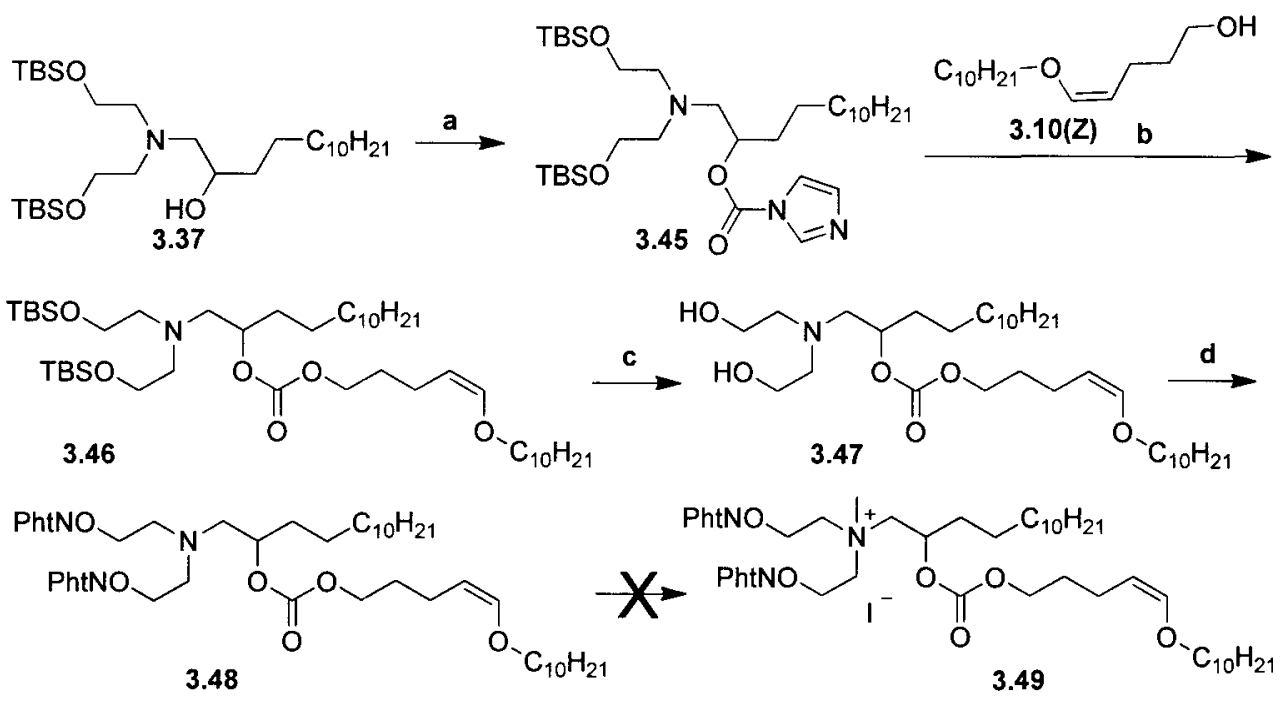

Scheme 26. Synthesis of cationic enol ether lipid 3.49 .

Conditions: a) 1,1'-carbonyldiimidazole, $\mathrm{Et}_{3} \mathrm{~N}, \mathrm{CH}_{2} \mathrm{Cl}_{2}$, rt., 16h, 96\%; b) LiHMDS, THF, $\mathrm{CH}_{2} \mathrm{Cl}_{2}, 17 \mathrm{~h}$, $89 \%$; c) TBAF, THF, rt., $16 \mathrm{~h}, 78 \%$; d) N-hydroxyphthalimide, $\mathrm{PPh}_{3}, \mathrm{DIAD}, \mathrm{THF}, 0^{\circ} \mathrm{C}$ to rt., $12 \mathrm{~h}$, $69 \%$.

Bridging two alcohols via ester bonds can be achieved through using 1,1'-carbonyldiimidazole (Scheme 26). Then, the synthesis of lipid 3.48 began with 
the reaction of 3.37 with 1,1'-carbonyldiimidazole to obtain product 3.45 in $96 \%$ yield. Enol ether alcohol $3.10(\mathrm{Z})$ was deprotonated by treatment with LiHMDS and then reacted with $\mathbf{3 . 4 5}$ to give $\mathbf{3 . 4 6}$ in $89 \%$ yield. Removal of TBS protecting group was achieved by using TBAF in $78 \%$ yield. Finally the bis-protected aminooxy reagent $\mathbf{3 . 4 8}$ was obtained in $69 \%$ yield by treatment with $N$-hydroxyphthalimide under Mitsunobu reaction conditions. Unfortunately, as noted previously, the synthesis route ended with a failure to quaternize. Neither methyl iodide nor trimethyloxonium tetrafluoroborate was effective at methylation of trialkylamine $\mathbf{3 . 4 8}$ without significant decomposition

problems. The absence of ${ }^{1} \mathrm{H}-\mathrm{NMR}$ signal in the range of 5.8-6.2 $\mathrm{ppm}$, which represents $\mathrm{C}_{10} \mathrm{H}_{21} \mathrm{OCH}=\mathrm{CHCH}_{2}$, indicated reaction of the enol ether linkage during methylation. Although it is highly possible to prepare compound $\mathbf{3 . 4 9}$ via methylation of 3.48, we didn't pursue this route since we successfully synthesized prototype enol ether lipid $\mathbf{3 . 1}$ and $\mathbf{3 . 2}$ using another strategy that also was under investigation at the time.

\subsubsection{Succinic Acid Linker}

Like 1,1'-carbonyldiimidazole, succinic acid is another commonly used linking agent for tethering two alcohol compounds. With headgroup 2.13 and tailgroups 3.10, 3.11 in hand, the synthesis of prototype lipid 3.1 and 3.2 began with joining these two parts together via a succinic acid linkage (Scheme 27). The protected aminooxy domain $\mathbf{2 . 1 3}$ was reacted with succinic anhydride in the presence of triethylamine to generate acid $\mathbf{3 . 5 0}$ in $81 \%$ yield. The acid $\mathbf{3 . 5 0}$ was then reacted with alcohol $\mathbf{3 . 1 0}$ (or 3.11) under DCC coupling conditions to produce ester 3.51 (or 3.52 ) in $66-88 \%$ yield. 

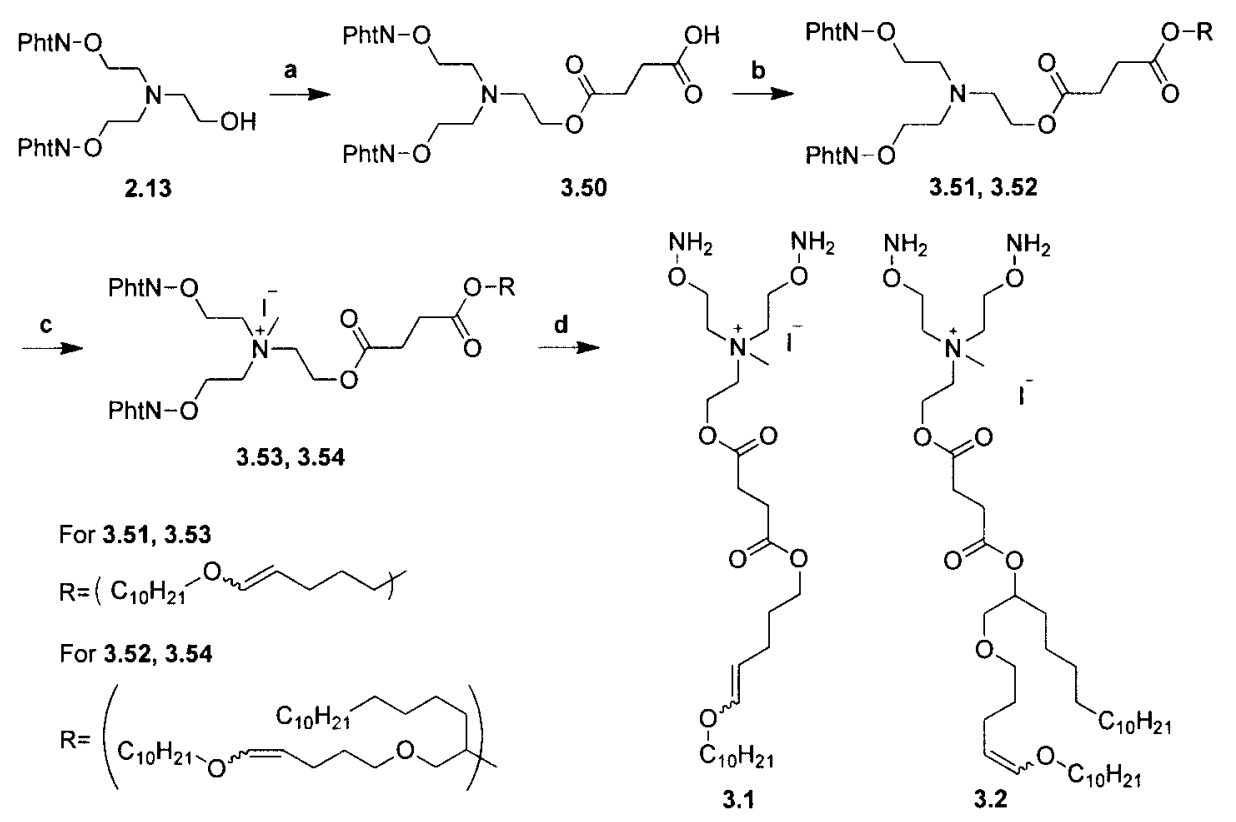

Scheme 27. Synthesis of cationic enol ether lipids 3.1 and 3.2 .

Conditions: a) succinic anhydride, $\mathrm{CH}_{2} \mathrm{Cl}_{2}$, triethylamine, rt., $18 \mathrm{~h}, 81 \%$; b) alcohol $(3.10,3.11)$, DCC, DMAP, $\mathrm{CH}_{2} \mathrm{Cl}_{2}$, rt., $12 \mathrm{~h}, 66 \%-88 \%$; c) Mel, $\mathrm{Na}_{2} \mathrm{CO}_{3}, \mathrm{CH}_{2} \mathrm{Cl}_{2}, 50^{\circ} \mathrm{C}, 12 \mathrm{~h}, 74 \%$ (3.53), $73 \%$ (3.54); d) MeNHNH ${ }_{2}, \mathrm{CH}_{2} \mathrm{Cl}_{2}$, ethanol, $-40^{\circ} \mathrm{C}, 1.5 \mathrm{~h}, 71 \%(3.1), 60 \%$ (3.2).

The methylation of compounds $\mathbf{3 . 5 1}$ and $\mathbf{3 . 5 2}$ were problematic, just as in the synthesis of compound 3.49. Decomposition of the enol ether moiety was observed when reacting lipids 3.51 and 3.52 with methyl iodide. We speculated that decomposition of the enol ether moieties is due to trace acid in methyl iodide. However, preincubating methyl iodide with sodium carbonate to remove trace acid also failed to prevent enol ether decomposition. Fortunately, we observed that adding sodium carbonate directly into the reaction mixture partly prevented enol ether decomposition. Eventually, using dichloromethane as solvent plus 0.2 eq. of sodium carbonate solved the problem. Quaternizations were accomplished to produce the salts 3.53 and 3.54 in $74 \%$ and $73 \%$ yield, respectively. It is worthy to mention that the moderate yield of 
3.53 and 3.54 is mainly due to phthalimide protection group decomposition on $\mathrm{SiO}_{2}$ when using methanol/ $\mathrm{CH}_{2} \mathrm{Cl}_{2}$ as eluent.

Removal of the phthalimide protection groups in 3.53 and 3.54 is another problematic step because commonly used hydrazine cleaves both phthalimide protection groups and ester bond at room temperature. While reducing reaction time did not solve the problem, reducing the reaction temperature to $-40^{\circ} \mathrm{C}$ gave promising results. At this temperature, the phthalimide deprotection was accomplished at 1.5 hours without significant ester cleavage. The solubility of salts 3.53 and 3.54 was very low in dichloromethane at $-40^{\circ} \mathrm{C}$. The solubility problem was solved by using ethanol/ $\mathrm{CH}_{2} \mathrm{Cl}_{2}(1: 1 \mathrm{v} / \mathrm{v})$ as solvent. The last modification was using methylhydrazine instead of hydrazine to facilitate the chromatographic separation of final products 3.1 and 3.2 from byproducts. Finally, the prototype lipid 3.1 was obtained in $71 \%$ yield ( $25 \%$ overall yield from decanol); and the lipid 3.2 was obtained in $60 \%$ yield ( $13 \%$ overall yield from decanol).

From the ${ }^{1} \mathrm{H}$ NMR spectrum $(500 \mathrm{MHz})$ of lipid $3.2(\mathrm{Z})$, the broad signal at $\delta 6.35$ ppm represents the four aminooxy protons (Figure 22 top). The quaternized amine methyl group $\mathrm{NCH}_{3}$ can be observed at $\delta 3.15 \mathrm{ppm}$. The $\alpha$ and $\beta$ protons of the enol ether are observed at $\delta 6.01 \mathrm{ppm}(\mathrm{J}=6.5 \mathrm{~Hz})$ and $\delta 4.27 \mathrm{ppm}(\mathrm{J}=6.5 \mathrm{~Hz})$. The protons on the succinic acid linkage can be found at $\delta 2.60 \mathrm{ppm}(\mathrm{m}, 4 \mathrm{H})$. With the additional information from COSY spectrum (Figure 22 below), the signal of $\delta 3.97 \mathrm{ppm}$ can be assigned to the $4 \mathrm{H}$ of the headgroup $\mathrm{CH}_{2}-\mathrm{ONH}_{2}$ while the signal around $\delta 3.70 \mathrm{ppm}$ can be assigned to $4 \mathrm{H}$ from $\mathrm{NCH}_{2} \mathrm{CH}_{2} \mathrm{ONH}_{2}$. The signal of $\delta 4.47 \mathrm{ppm}$ corresponds to $2 \mathrm{H}$ from $\mathrm{NCH}_{2} \mathrm{CH}_{2} \mathrm{OCOCH}_{2}$ and the signal $\delta 3.78 \mathrm{ppm}$ corresponds to the $2 \mathrm{H}$ from 
$\mathrm{NCH}_{2} \mathrm{CH}_{2} \mathrm{OCOCH}$. Other signals belong to the protons on the hydrophobic tail. The HRMS found $\mathrm{M}^{+}$at $758.6261\left(\mathrm{C}_{42} \mathrm{H}_{84} \mathrm{~N}_{3} \mathrm{O}_{8}{ }^{+}\right.$, calculated as 758.6253$)$.
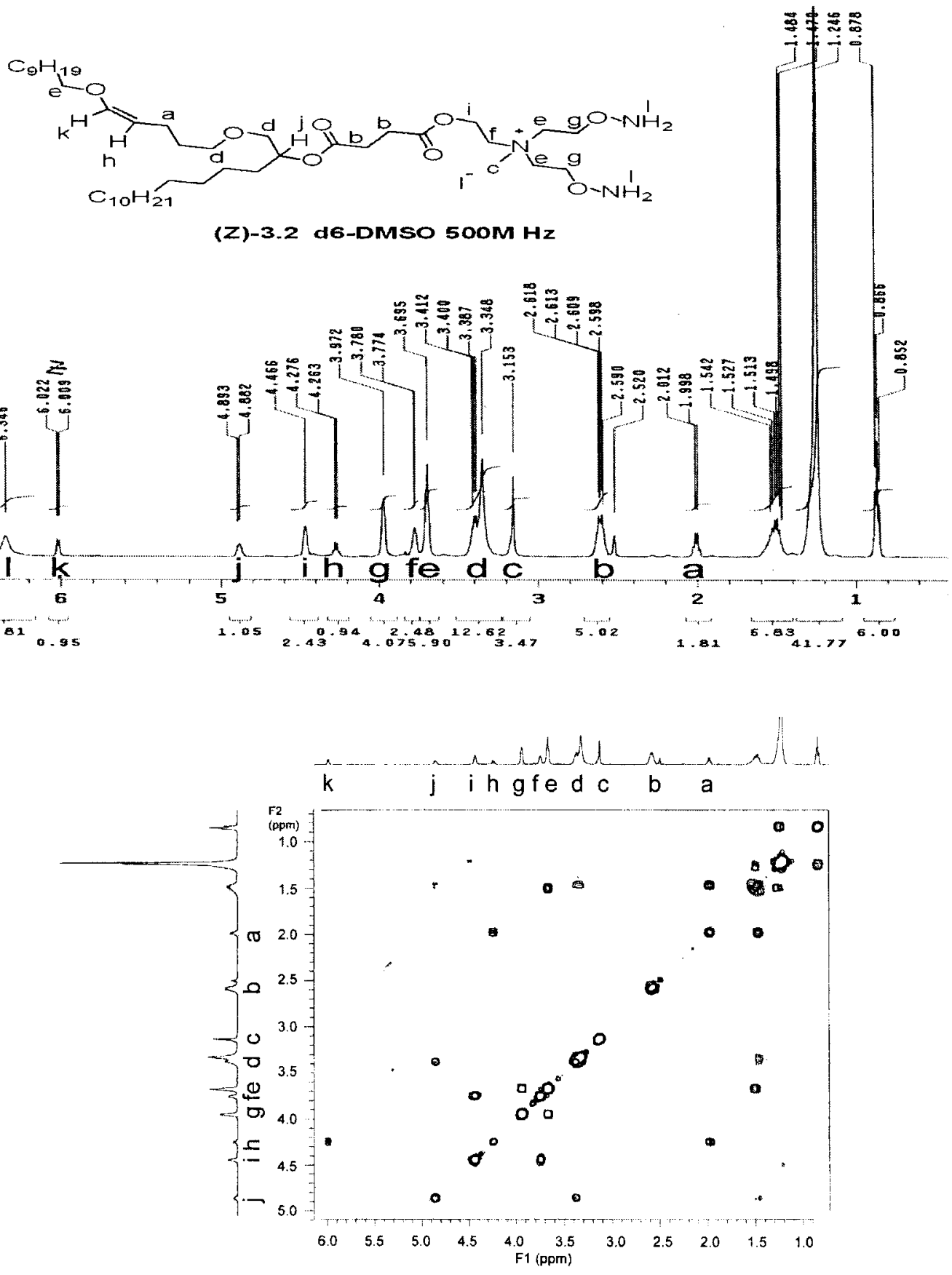

Figure 22. ${ }^{1} \mathrm{H}$ and COSY NMR spectra of lipid (Z)-3.2. 


\subsection{Polymerization Studies}

With cationic aminooxy enol ether lipids 3.1 and 3.2 in hand, we began lipid polymerization studies. Ideally, the prototype lipid $\mathbf{3 . 2}$ would form liposomes and then be polymerized under mild acid conditions to give stabilized liposomes (Figure 23). To establish preferred conditions for liposome polymerization, the acid-triggered enol ether hydrolysis and subsequent oximation of lipid $\mathbf{3 . 1}$ and $\mathbf{3 . 2}$ was studied. By using HPLC and NMR, we can observe the hydrolysis of the enol ether and follow the oximation reaction under different $\mathrm{pH}$ conditions.

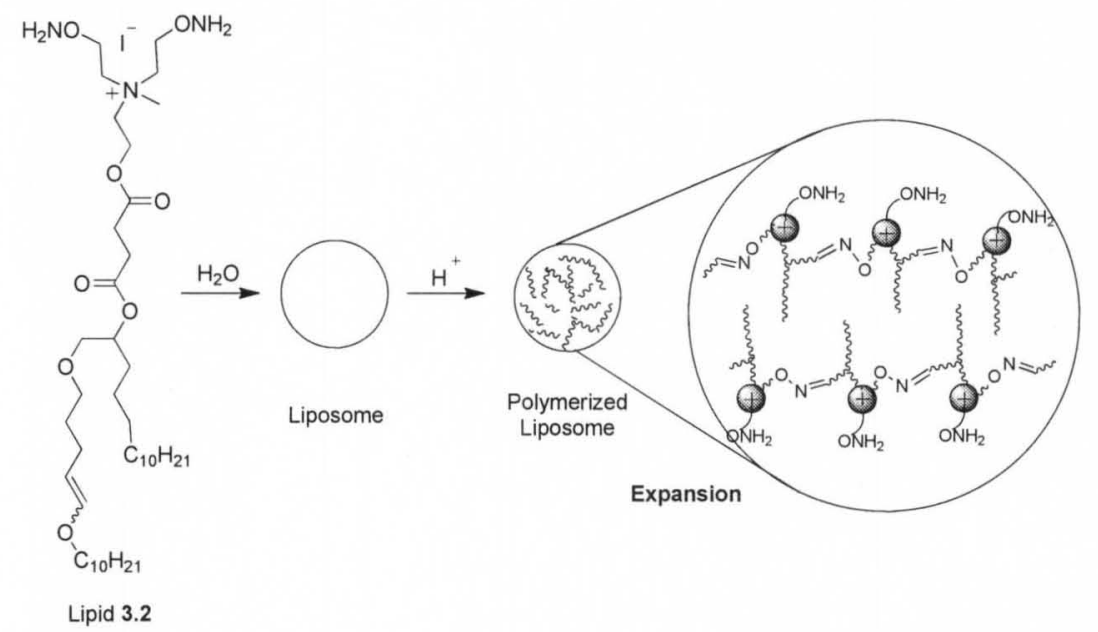

Figure 23. Polymerized liposome from enol ether lipid 3.2.

The hydrolysis of lipid 3.1 under different $\mathrm{pH}(1.3,3.2,4.3$ and 6.5$)$ conditions at certain time intervals was analyzed by HPLC. The amount of unhydrolyzed lipid $\mathbf{3 . 1}$ was determined by monitoring the HPLC peak area using $214 \mathrm{~nm}$ channel. The preliminary data showed that lipid $\mathbf{3 . 1}$ hydrolyzed faster at lower $\mathrm{pH}$ condition. The lipid 3.1 is nearly intact after prolonged incubation (17 h) at room temperature under neutral conditions ( $\mathrm{pH}$ 6.5), whereas it hydrolyzes under acid conditions. However, 
the hydrolysis required strong acid conditions $(\mathrm{pH}=1.3)$ instead of expected mild acid conditions ( $\mathrm{pH} 3.0)$. Furthermore, the time for $90 \%$ hydrolysis required considerable time (ca. $17 \mathrm{~h}$ ) even at the low $\mathrm{pH}$ conditions.

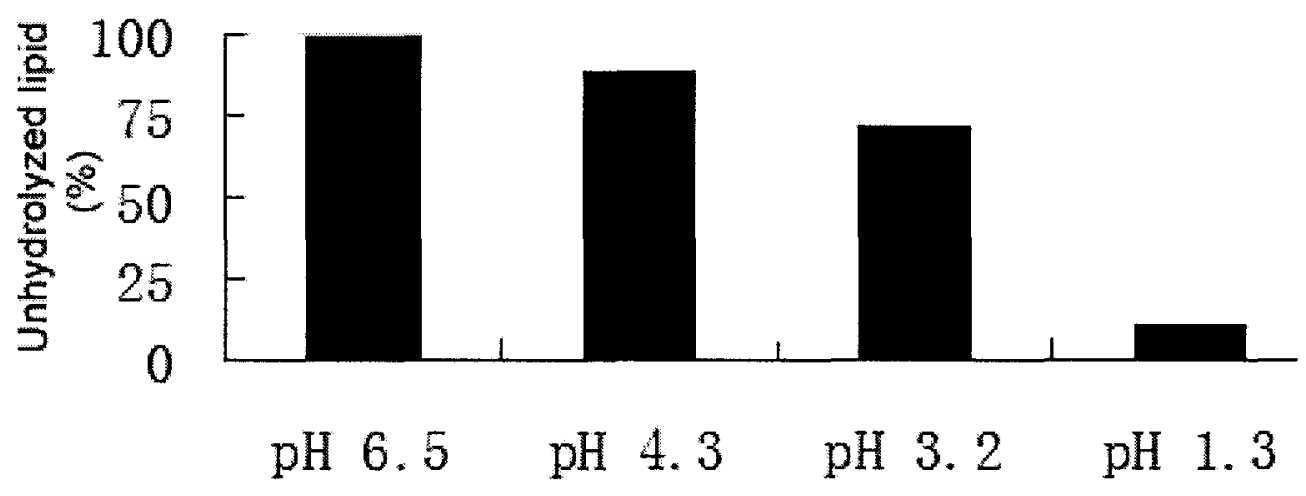

Figure 24. Preliminary study on hydrolysis of lipid 3.1.

Aliquot of Lipid 3.1 ( $60 \mu \mathrm{L}, 160 \mathrm{mg} / \mathrm{mL}$ in DMSO) was added to $240 \mu \mathrm{L}$ aqueous buffer $\left(\mathrm{H}_{2} \mathrm{O}, \mathrm{pH} 6.5\right.$; $0.1 \mathrm{M}$ acetic acid, $\mathrm{pH} 4.3 ; 0.1 \mathrm{M}$ trifluoroacetic acid, $\mathrm{pH} 3.2$ ) and incubated $17 \mathrm{~h}$ at room temperature. The samples then were analyzed by HPLC.

Based on the preliminary data, we then studied the enol ether lipids polymerization under strong acid conditions. While HPLC can only monitor the disappearance of lipid 3.1 due to hydrolysis, ${ }^{1} H$ NMR can provide more detailed information. For example, a decrease in the signals of the enol ether vinyl proton represents the hydrolysis of enol ether lipids, while an increase in the signals of the aldoxime ether proton represents lipid polymerization. In general, the transformation from enol ether to aldoxime causes the ipso-carbon (Figure $25, \cdot$ ) of the enol ether to become less electronegative, effecting an upfield shift for the attached proton. For 
instance, a proton shift from $\delta$ 5.8-6.3 ppm (enol ether) to $\delta \sim 7.5 \mathrm{ppm}$ (aldoxime ether) ${ }^{61}$ indicated hydrolysis followed by oximation.
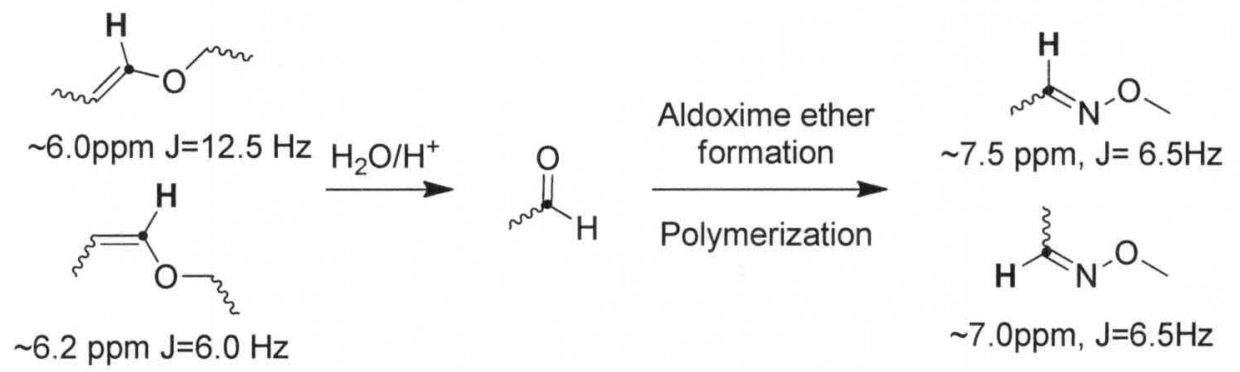

Figure 25. ${ }^{1} \mathrm{H}$ NMR analysis of the acid-triggered polymerization.

The hydrolysis samples of lipid 3.1 under acid conditions $\left(\mathrm{D}_{2} \mathrm{O} / \mathrm{d}_{6}-\mathrm{DMSO} / \mathrm{DCl} \mathrm{pH}\right.$ 1.0) at certain time intervals were analyzed by ${ }^{1} \mathrm{H}$ NMR (Figure 26). The peaks $\delta$ $\sim 6.0 \mathrm{ppm}(\mathrm{J}=12.5 \mathrm{~Hz})$ and $\delta \sim 6.2 \mathrm{ppm}(\mathrm{J}=6.0 \mathrm{~Hz})$ represent the vinyl proton $(\mathrm{RCH}=\mathrm{CHOR})$ on cis- and trans- enol ethers respectively. The integrals of these two peaks gradually decreased to zero due to the hydrolysis of lipid 3.1 under acidic conditions. The integrals of the peak $\delta \sim 6.0 \mathrm{ppm}$ decreased faster than the peak $\delta$ 6.2 ppm, which means cis-isomers hydrolyze faster.

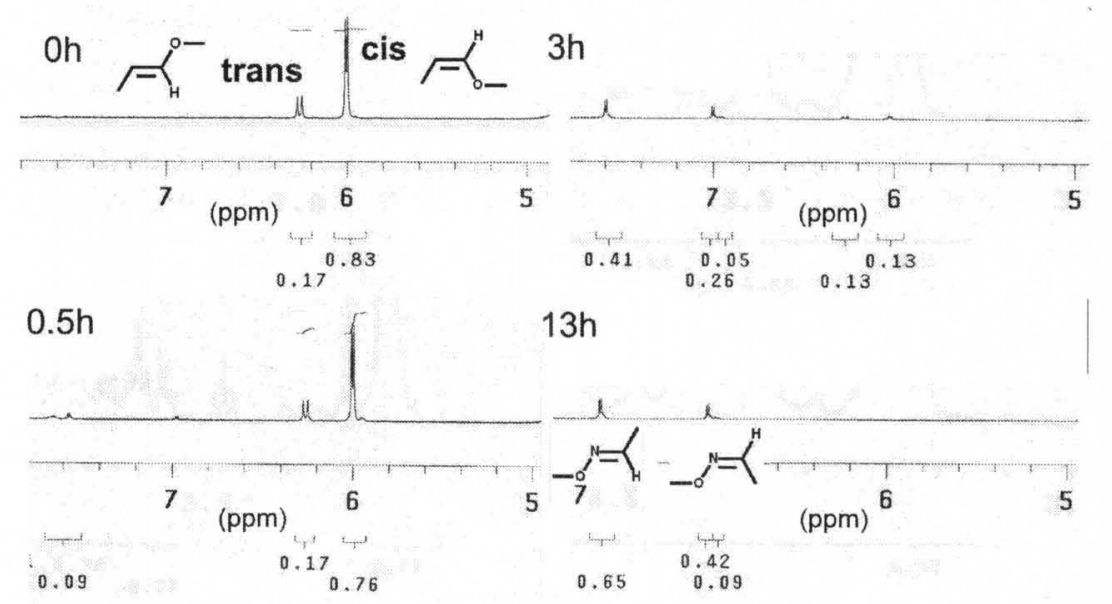

Figure 26. ${ }^{1} \mathrm{H}$ NMR spectra of lipid 3.1 under acid-triggered polymerization. 
The intermediate aldehyde, hydrolysis product of enol ether, usually has a distinct proton signal at $\delta 9-10 \mathrm{ppm}$. However, we failed to detect any signal in this area, possibly due to rapid oximation or hydration. The peaks $\delta \sim 7.0 \mathrm{ppm}$ and $\delta \sim 7.5 \mathrm{ppm}$ with the same $(J=6.5 \mathrm{~Hz})$ represent the oximyl proton of the $(E)$ and $(Z)$ isomers of the aldoxime ether. The gradually increasing integrals of these peaks represent the formation of aldoxime ether, a direct sign of lipid polymerization. It is worthy noting that the deuterated aldoxime ether $\left(\mathrm{RCHDCH}=\mathrm{NOCH}_{2} \mathrm{R}\right)$ was produced in this experiment due to the hydrolysis was carried in deuterated buffers. That is why the doublet for the a proton of aldoxime ether was observed in above NMR spectrum while the triplet of similar aldoxime ether was reported in our previous paper. ${ }^{61}$

The acid-triggered polymerization of lipid 3.2 was also studied by using ${ }^{1} \mathrm{H}$ NMR (Figure 27). By tracing the decreasing integrals of the vinyl protons ( $\delta 5.96 \mathrm{ppm}$ and $6.20 \mathrm{ppm}$ ) of the enol ether and increasing integrals of the oximyl protons ( $\delta 6.90 \mathrm{ppm}$ and $7.50 \mathrm{ppm}$ ) of the aldoxime ether, we studied the hydrolysis and oximation of lipid 3.2. No hydrolysis of lipid $\mathbf{3 . 2}$ was observed after incubation for one week under mild acid conditions $\left(\mathrm{pH} 3.40 \mathrm{D}_{2} \mathrm{O} / \mathrm{d}_{6}-\mathrm{DMSO} / \mathrm{d}_{4}\right.$-acetic acid). Complete hydrolysis (Figure 27 below) under strong acid conditions ( $\mathrm{pH} 1.76 \mathrm{D}_{2} \mathrm{O} / \mathrm{d}_{6}-\mathrm{DMSO} / \mathrm{d}$-trifluoroacetic acid) took more than one week. ( $\mathrm{pH}$ value was measured at the end of each experiment by $\mathrm{pH}$ meter.) At the end of the experiment, precipitation was observed in the NMR tube, a sign of polymerized lipids.

Both HPLC and NMR analysis experiments showed that the enol ether lipids were more stable than we anticipated, and it required strong acid conditions $(\mathrm{pH}<2)$ 
and long reaction times for complete hydrolysis to occur. Since strong acid pretreatment is not an ideal protocol for gene/drug delivery; we must find milder conditions to form stabilized liposomes. In hopes that partial polymerization of the enol ether lipids can still improve liposomes stability, we examined the feasibility of the concept that liposomes could be stabilized via partial oxime ether formation between lipids. 


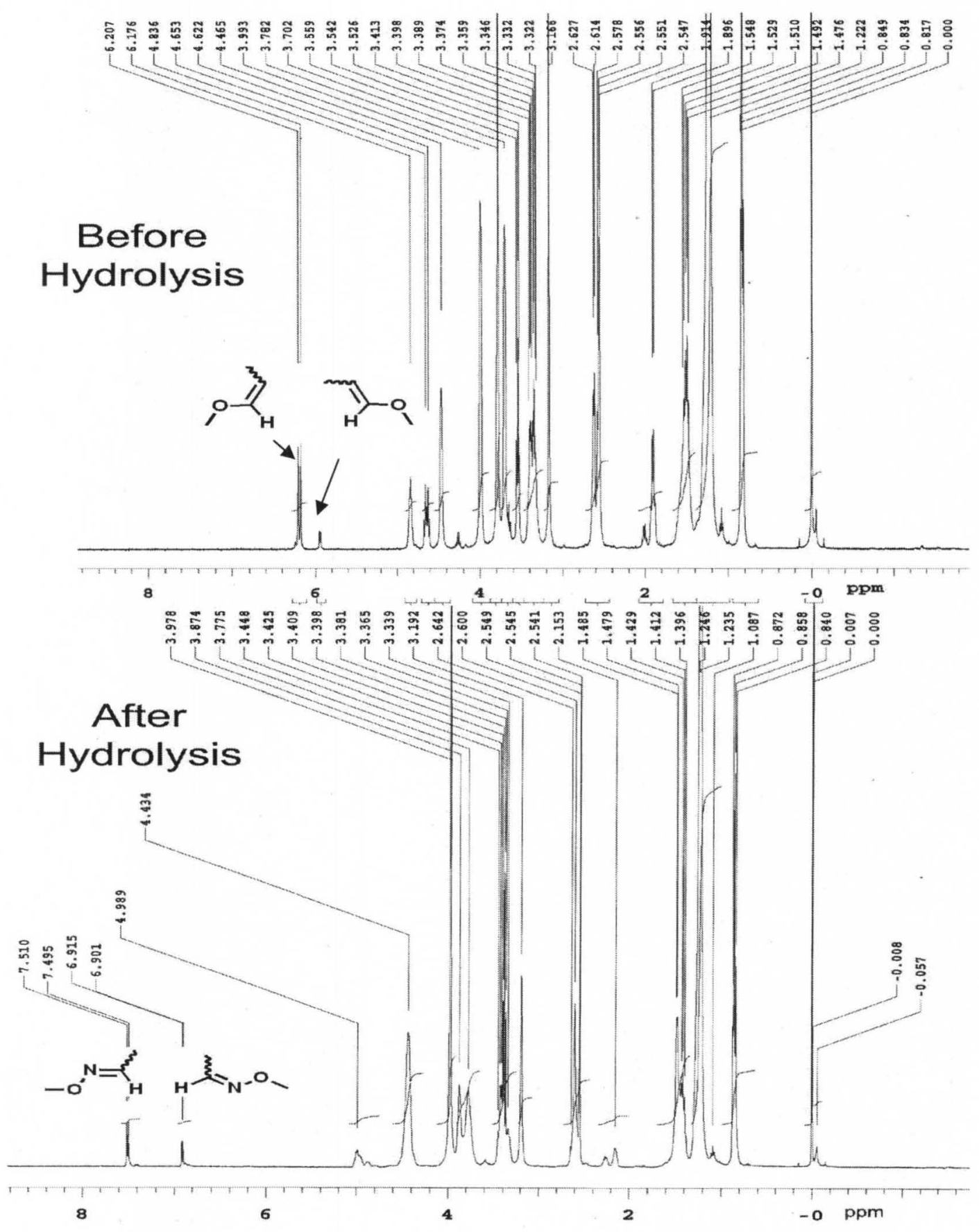

Figure 27. ${ }^{1} \mathrm{H}$ NMR spectra of lipid 3.2 before and after acid hydrolysis. 


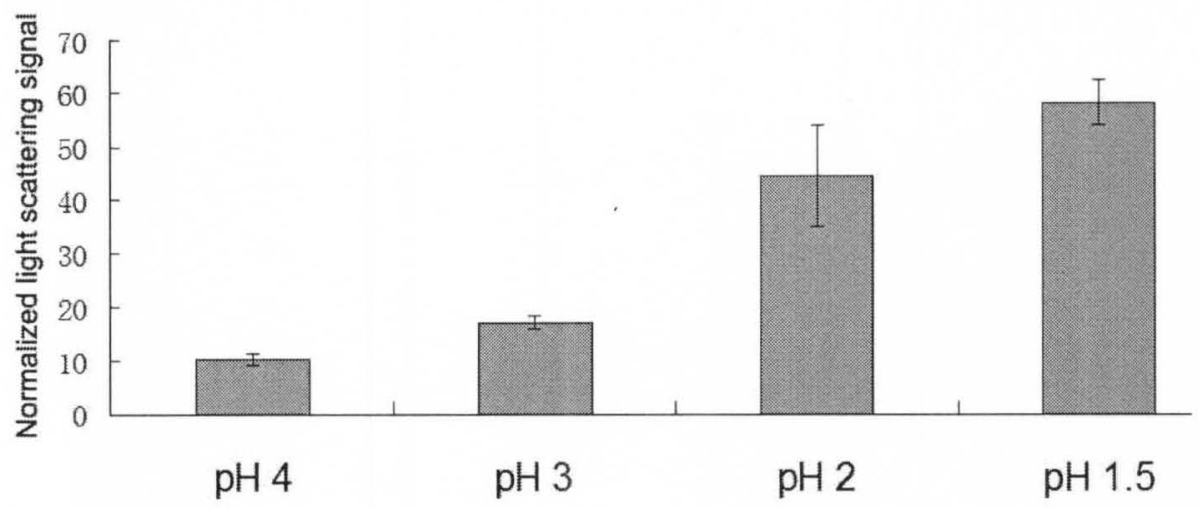

Figure 28. Acid triggered liposome polymerization.

Liposomes were formulated by sonicating a thin layer of lipid $3.2(1.6 \mathrm{mg})$ in HEPES buffer $(1.6 \mathrm{~mL}$, $20 \mathrm{mM}, \mathrm{pH} 7.4)$ for 20 minutes. The aliquots of liposome $(200 \mu \mathrm{L})$ were then mixed with buffer $(1.8$ $\mathrm{mL}, \mathrm{pH} 4, \mathrm{AcOH}, 0.1 \mathrm{M} ; \mathrm{pH} 3, \mathrm{AcOH}, 0.1 \mathrm{M} ; \mathrm{pH} 2, \mathrm{TFA} \mathrm{0.1M}, \mathrm{pH} 1.5, \mathrm{TFA}, 0.1 \mathrm{M})$. After standing 22 $\mathrm{h}$ at room temperature, Triton X-100 (final concentration $0.15 \%$, w/v) was added to solubilize any unstable liposomes. The light scattering signals before and after surfactant treatment were recorded. Normalized light scattering signal = Light scattering signals after surfactant treatment/ Light scattering signals before surfactant treatment. Each data point reflects the mean value of $n=2$ $(\mathrm{pH} 4,3,1.5)$ and $\mathrm{n}=4(\mathrm{pH} 2)$, and the standard deviation from the mean.

The stability of liposomes was determined by their ability to resist surfactant-mediated solubilization using a reported method. ${ }^{109}$ Surfactant solubilization of liposomes is a process where liposomes are disrupted to form surfactant-lipid micelles within a few minutes in the presence of surfactant, usually Triton X-100. By comparing the diameter of liposomes $(\sim 100 \mathrm{~nm})$ to the surfactant-lipid micelles $(\sim 5 \mathrm{~nm})$, one can easily see liposome disruption occur. The decreasing size of particles during surfactant solubilization can be observed as a decreasing turbidity of the liposome solution (cloudy solution turns transparent). The surfactant solubilization can be also quantified as a light scattering signal determined 
by a particle size analyzer because the bigger particles (liposome) scatter more light than smaller ones (micelles).

The liposomes from lipid $\mathbf{3 . 2}$ were incubated under different $\mathrm{pH}$ conditions, and their light scattering signals before and after Triton treatment were measured by particle size analyzer (Figure 28). As we would expect, the liposome gained extra stability under low $\mathrm{pH}$ conditions $(\mathrm{pH}=1.5,2)$ and more than $50 \%$ light scattering signal preserved after Triton treatment, while not much light scattering signal preserved for the samples under mild acid condition $(\mathrm{pH}=3,4)$. In another experiment, we observed that the liposomes made from the cationic aminooxy lipid without enol ether functionality (e.g. lipid 4.2), as a negative control, failed to be stabilized after mild or strong acid incubation. These results demonstrated that acid-triggered enol ether hydrolysis, which occurs under strong acid condition $(\mathrm{pH} \leq 2)$, is essential for lipid polymerization, and this is in agreement with our HPLC and NMR analysis results.

\subsection{Conclusions}

In summary, this chapter explored several methods to construct the hydrophobic enol ether component of our target lipids. Syntheses of the hydrophobic domains of lipids 3.10 and $\mathbf{3 . 1 1}$ were achieved. The general synthesis route can be adapted to synthesis of other acid-liable lipids which have been widely used as gene/drug delivery. Then, the headgroup and enol ether domain were conjugated by succinic acid to successfully deliver cationic aminooxy enol ether lipid 3.1 and 3.2. Finally, lipid polymerization study confirmed the acid-triggered strategy. However, the requirement 
of strong acid pretreatment is not an ideal protocol for gene/drug delivery. Therefore, an alternative less harsh strategy was developed, as discussed in the next chapter. 


\section{CHAPTER 4. \\ ‘CLICK’ STABILIZED LIPOSOMES}

\subsection{Introduction}

In chapter 3 , we demonstrated a $\mathrm{pH}$-triggered polymerization strategy and proved that the aldoxime crosslinking stabilized liposomes against surfactant-mediated disruption. However, the requirement of a strong acid pretreatment is not an ideal protocol for use in gene/drug delivery. To take advantage of aldehyde/aminooxy chemistry and avoid the use of strong acid, we explored an alternative 'click' stabilization strategy. Our next generation 'click' stabilization strategy uses external aldehydes, instead of aldehydes generated on hydrolysis of enol ethers, as the polymerizable functionality. This change not only avoids the use of acid, but also simplifies the requisite lipid structure and lipid synthesis.

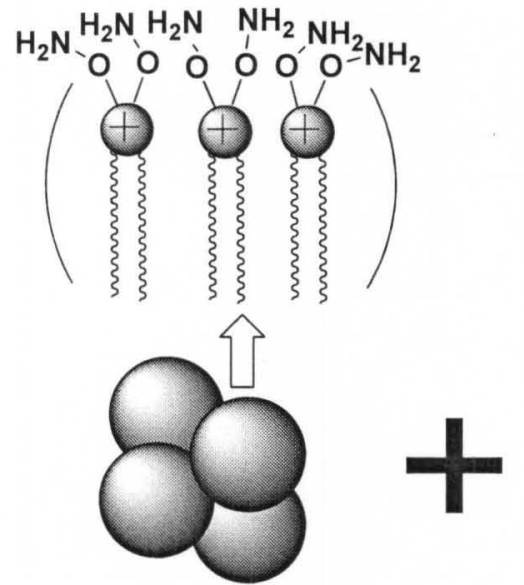

Liposomes

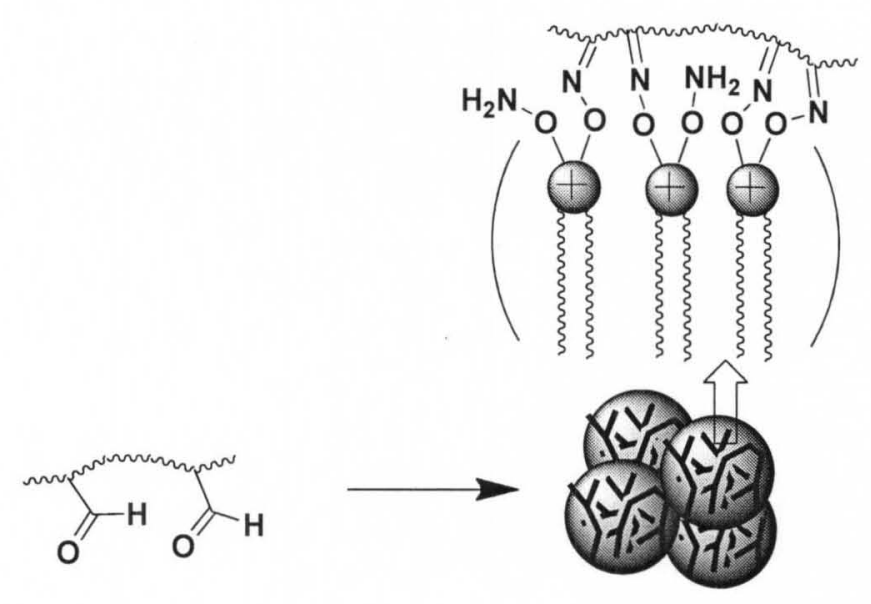

Aldehyde reagent/polymer
Stabilized liposomes

Figure 29. ' 'Click' stabilized liposomes -- revised strategy. 
We envisioned a 'click' stabilization strategy as follows: after cationic aminooxy lipid formulation in water to generate liposomes, an external reagent containing bis- or poly-aldehyde functional groups is added and followed by incubation for a given time to allow aminooxy-aldehyde oximations. As the result of intermolecular oximation reactions, the liposome surface will undergo lipid-reagent polymerization to generate a stabilized liposome (Figure 29). This stabilization process should proceed rapidly under aqueous conditions that are compatible with biological cargos. The resultant aldoxime ether crosslinks are expected to be robust and particularly stable to physiologic conditions. This chapter demonstrated our efforts to actuate this strategy.

\subsection{Synthesis of Cationic Aminooxy Lipids}

To test this hypothesis of 'click' stabilized liposomes, a series of cationic aminooxy lipids have been synthesized, such as cationic bisaminooxy lipid 4.1, 4.2 and cationic monoaminooxy lipid 4.3 (Figure 30). Among them, the lipid 4.1 was designed as a mimic of $\mathrm{N}, \mathrm{N}$-[bis(2-hydroxyethyl)-N-methyl-N-[2,3-di(tetradecanoyloxy)propyl] -ammonium iodide (TransFast $\left.{ }^{\mathrm{TM}}\right)^{54}$, a commercial transfection lipid previously developed by our lab. The difference between TransFast ${ }^{\mathrm{TM}}$ and lipid 4.1 is that lipid $\mathbf{4 . 1}$ equipped with a bisaminooxy group on its hydrophilic head while TransFast $^{\mathrm{TM}}$ possesses a bisalcohol group. The other two lipids have minor modifications, such as longer hydrophobic chain or monoaminooxy headgroup. 


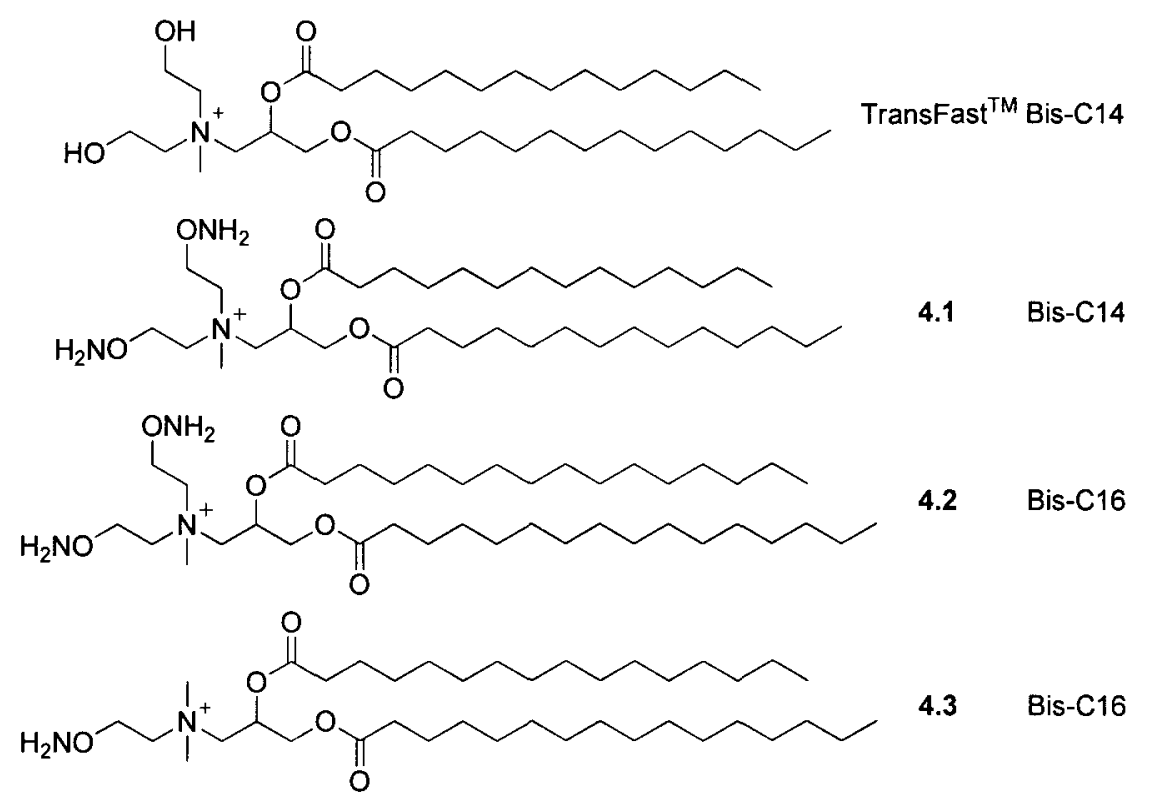

Figure 30. Structure of TransFast ${ }^{\mathrm{TM}}$ and cationic aminooxy lipid mimics.

Our synthesis route of lipid 4.1 is described in Scheme 28. First, the silylation of diethanolamine was accomplished by reaction with TBSCI. The resultant amine 2.15 was then reacted with glycidol under catalysis by lithium perchlorate. The principal adduct diol 4.4 was then acylated using myristoyl chloride to form the hydrophobic domain. Silyl ether deprotection using TBAF gave diol 4.6 in good yield. The resultant diol 4.6 was reacted with N-hydroxyphthalimide under Mitsunobu conditions ${ }^{73}$ to generate amine 4.7 with bis-protected aminooxy groups. Amine quaternization was best accomplished by heating the amine with methyl iodide in a sealed tube. Finally, the ammonium iodide $\mathbf{4 . 8}$ was treated with hydrazine to cleave the phthaloyl groups. After chromatography, product 4.1 was isolated as a white solid in 7 steps, $12 \%$ overall yield from diethanolamine. Following the same synthesis route, lipid $\mathbf{4 . 2}$ was synthesized using palmitoyl chloride without any problem ( 7 steps, $10 \%$ overall yield from diethanolamine) (Scheme 29). 


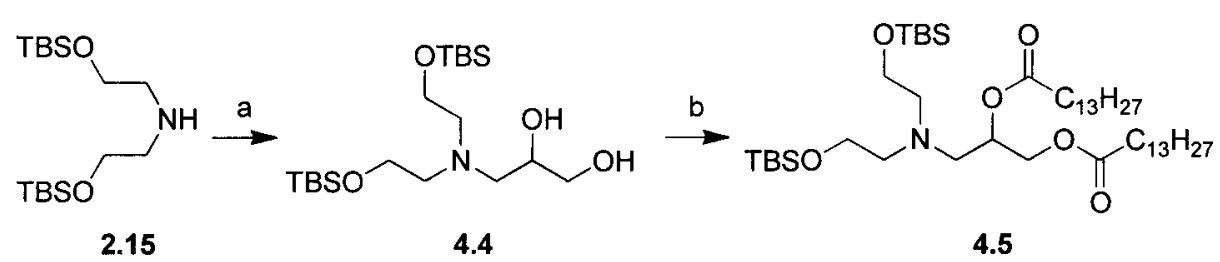

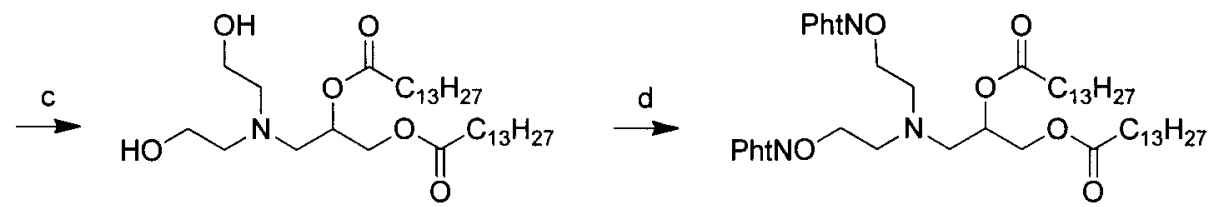

4.6

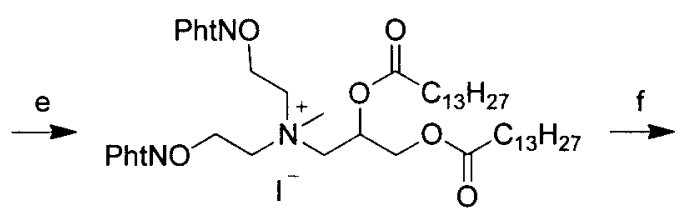

4.8

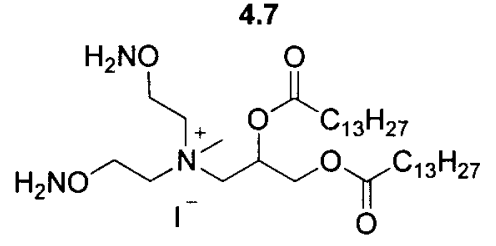

4.1

Scheme 28. Synthesis of cationic aminooxy lipid 4.1.

Conditions: Pht $=$ phthaloyl a) glycidol, $\mathrm{LiClO}_{4}$, ethanol, $0{ }^{\circ} \mathrm{C}$ to rt., $16 \mathrm{~h}, 85 \% ;$ b) $\mathrm{Et}_{3} \mathrm{~N}, \mathrm{DMAP}$, myristoyl chloride, $\mathrm{CH}_{2} \mathrm{Cl}_{2}, 0^{\circ} \mathrm{C}$ to $\mathrm{rt}, 16 \mathrm{~h}, 50 \%$; c) TBAF, THF, $0^{\circ} \mathrm{C}$ to $\mathrm{rt}, 12 \mathrm{~h}, 71 \%$; d) N-hydroxyphthalimide, $\mathrm{PPh}_{3}, \mathrm{DIAD}, \mathrm{THF}, 0^{\circ} \mathrm{C}$ to rt., $12 \mathrm{~h}, 86 \%$; e) $\mathrm{CH}_{3} \mathrm{l}$, sealed tube, $60^{\circ} \mathrm{C}, 48 \mathrm{~h}$, $74 \%$; f) $\mathrm{N}_{2} \mathrm{H}_{4} \cdot \mathrm{H}_{2} \mathrm{O}, \mathrm{CH}_{2} \mathrm{Cl}_{2}, 0^{\circ} \mathrm{C}$ to rt., $2 \mathrm{~h}, 67 \%$.
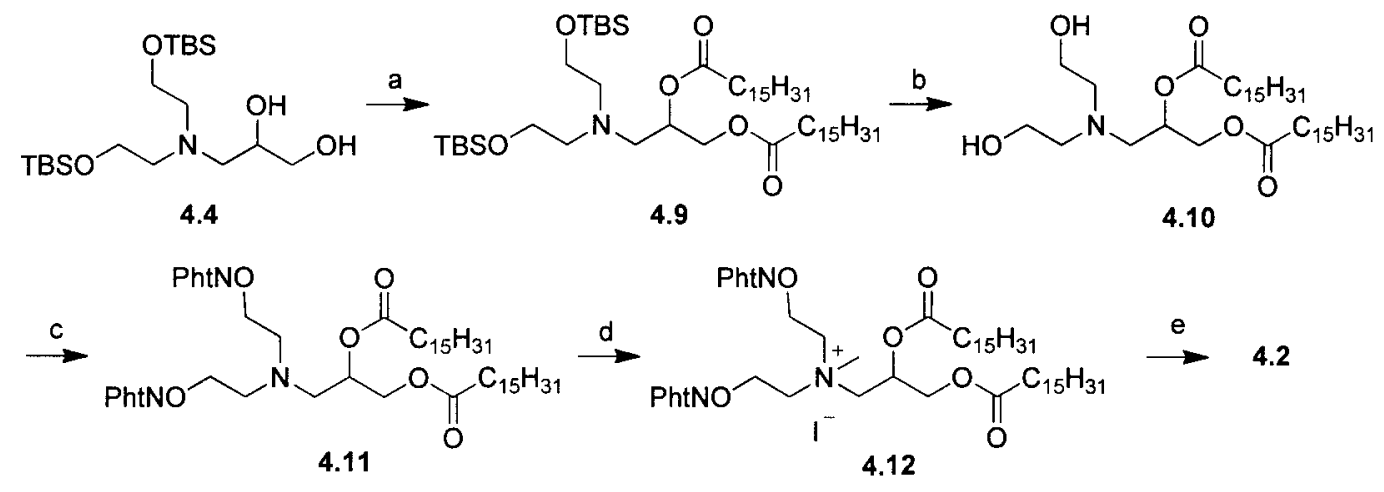

Scheme 29. Synthesis of cationic aminooxy lipid 4.2.

Conditions: $\mathrm{Pht}=$ phthaloyl a) $\mathrm{Et}_{3} \mathrm{~N}, \mathrm{DMAP}$, palmitoyl chloride, $\mathrm{CH}_{2} \mathrm{Cl}_{2}, 0^{\circ} \mathrm{C}$ to rt., $16 \mathrm{~h}, 61 \%$; b) TBAF, THF, $0^{\circ} \mathrm{C}$ to rt., $12 \mathrm{~h}, 60 \%$; c) $\mathrm{N}$-hydroxyphthalimide, $\mathrm{PPh}_{3}, \mathrm{DIAD}, \mathrm{THF}, 0^{\circ} \mathrm{C}$ to rt., $12 \mathrm{~h}, 86 \%$; d) $\mathrm{CH}_{3}$ l, sealed tube, $60^{\circ} \mathrm{C}, 48 \mathrm{~h}, 67 \%$; e) $\mathrm{N}_{2} \mathrm{H}_{4} \cdot \mathrm{H}_{2} \mathrm{O}, \mathrm{CH}_{2} \mathrm{Cl}_{2}, 0^{\circ} \mathrm{C}$ to rt., $2 \mathrm{~h}, 52 \%$. 
From the ${ }^{1} \mathrm{H}$ NMR spectrum $\left(400 \mathrm{MHz}, \mathrm{CDCl}_{3}\right)$ of lipid 4.1 , the broad signal at $\delta$ $6.07 \mathrm{ppm}$ represents the four aminooxy proton (Figure 31). The quaternized amine methyl group $\mathrm{NCH}_{3}$ can be observed at $\delta 3.43 \mathrm{ppm}$. The $\alpha$ and $\beta$ protons of two esters can be found at $\delta 2.30-2.37 \mathrm{ppm}$ as two triplets and around $\delta 1.57 \mathrm{ppm}$ as broad peak respectively. The protons on the hydrophobic tail can be found at $\delta 0.86 \mathrm{ppm}$ and $\delta$ 1.24-1.58 ppm. The signal at $\delta 5.66 \mathrm{ppm}$ can be assigned to $\mathrm{NCH}_{2} \mathrm{CH}(\mathrm{O}) \mathrm{CH}_{2}$. The HRMS found $\mathrm{M}^{+}$at $644.5582\left(\mathrm{C}_{36} \mathrm{H}_{74} \mathrm{~N}_{3} \mathrm{O}_{6}{ }^{+}\right.$, calculated as 644.5572$)$.

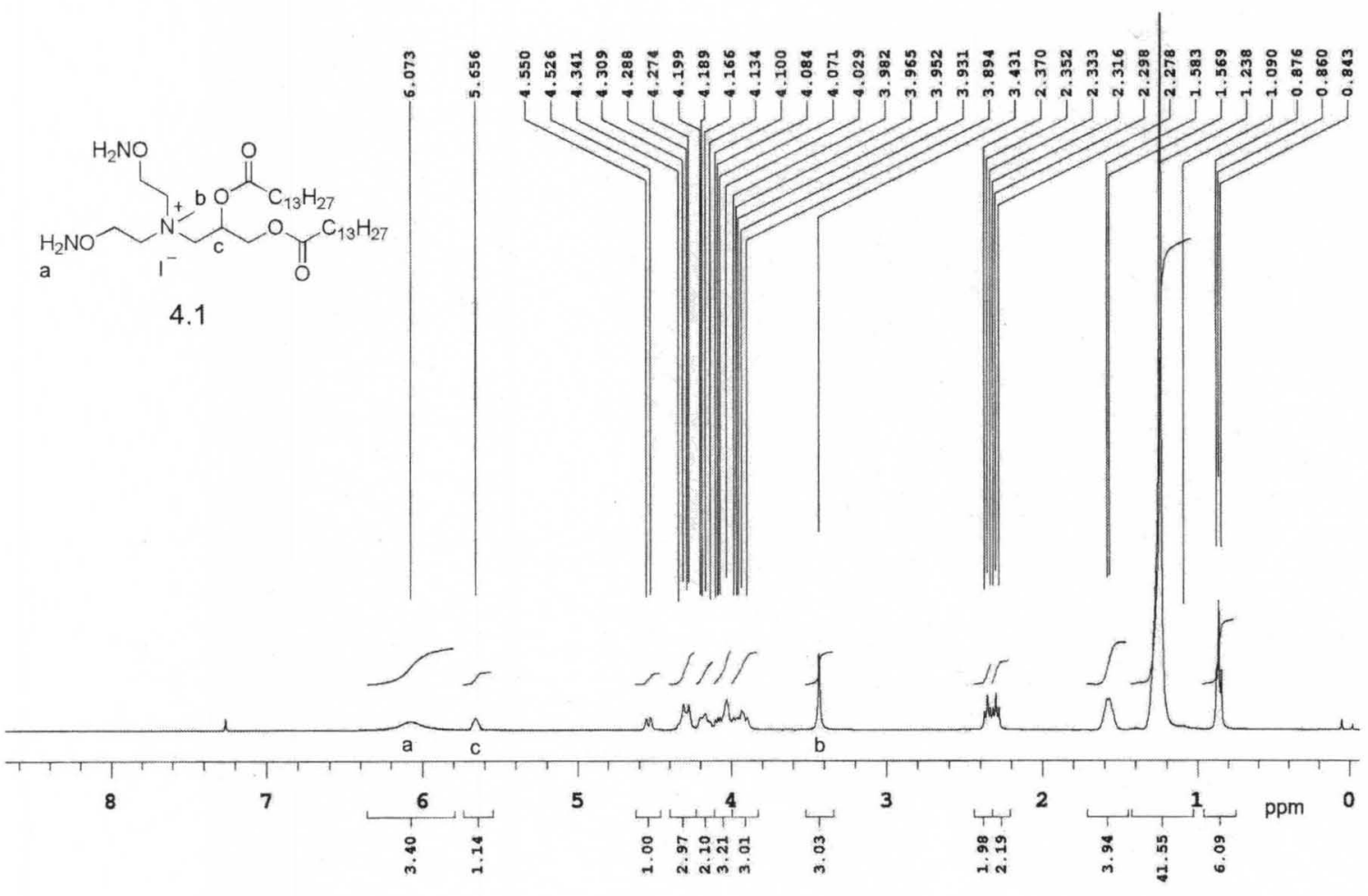

Figure 31. ${ }^{1} \mathrm{H}$ NMR spectrum of cationic aminooxy lipid 4.1.

The monoaminooxy lipid 4.3 was synthesized by Mr. Ralph Knipp, my colleague (Scheme 30). First, the silylation of 2-(methylamino)ethanol was accomplished by treatment with $\mathrm{TBSCl}$. The resultant amine 4.13 was then reacted with glycidol to obtain diol 4.14, which was then bis-esterified with palmitoyl chloride to generate 
compound 4.15. After the TBS protection group was cleaved using TBAF, alcohol 4.16 was reacted with $\mathrm{N}$-hydroxyphthalimide under Mitsunobu conditions ${ }^{73}$ to generate amine 4.17. The Pht protection group was cleaved by reaction with hydrazine to afford 4.18. In another route, the cationic lipid 4.3 was obtained after methylation and hydrazinolysis (7 steps, 6\% unoptimized overall yield from 2-(methylamino)ethanol).
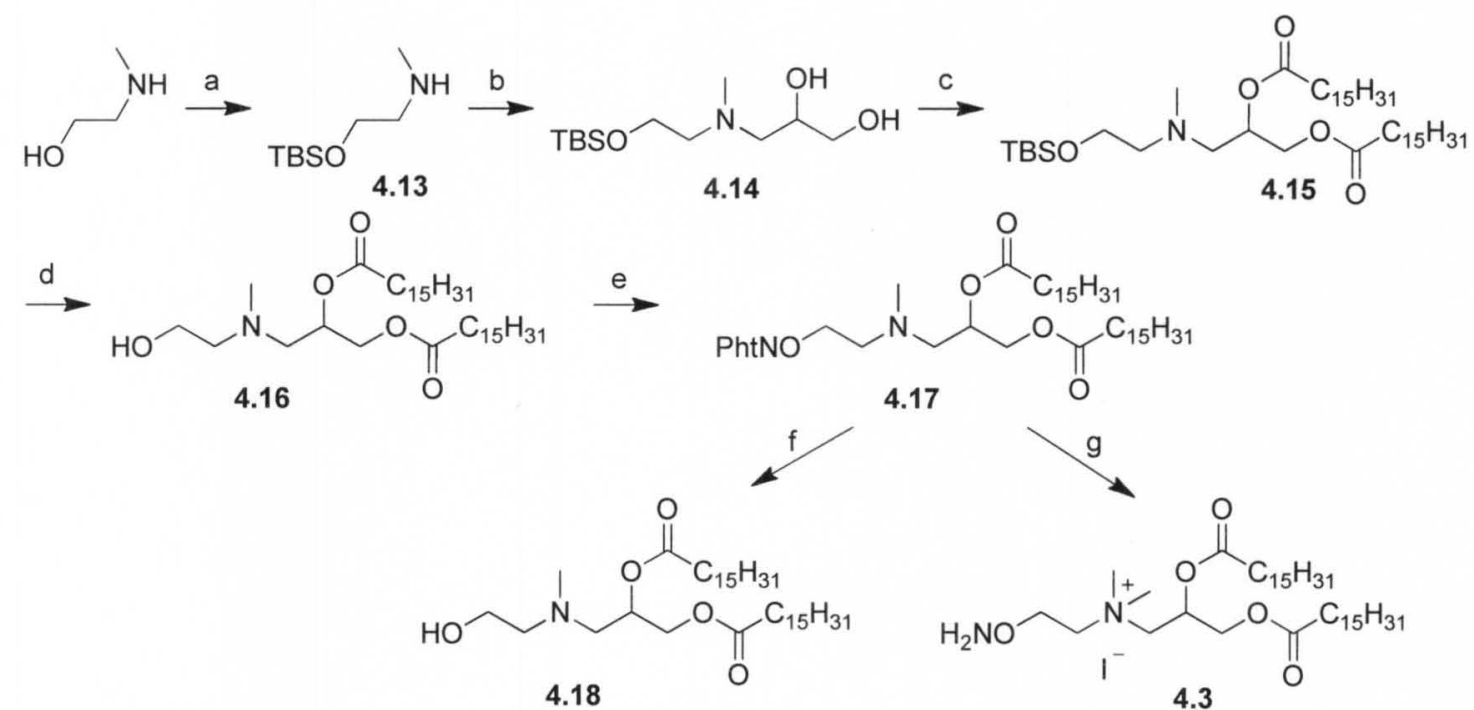

Scheme 30. Synthesis of aminooxy lipid 4.3. and 4.17.

Conditions: Pht $=$ phthaloyl a) $\mathrm{TBSCl}, \mathrm{Et}_{3} \mathrm{~N}$, imidazole(cat.), $\mathrm{CH}_{2} \mathrm{Cl}_{2}, 0^{\circ} \mathrm{C}$ to rt., $12 \mathrm{~h}, 100 \%$; b) glycidol, $\mathrm{LiClO}_{4}$, ethanol, $0^{\circ} \mathrm{C}$ to rt., $16 \mathrm{~h}, 43 \%$; c) $\mathrm{Et}{ }_{3} \mathrm{~N}$, DMAP, myristoyl chloride, $\mathrm{CH}_{2} \mathrm{Cl}_{2}, 0^{\circ} \mathrm{C}$ to rt., $12 \mathrm{~h}, 85 \%$; d) TBAF, THF, $0^{\circ} \mathrm{C}$ to rt., $12 \mathrm{~h}, 74 \%$; e) $\mathrm{N}$-hydroxyphthalimide, $\mathrm{PPh}_{3}$, DIAD, THF, $0^{\circ} \mathrm{C}$ to rt., $12 \mathrm{~h}, 64 \%$; f) $\mathrm{N}_{2} \mathrm{H}_{4} \cdot \mathrm{H}_{2} \mathrm{O}, \mathrm{CH}_{2} \mathrm{Cl}_{2}, 0^{\circ} \mathrm{C}$ to rt., $2 \mathrm{~h}, 69 \%$; g) 1) $\mathrm{CH}_{3} \mathrm{l}$, sealed tube, $45^{\circ} \mathrm{C}, 22 \mathrm{~h}, 67 \%$; 2) $\mathrm{N}_{2} \mathrm{H}_{4}, \mathrm{H}_{2} \mathrm{O}, \mathrm{CH}_{2} \mathrm{Cl}_{2}, 0^{\circ} \mathrm{C}$ to rt., $2 \mathrm{~h}, 55 \%$. 


\subsection{Liposome Stabilization Study}

\subsubsection{Liposome Formulation and Bis-aldehyde Stabilization Attempts}

With cationic aminooxy lipids in hand, we started to examine the feasibility of 'click' stabilized liposomes using external aldehydes. First, a thin layer of lipid 4.1 was sonicated in water to formulate liposomes (diameter $119 \mathrm{~nm}$; zeta potential $59 \mathrm{meV}$ ). The high zeta potential (surface surcharge) kept the liposomes from aggregating -- no precipitation was observed even after storage at room temperature for one week. Similarly, liposomes with $\sim 100 \mathrm{~nm}$ diameter were produced from lipid $\mathbf{4 . 2}$, whereas no liposomes were formed from lipid $\mathbf{4 . 3}$ using the same protocol.

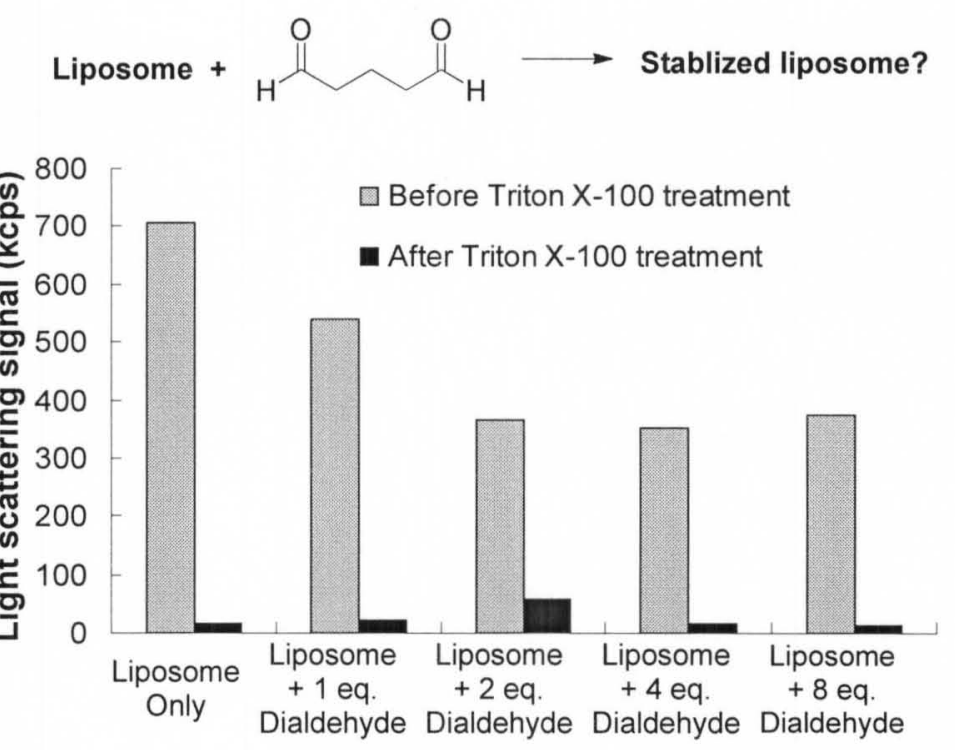

Figure 32. Effect of glutaric dialdehyde on liposome stabilization.

Liposomes were formulated by sonicating a thin layer of lipid $4.1(19.5 \mathrm{mg})$ in water $(4.87 \mathrm{~mL})$ for 20 minutes. The liposome solution $(200 \mu \mathrm{L})$ was mixed with water $(3.8 \mathrm{~mL})$. After incubated with glutaric dialdehyde $(0,1,2,4,8$ eq., aldehyde to aminooxy) for $0.5 \mathrm{~h}$ at room temperature, the liposome mixture was treated with Triton X-100 (final concentration $0.12 \%$, w/v). The light scattering signals before and after surfactant treatment were recorded. 
The stabilities of liposomes from 4.1 before and after addition of different eq. of dialdehyde reagents were measured using the surfactant solubilization method discussed previously. For untreated liposomes, the light scattering signals disappeared almost completely on Triton X-100 treatment due to surfactant-mediated solubilization (Figure 32). Disappointingly, the bis-aldehyde reagent (glutaric dialdehyde) treated liposomes also had little light scattering signal remaining after Triton $\mathrm{X}-100$ treatment, indicating that glutaric dialdehyde failed to stabilize the liposome formulation (Figure 32). This is possibly due to insufficient crosslinks on the liposome surface even excess glutaric dialdehyde (e.g., 8 eq.) was added. Due to the negative results from this one time experiment, we decided to abandon this approach. We hypothesized that a poly-aldehyde polymer may provide more crosslinks and consequently impart stability.

\subsubsection{DPA Synthesis and Aldehyde Titration}

Since hydrophilic polyaldehyde compounds are not commercially available, we set out to synthesize a panel. Polysaccharide derivatives were selected as polyaldehyde candidates due to their good biocompatibility, availability and wide application in biological studies. ${ }^{41,110,111}$ The first polysaccharides we studied were dextrans, a class of polysaccharides with molecular weights $\geq 1,000$ Dalton. ${ }^{112}$ Dextrans have a linear backbone of $\alpha$-linked D-glucopyranosyl repeating units. Due to different production resources, the glucose units can be linked through $a(1 \rightarrow 2), \alpha(1 \rightarrow 3), \alpha(1 \rightarrow 4)$ and $a(1 \rightarrow 6)$ linkage (Figure 33 ). 


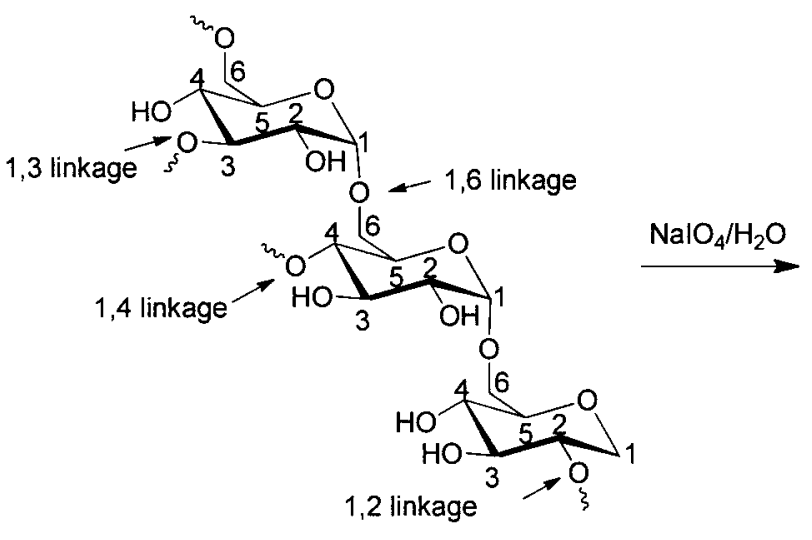

Dextran
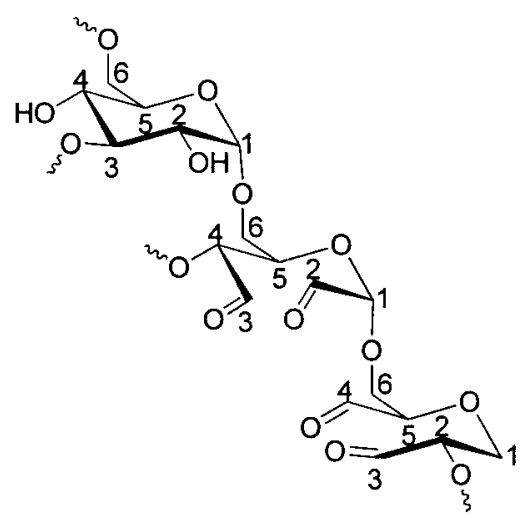

Dextran PolyAldehyde

Figure 33. Structure of dextran and dextran polyaldehyde.

A panel of dextran polyaldehydes (DPAs) was synthesized from dextran (sigma, MW 6kD) by using reported protocols (Figure 33$).{ }^{63}$ Briefly, dextran (1.62 g) was first reacted with varying ratios of $\mathrm{NalO}_{4}$ overnight at room temperature. The reactions were stopped by passing the reaction solution through a column filled with Dowex $1 \times 8-400$ ion exchange resins. The resultant light yellow solutions then were extensively dialyzed against distilled water for 3 days at $4{ }^{\circ} \mathrm{C}$. After concentration under reduced pressure and lyophilization, the purified DPAs were obtained as white powders $(1.32-1.37 \mathrm{~g})$

\begin{tabular}{|c|c|c|c|}
\hline DPA & Glu:NalO & $\begin{array}{c}\text { Aldehyde } \\
(\mathrm{mmol} / \mathrm{g})\end{array}$ & $\begin{array}{c}\text { Oxidized Glucose } \\
(\%)\end{array}$ \\
\hline A & $1: 1$ & 8.4 & 68 \\
\hline B & $3: 1$ & 3.0 & 24 \\
\hline C & $10: 1$ & 0.6 & 4.9 \\
\hline D & $30: 1$ & 0.3 & 2.3 \\
\hline E & $100: 1$ & 0.16 & 1.2 \\
\hline
\end{tabular}

Table 1. DPA aldehyde density as a function of $\mathrm{NaIO}_{4}$ stoichiometry.

Glu: $\mathrm{NaIO}_{4}=$ glucose units (mole) $: \mathrm{NaIO}_{4}$ (mole) 
Aldehyde content was determined by the hydroxylamine hydrochloride method according to the work of Zhao, et al.. ${ }^{113}$ In brief, DPA $(0.1 \mathrm{~g})$ was dissolved in an aqueous solution of hydroxylamine hydrochloride $(25 \mathrm{~mL}, 0.25 \mathrm{M}, \mathrm{pH} 4.0)$. The mixture was stirred for $2 \mathrm{~h}$ at room temperature and then titrated with aqueous sodium hydroxide $(0.1 \mathrm{M})$ until the $\mathrm{pH}$ returned to 4.0 (Digital $\mathrm{pH}$ meter: Thermo Orion, model 410). The aldehyde concentration was calculated by the equation:

$\mathrm{CHO}$ on DPA $(\mathrm{mmol} / \mathrm{g})=\mathrm{Vol}_{\mathrm{NaOH}} \mathrm{mL} \times 0.25 \mathrm{~mol} / \mathrm{L} /$ Weight of sample $(\mathrm{g})$

By using different molar ratios of dextran to $\mathrm{NalO}_{4}$, DPAs with different molar ratios of aldehydes were synthesized (Table 1).The greater equivalents of $\mathrm{NaIO}_{4}$ used, more was used, more aldehyde groups generated on the DPA sample. For example, the DPA-A was calculated to possess $8.4 \mathrm{mmol}$ of $-\mathrm{CHO}$ groups per gram of polymers.

\subsubsection{DPA-Stabilized Liposome Study}

The liposomes formulated from lipid 4.1 were incubated with 4 eq. (aldehyde to aminooxy ratio) of DPA-A at room temperature for 30 minutes. The resultant 'treated' liposomes had a similar diameter and surface charge $\left(D_{H}=117 \mathrm{~nm}, \zeta=62 \mathrm{meV}\right)$ as the untreated aminooxy liposomes derived from lipid 4.1. The surfactant solubilization experiments showed that DPA-A incubation dramatically increased liposome stability. In the negative control experiments, incubation of liposomes with unoxidized dextran (no polyaldehyde groups) or with DPA-A that had been pretreated with hydroxylamine (polyaldehydes capped as oximes) were not stabilized. In the positive control experiments, incubation of liposomes with dextran sulfate (a polyanion polymer) and hydroxylamine pretreated dextran sulfate improved liposome stability through electrostatic forces. These results clearly demonstrated that the DPA-A can stabilize 
liposomes (fromulated lipid 4.1) and the polyaldehyde functional group is essential for the stabilization effect. The stabilized liposomes also have remarkably long term stability. For example, stabilized liposomes were resistant to precipitation for more than 16 days at room temperature.

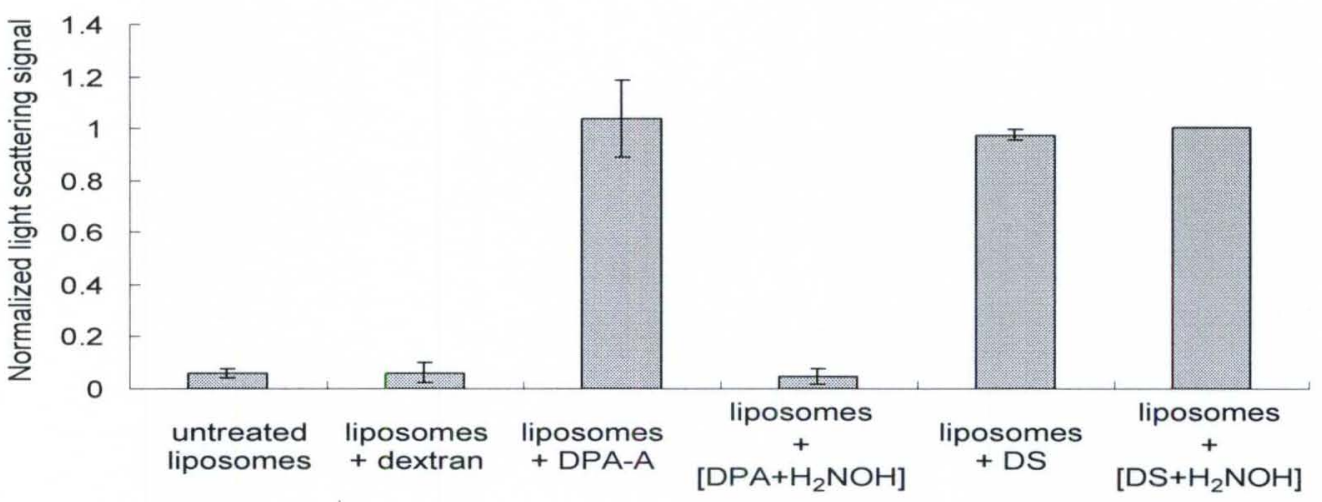

\begin{tabular}{|c|c|c|}
\hline Conditions & Expected Results & $\begin{array}{c}\text { Observed } \\
\text { Results }\end{array}$ \\
\hline $\begin{array}{c}\text { Untreated } \\
\text { liposomes }\end{array}$ & No stabilization since no oximation possible. & $\begin{array}{c}\text { No stabilization } \\
\text { observed }\end{array}$ \\
\hline $\begin{array}{c}\text { Liposomes }+ \\
\text { Dextran }\end{array}$ & No stabilization since no oximation possible. & $\begin{array}{c}\text { No stabilization } \\
\text { observed }\end{array}$ \\
\hline $\begin{array}{c}\text { Liposomes } \\
+ \text { DPA-A }\end{array}$ & Stabilization due to oximation. & $\begin{array}{c}\text { Stabilized } \\
\text { liposomes formed }\end{array}$ \\
\hline $\begin{array}{c}\text { Liposomes }+ \\
\text { (DPA-A }+ \\
\left.\mathrm{H}_{2} \mathrm{NOH}\right)\end{array}$ & $\begin{array}{c}\text { No stabilization since no oximation possible. } \\
\text { Hydroxylamine converts all RCHO groups into } \\
\text { RCHOH rendering them inactive with } \\
\text { aminooxy. }\end{array}$ & $\begin{array}{c}\text { No stabilization } \\
\text { observed }\end{array}$ \\
\hline $\begin{array}{c}\text { Liposomes }+ \\
\text { Dextran sulfate }\end{array}$ & $\begin{array}{c}\text { Stabilization due to electrostatic coating of } \\
\text { polymer onto liposome. }\end{array}$ & $\begin{array}{c}\text { Stabilized } \\
\text { liposomes formed }\end{array}$ \\
\hline $\begin{array}{c}\text { Liposomes }+ \\
\text { (Dextran sulfate } \\
\left.+\mathrm{H}_{2} \mathrm{NOH}\right)\end{array}$ & $\begin{array}{c}\text { Stabilization due to electrostatic coating of } \\
\text { polymer onto liposome because the presence } \\
\text { of hydroxylamine do not destabilize liposome. }\end{array}$ & $\begin{array}{c}\text { Stabilized } \\
\text { liposomes formed }\end{array}$ \\
\hline
\end{tabular}

Figure 34. Results of liposomes treated with Triton X-100. 
DS: Dextran sulfate. Liposomes formulated from lipid 4.1 in water $(1 \mathrm{~mL}, 0.2 \mathrm{mg} / \mathrm{mL})$ were treated with the indicated reagents $(4 \mu \mathrm{L}, 60 \mathrm{mg} / \mathrm{mL}$ ) for 30 min prior to addition of Triton $\mathrm{X}-100$ (final concentration $0.15 \% \mathrm{w} / \mathrm{v}$ ). Hydroxylamine pretreatment was carried out by incubation of DPA-A or DS $(4 \mu \mathrm{L}, 60 \mathrm{mg} / \mathrm{mL})$ with hydroxylamine $(8 \mu \mathrm{L}, 0.25 \mathrm{~mol} / \mathrm{L})$ at room temperature for $30 \mathrm{~min}$. The light scattering signals of samples before and after Triton treatment were measured. Normalized light scattering signal = Light scattering signals after surfactant treatment/ Light scattering signals before surfactant treatment. Each data point reflects the mean value of $n=3$, error bars show standard deviation from the mean.

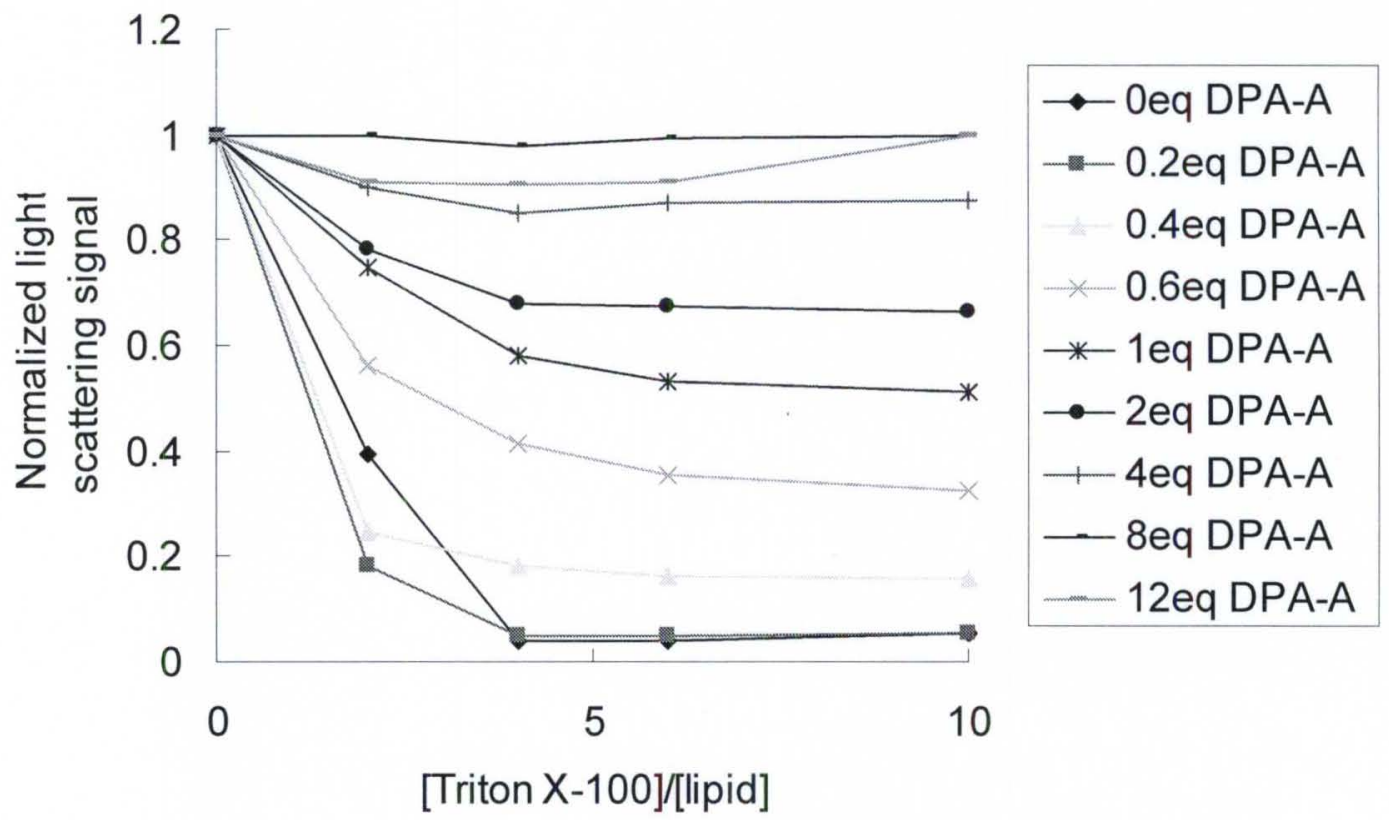

Figure 35. Effect of DPA-A on liposome stabilization.

Liposomes formulated from lipid 4.1 in water $(1 \mathrm{~mL}, 0.2 \mathrm{mg} / \mathrm{mL})$ were treated with the indicated eq. of DPA-A for $1 \mathrm{~h}$ prior to addition of Triton X-100 (final concentration $0.15 \% \mathrm{w} / \mathrm{v}$ ). The light scattering signals of samples before and after Triton treatment were measured. Normalized light scattering signal $=$ Light scattering signals after surfactant treatment/ Light scattering signals before surfactant treatment. 


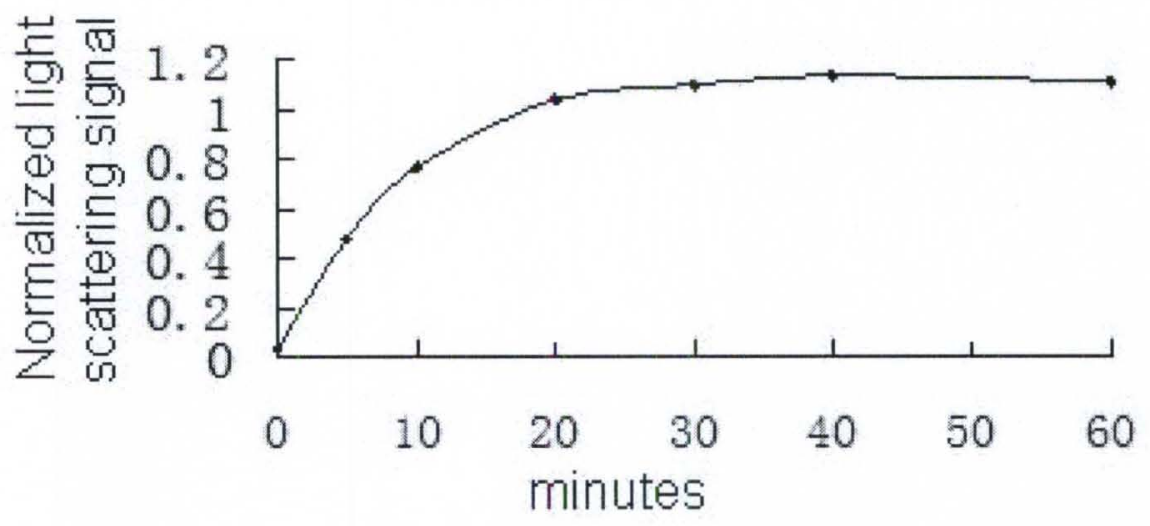

Figure 36. Effect of incubation time on liposome stabilization.

Liposomes formulated from lipid 4.1 in water $(1 \mathrm{~mL}, 0.2 \mathrm{mg} / \mathrm{mL})$ were treated with the DPA-A (4 $\mu \mathrm{L}$, $60 \mathrm{mg} / \mathrm{mL}$ ) for indicated time intervals prior to addition of Triton X-100 (final concentration $0.15 \%$ $w / v)$. The light scattering signals of samples before and after Triton treatment were measured. Normalized light scattering signal = Light scattering signals after surfactant treatment/ Light scattering signals before surfactant treatment.

In preliminary liposomes stabilization conditions study, liposomes formulated from lipid 4.1 were reacted with varying equivalents of DPA-A (from 0 eq. to 12 eq., aldehyde to aminooxy ratio) and then treated with various equivalent of surfactant Triton X-100. (Figure 35) The preliminary data shows that the untreated liposomes is not stable under the surfactant treatment and consequently the light scattering intensity decreases by an order of magnitude after addition of 10 eq. (final concentration $0.15 \% \mathrm{w} / \mathrm{v}$ ) of Triton $\mathrm{X}-100$. While incubation with DPA-A can stabilize liposomes in dose depended way and normalized light scattering intensity increased when more DPA-A was added. It shows that 4 equivalent of DPA-A can achieve good liposome stabilization result. In another preliminary study, the liposomes were incubated at various time internals with DPA-A (4 eq.) at room temperature before the 
addition of Triton X-100. The preliminary data (Figure 36) shows that 4 equivalents of DPA-A can fully stabilize liposomes within 30 minutes, and this stabilization condition was used in more controlled experiment. (Figure 34, liposomes+DPA-A)

Two synthesized DPAs with different aldehyde density (DPA-A $8.4 \mathrm{mmol} / \mathrm{g} \mathrm{CHO}$; DPA-B $3.0 \mathrm{mmol} / \mathrm{g} \mathrm{CHO}$ ) were tested for the ability to stabilize liposomes formulated from lipid 4.1 (Figure 37). The results show that both DPAs stabilized liposomes in a dose dependent way. Moreover, the DPA-A provided the better stabilization effect than DPA-B when using identical equivalents. This is possible due to higher density of aldehyde provides denser crosslinking and consequently leads to more stable liposomes.

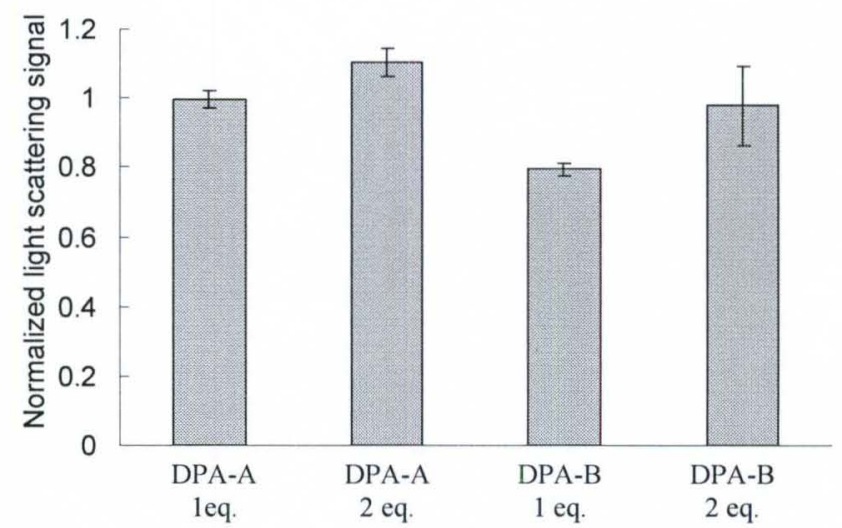

Figure 37. Liposomes stabilized by DPA-A and DPA-B.

Liposomes formulated from lipid 4.1 in AcOH buffer $(2 \mathrm{~mL}, 0.2 \mathrm{mg} / \mathrm{mL}, \mathrm{pH}$ 5) were incubated with the DPA-A or DPA-B (eq. aldehyde to aminooxy) at room temperature. Triton X-100 (final concentration $0.15 \% \mathrm{w} / \mathrm{v}$ ) was added after incubation for $4 \mathrm{~h}$. The light scattering signals of samples before and after Triton treatment were measured. Normalized light scattering signal = Light scattering signals after surfactant treatment/ Light scattering signals before surfactant treatment. Each data point reflects the mean value of $n=3$, error bars show standard deviation from the mean. 
Liposome stabilization under different $\mathrm{pH}$ conditions was also studied. We observed that liposome stabilization proceeds slightly faster when the incubation of liposome and DPA was performed under mild acid buffer rather than neutral buffer presumably because the oximation is catalyzed by acid. Considering that oximation is a fast reaction and most that biological cargos prefer neutral conditions, we conducted the majority of experiments in neutral conditions. In summary, liposomes made from lipid 4.1 can be stabilized by simply adding DPA-A (4 eq.) to the liposome suspension and then incubating for 30 minutes at $\mathrm{pH}$ 7.4. This represents an optimized protocol.

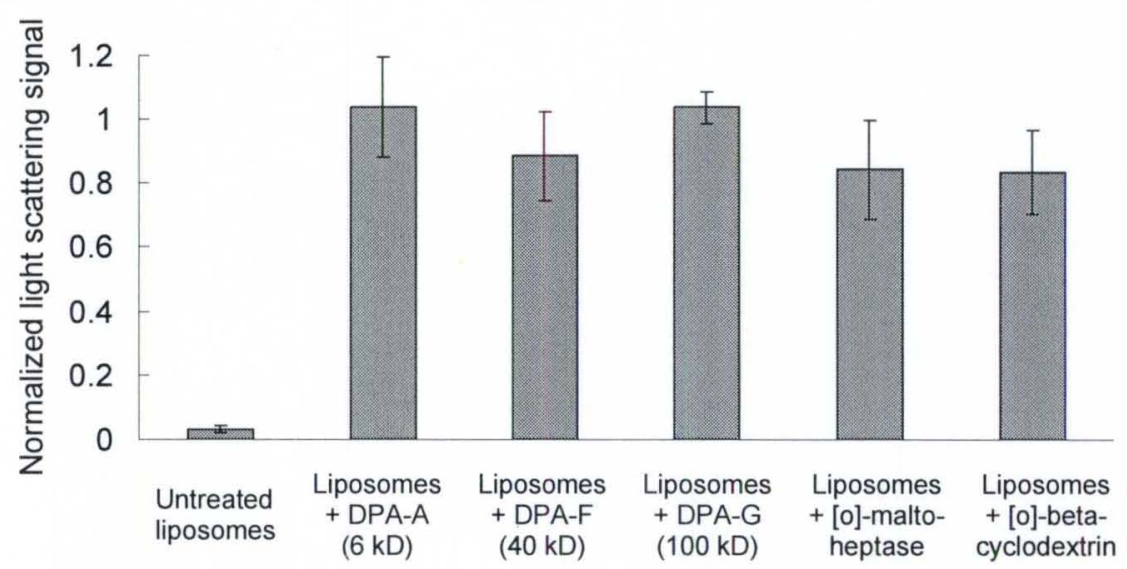

Figure 38. Liposomes stabilized by polyaldehyde compounds.

Liposomes formulated from lipid 4.1 ( $2 \mathrm{~mL}, 0.2 \mathrm{mg} / \mathrm{mL}$, HEPES $12 \mathrm{mM}, \mathrm{pH} 7.4$ ) were mixed with the indicated polyaldehyde compounds (4eq. aldehyde to aminooxy). Then Triton X-100 (final concentration $0.15 \% \mathrm{w} / \mathrm{v}$ ) was added after incubation after $1 \mathrm{~h}$ at room temperature. The light scattering signals of samples before and after Triton treatment were measured. Normalized light scattering signal $=$ Light scattering signals after surfactant treatment/ Light scattering signals before surfactant treatment. Each data point reflects the mean value of $n=2$, and error bars show standard deviation from the mean. 
Because click stabilization is based on oximation chemistry, there should be no reason why this strategy cannot be applied to other polysaccharides. Therefore, dextrans with different molecular weight $(40 \mathrm{kd}, 100 \mathrm{kd})$ and other polysaccharides (maltoheptaose, cyclodextrin) were oxidized by $\mathrm{NaIO}_{4}$ in similar fashion to produce the corresponding polyaldehyde polymers. The resultant DPA-F (from $40 \mathrm{kd}$ dextran, CHO $11.6 \mathrm{mmol} / \mathrm{g}$ ), DPA-G (from $100 \mathrm{kd}$ dextran, CHO $10.75 \mathrm{mmol} / \mathrm{g}$ ), Oxidized maltoheptaose $(\mathrm{CHO}, 8.8 \mathrm{mmol} / \mathrm{g})$ and $\beta$-cyclodextrin $(\mathrm{CHO}, 8.8 \mathrm{mmol} / \mathrm{g})$ were then used to stabilize liposomes using the same protocol mentioned above. The data show that all of the oxidized polysaccharides effectively stabilized liposomes (Figure 38).

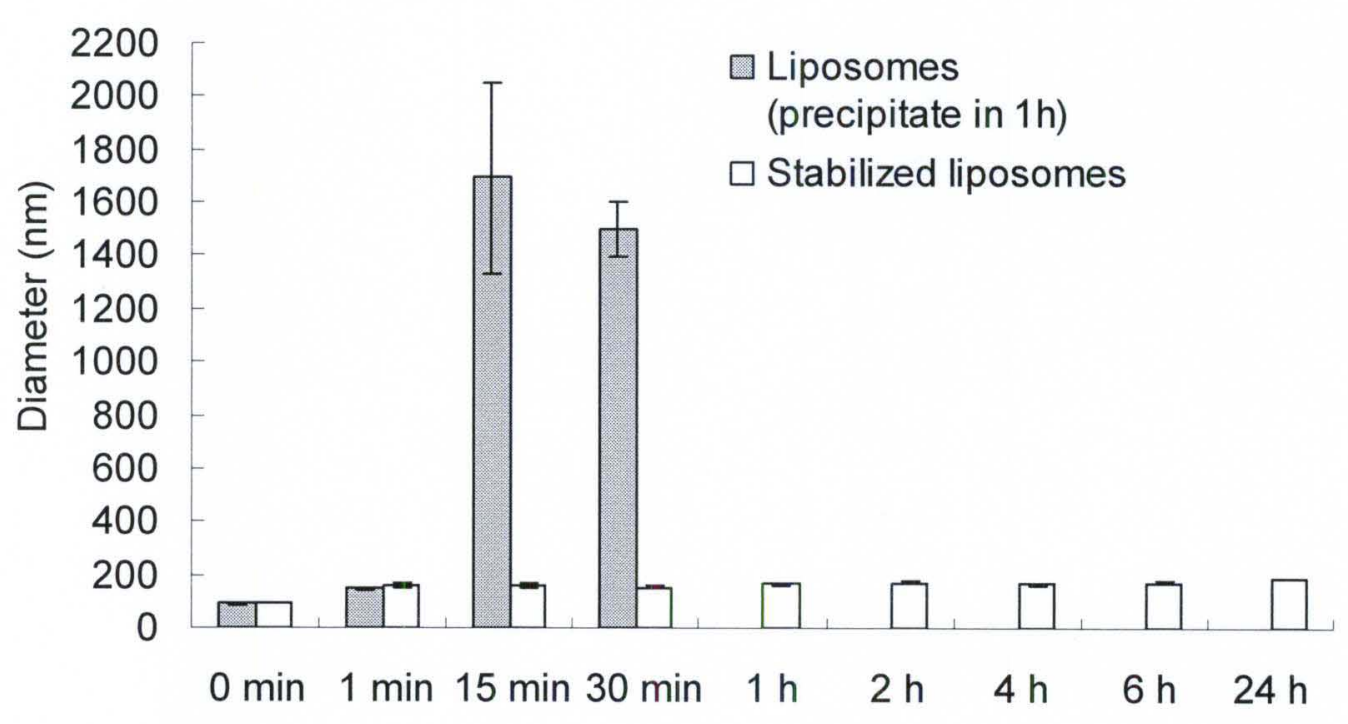

Figure 39. Aggregation behavior of liposomes and DPA stabilized liposomes.

The stabilized liposomes were prepared by incubating liposomes formulated from lipid 4.1 ( $1 \mathrm{~mL}, 1$ $\mathrm{mg} / \mathrm{mL}$ lipid, HEPES $20 \mathrm{mM}, \mathrm{pH}$ 7.4) and DPA-A (10 $\mu \mathrm{L}, 60 \mathrm{mg} / \mathrm{mL})$ overnight at room temperature. The untreated liposomes and the stabilized Liposomes were then incubated with $10 \%$ FBS at room temperature. The particle sizes (mean hydrodynamic diameter) of the samples were recorded at the indicated time. Each data point reflects the mean value of $n=3$, error bars show standard deviation from the mean. 
Considering dextran has been widely applied in intravenous usages, we believed that addition of DPA gives liposomes a coating that provides a "stealth" barrier against serum-induced aggregation. A liposome aggregation study showed that the particle size of untreated liposomes derived from lipid 4.1 increased very fast due to aggregation in 10\% FBS (Fetal Bovine Serum); precipitations were observed in $1 \mathrm{~h}$. In contrast, the particle size of DPA-A stabilized liposomes increased slowly to around $300 \mathrm{~nm}$ diameter; no precipitation was observed even after one day (Figure 39). This result proved that the DPA-A can help protect liposomes against 10\% FBS-induced aggregation.

In previous experiments, we observed that even partial oximation between DPA and liposomes provided some measure of stability to liposomes. We also observed that incubation with 4 eq. of DPA-A can provide extra stability to the liposomes that have at least $25 \%$ of lipid $\mathbf{4 . 1}$ in total lipids. Therefore, the cationic aminooxy lipid $\mathbf{4 . 1}$ could be applied as a co-lipid for liposome stabilization.

\subsubsection{IR Characterization}

For aminooxy compounds, the oximation reaction can be confirmed by analyzing the NMR spectra of adducts (described in chapter 3.4). However, it is difficult to follow the oximation reaction of liposomes using NMR. Fortunately, our collaborator, Prof. Donald P. Land (Department of Chemistry, University of California, Davis), has cutting-edge methods using Fourier Transform Reflection Absorption Infrared Spectroscopy, that can obtain IR absorption spectra of liposomes absorbed on the 
surface of an ATR crystal. ${ }^{114}$ By recording the IR spectrum during liposome incubation with DPA-A, the progress of oximation reaction can be traced.

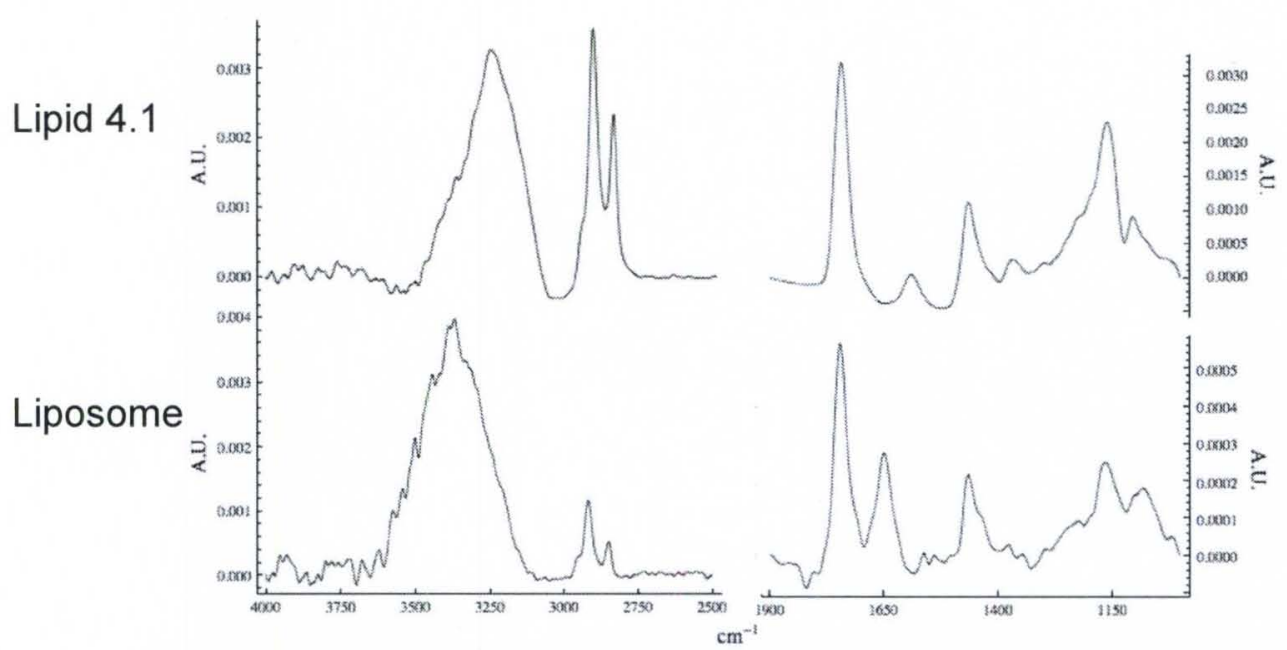

Figure 40. IR spectra of the lipid 4.1 and corresponding liposome.

First, the IR spectrum of dry cationic aminooxy lipid 4.1 on the surface of the ATR crystal (Figure 40 above) and the cationic aminooxy liposome freely floating in the solution above the surface of the ATR crystal (Figure 40 below) were obtained. We can see the characteristic $-\mathrm{CH}$ and $-\mathrm{NH}$ absorption bands between $3500-2800 \mathrm{~cm}^{-1}$. The fingerprint region within both spectra display the carbonyl absorption at $1730 \mathrm{~cm}^{-1}$, primary amine bending $1640-1560 \mathrm{~cm}^{-1}$, methylene bending $1465 \mathrm{~cm}^{-1}$, and the ester at $1175 \mathrm{~cm}^{-1}$.

Then, at certain time intervals the IR spectrum of the reaction mixtures of cationic aminooxy liposomes and DPA-A were recorded. The time dependent fingerprint region of the cationic liposomes are shown superimposed (Figure 41 left). The decreasing primary amine absorption band found at $1650 \mathrm{~cm}^{-1}$ is attributed to the ongoing chemical reaction between the aminooxy present on the lipid headgroups 
with the aldehyde groups on the DPA-A. The plot shows the integrated absorbance for that absorption band as a function of time, where the changes in absorbance no longer occur after 60 minutes of monitoring the liposome solution (Figure 41 right).
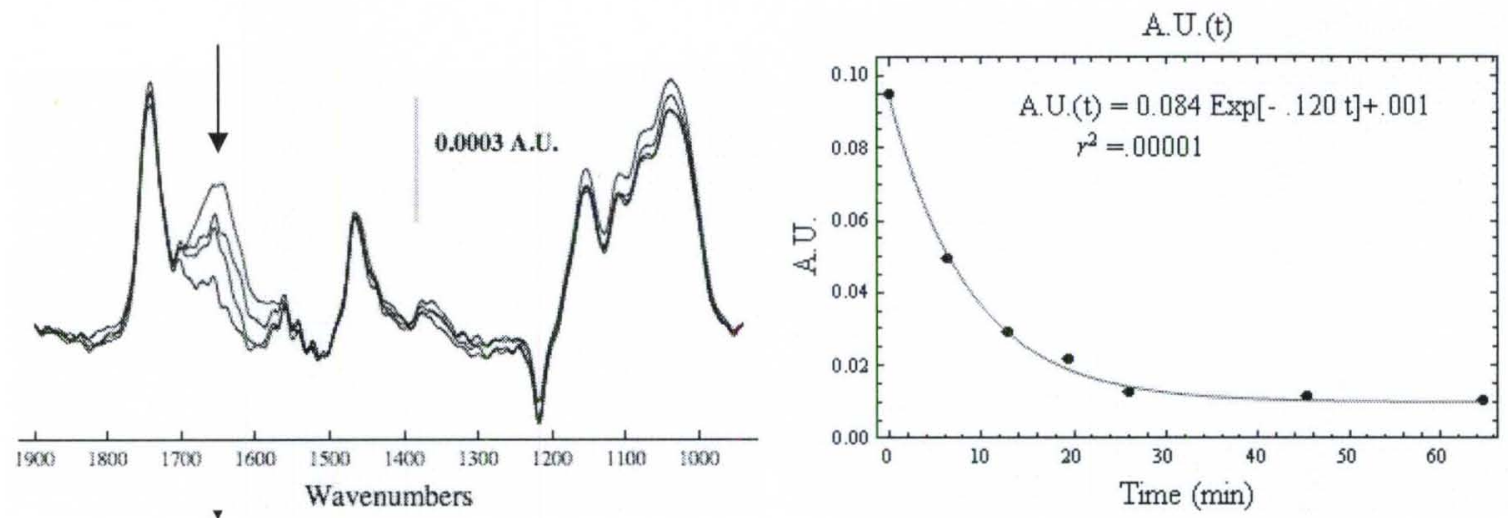

Figure 41. IR spectra of the cationic aminooxy liposome during reaction and integrated IR absorbance around $1650 \mathrm{~cm}^{-1}$ as a function of time.

From the IR spectrum analysis, more than $80 \%$ of aminooxy absorbance disappeared within $30 \mathrm{~min}$, meaning that most of the aldoxime bonds are generated in the first 30 min of incubation. It is interesting that 'click' liposome stabilization needed 30 minutes to stabilize liposomes against surfactant solubilization (Figure 36). Therefore, we can get a tentative conclusion: 'click' liposome stabilization requires around $80 \%$ of aminooxy functional groups crosslinking.

\subsection{Permeability Study of 'Click' Stabilized Liposomes}

The permeability of 'click' stabilized liposomes was studied by the encapsulated calcein leakage experiment. ${ }^{115}$ Calcein is a small molecular fluorescent dye with an excitation and emission wavelength of $495 / 515 \mathrm{~nm}$, respectively. Under high concentration (e.g, $50 \mathrm{mM}$ ), calcein emits a minimal fluorescent signal due to 
self-quenching. Thus, very low fluorescence is observed when calcein is entrapped in liposomes $(50 \mathrm{mM})$. However, once leaked from liposomes, an intensive fluorescent signal of calcein can be observed (Figure 42), since the probe dilutes into the bulk buffer. Therefore, liposome permeability can be determined through monitoring fluorescence generated from leaked calcein. ${ }^{116}$ The relative fraction (RF) of released calcein can be calculated using the formula below:

$$
\operatorname{RF}(\%)=100 X\left(I_{t}-I_{0}\right) /\left(I_{\max }-I_{0}\right)
$$

Where $I_{0}$ is fluorescence intensity at time $0, I_{t}$ is fluorescence intensity at time $t, I_{\max }$ is maximum fluorescence intensity and represents all calcein released.

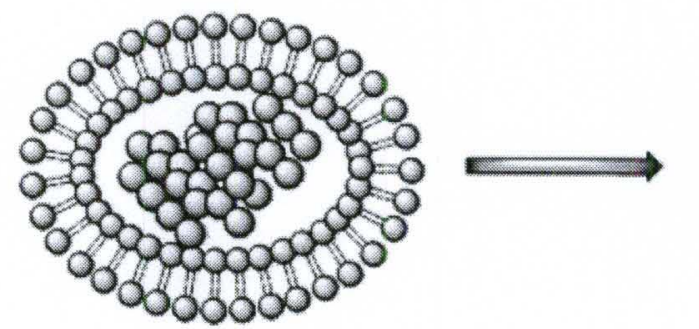

\section{Calcein encapsulated in liposomes $(50 \mathrm{mM})$}

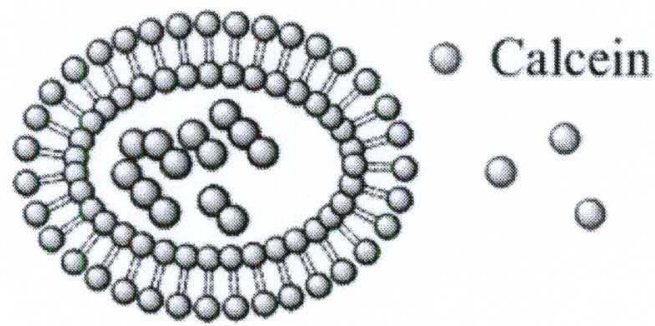

\section{Calcein Leak and becomes diluted}

Low fluorescent signal High fluorescent signal

Figure 42. Calcein released from liposomes. 

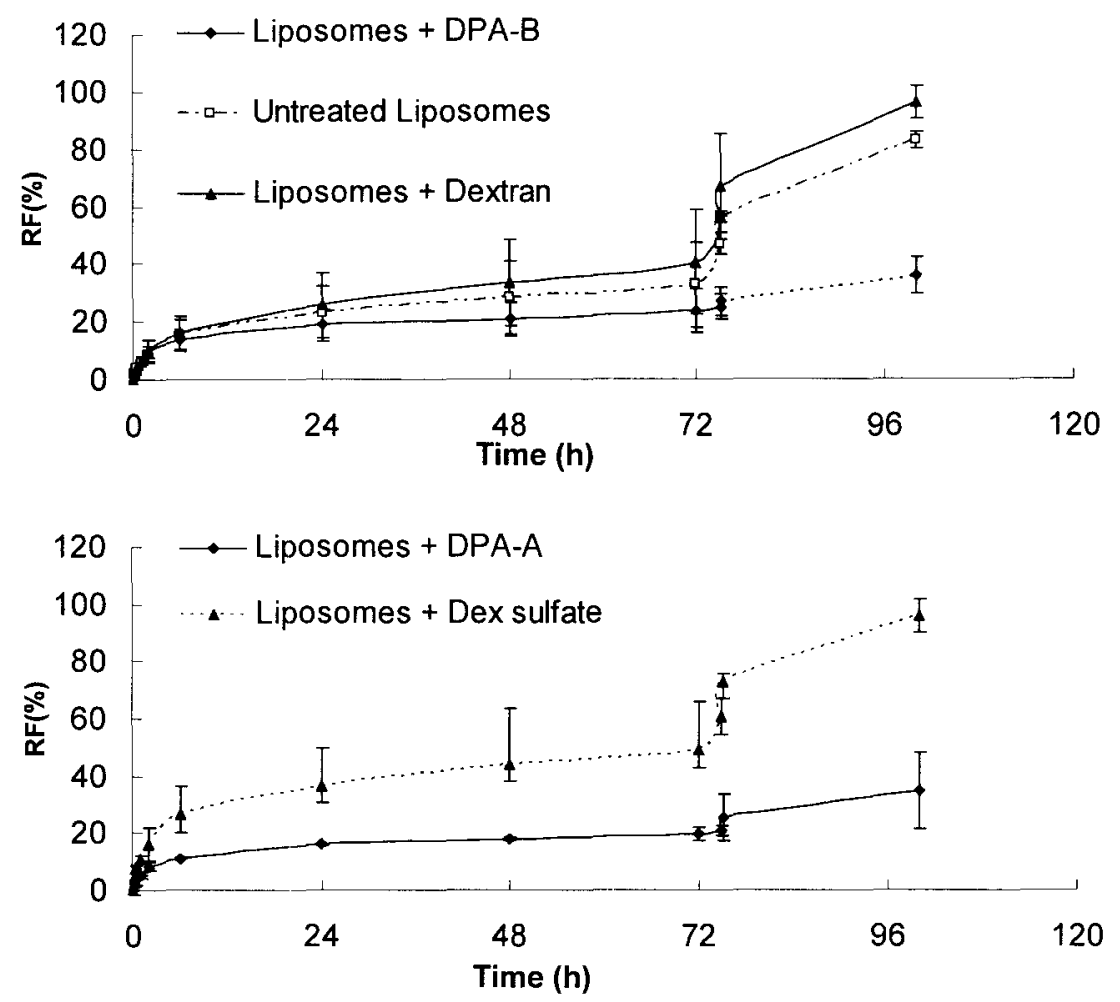

Figure 43. Calcein release study.

Liposomes formulated from lipid 4.1 and containing encapsulated calcein (50 mM) in HEPES buffer $(20 \mathrm{mM}, \mathrm{pH} 7.4)$ were treated with the indicated reagents prior to addition of Triton $\mathrm{X}-100$ (final concentration $0.15 \% \mathrm{w} / \mathrm{v}$ ) at $75 \mathrm{~h}$. The release of calcein from the liposome samples was measured fluorometrically at certain time intervals. The relative fraction (RF \%) was calculated using the formula: RF $(\%)=100 \times\left(I_{t}-I_{0}\right) /\left(I_{\max }-I_{0}\right)$. The RF (\%) was plotted as a function of time. Each data point represents the mean value of $n=2$, error bars show standard deviation from the mean.

Briefly, a thin lipid layer of 4.1 was first hydrated using a calcein buffer $(50 \mathrm{mM}, \mathrm{pH}$ 7.4) by vortex mixing and sonication. Then the resultant liposomes containing calcein were separated from free calcein using a Sephadex G-100 column. The aliquot of calcein liposomes samples then was incubated with different reagents and the 
fluorescent signal was recorded at certain time intervals. The effect of different reagents on the permeability of liposomes is shown in Figure 43. The result showed that DPA-A stabilized liposomes release calcein at the slowest rate -- less than $25 \%$ of calcein had leaked out of DPA-A stabilized liposomes. The dextran and dextran sulfate treated liposomes, like untreated liposomes, released almost all calcein payload during the same timeframe. This result clearly showed that the sugar coating of 'click' stabilized liposomes can effectively decrease cargo leakage, even after surfactant treatment.

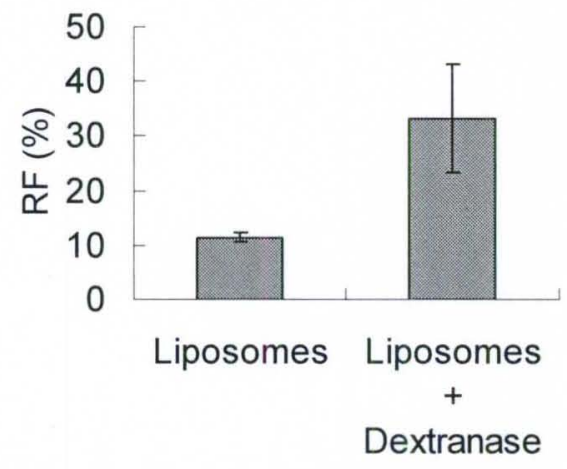

Figure 44. Calcein released from DPA-B stabilized liposomes.

Liposomes formulated from lipid 4.1 containing encapsulated calcein (50 mM) in HEPES buffer (20 mM, pH 7.4) were incubated with the DPA-B (4 eq. aldehyde to aminooxy) for $30 \mathrm{~min}$ at room temperature. The stabilized liposomes were purified by Sephadex G-100 column using buffer B (10 mM HEPES, $150 \mathrm{mM} \mathrm{NaCl}, \mathrm{pH}$ 7.4) as eluent. The aliquot of liposomes was incubated with dextranase $(10 \mathrm{U})$ at $37^{\circ} \mathrm{C}$ for $12 \mathrm{~h}$ or buffer only, and then Ttriton $\mathrm{X}-100$ was added to release entrapped calcein. The release of calcein from the liposome samples was measured fluorometrically at the given time intervals. The relative fraction (RF \%) was calculated using the formula: $\operatorname{RF}(\%)=100 \times\left(I_{t}-I_{0}\right) /\left(I_{\max }-I_{0}\right)$. a) The RF (\%) was plotted as a function of time. Each data point at figure $b$ represents the mean value of $n=3$, error bars show standard deviation from the mean. 
In a final demonstration, an enzyme-mediated liposome permeability change was examined using the same technique. We believed that the hydrolysis of dextran by dextranase may remove some of the polymer from the liposome surface or decrease crosslinking and consequently increase liposome permeability. Since the enzymatic activity of dextranase is strongly affected by the cross-linking density of dextran, ${ }^{117}$ the less crosslinked DPA-B was used in this experiment. The experimental results (Figure 44 ) confirmed that the calcein release rate of 'click' stabilized liposomes increased round 3 fold in the presence of dextranase.

The liposome permeability study showed that the dextran coating of 'click' stabilized liposome effectively decreases cargo leakage while incubation with dextranase can increase cargo leakage. Considering the anaerobic Gram-negative intestinal bacteria produce dextranase ${ }^{111,118}$, our 'click' stabilized liposomes have a potential to be a colon-specific drug carrier.

\section{5 'Click' Stabilized Liposomes as Nano-reactors}

Enzyme-containing liposomes have been studied as nano-reactors for medical and non-medical applications. ${ }^{119}$ The lipid layer of nano-reactors not only offers protection to encapsulated enzymes against denaturation or proteolysis, but also provides additional substrate selectivity due to different membrane permeability of external substrates. ${ }^{120}$ The enzyme-containing liposomes can serve as nanoreactor and the entrapped enzymes can catalyze specific substrates which permeate across the lipid bilayer(s). Those enzyme containing liposomes have great potential in bio-catalysis as nano-bioreactor and signal generator/amplifier in analytical 
chemistry. ${ }^{121-124}$ Considering the simplicity and ease to get click stabilized liposomes and their super stability, we believe this approach can offer great advantages when applied as nano-reactor.

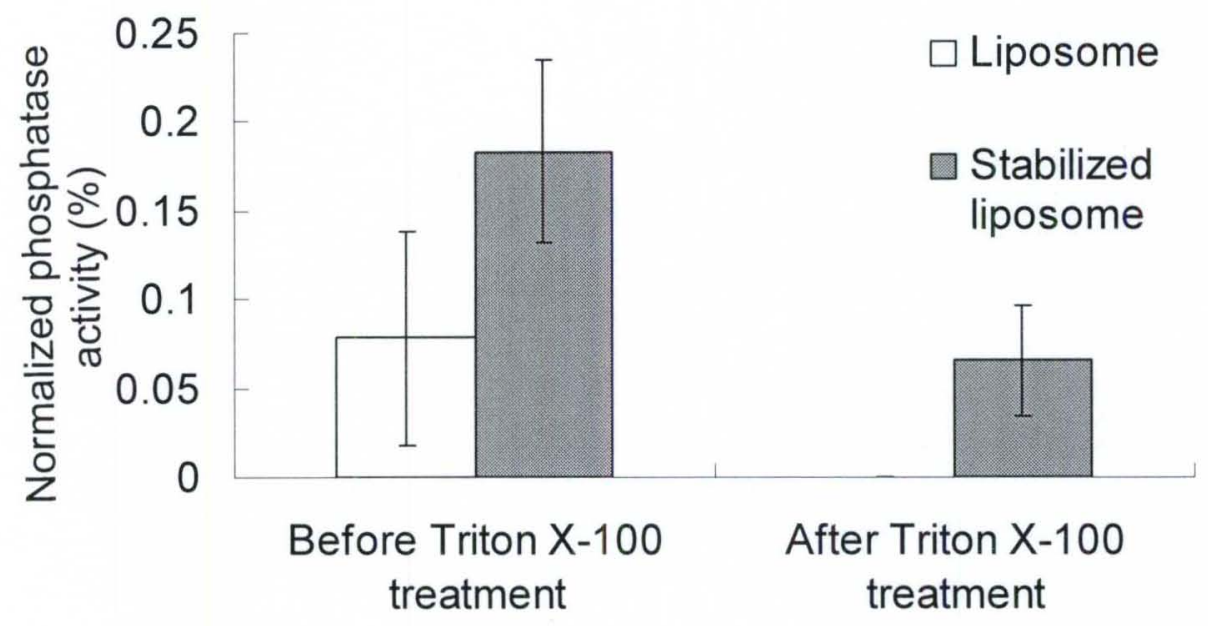

Figure 45. The activity of phosphatase encapsulated within liposomes.

The liposomes were formulated from lipid $\mathbf{4 . 1}$ and encapsulated within alkaline phosphatase. The stabilized liposomes were prepared by addition of DPA-A (1eq, aldehyde to aminooxy) followed by incubation overnight at room temperature. Unencapsulated enzyme was removed by repeated centrifugation, and the pelleted liposomes were resuspended in buffer $(5 \mathrm{mM}$ Tris, $5 \mathrm{mM} \mathrm{MgCl}$, $0.1 \mathrm{mM} \mathrm{ZnCl}_{2}, \mathrm{pH}$ 8). The redispersed liposomes then were treated with Triton $\mathrm{X}-100$ (final concentration $0.15 \% \mathrm{w} / \mathrm{v}$ ). The released enzymes were separated by repeated centrifugation. The alkaline phosphatase activity then was measured using the fluorogenic substrate 4-methylumbelliferyl phosphate. Normalized phosphatase activity = phosphatase activity / loaded phosphatase activity. Each data point represents the mean value of $n=2$, error bars show standard deviation from the mean.

In our click stabilized nano-reactor, the enzyme (alkaline phosphatase) was encapsulated in the aqueous core domain and its activity was measured by cleavage 
of the fluorogenic substrate 4-Methylumbelliferyl phosphate that diffuses through the lipid wall. Both liposome- and click stabilized liposome- encapsulated alkaline phosphatase were made. The free enzyme and liposomes were separated by repeated centrifugation. After Triton X-100 treatment, the disrupted liposomes and intact liposomes were separated by repeated centrifugation again. Final precipitation pellet were resuspended into the buffer and test their enzyme activity. The normal nano-reactor made from untreated liposomes was disrupted on surfactant treatment (no measured enzyme activity after treatment) whereas the click-stabilized nano-reactor preserved a significant amount of enzyme activity $(6.5 \pm 3.1 \%$ of total loaded enzyme activity) (Figure 45). This proof-of-concept experiment demonstrated that the 'click' stabilized liposomes can work as nano reactor under harsh conditions such as the presence of surfactant due to its enhanced stability.

\subsection{Aminooxy Lipids as 'Clickable' Co-lipids}

The bis-aminooxy functionality on the cationic aminooxy lipid not only provides reactive groups for stabilization but also provides 'clickable' functionality for liposome surface modification. By using a cationic aminooxy lipid as a co-lipid, a formulated liposome is formed that is now equipped with aminooxy functionality on the surface for future modification, such as conjugation to target ligands, fluorescent groups or PEG groups.

Our collaborator, Dr. Anu Puri (NCl-Frederick Center for Cancer Research Nanobiology Program) has developed a method to incorporate keto functionality on

the antibody through site-specific protein glycosylation. ${ }^{125}$ Considering the keto and 
aminooxy group are an ideal conjugation pair, they plan to use our cationic aminooxy lipid as a co-lipid for conjugation of an antibody to the liposome through ketoximation. The preliminary results demonstrated that the cationic lipid 4.2 can labeled with anti-HER2 scFv antibody, an antibody targeting breast cancer (Figure 46).

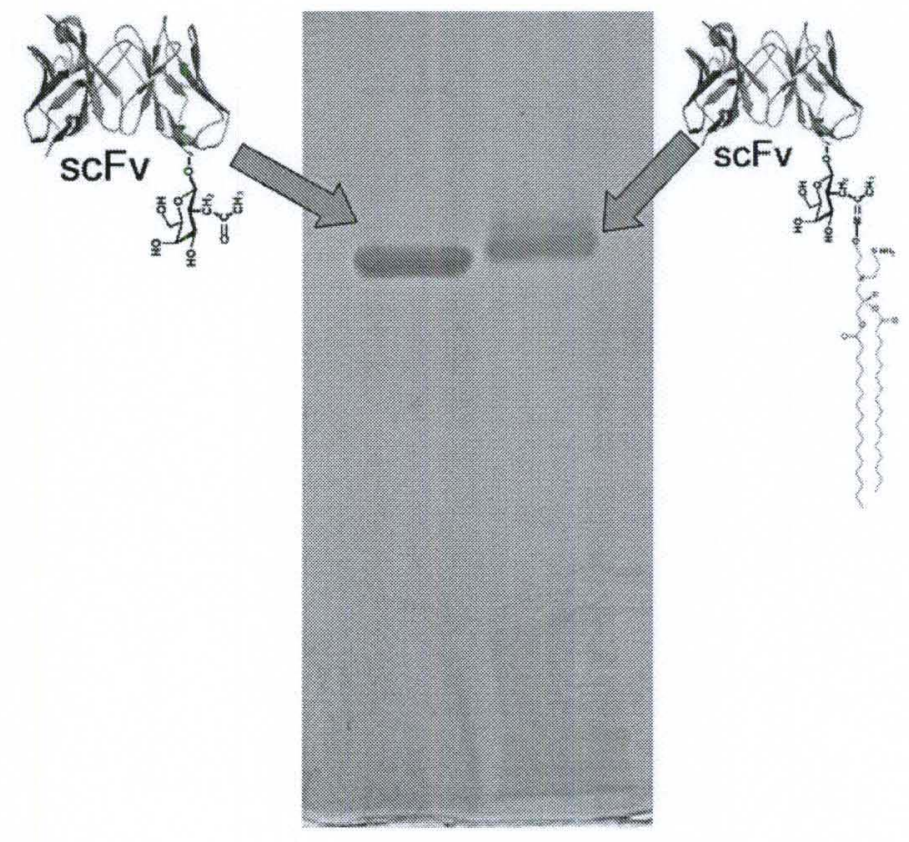

Figure 46. Antibody conjugated with aminoxy-lipid.

SDS-PAGE gel of the anti HER2 scFv with 2-keto-Gal before (left) and after (right)

Besides the cationic lipids 4.2, the mono-aminooxy lipids 4.18 and bis-aminooxy lipids 4.19 and 4.20 are also synthesized in $94 \%$ and $30 \%$ unoptimized yield respectively, at the request of our collaborator (Scheme 31). 

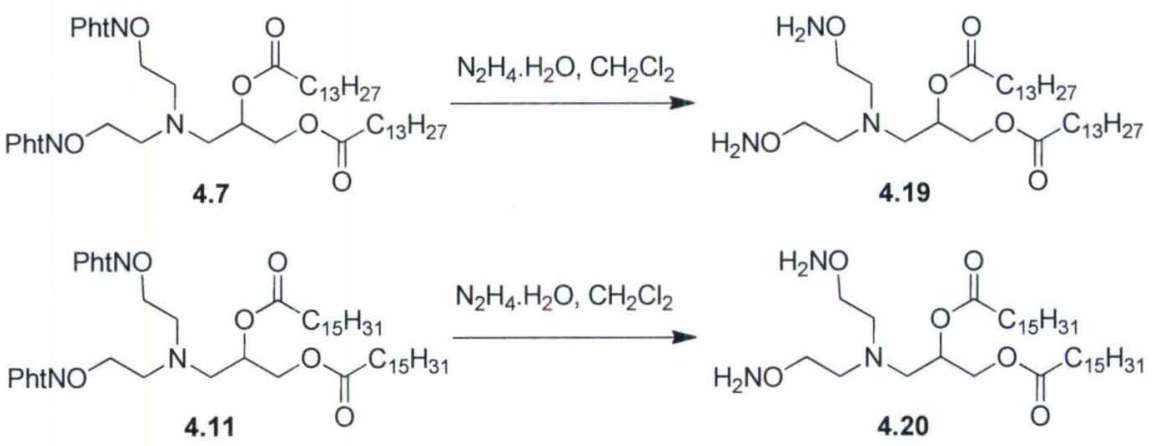

Scheme 31. Synthesis of aminooxy lipid 4.19 and 4.20.

\subsection{Conclusions}

In summary, we have demonstrated a convenient method to stabilize aminooxy liposomes via click chemistry of the aminooxy surface using externally added aldehyde-polymers. The resultant liposomes have super stability against surfactant solubilization and serum mediated aggregation. The stabilized liposomes also have reduced permeability compared with untreated liposomes. Moreover, the stabilized liposomes can be permeablized by treatment with an enzyme, such as dextranase. The stabilized liposomes may be useful in two potential applications: as a colon targeted drug carrier and as a robust nanoreactor. The aminooxy lipids we synthesized can also be used as co-lipids for liposome stabilization and liposome surface modification. 


\section{CHAPTER 5. \\ 'CLICK' STABILIZED LIPOSOMES FOR GENE TRANSFECTION}

\subsection{Introduction}

Gene therapy is a promising approach for the treatment of liver diseases including cancer. ${ }^{126-128}$ Compared to viral vectors, liposomal-directed gene delivery systems are nearly non-immunogenic, relatively safer, have a lower production cost and can carry multiple genetic materials. But the transfection efficiency of liposomal-directed gene delivery still needs to be improved. To achieve a high in-vivo, liver-targeted gene transfection efficiency, intact liposome vectors need to be efficiently delivered to the surface of liver cells. However, there are two hurdles that decrease delivery efficiency: off-target delivery (e.g, lungs) and instability in the blood. ${ }^{129}$ In this chapter, we attempt to overcome these two hurdles using a liver-targeted 'click' stabilized liposome.

The ligand we chose is targeted to the asialoglycopretein receptor, which is predominantly expressed on the sinusoidal surface of mammalian hepatocytes and specifically recognizes ligands fitted with terminal galactose or $\mathrm{N}$-acetylgalactosamine residues. ${ }^{130}$ It has been reported that the incorporation of the natural ligand for this receptor, asialofetuin, onto liposome exteriors can enhance liver uptake and gene delivery. ${ }^{131,132}$ However, the protein-based ligand suffers from a tedious purification procedure and potential immunoresponse. Thus, other ligands (i.e, galactose, lactose) 
that also are recognized by the asialoglycopretein receptor have been investigated. Many synthetic compounds with galactosylated residues have been developed to achieve liver targeting, such as galactosylated cholesterol ${ }^{133}$, galactosylated polymers $^{134-136}$ and galactosylated lipids ${ }^{137}$.

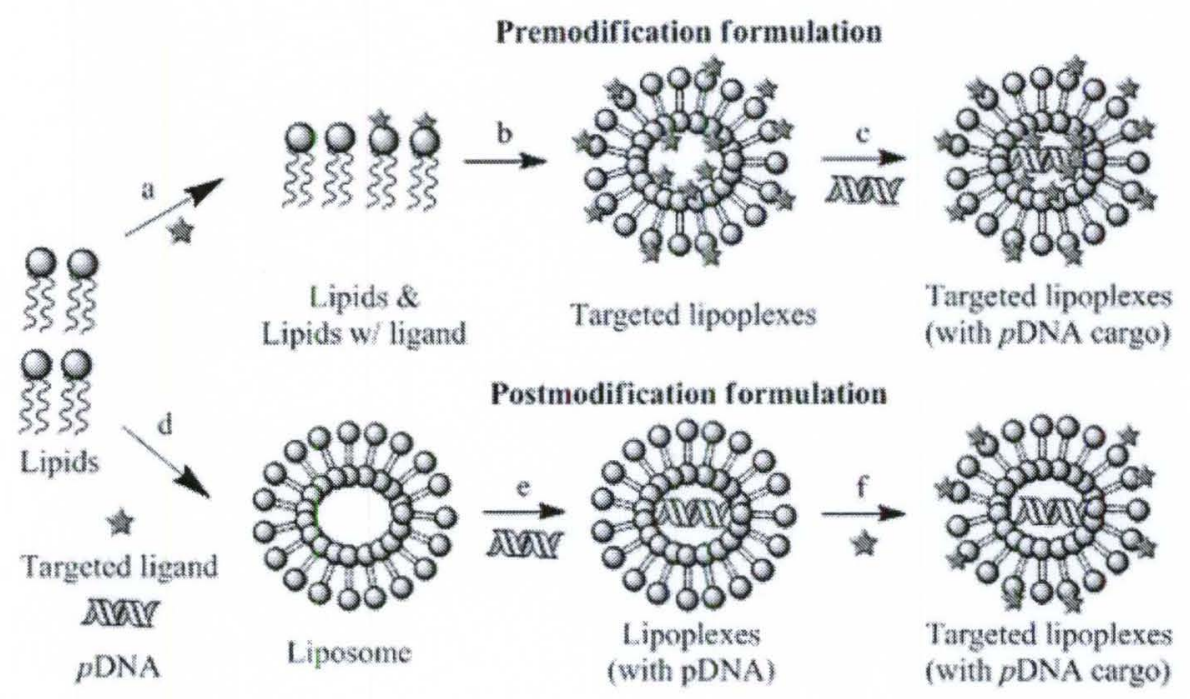

Figure 47. Pre- and Post-modification formulation.

Currently, most researchers use the premodification formulation process where galactosylated lipids are formulated to encapsulate a drug/gene payload (Figure 47). ${ }^{138,139}$ The resultant lipoplexes have galactosylated molecules distributed on both sides of the lipid bilayer. However, the presence of galactosylated functionality in the inner leaflet of lipoplexes is not preferred because it reduces the interior volume (carrying capacity) of the liposomes and may interfere with the interaction between lipid and cargos. The postmodification formulation process can overcome those drawbacks by incorporating galactosylated functionality on lipoplexes after lipoplexes formulation. Therefore, we plan adopt postmodification formulation strategy to create a liver-targeted, stabilized liposomal carrier. 
The newly developed 'click' stabilized liposomes are ideal vectors to overcome these hurdles. First, DPA stabilized liposomes are super stable and do not disassemble even under surfactant treatment. Second, DPA provides a dextran-like surface layer as "stealth" barrier against serum-induced aggregation. Last but not least, the unreacted aldehyde groups on the DPA exterior provide 'clickable' groups for attachment of a liver targeted ligand. Moreover, in this approach, the covalently conjugated ligands cannot dissociate from the liposomes, which is a major problem of other postmodification formulation strategies using absorbed targeted-lipids or targeted-polymers. ${ }^{140}$

We envisioned postmodification formulation of liver-targeted 'click' stabilized lipoplexes as follows (Figure 47): first, the cationic aminooxy lipid 4.1 is sonicated in aqueous buffer to generate liposomes; second, the liposomes are mixed with plasmid DNA to form lipoplexes; the resultant lipoplexes are then stabilized by incubation with DPA; finally, the stabilized lipoplexes are incubated with a 'clickable' liver-targeting element.

\subsection{In-vitro Gene Transfection}

It is well known that the chemical structure of cationic lipids can strongly influence the transfection potency of formulated lipoplexes. Although the lipid 4.1 is a mimic of commercial gene transfection vector TransFast $^{\top \mathrm{M}}$, the effect of headgroup functionality changing from alcohol (TransFast ${ }^{\top \mathrm{M}}$ ) to aminooxy (4.1) on its potency as gene transfection vector is unknown. We evaluated the gene transfection potency of lipoplexes in MCF-7 breast cancer cells using a luciferase reporter plasmid 
(pCMV-Luc). The data (Figure 48) indicated that the lipoplexes is roughly equivalent or slightly higher than that of the transfection agent Lipofectamine ${ }^{\mathrm{TM}} 2000$ (positive control) at various lipids:pDNA charge ratios, while uncomplexed pDNA (negative control) did not show significant transfection.

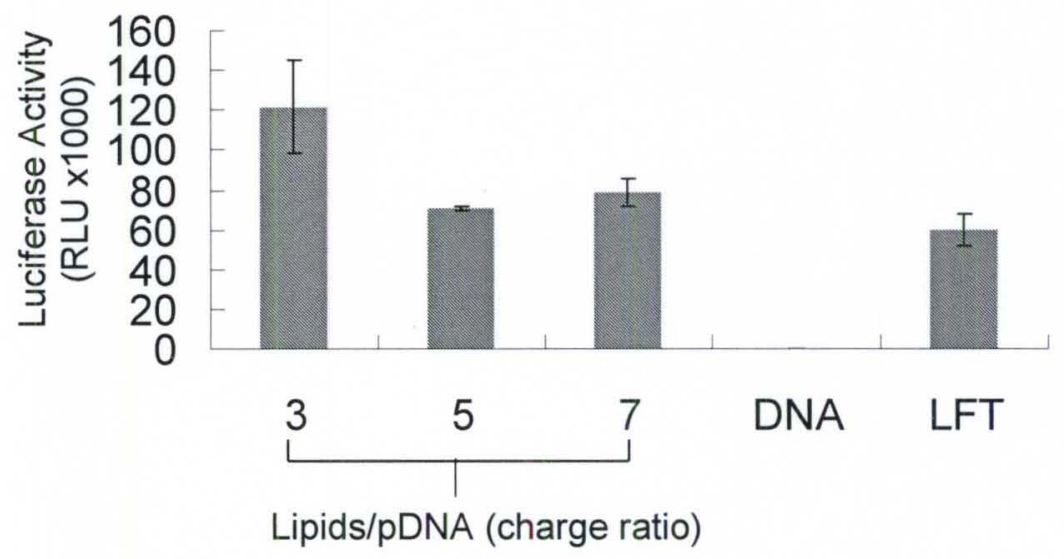

Figure 48. Transfection of MCF-7 cells using lipoplexes from lipid 4.1.

The results are expressed as Relative Light Units (RLU). MCF-7 cells were plated at $1 \mathrm{X} 10^{5} /$ well in a 24 well plate $24 \mathrm{~h}$ prior to transfection in DME/10\% FBS. Transfections were performed using $0.025 \mathrm{mg}$ luciferase reporter construct (pCMVLuc) per well with $39 \mathrm{~h}$ transfection time. Each data point reflects the mean value of three separate transfections. Error bars show the standard deviation from the mean. DNA: uncomplexed pDNA; LFT: Lipofectamine ${ }^{\mathrm{TM}} 2000$ (Invitrogen).

The above lipoplexes were formulated using equimolar lipid 4.1 and dioleoylphosphatidylethanolamine (DOPE), a 'helper' lipid to facilitate $H_{11}$ phase organization that promotes cytoplasmic release of plasmids. From preliminary experiments, we observed that DOPE did not significantly affect liposome stabilization. 
Compared to the liposomes from the lipid 4.1 only (diameter $119 \mathrm{~nm}$; zeta potential $59 \mathrm{meV}$ ), the liposomes formulated from the lipid 4.1 and DOPE have smaller size and lower zeta potential (diameter $82 \mathrm{~nm}, 19 \mathrm{meV}$ ). Then the formulated liposomes mixed with calf thymus DNA (Invitrogen) at 3:1 lipid:DNA charge ratio to get the resultant lipoplexes which have larger size and lower zeta potential (diameter $190 \mathrm{~nm}$; zeta potential $15 \mathrm{meV}$ ).

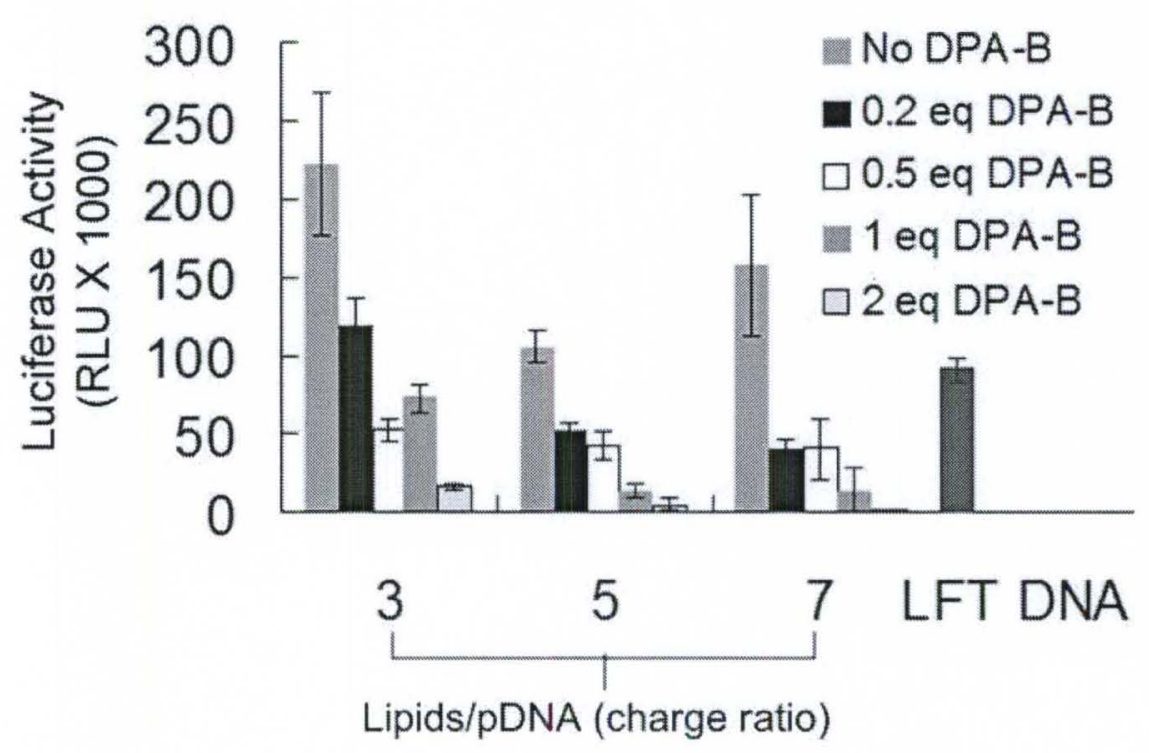

Figure 49. Transfection of MCF-7 cells using stabilized lipoplexes.

The results are expressed as thousand Relative Light Units (kRLU). MCF-7 cells were plated at $1 \mathrm{X}$ $10^{5} /$ well in a 24 well plate $24 \mathrm{~h}$ prior to transfection in DME/10\% FBS. Transfections were performed in 24-well tissue culture plates using $0.025 \mathrm{mg}$ luciferase reporter construct (pCMVLuc) per well with $39 \mathrm{~h}$ transfection time. Each data point reflects the mean value of three separate transfections. Error bars show the standard deviation from the mean. DNA: uncomplexed pDNA; LFT: Lipofectamine ${ }^{\mathrm{TM}} 2000$. 
The gene transfection potency of DPA-B stabilized lipoplexes was then evaluated in MCF-7 breast cancer cells using a luciferase reporter plasmid (pCMV-Luc). The formulated liposomes from lipid 4.1 and DOPE (1:1 molar ratio) were first incubated with $p D N A$ at various lipids:pDNA charge ratios for $20 \mathrm{~min}$ and then incubated with various eq. of PDA-B for stabilization. The resultant lipoplexes were then mixed with DMEM media and added to MFC7 cells for transfection. The data (Figure 49) indicated that the stabilized lipoplexes (e.g. lipids: pDNA charge ratio 3:1, stabilized by 1 eq. DPA-B) still preserved transfection potency, yet at a slightly lower level than that of the transfection agent Lipofectamine ${ }^{\mathrm{TM}} 2000$ (positive control). However, it also observed that the following trend of gene transfection potency: 0 eq DPA-B > Lipofectamine $^{T M} 2000>0.2$ eq DPA-B $>0.5$ eq DPA-B $>1$ eq DPA-B $>$ 2eq DPA-B > $p D N A$ only. The gene transfection efficiency decreases with an increasing amount of DPA-B. This is possible due to the more stable lipoplexes formulated, the slower $p D N A$ releasing from lipoplexes.

\subsection{Synthesis of Aminooxy Functionalized Lactose}

We felt that a mild, quick and convenient procedure for directly conjugating a galactosylated ligand to the liposomes would constitute a promising postmodification method. The oximation, which has been widely applied to conjugate carbohydrates to peptides $^{141}$, proteins $s^{142}$ and lipids ${ }^{44,75}$, was chosen due to the ease of reaction and the robust nature of the oxime ether linkage. Gur'eva reported the synthesis of aminooxy functionalized D-lactose 5.1 as an intermediate compound towards neoglycolipids (Figure 50). ${ }^{143}$ However, their conjugation strategy is DCC catalyzed amine and acid 
coupling reaction which is not compatible to physiological conditions. The lack of linker part also made this ligand hard to be recognized by receptor once conjugated on the liposome surface.

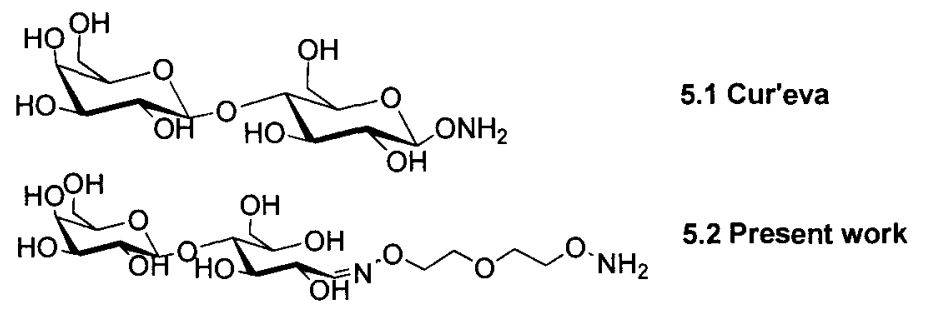

Figure 50. Aminooxy functionalized D-lactose.

Our designed ligand $\mathbf{5 . 2}$ has three parts (Figure 50), the 'clickable' aminooxy group which can conjugate on ketone or aldehyde carbonyl groups on the surface of liposomes or lipoplexes (e.g, DPA stabilized lipoplexes); the lactose as a liver-targeted ligand and the flexible linker provides extra space between two parts. By combining the aminooxy functionalized lactose and postmodification formulation, we simplify lipid synthesis by avoiding a lengthy glycolipid synthesis required for a premodification formulation. We also guarantee that the galactosylated functionality is present only on the outer layer of the liposomes/lipoplexes.

The aminooxy functionalized lactose $\mathbf{5 . 2}$ was prepared as described in Scheme 32. First, diethylene glycol was reacted with $\mathrm{N}$-hydroxyphthalimide under Mitsunobu conditions to generate $\mathbf{5 . 3}$ in $90 \%$ yield. ${ }^{144}$ The Pht protection group was cleaved by reaction with hydrazine to afford bis-aminooxy linker 5.4 in $87 \%$ yield. Mono-Boc protection of $\mathbf{5 . 4}$ was accomplished by reaction with $\mathrm{Boc}_{2} \mathrm{O}$ as the limiting reagent. The resultant, mono-Boc protected linker 5.5 was then condensed with lactose in pyridine, catalyzed using a solid phase acid catalyst, at $65 \square$ for $4 \mathrm{~h}$. All hydroxyl groups were then acetylated by adding acetic anhydride to generate 
Ac-lactose-linker-Boc 5.6 (E/Z 4:1) in $65 \%$ yield. The Boc group was removed by addition of acid (TFA) to afford the Ac-lactose-linker-aminooxy 5.7 (E/Z 57:43) in $91 \%$ yield. Finally, all acetyl protection groups were removed by treating in methanol with catalytic $\mathrm{CH}_{3} \mathrm{ONa}$ to give lactose-linker-aminooxy 5.2 (E/Z 73:27) in $96 \%$ yield. It is worth noting that we had a difficult time to get pure deacetylation product 5.2 by using $\mathrm{NH}_{3}$ aqueous solution as deprotection reagent. Due to variations of reaction and work up conditions, the E/Z ratio may vary from batch to batch.

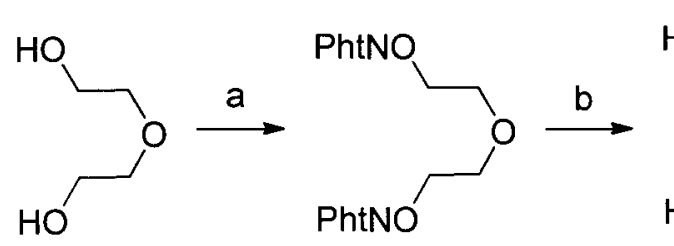

5.3

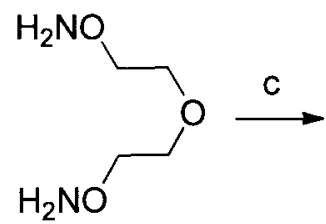

5.4

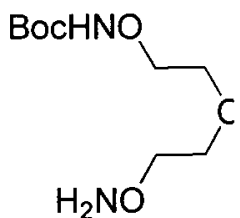

5.5

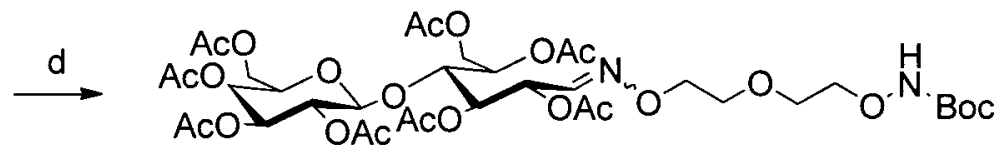

5.6
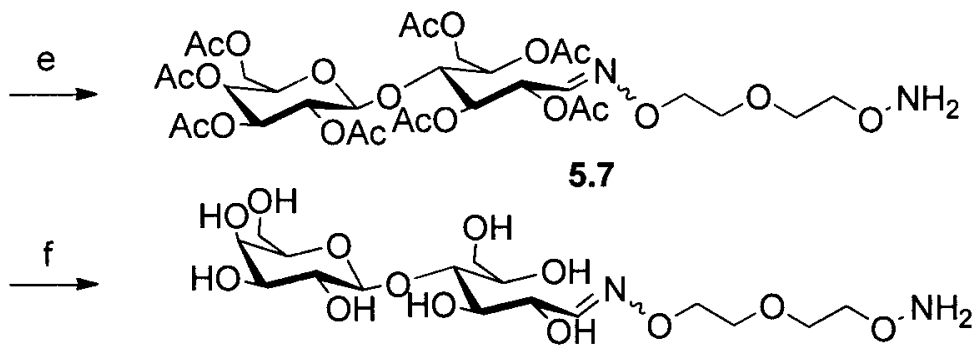

5.2

\section{Scheme 32. Synthesis aminooxy functionalized D-lactose 5.2.}

Conditions: $\mathrm{Pht}=$ phthaloyl a) $\mathrm{N}$-hydroxyphthalimide, $\mathrm{PPh}_{3}, \mathrm{DIAD}, \mathrm{THF}, 0^{\circ} \mathrm{C}$ to rt., $20 \mathrm{~h}, 90 \% ; \mathrm{b}$ ) $\mathrm{N}_{2} \mathrm{H}_{4} \cdot \mathrm{H}_{2} \mathrm{O}, \mathrm{CH}_{2} \mathrm{Cl}_{2}$, rt., $14 \mathrm{~h}, 87 \%$; c) di-tert-butyl dicarbonate, $\mathrm{CHCl}_{3}, 0^{\circ} \mathrm{C}$ to rt., $14 \mathrm{~h}, 90 \%$; d) (1) lactose monohydrate, pyridine, Amberlyst- 15 resin, $65^{\circ} \mathrm{C}, 12 \mathrm{~h}$; (2) $\left(\mathrm{CH}_{3} \mathrm{CO}\right)_{2} \mathrm{O}, 0^{\circ} \mathrm{C}$ to rt., $12 \mathrm{~h}$, $65 \%$; e) TFA, $\mathrm{H}_{2} \mathrm{O}, \mathrm{CH}_{2} \mathrm{Cl}_{2}, 0^{\circ} \mathrm{C}$ to rt., $12 \mathrm{~h}, 83 \%$; f) $\mathrm{CH}_{3} \mathrm{ONa} /$ methanol, rt. $12 \mathrm{~h}, 96 \%$. 
From the ${ }^{1} \mathrm{H}$ NMR (400 MHz, $\mathrm{CD}_{3} \mathrm{OD}$ ) spectrum of aminooxy lactose 5.2, the duplet signals of $\delta 7.55,6.87 \mathrm{ppm}$ represent the $E$ and $Z$ aldoxime ether aminooxy proton respectively (Figure 51 ). The acetal proton can be found at $4.95 \mathrm{ppm}$. The HRMS found $\mathrm{M}+\mathrm{Na}^{+}$at $483.1797\left(\mathrm{C}_{16} \mathrm{H}_{32} \mathrm{~N}_{2} \mathrm{NaO}_{13}{ }^{+}\right.$calculated as 483.1797$)$. The obtained aminooxy functionalized D-lactose 5.2 has the following potential applications: 1) can be applied to the DPA stabilized lipoplexes for in-vivo liver targeted gene delivery (Figure 47 ); 2) can be applied as a lactosylation reagent for liver-targeted lipid or polymer syntheses; 3 ) can be applied as a lactosylation reagent in postmodification formulation of other liver-targeted nano-carriers including micelles, nanoparticles, dendrimers and polysomes as long as these possess carbonyl groups at their exterior.

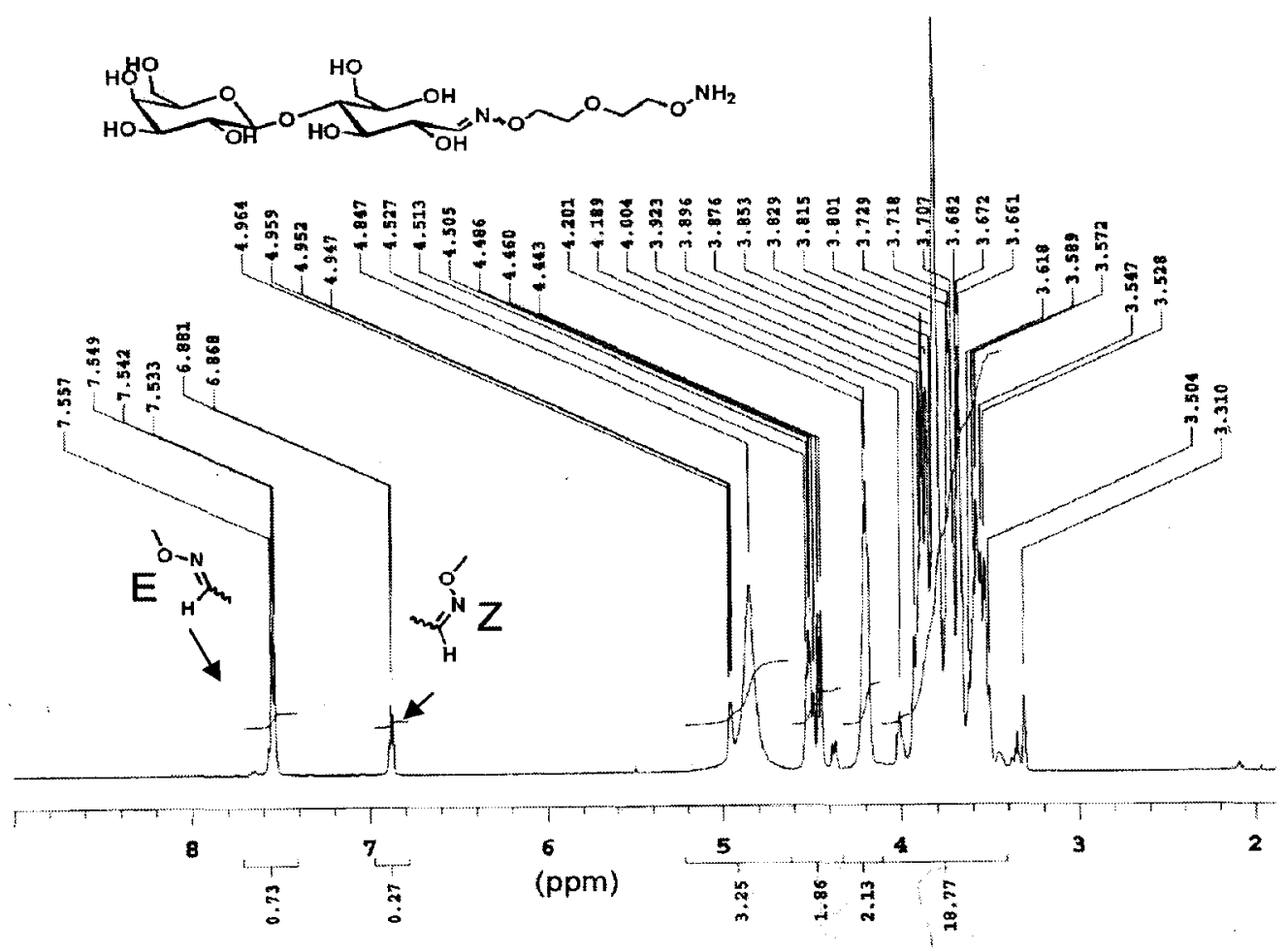

Figure 51. ${ }^{1} \mathrm{H}$ NMR spectrum of aminooxy functionalized D-lactose 5.2. 


\subsection{Conclusions}

Initial results of in vitro transfection studies revealed that the lipid 4.1 has roughly equivalent or slightly higher gene transfection efficiency than that of the commercial transfection agent Lipofectamine ${ }^{T M} 2000$ at various lipids:pDNA charge ratios. The stabilized lipoplexes formulated from lipid 4.1, DOPE and DPA-B can successfully transfect MCF-7 cells, but with lower transfection potency than Lipofectamine ${ }^{T M} 2000$. It is important to note that these results are preliminary and require further optimization to achieve ideal transfection efficiency. We feel that formulation lipoplexes with co-lipids having control-release function or incorporate control-release function on the lipid 4.1 may provide efficient way for pDNA releasing in the cells. Those control-release functions could be $\mathrm{pH}$-sensitive, temperature-sensitive, redox-potential sensitive, light-sensitive or other external stimuli sensitive (e.g. magnetic field, ultrasound, enzyme etc. $)^{145-147}$.

An aminooxy-functionalized lactose-based ligand was synthesized in 0.863 gram with $35 \%$ overall yield from biethanol amine. This targeting ligand is suitable for use in in vivo liver targeted gene delivery. The clickable ligand may be also applied to functionalize lipids polymers and nano carriers (liposomes, polysomes, micelles and nanoparticles) via click chemistry. 


\section{CHAPTER 6. \\ EXPERIMENTAL PROCEDURES, NMR SPECTROSCOPY}

\subsection{General Experimental Procedures}

Unless otherwise noted, all reagents were purchased from commercial suppliers and were used as without further purification. The progress of reactions was monitored by thin-layer chromatography (TLC) using silica gel $60 F_{254}$ TLC plates. Visualization was accomplished by staining the plates with iodine or PMA ( $3 \%$ phosphomolybdic acid/ethanol solution) stain. Silica gel 60 (230-400 mesh) was used for flash column chromatography. ${ }^{1} \mathrm{H}$ NMR spectra were recorded at 400 or $500 \mathrm{MHz}$, and ${ }^{13} \mathrm{C}$ spectra were recorded at 100 or $125 \mathrm{MHz}$, respectively, in the indicated solvents. The chemical shifts are reported in $\mathrm{ppm}$ values relative to the solvent residual peak $\mathrm{CDCl}_{3}\left(7.26 \mathrm{ppm}\right.$ for ${ }^{1} \mathrm{H}$ NMR and $77.26 \mathrm{ppm}$ for ${ }^{13} \mathrm{C} \mathrm{NMR}$ ); $\mathrm{CD}_{3} \mathrm{OD}$ (3.31 ppm for ${ }^{1} \mathrm{H}$ NMR and 49.00 for ${ }^{13} \mathrm{C} \mathrm{NMR}$ ); $\left(\mathrm{CD}_{3}\right)_{2} \mathrm{SO}$ (2.50 ppm for ${ }^{1} \mathrm{H}$ NMR and 39.52 for ${ }^{13} \mathrm{C}$ NMR) and TMS (0.00 ppm). Coupling constants are reported in hertz $(\mathrm{Hz})$. High resolution ESI-MS were obtained using a MS-FTICR-MS ${ }_{n}$ system (LTQ FT, Thermo Electron Corp.) at the CREAM Mass Spectrometry Facility, University of Louisville, Kentucky. ST-IR cards (thermo Electron Co.) were used to determine the IR absorptions. Melting points are uncorrected. All sonications were performed in a bath 
sonicator (Laboratory Supplies Inc.). Dynamic light scattering was carried by Brookhaven 90 Plus Nanoparticle Size Analyzer.

\subsection{Chapter 2. Cationic Aminooxy Reagent}

6.2.1 2-(N-(2-tert-butyldimethylsilyloxyethyl)-2-hydroxyethylamino) ethanol (2.11)

6.2.2 N,N-bis(2-phthalimidooxyethyl)-2-(tert-butyldimethyl-silyloxy) ethyl amine (2.12)

6.2.3 2-(N,N-bis(2-phthalimidooxyethyl)amino)ethanol (2.13)

6.2.4 N,N-bis(2-phthalimidooxyethyl)- $N$-(2-hydroxyethyl)- $N$-methyl-ammonium iodide (2.14)

6.2.5 N,N-bis(2-aminooxyethyl)- $N$-(2-hydroxyethyl)- $N$-methyl-ammonium iodide (2.1)

6.2.6 bis(2-((tert-butyldimethylsilyl)oxy)ethyl)amine (2.15)

6.2.7 di-tert-butyl((((2-hydroxy-3-(trityloxy)propyl)azanediyl)bis(ethane-2,1-diyl))bis (oxy)) dicarbamate (2.29)

6.2.8 N,N-bis(2-(((tert-butoxycarbonyl)amino)oxy)ethyl)-2-hydroxy- $N$-methyl-3-(trit yloxy)propan-1-aminium iodide (2.30)

6.2.9 $N, N$-bis(2-(aminooxy)ethyl)-2,3-dihydroxy- $N$-methylpropan-1-aminium iodide (2.2) 


\subsubsection{2-(N-(2-tert-butyldimethylsilyloxyethyl)-2-hydroxyethylamino)ethanol}
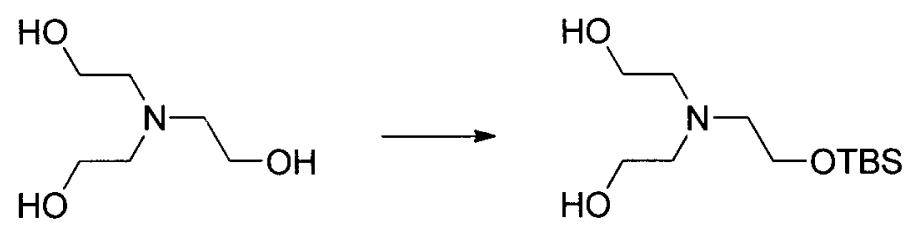

2.11

To a solution of triethanolamine $(5.96 \mathrm{~g}, 40.0 \mathrm{mmol})$ and triethylamine $(5.6 \mathrm{~mL}$, $40 \mathrm{mmol})$ in $\mathrm{CH}_{2} \mathrm{Cl}_{2}(10 \mathrm{~mL})$ at $0{ }^{\circ} \mathrm{C}$ was added slowly via cannula a solution of tert-butyldimethylsilyl chloride $(1.21 \mathrm{~g}, 8.03 \mathrm{mmol})$ in $\mathrm{CH}_{2} \mathrm{Cl}_{2}(40 \mathrm{~mL})$. The reaction mixture was stirred $1 \mathrm{~h}$ at $0{ }^{\circ} \mathrm{C}$ and then allowed to warm to room temperature. After 12 $\mathrm{h}$, the reaction solvent was removed by rotary evaporation. The crude residue was dissolved in ethyl acetate $(40 \mathrm{~mL})$ and washed successively with saturated aq. $\mathrm{NaHCO}_{3}(2 \times 40 \mathrm{~mL})$ and brine $(40 \mathrm{~mL})$. The organic layer was dried $\left(\mathrm{Na}_{2} \mathrm{SO}_{4}\right)$, filtered, and the solvent was removed by rotary evaporation. The crude product was purified by flash chromatography $\left(\mathrm{SiO}_{2}\right)$ using 19:1 $\mathrm{CH}_{2} \mathrm{Cl}_{2}: \mathrm{MeOH}$ as eluent (product $\mathrm{Rf}=0.25$ ) to obtain $2.11\left(1.90 \mathrm{~g}, 90 \%\right.$ ) as a colorless oil. IR (neat) $3389,2928,2858,1472 \mathrm{~cm}^{-1}$; ${ }^{1} \mathrm{H} \mathrm{NMR}\left(\mathrm{CDCl}_{3}, 500 \mathrm{MHz}\right) \delta 3.59(\mathrm{t}, \mathrm{J}=5.0 \mathrm{~Hz}, 2 \mathrm{H}), 3.50(\mathrm{t}, \mathrm{J}=5.5 \mathrm{~Hz}, 4 \mathrm{H}), 3.04(\mathrm{br}$, 2H), $2.65(\mathrm{~m}, 6 \mathrm{H}), 0.82(\mathrm{~s}, 9 \mathrm{H}), 0.00(\mathrm{~s}, 6 \mathrm{H}) ;{ }^{13} \mathrm{C} \mathrm{NMR}\left(\mathrm{CDCl}_{3}, 125 \mathrm{MHz}\right) \delta 62.0,60.0$, $57.1,56.5,26.1,18.5,-5.2$. 


\subsubsection{N,N-bis(2-phthalimidooxyethyl)-2-(tert-butyldimethyl-silyloxy)ethyl amine}

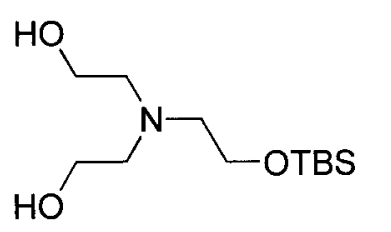

2.11

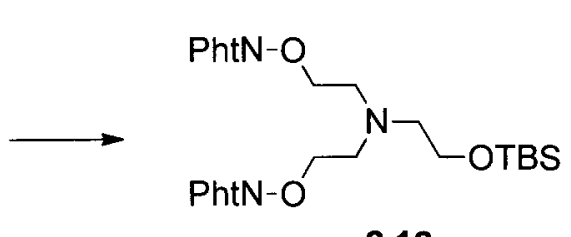

2.12

To a solution of diol $2.11(2.38 \mathrm{~g}, 9.03 \mathrm{mmol}), \mathrm{N}$-hydroxyphthalimide $(3.23 \mathrm{~g}$, $19.8 \mathrm{mmol})$ and $\mathrm{PPh}_{3}(5.19 \mathrm{~g}, 19.8 \mathrm{mmol})$ in THF $(50 \mathrm{~mL})$ at $0{ }^{\circ} \mathrm{C}$ was added DIAD ( $3.93 \mathrm{~mL}, 19.8 \mathrm{mmol}$ ) over $5 \mathrm{~min}$. The reaction was stirred at $0{ }^{\circ} \mathrm{C}$ for $0.5 \mathrm{~h}$ and then warmed to room temperature. After $12 \mathrm{~h}$, the reaction solvent was removed by rotary evaporation. The orange residue was dissolved in ethyl acetate $(150 \mathrm{~mL})$ and washed successively with saturated aq. $\mathrm{NaHCO}_{3}(3 \times 100 \mathrm{~mL})$, brine $(100 \mathrm{~mL})$ and cold aq. $5 \%$ $\mathrm{HCl}(2 \times 120 \mathrm{~mL})$. The organic layer was stored at $0^{\circ} \mathrm{C}$ for $2 \mathrm{~h}$ (or overnight) to effect precipitation of the product as its hydrochloride salt. The solids were collected by filtration and washed with cold ethyl acetate. The collected hydrochloride salt was suspended in a 1:1 mixture of ethyl acetate: saturated aq. $\mathrm{NaHCO}_{3}$ and stirred for 0.5 h. The organic layer was separated and washed successively with saturated aq. $\mathrm{NaHCO}_{3}$, brine, and then dried $\left(\mathrm{Na}_{2} \mathrm{SO}_{4}\right)$. The solvent was removed by rotary evaporation and the crude product was purified by flash chromatography $\left(\mathrm{SiO}_{2}\right)$ eluting with a 2:1 hexanes: ethyl acetate (product $\left.R_{f}=0.23\right)$ to obtain $2.12(4.10 \mathrm{~g}$, $82 \%)$ as a light yellow solid. $\mathrm{mp}=56-58^{\circ} \mathrm{C} ;{ }^{1} \mathrm{H}$ NMR $\left(\mathrm{CDCl}_{3}, 500 \mathrm{MHz}\right) \delta 7.78(\mathrm{~m}, 4 \mathrm{H})$, $7.70(\mathrm{~m}, 4 \mathrm{H}), 4.32(\mathrm{t}, J=6.0 \mathrm{~Hz}, 4 \mathrm{H}), 3.71(\mathrm{t}, J=6.0 \mathrm{~Hz}, 2 \mathrm{H}), 3.16(\mathrm{t}, J=6.0 \mathrm{~Hz}, 4 \mathrm{H})$, $2.86(\mathrm{t}, J=6.0 \mathrm{~Hz}, 2 \mathrm{H}), 0.84(\mathrm{~s}, 9 \mathrm{H}), 0.02(\mathrm{~s}, 6 \mathrm{H}) ;{ }^{13} \mathrm{C} \mathrm{NMR}\left(\mathrm{CDCl}_{3}, 125 \mathrm{MHz}\right) \delta 163.6$, $134.6,129.2,123.7,62.3,56.9,53.4,26.1,18.5,-5.2$. 


\subsubsection{2-(N,N-bis(2-phthalimidooxyethyl)amino)ethanol}

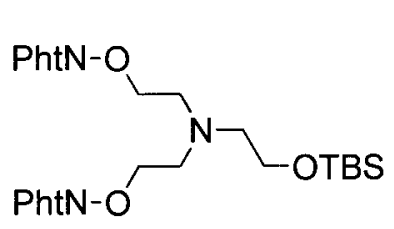

2.12

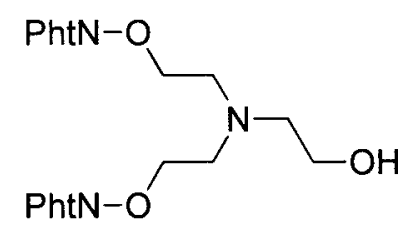

2.13

To a solution of bis-phthalimide $2.12(2.77 \mathrm{~g}, 5.00 \mathrm{mmol})$ in THF $(15 \mathrm{~mL})$ at $0{ }^{\circ} \mathrm{C}$ was added a mixture of $\mathrm{HF}(2 \mathrm{~mL}$ of $48 \%$ aq. HF) in THF (14 mL) over $2 \mathrm{~min}$. The reaction mixture was stirred at $0{ }^{\circ} \mathrm{C}$ for $1 \mathrm{~h}$ before warming to room temperature. After $12 \mathrm{~h}$, the solvents were removed by rotary evaporation. The crude residue was dissolved in ethyl acetate $(100 \mathrm{~mL})$ and washed successively with saturated aq. $\mathrm{NaHCO}_{3}(3 \times 100 \mathrm{~mL})$, brine $(100 \mathrm{~mL})$ and then dried $\left(\mathrm{Na}_{2} \mathrm{SO}_{4}\right)$. The solvent was removed by rotary evaporation and the crude product was recrystallized in ethyl acetate to yield $2.13(1.88 \mathrm{~g}, 86 \%)$ as a light yellow solid. $\mathrm{mp}=136-138{ }^{\circ} \mathrm{C} ; \mathrm{IR} 3066$, $1731 \mathrm{~cm}^{-1} ;{ }^{1} \mathrm{H} \mathrm{NMR}\left(\mathrm{CDCl}_{3}, 500 \mathrm{MHz}\right) \delta 7.80(\mathrm{~m} \mathrm{4H}), 7.72(\mathrm{~m} \mathrm{4H}), 4.36(\mathrm{t}, \mathrm{J}=5.0 \mathrm{~Hz}$, $4 \mathrm{H}), 3.65(\mathrm{t}, \mathrm{J}=5.0 \mathrm{~Hz}, 2 \mathrm{H}), 3.13(\mathrm{t}, J=5.0 \mathrm{~Hz}, 4 \mathrm{H}), 2.91(\mathrm{t}, J=5.0 \mathrm{~Hz}, 2 \mathrm{H}) ;{ }^{13} \mathrm{C} \mathrm{NMR}$ $\left(\mathrm{CDCl}_{3}, 125 \mathrm{MHz}\right) \delta 163.7,134.7,129.1,123.8,77.4,59.4,57.6,53.0$; Anal. calcd. for $\mathrm{C}_{22} \mathrm{H}_{21} \mathrm{~N}_{3} \mathrm{O}_{7}: \mathrm{C}, 60.13 ; \mathrm{H}, 4.82 ; \mathrm{N}, 9.56$; Found: $\mathrm{C}, 59.87 ; \mathrm{H}, 4.82 ; \mathrm{N} 9.49$. 


\subsubsection{N,N-bis(2-phthalimidooxyethyl)-N-(2-hydroxyethyl)-N-methyl-ammonium}

iodide

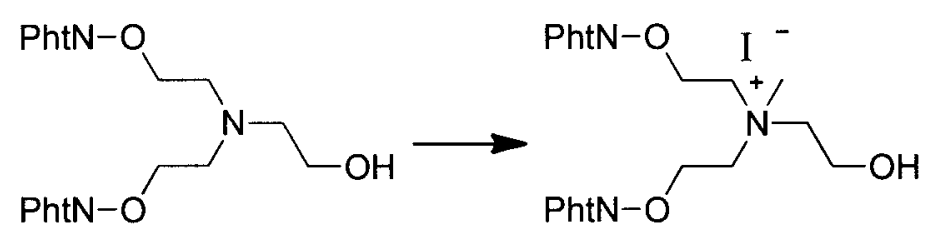

2.13

2.14

In a sealed tube, bis-phthalimide $2.13(0.88 \mathrm{~g}, 2.0 \mathrm{mmol})$ was dissolved in iodomethane $(5 \mathrm{~mL})$. The reaction mixture was degassed using a stream of $\mathrm{N}_{2}$ before sealing the tube. After stirred $3 \mathrm{~h}$ at $50{ }^{\circ} \mathrm{C}$, the reaction was cooled and the iodomethane was evaporated (Caution: fume hood required) to afford the corresponding ammonium iodide $2.14(1.14 \mathrm{~g}, 98 \%) . \mathrm{mp}=201^{\circ} \mathrm{C}(\mathrm{dec}) ; \mathrm{IR} 3256$, 2921, $1583 \mathrm{~cm}^{-1} ;{ }^{1} \mathrm{H}$ NMR (DMSO-d $\left.6,500 \mathrm{MHz}\right) \delta 7.87(\mathrm{~s}, 8 \mathrm{H}), 5.36(\mathrm{t}, J=4.5 \mathrm{~Hz}, 1 \mathrm{H}$ ), $4.74(\mathrm{t}, J=4.5 \mathrm{~Hz}, 4 \mathrm{H}), 4.06(\mathrm{~s}, 4 \mathrm{H}), 3.92(\mathrm{~s}, 2 \mathrm{H}), 3.78(\mathrm{t}, J=4.5 \mathrm{~Hz}, 2 \mathrm{H}), 3.42(\mathrm{~s}, 3 \mathrm{H})$; ${ }^{13} \mathrm{C}$ NMR (DMSO- $\left.d_{6}, 125 \mathrm{MHz}\right) \delta 164.0,135.9,129.4,124.4,72.1,65.5,61.7,55.7$, 50.7 . 


\subsubsection{N,N-bis(2-aminooxyethyl)-N-(2-hydroxyethyl)- $N$-methyl-ammonium iodide}

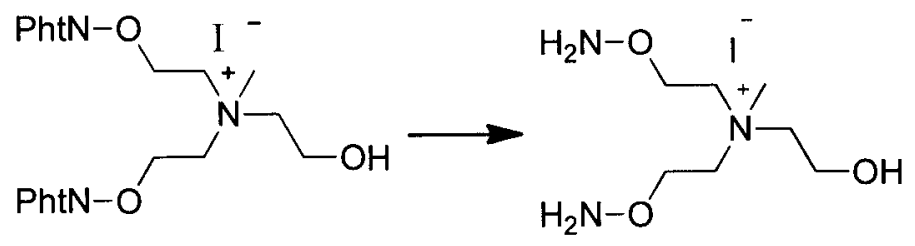

2.14

2.1

To a solution of the ammonium iodide $2.14(1.05 \mathrm{~g}, 1.8 \mathrm{mmol})$ in a $19: 1$ mixture of EtOH: $\mathrm{H}_{2} \mathrm{O}(8.0 \mathrm{~mL})$ at room temperature was added via syringe hydrazine monohydrate $(0.20 \mathrm{~mL}, 4.1 \mathrm{mmol})$. After stirring $12 \mathrm{~h}$ at room temperature, the solvents were removed by rotary evaporation. The residue was dissolved in $\mathrm{H}_{2} \mathrm{O}(100$ $\mathrm{mL}$ ) and washed with ethyl acetate $(3 \times 100 \mathrm{~mL})$. The aqueous layer then was concentrated to $\sim 2 \mathrm{~mL}$ and loaded onto $\mathrm{HPLC}$ (reverse phase, $\mathrm{C}_{18}$ ) using $\mathrm{H}_{2} \mathrm{O}$ as the eluent to obtain 2.1 as a colorless oil $(0.40 \mathrm{~g}, 70 \%)$. IR (neat) $3256,3135,2921,1583$, 1203, 1149, 1052, $950 \mathrm{~cm}^{-1}$; ${ }^{1} \mathrm{H}$ NMR (DMSO-d $6,500 \mathrm{MHz}$ ) $\delta 6.29$ (br, 4H), 5.26 (s, $1 \mathrm{H}), 3.97(\mathrm{br}, 4 \mathrm{H}), 3.87(\mathrm{~s}, 2 \mathrm{H}), 3.69(\mathrm{~m}, 4 \mathrm{H}), 3.54(\mathrm{t}, \mathrm{J}=5.0 \mathrm{~Hz}, 2 \mathrm{H}), 3.16(\mathrm{~s}, 3 \mathrm{H}) ;{ }^{13} \mathrm{C}$ NMR (DMSO-d $d_{6}, 125 \mathrm{MHz}$ ) $\delta 69.1,64.9,61.5,55.7,50.4$; Anal. calcd. for $\mathrm{C}_{7} \mathrm{H}_{20} \mathrm{IN}_{3} \mathrm{O}_{3}$ : C, 26.18; H, 6.28; N, 13.08, Found: C, 26.22; H, 6.14; N 12.73. 


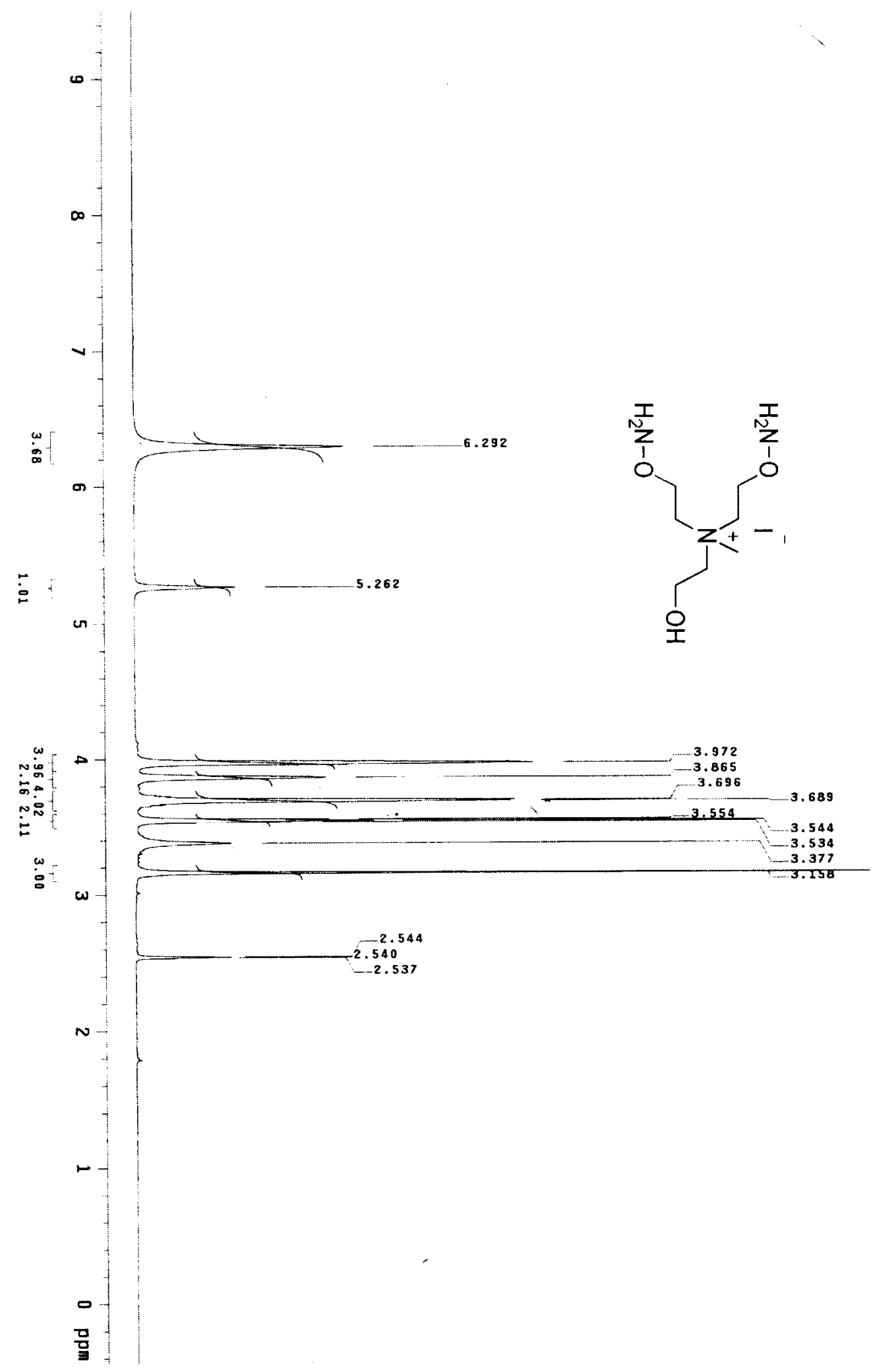

${ }^{1} \mathrm{H}$ NMR spectrum of compound 2.1 


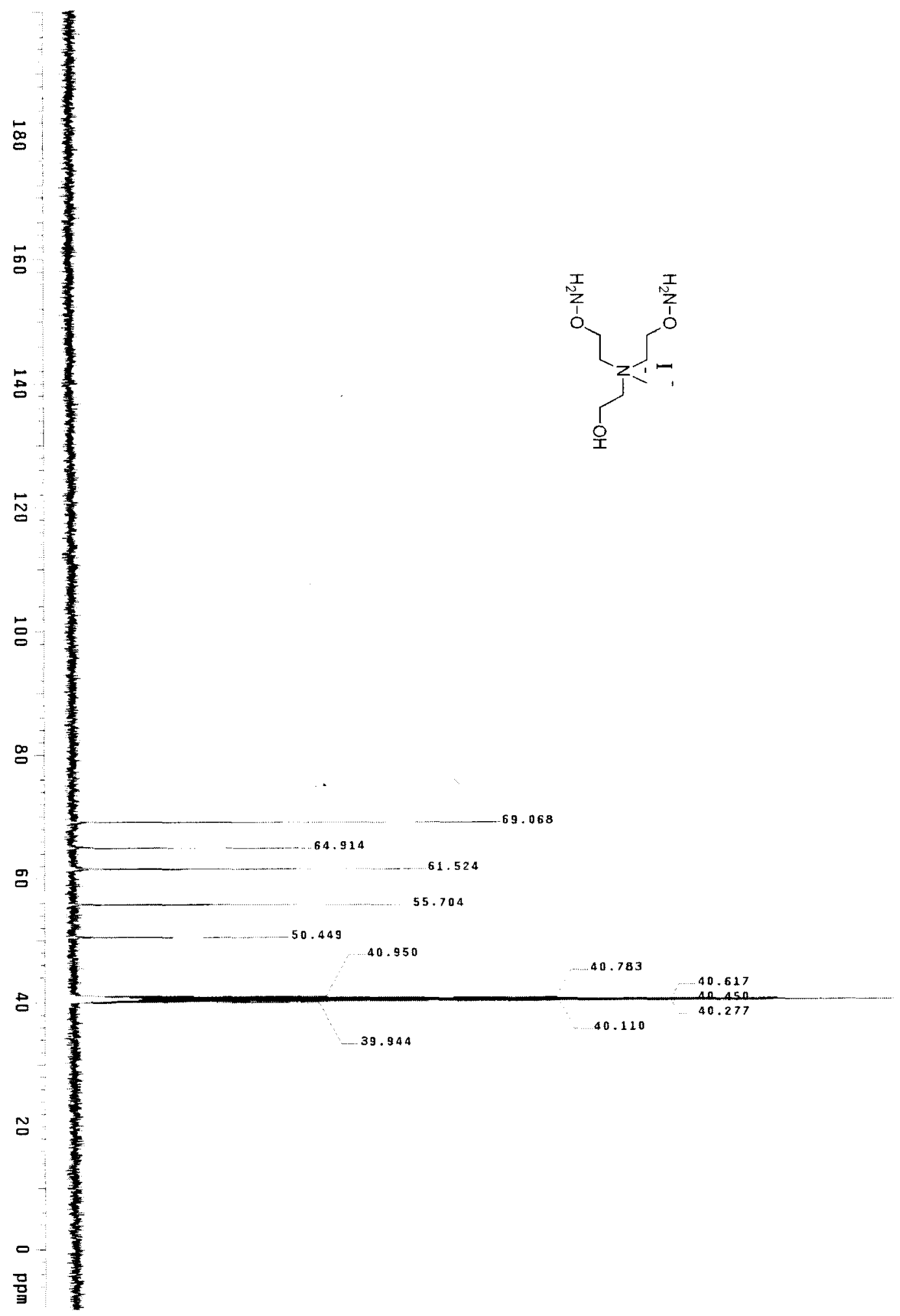

${ }^{13} \mathrm{C}$ NMR spectrum of compound 2.1 


\subsection{6 bis(2-((tert-butyldimethylsilyl)oxy)ethyl)amine}

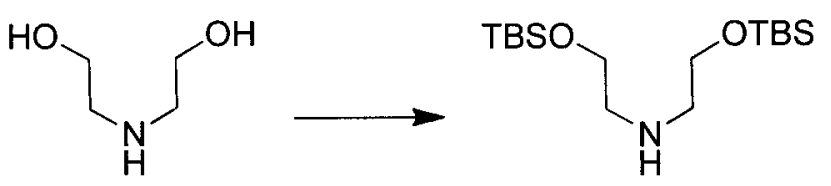

2.15

To a solution of diethanolamine $(4.20 \mathrm{~g}, 40.0 \mathrm{mmol})$ and triethylamine $(20 \mathrm{~g}, 200$ mmol) in $\mathrm{CH}_{2} \mathrm{Cl}_{2}(30 \mathrm{~mL})$ was slowly added a solution of tert-butyldimethylsilyl chloride (13.3 $\mathrm{g}, 88.0 \mathrm{mmol})$ in $\mathrm{CH}_{2} \mathrm{Cl}_{2}(30 \mathrm{~mL})$. The reaction mixture was stirred $48 \mathrm{~h}$ at room temperature and then washed by two times of brine $(100 \mathrm{~mL})$. The organic layer was dried, filtered, and the solvent was removed by rotary evaporation. The crude product was purified by flash chromatography $\left(\mathrm{SiO}_{2}\right)$ using $19: 1 \quad \mathrm{CH}_{2} \mathrm{Cl}_{2}: \mathrm{MeOH}$ as eluent (product $\mathrm{Rf}=0.30)$ to afford $2.15(12.50 \mathrm{~g}, 94 \%)$ as a clear oil. The product have also been purified by distillation ${ }^{148} .{ }^{1} \mathrm{H} \mathrm{NMR}\left(\mathrm{CDCl}_{3}, 500 \mathrm{MHz}\right) \delta 3.72(\mathrm{t}, \mathrm{J}=5.0 \mathrm{~Hz}, 4 \mathrm{H}), 2.72$ $(\mathrm{t}, \mathrm{J}=5.0 \mathrm{~Hz}, 4 \mathrm{H}), 1.88(\mathrm{br}, 1 \mathrm{H}), 0.90(\mathrm{~m}, 18 \mathrm{H}), 0.05(\mathrm{~s}, 12 \mathrm{H}) ;{ }^{13} \mathrm{C} \mathrm{NMR}\left(\mathrm{CDCl}_{3}, 125\right.$ $\mathrm{MHz}) \delta 62.9,52.1,26.3,18.7,-5.0$. 


\subsection{7 di-tert-butyl ((((2-hydroxy-3-(trityloxy)propyl)azanediyl)}

\section{bis(ethane-2,1-diyl))bis(oxy))dicarbamate}

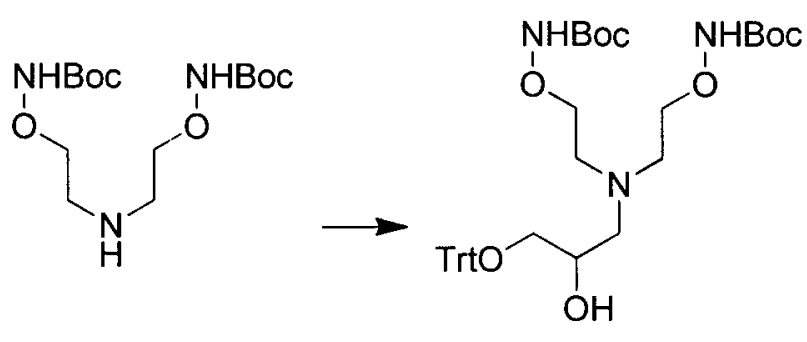

2.26

2.29

To a solution of 2-(trityloxy)oxirane $(0.316 \mathrm{~g}, 1.0 \mathrm{mmol})$ in ethanol $(5 \mathrm{~mL})$ was added amine $2.26(0.335 \mathrm{~g}, 1.0 \mathrm{mmol})$ and $\mathrm{Na}_{2} \mathrm{CO}_{3}(0.106 \mathrm{~g}, 1.0 \mathrm{mmol})$. The reaction was stirred $17 \mathrm{~h}$ at $\mathrm{rt}$. and then at $60^{\circ} \mathrm{C}$ for $22 \mathrm{~h}$. After evaporated ethanol, the crude residue was dissolved in $\mathrm{CH}_{2} \mathrm{Cl}_{2}(20 \mathrm{~mL})$ and then washed successively with saturated aq. $\mathrm{NaHCO}_{3}(2 \times 20 \mathrm{~mL})$ and brine $(20 \mathrm{~mL})$ and dried $\left(\mathrm{Na}_{2} \mathrm{SO}_{4}\right)$. After evaporated solvent, the crude product was purified by flash chromatography $\left(\mathrm{SiO}_{2}\right)$ using $9: 1$ $\mathrm{CH}_{2} \mathrm{Cl}_{2}: \mathrm{MeOH}$ as eluent (product $\left.\mathrm{Rf}=0.43\right)$ to afford $2.29(0.42 \mathrm{~g}, 64 \%)$ as a clear oil. ${ }^{1} \mathrm{H} \mathrm{NMR}\left(\mathrm{CDCl}_{3}, 500 \mathrm{MHz}\right) \delta 8.15(\mathrm{~s}, 2 \mathrm{H}), 7.49(\mathrm{~d}, \mathrm{~J}=7.5 \mathrm{~Hz}, 6 \mathrm{H}), 7.30(\mathrm{t}, \mathrm{J}=7.5 \mathrm{~Hz}$, $6 \mathrm{H}), 7.22(\mathrm{t}, \mathrm{J}=7.0 \mathrm{~Hz}, 3 \mathrm{H}), 3.87-3.96(\mathrm{~m}, 5 \mathrm{H}), 3.22(\mathrm{~m}, \mathrm{~J}=5.0 \mathrm{~Hz}, 1 \mathrm{H}), 3.11(\mathrm{~m}, \mathrm{~J}=$ $5.0 \mathrm{~Hz}, 1 \mathrm{H}), 2.90(\mathrm{~m}, 2 \mathrm{H}), 2.75(\mathrm{~m}, 2 \mathrm{H}), 2.66(\mathrm{~m}, 1 \mathrm{H}), 2.59(\mathrm{~m}, 1 \mathrm{H}), 1.48(\mathrm{~s}, 18 \mathrm{H}) ;{ }^{13} \mathrm{C}$ NMR $\left(\mathrm{CDCl}_{3}, 125 \mathrm{MHz}\right) \delta 156.9,143.9,128.6,127.7,126.9,86.4,81.3,74.2,67.6$, $58.4,53.3,28.2$. 


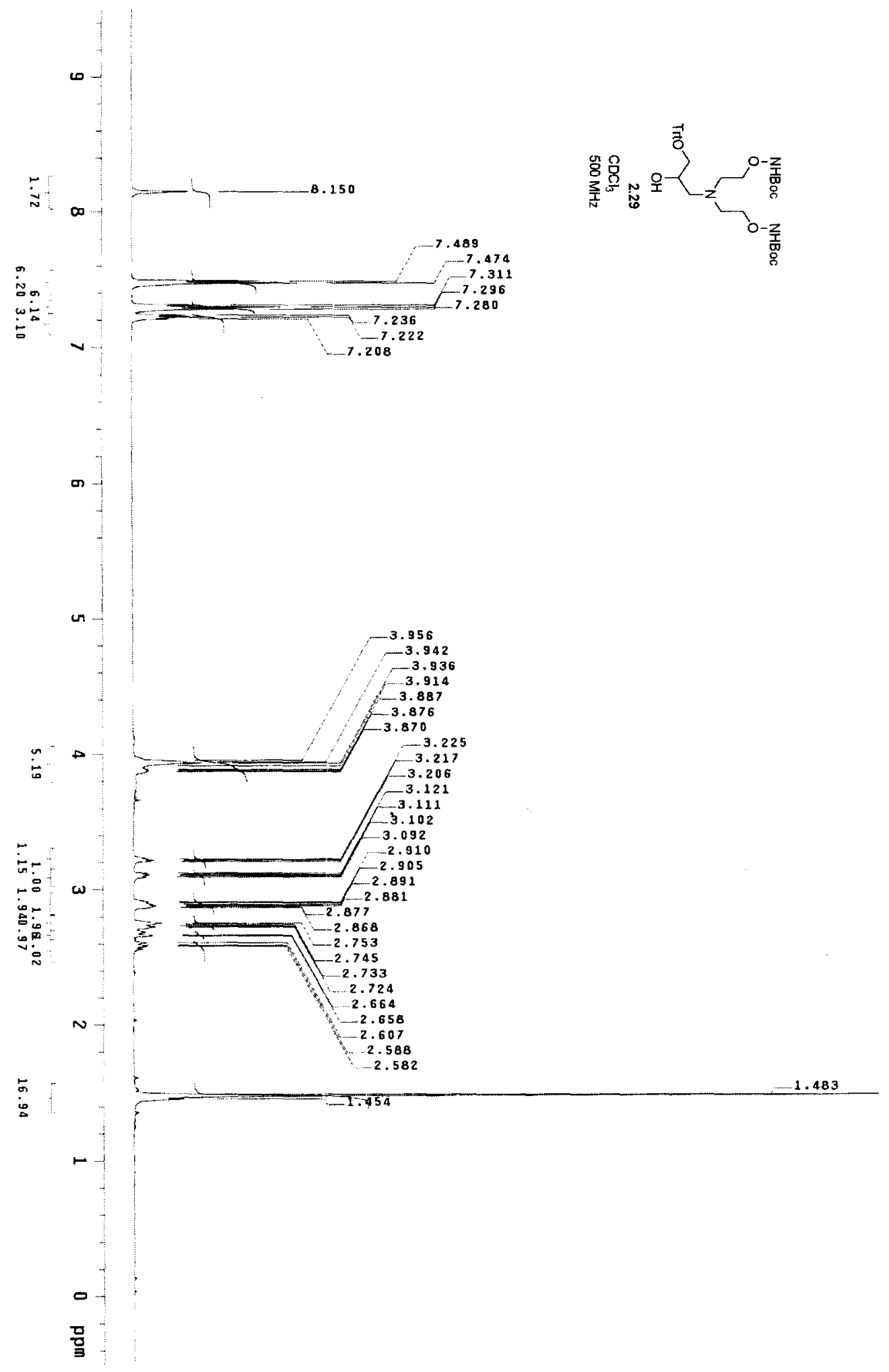

${ }^{1} \mathrm{H}$ NMR spectrum of compound 2.29 


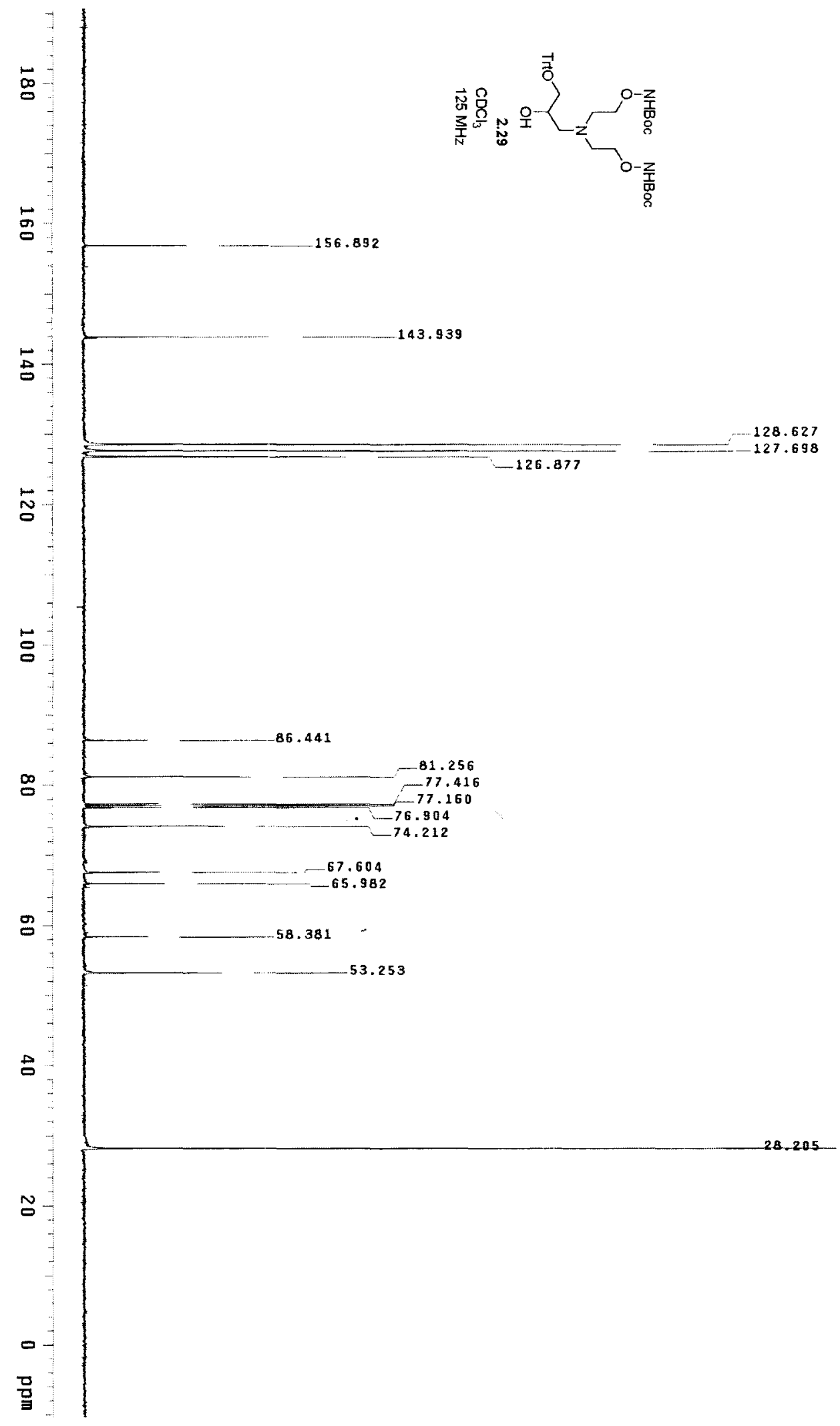

${ }^{13} \mathrm{C}$ NMR spectrum of compound 2.29 


\subsubsection{N,N-bis(2-(((tert-butoxycarbonyl)amino)oxy)ethyl)}

\section{-2-hydroxy-N-methyl-3-(trityloxy)propan-1-aminium iodide}

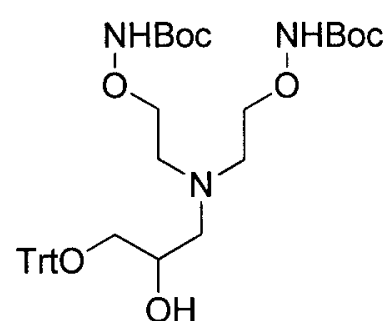

2.29

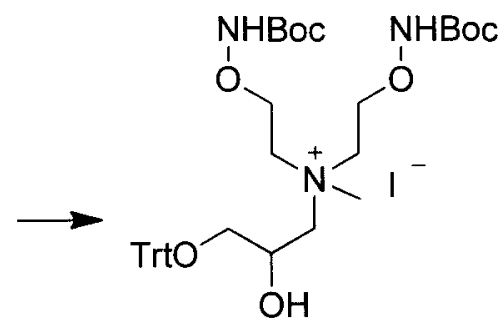

2.30

In a sealed tube, the amine $2.29(1.70 \mathrm{~g}, 2.6 \mathrm{mmol})$ was dissolved in $\mathrm{CH}_{2} \mathrm{Cl}_{2}(5$ $\mathrm{mL})$ then iodomethane $(2 \mathrm{~mL})$ was added. The reaction mixture was stirred at $60^{\circ} \mathrm{C}$ for $24 \mathrm{~h}$. The colorless solution turned to yellow and finally to brown color. After iodomethane and $\mathrm{CH}_{2} \mathrm{Cl}_{2}$ was removed by rotary evaporator, the crude product was purified by flash chromatography $\left(\mathrm{SiO}_{2}\right)$ using $24: 1 \mathrm{CH}_{2} \mathrm{Cl}_{2}: \mathrm{MeOH}$ as eluent (product $\mathrm{Rf}=0.70$ in $\left.9: 1 \mathrm{CH}_{2} \mathrm{Cl}_{2}: \mathrm{MeOH}\right)$ to afford the corresponding ammonium iodide $\mathbf{2 . 3 0}$ $(1.65 \mathrm{~g}, 80 \%)$ as a yellow oil. ${ }^{1} \mathrm{H}$ NMR $\left(\mathrm{CDCl}_{3} 500 \mathrm{MHz}\right) \delta 8.41(\mathrm{~d}, 2 \mathrm{H}), 7.37(\mathrm{~d}, \mathrm{~J}=7.5$ $\mathrm{Hz}, 6 \mathrm{H}), 7.26(\mathrm{t}, \mathrm{J}=7.5 \mathrm{~Hz}, 6 \mathrm{H}), 7.17(\mathrm{t}, \mathrm{J}=7.0 \mathrm{~Hz}, 3 \mathrm{H}), 4.49(\mathrm{~s}, 1 \mathrm{H}), 4.25(\mathrm{~m}, 4 \mathrm{H})$, 4.07-4.15 (m, 5H), $3.64(\mathrm{~s}, 2 \mathrm{H}), 3.42(\mathrm{~s}, 3 \mathrm{H}), 3.23(\mathrm{~m}, 1 \mathrm{H}), 3.25(\mathrm{~m}, 1 \mathrm{H}), 1.36(\mathrm{~s}, 18 \mathrm{H})$; ${ }^{13} \mathrm{C} \mathrm{NMR}\left(\mathrm{CDCl}_{3}, 125 \mathrm{MHz}\right) \delta 156.5,143.2,128.4,127.9,127.0,87.0,81.9$ (2 signals), $69.9,69.8,65.5,65.2,64.3,62.5,62.0,53.4,51.2,28.0$. 


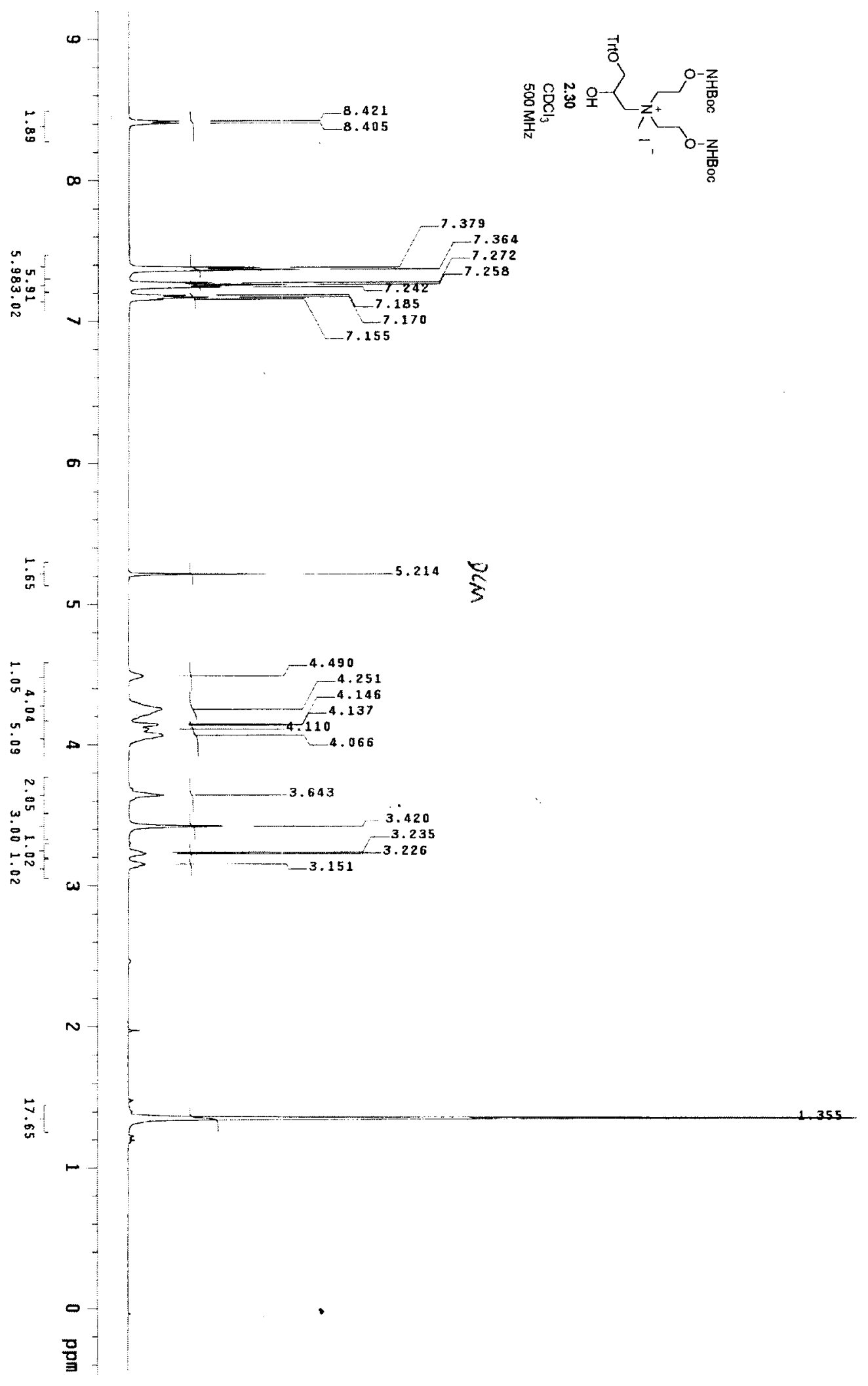

${ }^{1} \mathrm{H}$ NMR spectrum of compound 2.30 


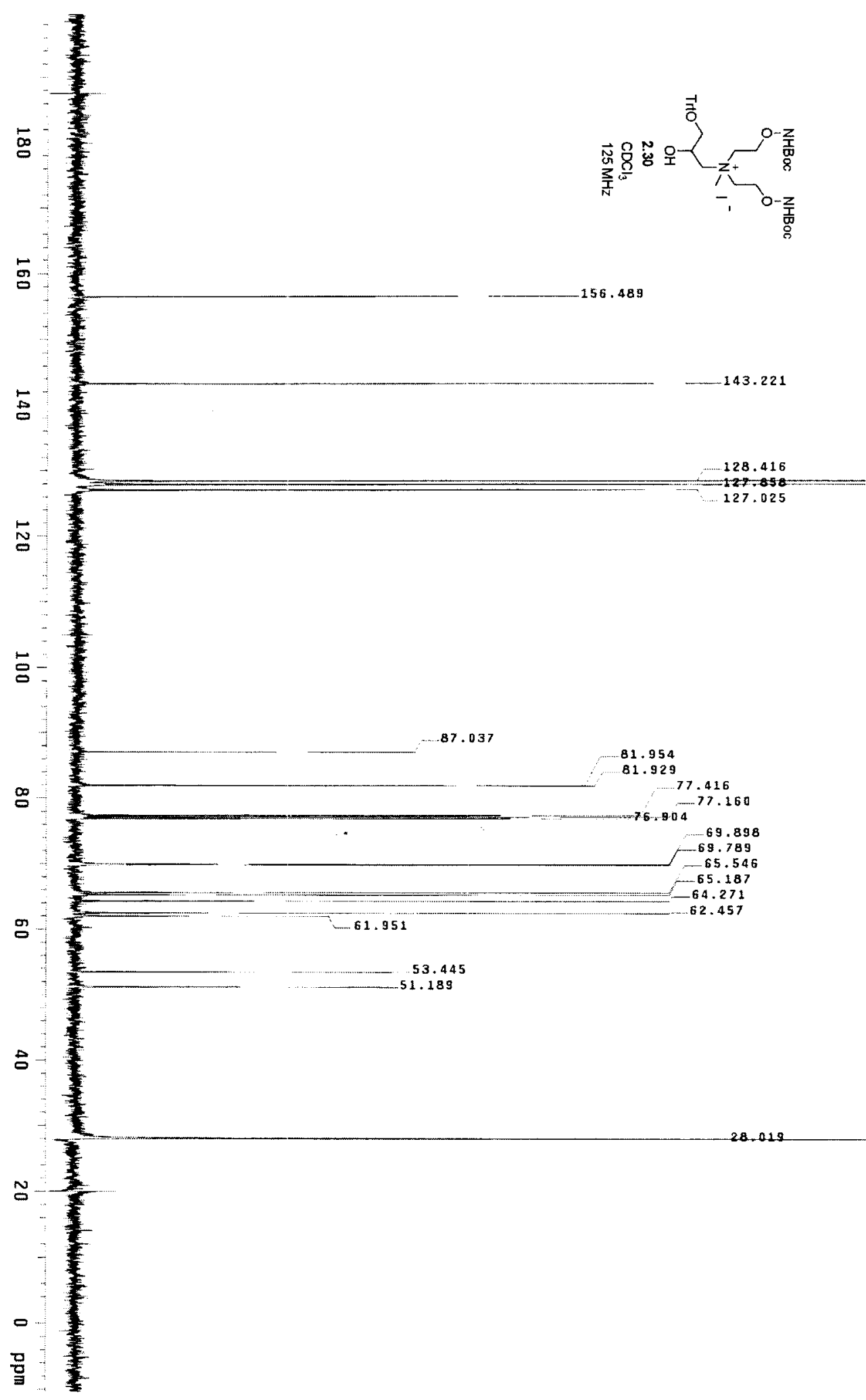

${ }^{13} \mathrm{C}$ NMR spectrum of compound 2.30 


\subsection{9 $\mathrm{N}, \mathrm{N}$-bis(2-(aminooxy)ethyl)-2,3-dihydroxy- $\mathrm{N}$-methylpropan-1-aminium iodide}

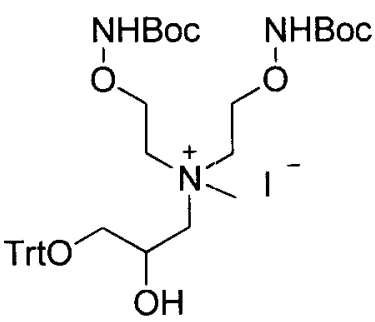

2.30

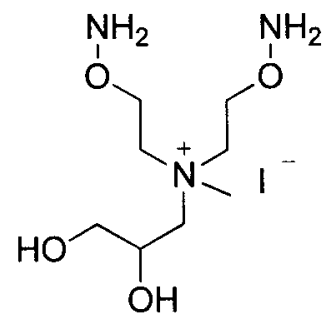

2.2

To a solution of the ammonium iodide $2.30(0.50 \mathrm{~g}, 0.63 \mathrm{mmol})$ in $\mathrm{CH}_{2} \mathrm{Cl}_{2}(7 \mathrm{ml})$ was added triethylsilane $(2 \mathrm{~mL})$ and trifluoroacetic acid $(1 \mathrm{~mL})$ at $0{ }^{\circ} \mathrm{C}$. The reaction mixture was stirred at $0{ }^{\circ} \mathrm{C}$ for $2 \mathrm{~h}$ and then stirred $2.5 \mathrm{~h}$ at room temperature. After solvent was removed by rotary evaporation, the yellow residue was dissolved in $\mathrm{H}_{2} \mathrm{O}$ $(10 \mathrm{~mL})$ and washed with $\mathrm{CH}_{2} \mathrm{Cl}_{2}(3 \times 10 \mathrm{~mL})$. The red aqueous layer was concentrated to $\sim 2 \mathrm{~mL}$ and purified by flash chromatography (reverse phase, $\mathrm{C}_{18}$ ) two times using water as eluent to afford the corresponding ammonium iodide 2.2 (83 $\mathrm{mg}$, $38 \%)$ as red liquid. ${ }^{1} \mathrm{H}$ NMR $\left(\mathrm{CD}_{3} \mathrm{OD}, 500 \mathrm{MHz}\right) \delta 5.08(\mathrm{br}, 6 \mathrm{H}), 4.50(\mathrm{~m}, 2 \mathrm{H}), 4.44(\mathrm{~m}$, $2 \mathrm{H}), 4.23(\mathrm{~m}, 2 \mathrm{H}), 4.02(\mathrm{~m}, 3 \mathrm{H}), 3.94(\mathrm{~m}, 1 \mathrm{H}), 3.62-3.75(\mathrm{~m}, 2 \mathrm{H}), 3.58(\mathrm{~m}, 1 \mathrm{H}), 3.50(\mathrm{~m}$, $1 \mathrm{H}) ; 3.33(\mathrm{~s}, 3 \mathrm{H}){ }^{13} \mathrm{C}$ NMR $\left(\mathrm{CD}_{3} \mathrm{OD}, 125 \mathrm{MHz}\right) \overline{0} 69.7,67.3,66.9,65.1,63.3,63.0,51.7$; HRMS (ESI): calcd. for $\mathrm{C}_{8} \mathrm{H}_{22} \mathrm{~N}_{3} \mathrm{O}_{4}{ }^{+}\left[\mathrm{M}^{+}\right]$: 224.1605, found: 224.1605 . 


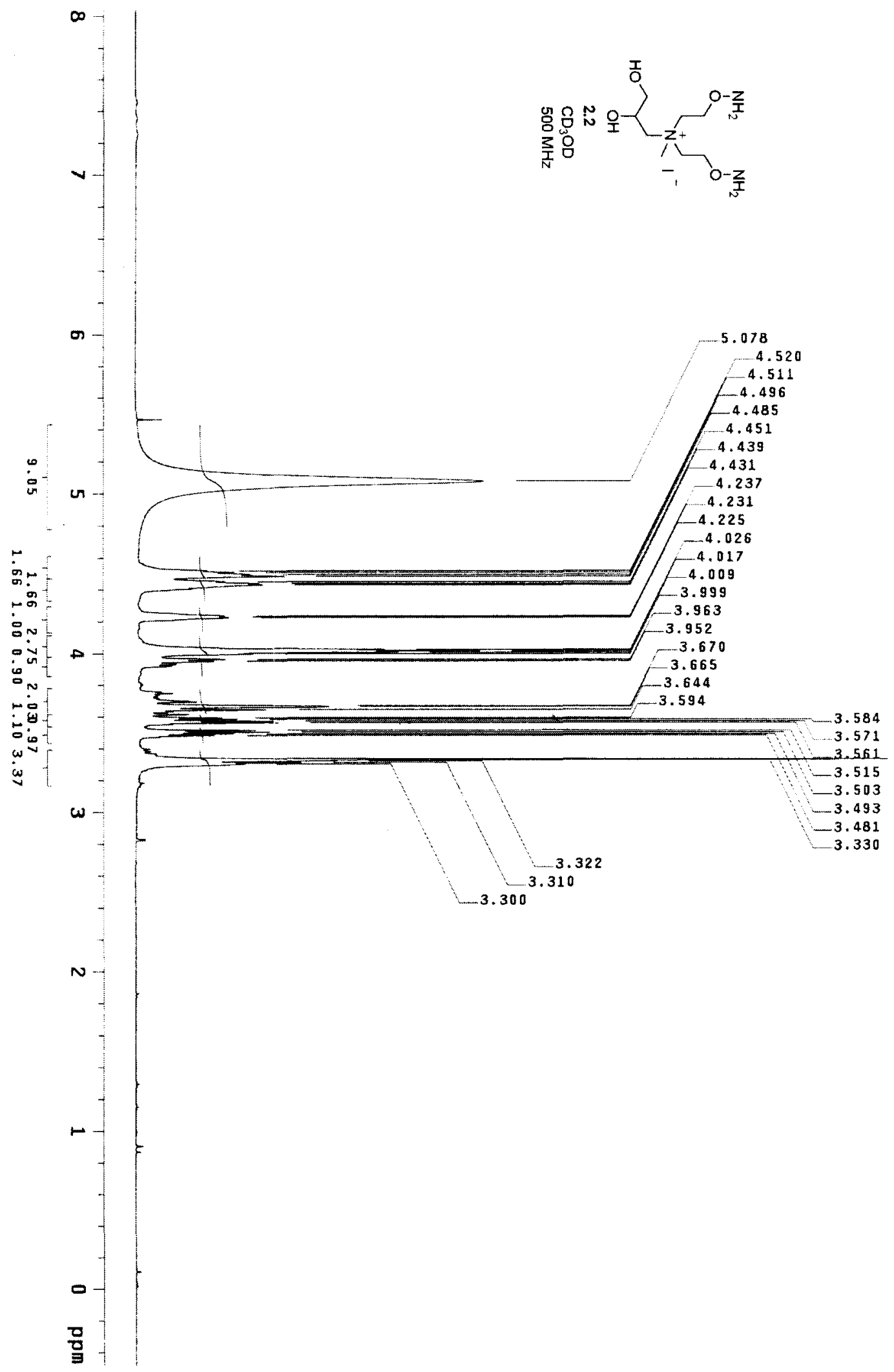

${ }^{1} \mathrm{H}$ NMR spectrum of compound 2.2 


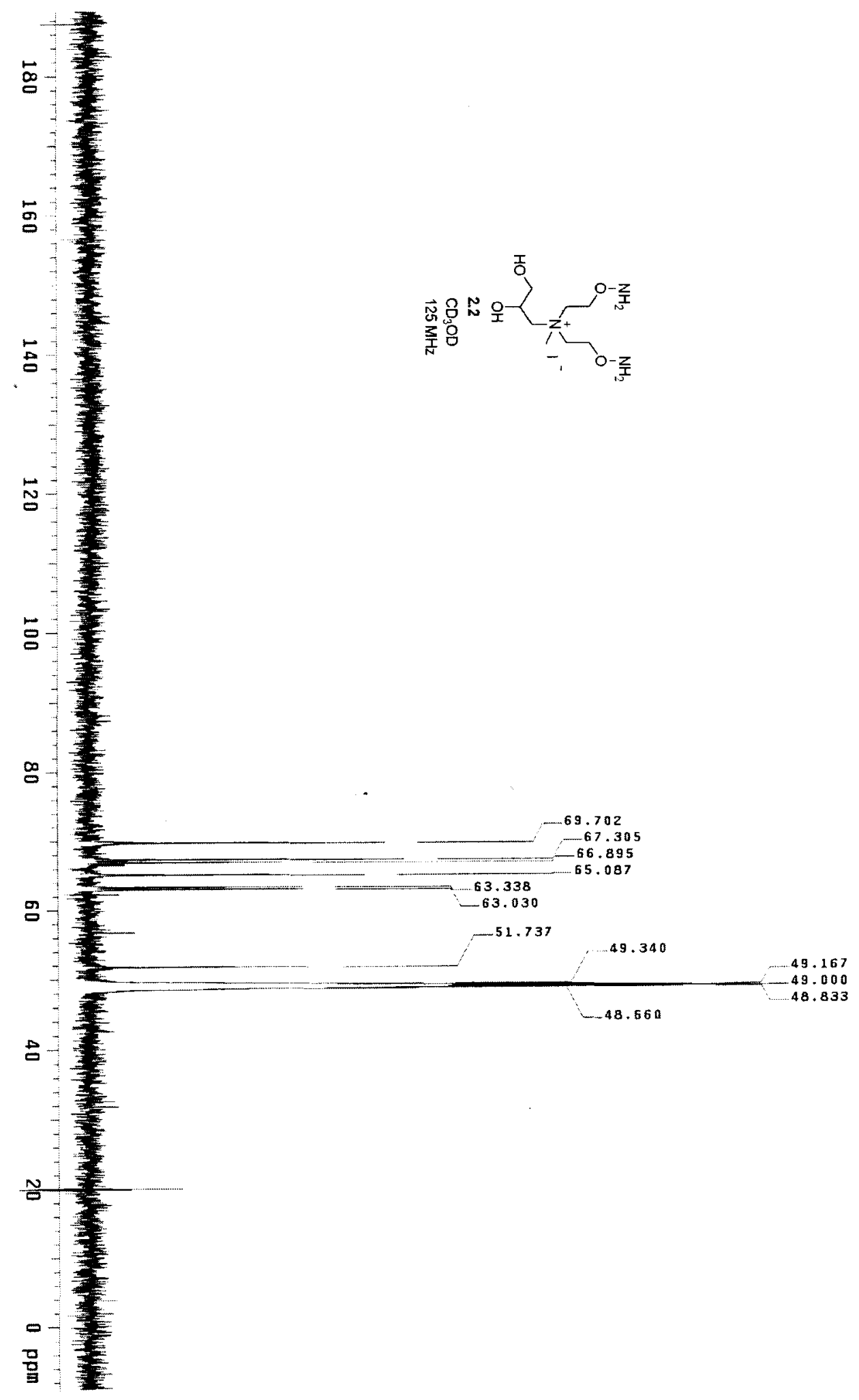

${ }^{13} \mathrm{C}$ NMR spectrum of compound 2.2 


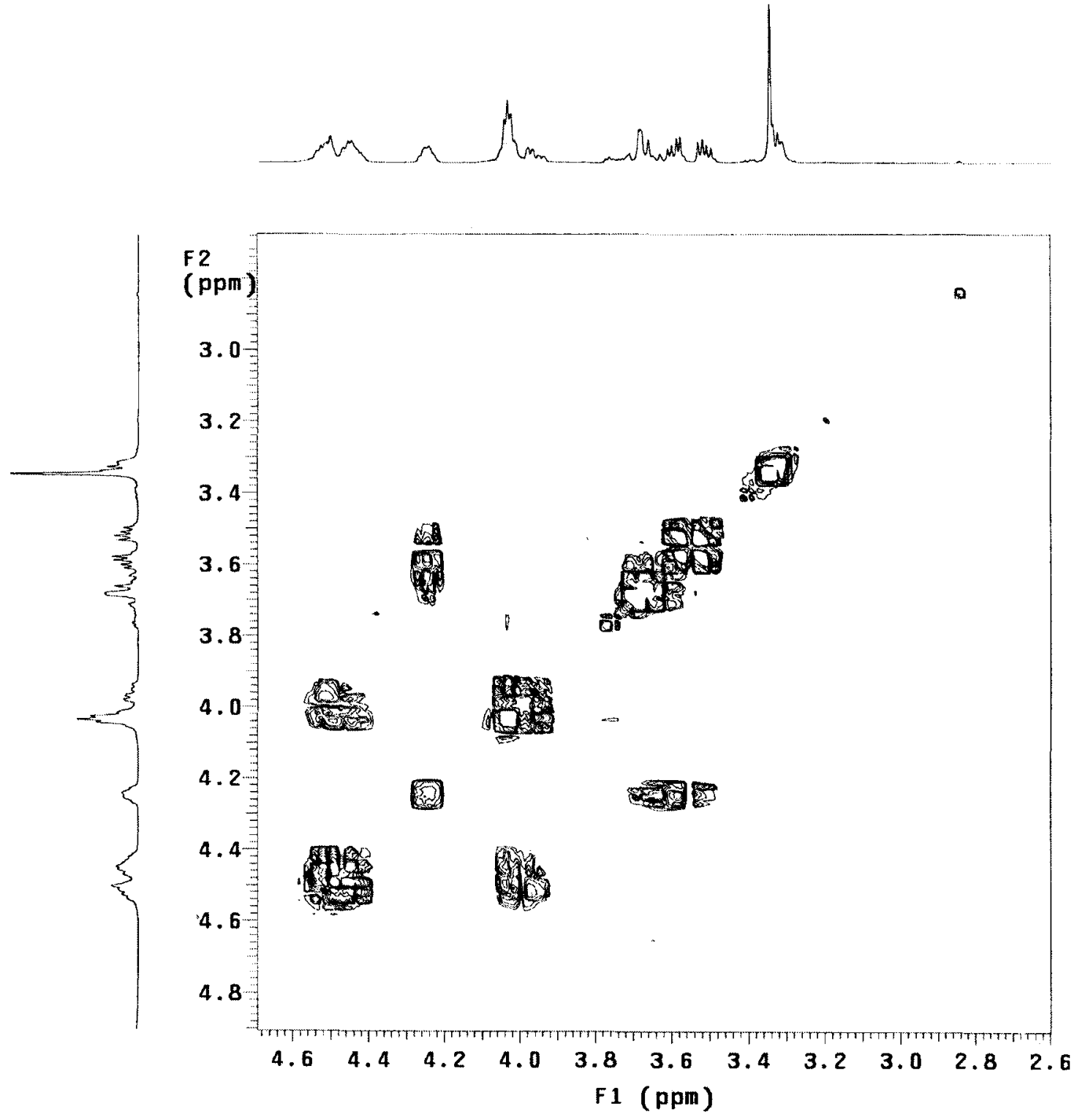

COSY NMR spectrum of compound $\mathbf{2 . 2}$ 


\subsection{Chapter 3. Cationic Aminooxy Lipids for $\mathrm{pH}$-Triggered Liposome Polymerization--First Generation Concept}

6.3.1 2-(decyloxy)tetrahydro-2H-pyran (3.8)

6.3.2 ((5-(decyloxy)pent-4-en-1-yl)oxy)triethylsilane (3.9)

6.3.3 5-(decyloxy)pent-4-en-1-ol (3.10)

6.3.4 (Z)-1-((5-(decyloxy)pent-4-en-1-yl)oxy)hexadecan-2-ol (3.11)

6.3.5 2-((dodecyloxy)methyl)-3,4-dihydro-2H-pyran (3.12)

6.3.6 (Z)-6-(decyloxy)-1-(dodecyloxy)hex-5-en-2-ol (3.15)

6.3.7 2-(5,6-dihydro-1,4,2-dioxazin-3-yl)-N-tetradecylbenzamide (3.36)

6.3.8 4-(2-(bis(2-((1,3-dioxoisoindolin-2-yl)oxy)ethyl)amino)ethoxy)-4-oxobutanoi c acid (3.50)

6.3.9 2-(bis(2-((1,3-dioxoisoindolin-2-yl)oxy)ethyl)amino)ethyl(5-(decyloxy)pent-4 -en-1-yl) succinate (3.51)

6.3.10 2-((4-((5-(decyloxy)pent-4-en-1-yl)oxy)-4-oxobutanoyl)oxy)- $N, N$-bis(2-((1,3dioxoisoindolin-2-yl)oxy)ethyl)- $N$-methylethanaminium iodide (3.53)

6.3.11 2-(aminooxy)-N-(2-(aminooxy)ethyl)- $N$-(2-((4-((5-(decyloxy)pent-4-en-1-yl) oxy)-4-oxobutanoyl)oxy)ethyl)- $N$-methylethanaminium iodide (3.1)

6.3.12 2-(bis(2-((1,3-dioxoisoindolin-2-yl)oxy)ethyl)amino)ethyl(1-((5-(decyloxy)pe nt-4-en-1-yl)oxy)hexadecan-2-yl) succinate (3.52)

6.3.13 N,N-bis(2-((1,3-dioxoisoindolin-2-yl)oxy)ethyl)- $N$-methyl-4,7-dioxo-9-tetrad ecyl-3,8,11,17-tetraoxaheptacos-15-en-1-aminium iodide (3.54)

6.3.14 N,N-bis(2-(aminooxy)ethyl)-N-methyl-4,7-dioxo-9-tetradecyl-3,8,11,17-tetra oxaheptacos-15-en-1-aminium (3.2) 


\subsubsection{2-(decyloxy)tetrahydro-2H-pyran}

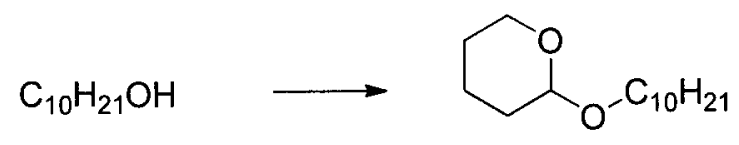

3.8

To a solution of decanol $(7.90 \mathrm{~g}, 50 \mathrm{mmol})$ and $p$-toluenesulfonic acid in $\mathrm{CH}_{2} \mathrm{Cl}_{2}$ $(50 \mathrm{ml})$ was added 3,4-dihydro- $2 \mathrm{H}$-pyran $(8.40 \mathrm{~g}, 100 \mathrm{mmol})$ at $0^{\circ} \mathrm{C}$. The reaction mixture was stirred at $0^{\circ} \mathrm{C}$ for $1 \mathrm{~h}$ and then warm up to room temperature. After $12 \mathrm{~h}$, the solvent was removed by rotary evaporation. The crude residue was dissolved in $\mathrm{Et}_{2} \mathrm{O}(200 \mathrm{~mL})$ and then washed successively with saturated aq. $\mathrm{NaHCO}_{3}(2 \times 100 \mathrm{~mL})$ and brine $(100 \mathrm{~mL})$. The organic layer was dried $\left(\mathrm{Na}_{2} \mathrm{SO}_{4}\right)$, filtered, and the solvent was removed by rotary evaporation. The crude product was purified by flash chromatography $\left(\mathrm{SiO}_{2}\right)$ using 19:1 hexanes: ethyl acetate as eluent (product $\mathrm{Rf}=0.35$ ) to afford $3.8(11.83 \mathrm{~g}, 98 \%)$ as a colorless liquid. ${ }^{1} \mathrm{H} \mathrm{NMR}\left(\mathrm{CDCl}_{3}, 500 \mathrm{MHz}\right) \delta 4.56(\mathrm{t}$, $J=2.0 \mathrm{~Hz}, 1 \mathrm{H},), 3.86(\mathrm{~m}, 1 \mathrm{H}), 3.72(\mathrm{~m}, 1 \mathrm{H}), 3.49(\mathrm{~m}, 1 \mathrm{H}), 3.37(\mathrm{~m}, 1 \mathrm{H}), 1.82(\mathrm{~m}, 1 \mathrm{H})$, $1.70(\mathrm{~m}, 1 \mathrm{H}), 1.50-1.58(\mathrm{~m}, 6 \mathrm{H}), 1.25-1.34(\mathrm{~m}, 14 \mathrm{H}), 0.86(\mathrm{t}, \mathrm{J}=7.0 \mathrm{~Hz}, 3 \mathrm{H}) ;{ }^{13} \mathrm{C}$ NMR $\left(\mathrm{CDCl}_{3}, 125 \mathrm{MHz}\right) \delta 99.2,68.0,62.7,32.2,31.1,30.1,29.9$ (2 peaks), 29.8, 29.7, 26.6, $25.9,23.0,20.0,14.4$. 


\subsection{2 ((5-(decyloxy)pent-4-en-1-yl)oxy)triethylsilane}

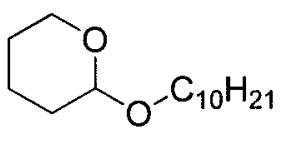

3.8

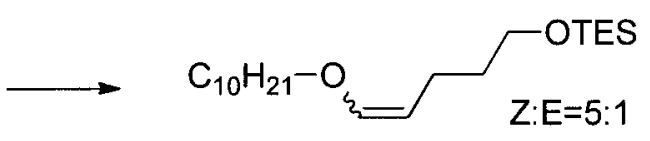

3.9

To a solution of acetal $3.8(0.242 \mathrm{~g}, 1.0 \mathrm{mmol})$ and 2,6 -lutidine $(0.428 \mathrm{~g}, 4.0$ $\mathrm{mmol})$ in dry $\mathrm{CH}_{2} \mathrm{Cl}_{2}(10 \mathrm{ml})$ was added triethylsilyltriflate $(0.473 \mathrm{~g}, 2.0 \mathrm{mmol})$ dropwise at $0{ }^{\circ} \mathrm{C}$. The reaction mixture was stirred at $0{ }^{\circ} \mathrm{C}$ for $0.5 \mathrm{~h}$ and then at room temperature for $12 \mathrm{~h}$. The yellow reaction mixture was quenched by saturated aq. $\mathrm{NaHCO}_{3}(2 \mathrm{~mL})$ and the $\mathrm{CH}_{2} \mathrm{Cl}_{2}$ was removed by rotary evaporation. The crude residue was dissolved in ethyl acetate $(30 \mathrm{~mL})$ and then washed successively with saturated aq. $\mathrm{NaHCO}_{3}(30 \mathrm{~mL})$, brine $(30 \mathrm{~mL})$ and dried $\left(\mathrm{Na}_{2} \mathrm{SO}_{4}\right)$. After filtration, the solvent was evaporated and then dried by oil pump. The crude product was purified by flash chromatography $\left(\mathrm{SiO}_{2}\right)$ using 49:1 hexanes: ethyl acetate as eluent $($ product $\mathrm{Rf}=$ $0.20)$ to afford $3.9(0.323 \mathrm{~g}, \mathrm{Z}: \mathrm{E}=5: 1,91 \%) .{ }^{1} \mathrm{H} \mathrm{NMR}\left(\mathrm{CDCl}_{3}, 500 \mathrm{MHz}\right) \delta 6.22(\mathrm{~d}, \mathrm{~J}=$ $12.5 \mathrm{~Hz}, 0.16 \mathrm{H}$ ), 5.91 (dt, J = 6.5 Hz, $1.0 \mathrm{~Hz}, 0.94 \mathrm{H}), 4.74$ (dt, J = 12.5, $5.5 \mathrm{~Hz}, 0.16 \mathrm{H}$ ), $4.32(\mathrm{dt}, \mathrm{J}=6.5,2.0 \mathrm{~Hz}, 0.94 \mathrm{H}), 3.68(\mathrm{t}, \mathrm{J}=6.5 \mathrm{~Hz}, 2 \mathrm{H}), 3.59(\mathrm{~m}, 2 \mathrm{H}), 2.10(\mathrm{~m}, 1.88 \mathrm{H})$, $1.80(\mathrm{~m}, 0.32 \mathrm{H}), 1.59(\mathrm{~m}, 4 \mathrm{H}), 1.26-1.34(\mathrm{~m}, 14 \mathrm{H}), 0.94-0.97(\mathrm{~m}, 9 \mathrm{H}), 0.88(\mathrm{t}, \mathrm{J}=7.0$ $\mathrm{Hz}, 3 \mathrm{H}), 0.59(\mathrm{~m}, 6 \mathrm{H}) ;{ }^{13} \mathrm{C} \mathrm{NMR}\left(\mathrm{CDCl}_{3}, 125 \mathrm{MHz}\right) \delta 146.8,145.5$ (2 peaks), 106.4, 103.7, 72.5, 69.6, 63.0, 62.5, 34.2, 33.4, 32.3, 30.1, 29.9, 29.7 (2 peaks), 26.4, 26.2, $24.4,23.0,20.7,14.4,7.1,4.8$. 


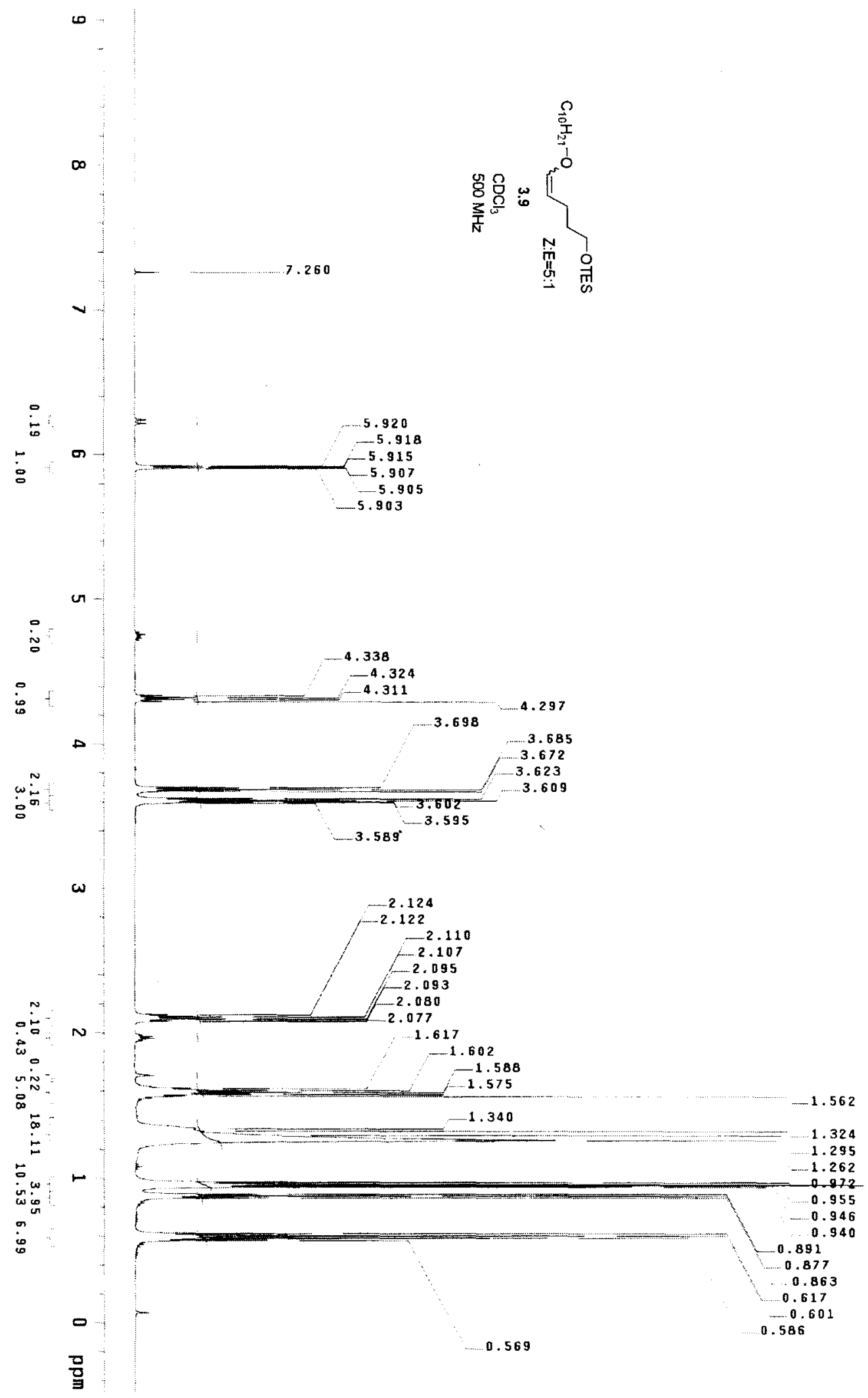

${ }^{1} \mathrm{H}$ NMR spectrum of compound 3.9 


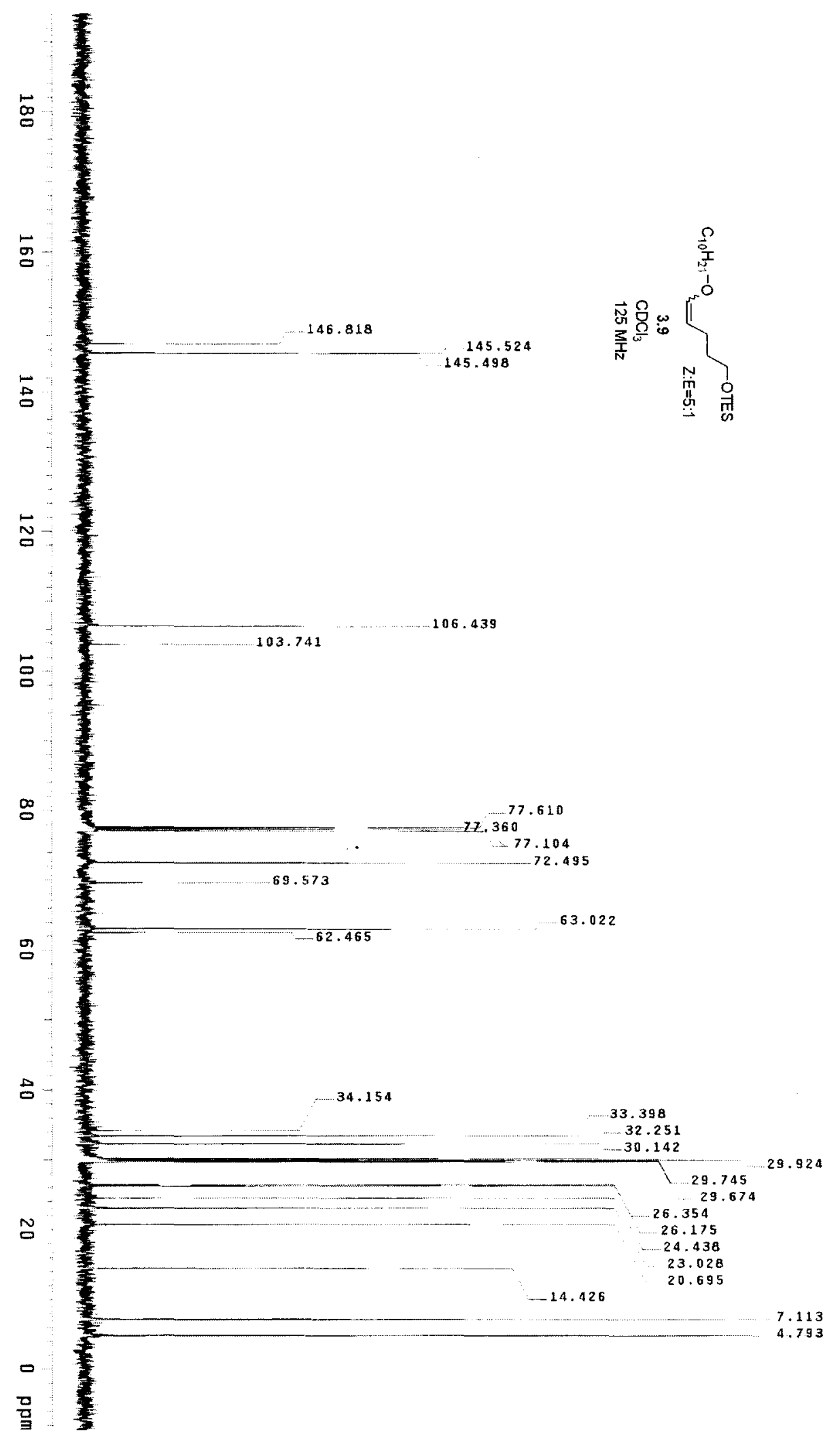

${ }^{13} \mathrm{C}$ NMR spectrum of compound 3.9 


\subsubsection{5-(decyloxy)pent-4-en-1-ol}

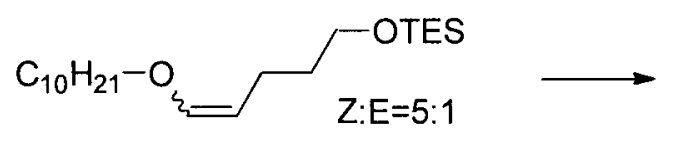

3.9

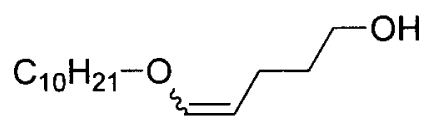

3.10

To a solution of $3.9(6.41 \mathrm{~g}, 18.0 \mathrm{mmol})$ was added TBAF ( $27 \mathrm{~mL}, 1 \mathrm{M}$ in THF) dropwise at $0{ }^{\circ} \mathrm{C}$. The reaction mixture was stirred at $0{ }^{\circ} \mathrm{C}$ for $12 \mathrm{~h}$ and then warm up to room temperature. After $12 \mathrm{~h}$, the solvent was removed by rotary evaporation and the yellow crude residue was dissolved in ethyl acetate $(100 \mathrm{~mL})$. The organic solution was washed successively with saturated aq. $\mathrm{NaHCO}_{3}(100 \mathrm{~mL} \times 3)$, brine $(100 \mathrm{~mL})$ and dried $\left(\mathrm{Na}_{2} \mathrm{SO}_{4}\right)$. After filtration, the solvent was removed and the crude product was purified by flash chromatography $\left(\mathrm{SiO}_{2}\right)$ using $5: 1$ hexanes: ethyl acetate as eluent (product $\mathrm{E} \mathrm{Rf}=0.21, \mathrm{ZRf}=0.31)$ to afford $3.10(\mathrm{Z})(2.63 \mathrm{~g}, 60 \%)$ and $3.10(\mathrm{E})$ (0.41 g, 9.4\%) as white solid. ${ }^{1} \mathrm{H} \mathrm{NMR}\left(\mathrm{CDCl}_{3}, 500 \mathrm{MHz}\right) 3.10(\mathrm{Z}) \delta 5.98(\mathrm{~d}, \mathrm{~J}=6.5 \mathrm{~Hz}$, $1 \mathrm{H}), 4.33(\mathrm{dt}, \mathrm{J}=6.5 \mathrm{~Hz}, 2.5 \mathrm{~Hz}, 1 \mathrm{H}), 3.71(\mathrm{t}, \mathrm{J}=6.5 \mathrm{~Hz}, 2 \mathrm{H}), 3.62(\mathrm{t}, \mathrm{J}=6.5 \mathrm{~Hz}, 2 \mathrm{H})$, $2.16(\mathrm{~m}, \mathrm{~J}=7.0 \mathrm{~Hz}, 2 \mathrm{H}), 2.09(\mathrm{br}, 1 \mathrm{H}), 1.60(\mathrm{~m}, 4 \mathrm{H}), 1.25-1.34(\mathrm{~m}, 14 \mathrm{H}), 0.87(\mathrm{t}, \mathrm{J}=$ $7.0 \mathrm{~Hz}, 3 \mathrm{H}$ ); $3.10(\mathrm{E}) \delta 6.24(\mathrm{~d}, \mathrm{~J}=12.5 \mathrm{~Hz}, 1 \mathrm{H}), 4.76(\mathrm{dt}, \mathrm{J}=12.5,7.5 \mathrm{~Hz}, 1 \mathrm{H}$ ), 3.61-3.67 (m, 4H), $2.02(\mathrm{t}, \mathrm{J}=7.0 \mathrm{~Hz}, 2 \mathrm{H}), 1.61(\mathrm{~m}, 4 \mathrm{H}), 1.26-1.35(\mathrm{~m}, 14 \mathrm{H}), 0.88(\mathrm{t}, \mathrm{J}$

$=7.0 \mathrm{~Hz}, 3 \mathrm{H}) ;{ }^{13} \mathrm{C} \mathrm{NMR}\left(\mathrm{CDCl}_{3}, 125 \mathrm{MHz}\right) 3.10(\mathrm{Z}) \delta 146.2,105.6,72.7,62.0,32.2(2$ peaks), 30.0, 29.9, 29.7, 29.6, 26.1, 23.0, 20.0, 14.4; 3.10(E) $\delta 147.0,103.5,69.7$, 62.7, 33.9, 32.2, 29.9 (2 peaks), 29.7 (2 peaks), 29.6, 26.3, 24.5, 23.0, 14.4. HRMS (ESI): calcd. for $\mathrm{C}_{30} \mathrm{H}_{60} \mathrm{NaO}_{4}{ }^{+}\left[2 \mathrm{M}+\mathrm{Na}^{+}\right]: 507.4384$, found :507.4387. 


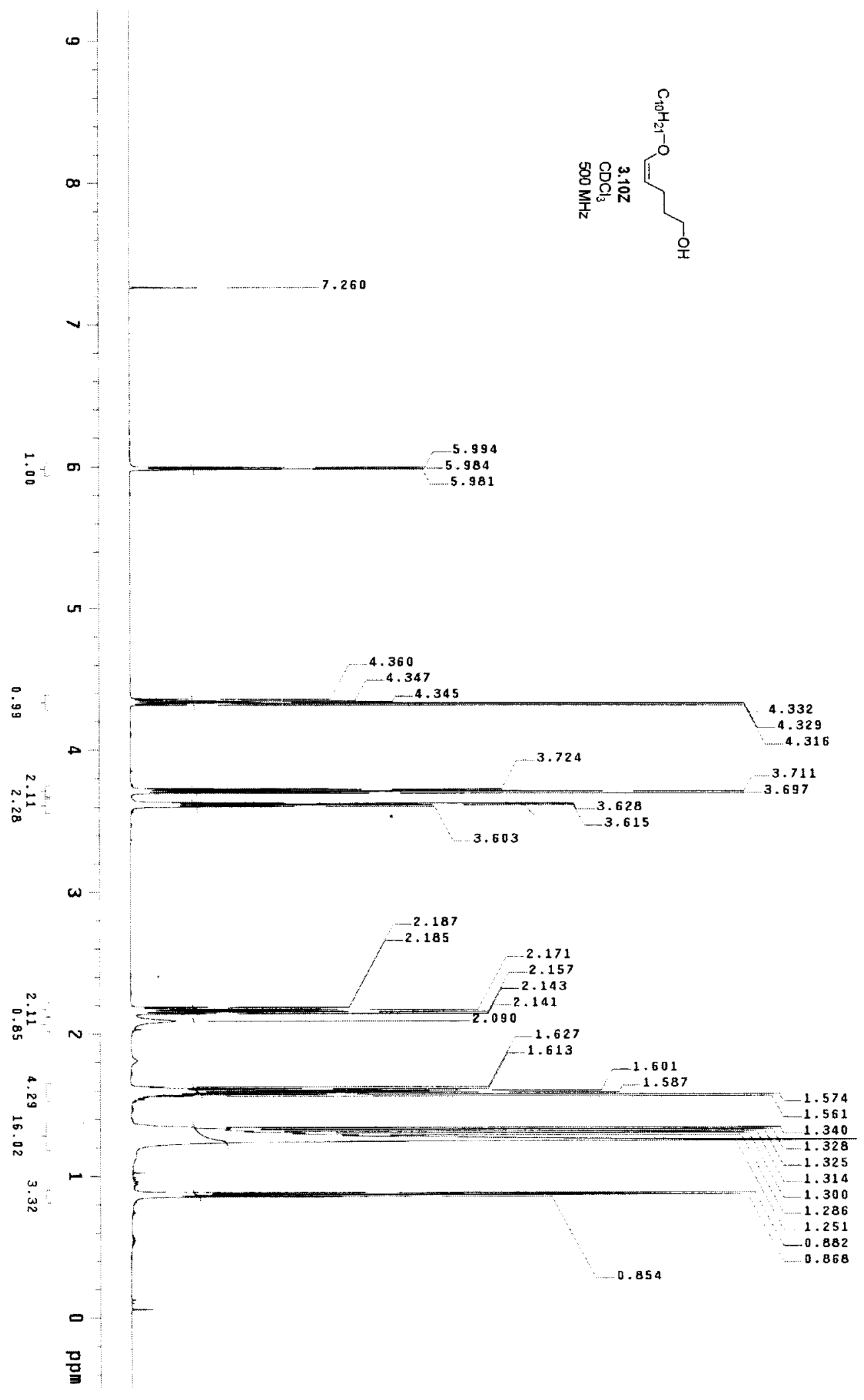

${ }^{1} \mathrm{H}$ NMR spectrum of compound $3.10(\mathrm{Z})$ 


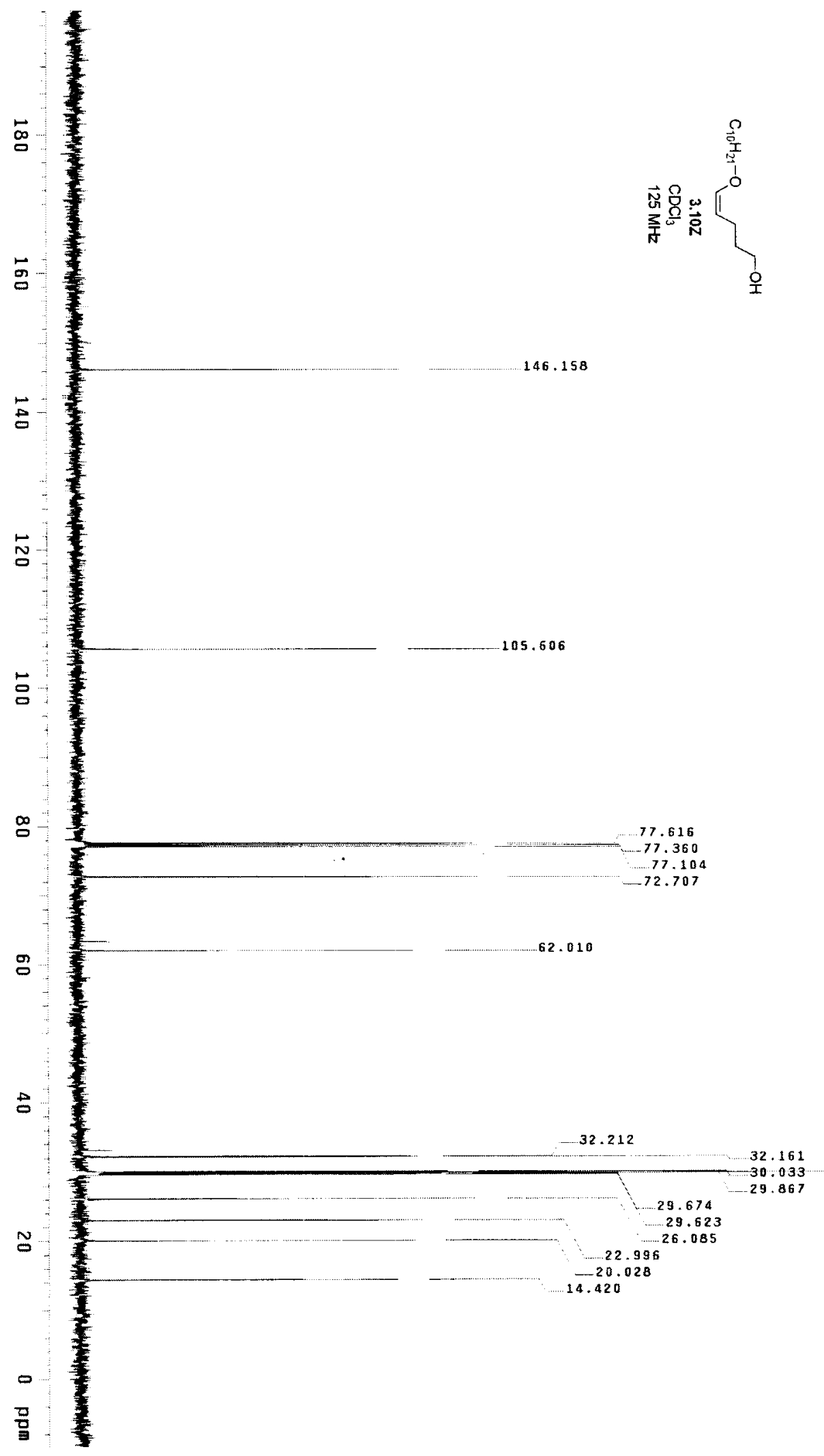

${ }^{13} \mathrm{C}$ NMR spectrum of compound $3.10(\mathrm{Z})$ 


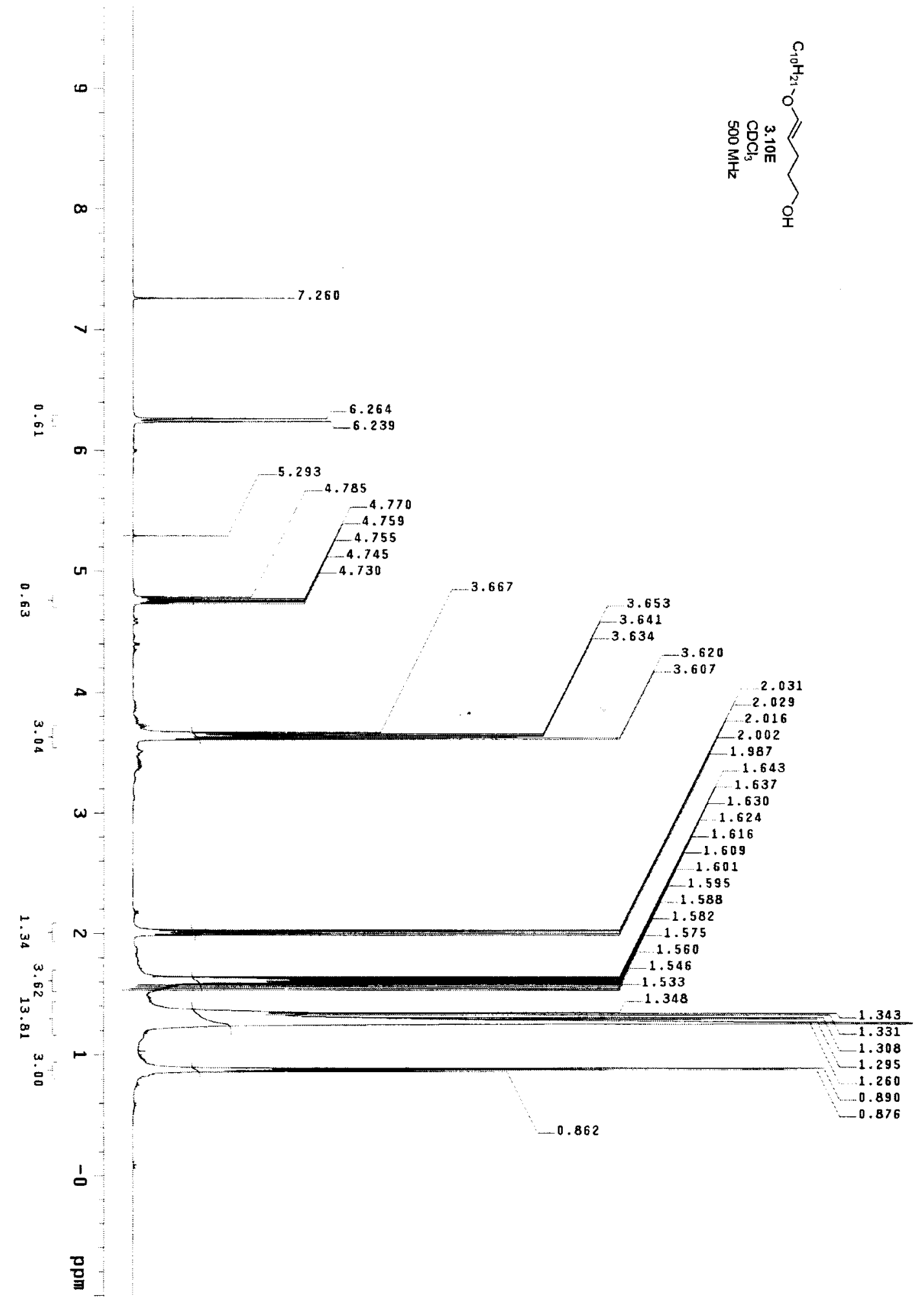

${ }^{1} \mathrm{H}$ NMR spectrum of compound $3.10(E)$ 


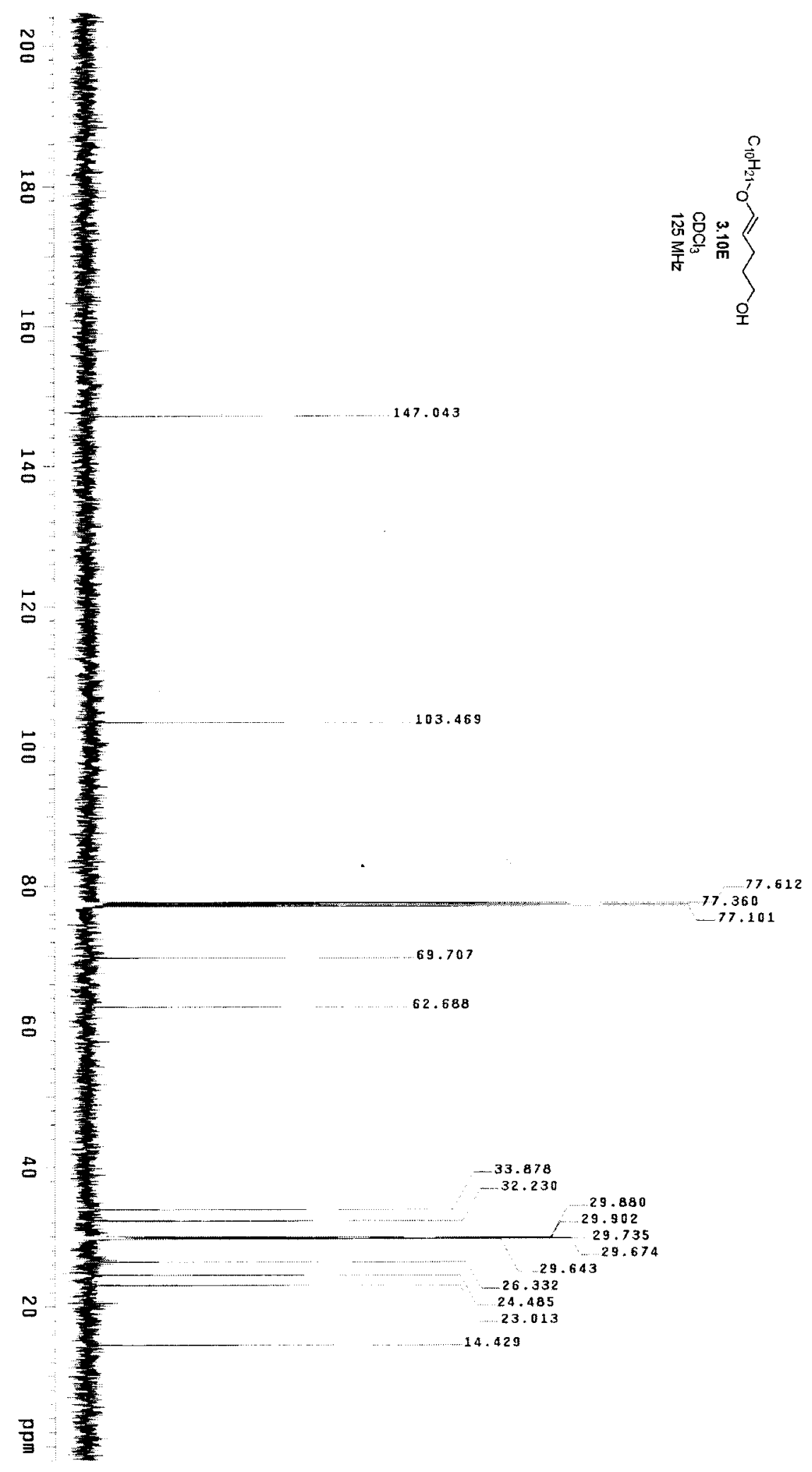

${ }^{13} \mathrm{C}$ NMR spectrum of compound 3.10 (E) 


\subsection{4 (Z)-1-((5-(decyloxy)pent-4-en-1-yl)oxy)hexadecan-2-ol}

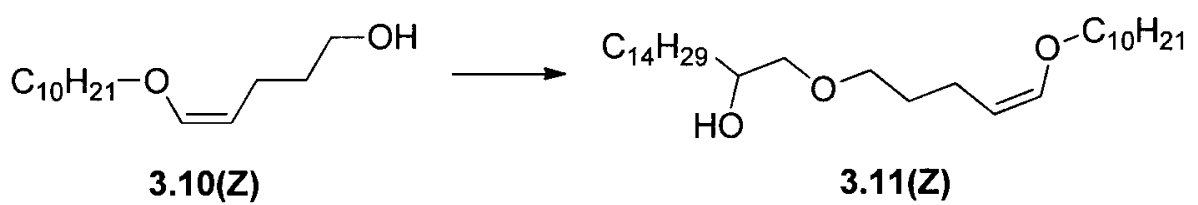

The commercial available 1,2-epoxyhexadecane (Sigma, 260215) is technical grade with $85 \%$ purity and requires purification by $\mathrm{SiO}_{2}$ chromatograph using 9:1 hexanes: ethyl acetate as eluent. After evaporated the solvents, the purified epoxy was dried overnight by oil pump.

To a solution of $3.10(2.03 \mathrm{~g}, 8.38 \mathrm{mmol})$ in dry DMSO $(20 \mathrm{~mL})$ was added $\mathrm{NaH}$ $(0.40 \mathrm{~g}, 60 \%, 10.1 \mathrm{mmol})$ at room temperature. After $1 \mathrm{~h}$, purified 1,2-epoxyhexadecane $(2.22 \mathrm{~g}, 9.22 \mathrm{mmol})$ in dry DMSO $(10 \mathrm{~mL})$ was added and the reaction mixture was stirred at $50^{\circ} \mathrm{C}$ for $12 \mathrm{~h}$. The reaction was quenched by adding saturated aq. $\mathrm{NaHCO}_{3}(100 \mathrm{~mL})$. The mixture was extracted by $\mathrm{Et}_{2} \mathrm{O}(30 \mathrm{~mL} \times 3)$ and the combined organic layer was washed successively with saturated aq. $\mathrm{NaHCO}_{3}$ $(100 \mathrm{~mL} \times 3)$, brine $(100 \mathrm{~mL})$ and dried $\left(\mathrm{Na}_{2} \mathrm{SO}_{4}\right)$. After filtration, the solvent was removed by rotary evaporation. The crude product was then purified by flash chromatography $\left(\mathrm{SiO}_{2}\right)$ using 9:1 hexanes: ethyl acetate as eluent (product $\mathrm{Rf}=0.55$ 4:1 hexanes: ethyl acetate) to afford $3.11(\mathrm{Z})(2.11 \mathrm{~g}, 83 \%)$ as grease and unreacted 3.10(Z) $(0.76 \mathrm{~g})$ was recovered. Using the same method, the 3.11(E) isomer was synthesized from 3.10(E). ${ }^{1} \mathrm{H}$ NMR $\left(\mathrm{CDCl}_{3}, 500 \mathrm{MHz}\right) 3.11(\mathrm{Z}) \delta 5.94(\mathrm{~d}, \mathrm{~J}=6.0 \mathrm{~Hz}$, $1 \mathrm{H}), 4.30(\mathrm{dt}, \mathrm{J}=7.0 \mathrm{~Hz}, 7.0 \mathrm{~Hz}, 1 \mathrm{H}), 3.75(\mathrm{~m}, 1 \mathrm{H}), 3.70(\mathrm{~m}, 2 \mathrm{H}), 3.50(\mathrm{~m}, 3 \mathrm{H}), 3.23(\mathrm{t}$, $J=9.0 \mathrm{~Hz}, 1 \mathrm{H}), 2.43(\mathrm{br}, 1 \mathrm{H}), 2.13(\mathrm{~m}, 2 \mathrm{H}), 1.60(\mathrm{~m}, 4 \mathrm{H}), 1.25-1.35(\mathrm{~m}, 40 \mathrm{H}), 0.88(\mathrm{t}$, $J=7.0 \mathrm{~Hz}, 6 \mathrm{H}) ; 3.11(E) \delta 6.21(\mathrm{~d}, J=12.5 \mathrm{~Hz}, 1 \mathrm{H}), 4.71(\mathrm{dt}, \mathrm{J}=12.5,7.5 \mathrm{~Hz}, 1 \mathrm{H}), 3.76$ $(\mathrm{m}, 1 \mathrm{H}), 3.60(\mathrm{t}, \mathrm{J}=6.5 \mathrm{~Hz}, 2 \mathrm{H}), 3.44(\mathrm{~m}, 3 \mathrm{H}), 3.22(\mathrm{t}, \mathrm{J}=9.0 \mathrm{~Hz}, 1 \mathrm{H}), 2.44(\mathrm{br}, 1 \mathrm{H})$, 
$1.97(\mathrm{t}, \mathrm{J}=8.0 \mathrm{~Hz}, 2 \mathrm{H}), 1.57-1.63(\mathrm{~m}, 4 \mathrm{H}), 1.24-1.41(\mathrm{~m}, 4 \mathrm{OH}), 0.86(\mathrm{t}, \mathrm{J}=7.0 \mathrm{~Hz}, 6 \mathrm{H})$;

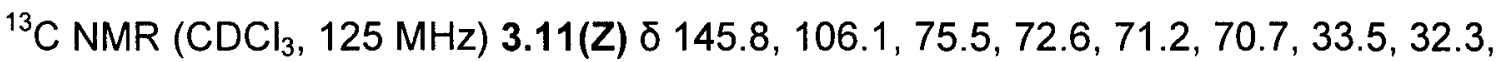
$30.1,30.0$ (2 peaks), 29.9, 29.7 (2 peaks), 26.1, 25.9, 23.0, 20.8, 14.5; 3.11(E) ठ 146.9, 103.3, 75.5, 70.8, 70.6, 69.5, 33.5, 32.2 (2 peaks), 30.8, 30.0, 29.9 (2 peaks), 29.7 (2peaks), 29.6, 26.3, 25.9, 24.7, 23.0, 14.4; HRMS (ESI): calcd. for $\mathrm{C}_{31} \mathrm{H}_{62} \mathrm{NaO}_{3}{ }^{+}$ $\left[\mathrm{M}+\mathrm{Na}^{+}\right]: 505.4591$, found: 505.4598 . 


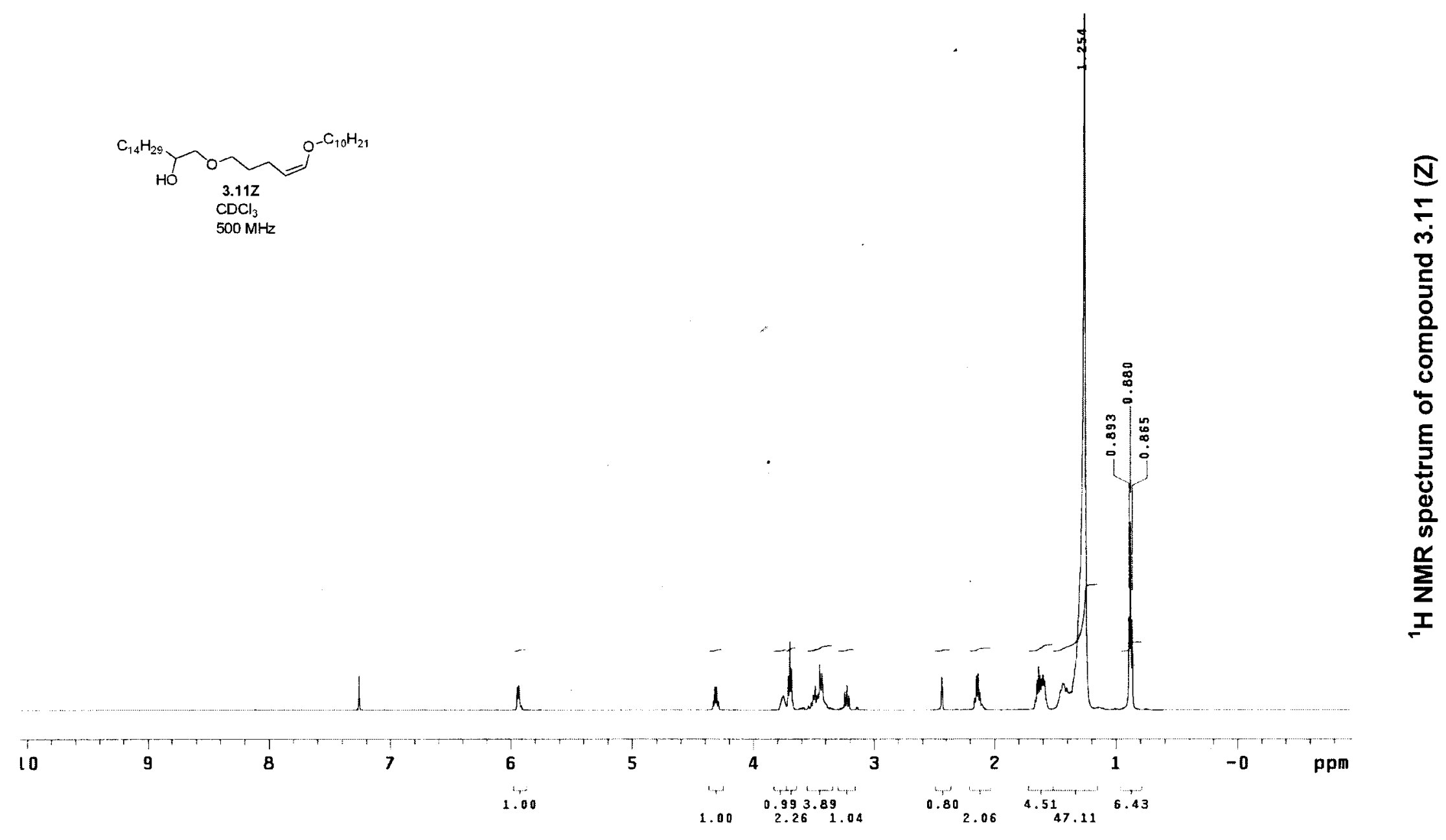




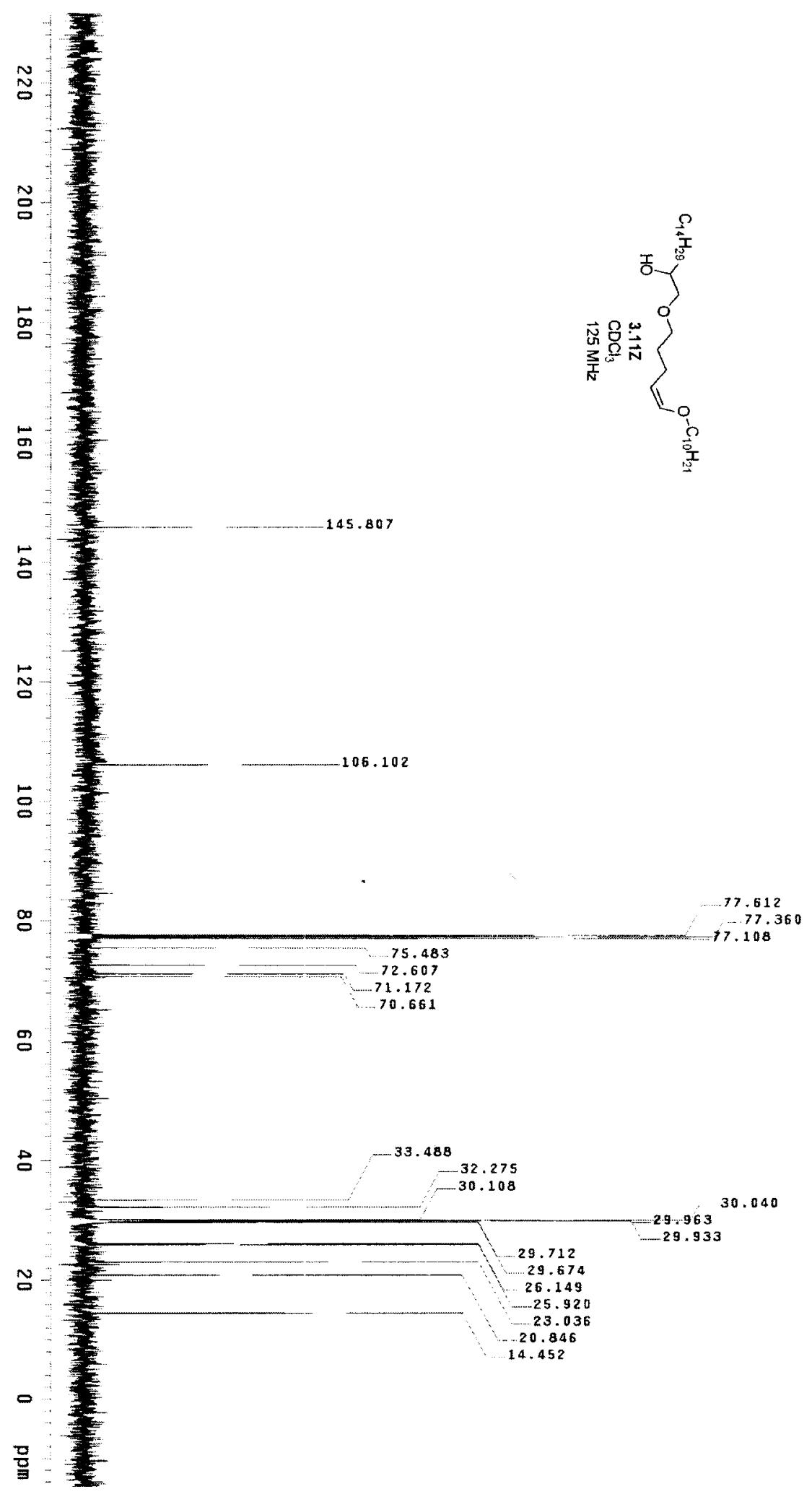

${ }^{13} \mathrm{C}$ NMR spectrum of compound 3.11 (Z) 


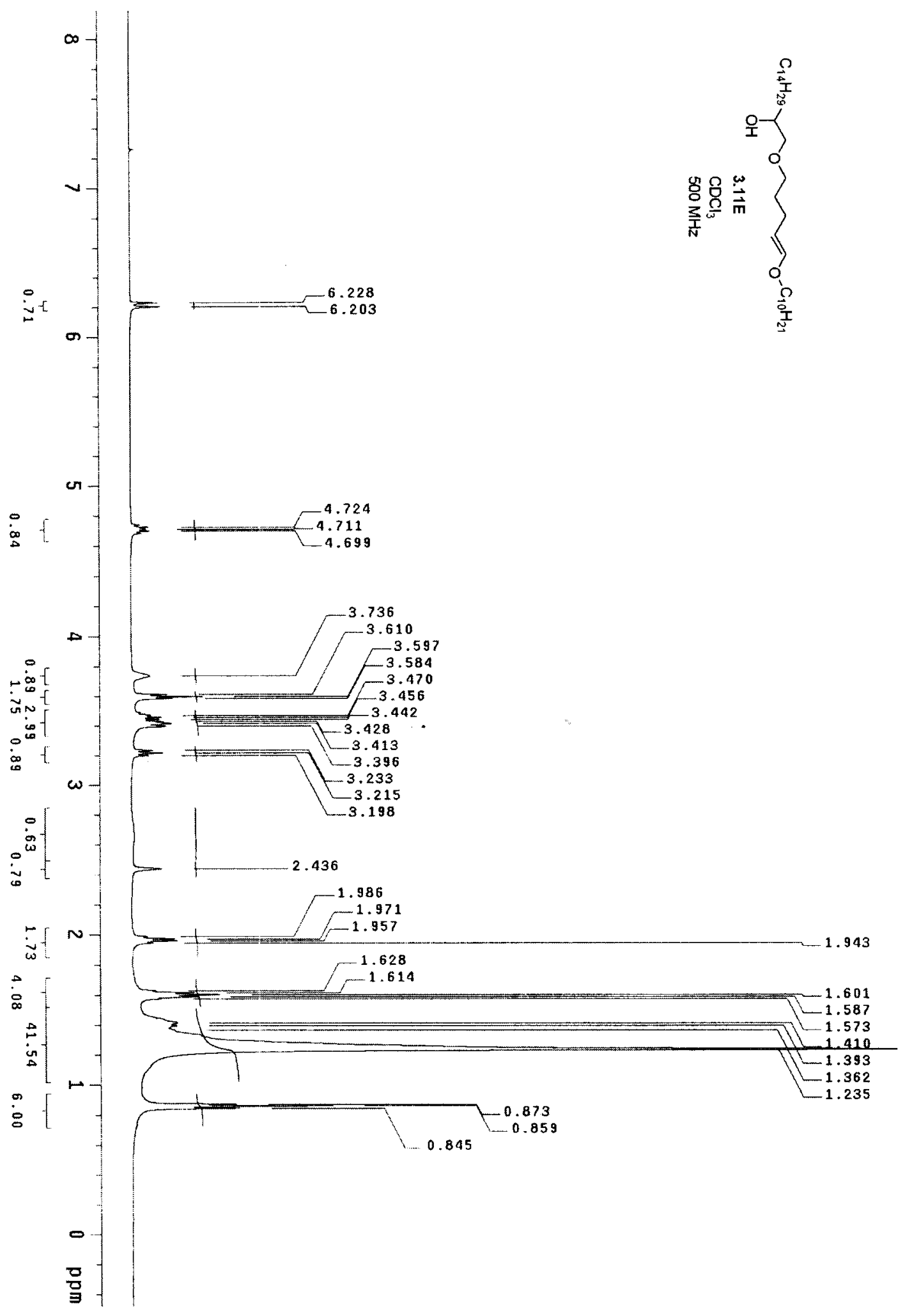

${ }^{1} \mathrm{H}$ NMR spectrum of compound 3.11 (E) 


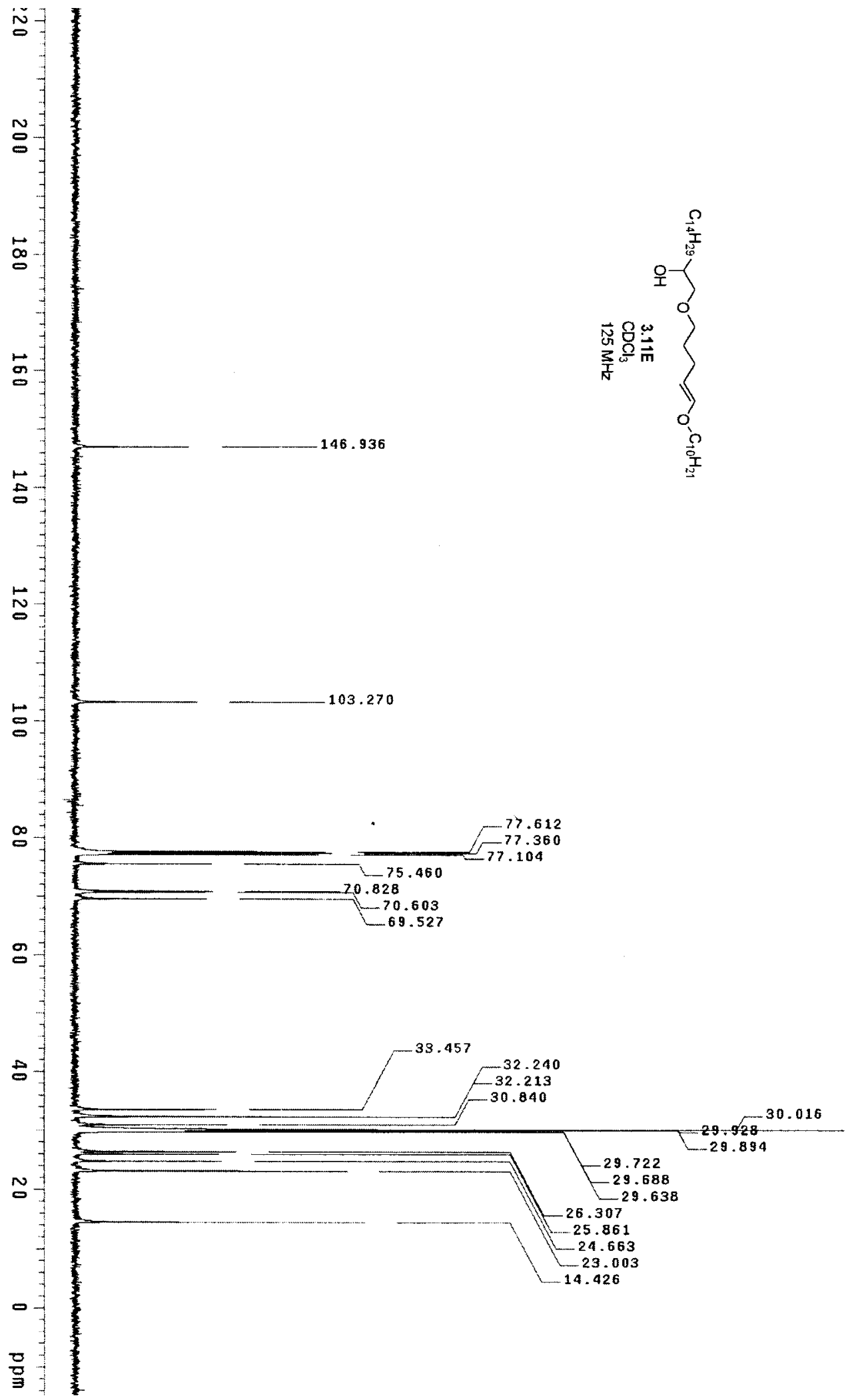

${ }^{13} \mathrm{C}$ NMR spectrum of compound 3.11 (E) 


\subsubsection{2-((dodecyloxy)methyl)-3,4-dihydro-2H-pyran}

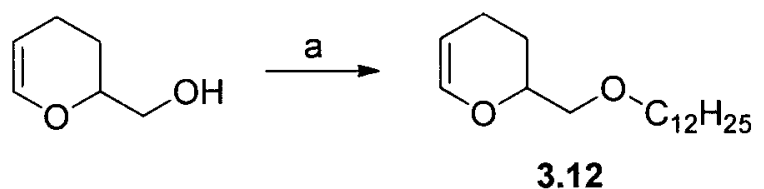

To a solution of sodium hydride $(57.6 \mathrm{mg}, 2.4 \mathrm{mmol})$ in dry DMF $(10 \mathrm{~mL})$ was added (3,4-dihydro-2H-pyran-2-yl)methanol $(0.228 \mathrm{~g}, 2.0 \mathrm{mmol})$. After the reaction mixture was stirred at room temperature for $1 \mathrm{~h}, 1$-bromododecane $(0.784 \mathrm{~g}, 3.0 \mathrm{mmol})$ was added and the reaction mixture was stirred at room temperature for $24 \mathrm{~h}$. The reaction was quenched by adding saturated aq. $\mathrm{NaHCO}_{3}(50 \mathrm{~mL})$. The mixture was extracted by $\mathrm{Et}_{2} \mathrm{O}(40 \mathrm{~mL} \times 2)$ and the combined organic layer was washed successively with saturated aq. $\mathrm{NaHCO}_{3}(100 \mathrm{~mL} \times 3)$, brine $(100 \mathrm{~mL})$ and dried $\left(\mathrm{Na}_{2} \mathrm{SO}_{4}\right)$. After filtration, the solvent was removed by rotary evaporation. The crude product was then purified by flash chromatography $\left(\mathrm{SiO}_{2}\right)$ using hexanes as eluent (product $\mathrm{Rf}=0.744: 1$ hexanes: ethyl acetate) to afford $3.12(0.51 \mathrm{~g}, 90 \%)$ as colorless liquid. ${ }^{1} \mathrm{H} \mathrm{NMR}\left(\mathrm{CDCl}_{3}, 500 \mathrm{MHz}\right) \delta 6.38(\mathrm{~d}, \mathrm{~J}=5.5 \mathrm{~Hz}, 1 \mathrm{H}), 4.67(\mathrm{~s}, 1 \mathrm{H}), 3.97(\mathrm{~m}, 1 \mathrm{H})$, $3.54(\mathrm{~m}, 1 \mathrm{H}), 3.47(\mathrm{~m}, 3 \mathrm{H}), 2.10(\mathrm{~m}, 1 \mathrm{H}), 1.98(\mathrm{~m}, 1 \mathrm{H}), 1.86(\mathrm{~m}, 1 \mathrm{H}), 1.56-1.68(\mathrm{~m}, 3 \mathrm{H})$, $1.25(\mathrm{~m}, 18 \mathrm{H}), 0.87(\mathrm{t}, \mathrm{J}=6.5 \mathrm{~Hz}, 3 \mathrm{H}),{ }^{13} \mathrm{C} \mathrm{NMR}\left(\mathrm{CDCl}_{3}, 125 \mathrm{MHz}\right) \delta 144.0,100.7,74.4$, 73.6, 72.2, 32.6, 30.0 (3 peaks), 29.8, 29.7, 26.4, 25.0, 23.0, 19.7, 14.4. 


\subsection{6 (Z)-6-(decyloxy)-1-(dodecyloxy)hex-5-en-2-ol}

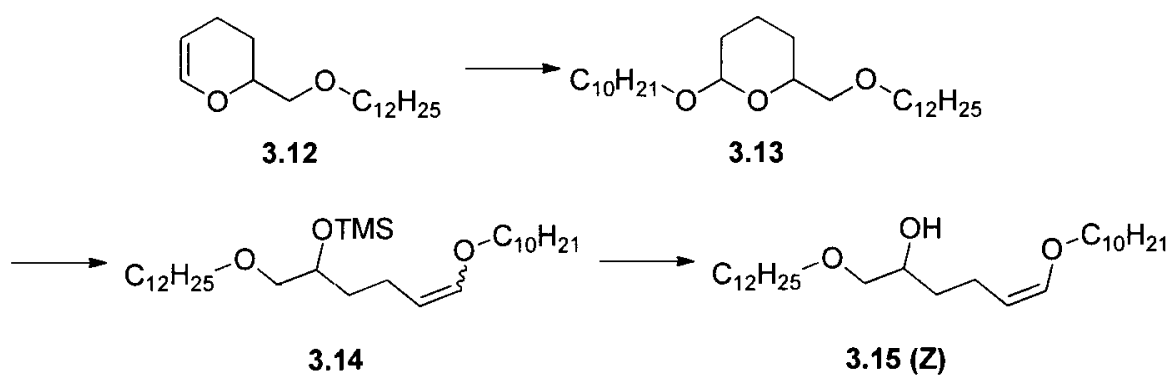

To a solution of $3.12(0.282 \mathrm{~g}, 1.0 \mathrm{mmol})$ and decan-1-ol $(0.316 \mathrm{~g}, 2.0 \mathrm{mmol})$ in $\mathrm{CH}_{2} \mathrm{Cl}_{2}(10 \mathrm{ml})$ was added $p$-toluenesulfonic acid monohydrate $(5.7 \mathrm{mg}, 0.03 \mathrm{mmol})$. After stirred at room temperature for $14 \mathrm{~h}$, the solvent was removed. The residue was purified by flash chromatography $\left(\mathrm{SiO}_{2}\right)$ using $49: 1$ hexanes: ethyl acetate as eluent (product $\operatorname{Rf}=0.53$ 9:1 hexanes:ethyl acetate ) to afford crude $3.13(0.44 \mathrm{~g})$.

To a solution of above crude 3.13 and 2,6 -lutidine $(0.321 \mathrm{~g}, 3.0 \mathrm{mmol})$ in dry $\mathrm{CH}_{2} \mathrm{Cl}_{2}(5 \mathrm{ml})$ was added trimethylsilyltriflate $(0.222 \mathrm{~g}, 1.2 \mathrm{mmol})$ dropwise at $0{ }^{\circ} \mathrm{C}$. The mixture was stirred at $0{ }^{\circ} \mathrm{C}$ for $0.5 \mathrm{~h}$ and then at room temperature for $12 \mathrm{~h}$. Saturated aq. $\mathrm{NaHCO}_{3}(20 \mathrm{~mL})$ was added to yellow mixture to quench reaction. After the solvent was removed by rotary evaporation, the crude residue was dissolved in ethyl acetate $(50 \mathrm{~mL})$. The solution was washed successively with saturated aq. $\mathrm{NaHCO}_{3}$ $(50 \mathrm{~mL} \times 2)$, brine $(50 \mathrm{~mL})$ and dried $\left(\mathrm{Na}_{2} \mathrm{SO}_{4}\right)$. After filtration, the solvent was removed by rotary evaporation. The crude product was purified by flash chromatography $\left(\mathrm{SiO}_{2}\right)$ using 49:1 hexanes:ethyl acetate as eluent (product $\mathrm{Rf}=0.20$ ) to afford crude $3.14(0.392 \mathrm{~g}, 77 \%)$.

To a solution of $3.14(0.38 \mathrm{~g}, 0.74 \mathrm{mmol})$ was added TBAF $(0.89 \mathrm{~mL}, 1 \mathrm{M}$ in THF) dropwise at $0{ }^{\circ} \mathrm{C}$. After stirring $12 \mathrm{~h}$ at room temperature, the solvent of yellow reaction mixture was removed by rotary evaporation. The crude residue was dissolved in ethyl 
acetate $(20 \mathrm{~mL})$ and then washed successively with saturated aq. $\mathrm{NaHCO}_{3}(20 \mathrm{~mL} \times 3)$ and brine $(20 \mathrm{~mL})$. Then the combined aqueous layer was extracted by ethyl acetate $(20 \mathrm{~mL})$. The organic layer was combined, washed by brine $(20 \mathrm{~mL})$ and dried $\left(\mathrm{Na}_{2} \mathrm{SO}_{4}\right)$. After filtration, the solvent was removed by rotary evaporation. The crude product was then purified by flash chromatography $\left(\mathrm{SiO}_{2}\right)$ using 9:1 hexanes: ethyl acetate as eluent (product $\mathrm{Rf}=0.45,4: 1$ hexanes: ethyl acetate) to afford $3.15(\mathrm{Z})$ (0.192 g, 59\%) as white solid. ${ }^{1} \mathrm{H}$ NMR $\left(\mathrm{CDCl}_{3}, 500 \mathrm{MHz}\right) 3.10(\mathrm{Z}) \delta 5.96(\mathrm{br}, 1 \mathrm{H}), 4.34$ $(\mathrm{d}, \mathrm{J}=6.0 \mathrm{~Hz}, 1 \mathrm{H}), 3.80(\mathrm{t}, \mathrm{J}=3.0 \mathrm{~Hz}, 1 \mathrm{H}), 3.70(2 \mathrm{H}), 3.45(\mathrm{~m}, 3 \mathrm{H}), 3.30(\mathrm{~m}, 1 \mathrm{H}), 2.52$ $(\mathrm{s}, 1 \mathrm{H}), 2.20(\mathrm{~m}, 2 \mathrm{H}), 1.47-1.63(\mathrm{~m}, 7 \mathrm{H}), 1.26(\mathrm{~m}, 33 \mathrm{H}), 0.88(\mathrm{~m}, 6 \mathrm{H}) ;{ }^{13} \mathrm{C} \mathrm{NMR}\left(\mathrm{CDCl}_{3}\right.$, $125 \mathrm{MHz}$ ) $\delta 145.9,106.0,75.3,72.7,71.9,70.1,33.4,32.2,30.1,30.0$ (2 peaks), 29.9, 29.8, 29.7 (2 peaks), 26.5, 26.1, 23.0, 20.3, 14.4. 


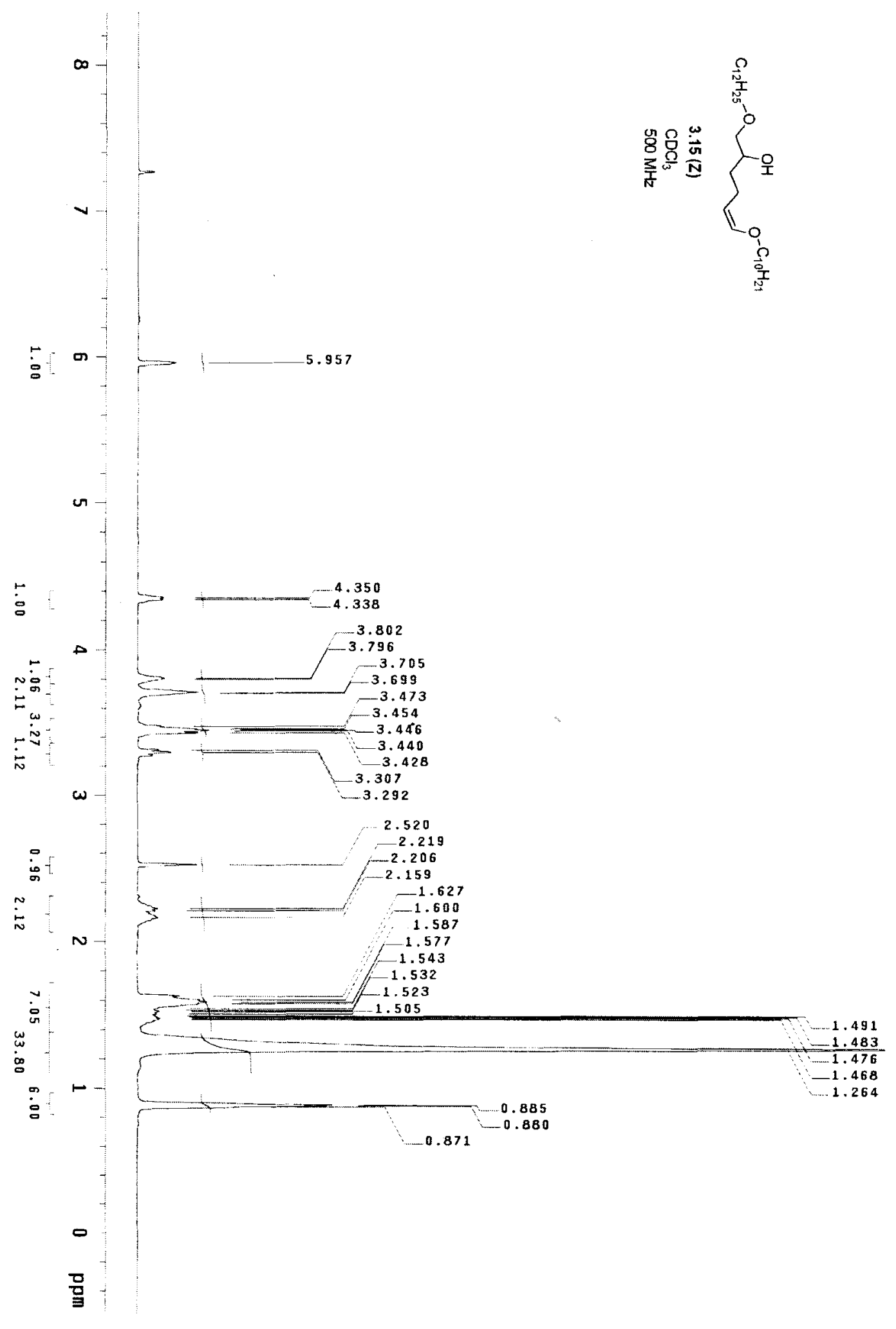

${ }^{1} \mathrm{H}$ NMR spectrum of compound $3.15(\mathrm{Z})$ 


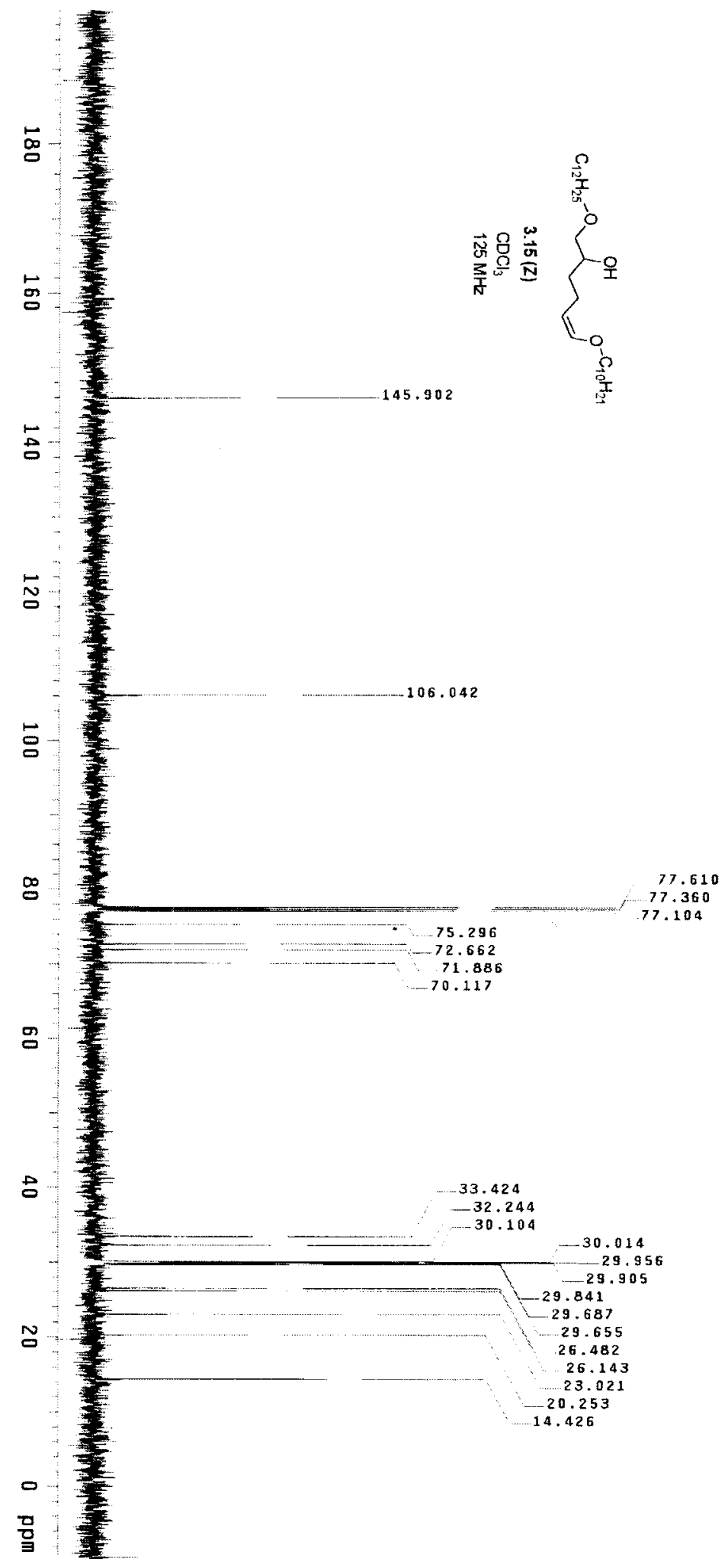

${ }^{13} \mathrm{C}$ NMR spectrum of compound $3.15(Z)$ 


\subsubsection{2-(5,6-dihydro-1,4,2-dioxazin-3-yl)-N-tetradecylbenzamide}
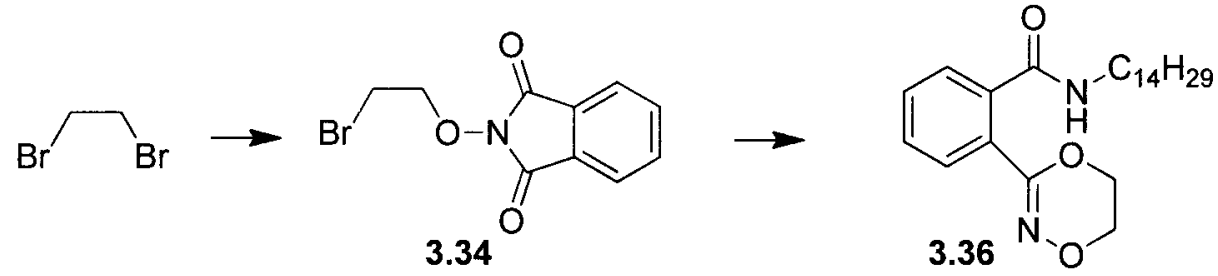

A solution of $\mathrm{N}$-hydroxyphthalimide $(3.26 \mathrm{~g}, 20 \mathrm{mmol})$ in DMF $(50 \mathrm{~mL})$, ethylene bromide $(9.4 \mathrm{~g}, 50 \mathrm{mmol})$ and $\mathrm{Et}_{3} \mathrm{~N}(2.52 \mathrm{~g}, 25 \mathrm{mmol})$ was stirred at rt. for $17 \mathrm{~h}$. The precipitation product was filtered off, washed with water and then recrystallized in $70 \%$ ethanol to afford compound 3.34 as colorless needles (1.53 g, $28 \%$ ).

To a solution of $3.34(568 \mathrm{mg}, 2.1 \mathrm{mmol})$ and tetradecan-1-amine $(214 \mathrm{mg}, 1.0$ $\mathrm{mmol})$ in DMF $\left(7.0 \mathrm{ml}\right.$, dry) was added $\mathrm{Et}_{3} \mathrm{~N}(638 \mathrm{mg}, 6.3 \mathrm{mmol})$. The reaction was stirred at $\mathrm{rt}$. for $13 \mathrm{~h}$. The white precipitation was come out after water $(50 \mathrm{ml})$ was added. The precipitation was filtered and dissolved in ethyl ether $(100 \mathrm{ml})$. The aqueous phase was extracted with ethyl ether $(2 \times 50 \mathrm{ml})$. The combined organic layer was washed with Brine $(60 \mathrm{ml})$, dried $\left(\mathrm{Na}_{2} \mathrm{SO}_{4}\right)$ and filtered. After the solvent was removed by rotary evaporation, the residue was purified by flash chromatography using $1: 1$ hexanes:ethyl acetate as eluent (product $R f=0.4$ ) to afford the product 3.36 (340 mg, 84\%) as white solid. m.p. $358--359 \mathrm{~K} ; \mathrm{IR}\left(\mathrm{cm}^{-1}\right): 3272(\mathrm{~N}-\mathrm{H}), 3263,3069$, $2955,2914,2851,1634,1540,1475,1357,1341,1106,1045,911,765 ;{ }^{1}$ H NMR (500 $\left.\mathrm{MHz}, \mathrm{CDCl}_{3}\right): 0.88(\mathrm{t}, \mathrm{J}=7.0 \mathrm{~Hz}, 3 \mathrm{H}), 1.35(\mathrm{~m}, 22 \mathrm{H}), 1.61(\mathrm{~m}, \mathrm{~J}=7.5,7.5 \mathrm{~Hz}, 2 \mathrm{H}), 3.41$ (dd, J= 7.5, $7 \mathrm{~Hz}, 2 \mathrm{H}), 4.19(\mathrm{t}, \mathrm{J}=4.0 \mathrm{~Hz}, 2 \mathrm{H}), 4.44(\mathrm{t}, \mathrm{J}=4.0 \mathrm{~Hz}, 2 \mathrm{H}), 5.99(\mathrm{~s}, 1 \mathrm{H}, \mathrm{NH})$, $7.44(\mathrm{~m}, 2 \mathrm{H}), 7.50(\mathrm{~m}, 1 \mathrm{H}), 7.60(\mathrm{~m}, 1 \mathrm{H}) ;{ }^{13} \mathrm{C}$ NMR $\left(125 \mathrm{MHz}, \mathrm{CDCl}_{3}\right): 14.2,22.8,27.1$, $29.5,29.7,29.8,32.0,40.3,63.7,65.0,127.9,129.2,129.3,129.8,130.4,136.7,155.8$, 169.0; HRMS (ESI): calcd. for $\mathrm{C}_{24} \mathrm{H}_{38} \mathrm{NaN}_{2} \mathrm{O}_{3}{ }^{+}\left[\mathrm{M}+\mathrm{Na}^{+}\right]$]: 425.2780, found :425.2761. 


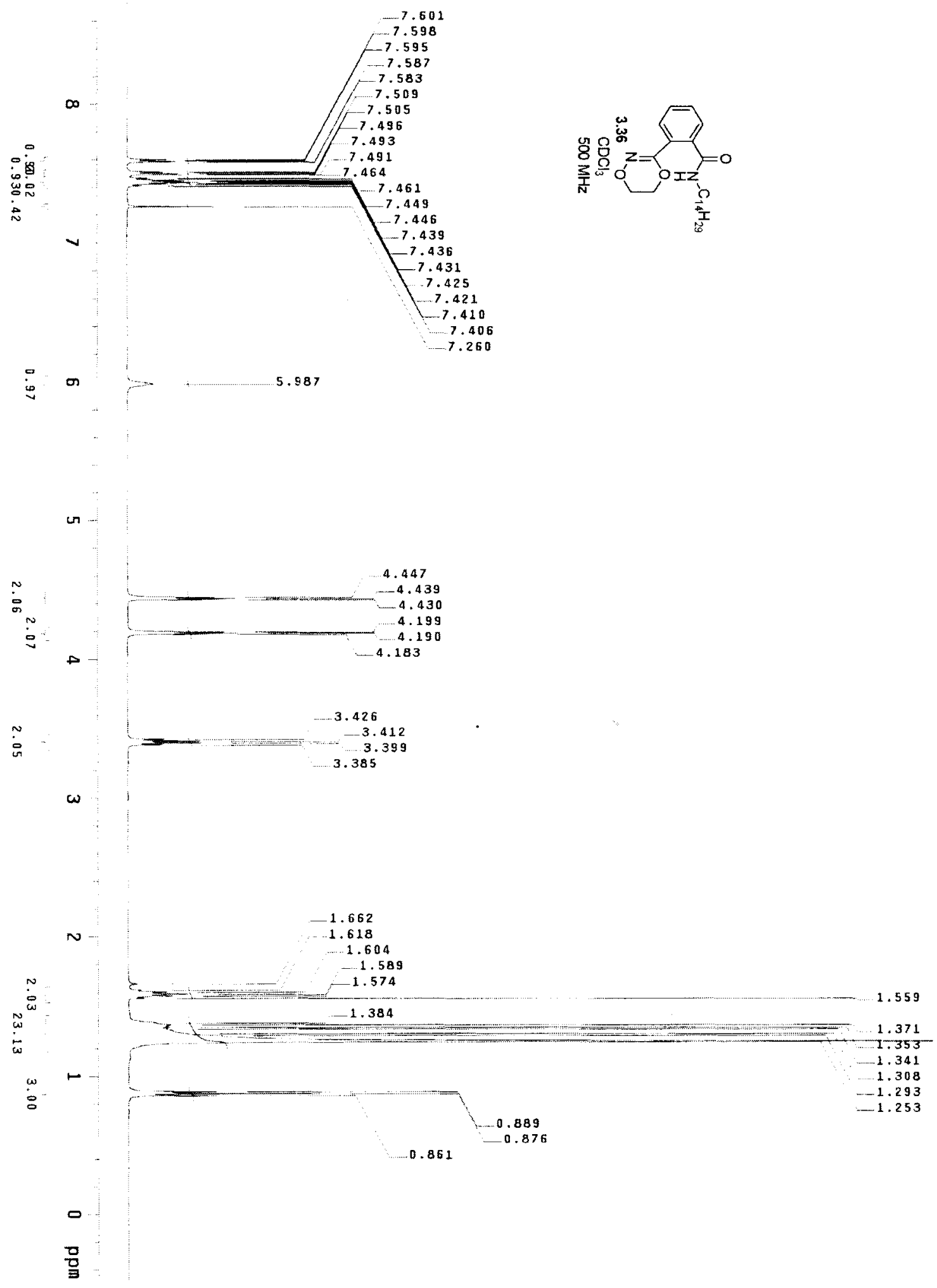

${ }^{1} \mathrm{H}$ NMR spectrum of compound 3.36 


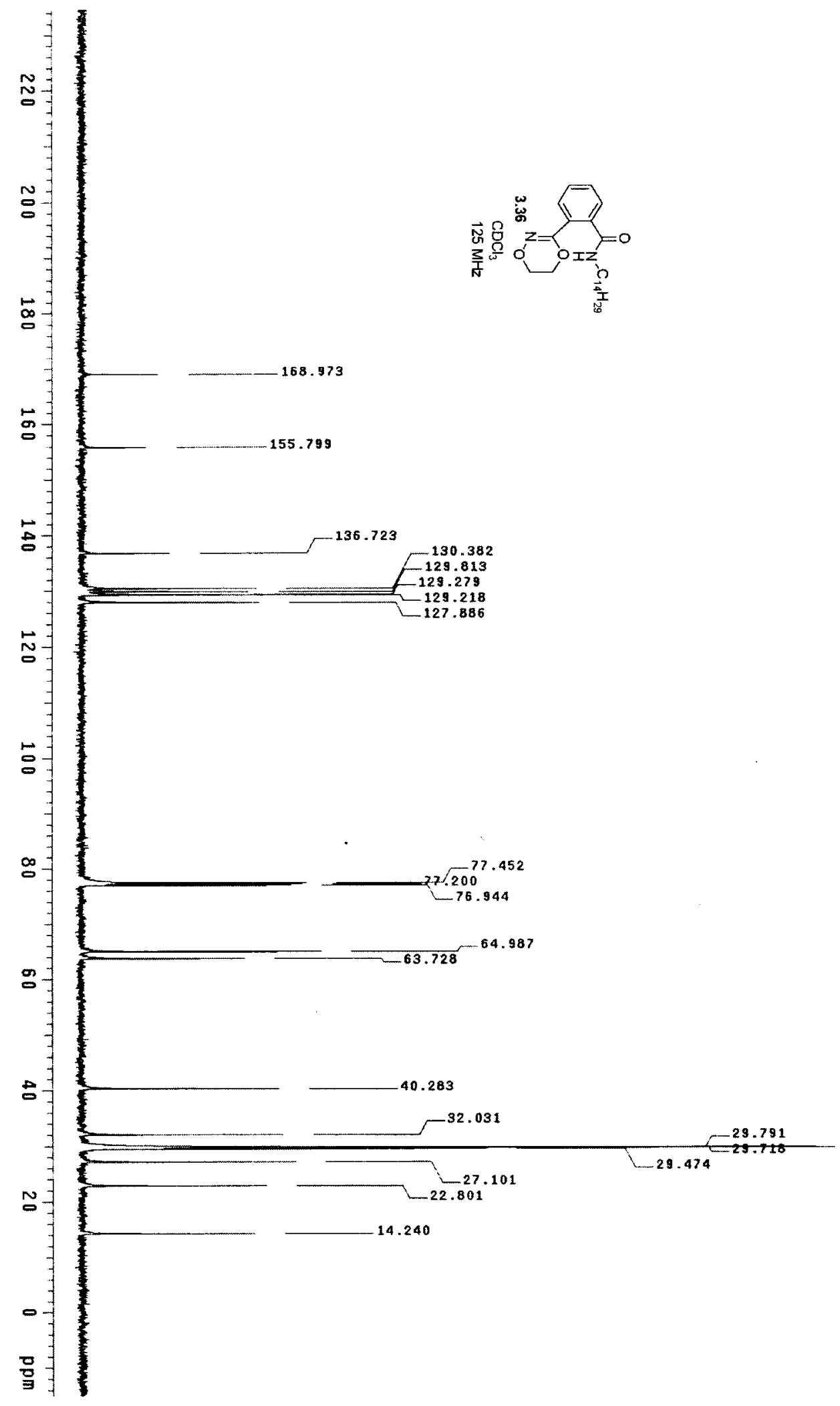

${ }^{13} \mathrm{C}$ NMR spectrum of compound 3.36 


\subsubsection{4-(2-(bis(2-((1,3-dioxoisoindolin-2-yl)oxy)}

\section{ethyl)amino)ethoxy)-4-oxobutanoic acid}

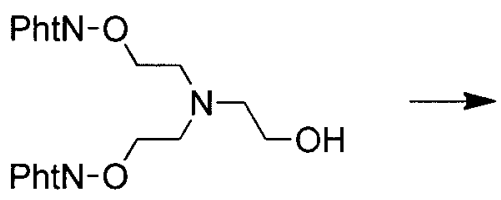

2.13

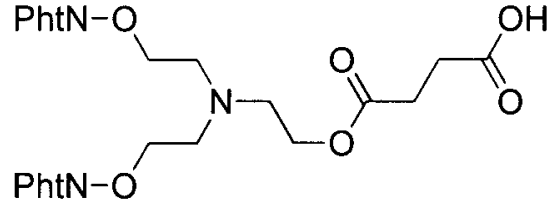

3.50

A solution of compound $2.13(1.0 \mathrm{~g}, 2.27 \mathrm{mmol})$, succinic anhydride $(0.683 \mathrm{~g}$, $6.83 \mathrm{mmol})$ in $\mathrm{CH}_{2} \mathrm{Cl}_{2}(10 \mathrm{~mL})$ was added triethylamine $(0.68 \mathrm{~g}, 6.83 \mathrm{mmol})$. After stirred for $18 \mathrm{~h}$ at it., the colorless reaction mixture turned to black color. After solvent was removed by rotary evaporation, aq. $\mathrm{NaHPO}_{4}(100 \mathrm{~mL}, 0.5 \mathrm{M}, \mathrm{pH} 7.0)$ was added. The aqueous solution was then extracted by $\mathrm{CH}_{2} \mathrm{Cl}_{2}(50 \mathrm{~mL} \times 3)$. The combined organic layer was washed by brine $(50 \mathrm{~mL})$, dried $\left(\mathrm{Na}_{2} \mathrm{SO}_{4}\right)$. The crude product was purified by column chromatography $\left(\mathrm{SiO}_{2}\right)$ eluting with $0 \%$ to $5 \%$ Methanol in $\mathrm{CH}_{2} \mathrm{Cl}_{2}$ (product $\mathrm{Rf}=0.33$ Methanol: $\left.\mathrm{CH}_{2} \mathrm{Cl}_{2}=1: 12\right)$ to afford $3.50(0.99 \mathrm{~g}, 81 \%$ ) as yellow solid. ${ }^{1} \mathrm{H}$ NMR $\left(\mathrm{CDCl}_{3}, 500 \mathrm{MHz}\right) \delta 8.95(\mathrm{br}, 1 \mathrm{H}), 7.77(\mathrm{~m}, 4 \mathrm{H}), 7.71(\mathrm{~m}, 4 \mathrm{H}), 4.33(\mathrm{t}, \mathrm{J}=5.5$ $\mathrm{Hz}, 4 \mathrm{H}), 4.23(\mathrm{t}, \mathrm{J}=5.5 \mathrm{~Hz}, 2 \mathrm{H}), 3.16(\mathrm{t}, \mathrm{J}=5.5 \mathrm{~Hz}, 4 \mathrm{H}), 3.06(\mathrm{~J}=5.5 \mathrm{~Hz}, 2 \mathrm{H}), 2.62(\mathrm{t}$, $\mathrm{J}=3.0 \mathrm{~Hz}, 4 \mathrm{H}) ;{ }^{13} \mathrm{C} \mathrm{NMR}\left(\mathrm{CDCl}_{3}, 125 \mathrm{MHz}\right) 176.8,172.5,163.6,134.7,129.0,123.7$, 76.8, 62.8, 53.2, 52.6, 29.3; HRMS (ESI): calcd. for $\mathrm{C}_{26} \mathrm{H}_{26} \mathrm{~N}_{3} \mathrm{O}_{10}{ }^{+}\left[\mathrm{M}+\mathrm{H}^{+}\right]: 540.1613$, found $: 540.1615$. 


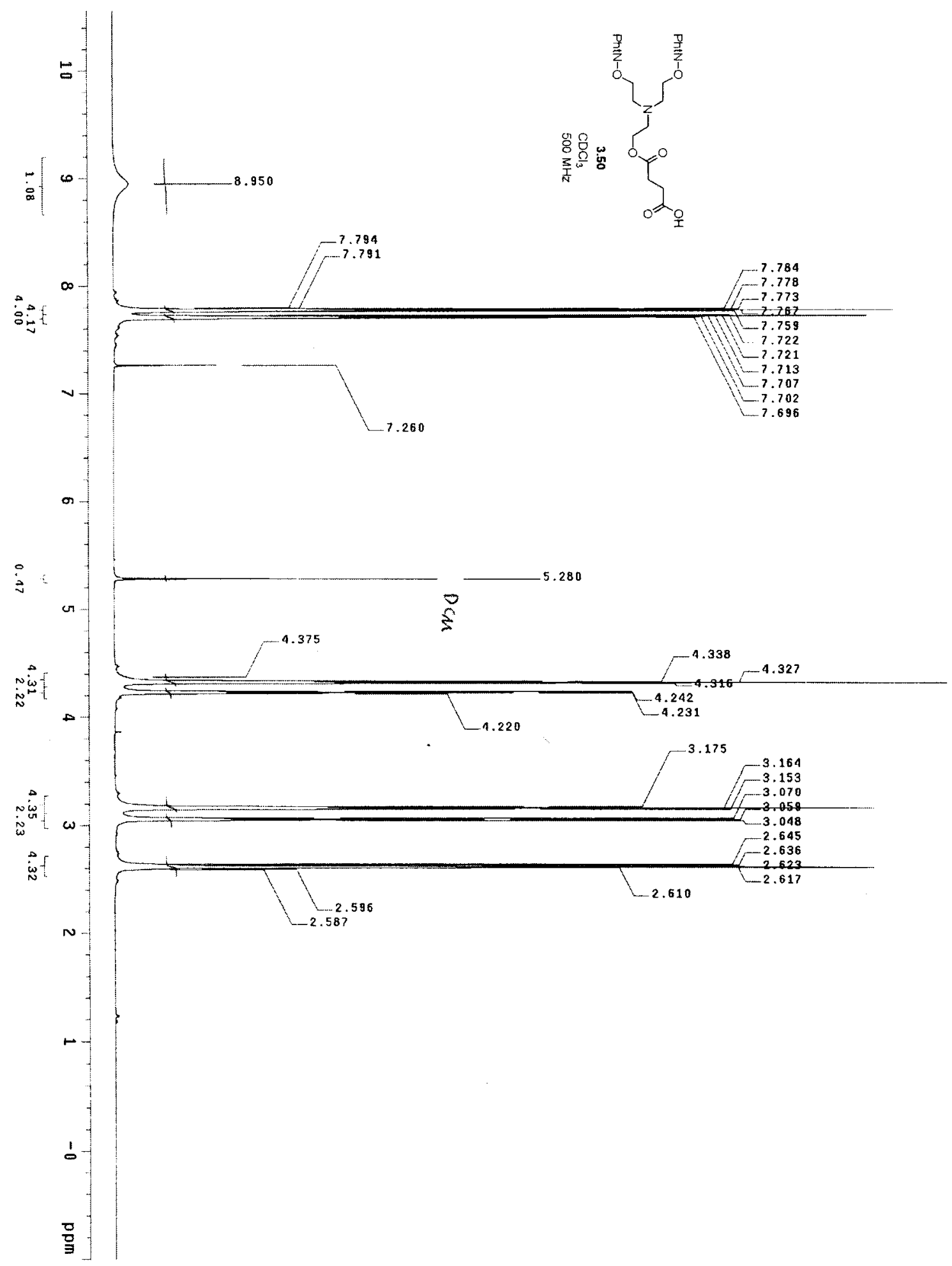

${ }^{1} \mathrm{H}$ NMR spectrum of compound 3.50 


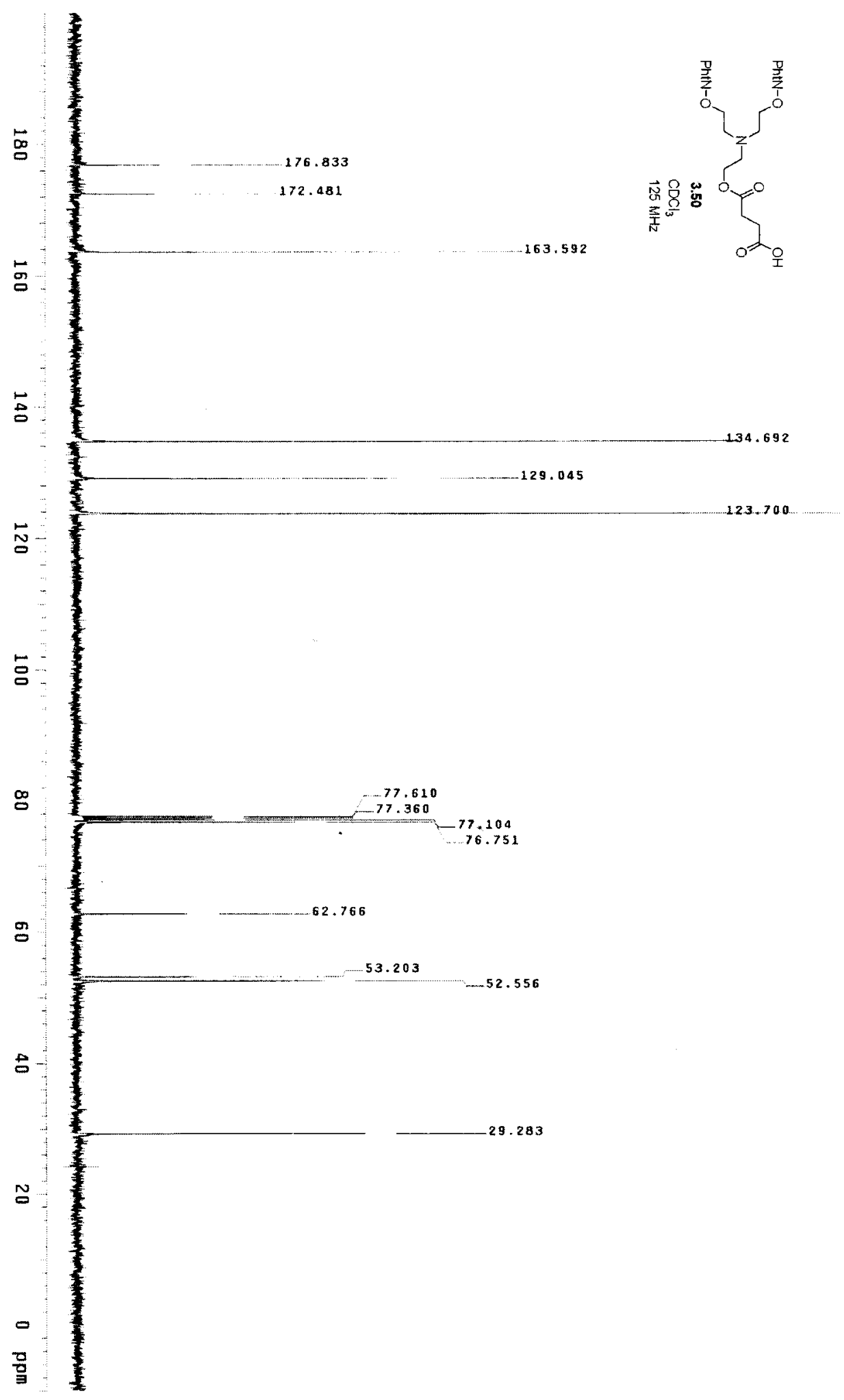

${ }^{13} \mathrm{C}$ NMR spectrum of compound $\mathbf{3 . 5 0}$ 


\subsubsection{2-(bis(2-((1,3-dioxoisoindolin-2-yl)oxy)ethyl)amino)ethyl}

\section{(5-(decyloxy)pent-4-en-1-yl) succinate}

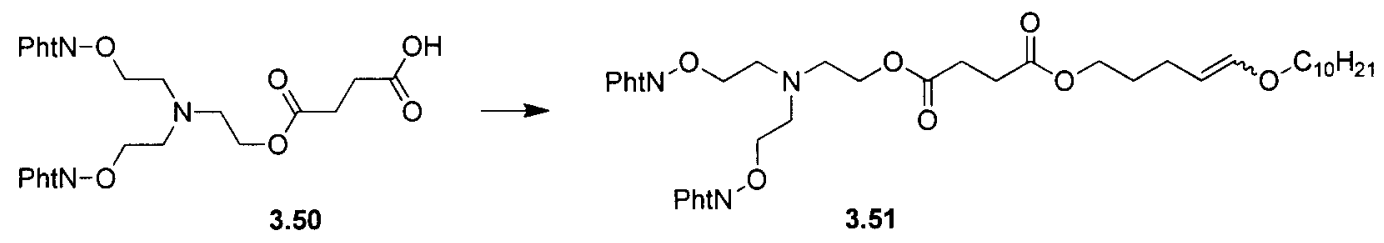

A solution of compound $3.50(0.81 \mathrm{~g}, 1.5 \mathrm{mmol})$, DMAP $(0.037 \mathrm{~g}, 0.030 \mathrm{mmol})$, DCC $(0.37 \mathrm{~g}, 1.8 \mathrm{mmol})$, in $\mathrm{CH}_{2} \mathrm{Cl}_{2}(20 \mathrm{~mL})$ was added 3.10 (E) $(0.36 \mathrm{~g}, 1.5 \mathrm{mmol})$. After reaction mixture was stirred for $12 \mathrm{~h}$ at room temperature, the percipataion was filetered off and the solvent was removed by rotary evaporation. The crude product was purified by column chromatography $\left(\mathrm{SiO}_{2}\right)$ eluting with $1: 1$ hexanes:ethyl acetate (product $\mathrm{Rf}=0.34)$ to afford $3.51(\mathrm{E})(1.0 \mathrm{~g}, 88 \%)$ as light yellow solid. ${ }^{1} \mathrm{H} \mathrm{NMR}\left(\mathrm{CDCl}_{3}\right.$, $500 \mathrm{MHz}) 7.77(\mathrm{~m}, 4 \mathrm{H}), 7.71(\mathrm{~m}, 4 \mathrm{H}), 6.20(\mathrm{~d}, \mathrm{~J}=12.5 \mathrm{~Hz}, 1 \mathrm{H}), 4.68(\mathrm{dt}, \mathrm{J}=12.5$, $7.0 \mathrm{~Hz}, 1 \mathrm{H}), 4.31(\mathrm{t}, \mathrm{J}=5.5 \mathrm{~Hz}, 4 \mathrm{H}), 4.21(\mathrm{t}, \mathrm{J}=5.5 \mathrm{~Hz}, 2 \mathrm{H}), 4.04(\mathrm{t}, \mathrm{J}=7.0 \mathrm{~Hz}, 2 \mathrm{H})$, $3.58(\mathrm{t}, \mathrm{J}=6.5 \mathrm{~Hz}, 2 \mathrm{H}), 3.14(\mathrm{t}, \mathrm{J}=5.5 \mathrm{~Hz}, 4 \mathrm{H}), 3.03(\mathrm{t}, \mathrm{J}=6.0 \mathrm{~Hz}, 2 \mathrm{H}), 2.60(\mathrm{~m}, 4 \mathrm{H})$, $1.93(\mathrm{dt}, \mathrm{J}=7.0,7.0 \mathrm{~Hz}, 2 \mathrm{H}), 1.55-1.64(\mathrm{~m} \mathrm{4H}), 1.21-1.31(\mathrm{~m}, 14 \mathrm{H}), 0.85(\mathrm{t}, \mathrm{J}=7.0 \mathrm{~Hz}$, $3 \mathrm{H}) ;{ }^{13} \mathrm{C} \mathrm{NMR}\left(\mathrm{CDCl}_{3}, 125 \mathrm{MHz}\right) 172.6,163.6,147.3,134.7,129.3,123.7,102.7,77.2$, $69.6,64.3,63.2,53.4,53.1,32.2,29.8$ (3 peaks), 29.7, 29.6, 29.4, 26.3, 24.4, 22.9, 14.5. $3.51(Z)$ can be synthesized from $3.10(Z)$ using the same method with $81 \%$ yield. ${ }^{1} \mathrm{H} \mathrm{NMR}\left(\mathrm{CDCl}_{3}, 500 \mathrm{MHz}\right) 7.73(\mathrm{~m}, 4 \mathrm{H}), 7.66(\mathrm{~m}, 4 \mathrm{H}), 5.87(\mathrm{~d}, \mathrm{~J}=5.5 \mathrm{~Hz}, 1 \mathrm{H})$, 4.17-4.28 (m, 7H), $3.99(t, J=7.0 \mathrm{~Hz}, 2 \mathrm{H}), 3.62(\mathrm{t}, \mathrm{J}=7.0 \mathrm{~Hz}, 2 \mathrm{H}), 3.10(\mathrm{t}, \mathrm{J}=5.0 \mathrm{~Hz}$, $4 \mathrm{H}), 2.98(\mathrm{t}, \mathrm{J}=6.0 \mathrm{~Hz}, 2 \mathrm{H}), 2.55(\mathrm{~m}, 4 \mathrm{H}), 2.03(\mathrm{~m}, \mathrm{~J}=6.5 \mathrm{~Hz}, 2 \mathrm{H}), 1.51-1.61(\mathrm{~m} 4 \mathrm{H})$, $1.18(\mathrm{~m}, 14 \mathrm{H}), 0.80(\mathrm{t}, \mathrm{J}=7.0 \mathrm{~Hz}, 3 \mathrm{H}) ;{ }^{13} \mathrm{C} \mathrm{NMR}\left(\mathrm{CDCl}_{3}, 125 \mathrm{MHz}\right) 172.3,163.4,145.3$, $134.5,129.0,123.5,104.9,77.0,72.3,64.5,63.0,53.2,52.8,31.9,29.8,29.6,29.4$, $29.3,29.2,28.7,28.6,25.8,22.7,20.4,14.2$. 


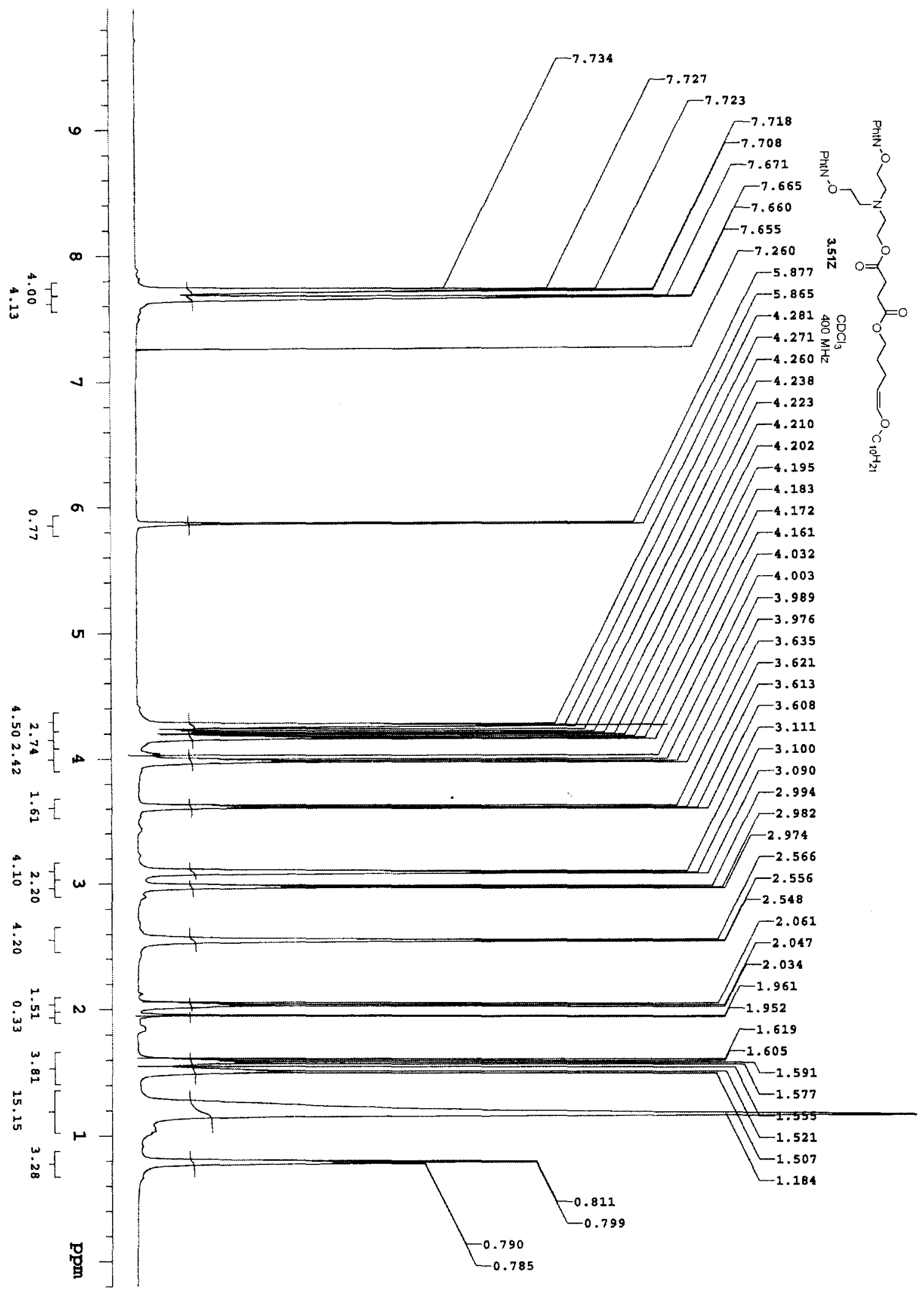

${ }^{1} \mathrm{H}$ NMR spectrum of compound $3.51(\mathrm{Z})$ 


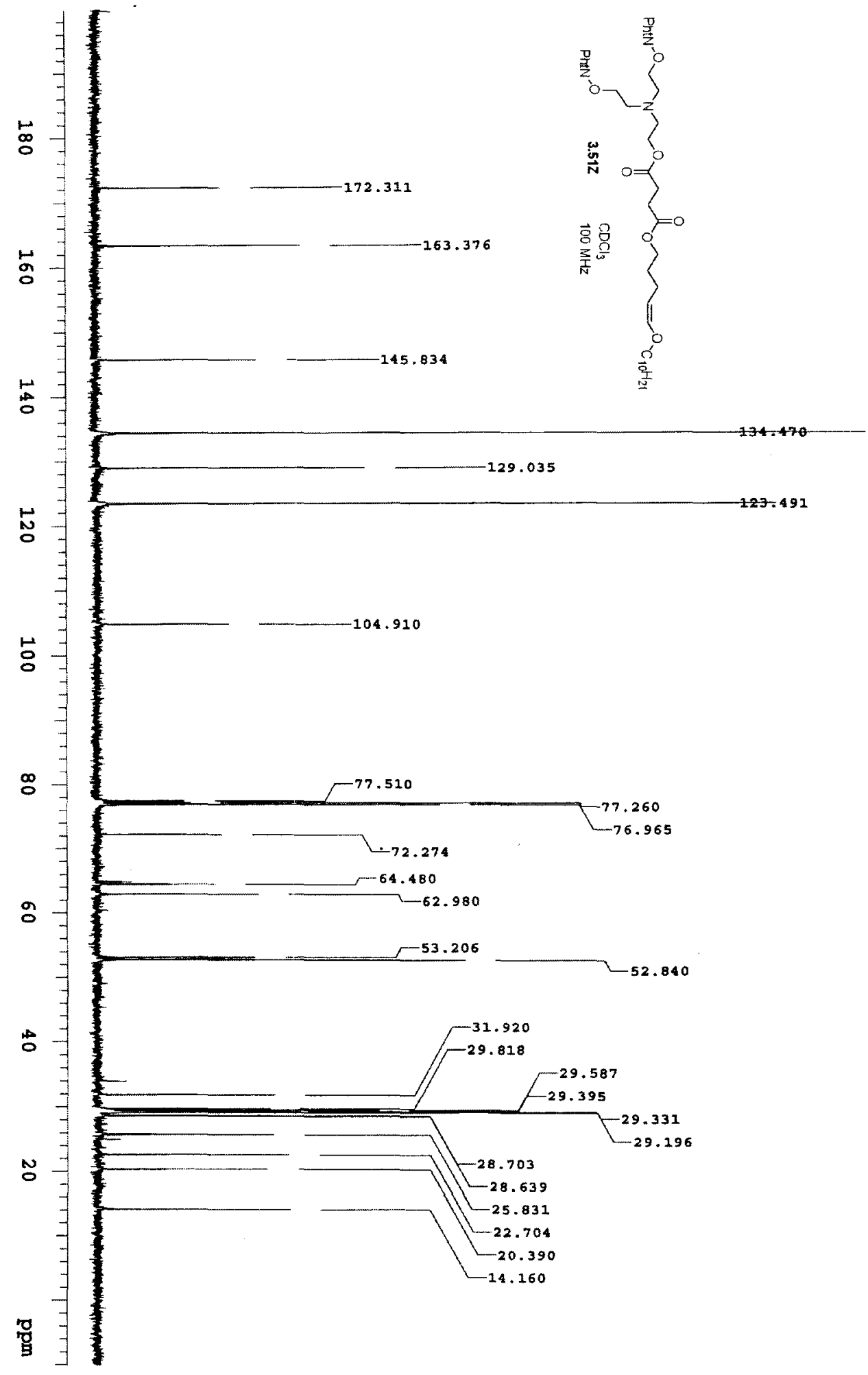

${ }^{13} \mathrm{C}$ NMR spectrum of compound $3.51(\mathrm{Z})$ 


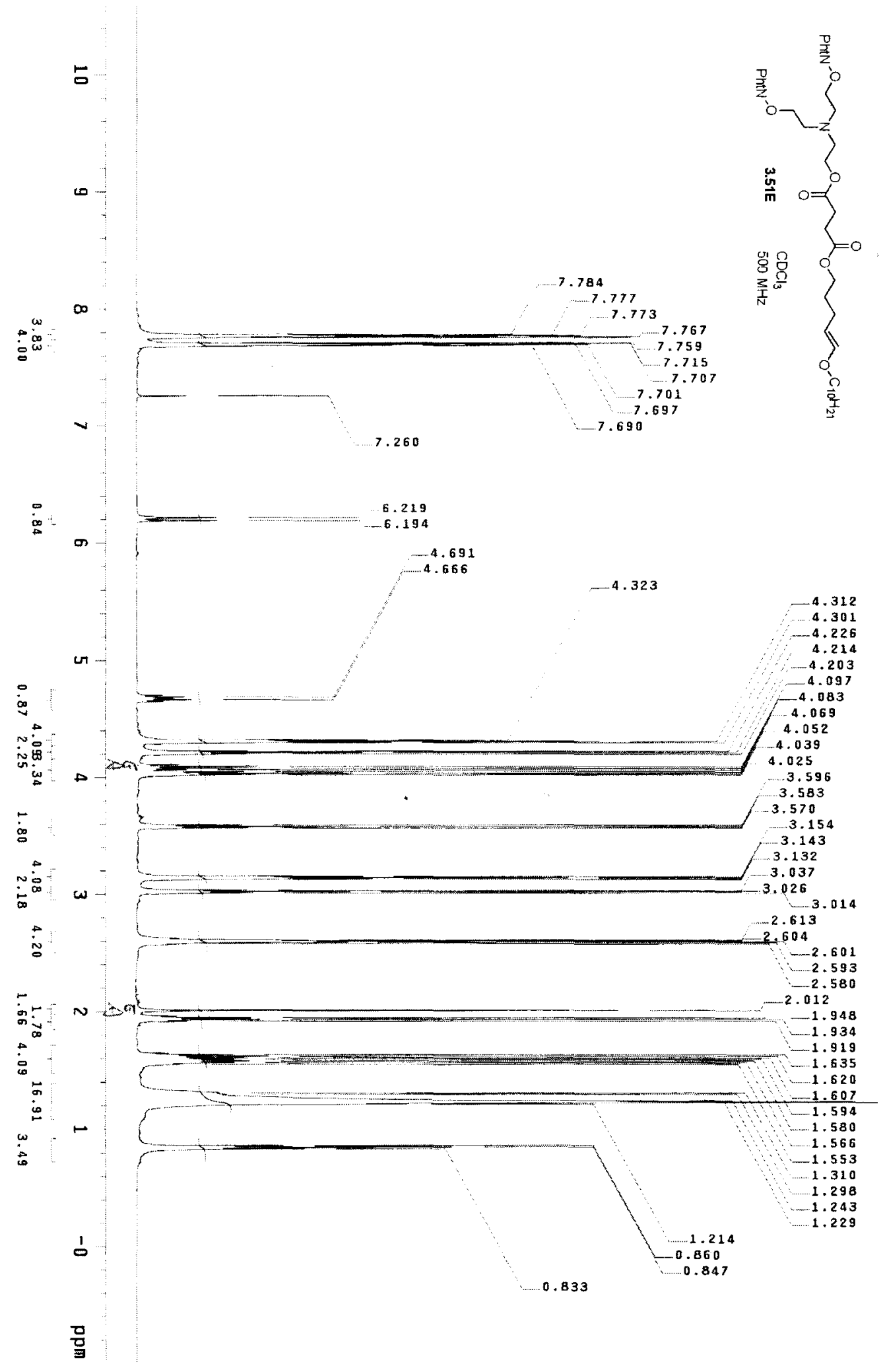

${ }^{1} \mathrm{H}$ NMR spectrum of compound 3.51 (E) 


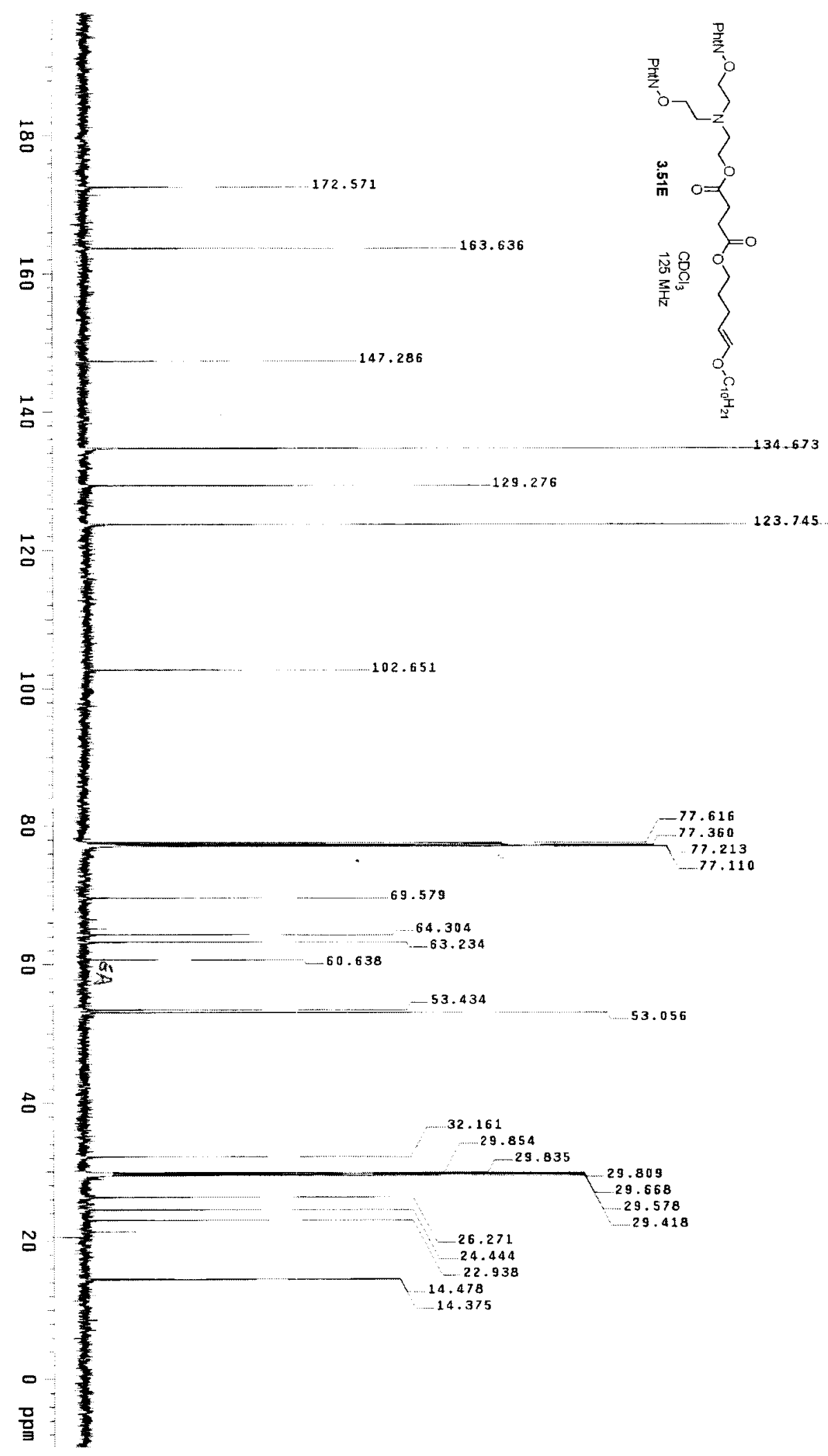

${ }^{13} \mathrm{C}$ NMR spectrum of compound 3.51 (E) 


\subsubsection{2-((4-((5-(decyloxy)pent-4-en-1-yl)oxy)-4-oxobutanoyl)oxy)-}

\section{$\mathrm{N}, \mathrm{N}$-bis(2-((1,3-dioxoisoindolin-2-yl)oxy)ethyl)-N-methylethanaminium iodide}

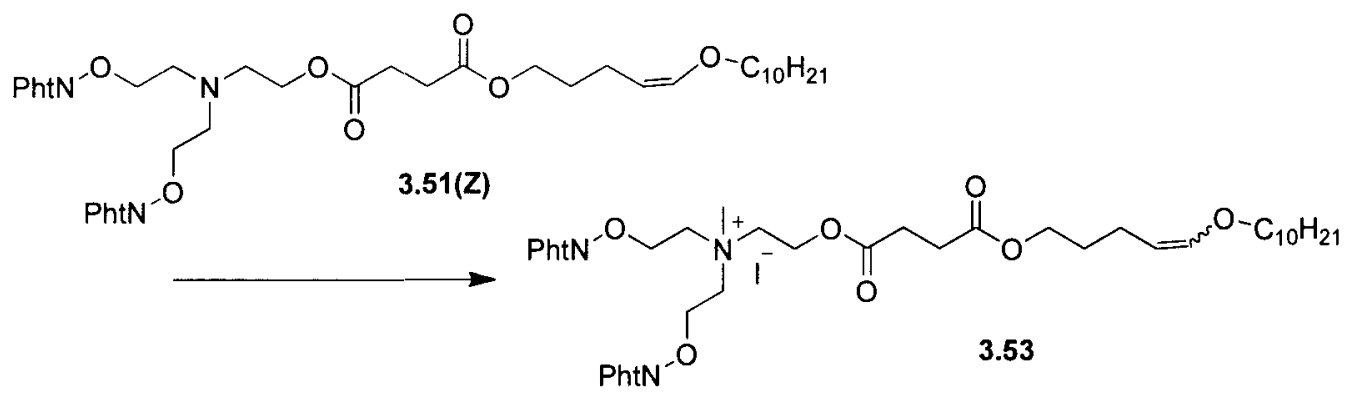

A solution of compound $3.51(0.76 \mathrm{~g}, 1.0 \mathrm{mmol})$, sodium carbonate $(0.021 \mathrm{~g}, 0.2$ mmol) in $\mathrm{CH}_{2} \mathrm{Cl}_{2}(5 \mathrm{~mL})$ was added $\mathrm{CH}_{3} \mathrm{l}(2.28 \mathrm{~g}, 16.1 \mathrm{mmol})$. After stirred in $55^{\circ} \mathrm{C}$ for $12 \mathrm{~h}$, the solvent was removed by rotary evaporation. The crude product was purified by column chromatography $\left(\mathrm{SiO}_{2}\right)$ eluting with 1:24 methanol: $\mathrm{CH}_{2} \mathrm{Cl}_{2}$ (product $R f=0.25)$ to afford compound $3.53(0.67 \mathrm{~g}, 74 \%, \mathrm{Z}: \mathrm{E}=0.78: 0.22)$ as yellow solid. ${ }^{1} \mathrm{H}$ $\operatorname{NMR}\left(\mathrm{CDCl}_{3}, 500 \mathrm{MHz}\right) 7.83(\mathrm{~m}, 4 \mathrm{H}), 7.77(\mathrm{~m}, 4 \mathrm{H}), 6.21(\mathrm{~d}, \mathrm{~J}=13.0 \mathrm{~Hz}, 0.22 \mathrm{H}), 5.92$ $(\mathrm{d}, \mathrm{J}=6.0 \mathrm{~Hz}, 0.78 \mathrm{H}), 4.86(\mathrm{~m}, 4 \mathrm{H}), 4.78(\mathrm{~m}, 2 \mathrm{H}), 4.69(\mathrm{~m}, 0.22 \mathrm{H}), 4.57(\mathrm{~m}, 4 \mathrm{H}), 4.49$ $(\mathrm{m}, 2 \mathrm{H}), 4.26(\mathrm{~m}, 0.88 \mathrm{H}), 3.96(\mathrm{~m}, \mathrm{~J}=7.0 \mathrm{~Hz}, 2 \mathrm{H}), 3.88(\mathrm{~s}, 3 \mathrm{H}), 3.68(\mathrm{t}, \mathrm{J}=6.5 \mathrm{~Hz}$, 1.56H), $3.6(\mathrm{t}, 0.44 \mathrm{H}), 2.68(\mathrm{~m}, 4 \mathrm{H}), 2.08(\mathrm{dt}, \mathrm{J}=7.5,6.5 \mathrm{~Hz}, 1.56 \mathrm{H}), 1.93(\mathrm{dt}, \mathrm{J}=8.0$ $\mathrm{Hz}, 0.44 \mathrm{H}), 1.54-1.64(\mathrm{~m}, 4 \mathrm{H}), 1.20-1.28(\mathrm{~m}, 14 \mathrm{H}), 0.87(\mathrm{t}, \mathrm{J}=7.5 \mathrm{~Hz}, 3 \mathrm{H}) ;{ }^{13} \mathrm{C} N M R$ $\left(\mathrm{CDCl}_{3}, 125 \mathrm{MHz}\right) 172.7,172.1,163.4,146.0,135.3,128.8,124.2,105.1,72.5,72.4$, $64.9,63.9,62.3,58.2,51.3,32.1,30.0,29.8,29.6,29.5,29.4,29.2,28.9,28.8,26.1$, $26.0,22.9,20.6,19.8,14.3$. 


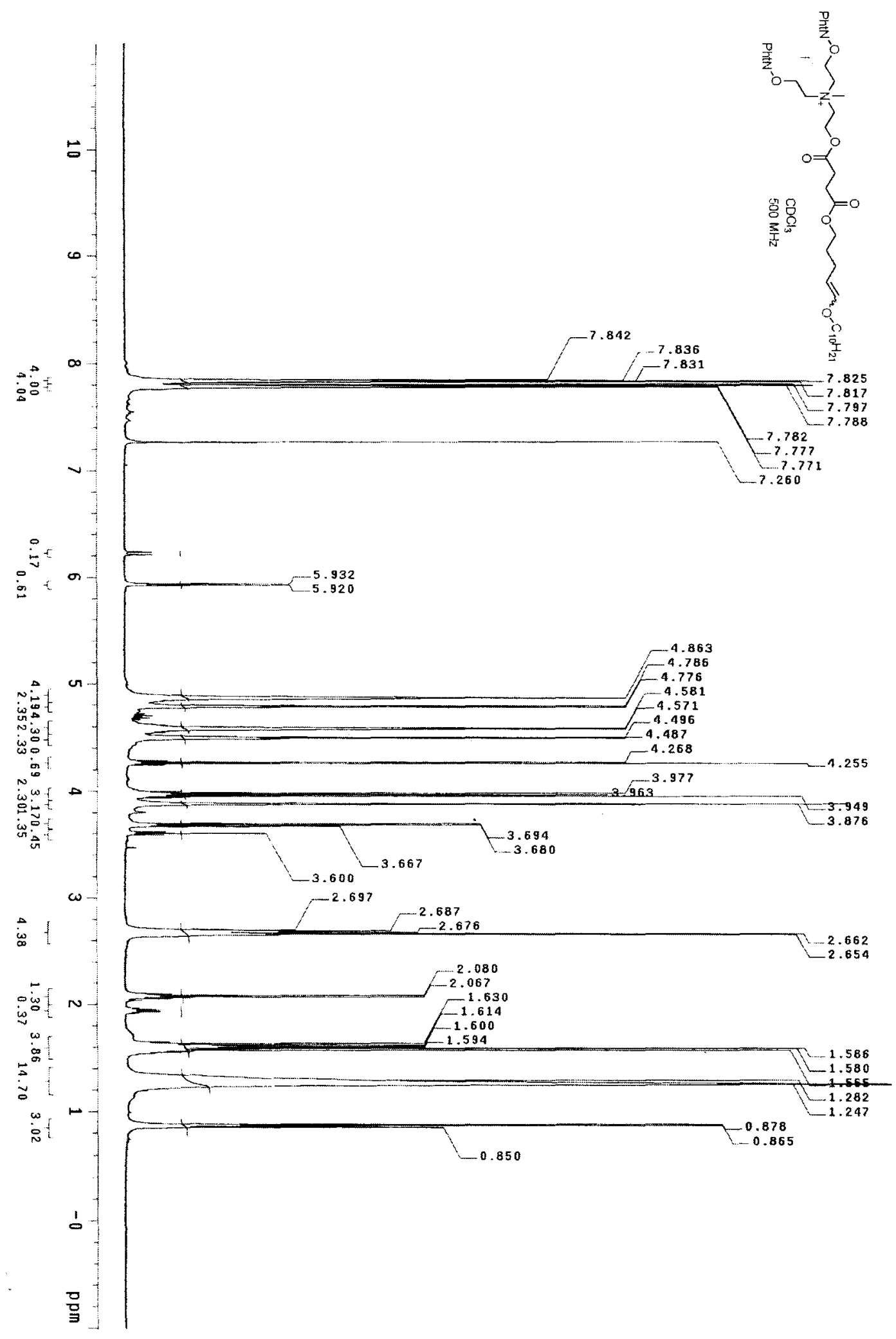

${ }^{1} \mathrm{H}$ NMR spectrum of compound 3.53 


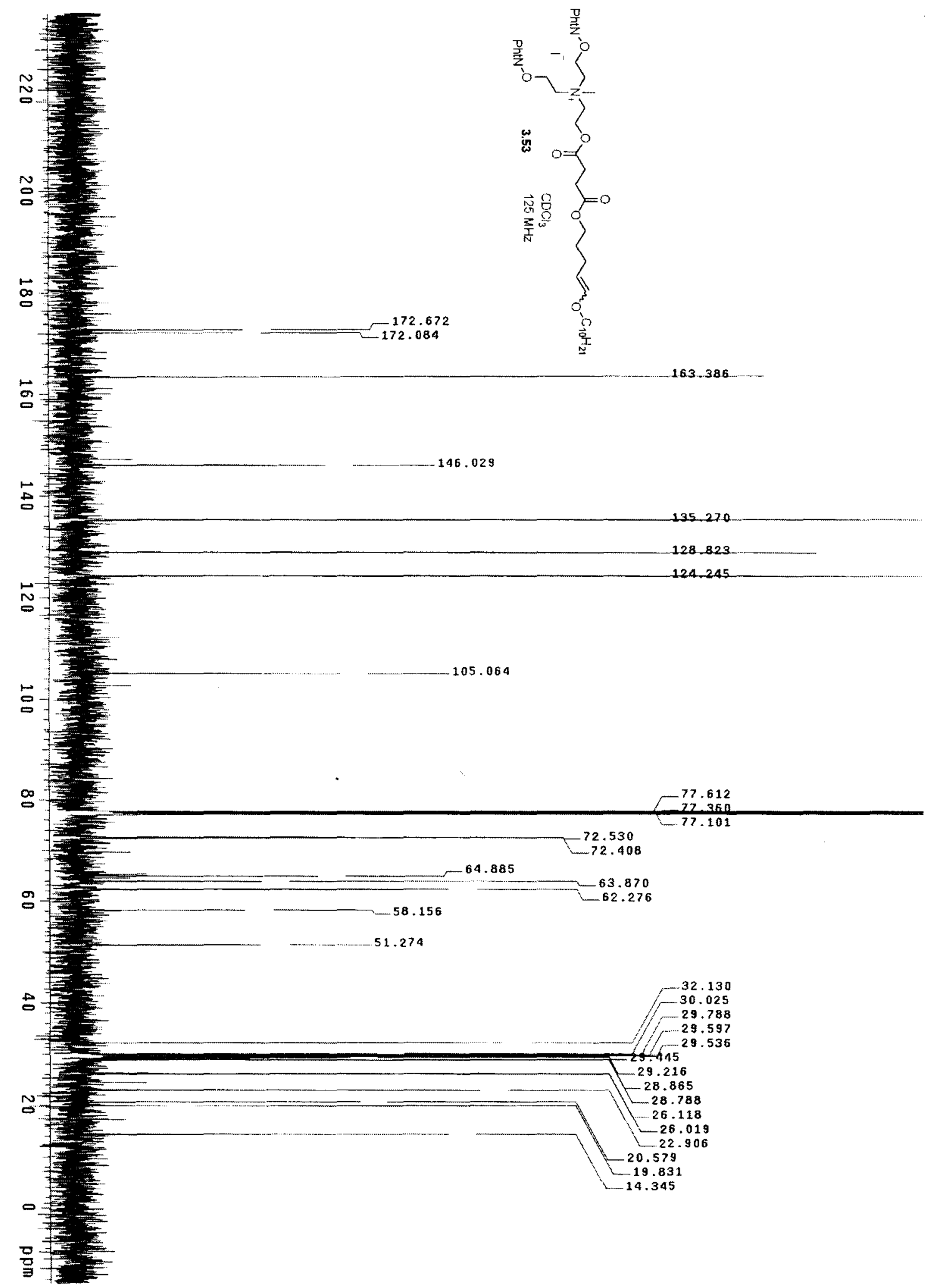

${ }^{13} \mathrm{C}$ NMR spectrum of compound 3.53 


\subsubsection{2-(aminooxy)-N-(2-(aminooxy)ethyl)-N-(2-((4-((5-(decyloxy)pent-}

\section{4-en-1-yl)oxy)-4-oxobutanoyl)oxy)ethyl)-N-methylethanaminium iodide}

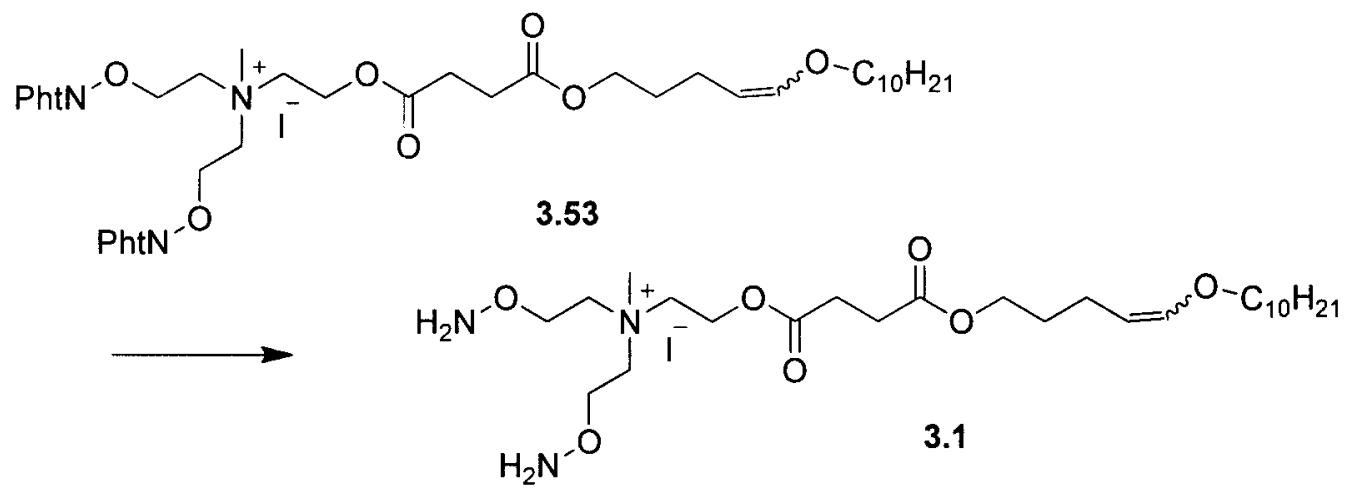

A solution of compound $3.53(1.27 \mathrm{~g}, 1.4 \mathrm{mmol})$ in $\mathrm{CH}_{2} \mathrm{Cl}_{2}(20 \mathrm{~mL})$ and ethanol $(20 \mathrm{~mL})$ was added methylhydrazine $(0.387 \mathrm{~g}, 8.4 \mathrm{mmol})$ at $-40^{\circ} \mathrm{C}$. The reaction mixture was stirred in for $1.5 \mathrm{~h}$ at $-40^{\circ} \mathrm{C}$. The solvent was removed by rotary evaporation and the crude product was purified by column chromatography $\left(\mathrm{SiO}_{2}\right)$ eluting with 8:92 methanol: $\mathrm{CH}_{2} \mathrm{Cl}_{2}$ (product $\left.\mathrm{Rf}=0.10\right)$ to afford $3.1(0.64 \mathrm{~g}, 71 \%, \mathrm{Z}: \mathrm{E}=$ 0.92:0.08) as yellow solid. ${ }^{1} \mathrm{H}$ NMR $\left(\mathrm{CD}_{3} \mathrm{OD}, 500 \mathrm{MHz}\right) 6.24(\mathrm{~d}, \mathrm{~J}=13.0 \mathrm{~Hz}, 0.92 \mathrm{H})$, $5.98(\mathrm{~d}, \mathrm{~J}=6.5 \mathrm{~Hz}, 0.08 \mathrm{H}), 4.82(\mathrm{~s}, 4 \mathrm{H}), 4.69(\mathrm{~m}, 0.92 \mathrm{H}), 4.55(\mathrm{~m}, 2 \mathrm{H}), 4.28(\mathrm{~m}$, $0.08 \mathrm{H}), 4.06(\mathrm{~m}, 6 \mathrm{H}), 3.88(\mathrm{t}, \mathrm{J}=4.5 \mathrm{~Hz}, 2 \mathrm{H}), 3.79(\mathrm{~m}, 4 \mathrm{H}), 3.69(\mathrm{t}, 0.16 \mathrm{H}), 3.60(\mathrm{t}, \mathrm{J}=$ $6.5 \mathrm{~Hz}, 1.84 \mathrm{H}), 3.26(\mathrm{~m}, 4 \mathrm{H}), 2.66(\mathrm{~m}, 4 \mathrm{H}), 2.08(\mathrm{~m}, 0.16 \mathrm{H}), 1.96(\mathrm{dt}, \mathrm{J}=6.5 \mathrm{~Hz}$, $1.84 \mathrm{H}), 1.56-1.66(\mathrm{~m}, 4 \mathrm{H}), 1.27(\mathrm{~m}, 14 \mathrm{H}), 0.87(\mathrm{t}, \mathrm{J}=7.5 \mathrm{~Hz}, 3 \mathrm{H}) ;{ }^{13} \mathrm{C}$ NMR $\left(\mathrm{CD}_{3} \mathrm{OD}\right.$, $125 \mathrm{MHz}) 172.7,172.1,163.4,146.0,135.3,128.8,124.2,105.1,72.5,72.4,64.9$, $63.9,62.3,58.2,51.3,32.1,30.0,29.8,29.6,29.5,29.4,29.2,28.9,28.8,26.1,26.0$, 22.9, 20.6, 19.8, 14.3. HRMS (ESI): calcd. for $\mathrm{C}_{26} \mathrm{H}_{52} \mathrm{~N}_{3} \mathrm{O}_{7}^{+}\left[\mathrm{M}+\mathrm{Na}^{+}\right]$: 518.3800, found :518.3803. 


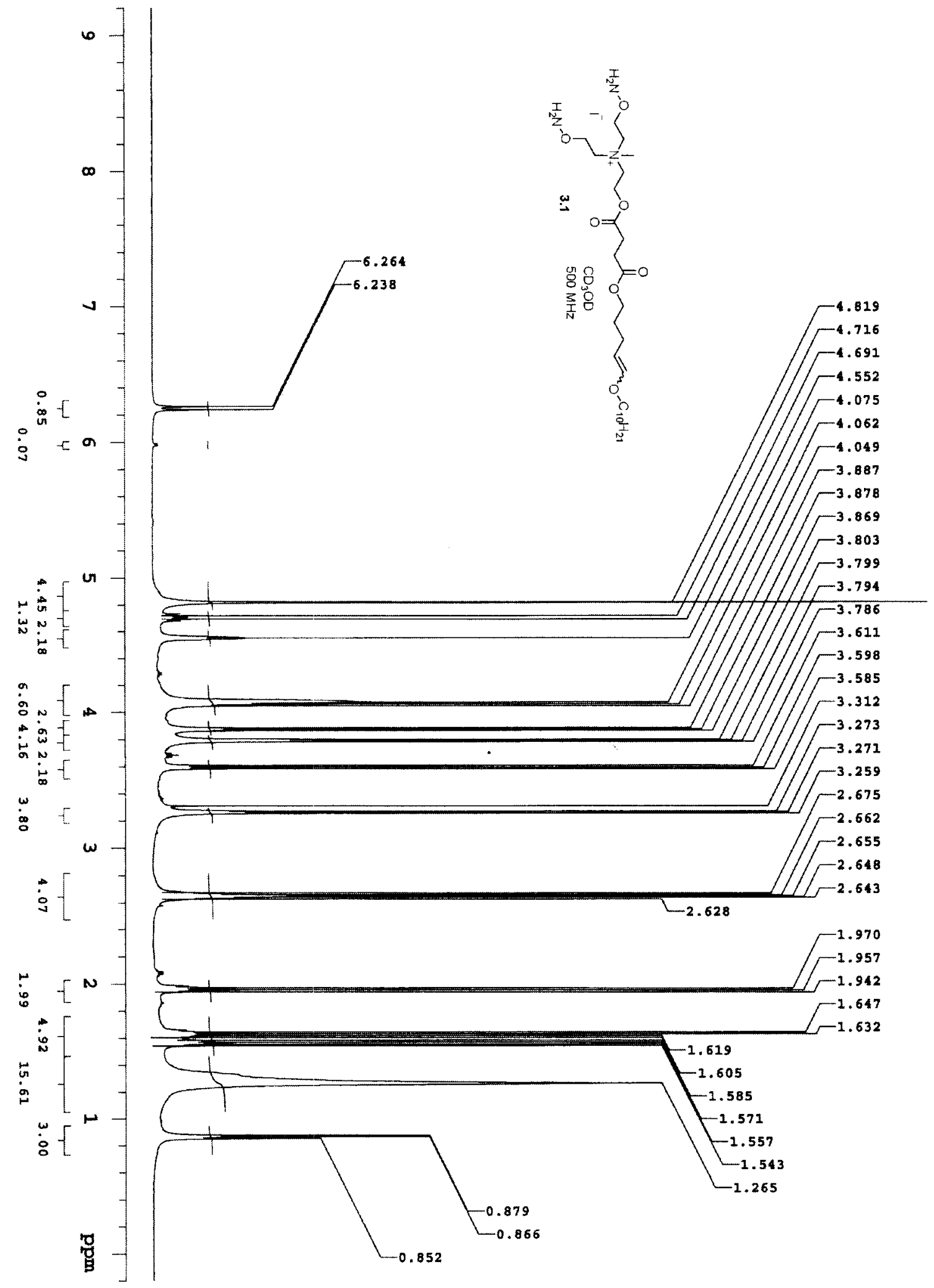

${ }^{1} \mathrm{H}$ NMR spectrum of compound 3.1 


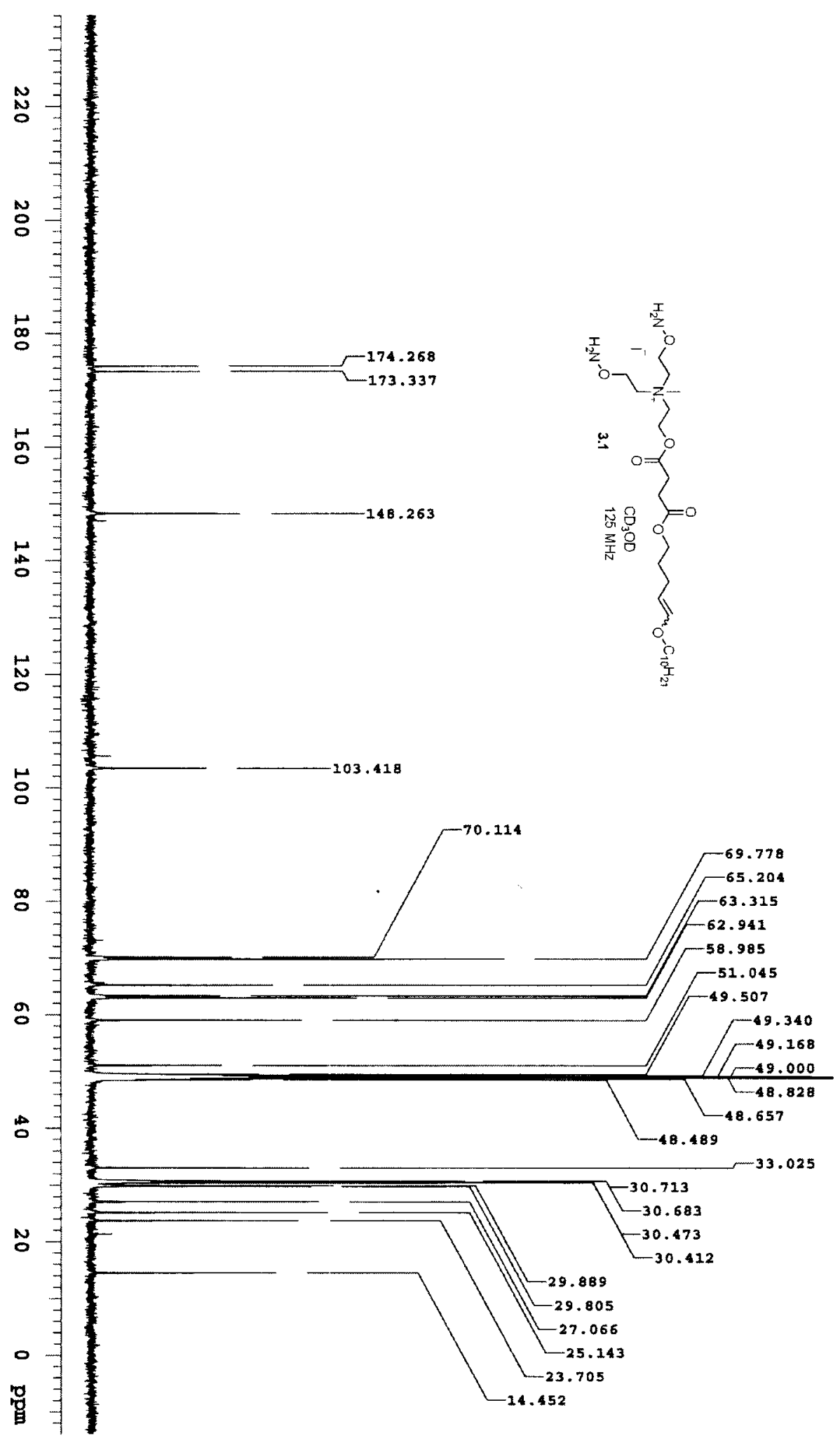

${ }^{13} \mathrm{C}$ NMR spectrum of compound 3.1 


\subsubsection{2-(bis(2-((1,3-dioxoisoindolin-2-yl)oxy)ethyl)amino)ethyl}

\section{(1-((5-(decyloxy)pent-4-en-1-yl)oxy)hexadecan-2-yl) succinate}

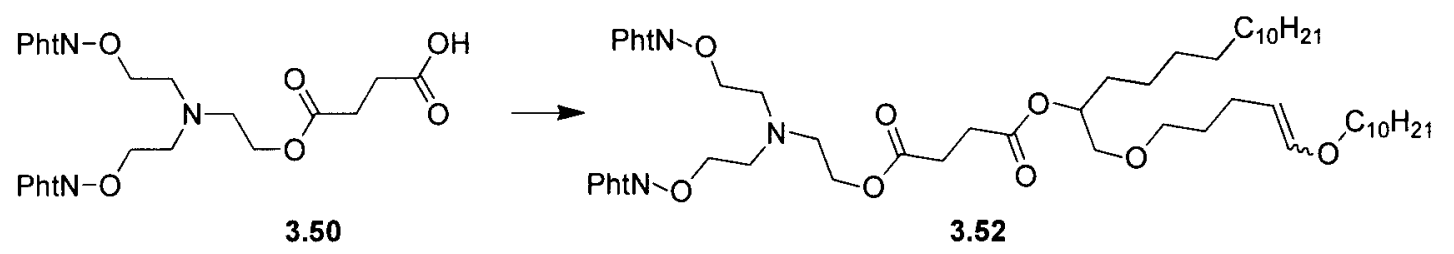

A solution of compound $3.50(0.189 \mathrm{~g}, 0.35 \mathrm{mmol})$, DMAP ( $7 \mathrm{mg}, 0.058 \mathrm{mmol})$, $N, N^{\prime}$-Dicyclohexylcarbodiimide $(0.072 \mathrm{~g}, 0.35 \mathrm{mmol})$ in $\mathrm{CH}_{2} \mathrm{Cl}_{2}(1.0 \mathrm{~mL})$ was added $3.11(E)(0.14 \mathrm{~g}, 0.29 \mathrm{mmol})$. After stirred for $12 \mathrm{~h}$ at $\mathrm{rt}$, the reaction mixture was filtered. The solution was concentrated by rotary evaporation. The crude product was purified by column chromatography $\left(\mathrm{SiO}_{2}\right)$ eluting with $1: 1$ hexanes:ethyl acetate (product $\mathrm{Rf}=0.40)$ to afford $\mathbf{3 . 5 2 ( E )}(0.19 \mathrm{~g}, 66 \%)$ as light yellow solid. $3.52(\mathrm{Z})$ can be synthesized from $3.11(\mathrm{Z})$ using the same method in $68 \%$ yield. ${ }^{1} \mathrm{H}$ NMR $\left(\mathrm{CDCl}_{3}, 500\right.$ $M H z) 3.52(E) 7.74(m, 4 H), 7.67(m, 4 H), 6.16(d, J=12.5 \mathrm{~Hz}, 1 H), 4.92(m, J=5.5 \mathrm{~Hz}$, 1H), $4.66(d t, J=12.5,7.5 \mathrm{~Hz}, 1 \mathrm{H}), 4.28(\mathrm{t}, \mathrm{J}=5.5 \mathrm{~Hz}, 4 \mathrm{H}), 4.18(\mathrm{t}, \mathrm{J}=5.5 \mathrm{~Hz}, 2 \mathrm{H})$, $3.55(\mathrm{t}, \mathrm{J}=6.5 \mathrm{~Hz}, 2 \mathrm{H}), 3.30-3.42(\mathrm{~m}, 4 \mathrm{H}), 3.11(\mathrm{t}, \mathrm{J}=5.5 \mathrm{~Hz}, 4 \mathrm{H}), 3.00(\mathrm{t}, \mathrm{J}=5.5 \mathrm{~Hz}$, 2H), $2.58(\mathrm{~s}, 4 \mathrm{H}), 1.89(\mathrm{dt}, \mathrm{J}=7.5,7.5 \mathrm{~Hz}, 2 \mathrm{H}), 1.55(\mathrm{~m}, 6 \mathrm{H}), 1.28(\mathrm{~m}, 38 \mathrm{H}), 0.81(\mathrm{t}, \mathrm{J}$ $=6.5 \mathrm{~Hz}, 6 \mathrm{H}) ; 3.52(\mathrm{Z}) 7.76(\mathrm{~m}, 4 \mathrm{H}), 7.70(\mathrm{~m}, 4 \mathrm{H}), 5.88(\mathrm{~d}, \mathrm{~J}=6.5 \mathrm{~Hz}, 1 \mathrm{H}), 4.95(\mathrm{~m}, \mathrm{~J}$ $=5.0 \mathrm{~Hz}, 1 \mathrm{H}), 4.30(\mathrm{~m}, 5 \mathrm{H}), 4.20(\mathrm{t}, \mathrm{J}=5.5 \mathrm{~Hz}, 4 \mathrm{H}), 3.65(\mathrm{t}, \mathrm{J}=6.5 \mathrm{~Hz}, 2 \mathrm{H}), 3.35-3.44$ $(\mathrm{m}, 4 \mathrm{H}), 3.14(\mathrm{t}, \mathrm{J}=5.5 \mathrm{~Hz}, 4 \mathrm{H}), 3.02(\mathrm{t}, \mathrm{J}=5.5 \mathrm{~Hz}, 2 \mathrm{H}$ ), 2.60 (s, 4H), 2.06 (dt, J=7.0, $7.0 \mathrm{~Hz}, 2 \mathrm{H}), 1.55(\mathrm{~m}, 6 \mathrm{H}), 1.28(\mathrm{~m}, 38 \mathrm{H}), 0.84(\mathrm{t}, \mathrm{J}=6.5 \mathrm{~Hz}, 6 \mathrm{H}) ;{ }^{13} \mathrm{C} \mathrm{NMR}\left(\mathrm{CDCl}_{3}, 125\right.$ MHz) 3.52(E) 172.4, 172.1, 163.5, 146.8, 134.6, 129.1, 123.6, 103.2, 77.0, 73.3, 71.9, $70.7,69.3,53.3,52.9,32.1$ (2 peaks), 31.1, 30.7, 29.9 (2peaks), 29.8, 29.7, 29.6, 29.5 (2 peaks), 29.3, 26.2, 25.4, 24.5, 22.9, 14.3. 64.5, 63.0, 53.2, 52.8, 31.9, 29.8, 29.6, $29.4,29.3,29.2,28.7,28.6,25.8,22.7,20.4,14.2 ; 3.52(Z) 172.5,172.2,163.6,145.5$, 
134.6, 129.2, 123.7, 106.0, 77.1, 73.5, 72.4, 71.9, 71.3, 63.1, 53.4, 53.0, 32.1 (2 peaks), 31.1, 30.0, 29.9 (2 peaks), 29.8 (2 peaks), 29.7, 29.6 (2 peaks), 29.5, 29.4, $26.0,25.5,22.9,20.7,14.4$. 


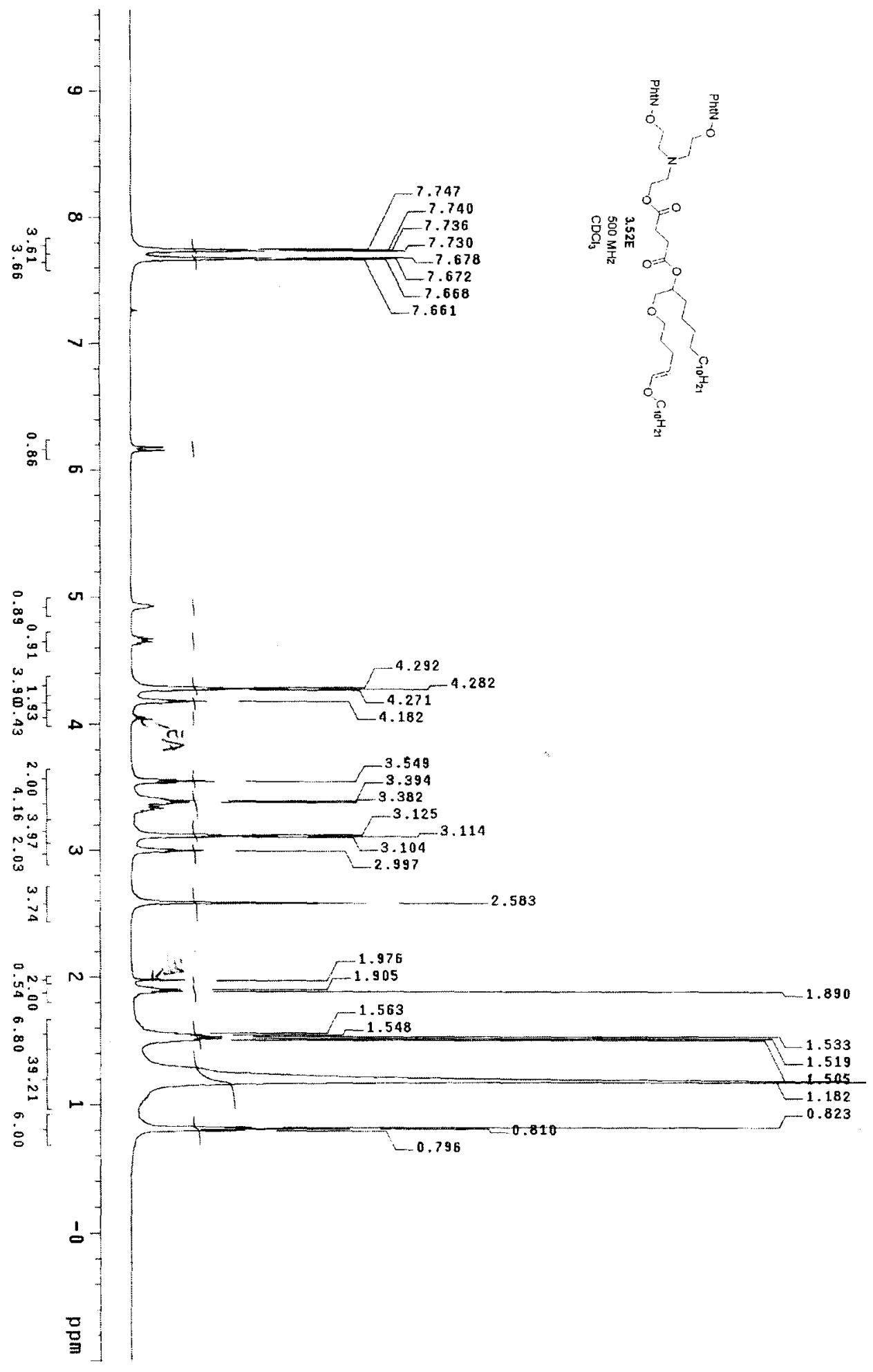

${ }^{1} \mathrm{H}$ NMR spectrum of compound 3.52 (E) 


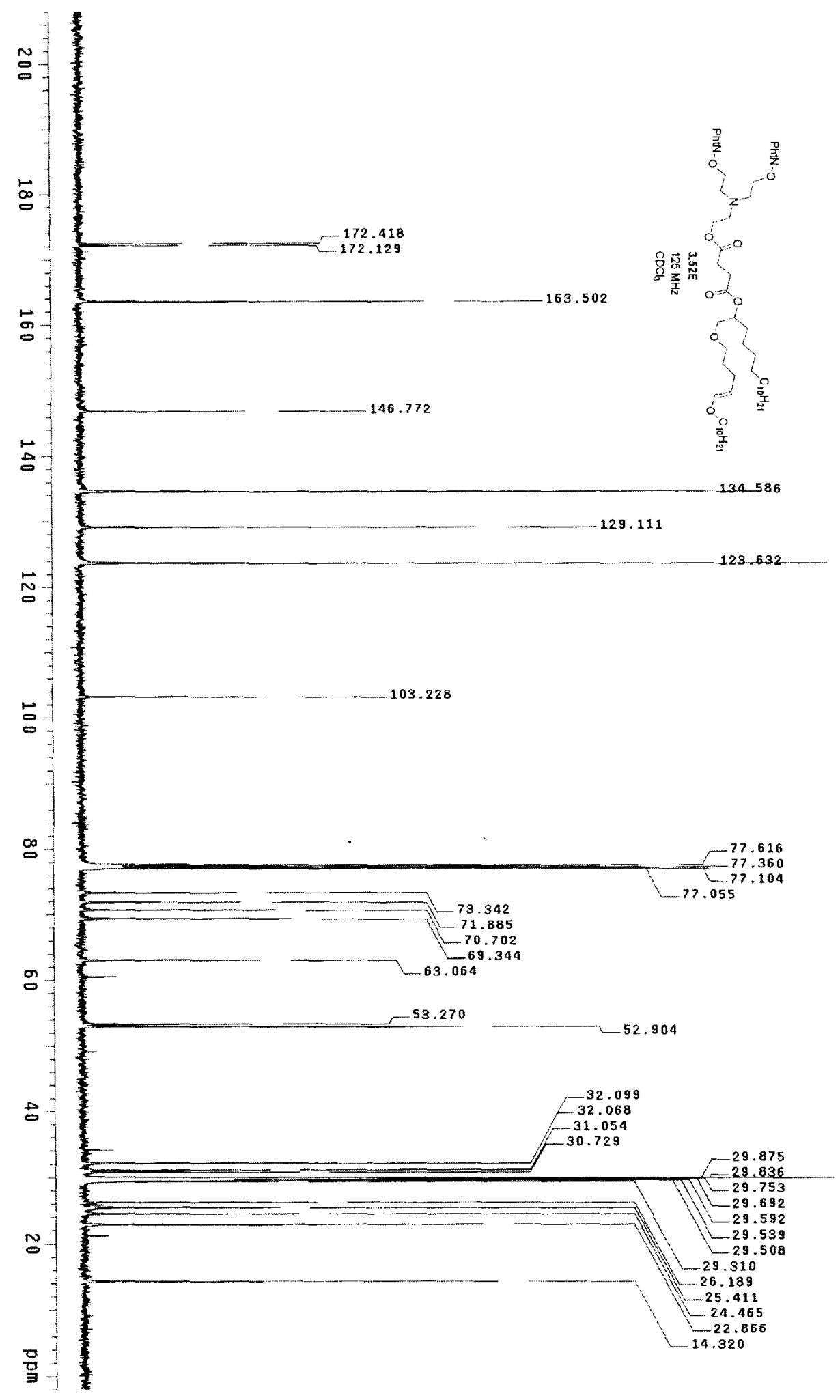

${ }^{13} \mathrm{C}$ NMR spectrum of compound 3.52 (E) 


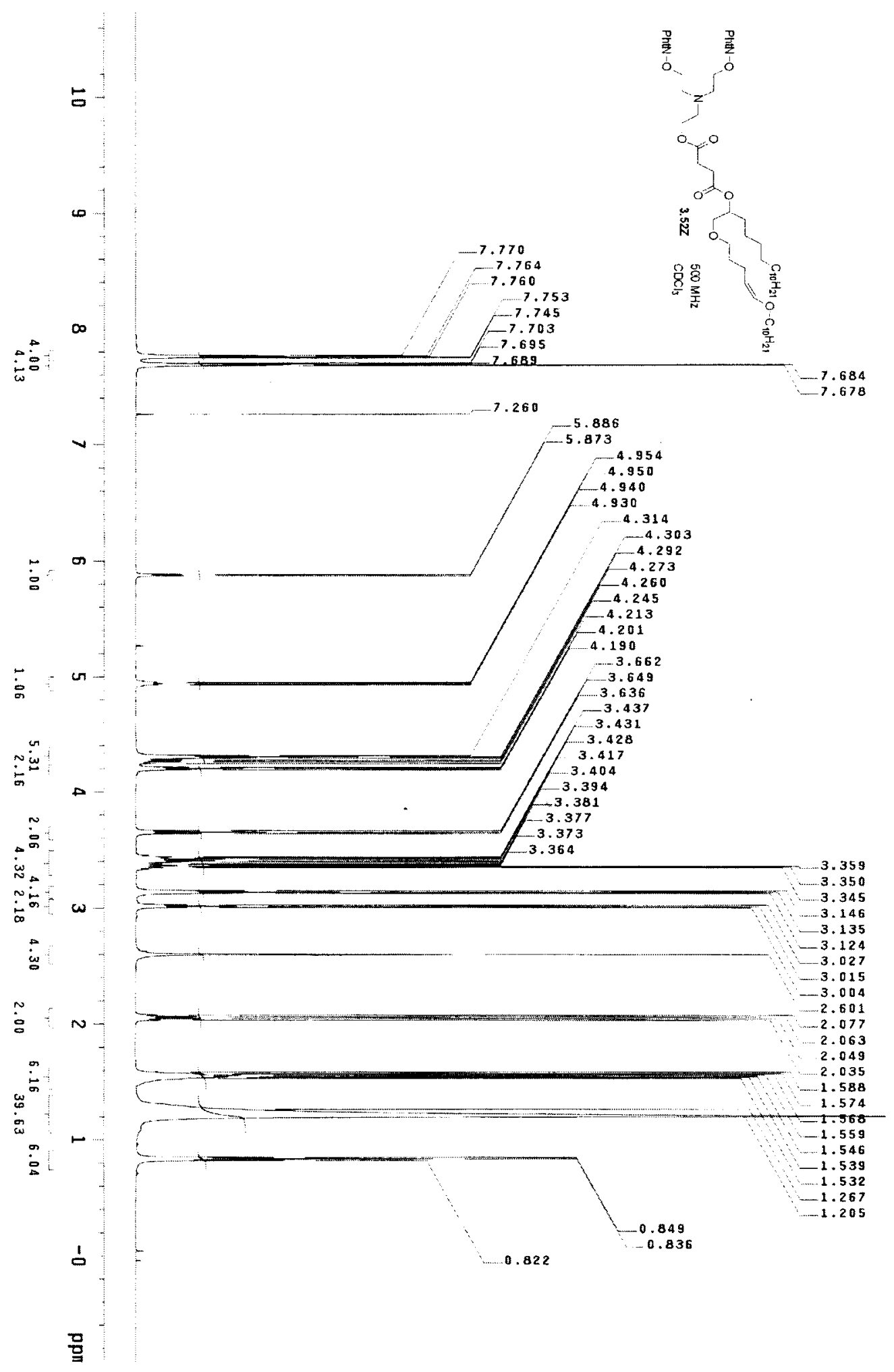

${ }^{1} \mathrm{H}$ NMR spectrum of compound 3.52 (Z) 


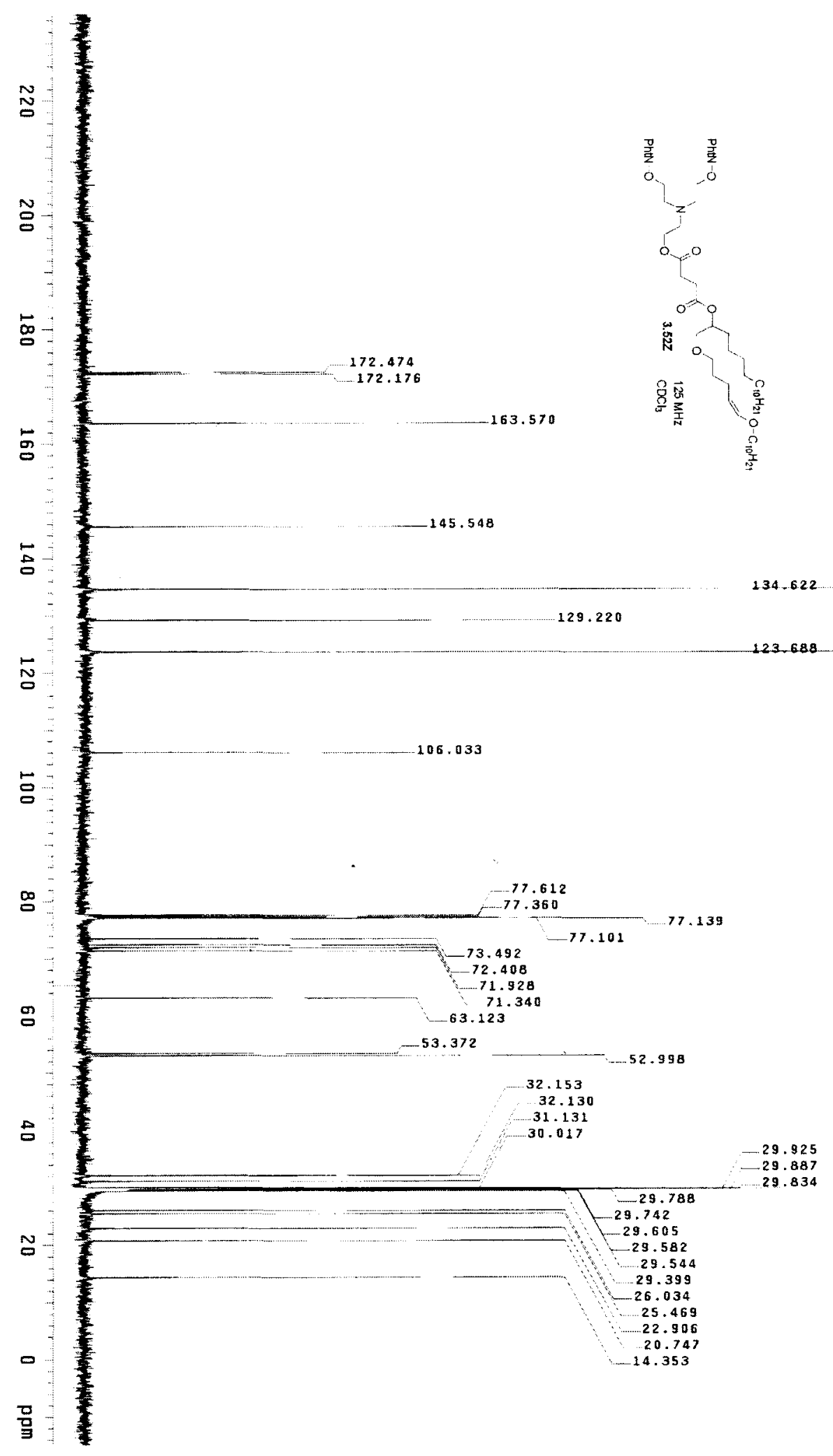

${ }^{13} \mathrm{C}$ NMR spectrum of compound $3.52(\mathrm{Z})$ 


\subsubsection{N,N-bis(2-((1,3-dioxoisoindolin-2-yl)oxy)ethyl)- $N$-methyl-4,7-dioxo}

\section{-9-tetradecyl-3,8,11,17-tetraoxaheptacos-15-en-1-aminium iodide}

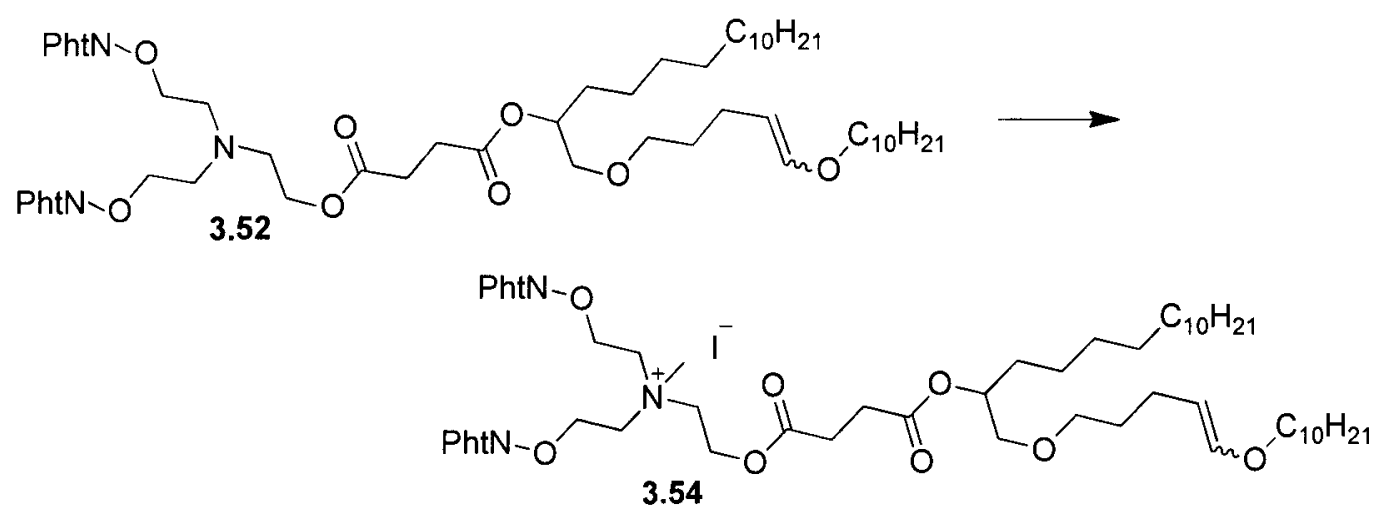

A solution of compound $3.52(1.00 \mathrm{~g}, 1.0 \mathrm{mmol})$, sodium carbonate $(0.21 \mathrm{~g}, 2.0$ mmol) in $\mathrm{CH}_{2} \mathrm{Cl}_{2}(10 \mathrm{~mL})$ was added methyl iodide $(2.0 \mathrm{~g}, 14.0 \mathrm{mmol})$. The reaction mixture was stirred in $50^{\circ} \mathrm{C}$ for $21 \mathrm{~h}$. The solvent was removed by rotary evaporation and the crude product was purified by column chromatography $\left(\mathrm{SiO}_{2}\right)$ eluting with $0 \%$ to $10 \%$ gradient methanol in $\mathrm{CH}_{2} \mathrm{Cl}_{2}$ (product $\mathrm{Rf}=0.33$ in $1: 9 \mathrm{MeOH}: \mathrm{CH}_{2} \mathrm{Cl}_{2}$ ) to afford $3.54(0.84 \mathrm{~g}, 73 \%)$ as yellow solid. m.p. $119-121^{\circ} \mathrm{C}$; HRMS (ESI): calcd. for $\mathrm{C}_{58} \mathrm{H}_{88} \mathrm{~N}_{3} \mathrm{O}_{12}{ }^{+}\left[\mathrm{M}^{+}\right]:$: 1018.6363, found:1018.6383. 


\subsubsection{N,N-bis(2-(aminooxy)ethyl)- $N$-methyl-4,7-dioxo-9-tetradecyl}

-3,8,11,17-tetraoxaheptacos-15-en-1-aminium

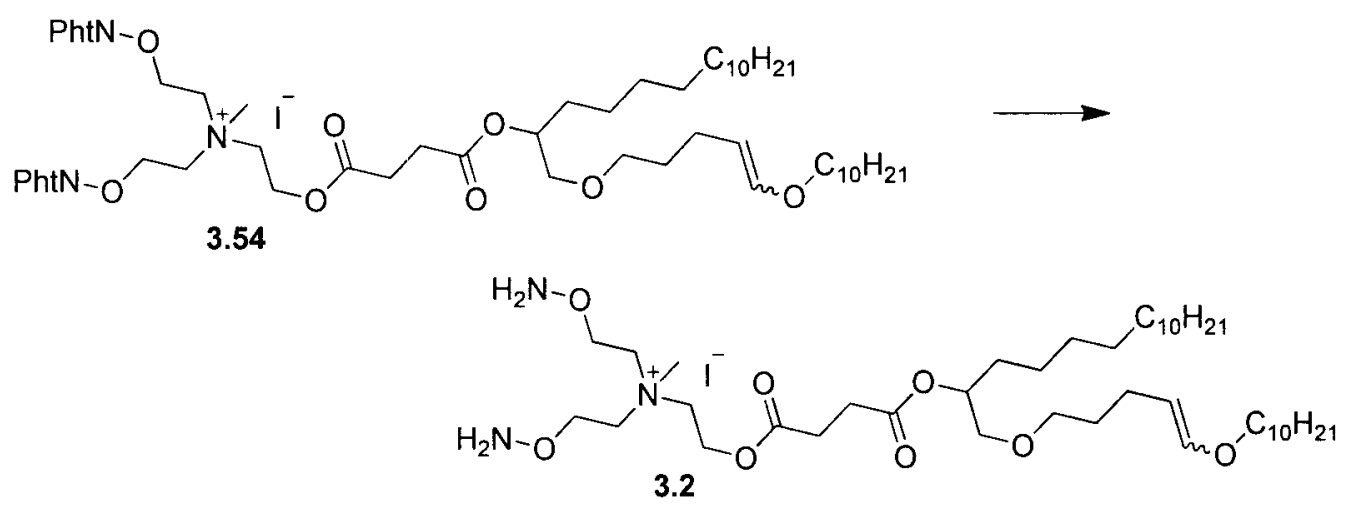

A solution of $3.54(\mathrm{Z})(0.82 \mathrm{~g}, 0.71 \mathrm{mmol})$ in $\mathrm{CH}_{2} \mathrm{Cl}_{2}$ :ehtanol $(20 \mathrm{~mL}, 1: 1 \mathrm{v} / \mathrm{v})$ was added methylhydrazine $(0.198 \mathrm{~g}, 4.3 \mathrm{mmol})$ at $-40^{\circ} \mathrm{C}$. After stirred in $-40^{\circ} \mathrm{C}$ for $1.5 \mathrm{~h}$, the solvent was removed by rotary evaporation. The crude product was purified by column chromatography $\left(\mathrm{SiO}_{2}\right)$ eluting with $0 \%$ to $10 \%$ gradient methanol in $\mathrm{CH}_{2} \mathrm{Cl}_{2}$ (product $\left.\mathrm{Rf}=0.181: 9 \mathrm{MeOH}: \mathrm{CH}_{2} \mathrm{Cl}_{2}\right)$ to get product $3.2(\mathrm{Z})(0.38 \mathrm{~g}, 60 \%)$ as white grease. ${ }^{1} \mathrm{H}$ NMR (d6-DMSO, $\left.500 \mathrm{MHz}\right) 6.35(\mathrm{br}, 4 \mathrm{H}), 6.01(\mathrm{~d}, \mathrm{~J}=6.5 \mathrm{~Hz}, 1 \mathrm{H}), 4.89(\mathrm{~m}$, $J=6.0 \mathrm{~Hz}, 1 \mathrm{H}), 4.47(\mathrm{~s}, 2 \mathrm{H}), 4.27(\mathrm{dt}, \mathrm{J}=6.5 \mathrm{~Hz}, 1 \mathrm{H}), 3.97(\mathrm{~s}, 4 \mathrm{H}), 3.77(\mathrm{~d}, 2 \mathrm{H}), 3.70$ $(\mathrm{s}, 6 \mathrm{H}), 3.41(\mathrm{t}, 2 \mathrm{H}), 3.15(\mathrm{~s}, 3 \mathrm{H}), 2.60(\mathrm{~m}, 4 \mathrm{H}), 2.00(\mathrm{~m}, \mathrm{~J}=7.0 \mathrm{~Hz}, 2 \mathrm{H}), 1.49(\mathrm{~m}, 6 \mathrm{H})$, $1.24(\mathrm{~m}, 38 \mathrm{H}), 0.87(\mathrm{t}, \mathrm{J}=6.0 \mathrm{~Hz}, 6 \mathrm{H}) ;{ }^{13} \mathrm{C}$ NMR (d6-DMSO, $\left.125 \mathrm{MHz}\right) 171.5,171.4$, $145.5,104.8,72.5,71.2,70.9,70.1,68.0,60.8,60.4,57.6,49.3,40.0,31.3,30.3$, 29.2, 29.0 (2 peaks), 28.8, 28.7 (2 peaks), 28.5, 25.2, 24.5, 22.1, 20.2, 18.8, 13.9; HRMS (ESI): calcd. for $\mathrm{C}_{42} \mathrm{H}_{84} \mathrm{~N}_{3} \mathrm{O}_{8}{ }^{+}\left[\mathrm{M}^{+}\right]$: 758.6253 , found: 758.6261 . 


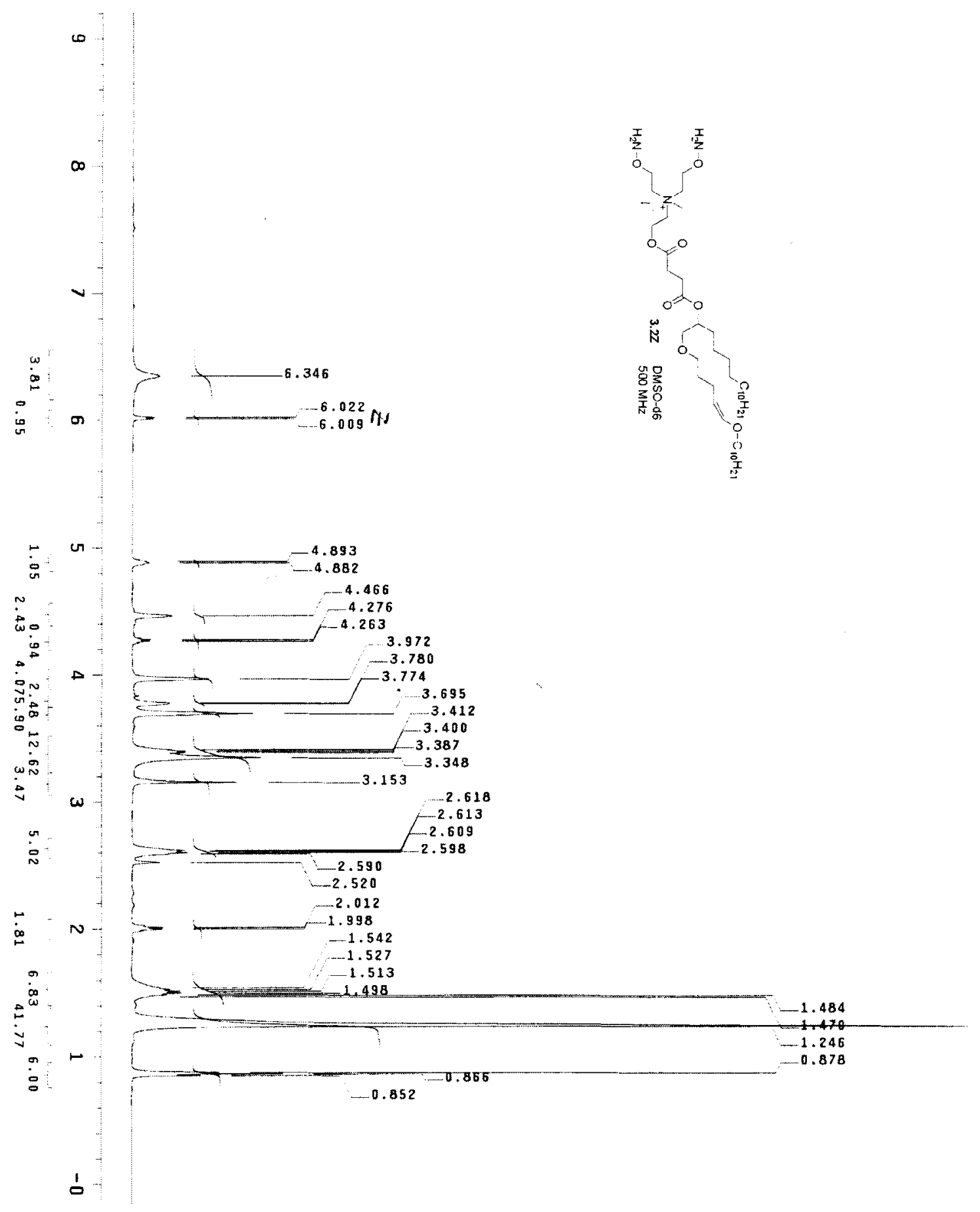

${ }^{1} \mathrm{H}$ NMR spectrum of compound $3.2(\mathrm{Z})$ 


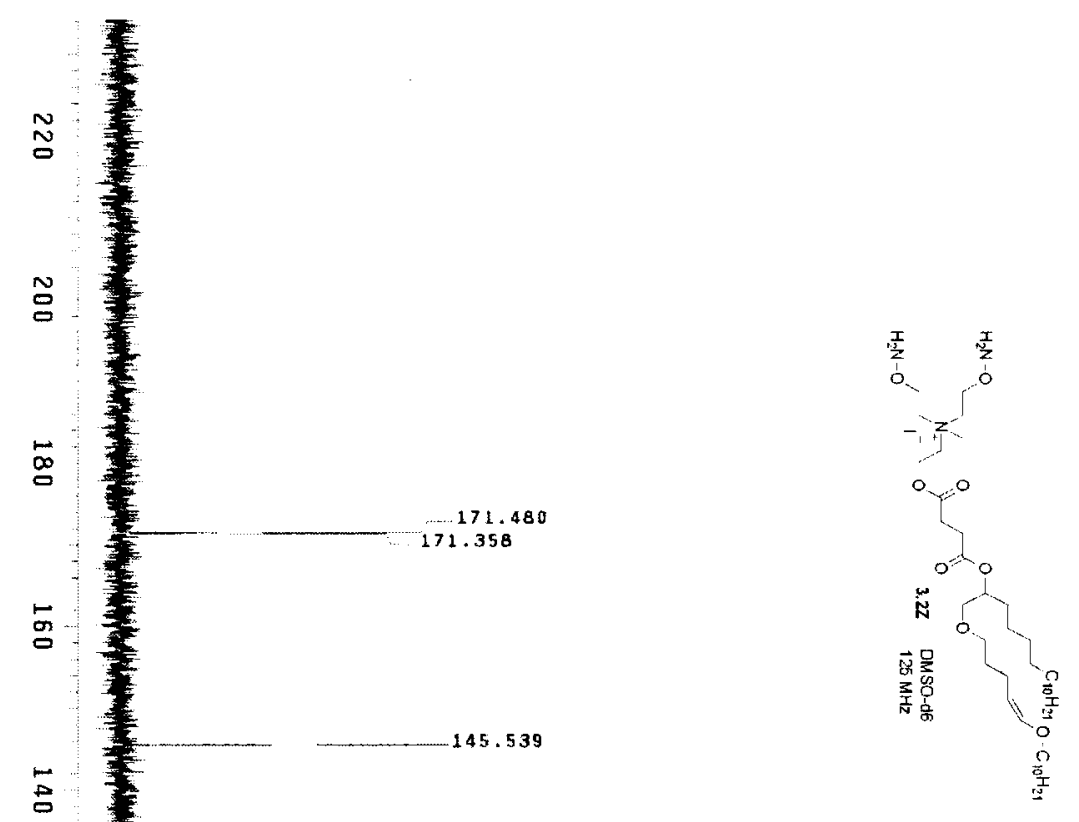

$\stackrel{2}{\circ}$

N

$\infty$

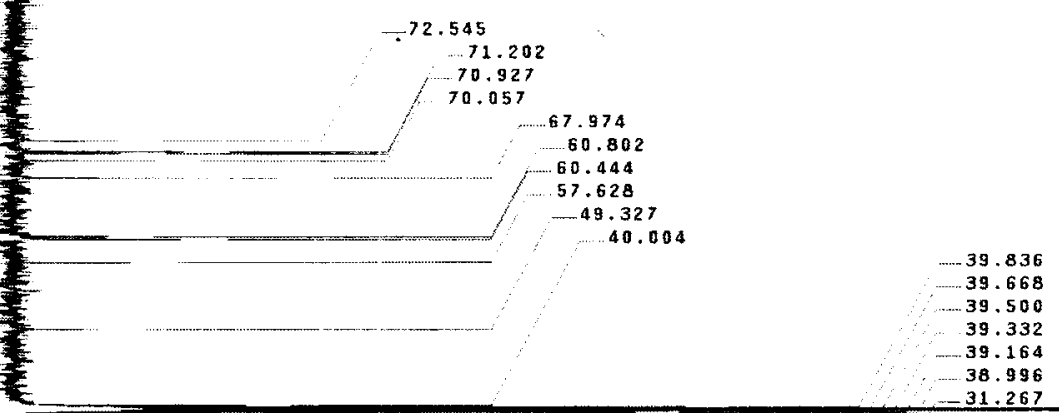

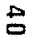

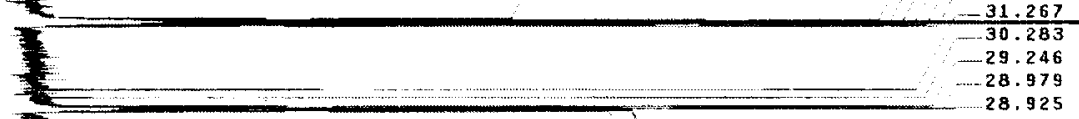

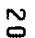

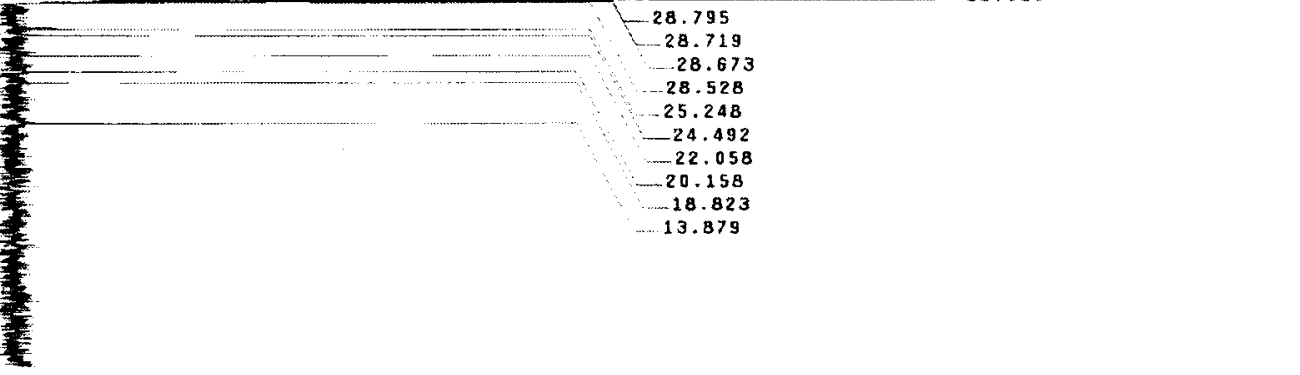

${ }^{13} \mathrm{C}$ NMR spectrum of compound $3.2(\mathrm{Z})$ 


\subsection{Chapter 4. 'Click' Stabilized Liposomes}

6.4.1 3-[N,N-[Bis-[2-(tert-butyl-dimethyl-silyloxy)ethyl]]-amino]-1,2-propanediol (4.4)

6.4.2 3-(bis(2-((tert-butyldimethylsilyl)oxy)ethyl)amino)propane-1,2-diylditetradec anoate (4.5)

3-(bis(2-((tert-butyldimethylsilyl)oxy)ethyl)amino)propane-1,2-diyldipalmitat e (4.9)

6.4.3 3-(bis(2-hydroxyethyl)amino)propane-1,2-diyl ditetradecanoate (4.6)

3-(bis(2-hydroxyethyl)amino)propane-1,2-diyl dipalmitate (4.10)

6.4.4 3-(N,N-Bis-(2-phthalimidooxyethyl)amino)propane-1,2-diylditetradecanoate (4.7)

3-(N,N-Bis-(2-phthalimidooxyethyl)amino)propane-1,2-diyldipalmitate (4.11)

6.4.5 N,N-bis(2-phthalimidooxyethyl)- $N$-methyl- $N$-[2,3-di(tetradecanoyloxy)propyl ]-ammonium iodide (4.8)

$N, N$-bis(2-phthalimidooxyethyl)- $N$-methyl- $N$-[2,3-di(palmityloxy)propyl]-am monium iodide (4.12)

6.4.6 $N, N$-bis(2-(aminooxy)ethyl)- $N$-methyl-2,3-bis(tetradecanoyloxy)propan-1-a minium iodide (4.1)

$N, N$-bis(2-(aminooxy)ethyl)- $N$-methyl-2,3-bis(palmityloxy)propan-1-aminiu $\mathrm{m}$ iodide (4.2)

6.4.7 2-((tert-butyldimethylsilyl)oxy)- $N$-methylethanamine (4.13)

6.4.8 3-((2-((tert-butyldimethylsilyl)oxy)ethyl)(methyl)amino)propane-1,2-diol (4.14)

6.4.9 3-((2-((tert-butyldimethylsilyl)oxy)ethyl)(methyl)amino)propane-1,2-diyl dipalmitate (4.15)

6.4.10 3-((2-hydroxyethyl)(methyl)amino)propane-1,2-diyl dipalmitate (4.16)

6.4.11 3-((2-phthalimidooxyethyl)(methyl)amino)propane-1,2-diyldipalmitate (4.17)

6.4.12 3-((2-hydroxyethyl)(methyl)amino)propane-1,2-diyl dipalmitate (4.18)

6.4.13 $N$-(2-(aminooxy)ethyl)- $N, N$-dimethyl-2,3-bis(palmitoyloxy)propan-1-aminiu $\mathrm{m}$ iodide (4.3) 
6.4.14 3-(bis(2-(aminooxy)ethyl)amino)propane-1,2-diyl ditetradecanoate (4.19)

6.4.15 3-(bis(2-(aminooxy)ethyl)amino)propane-1,2-diyl dipalmitate (4.20)

6.4.16 Synthesis of DPA and other polysaccharides

6.4.17 Liposome formulation and stabilization

6.4.18 Calcein experiment

6.4.19 Liposomes encapsulated phosphatase 


\subsubsection{3-[N,N-[Bis-[2-(tert-butyl-dimethyl-silyloxy)ethyl]]-amino]}

-1,2-propanediol

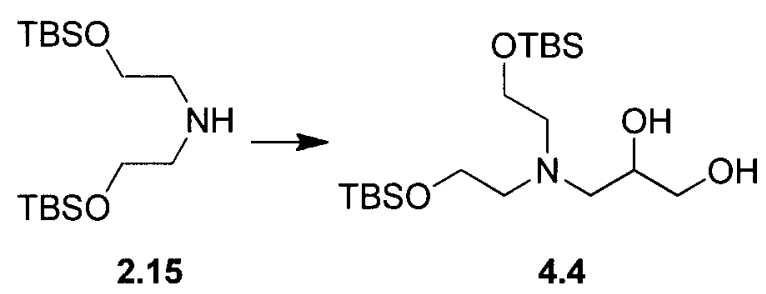

To a mixture of glycidol $(1.56 \mathrm{~g}, 21 \mathrm{mmol})$ and lithium perchlorate $(1.06 \mathrm{~g}, 10$ $\mathrm{mmol})$ in absolute ethanol $(30 \mathrm{~mL})$ was added the amine $2.15(6.70 \mathrm{~g}, 20 \mathrm{mmol})$ in $0^{\circ} \mathrm{C}$. The reaction mixture was warmed to room temperature and allowed to stir for $\sim 16$ hours. Determine reaction completeness by TLC (silica, Ethyl acetate: Hexane=1:1, $I_{2}$ stain). When complete, the reaction solvent was evaporated (in vacuo), redisolved in thyl acetate $(50 \mathrm{~mL})$ and washed with saturated aqueous sodium bicarbonate (50 $\mathrm{mL} \times 3)$ and brine $(50 \mathrm{~mL})$. The organic layer was dried $\left(\mathrm{Na}_{2} \mathrm{SO}_{4}\right)$ and the solvent was evaporated (in vacuo) to afford crude product. The compound was purified via silica chromatography (33\%-67\% ethyl acetate in hexanes) to afford 4.4 as yellow oil $(6.94 \mathrm{~g}$, $85 \%) . R f=0.34$ (ethyl acetate: hexane $=1: 1, \mathrm{I}_{2}$ stain). ${ }^{1} \mathrm{H}-\mathrm{NMR}\left(400 \mathrm{MHz}, \mathrm{CDCl}_{3}\right) \delta \mathrm{ppm}$ $0.02(\mathrm{~s}, 12 \mathrm{H}), 0.85(\mathrm{~s}, 18 \mathrm{H}), 2.61(\mathrm{~m}, 2 \mathrm{H}), 2.69(\mathrm{~s}, 4 \mathrm{H}), 3.44(\mathrm{~m}, 1 \mathrm{H}), 3.63(\mathrm{~m}, 6 \mathrm{H})$; ${ }^{13} \mathrm{C}-\mathrm{NMR}\left(100 \mathrm{MHz}, \mathrm{CDCl}_{3}\right) \delta \mathrm{ppm}-5.32,18.32,25.98,57.43,57.90,61.66,64.68$, 68.66. 


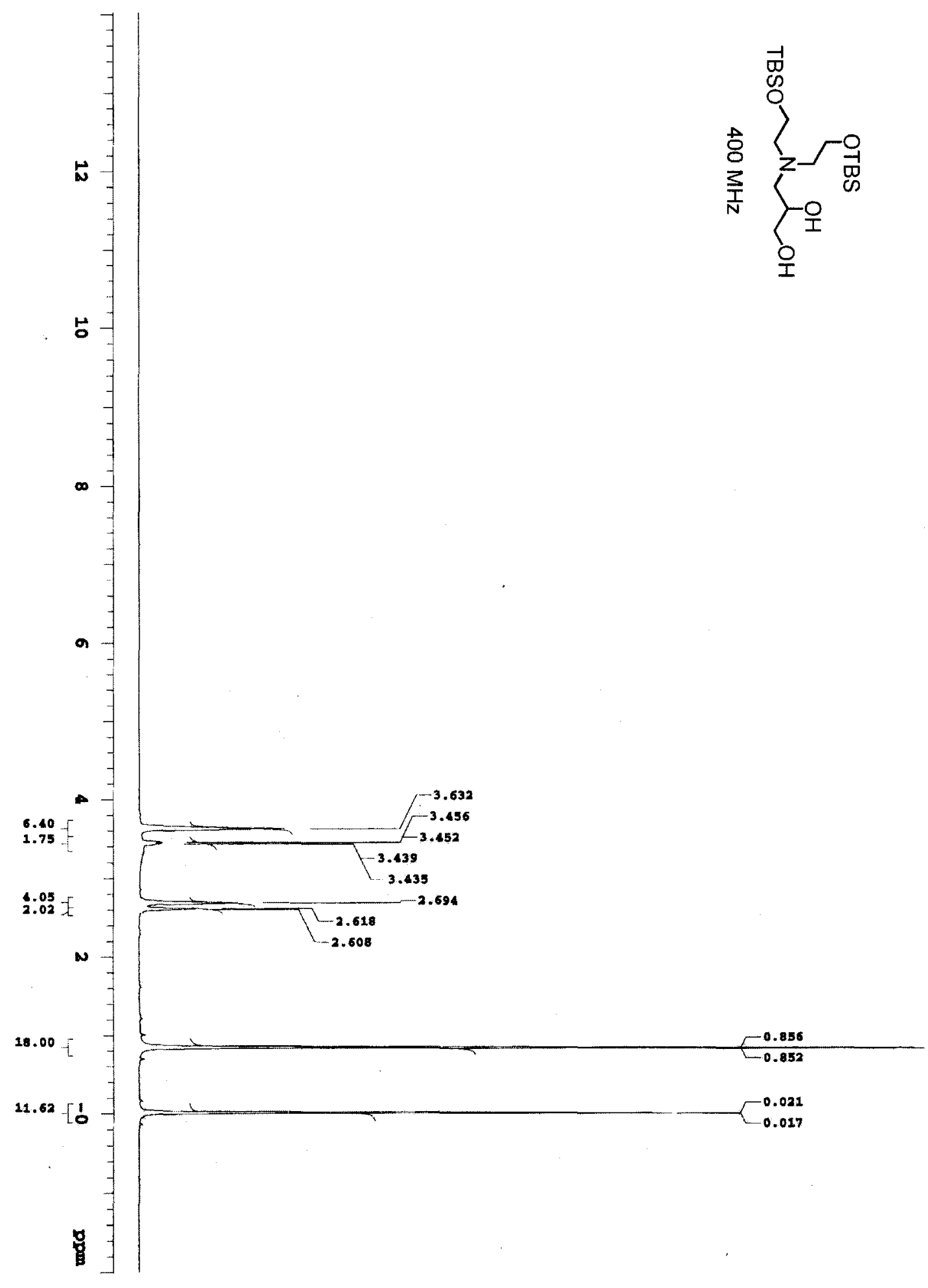

${ }^{1} \mathrm{H}$ NMR spectrum of compound 4.4 


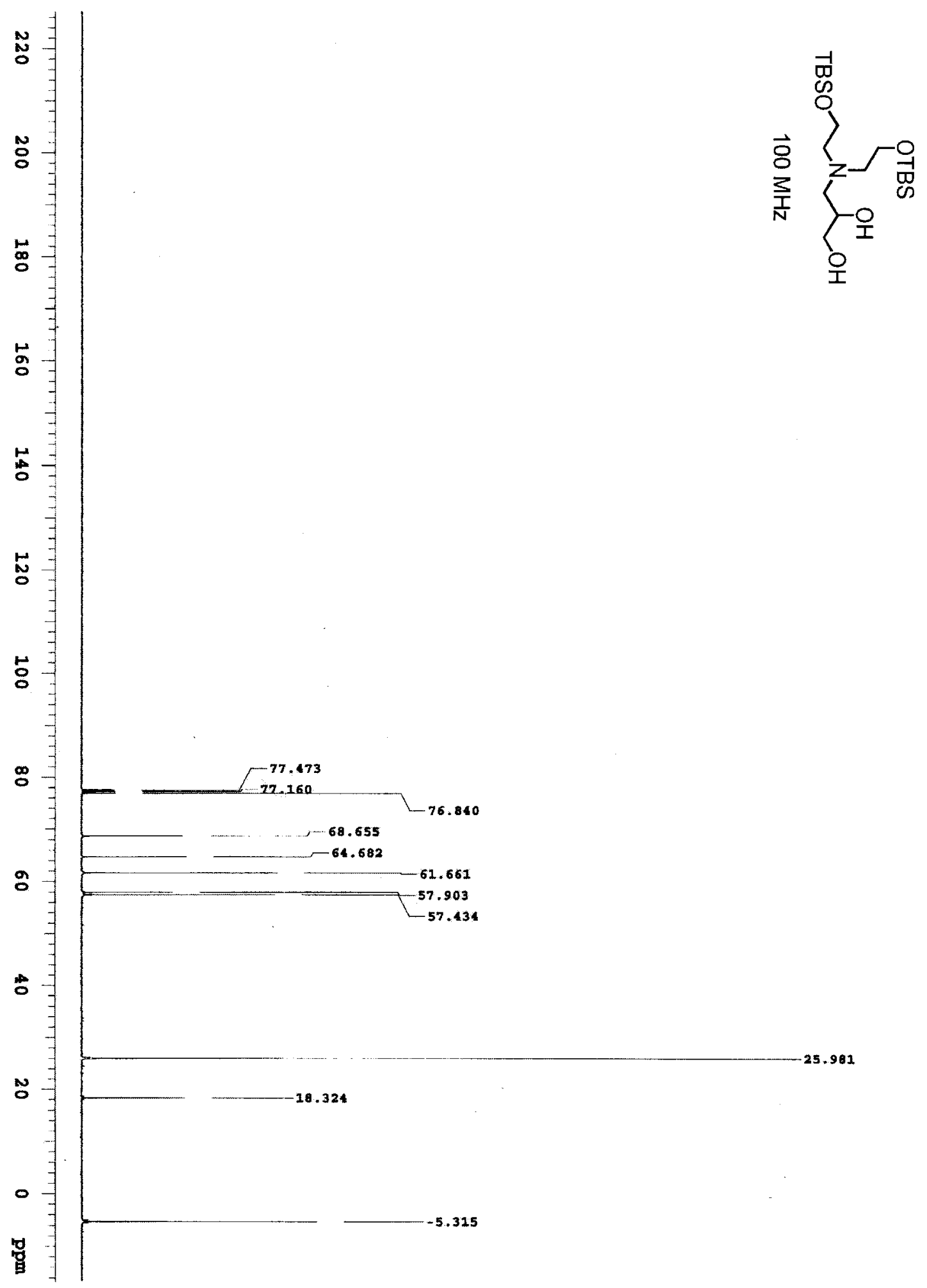

${ }^{13} \mathrm{C}$ NMR spectrum of compound 4.4 


\subsubsection{3-(bis(2-((tert-butyldimethylsilyl)oxy)ethyl)amino)propane-1,2-diyl ditetradecanoate \&}

\section{3-(bis(2-((tert-butyldimethylsilyl)oxy)ethyl)amino)propane-1,2-diyl dipalmitate}

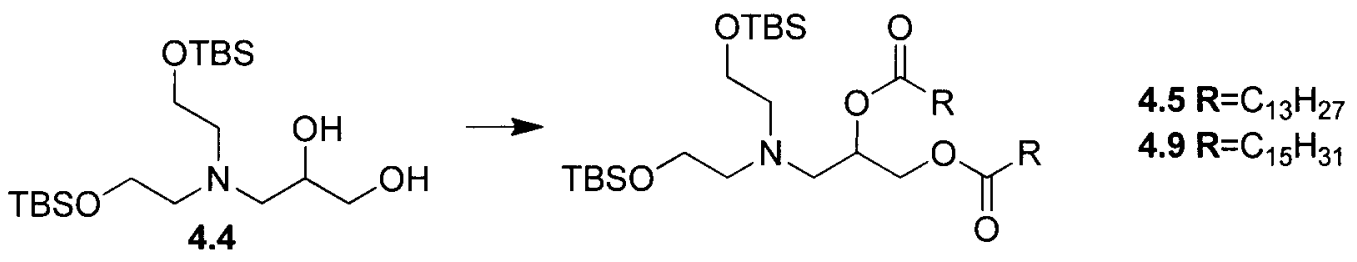

To a mixture of diol $4.4(5.93 \mathrm{~g}, 14.5 \mathrm{mmol}), \mathrm{Et}_{3} \mathrm{~N}(4.40 \mathrm{~g}, 43.5 \mathrm{mmol})$ and DMAP (0.177 g, $1.45 \mathrm{mmol})$ in $\mathrm{CH}_{2} \mathrm{Cl}_{2}\left(100 \mathrm{~mL}\right.$, dry) at $0^{\circ} \mathrm{C}$ was slowly added myristoyl chloride $(8.94 \mathrm{~g}, 36.3 \mathrm{mmol})$ in $\mathrm{CH}_{2} \mathrm{Cl}_{2}(30 \mathrm{~mL}$, dry). After addition, the pink color reaction mixture was stirred in room temperature for 16 hours. Determine reaction completeness by TLC (silica, $5 \%$ ethyl acetate in hexanes, $I_{2}$ stain). Upon completion, the reaction mixture was washed with saturated aq. $\mathrm{NaHCO}_{3}(250 \mathrm{~mL} \times 3)$ and $(250 \mathrm{~mL})$ and dried $\left(\mathrm{Na}_{2} \mathrm{SO}_{4}\right)$. After the solvent was evaporated (in vacuo), the crude product was purified by flash chromatography $\left(\mathrm{SiO}_{2}\right)$ using (1\%-5\%) ethyl acetate in hexanes as eluent to afford compound 4.5 as colorless solution $(5.96 \mathrm{~g}, 50 \%$ ). (product $\mathrm{Rf}=0.33$ ethyl acetate: hexane=1:19). ${ }^{1} \mathrm{H}-\mathrm{NMR}\left(400 \mathrm{MHz}, \mathrm{CDCl}_{3}\right) \delta \mathrm{ppm} 0.04(\mathrm{~s}, 12 \mathrm{H}), 0.88(\mathrm{~m}$, 24H), 1.25-1.57(m, 40H), 1.60(m, 4H), $2.27(\mathrm{~m}, \mathrm{~J}=7.2 \mathrm{~Hz}, 4 \mathrm{H}), 2.69(\mathrm{~m}, 6 \mathrm{H}), 3.63(\mathrm{t}, \mathrm{J}$ $=6.4 \mathrm{~Hz}, 4 \mathrm{H}), 4.11(\mathrm{dd}, \mathrm{J}=11.8,3.2 \mathrm{~Hz}, 1 \mathrm{H}), 4.37(\mathrm{~d}, \mathrm{t}=11.6 \mathrm{~Hz}, 1 \mathrm{H}), 5.08(\mathrm{~m}, \mathrm{~J}=3.2$ $\mathrm{Hz}, 1 \mathrm{H}) ;{ }^{13} \mathrm{C}-\mathrm{NMR}\left(100 \mathrm{MHz}, \mathrm{CDCl}_{3}\right) \delta \mathrm{ppm}-5.23,14.25,18.38,22.83,25.09,25.12$, $26.06,29.29,29.31,29.47,29.51,29.66,29.81,29.84,32.07,34.35,34.59,55.81$, $57.75,62.06,63.80,70.34,173.23,173.61$; HRMS (ESI) calcd. for $\mathrm{C}_{47} \mathrm{H}_{98} \mathrm{NO}_{6} \mathrm{Si}_{2}{ }^{+}$ $[\mathrm{M}+\mathrm{H}]^{+}: 828.6927$, found: 828.6928 . 
Using the same method, compound 4.9 can be made from palmitoyl chloride in $61 \%$ yield. ${ }^{1} \mathrm{H}-\mathrm{NMR}\left(500 \mathrm{MHz}, \mathrm{CDCl}_{3}\right) \delta \mathrm{ppm} 0.04(\mathrm{~s}, 12 \mathrm{H}), 0.88(\mathrm{~m}, 24 \mathrm{H}), 1.25-1.29$ $(\mathrm{m}, 48 \mathrm{H}), 1.59(\mathrm{t}, \mathrm{J}=7.0 \mathrm{~Hz}, 4 \mathrm{H}), 2.28(\mathrm{~m}, \mathrm{~J}=7.5 \mathrm{~Hz}, 4 \mathrm{H}), 2.69(\mathrm{~m}, 6 \mathrm{H}), 3.62(\mathrm{t}, \mathrm{J}=$ $6.5 \mathrm{~Hz}, 4 \mathrm{H}), 4.11(\mathrm{dd}, \mathrm{J}=12.0,6.0 \mathrm{~Hz}, 1 \mathrm{H}), 4.37(\mathrm{dd}, \mathrm{t}=12.0,3.0 \mathrm{~Hz}, 1 \mathrm{H}), 5.08(\mathrm{~m}, \mathrm{~J}=$

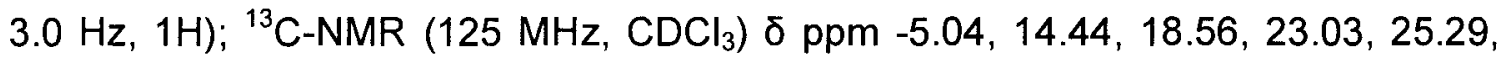
$25.31,26.25,29.48,29.50,29.65,29.70,29.85,30.00,30.04,32.27,34.54,34.79$, $56.01,57.96,62.25,63.99,70.54,173.41,173.79$. 


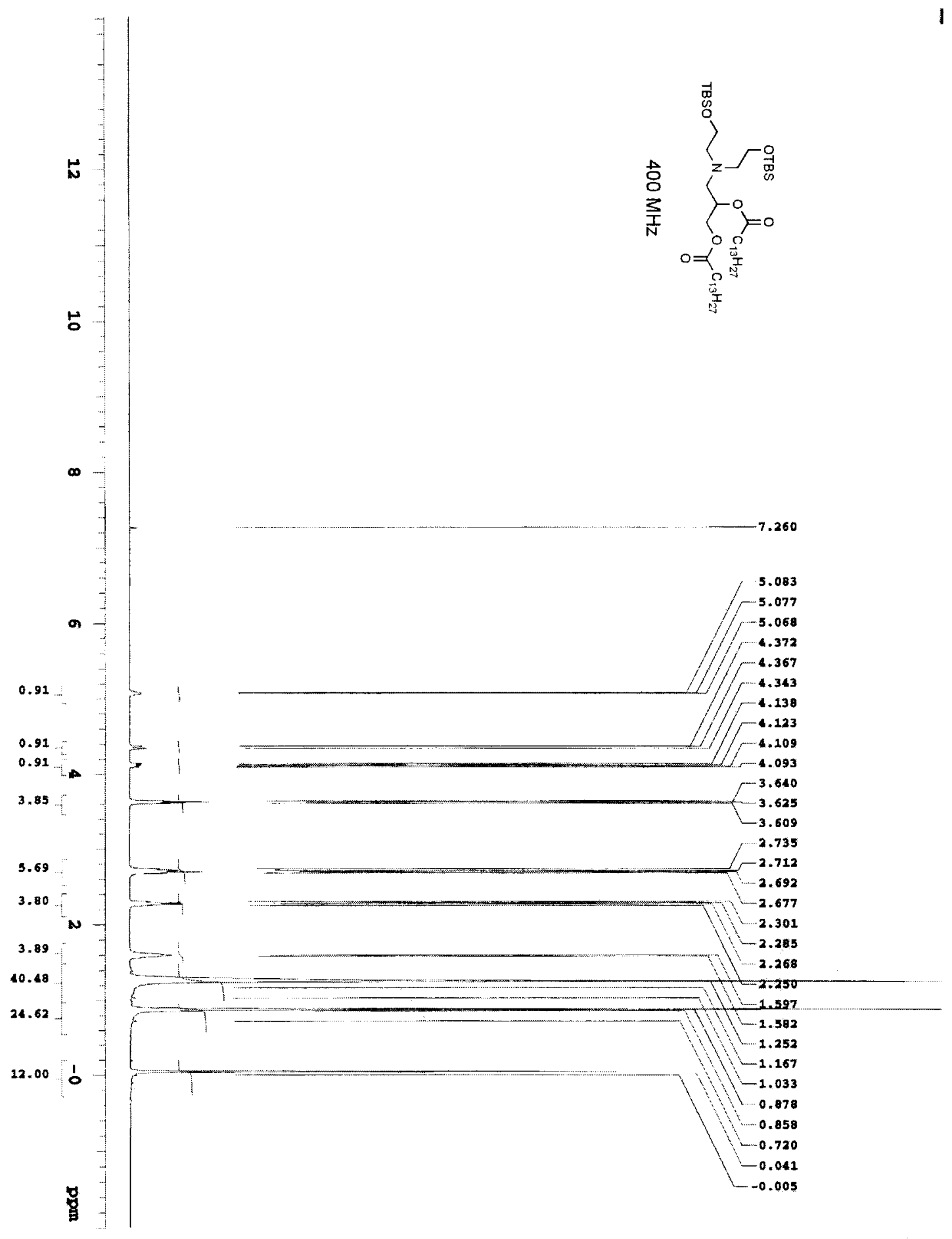

${ }^{1} \mathrm{H}$ NMR spectrum of compound 4.5 


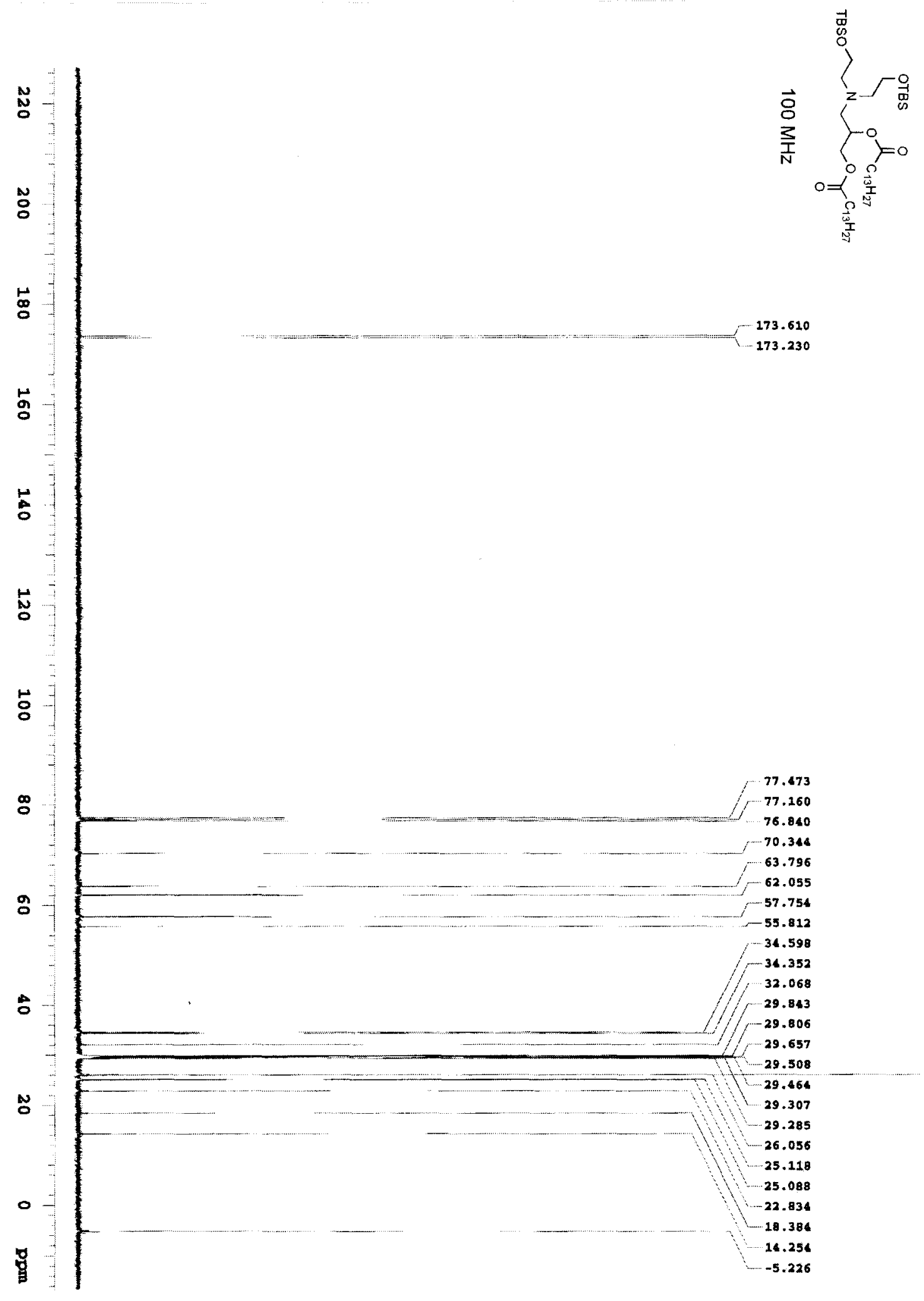

${ }^{13} \mathrm{C}$ NMR spectrum of compound 4.5 


\subsubsection{3-(bis(2-hydroxyethyl)amino)propane-1,2-diyl ditetradecanoate}

\section{\& 3-(bis(2-hydroxyethyl)amino)propane-1,2-diyl dipalmitate}<smiles>[R]C(=O)OCC(CN(CCO)CCO)OC([R])=O</smiles>

To a solution of amine $4.5(3.66 \mathrm{~g}, 4.42 \mathrm{mmol})$ in THF $\left(20 \mathrm{~mL}\right.$, dry) at $0^{\circ} \mathrm{C}$ was added TBAF (9.72 $\mathrm{mL}, 1 \mathrm{M}$ in THF) dropwise. After addition, the reaction mixture was stirred in room temperature for 12 hours. The solvent was removed by rotary evaporation and ethylacetate $(100 \mathrm{~mL})$ was added. The reaction mixture was washed with saturated aq. $\mathrm{NaHCO}_{3}(100 \mathrm{~mL} \times 3)$, brine $(100 \mathrm{~mL})$ and dried $\left(\mathrm{Na}_{2} \mathrm{SO}_{4}\right)$. The solvent was removed by rotary evaporation and the crude product was purified via silica chromatography (30\%-50\% ethyl acetate in hexanes) to afford compound 4.6 as white waxy solid $(1.89 \mathrm{~g}, 71 \%)$. (Rf=0.45, ethyl acetate). ${ }^{1} \mathrm{H}-\mathrm{NMR}\left(400 \mathrm{MHz}, \mathrm{CDCl}_{3}\right) \delta$ ppm $0.85(\mathrm{~m}, 6 \mathrm{H}), 1.25-1.26(\mathrm{~m}, 40 \mathrm{H}), 1.57(\mathrm{t}, \mathrm{J}=6.4 \mathrm{~Hz}, 4 \mathrm{H}), 2.28(\mathrm{~m}, 4 \mathrm{H}), 2.69(\mathrm{~m}$, $6 \mathrm{H}), 3.14(\mathrm{~s}, 2 \mathrm{H}), 3.57(\mathrm{t}, \mathrm{J}=5.2 \mathrm{~Hz}, 4 \mathrm{H}), 4.09(\mathrm{dd}, \mathrm{J}=12.0,6.0 \mathrm{~Hz}, 1 \mathrm{H}), 4.34$ (dd, $\mathrm{J}=12.0,2.8 \mathrm{~Hz}, 1 \mathrm{H}), 5.15(\mathrm{~m}, \mathrm{~J}=3.2 \mathrm{~Hz}, 1 \mathrm{H}) ;{ }^{13} \mathrm{C}-\mathrm{NMR}\left(100 \mathrm{MHz}, \mathrm{CDCl}_{3}\right) \delta \mathrm{ppm} \mathrm{14.17}$, $22.75,24.94,24.95,29.18,29.21,29.37,29.43,29.57,29.71,29.72,29.74,29.76$, $31.99,34.20,34.45,55.80,57.33,59.88,63.66,70.11,173.73,173.83$. HRMS (ESI): calcd. for $\mathrm{C}_{35} \mathrm{H}_{70} \mathrm{NO}_{6}^{+}[\mathrm{M}+\mathrm{H}]^{+}: 600.5198$, found: 600.5205 .

Using the same method, compound 4.10 can be made from compound 4.9 in $60 \%$ yield. ${ }^{1} \mathrm{H}-\mathrm{NMR}\left(500 \mathrm{MHz}, \mathrm{CDCl}_{3}\right) \delta \mathrm{ppm} 0.85(\mathrm{t}, \mathrm{J}=6.5 \mathrm{~Hz}, 6 \mathrm{H}), 1.23-1.26(\mathrm{~m}$, $48 \mathrm{H}), 1.59(\mathrm{t}, 4 \mathrm{H}), 2.29(\mathrm{~m}, \mathrm{~J}=7.5 \mathrm{~Hz}, 4 \mathrm{H}), 2.69(\mathrm{~m}, 6 \mathrm{H}), 3.03(\mathrm{~s}, 2 \mathrm{H}), 3.57(\mathrm{t}, 4 \mathrm{H}), 4.09$ $(\mathrm{dd}, \mathrm{J}=12.0,6.0 \mathrm{~Hz}, 1 \mathrm{H}), 4.34(\mathrm{~d}, \mathrm{~J}=12.0 \mathrm{~Hz}, 1 \mathrm{H}), 5.15(\mathrm{~m}, \mathrm{~J}=3.0 \mathrm{~Hz}, 1 \mathrm{H}) ;{ }^{13} \mathrm{C}-\mathrm{NMR}$ 
(125 MHz, $\mathrm{CDCl}_{3}$ ) $\delta$ ppm 14.40, 22.98, 25.17, 29.43, 29.59, 29.66, 29.80, 29.96, 29.99, $32.22,34.43,34.68,56.10,57.55,60.12,63.89,70.36,173.96,174.09$. HRMS (ESI) calcd. for $\mathrm{C}_{39} \mathrm{H}_{77} \mathrm{NNaO}_{6}{ }^{+}[\mathrm{M}+\mathrm{Na}]^{+}: 678.5649$, found: 678.5644 . 


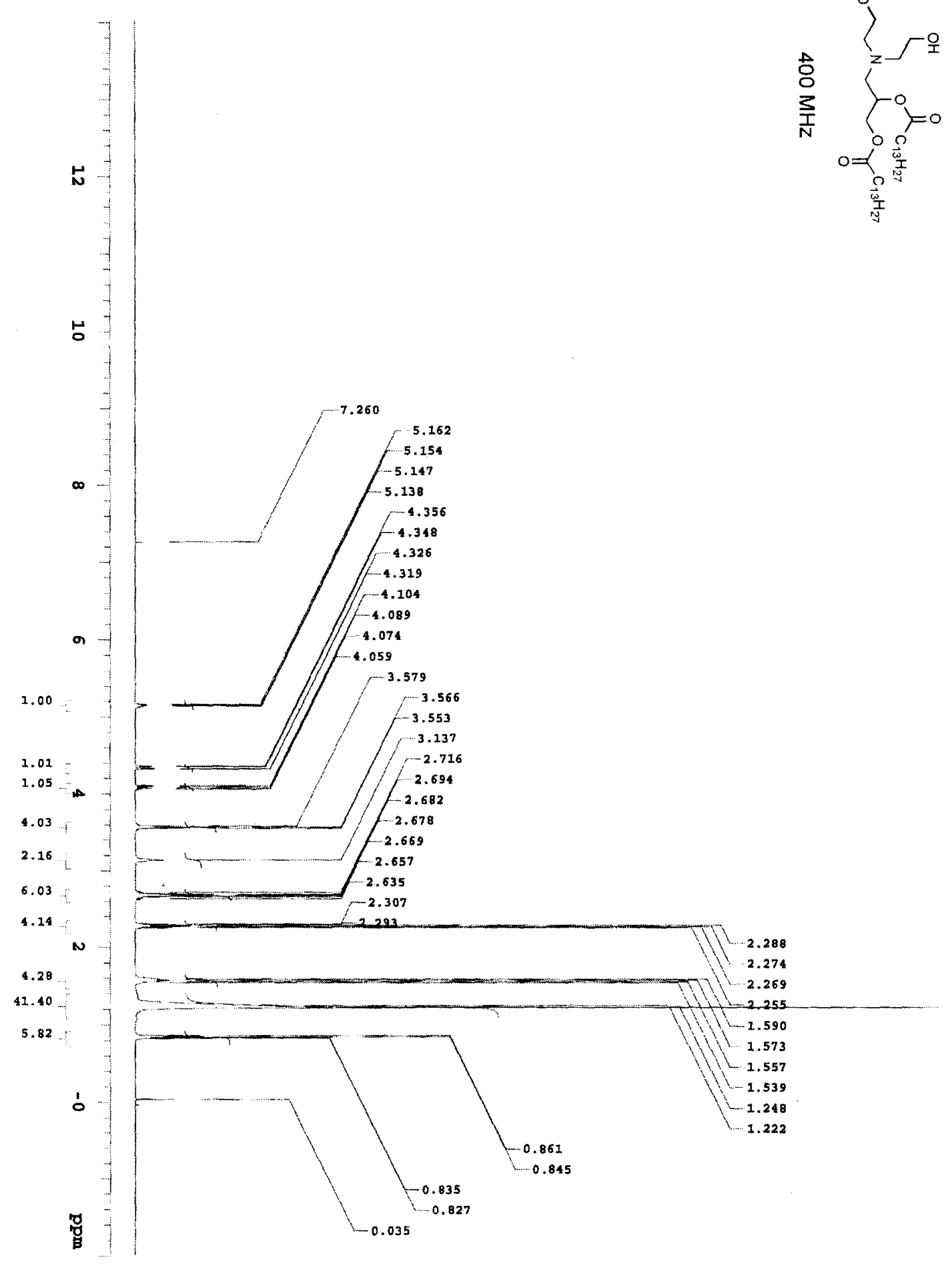

${ }^{1} \mathrm{H}$ NMR spectrum of compound 4.6 


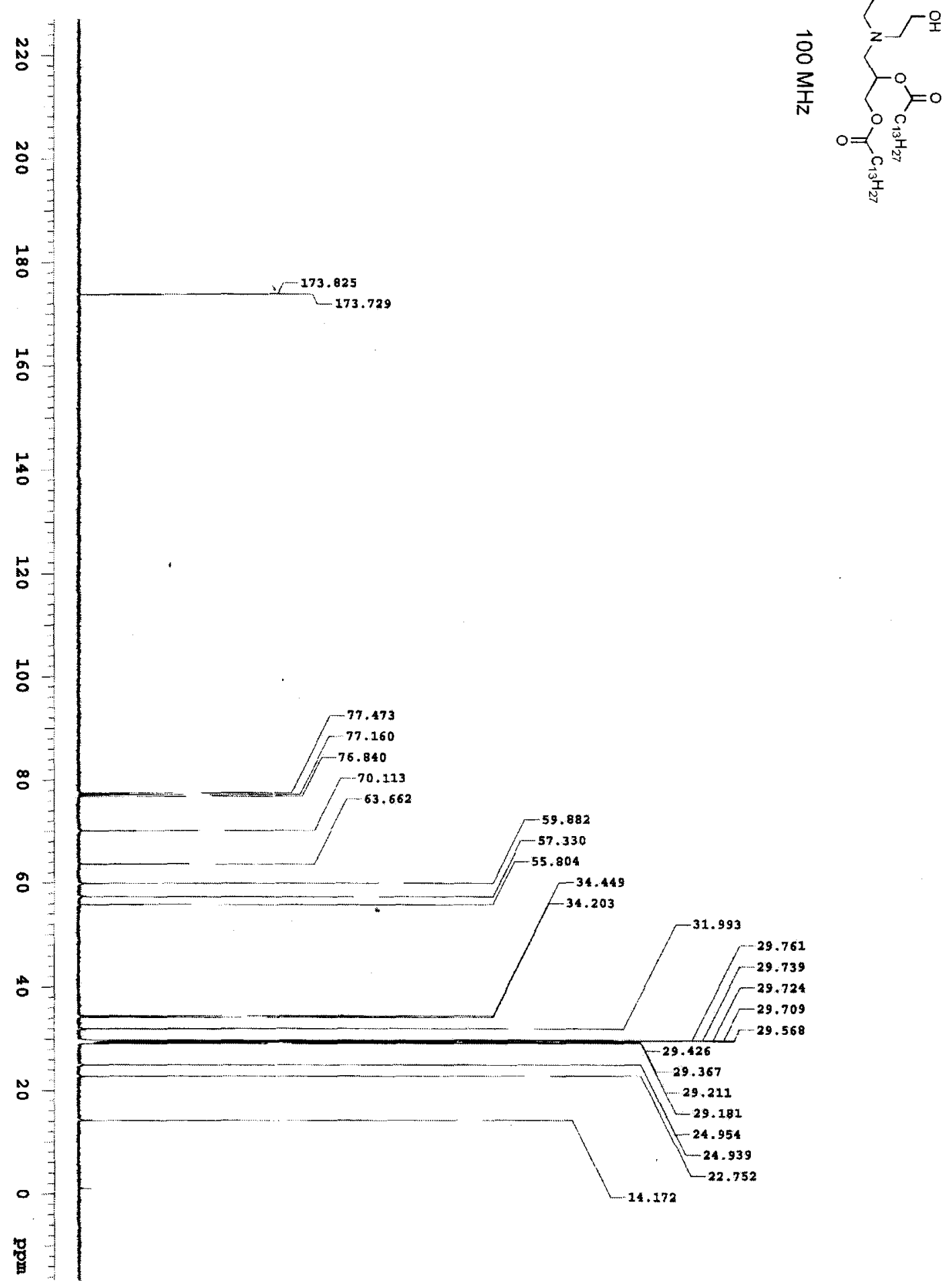

${ }^{13} \mathrm{C}$ NMR spectrum of compound 4.6 


\subsubsection{3-(N,N-Bis-(2-phthalimidooxyethyl)amino)propane-1,2-diyl ditetradecanoate}

\section{\& 3-(N,N-Bis-(2-phthalimidooxyethyl)amino)propane-1,2-diyl dipalmitate}<smiles>[R]C(=O)OCC(CN(CCO)CCO)OC([R])=O</smiles>

4.6/4.10<smiles>[R]C(=O)OCC(CN(CCONc1ccccc1)CCONc1ccccc1)OC([R])=O</smiles>

4.7/4.11
4.6, $4.7 \quad \mathrm{R}=\mathrm{C}_{13} \mathrm{H}_{27}$ 4.10, 4.11 R= $\mathrm{C}_{15} \mathrm{H}_{31}$

To a solution of diol $4.6(0.650 \mathrm{~g}, 1.10 \mathrm{mmol}), \mathrm{N}$-hydroxyphthalimide $(0.391 \mathrm{~g}$, $2.40 \mathrm{mmol})$ and triphenylphosphine $(0.629 \mathrm{~g}, 2.40 \mathrm{mmol})$ in THF $(30 \mathrm{~mL})$ at $0{ }^{\circ} \mathrm{C}$ was added diisopropyldiazodicarboxylate $(0.485 \mathrm{~g}, 2.40 \mathrm{mmol})$ over $5 \mathrm{~min}$. The reaction was stirred at $0{ }^{\circ} \mathrm{C}$ for $0.5 \mathrm{~h}$ and then warmed to room temperature. Determine reaction completeness by TLC (silica, ethyl acetate: hexanes=1:1, UV light and $I_{2}$ stain). When completed $(\sim 12 \mathrm{~h})$, the reaction solvent was removed by rotary evaporation. The orange residue was dissolved in ethyl acetate $(30 \mathrm{~mL})$ and washed successively with saturated aq. $\mathrm{NaHCO}_{3}(3 \times 30 \mathrm{~mL})$, brine $(30 \mathrm{~mL})$ and dried $\left(\mathrm{Na}_{2} \mathrm{SO}_{4}\right)$. After the solvent was evaporated, the crude product was dissolved in hot hexanes and slowly cooled down to room temperature and the side product was crystallized and removed through filtration. The solvent was evaporated and purified via silica chromatography (20\%-35\% ethyl acetate in hexanes) to afford light yellow liquid $(0.83 \mathrm{~g}, 86 \%)$. $(\mathrm{Rf}=0.74$ ethyl acetate: hexanes=1:1). $I R($ neat) $2922,2852,1789$, 1187, 1151, 992, 701 $\mathrm{cm}^{-1} ;{ }^{1} \mathrm{H}-\mathrm{NMR}\left(\mathrm{CDCl}_{3} 400 \mathrm{MHz}\right) \delta \mathrm{ppm} 0.88(\mathrm{~m}, 6 \mathrm{H}), 1.23(\mathrm{~s}$, $40 \mathrm{H}), 1.58(\mathrm{~m}, 4 \mathrm{H}), 2.29(\mathrm{t}, \mathrm{J}=6.4 \mathrm{~Hz}, 4 \mathrm{H}), 2.93(\mathrm{dd}, \mathrm{J}=11.2,4.8 \mathrm{~Hz}, 1 \mathrm{H}), 3.00(\mathrm{dd}, \mathrm{J}$ $=11.2,4.8 \mathrm{~Hz}, 1 \mathrm{H}), 3.16(\mathrm{~m}, 4 \mathrm{H}), 4.18(\mathrm{dd}, \mathrm{J}=9.6,4.8 \mathrm{~Hz}, 1 \mathrm{H}), 4.33(\mathrm{t}, \mathrm{J}=4.4 \mathrm{~Hz}, 4 \mathrm{H})$, $4.43(\mathrm{dd}, \mathrm{J}=4.8,2.4 \mathrm{~Hz}, 1 \mathrm{H}), 5.17(\mathrm{ddd}, \mathrm{J}=9.6,4.8,2.4 \mathrm{~Hz}, 1 \mathrm{H}), 7.74(\mathrm{~m} 4 \mathrm{H}), 7.79(\mathrm{~m}$ 
4H); ${ }^{13} \mathrm{C}-\mathrm{NMR}\left(100 \mathrm{MHz}, \mathrm{CDCl}_{3}\right) \delta \mathrm{ppm} 14.11,22.67,24.92,29.11,29.14,29.30$, $29.32,29.35,29.49,29.64,29.66,29.68,31.90,34.17,34.37,52.94,54.93,63.52$, $69.79,77.16,123.44,128.94,134.39,163.29,173.17,173.42$. HRMS (ESI) Calcd. for $\mathrm{C}_{51} \mathrm{H}_{75} \mathrm{~N}_{3} \mathrm{O}_{10} \mathrm{Na}^{+}\left[\mathrm{M}+\mathrm{Na}^{+}\right]: 912.5350$, found: 912.5339 .

Using the same method, compound 4.11 can be made from compound 4.10 in $86 \%$ yield. ${ }^{1} \mathrm{H}-\mathrm{NMR}\left(\mathrm{CDCl}_{3} 500 \mathrm{MHz}\right) \delta \mathrm{ppm} 0.86(\mathrm{t}, \mathrm{J}=7.0 \mathrm{~Hz}, 6 \mathrm{H}), 1.23(\mathrm{~s}, 48 \mathrm{H})$, $1.56(\mathrm{~m}, 4 \mathrm{H}), 2.28(\mathrm{t}, \mathrm{J}=7.0 \mathrm{~Hz}, 4 \mathrm{H}), 2.94(\mathrm{~m}, 2 \mathrm{H}), 3.16(\mathrm{~m}, 4 \mathrm{H}), 4.18(\mathrm{dd}, 1 \mathrm{H}), 4.33(\mathrm{t}$, $J=4.0 \mathrm{~Hz}, 4 \mathrm{H}), 4.43(\mathrm{dd}, 1 \mathrm{H}), 5.19(\mathrm{~m}, 1 \mathrm{H}), 7.71(\mathrm{~m} 4 \mathrm{H}), 7.78(\mathrm{~m} \mathrm{4H}) ;{ }^{13} \mathrm{C}-\mathrm{NMR}(125$ $\mathrm{MHz}, \mathrm{CDCl}_{3}$ ) $\delta \mathrm{ppm} 14.41,22.88,24.98,25.22,29.45,29.63,29.66,29.81,29.96$, $30.00,32.22,34.48,34.69,53.24,55.25,63.84,70.09,77.10,123.76,129.27,134.69$, 163.63, 173.52, 173.78. HRMS (ESI) Calculated for $\mathrm{C}_{55} \mathrm{H}_{83} \mathrm{~N}_{3} \mathrm{O}_{10} \mathrm{Na}^{+}\left[\mathrm{M}+\mathrm{Na}^{+}\right]$: 968.5979, found: 968.5973 . 


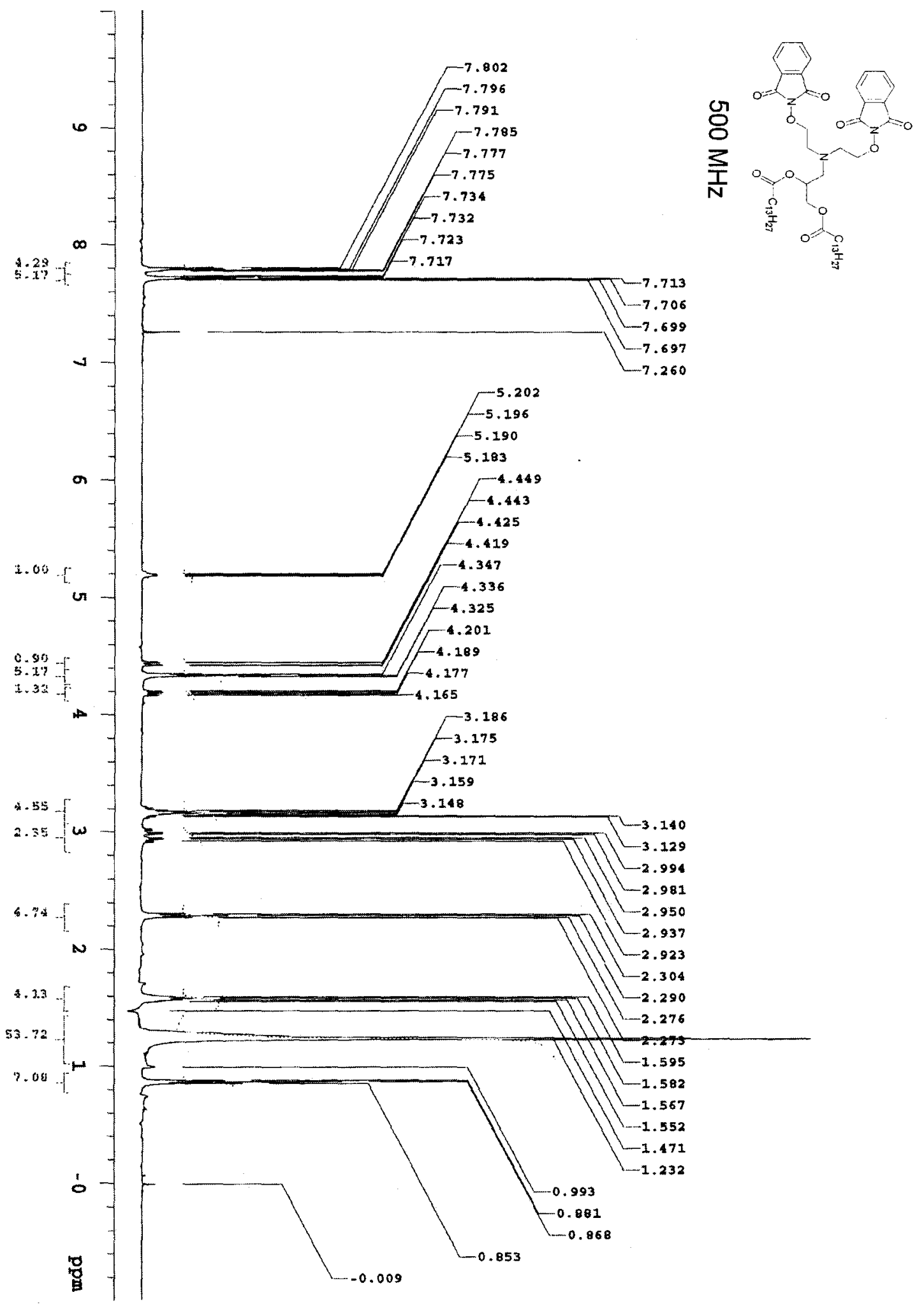

${ }^{1} \mathrm{H}$ NMR spectrum of compound 4.7 


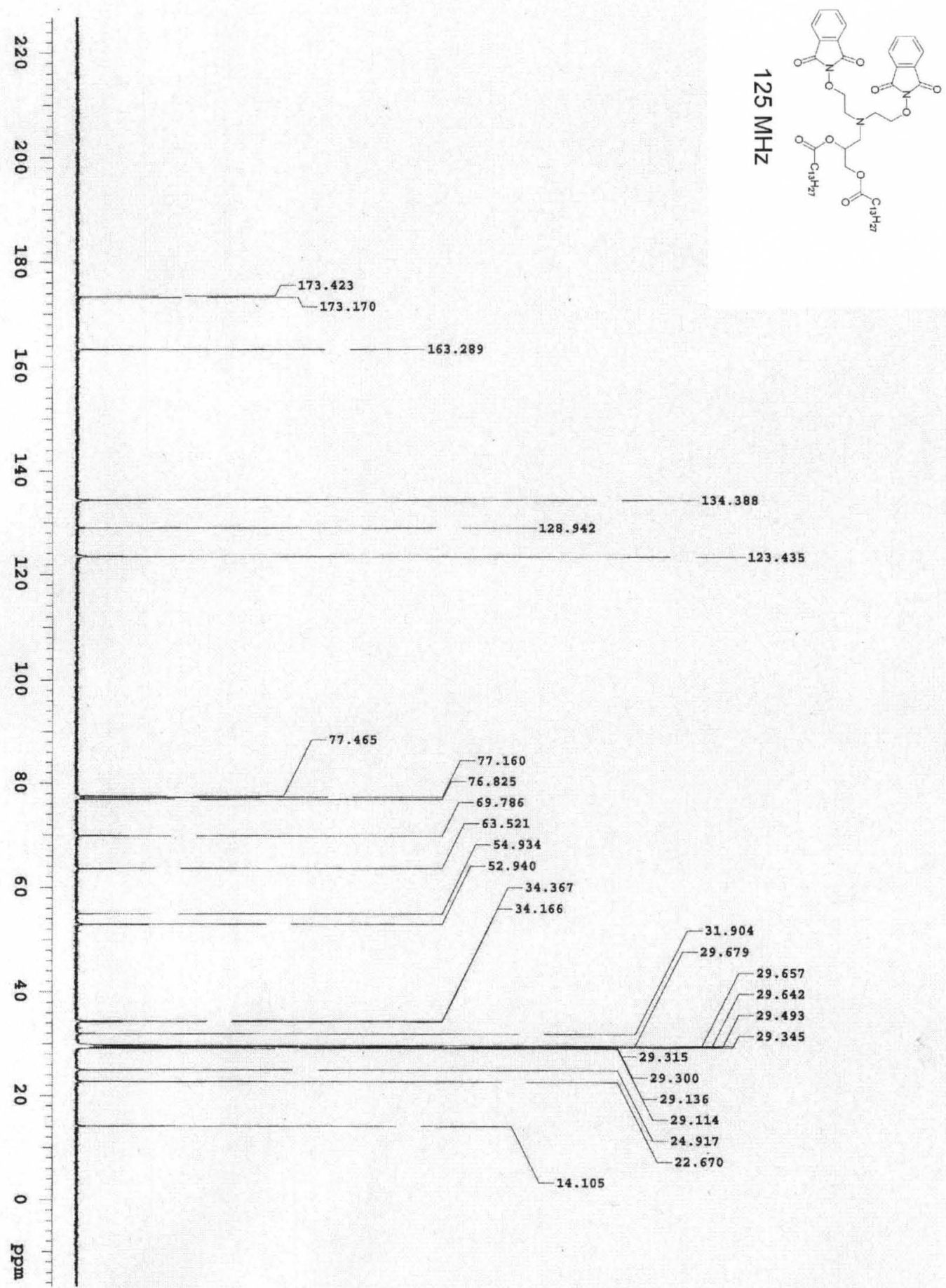

${ }^{13} \mathrm{C}$ NMR spectrum of compound 4.7 


\subsubsection{N,N-bis(2-phthalimidooxyethyl)-N-methyl-N-[2,3- di(tetradecanoyloxy)propyl]-ammonium iodide \&}

$N, N$-bis(2-phthalimidooxyethyl)-N-methyl-N-[2,3-di(palmityloxy)propyl]-ammoni um iodide

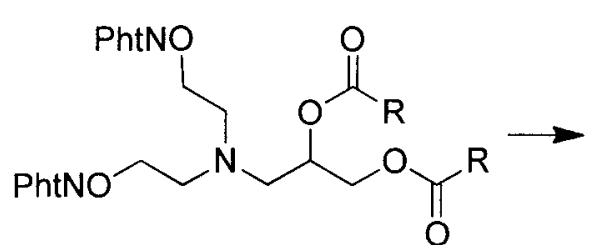

4.7/4.11

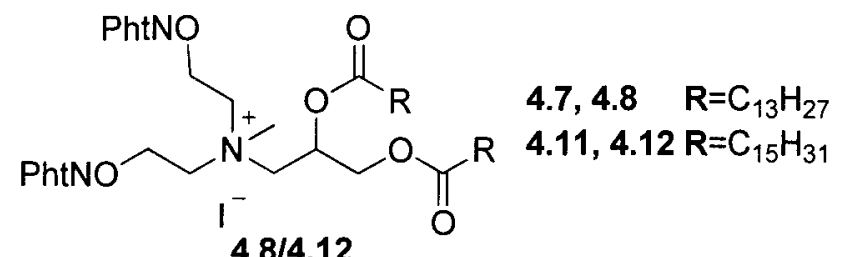

4.8/4.12

In a sealed tube, to the amine $4.7(0.712 \mathrm{~g}, 0.8 \mathrm{mmol})$ dissolved in $3 \mathrm{~mL}$ dichloromethane was added Mel $(2 \mathrm{~mL})$. The reaction mixture was degassed using a stream of $\mathrm{N}_{2}$ before sealing the tube. The reaction was heated to $60^{\circ} \mathrm{C}$ for $48 \mathrm{~h}$ and the solvent was evaporated (Caution: fume hood required). The product was purified via silica chromatography (ethyl acetate) to afford compound 4.8 as yellow solid $(0.611 \mathrm{~g}, 74 \%) .(\mathrm{Rf}=0.10$ ethyl acetate $)$ m.p. $=95 \sim 97^{\circ} \mathrm{C} .{ }^{1} \mathrm{H}-\mathrm{NMR}\left(400 \mathrm{MHz}, \mathrm{CDCl}_{3}\right) \delta$ ppm $0.85(\mathrm{t}, \mathrm{J}=6.4 \mathrm{~Hz}, 6 \mathrm{H}), 1.22(\mathrm{~s}, 40 \mathrm{H}), 1.52(\mathrm{t}, \mathrm{J}=6.4 \mathrm{~Hz}, 2 \mathrm{H}), 1.62(\mathrm{t}, \mathrm{J}=6.4$ $\mathrm{Hz}, 2 \mathrm{H}$ ), 2.29 (t, J = $7.6 \mathrm{~Hz}, 2 \mathrm{H}$ ), $2.42(\mathrm{dt}, \mathrm{J}=6.4 \mathrm{~Hz}, 2 \mathrm{H}$ ), $3.79(\mathrm{~s}, 3 \mathrm{H}), 4.15$ (dd, J = 12.0, $4.4 \mathrm{~Hz}, 1 \mathrm{H}) 4.42(\mathrm{dd}, \mathrm{J}=14.8,8.8 \mathrm{~Hz}, 1 \mathrm{H}), 4.51-4.67(\mathrm{~m}, 6 \mathrm{H}), 4.87(\mathrm{~s}, 4 \mathrm{H}), 5.78$ $(\mathrm{m}, 1 \mathrm{H}), 7.78(\mathrm{~m}, 8 \mathrm{H}){ }^{13} \mathrm{C}-\mathrm{NMR}\left(100 \mathrm{MHz}, \mathrm{CDCl}_{3}\right) \delta \mathrm{ppm} 14.27,22.84,24.78,24.88$, $29.26,29.29,29.47,29.51,29.68,29.81,29.84,29.85,32.07,34.07,34.49,51.25$, $62.13,62.44,63.25,64.93,65.96,72.27,124.21,128.63,135.25,163.21,163.25$, $173.02,173.32$.

Using the same method, compound 4.12 can be made from compound 4.11 in $67 \%$ yield. ${ }^{1} \mathrm{H}-\mathrm{NMR}\left(500 \mathrm{MHz}, \mathrm{CDCl}_{3}\right) \delta \mathrm{ppm} 0.84(\mathrm{t}, \mathrm{J}=7.0 \mathrm{~Hz}, 6 \mathrm{H}), 1.19-1.24(\mathrm{~m}$, $48 \mathrm{H}), 1.50(\mathrm{t}, J=6.5 \mathrm{~Hz}, 2 \mathrm{H}), 1.60(\mathrm{t}, \mathrm{J}=6.5 \mathrm{~Hz}, 2 \mathrm{H}), 2.28(\mathrm{t}, \mathrm{J}=7.5 \mathrm{~Hz}, 2 \mathrm{H}), 2.39(\mathrm{~m}$, 
$\mathrm{J}=8.5 \mathrm{~Hz}, 2 \mathrm{H}), 3.78(\mathrm{~s}, 3 \mathrm{H}), 4.13(\mathrm{dd}, \mathrm{J}=12.0,4.5 \mathrm{~Hz}, 1 \mathrm{H}) 4.42(\mathrm{dd}, \mathrm{J}=14.5,5.5 \mathrm{~Hz}$, 1H), 4.49-4.54 (m, 5H), $4.62(\mathrm{~d}, \mathrm{~J}=9.0 \mathrm{~Hz}, 1 \mathrm{H}), 4.86(\mathrm{~s}, 4 \mathrm{H}), 5.77(\mathrm{~m}, 1 \mathrm{H}), 7.76(\mathrm{~m}, 4 \mathrm{H})$, $7.79(\mathrm{~m}, 4 \mathrm{H}) ;{ }^{13} \mathrm{C}-\mathrm{NMR}\left(125 \mathrm{MHz}, \mathrm{CDCl}_{3}\right) \delta \mathrm{ppm} 14.35,22.91,24.85,24.96,29.37$, $29.56,29.59,29.76,29.89,29.94,32.15,34.15,34.57,51.29,62.20,62.50,63.33$, $64.96,66.07,72.36,124.26,128.73,135.31,163.28,163.33,173.08,173.39$. 


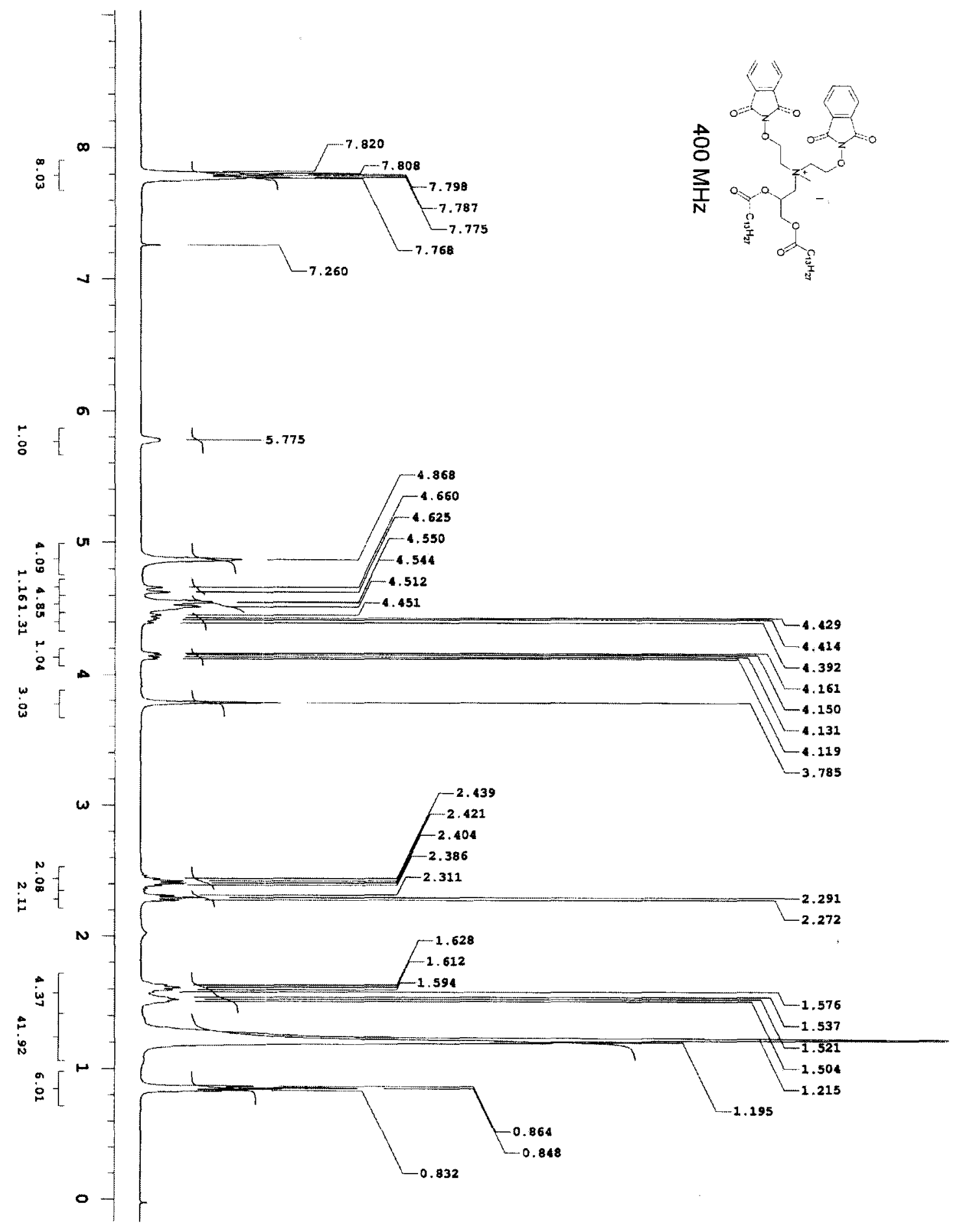

${ }^{1} \mathrm{H}$ NMR spectrum of compound 4.8 


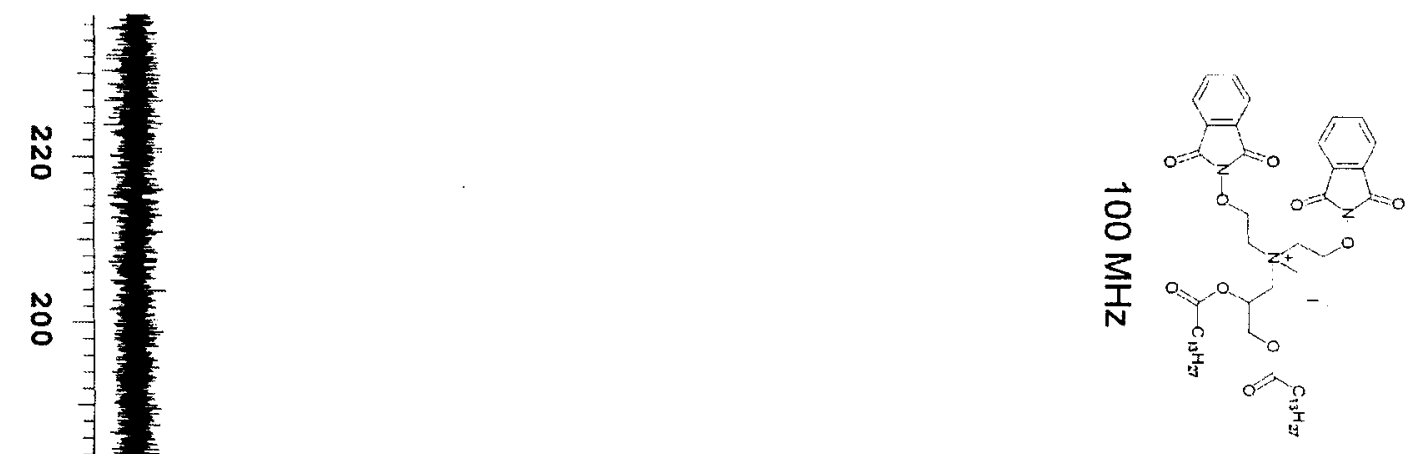

응 $\Gamma^{173.321}$

$-173.019$

영

$\stackrel{5}{\circ}$

N

N

흥

$\infty$

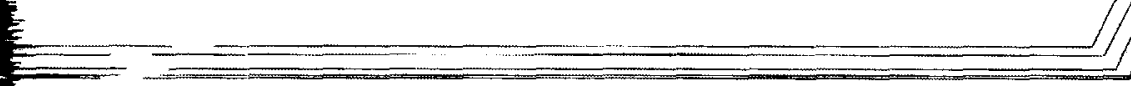

$-163.252$

135.254

$-128.625$

$\Delta$

将

N

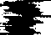

$\circ$

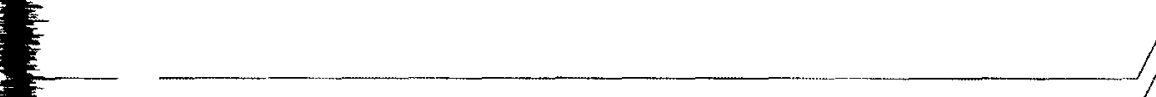

$-51.252$

$-34.492$

$-34.074$

$-32.068$

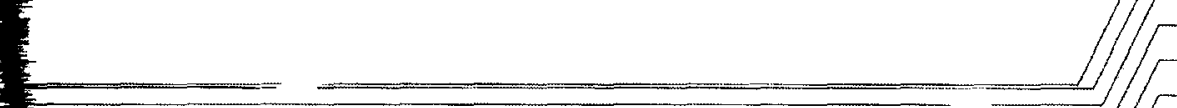

29.838

$-29.814$

29.512

29.288

$-29.264$

$-24.881$

$-24.780$

$-22.836$

$\pi$

$7=$

${ }^{13} \mathrm{C}$ NMR spectrum of compound 4.8 


\subsection{6}

\section{$N, N$-bis(2-(aminooxy)ethyl)-N-methyl-2,3-bis(tetradecanoyloxy)propan-1-aminiu}

m iodide \& $N, N$-bis(2-(aminooxy)ethyl)-N-methyl-2,3-

\section{bis(palmityloxy)propan-1-aminium iodide}

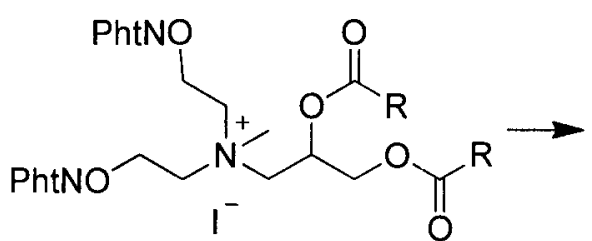

4.8/4.12<smiles>[R]C(=O)OCC(C[N+](C)(CCON)CCON)OC([R])=O</smiles>

4.1/4.2
4.8, 4.1 $R=\mathrm{C}_{13} \mathrm{H}_{27}$ 4.12, 4.2 $\mathrm{R}=\mathrm{C}_{15} \mathrm{H}_{31}$

To the ammonium salt $4.8(0.601 \mathrm{~g}, 0.583 \mathrm{mmol})$ in $\mathrm{CH}_{2} \mathrm{Cl}_{2}(10 \mathrm{~mL})$ was added hydrazine $(177 \mathrm{mg}, 3.50 \mathrm{mmol})$ at $0^{\circ} \mathrm{C}$ and the white percipatition come out. When reaction complete $(\sim 2 \mathrm{~h})$, the percipatition was filtered off. After the solvent was removed by rotary evaporation, the crude residue was purified via silica chromatography using 1:9 $\mathrm{MeOH}: \mathrm{CH}_{2} \mathrm{Cl}_{2}$ as elutent (product $\mathrm{Rf}=0.28$ ) to afford 4.1 as white solid $(0.311 \mathrm{~g}, 67 \%)$. IR(neat) 2955, 2850, 1736, 1467, 1277, 1145, 569, 548 $\mathrm{cm}^{-1}$; m.p. $=125 \sim 127^{\circ} \mathrm{C} ;{ }^{1} \mathrm{H}-\mathrm{NMR}\left(400 \mathrm{MHz}, \mathrm{CDCl}_{3}\right) \delta \mathrm{ppm} 0.86(\mathrm{t}, \mathrm{J}=6.4 \mathrm{~Hz}, 6 \mathrm{H})$, $1.25(40 \mathrm{H}, \mathrm{s}), 1.58(\mathrm{br}, 4 \mathrm{H}), 2.30(\mathrm{t}, \mathrm{J}=7.2 \mathrm{~Hz}, 2 \mathrm{H}), 2.35(\mathrm{t}, \mathrm{J}=7.2 \mathrm{~Hz}, 2 \mathrm{H}), 3.43(\mathrm{~s}$, 3H), 3.90-3.98 (m, 3H), 4.03-4.10 (m, 3H), $4.19(\mathrm{~m}, 2 \mathrm{H}), 4.27-4.31(\mathrm{~m}, 3 \mathrm{H}), 4.53(\mathrm{~d}, \mathrm{~J}$ $=9.6 \mathrm{~Hz}, 1 \mathrm{H}), 5.66(\mathrm{~s}, 1 \mathrm{H}), 6.07(\mathrm{br}, 4 \mathrm{H}) ;{ }^{13} \mathrm{C}-\mathrm{NMR}\left(100 \mathrm{MHz}, \mathrm{CDCl}_{3}\right) \delta \mathrm{ppm}$ 14.31, $22.88,24.90,24.95,29.33,29.37,29.54,29.57,29.75,29.88,29.92,32.12,34.25$, $34.51,51.31,62.50,63.49,65.81,69.08,65.74,173.17,173.54$. HRMS (ESI) calcd. for $\mathrm{C}_{36} \mathrm{H}_{74} \mathrm{~N}_{3} \mathrm{O}_{6}^{+}\left[\mathrm{M}^{+}\right]: 644.5572$, found: 644.5582 .

Using the same method, compound 4.2 can be made from compound 4.12 in $52 \%$ yield. ${ }^{1} \mathrm{H}-\mathrm{NMR}\left(500 \mathrm{MHz}, \mathrm{CDCl}_{3}\right) \delta \mathrm{ppm} 0.86(\mathrm{t}, \mathrm{J}=6.5 \mathrm{~Hz}, 6 \mathrm{H}), 1.24(48 \mathrm{H}, \mathrm{s})$, $1.58(\mathrm{~m}, 4 \mathrm{H}), 2.30(\mathrm{t}, \mathrm{J}=7.0 \mathrm{~Hz}, 2 \mathrm{H}), 2.35(\mathrm{t}, \mathrm{J}=7.0 \mathrm{~Hz}, 2 \mathrm{H}), 3.44(\mathrm{~s}, 3 \mathrm{H}), 3.91-4.10$ 
$(\mathrm{m}, 6 \mathrm{H}), 4.18(\mathrm{t}, \mathrm{J}=9.0 \mathrm{~Hz}, 2 \mathrm{H}), 4.28(\mathrm{~m}, 3 \mathrm{H}), 4.53(\mathrm{~d}, \mathrm{~J}=11.5 \mathrm{~Hz}, 1 \mathrm{H}), 5.66(\mathrm{~s}, 1 \mathrm{H})$, $6.08(\mathrm{br}, 4 \mathrm{H}) ;{ }^{13} \mathrm{C}$ NMR $\left(125 \mathrm{MHz}, \mathrm{CDCl}_{3}\right) \delta \mathrm{ppm} 14.41,22.70,22.74,23.00,25.02$, $25.06,29.44,29.49,29.68,29.87,30.04,32.23,34.37,34.62,51.43,62.60,62.89$, 63.60, 65.91, 69.22 173.28, 173.66; HRMS (ESI) calcd. for $\mathrm{C}_{40} \mathrm{H}_{82} \mathrm{~N}_{3} \mathrm{O}_{6}{ }^{+}$ $\left[\mathrm{M}^{+}\right]: 700.6198$, found: 700.6201 . 


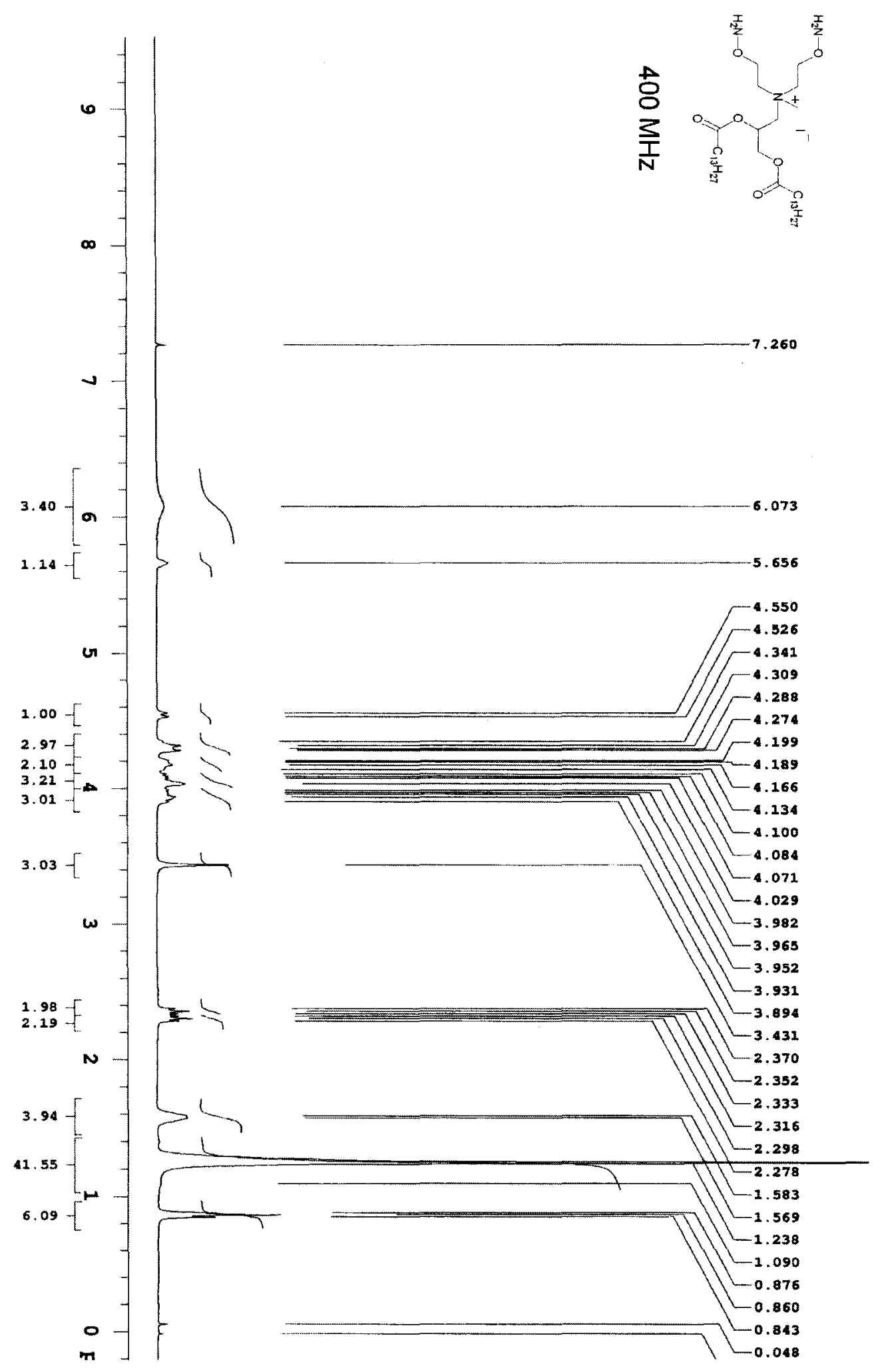

${ }^{1} \mathrm{H}$ NMR spectrum of compound 4.1 


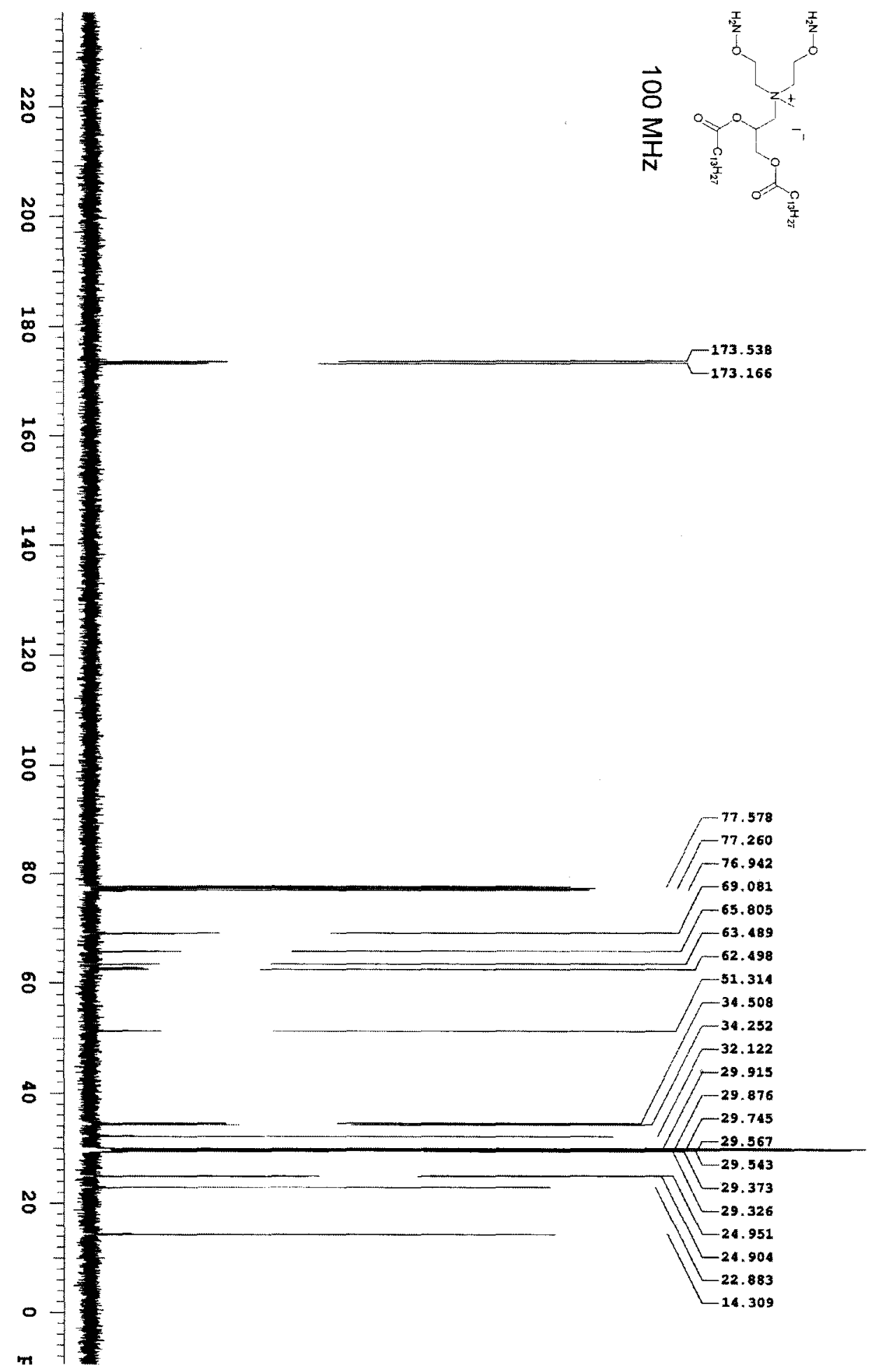

${ }^{13} \mathrm{C}$ NMR spectrum of compound 4.1 


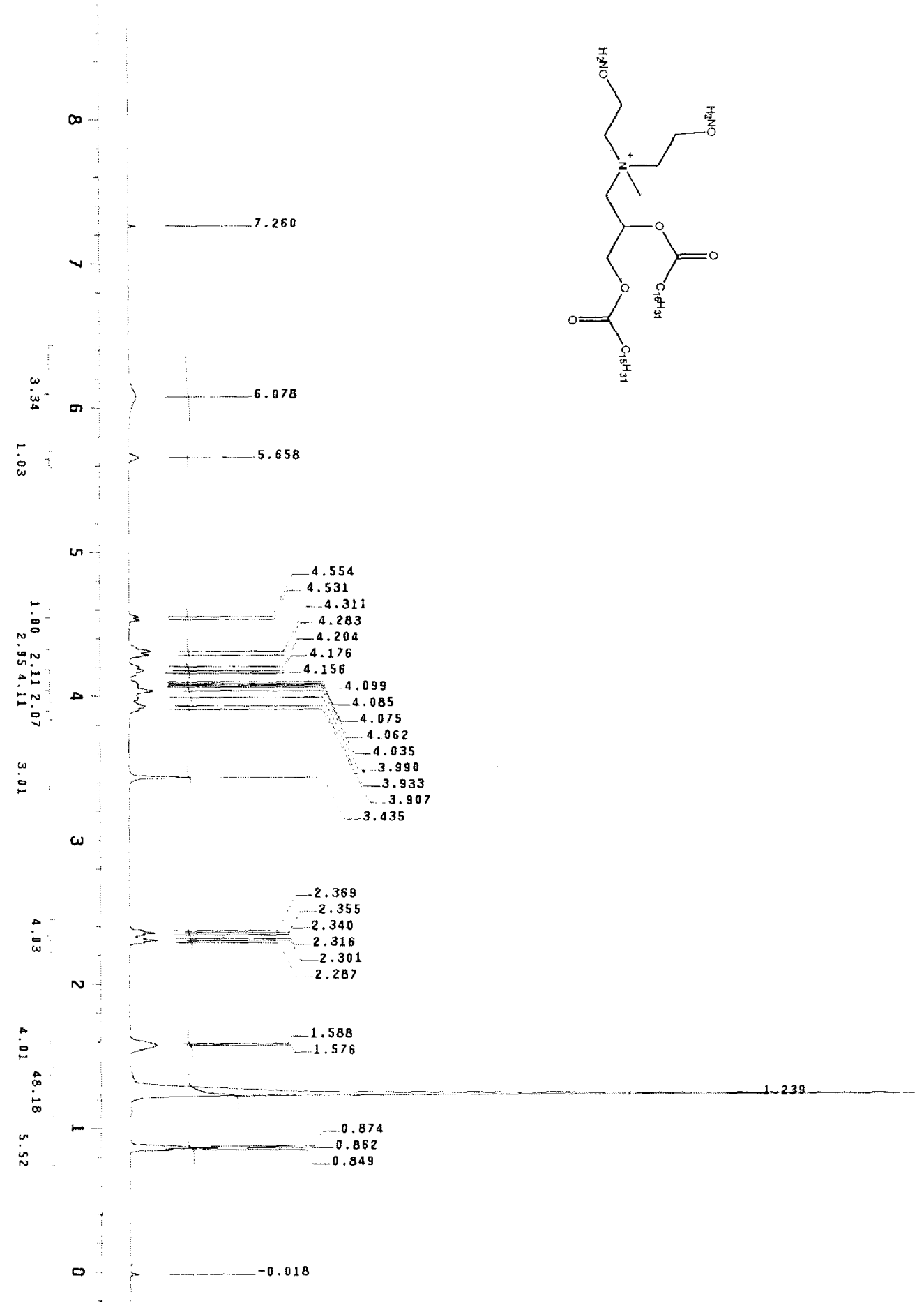

${ }^{1} \mathrm{H}$ NMR spectrum of compound $\mathbf{4 . 2}$ 


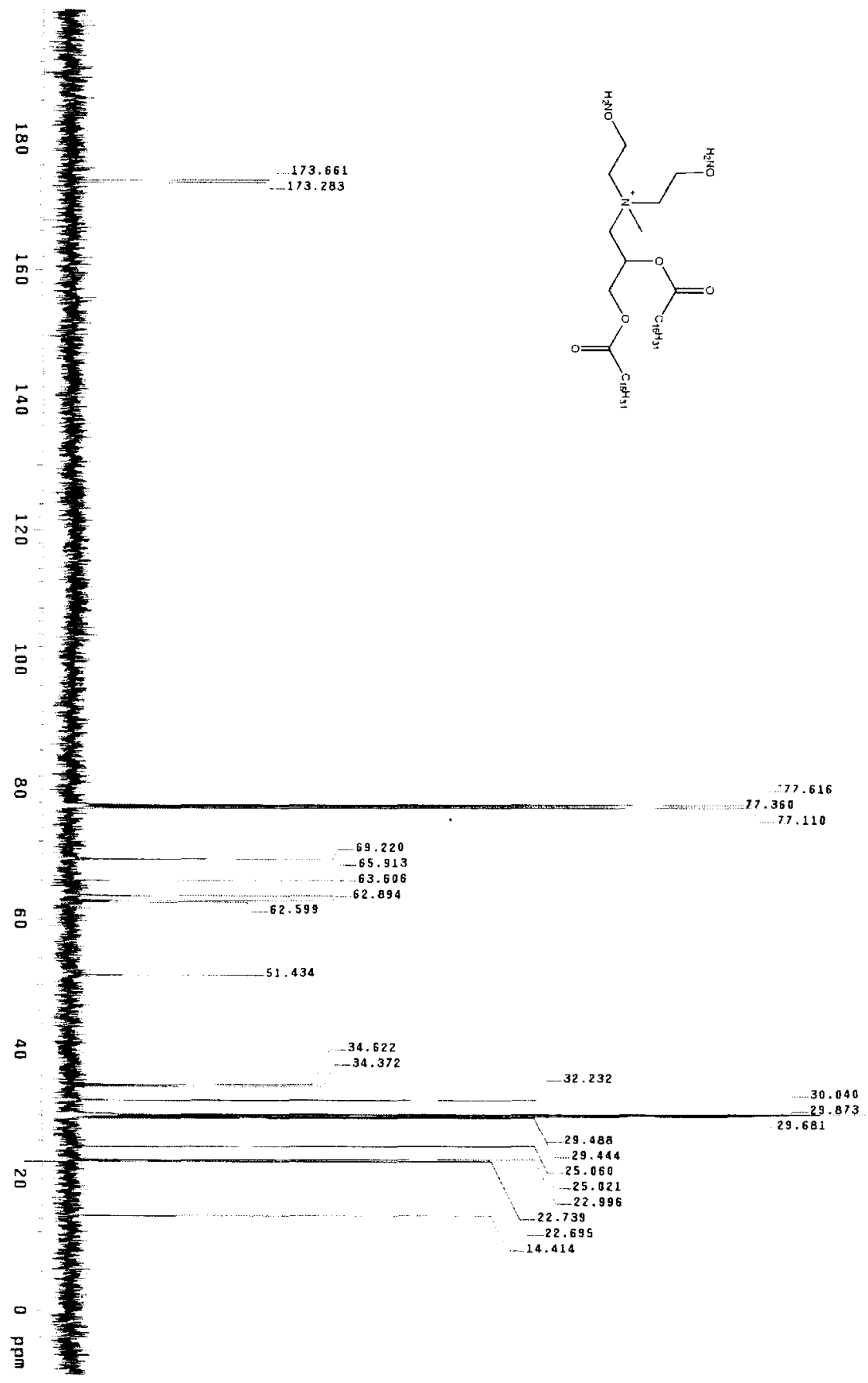

${ }^{13} \mathrm{C}$ NMR spectrum of compound 4.2 


\subsubsection{2-((tert-butyldimethylsilyl)oxy)- $N$-methylethanamine}

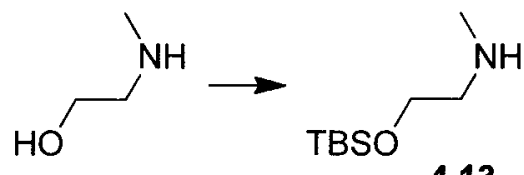

Add 2-methylaminoethanol $(5.0 \mathrm{~g}, 66.6 \mathrm{mmol})$, dichloromethane $(220 \mathrm{~mL})$, triethylamine $(11.2 \mathrm{~mL}, 79.9 \mathrm{mmol})$, and imidazole $(11.33 \mathrm{~g}, 166.4 \mathrm{mmol})$ to a round bottom flask fitted with a stir bar, $\mathrm{N}_{2}$ sweep, and an addition funnel. Cool to $0^{\circ} \mathrm{C}$ with an ice water bath. Dissolve the TBSCl $(12.1 \mathrm{~g}, 79.9 \mathrm{mmol})$ in dry DCM and add dropwise to the reactor through the addition funnel. Keep temperature between $0-10{ }^{\circ} \mathrm{C}$. After addition is complete, let the reaction warm to room temperature and stir for $\sim 12$ hours. Determine reaction completeness by TLC (silica, 10\% MeOH-DCM, $\mathrm{I}_{2}$ stain). When complete, add $200 \mathrm{~mL}$ DI water to the cooled reaction through the addition funnel. Separate off the water and wash the organic phase with saturated $\mathrm{NaHCO}_{3}$ (aq.) solution. Separate the layer and combine the water layers. Extract the water layer twice with diethyl ether and combine extractions with the organic phase. Wash organic phase with brine and dry over $\mathrm{Na}_{2} \mathrm{SO}_{4}$. Rota-vap off solvent. Flash distill product to afford product $\mathbf{4 . 1 3}$ in $102 \%$ yield (a pot temperature of $89^{\circ} \mathrm{C}$, the head temperature at $64^{\circ} \mathrm{C}$, and the pressure at $\sim 33$ torr, ended at a pot temperature of $113^{\circ} \mathrm{C}$.). Estimated b.p. $\sim 157^{\circ} \mathrm{C}$ at 760 torr. $\quad(\mathrm{Rf}=0.34$ TLC, silica 10\% MeOH-DCM) 1H NMR (400 MHz, CDCl $)_{3}$ \& 3.67-3.64 (dd, $\mathrm{J}=4.8,4.0 \mathrm{~Hz}$, $2 \mathrm{H} \mathrm{OCH} \mathrm{CH}_{2}$ ), 2.62-2.59 (dd, J = 5.0, $\left.5.0 \mathrm{~Hz}, 2 \mathrm{H}, \mathrm{CH}_{2} \mathrm{CH}_{2} \mathrm{NH}\right), 2.39-2.35(\mathrm{~d}, \mathrm{~J}=4.0 \mathrm{~Hz}$, $\left.3 \mathrm{H}, \mathrm{NCH}_{3}\right), 0.85-0.81\left(\mathrm{~m}, 9 \mathrm{H}, \mathrm{SiC}\left(\mathrm{CH}_{3}\right)_{3}\right), 0.01--0.02\left(\mathrm{~m}, 6 \mathrm{H}, \mathrm{Si}\left(\mathrm{CH}_{3}\right)_{2}\right)$. 


\subsubsection{3-((2-((tert-butyldimethylsilyl)oxy)ethyl)(methyl)amino)propane-1,2-diol}

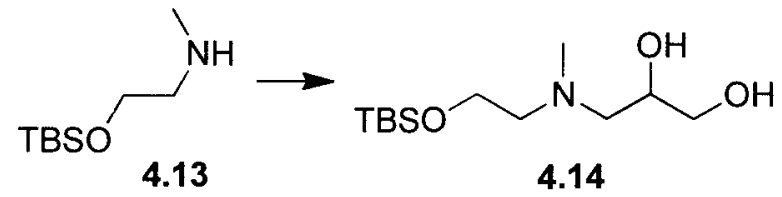

To a mixture of glycidol $(6.47 \mathrm{~g}, 87.30 \mathrm{mmol})$ and $\mathrm{LiClO}_{4}(3.49 \mathrm{~g}, 32.84 \mathrm{mmol})$ in absolute ethanol $(100 \mathrm{~mL})$ the protected amine 4.13 was added dropwise with stirring and an ice water bath. Allow the reaction to warm to room temperature and stirred for $\sim 16$ hours. Determine reaction completeness by TLC (silica, 10\% MeOH-DCM, $I_{2}$ stain). When complete, rota-vap off the ethanol then add ethyl acetate $(170 \mathrm{~mL})$. Wash with saturated $\mathrm{NaHCO}_{3}(\mathrm{aq}$.) solution $(3 \times 100 \mathrm{~mL})$ and then wash with brine (1 $1 \times 100 \mathrm{~mL})$. Dry over $\mathrm{Na}_{2} \mathrm{SO}_{4}$ the rota-vap off solvent. Flash chromatography on silica using $4 \rightarrow 10 \% \mathrm{MeOH}-\mathrm{DCM}$ gave the aminodiol ( $7.44 \mathrm{~g}, 43.0 \%$ over two columns) as a yellow oil $\left(R f=0.35, T L C\right.$, silica $10 \% \mathrm{MeOH}-\mathrm{DCM}, \mathrm{I}_{2}$ stain $) . \quad{ }^{1} \mathrm{H} \mathrm{NMR}(400 \mathrm{MHz}$, $\left.\mathrm{CDCl}_{3}\right) \delta 3.76-3.72(\mathrm{~m}, 1 \mathrm{H}, \mathrm{CH}(\mathrm{OH})), 3.68-3.66\left(\mathrm{dd}, \mathrm{J}=5.6,5.6 \mathrm{~Hz}, 2 \mathrm{H}, \mathrm{OCH}_{2}\right)$, 3.62-3.58 (dd, J = 8.0, 3.6 Hz, 1H, CH(H)OH), 3.46-3.43(dd, J = 6.4, $5.2 \mathrm{~Hz}, 1 \mathrm{H}$, $\mathrm{CH}(\mathrm{H}) \mathrm{OH}$ ), $3.35(\mathrm{~s}, 2 \mathrm{H}, 2 \times \mathrm{OH}), 2.69-2.65(\mathrm{dd}, \mathrm{J}=6.8,6.4 \mathrm{~Hz}, 1 \mathrm{H} \mathrm{NCH}(\mathrm{H}) \mathrm{CHOH}$ ), 2.61-2.56 (dd, J = 7.2, 5.8 Hz, 2H, $\mathrm{CH}_{2} \mathrm{CH}_{2} \mathrm{~N}$ ), 2.50-2.46 (dd, J = 8.4, $1 \mathrm{H} 4.0 \mathrm{~Hz}$, $\mathrm{NCH}(\mathrm{H}) \mathrm{CHOH}), 2.36\left(\mathrm{~s}, 3 \mathrm{H}, \mathrm{NCH}_{3}\right), 0.82\left(\mathrm{~s}, 9 \mathrm{H}, \mathrm{SiC}\left(\mathrm{CH}_{3}\right)_{3}\right),-0.01\left(\mathrm{~s}, 6 \mathrm{H}, \mathrm{Si}\left(\mathrm{CH}_{3}\right)_{2}\right)$. 


\subsubsection{3-((2-((tert-butyldimethylsilyl)oxy)ethyl)(methyl)amino)propane}

\section{-1,2-diyl dipalmitate}

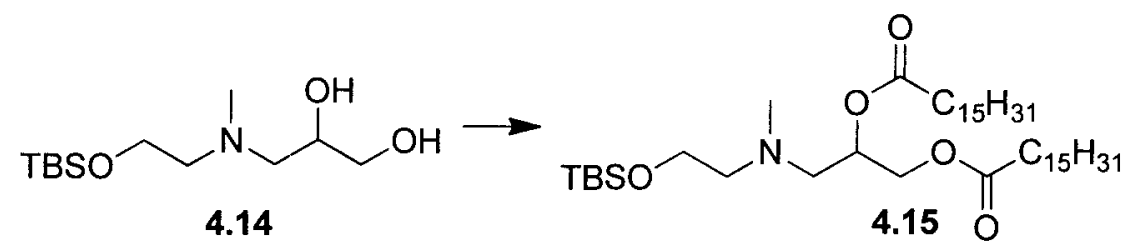

To a round bottom flask add diol $4.14(2.09 \mathrm{~g}, 7.94 \mathrm{mmol})$, DMAP $(0.10 \mathrm{~g}, 0.79$ $\mathrm{mmol}), \mathrm{Et}_{3} \mathrm{~N}(3.35 \mathrm{~mL}, 23.8 \mathrm{mmol})$, and $\mathrm{DCM}(68 \mathrm{~mL})$ and cool with an ice water bath. Add palmitoyl chloride $(5.46 \mathrm{~g}, 19.9 \mathrm{mmol})$ in solution with $\mathrm{DCM}(22 \mathrm{ml})$ to the reaction dropwise. Allow to warm to room temperature and stir overnight. Determine reaction completeness by TLC (silica, $5 \%$ EtOAc-Hexanes, $I_{2}$ stain). When complete, dilute product with hexane and wash $3 x$ with $\mathrm{NaHCO}_{3}$ (aq.) solution. A rag will form. Separate off rag layer and add a small amount of $\mathrm{HCl}($ aq.) and stir to break rag. Keep $\mathrm{pH} \sim 7$. Extract the rag layer $2 x$ with hexanes and combine with the organic phase. Wash organic with brine and dry over $\mathrm{Na}_{2} \mathrm{SO}_{4}$. Rota-vap off hexanes. Flash chromatography on silica using $4 \rightarrow 14 \%$ EtOAc-Hexanes gave the diester 4.15 (4.97 $\mathrm{g}, 84.5 \%)$ as a yellow oil $\left(R f=0.28, T L C\right.$, silica $5 \%$ EtOAc-Hexanes, $I_{2}$ stain). ${ }^{1} \mathrm{H} N M R$ $\left(400 \mathrm{MHz}, \mathrm{CDCl}_{3}\right) \delta 5.12\left(\mathrm{~m}, 1 \mathrm{H}, \mathrm{CH}\left(\mathrm{O}_{2} \mathrm{C}_{16}\right), 4.34-4.31\right.$ (dd, $\mathrm{J}=12.0 \mathrm{~Hz}, 1 \mathrm{H}$, $\left.\mathrm{CH}(\mathrm{H}) \mathrm{O}_{2} \mathrm{C}_{16}\right), 4.08-4.06\left(\mathrm{~m}, 1 \mathrm{H}, \mathrm{CH}(\mathrm{H}) \mathrm{O} 2 \mathrm{C}_{16}\right), 3.63-3.62(\mathrm{dd}, \mathrm{J}=3.2,2 \mathrm{H}$, $\left.\mathrm{OCH}_{2} \mathrm{CH}_{2} \mathrm{~N}\right), 2.54-2.53\left(\mathrm{~m}, 4 \mathrm{H}, \mathrm{CH}_{2} \mathrm{NCH}_{2}\right), 2.27\left(\mathrm{~s}, 3 \mathrm{H}, \mathrm{NCH}_{3}\right), 2.24(\mathrm{~m}, 4 \mathrm{H}, 2 \times$ $\left.\mathrm{CO}_{2} \mathrm{CH}_{2}\right), 1.56\left(\mathrm{~m}, 4 \mathrm{H}, 2 \times \mathrm{CO}_{2} \mathrm{CH}_{2} \mathrm{CH}_{2}\right), 1.22\left(\mathrm{~m}, 48 \mathrm{H}, 2 \times\left(\mathrm{CH}_{2}\right)_{12}\right), 0.85(\mathrm{~m}, 6 \mathrm{H}, 2 \times$ $\left.\left(\mathrm{CH}_{2}\right)_{12} \mathrm{CH}_{3}\right), 0.84\left(\mathrm{~s}, 9 \mathrm{H}, \mathrm{SiC}\left(\mathrm{CH}_{3}\right)_{3}\right), 0.01-0.00\left(\mathrm{~m}, 6 \mathrm{H}, \mathrm{Si}\left(\mathrm{CH}_{3}\right)_{2}\right)$. 


\subsubsection{3-((2-hydroxyethyl)(methyl)amino)propane-1,2-diyl dipalmitate}

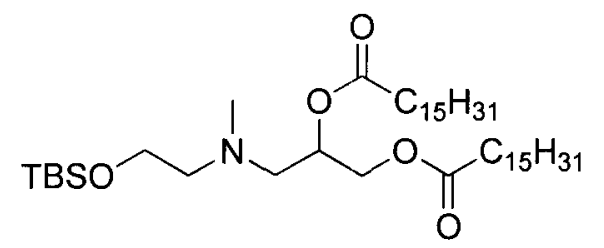

4.15

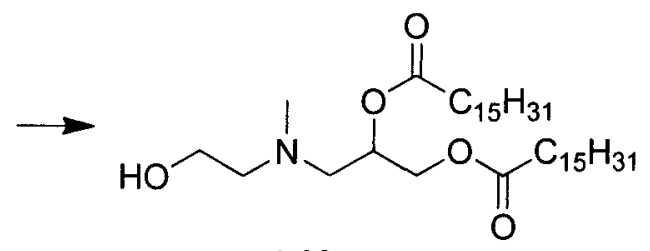

4.16

Dissolve the amine $4.15(2.43 \mathrm{~g}, 3.28 \mathrm{mmol})$ in THF $(49 \mathrm{~mL})$ and cool with an ice water bath. Add 1M TBAF solution in THF $(4.27 \mathrm{~mL}, 4.27 \mathrm{mmol})$ dropwise through an addition funnel, then stir overnight while allowing to warm to room temperature. Determine reaction completeness by TLC (silica, $50 \%$ EtOAC-Hexanes, $\mathrm{I}_{2}$ stain). When complete, dilute reaction with diethyl ether and wash with $\mathrm{NaHCO}_{3(\mathrm{aq})}$ solution $(3 \times 75 \mathrm{~mL})$. Extract the water layer with $\mathrm{Et}_{2} \mathrm{O}$, then wash combined organic layers with brine $(75 \mathrm{~mL})$. Rota-vap off solvent. Flash chromatography on silica using $40 \rightarrow 70 \%$ $\mathrm{EtO}_{2}-\mathrm{Hexanes}$ gave the deprotected alcohol $4.16(1.50 \mathrm{~g}, 74.1 \%)$ as a white amorphous powder $\left(\mathrm{Rf}=0.53, \mathrm{TLC}\right.$, silica $50 \%$ EtOAC-Hexanes, $\mathrm{I}_{2}$ stain). ${ }^{1} \mathrm{H}$ NMR $\left(400 \mathrm{MHz}, \mathrm{CDCl}_{3}\right) \delta 5.23-5.21$ (dd, $J=3.2,2.8 \mathrm{~Hz}, 1 \mathrm{H}, \mathrm{CH}\left(\mathrm{CO}_{2}\right), 4.37-4.33$ (dd, $J=8.8$, $3.0 \mathrm{~Hz}, 1 \mathrm{H}, \mathrm{CHCH}(\mathrm{H}) \mathrm{O}), 4.14-4.10(\mathrm{dd}, J=6.0,5.8 \mathrm{~Hz}, 1 \mathrm{H}, \mathrm{CHCH}(\mathrm{H}) \mathrm{O}), 3.60-3.58$ (dd, $\left.J=5.0,5.0 \mathrm{~Hz}, 2 \mathrm{H}, \mathrm{HOCH} \mathrm{H}_{2}\right), 2.64-2.60\left(\mathrm{~m}, 4 \mathrm{H}, \mathrm{CH}_{2} \mathrm{NCH}_{2}\right), 2.35\left(\mathrm{~s}, 3 \mathrm{H}, \mathrm{NCH}_{3}\right.$ ), 2.34-2.32 (m, $\left.4 \mathrm{H}, 2 \times \mathrm{CO}_{2} \mathrm{CH}_{2}\right), 1.66-1.63\left(\mathrm{dd}, \mathrm{J}=6.6,6.6 \mathrm{~Hz}, 4 \mathrm{H}, 2 \times \mathrm{CO}_{2} \mathrm{CH}_{2} \mathrm{CH}_{2}\right)$, $1.46(\mathrm{~s}, 1 \mathrm{H}, \mathrm{OH}), 1.32-1.29\left(\mathrm{~m}, 48 \mathrm{H}, 2 \times\left(\mathrm{CH}_{2}\right)_{12}\right), 0.93-0.90(\mathrm{dd}, \mathrm{J}=6.8,6.8 \mathrm{~Hz}, 6 \mathrm{H}$, $\left.2 \times\left(\mathrm{CH}_{2}\right)_{12} \mathrm{CH}_{3}\right) ;{ }^{13} \mathrm{C}$ NMR $(100 \mathrm{MHz}) \delta 172.2,172.0,69.6,64.0,60.1,59.1,58.2$, $43.3,35.3,35.0,32.8,30.7,30.6,30.6,30.5,30.3,30.3,30.1,30.1,26.0,25.9,23.8$, 15.3. 


\subsubsection{3-( (2-phthalimidooxyethyl)(methyl)amino)propane-1,2-diyl dipalmitate}

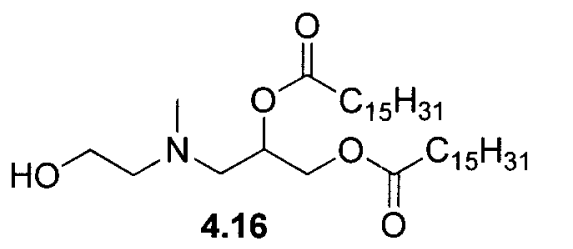

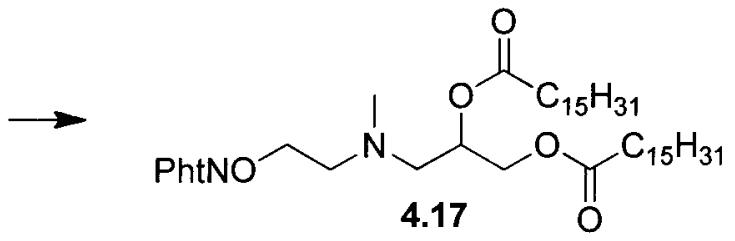

Alcohol 4.16 ( $1.90 \mathrm{~g}, 3.0 \mathrm{mmol}), \mathrm{N}$-hydroxyphthalimide $(645 \mathrm{mg}, 3.95 \mathrm{mmol})$, and triphenylphosphine $(1.04 \mathrm{~g}, 3.95 \mathrm{mmol})$ in THF $(30 \mathrm{~mL})$ was added DIAD $(0.78 \mathrm{~mL}$, $3.95 \mathrm{mmol}$ ) dropwise at $0^{\circ} \mathrm{C}$ under $\mathrm{N}_{2}$. The reaction was then reacted at room temperature overnight. Determine reaction completeness by TLC (silica, 50\% EtOAc-Hexanes, UV light and $I_{2}$ stain). When complete, the THF was evaporated and the residue was dissolved with EtOAc $(60 \mathrm{~mL})$. The organic layer was washed with $\mathrm{NaHCO}_{3}$ (aq.) solution $(3 \times 60 \mathrm{~mL})$ and then extract the combined water layers with EtOAc. The combine organic layers were washed with brine $(60 \mathrm{~mL})$ and dried $\left(\mathrm{Na}_{2} \mathrm{SO}_{4}\right)$. After evaporated solvent, the product was purified by flash chromatography on Teldyne CombiFlash with silica using $10 \rightarrow 25 \%$ EtOAc-Hexanes gave the amino phthalimide $4.17(1.50 \mathrm{~g}, 64 \%)$ as a white amorphous powder ( $R f=0.80, T L C$, silica $50 \%$ EtOAc-Hexanes, UV light and $\mathrm{I}_{2}$ stain). ${ }^{1} \mathrm{H}$ NMR $\left(400 \mathrm{MHz}, \mathrm{CDCl}_{3}\right) \delta 7.82-7.80(\mathrm{~m}$, $2 \mathrm{H}, \mathrm{ArH}), 7.73-7.71(\mathrm{~m}, 2 \mathrm{H}, \mathrm{ArH})$, 5.18-5.16 $\left(\mathrm{m}, 1 \mathrm{H}, \mathrm{CH}\left(\mathrm{O}_{2} \mathrm{C}_{16}\right)\right), 4.36-4.33(\mathrm{dd}, \mathrm{J}=8.8$, $3.2 \mathrm{~Hz}, 1 \mathrm{H}, \mathrm{CHCH}(\mathrm{H}) \mathrm{O}_{2} \mathrm{C}_{16}$ ), 4.27-4.25 (dd, J=5.4, $5.4 \mathrm{~Hz}, 2 \mathrm{H}, \mathrm{OCH}_{2} \mathrm{CH}_{2}$ ), 4.11-4.06 (dd, J=6.4, $\left.5.2 \mathrm{~Hz}, 1 \mathrm{H}, \mathrm{CHCH}(\mathrm{H}) \mathrm{O}_{2} \mathrm{C}_{16}\right), 2.89-2.86\left(\mathrm{~m}, 2 \mathrm{H}, \mathrm{CH}_{2} \mathrm{CH}_{2} \mathrm{~N}\right), 2.68-2.64(\mathrm{~m}$, $2 \mathrm{H}, \mathrm{NCH}_{2} \mathrm{CH}$ ), $2.38\left(\mathrm{~s}, 3 \mathrm{H}, \mathrm{NCH}_{3}\right), 2.29-2.25\left(\mathrm{~m}, 4 \mathrm{H}, 2 \times \mathrm{CO}_{2} \mathrm{CH}_{2}\right.$ ), 1.59-1.54 (dd, $\left.\mathrm{J}=6.8,6.8 \mathrm{~Hz}, 4 \mathrm{H}, \quad 2 \times \mathrm{CO}_{2} \mathrm{CH}_{2} \mathrm{CH}_{2}\right), 1.22\left(\mathrm{~m}, 48 \mathrm{H}, 2 \times\left(\mathrm{CH}_{2}\right)_{12}\right), 0.87-0.83(\mathrm{dd}, \mathrm{J}=6.8$, $\left.6.8 \mathrm{~Hz}, 6 \mathrm{H}, 2 \times \mathrm{CH}_{2} \mathrm{CH}_{3}\right) ;{ }^{13} \mathrm{C} \mathrm{NMR}(100 \mathrm{MHz}) \delta 172.2,171.9,162.3,133.8,128.3$, $123.0,76.5,69.7,64.2,57.9,56.4,43.9,35.3,35.1,32.9,30.7,30.6,30.6,30.6,30.5$, $30.3,30.3,30.1,30.1,26.0,26.0,23.8,15.3$. 


\subsubsection{3-((2-hydroxyethyl)(methyl)amino)propane-1,2-diyl dipalmitate}

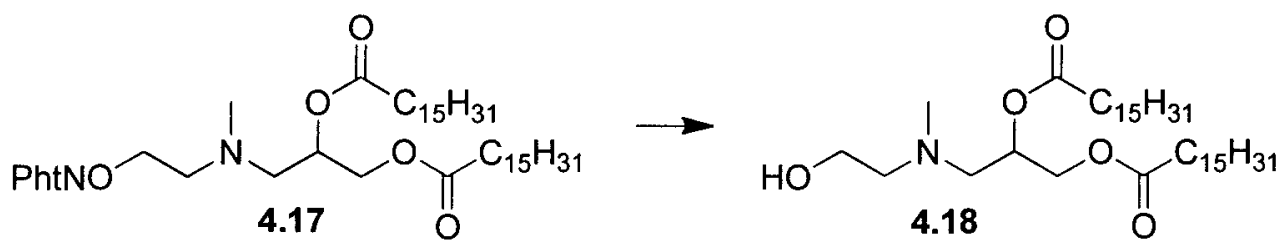

The amine $4.17(522 \mathrm{mg}, 0.68 \mathrm{mmol})$ in dichloromethane $(90 \mathrm{~mL})$ was added $\mathrm{N}_{2} \mathrm{H}_{4} \cdot \mathrm{H}_{2} \mathrm{O}(170 \mathrm{mg}, 3.39 \mathrm{mmol})$ at $0^{\circ} \mathrm{C}$. After stirred at $0^{\circ} \mathrm{C}$ for two hours, the reaction mixture was washed with $\mathrm{NaHCO}_{3}$ (aq.) solution $(3 \times 60 \mathrm{~mL})$ then with brine $(60 \mathrm{~mL})$. After dried over $\mathrm{Na}_{2} \mathrm{SO}_{4}$ and rota-vap off solvent, the residue was purified by flash chromatography on Teldyne CombiFlash with silica using $10 \rightarrow 25 \%$ EtOAc-Hexanes gave the aminooxy compound $4.18(0.36 \mathrm{~g}, 69 \%)$ as a white amorphous powder ( $R f=0.28, T L C$, silica 1:1 EtOAc-Hexanes, UV light and $\mathrm{I}_{2}$ stain). ${ }^{1} \mathrm{H}$ NMR $(400 \mathrm{MHz}$, $\left.\mathrm{CDCl}_{3}\right) \delta 5.20-5.18$ (dddd, $\mathrm{J}=3.2,3.2,3.2,3.2 \mathrm{~Hz}, 1 \mathrm{H}, \mathrm{CH}\left(\mathrm{O}_{2} \mathrm{C}_{16}\right), 4.39-4.35$ (dd, $\mathrm{J}=$ 8.8, 3.0 Hz, $\left.1 \mathrm{H}, \mathrm{CHCH}(\mathrm{H}) \mathrm{O}_{2} \mathrm{C}_{16}\right), 4.13-4.09$ (dd, J = 5.2, $6.4 \mathrm{~Hz}, 1 \mathrm{H}, \quad \mathrm{CHCH}(\mathrm{H}) \mathrm{O}_{2} \mathrm{C}_{16}$ ), 3.75-3.72 (dd, J = 5.4, 5.4 Hz, 2H, OCH $\mathrm{CH}_{2}$ ), 2.66-2.63 (dd, J = 5.4, $5.4 \mathrm{~Hz}, 2 \mathrm{H}$, $\mathrm{CH}_{2} \mathrm{CH}_{2} \mathrm{~N}$ ), 2.58-2.57 (dd, J = 6.4, $6.4 \mathrm{~Hz}, 2 \mathrm{H}, \mathrm{NCH}_{2} \mathrm{CH}$ ), $2.33\left(\mathrm{~s}, 3 \mathrm{H}, \mathrm{NCH}_{3}\right.$ ), 2.32-2.28 (dd, J = 7.6, 7.6 Hz, 4H, $2 \times \mathrm{CO}_{2} \mathrm{CH}_{2}$ ), 1.62-1.59 (dd, J=6.8, $6.8 \mathrm{~Hz}, 4 \mathrm{H}, 2 \mathrm{x}$ $\left.\mathrm{CO}_{2} \mathrm{CH}_{2} \mathrm{CH}_{2}\right), 1.28-1.25\left(\mathrm{~m}, 48 \mathrm{H}, 2 \times\left(\mathrm{CH}_{2}\right)_{12}\right), 0.89-0.86(\mathrm{dd}, \mathrm{J}=6.6,6.6 \mathrm{~Hz}, 6 \mathrm{H}, 2 \times$ $\left.\mathrm{CH}_{2} \mathrm{CH}_{3}\right) ;{ }^{13} \mathrm{C}$ NMR $(100 \mathrm{MHz}) \delta 173.8,173.4,73.5,69.6,64.1,57.9,56.6,43.6,34.6$, $34.4,32.1,29.9,29.9,29.8,29.7,29.6,29.5,29.4,29.3,25.2,25.1,22.9,14.3$; HRMS (ESI) calcd. for $\mathrm{C}_{38} \mathrm{H}_{77} \mathrm{~N}_{2} \mathrm{O}_{5}{ }^{+}\left[\mathrm{M}^{+}\right] 641.5827$, found 641.5847 . 


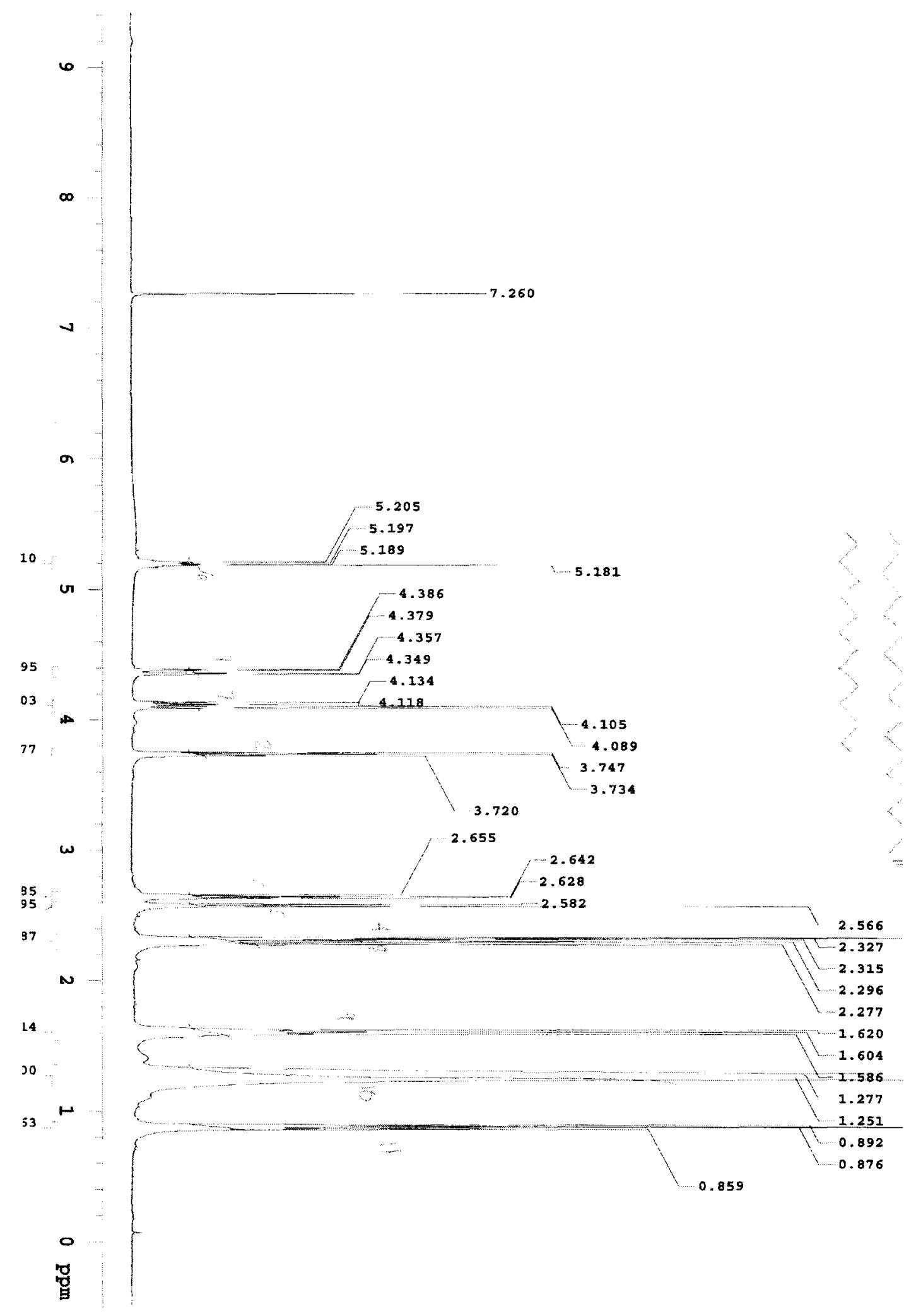

${ }^{1} \mathrm{H}$ NMR spectrum of compound 4.18 


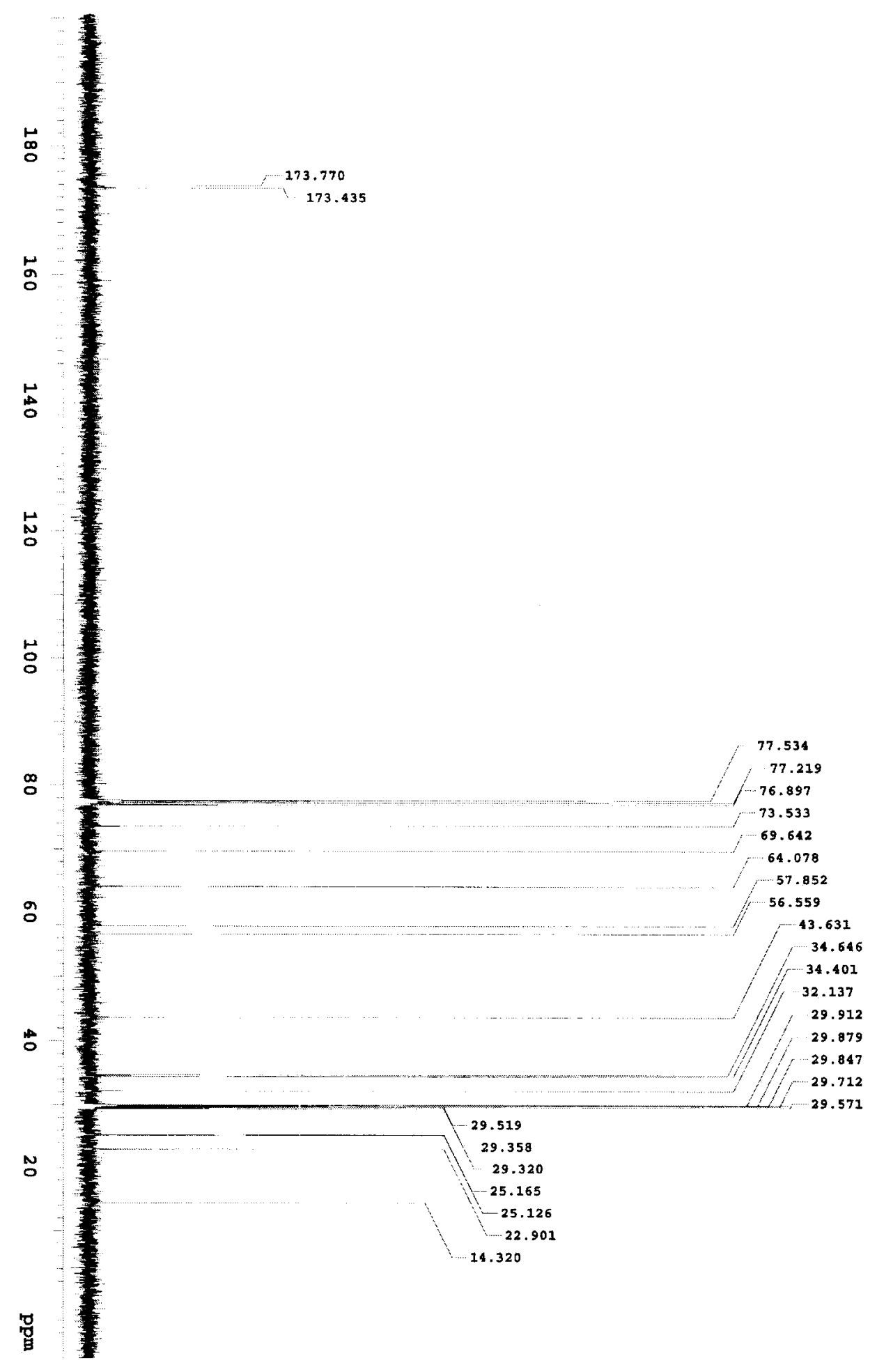

${ }^{13} \mathrm{C}$ NMR spectrum of compound 4.18 


\subsubsection{N-(2-(aminooxy)ethyl)-N,N-dimethyl-2,3-bis(palmitoyloxy)propan}

\section{-1-aminium iodide}

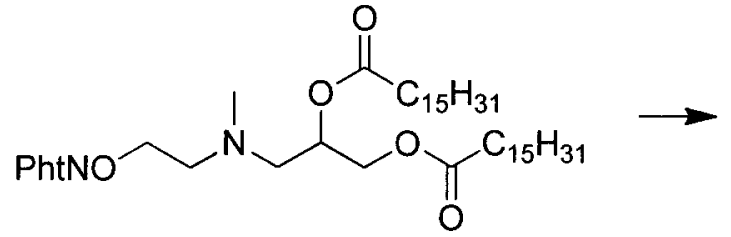

4.17

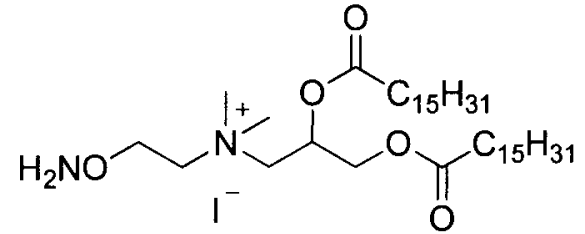

4.3

To a solution of the amine $4.17(500 \mathrm{mg}, 0.65 \mathrm{mmol})$ in $\mathrm{CH}_{2} \mathrm{Cl}_{2}(3 \mathrm{~mL})$ in a sealed tube was added $\mathrm{CH}_{3} \mathrm{l}(888 \mu \mathrm{L}, 14.3 \mathrm{mmol})$. The tube was then sealed and heated to $40-50^{\circ} \mathrm{C}$ for 29 hours. After the solvent was removed, $\mathrm{CH}_{2} \mathrm{Cl}_{2}(10 \mathrm{~mL})$ and hydrazine (168 $\mu \mathrm{L}, 3.47 \mathrm{mmol}$ ) was added at $0^{\circ} \mathrm{C}$. The mixture was stirred overnight while slowly warming to room temperature. Mixture turned from opaque yellow to opaque white upon addition of hydrazine. Determine reaction completeness by TLC (silica, 10\% MeOH-DCM, UV light and PMA stain). When complete, filter off solids and rota-vap off solvent. Flash chromatography with silica using $4-10 \% \mathrm{MeOH}$ in $\mathrm{DCM}$ gave the salt $4.3(0.278 \mathrm{~g}, 55 \%)$ as a white amorphous powder $\left(\mathrm{Rf}=0.291: 9 \mathrm{MeOH}: \mathrm{CH}_{2} \mathrm{Cl}_{2}, \mathrm{UV}\right.$ light and PMA stain). ${ }^{1} \mathrm{H}$ NMR $\left(400 \mathrm{MHz}, \mathrm{CDCl}_{3}\right) \delta 5.98(\mathrm{br} \mathrm{s}, 1 \mathrm{H}), 5.65(\mathrm{~s}, 1 \mathrm{H})$, 4.54-4.51 (dd, J = 12.0 Hz, 1H), 4.44-4.40 (dd, J = 14.0 Hz, 1H,), 4.28-4.22 (dd, J = 7.6, $6.2 \mathrm{~Hz}, 1 \mathrm{H}), 4.14-4.11(\mathrm{dd}, \mathrm{J}=8.0,4.4 \mathrm{~Hz}, 1 \mathrm{H}), 4.09-4.06(\mathrm{dd}, \mathrm{J}=6.6,6.6 \mathrm{~Hz}, 2 \mathrm{H}$ ), 4.02-3.97 (dd, J = 8.8, $5.4 \mathrm{~Hz}, 1 \mathrm{H}), 3.94-3.89(\mathrm{dd}, \mathrm{J}=8.6,6.0 \mathrm{~Hz}, 1 \mathrm{H}), 3.51(\mathrm{~s}, 3 \mathrm{H})$, $3.49(\mathrm{~s}, 3 \mathrm{H}), 2.38-2.32(\mathrm{dd}, \mathrm{J}=8.4,7.6 \mathrm{~Hz}), 1.61-1.59(\mathrm{~d}, \mathrm{~J}=6.8 \mathrm{~Hz}, 4 \mathrm{H}), 1.25(\mathrm{~m}$, $48 \mathrm{H}), 0.89-0.86(\mathrm{dd}, \mathrm{J}=6.6,6.6 \mathrm{~Hz}, 6 \mathrm{H}) ;{ }^{13} \mathrm{C}$ NMR $(100 \mathrm{MHz}) \delta 171.9,171.5,69.1$, $65.9,64.2,63.5,53.7,35.1,34.9,32.9,30.7,30.6,30.5,30.5,30.3,30.3,30.2,30.1$, $30.1,25.8,25.7,23.8,15.3$; HRMS calcd. for $\mathrm{C}_{39} \mathrm{H}_{79} \mathrm{~N}_{2} \mathrm{O}_{5}^{+}\left[\mathrm{M}^{+}\right]: 655.5984$, found: 655.5997. 
Sample: RJK-I-33

Sapple ID: Ralphx 2010062801

711e: Relphr 20100628_01/data/Proton 01. fid

Pul se Sequence: s2pul

Solvent: ede13

Tomp. $25.0 \mathrm{C} / 290.1 \mathrm{x}$

Operator: Rulphr

F11.: Proton 01

VNMRS -400 -ulnmr400.

Relax. delay 1.000 sec

Pulae 45.0 degrees

Acq. tim $2.048 \mathrm{sec}$

W1dth 2006.4 Hz

16 repetitions
OBSERV H1, $399.7698128 \mathrm{mgr}$

OBSERV H1, 390

DATA PROCESSING

Resol. Snbancent

time $O \mathrm{~min}, 55 \mathrm{sec}$

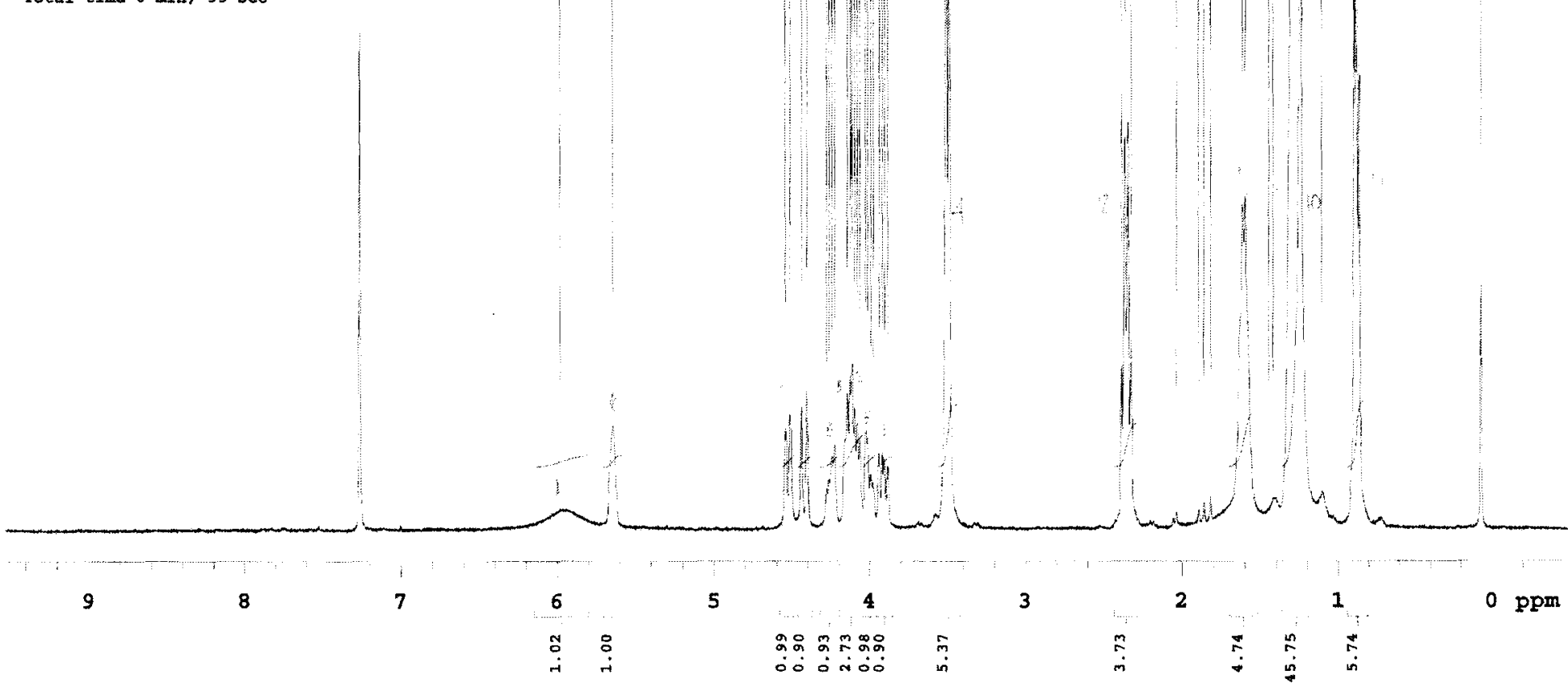




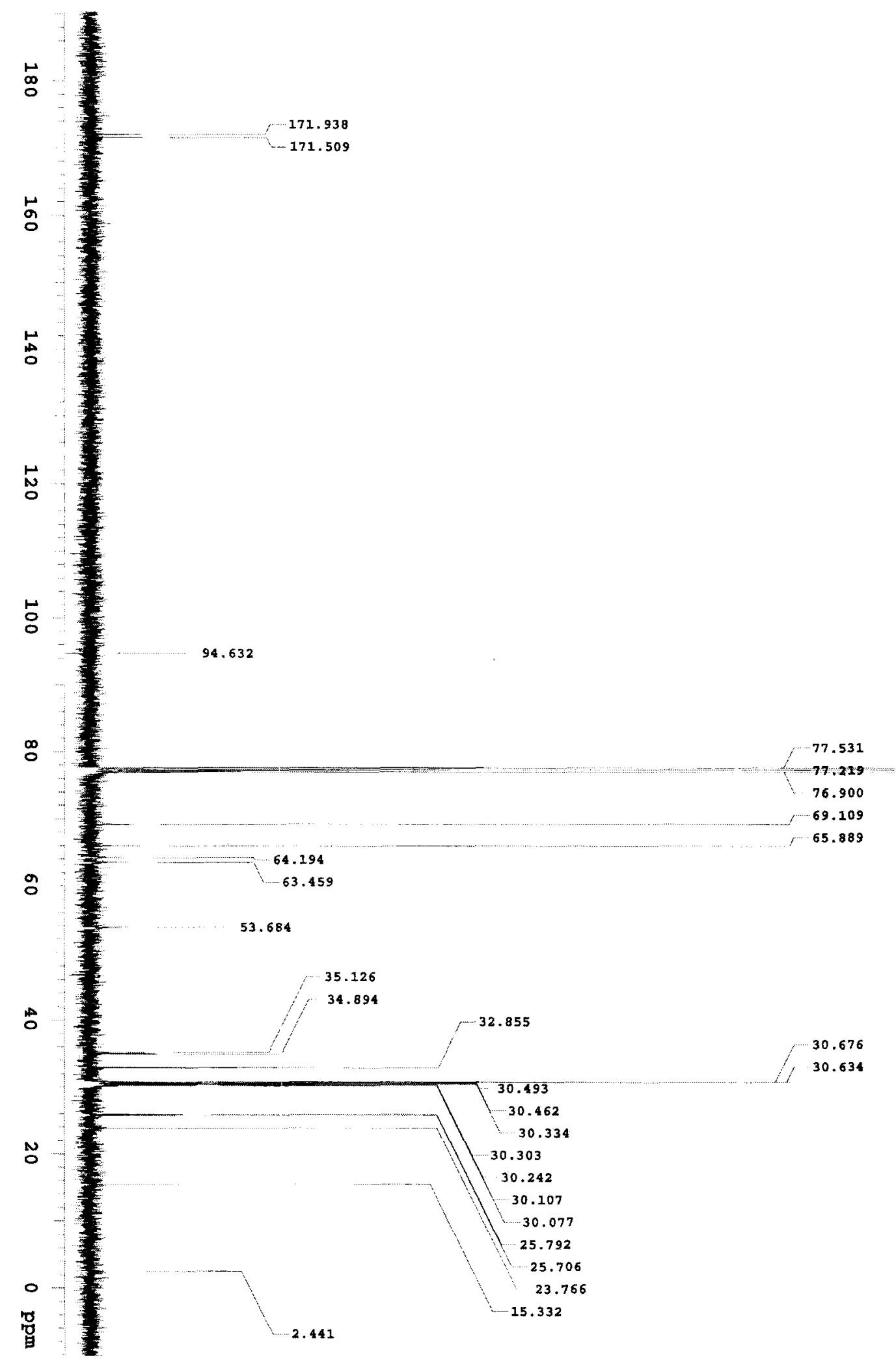

${ }^{13} \mathrm{C}$ NMR spectrum of compound 4.3 


\subsubsection{3-(bis(2-(aminooxy)ethyl)amino)propane-1,2-diyl ditetradecanoate}

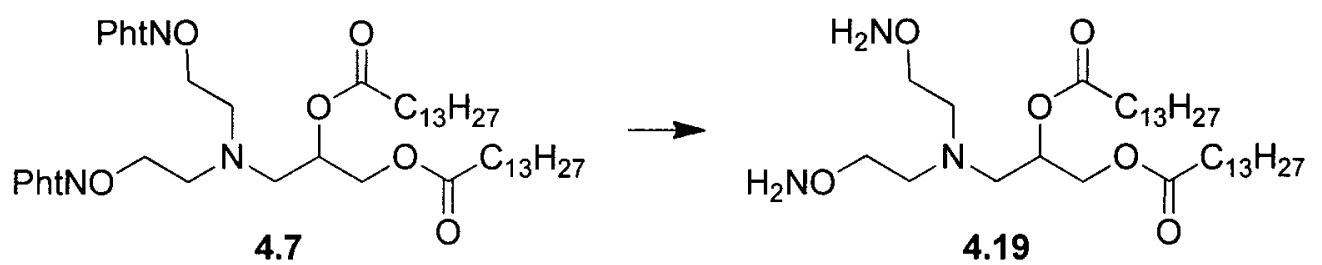

To a solution of the amine $4.7(0.67 \mathrm{~g}, 0.75 \mathrm{mmol})$ in dichloromethane $(3 \mathrm{~mL})$ was added hydrazine $(0.225 \mathrm{~g}, 4.5 \mathrm{mmol})$ at $0^{\circ} \mathrm{C}$. After filter off precipitation, the organic solution was washed by sat. $\mathrm{NaHCO}_{3}$, brine and then dried $\left(\mathrm{Na}_{2} \mathrm{SO}_{4}\right)$. After removed solvent by rota-vap, the crude product was purified by column chromatography $\left(\mathrm{SiO}_{2}\right)$ eluting with $3 \% \mathrm{MeOH}$ in DCM and give product $4.19(0.44 \mathrm{~g}, 94 \%)$ as white solid. (Rf $=0.29$, ethylacetate). ${ }^{1} \mathrm{H}$ NMR $\left(400 \mathrm{MHz}, \mathrm{CDCl}_{3}\right) \delta 5.45(\mathrm{br} \mathrm{s}, 1 \mathrm{H}), 5.11(\mathrm{~m}, 1 \mathrm{H}), 4.38$ (d, J = 12.0 Hz, 1H), $4.08(d d, J=12.0,6.4 \mathrm{~Hz}, 1 \mathrm{H}), 3.67(\mathrm{t}, \mathrm{J}=6.4 \mathrm{~Hz}, 4 \mathrm{H}), 2.73(\mathrm{~m}$, 4H), $2.64(\mathrm{~d}, \mathrm{~J}=6.4 \mathrm{~Hz}, 2 \mathrm{H}), 2.24(\mathrm{t}, \mathrm{J}=7.6 \mathrm{~Hz}, 4 \mathrm{H}), 1.55(\mathrm{t}, \mathrm{J}=6.4 \mathrm{~Hz}, 4 \mathrm{H}), 1.22(\mathrm{~m}$, $40 \mathrm{H}), 0.82(\mathrm{t}, \mathrm{J}=6.4 \mathrm{~Hz}, 6 \mathrm{H}) ;{ }^{13} \mathrm{C}$ NMR $(100 \mathrm{MHz}) \delta 173.5,173.2,73.7,70.0,63.8$, 55.1, 53.8, 34.4, 34.2, 31.9, 29.7 (4 peaks), 29.5, 29.4, 29.3, 29.2, 29.1, 24.9 (2 peaks), 22.7, 14.1; HRMS calcd. for $\mathrm{C}_{35} \mathrm{H}_{72} \mathrm{~N}_{3} \mathrm{O}_{6}{ }^{+}\left[\mathrm{M}+\mathrm{H}^{+}\right]$: 630.5421 , found: 630.5430 . 


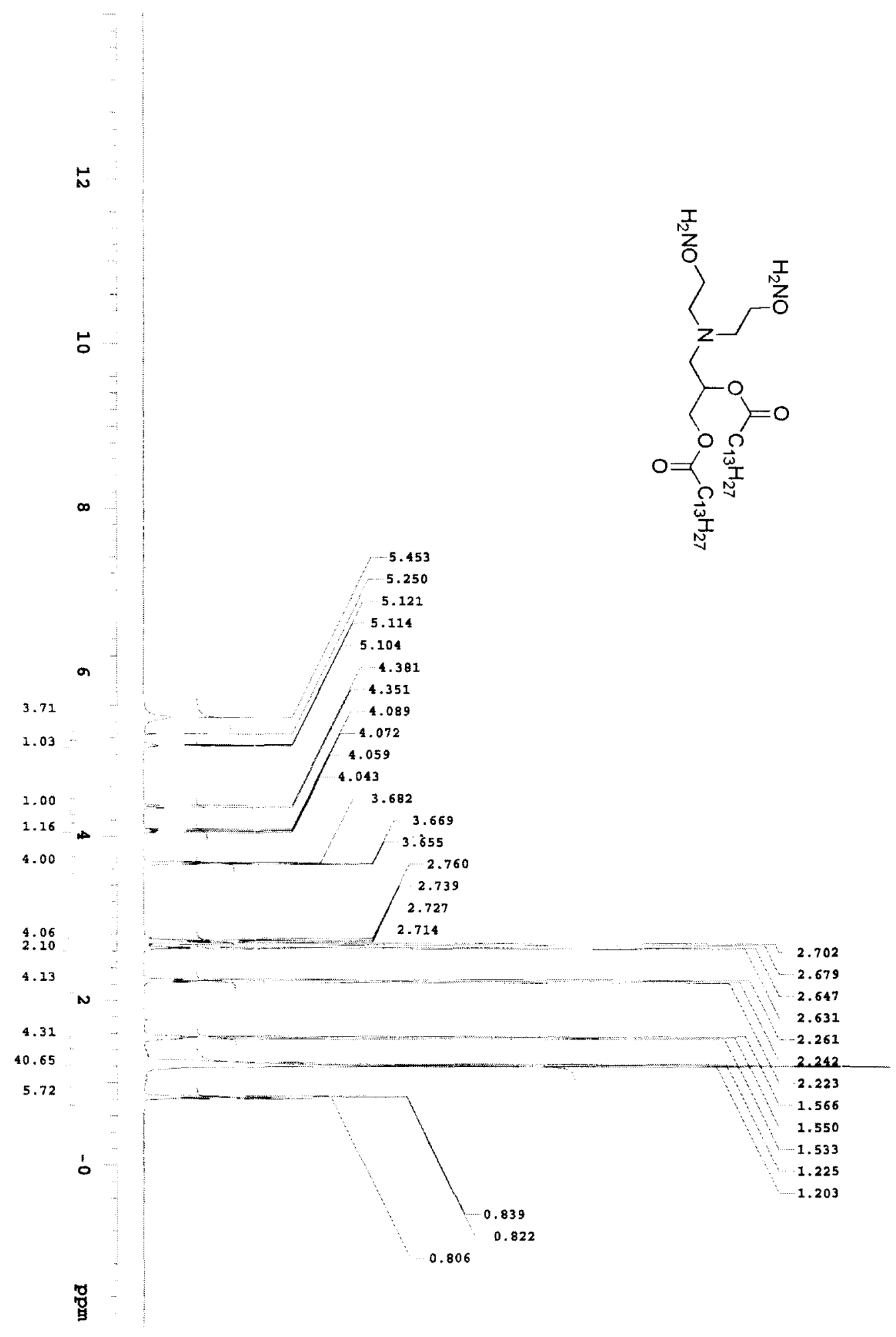

${ }^{1} \mathrm{H}$ NMR spectrum of compound 4.19 


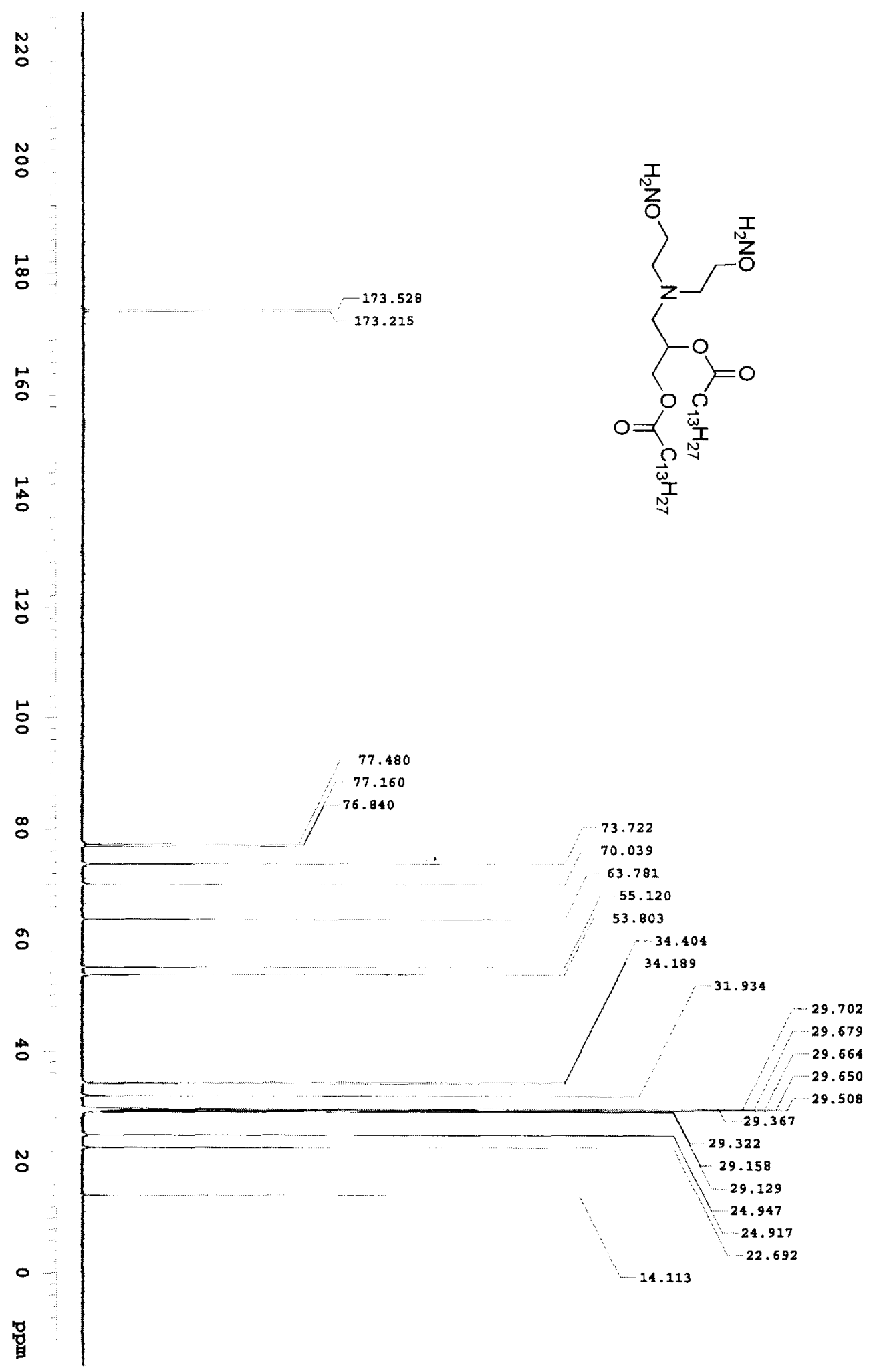

${ }^{13} \mathrm{C}$ NMR spectrum of compound 4.19 


\subsubsection{3-(bis(2-(aminooxy)ethyl)amino)propane-1,2-diyl dipalmitate}

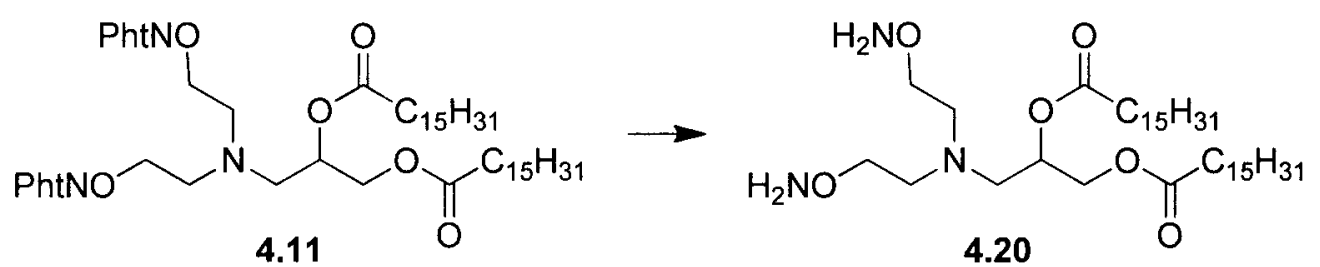

To a solution of the amine $4.11(2.69 \mathrm{~g}, 2.93 \mathrm{mmol})$ in dichloromethane $(10 \mathrm{~mL})$ was added hydrazine $(0.88 \mathrm{~g}, 17.6 \mathrm{mmol})$ at $0^{\circ} \mathrm{C}$. After filter off precipitation, the organic solution was washed by sat. $\mathrm{NaHCO}_{3}$, brine and then dried $\left(\mathrm{Na}_{2} \mathrm{SO}_{4}\right)$. After remove solvent by rota-vap, the crude product was purified twice by column chromatography $\left(\mathrm{SiO}_{2}\right)$ using $0-5 \% \mathrm{MeOH}$ in $\mathrm{DCM}$ as eluent to afford product 4.19 $(0.60 \mathrm{~g}, 30 \%)$ as white solid. ( $\mathrm{Rf}=0.29$, ethylacetate). ${ }^{1} \mathrm{H} \mathrm{NMR}\left(400 \mathrm{MHz}, \mathrm{CDCl}_{3}\right) \delta$ $5.43(\mathrm{br} \mathrm{s}, 1 \mathrm{H}), 5.13(\mathrm{~m}, \mathrm{~J}=6.4,2.8 \mathrm{~Hz}, 1 \mathrm{H}), 4.38(\mathrm{dd}, \mathrm{J}=12.0,2.8 \mathrm{~Hz}, 1 \mathrm{H}), 4.08$ (dd, $J=12.0,6.4 \mathrm{~Hz}, 1 \mathrm{H}), 3.69(\mathrm{t}, \mathrm{J}=5.6 \mathrm{~Hz}, 4 \mathrm{H}), 2.65-2.78(\mathrm{~m}, 6 \mathrm{H}), 2.26(\mathrm{td}, \mathrm{J}=7.6,2.8$ $\mathrm{Hz}, 4 \mathrm{H}), 1.55(\mathrm{~m}, \mathrm{~J}=6.8 \mathrm{~Hz}, 4 \mathrm{H}), 1.25(\mathrm{~m}, 48 \mathrm{H}), 0.83(\mathrm{t}, \mathrm{J}=6.8 \mathrm{~Hz}, 6 \mathrm{H}) ;{ }^{13} \mathrm{C}$ NMR $(100$ $\mathrm{MHz}) \delta 173.6,173.3,73.8,70.1,63.8,55.2,53.9,34.5,34.3,31.9,29.7$ (4 peaks), 29.6, 29.4 (2 peaks), 29.2 (2 peaks), 25.0 (2 peaks), 22.8, 14.2; HRMS calcd. for $\mathrm{C}_{39} \mathrm{H}_{80} \mathrm{~N}_{3} \mathrm{O}_{6}^{+}\left[\mathrm{M}+\mathrm{H}^{+}\right]$686.6047, found 686.6050 . 


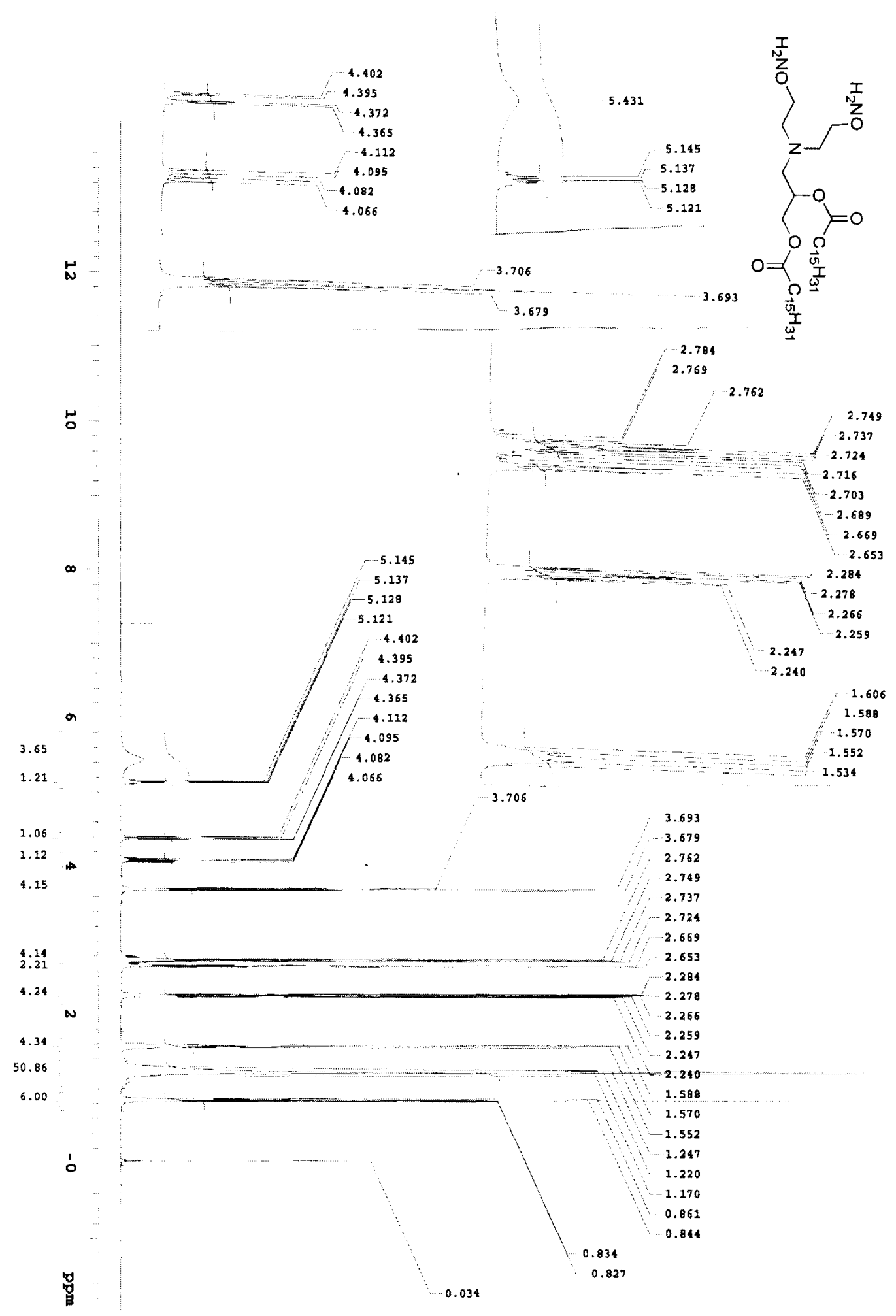

${ }^{1} \mathrm{H}$ NMR spectrum of compound $\mathbf{4 . 2 0}$ 


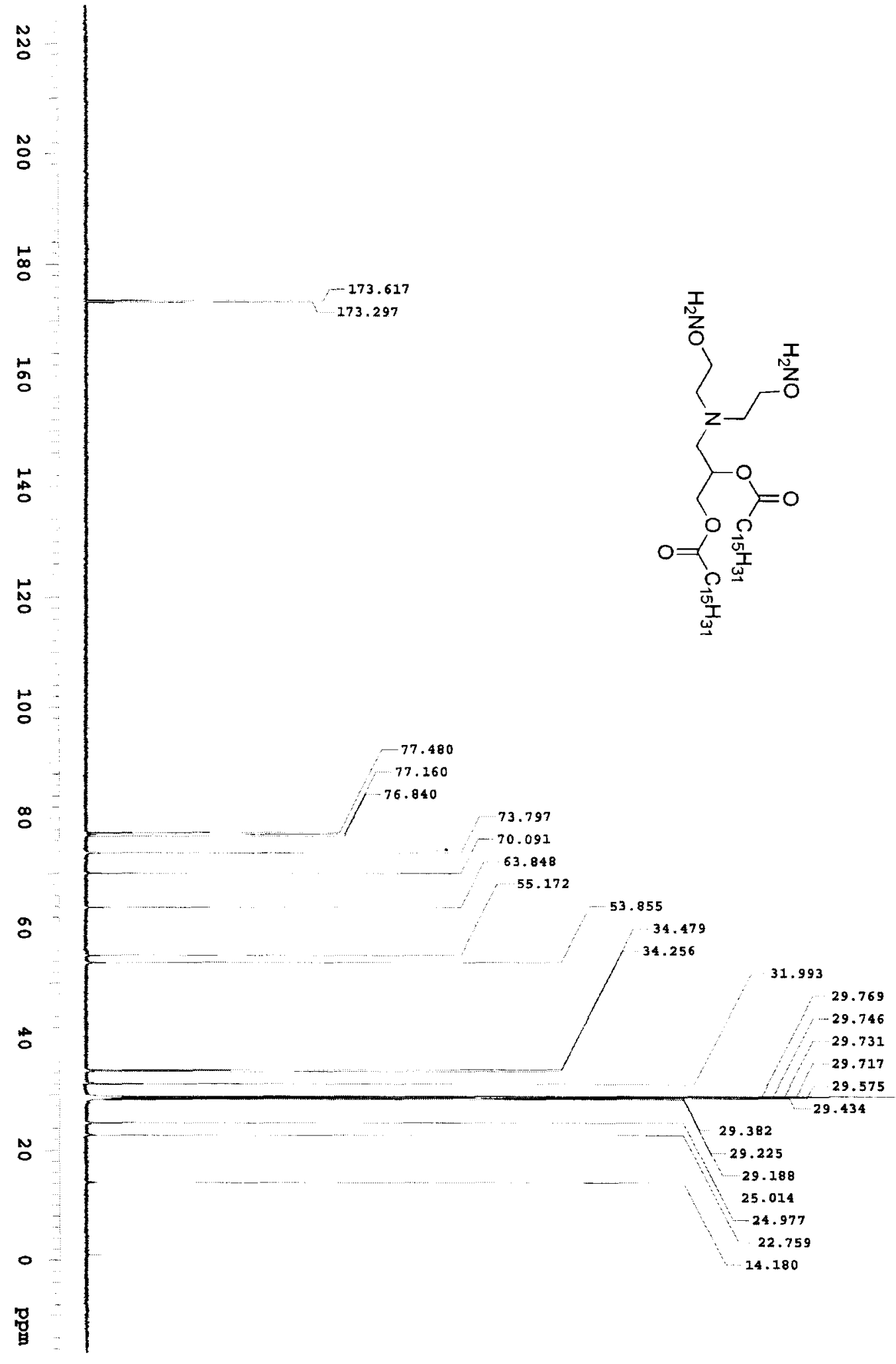

${ }^{13} \mathrm{C}$ NMR spectrum of compound 4.20 


\subsubsection{Synthesis of DPA and other polysaccharides}

Dextran Polyaldehyde A (DPA-A) was prepared through oxidation of polysaccharide dextran by using reported protocols with minor modification. ${ }^{63}$ Dextran $(6 \mathrm{kD}, 1.62 \mathrm{~g}, 10 \mathrm{mmol}$ of glucose units) was dissolved in $50 \mathrm{~mL}$ distilled water and then sodium periodate $(2.14 \mathrm{~g}, 10 \mathrm{mmol})$ was added. The mixture was stirred overnight in the dark at room temperature to get afford yellow solution. After gravity passing through Dowex $1 \times 8-400$ ion exchange chromatography $(20 \mathrm{~g})$, the resultant colorless solution was extensively dialyzed against $6 \times 5 \mathrm{~L}$ distilled water $(2 \mathrm{kD}$ cutoff cellulose tubing from sigma) for 3 days at $4^{\circ} \mathrm{C}$. The purified DPA was concentrated under reduced pressure and lyophilized to obtain a white solid. For DPA-B, DPA-C, DPA-D, DPA-E, the same protocol was followed with different molar ratio of sodium periodate. DPA-F (from 40kd dextran, $\mathrm{CHO} 11.6 \mathrm{mmol} / \mathrm{g}$ ) and DPA-G (from 100kd dextran, $\mathrm{CHO} 10.75 \mathrm{mmol} / \mathrm{g}$ ) were prepared and titrated as the same way as DPA-A. Usually, $1.32-1.37 \mathrm{~g}$ DPA can be obtained by this way. The oxidized Maltoheptaose $(\mathrm{CHO}, 8.8 \mathrm{mmol} / \mathrm{g})$ and $\beta$-cyclodextrin $(\mathrm{CHO}, 8.8 \mathrm{mmol} / \mathrm{g})$ were prepared and titrated as DPA-A with minor change. (100 Da cut off dialysis membrane was used due to product's relatively small molecular weight.)

\subsubsection{Liposome formulation and stabilization}

\section{Liposome formulation}

The lipid 4.1 (10 mg) was dissolved in $\sim 1 \mathrm{~mL}$ chloroform solutions to $20 \mathrm{~mL}$ sample vials. The chloroform was removed via rotary vacuum evaporation. The resulting thin lipid film was placed under vacuum for at least 2 hours to ensure that all traces of 
solvent were removed. The dry lipid films were hydrated in water $(4 \mathrm{~mL})$ followed by 20 min's sonication to form transparent liposome stock solution (lipid concentration 3.24 $\mathrm{mM})$. We observed that the required sonication time to get liposomes $(\sim 100 \mathrm{~nm}$ diamter) was depended on the life/power of sonicator. The brand new sonicator can make liposomes in 5 minutes while the older one may need longer time to get the same results. The solution contain liposomes with a mean hydrodynamic diameter of $119 \mathrm{~nm}(\zeta=59 \mathrm{eV})$ as determined by dynamic light scattering (DLS) measurements (Brookhaven 90 Plus Nanoparticle Size Analyzer).

\section{Liposome stabilization study}

Glutaric dialdehyde was diluted by water to get $0.5 \mathrm{M}$ final concentration. Dextran polyaldehyde A (DPA-A, $60 \mathrm{mg})$ was dissolved in water $(1 \mathrm{~mL})$ to get DPA-A $(50 \mathrm{mM}$ aldehyde concentration) solution. Dextran and dextran sulfate was dissolved in water

to get $60 \mathrm{mg} / \mathrm{L}$ concentration. Hydroxylamine pretreatment was carried by mixture hydroxylamine $(8 \mu \mathrm{L} 0.25 \mathrm{M})$ with DPA-A or Dextran sulfate $(4 \mu \mathrm{L}, 60 \mathrm{mg} / \mathrm{mL})$ in room temperature for $30 \mathrm{~min}$.

The liposome stock solution $(77 \mu \mathrm{L})$ was mixed with water $(923 \mu \mathrm{L})$ in cuvettes and stabilize reagents $(4 \mu \mathrm{L})$ or hydroxylamine pretreatment stabilize reagent $(12 \mu \mathrm{L})$ were added to each cuvettes. Then Triton X-100 (final concentration $0.15 \% \mathrm{w} / \mathrm{v}$ ) was added after incubated the indicated time intervals at room temperature. The light scattering signals were recorded before and after. 


\subsubsection{Calcein experiment}

The lipid $4.1(2.0 \mathrm{mg})$ was dissolved in $\sim 1 \mathrm{~mL}$ chloroform solutions. The chloroform was removed via rotary vacuum evaporation. The resulting thin lipid film was placed under vacuum for at least 2 hours. The dry lipid films were hydrated in calcein solution $(2.0 \mathrm{~mL}, 50 \mathrm{mM}$ calcein and $20 \mathrm{mM}$ HEPES pH 7.4$)$ by 30 seconds vortex mixing and followed by 10 min's sonication. The solution was then purified by Sephadex G-100 column using HEPES buffer $(50 \mathrm{mM}, \mathrm{pH} 7.4)$ as eluent. The free calcein passed through column first and the later fraction was collected as liposome encapsulated calcein.

The aliquot $(200 \mu \mathrm{L})$ of calcein liposome samples were then mixed with HEPES buffer $(1.8 \mathrm{~mL}, 50 \mathrm{mM}, \mathrm{pH} 7.4)$ and stabilization reagents $(5 \mu \mathrm{L}, 60 \mathrm{mg} / \mathrm{mL})$. The release of calcein from the liposomes was measured fluorometrically (excitation 495 $\mathrm{nm}$ and emission $515 \mathrm{~nm}$, respectively, the slit widths were $5 \mathrm{~nm}$ ) at certain time intervals. The relative fraction of released calcein was calculated using the formula:

$$
\operatorname{RF}(\%)=100 \times\left(I_{t}-I_{0}\right) /\left(I_{\max }-I_{0}\right)
$$

Where $I_{0}$ is fluorescence intensity at time $0, I_{t}$ is fluorescence intensity at time $t, I_{\max }$ is maximum fluorescence intensity and represents all calcein released.

\section{Dextranase-mediated calcein release from stabilized liposomes}

The liposome encapsulated calcein was incubating with 4 eq. DPA-B for 30 mins and the resultant stabilized liposomes were purified by Sephadex G-100 column using buffer $B(10 \mathrm{mM}$ HEPES, $150 \mathrm{mM} \mathrm{NaCl}, \mathrm{pH} \mathrm{7.4)}$ ) as eluent. The aliquot of liposomes (1 $\mathrm{mL}$ ) was treated with dextranase (sigma D4668, $10 \mathrm{U}$ ) and incubated at $37^{\circ} \mathrm{C}$. At the 
given time intervals, samples (100 uL) were taken out and mixed with buffer $B(2 \mathrm{~mL})$. Their fluorescent signal of samples was recorded and relative fraction of released calcein was calculated using the same formula.

\subsubsection{Liposome encapsulated phosphatase}

The lipid 4.1 ( $8 \mathrm{mg}$ ) was dissolved in $\sim 1 \mathrm{~mL}$ chloroform solutions to $20 \mathrm{~mL}$ sample vials. The chloroform was removed via rotary vacuum evaporation. The resulting thin lipid film was placed under vacuum for 2 hours. The dry lipid films were hydrated in alkaline phosphatase (from Sigma P0114) solution (4 mL, $0.5 \mathrm{mg} / \mathrm{mL}$ alkaline phosphatase in buffer $\mathrm{A}$ (Tris $5 \mathrm{mM} \mathrm{pH} 8, \mathrm{MgCl}_{2} 5 \mathrm{mM}, \mathrm{ZnCl}_{2} 0.1 \mathrm{mM}$ ) followed by 20 min's sonication to form transparent liposome solution. To generate stabilized liposomes, $2 \mathrm{~mL}$ of liposomes were incubated with 1 equivalent of DPA-A $(20 \mu \mathrm{L}, 60$ $\mathrm{mg} / \mathrm{mL}$ ) overnight at room temperature. The free enzyme and liposomes were separated by repeated centrifugation $\left(16,100 \mathrm{~g}, 30 \mathrm{~min}, 4^{\circ} \mathrm{C}\right)$. The pelleted liposomes are resuspended in buffer $A$. The redispersed liposomes are then treated by Triton $\mathrm{X}-100$ (final concentration $0.15 \% \mathrm{w} / \mathrm{v}$ ) and separated free enzyme from liposomes. The alkaline phosphatase activity was tested before and after triton X-100 treatment.

The alkaline phosphatase activity was measured using fluorogenic substrate. Within $1.98 \mathrm{~mL}$ of Buffer A, 4-methylumbelliferyl phosphate disodium salt (Sigma, $\mathrm{M} 8168,10 \mu \mathrm{L}, 10 \mathrm{mM})$ and phosphatase contain liposome sample $(10 \mu \mathrm{L})$ was added and incubate in $37^{\circ} \mathrm{C}$ for $1 \mathrm{~h}$. Detection of the products of the enzymatic reaction is performed with a fluorescence spectrometer (PerkinEImer, LS55 Fluorescence Spectrometer) with an excitation $360 \mathrm{~nm}$ and emission $440 \mathrm{~nm}$. 


\subsection{Chapter 5. 'Click' Stabilized Liposomes for Gene Transfection}

6.5.1 Lipoplexes formulation and in-virto gene transfection

6.5.2 2, 2'-diphthalimidooxy diethyl ether (5.3)

6.5.3 2,2'-diaminooxy diethyl ether (5.4)

6.5.4 tert-butyl 2-(2-(aminooxy)ethoxy)ethoxycarbamate (5.5)

6.5.5 2,3,4,6-tetra-O-acetyl- $\beta$-D-Glucopyranosyl-(1 $\rightarrow 4)-2,3,5,6$-tetraacetate- $\beta$-Dglucose $\{7-[(9 \mathrm{H}-9$-tert-butoxycarbonyl)amino]-1,4,7-trioxaheptyimine (5.6)

6.5.6 2,3,4,6-tetra-O-acetyl- $\beta$-D-Glucopyranosyl-(1 $\rightarrow 4)-2,3,5,6$-tetraacetate$\beta$-D-glucose(7-amino-1,4,7-trioxaheptyl)imine (5.7)

6.5.7 $\beta$-D-Glucopyranosyl-(1 $\rightarrow 4)-\beta$-D-glucose(7-amino-1,4,7-trioxaheptyl)imine (5.8) 


\subsubsection{Lipoplexes formulation and in-vitro gene transfection}

Human breast cancer cells (MCF-7) were purchased from American Type Culture Collection VA, USA. Cells were grown to $50-60 \%$ confluency in DMEM and $1 \%$ Pennstrep (Mediatech, Inc, VA) with 10\% FBS (Valley Biomedical, Winchester, VA). Luciferase transfections were performed in triplicate using $0.025 \mathrm{mg}$ of $p \mathrm{DNA}$ (pCMV Luc)/well in MCF-7 cells.

The lipid $4.1(11.5 \mu \mathrm{L}, 10 \mathrm{mg} / \mathrm{mL}$ in chloroform $)$ and DOPE $(11.2 \mu \mathrm{L}, 10 \mathrm{mg} / \mathrm{mL}$ in chloroform) was added to $\sim 0.2 \mathrm{~mL}$ chloroform solutions to $2 \mathrm{~mL}$ sample vials. The chloroform was removed via rotary vacuum evaporation. The resulting thin lipid film was placed under vacuum for at least 2 hours to ensure that all traces of solvent were removed. The dry lipid films were hydrated in HEPES buffer $(0.2 \mathrm{~mL}, 20 \mathrm{mM}, \mathrm{pH} 7.4)$ followed by 10 min's sonication to form transparent liposome solution.

Lipoplex was prepared by adding the required volume of liposomes (fresh made) to a $p D N A$ solution (lipids:pDNA charge ratios of $3,5,7$ ). After brief mixing (votex 5 seconds), the samples were incubated at room temperature for $20 \mathrm{~min}$ to gave the lipoplexes. For stabilized lipoplexes, required volume of DPA-B $(0.752 \mathrm{mM})$ was added to the mentioned lipoplexes and incubated $3 \mathrm{~h}$ at $37.5^{\circ} \mathrm{C}$.

The lipoplexes and stabilized lipoplexes were then mix with serum free DMEM media and added to cell culture $(200 \mu \mathrm{L} /$ well). After $2 \mathrm{~h}$, the DMEM media with $20 \%$ FBS $\left(200 \mu \mathrm{L} /\right.$ well) was added to cell culture. After $39 \mathrm{~h}$ incubation at $37.5^{\circ} \mathrm{C}$, the cells were lysed and luciferase gene expression was quantified using a commercial kit (Promega) and luminometer according to the vendor's protocol. Lipofectamine 2000 (Invitrogen) was used as a positive control while pDNA was used as negative control. 


\subsubsection{2, 2'-diphthalimidooxy diethyl}

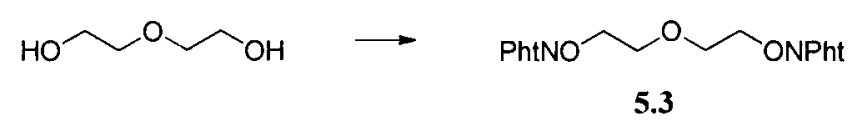

To a solution of diethylene-glycol (3.0 g, $28.3 \mathrm{mmol}), \mathrm{PPh}_{3}(18.5 \mathrm{~g}, 70.8 \mathrm{mmol})$, and $\mathrm{N}$-hydroxyphthalimide $(11.5 \mathrm{~g}, 70.8 \mathrm{mmol})$ in THF $(200 \mathrm{~mL}$, dry) was added DIAD $(14.0 \mathrm{~mL}, 70.8 \mathrm{mmol})$ at $0^{\circ} \mathrm{C}$. After $30 \mathrm{~min}$, the reaction solution was warmed to room temperature and stirred for $\sim 20$ hours. The solid was filtered and washed by ethyl acetate $(40 \mathrm{~mL})$ twice to give compound 5.3 as a white solid in $(10.04 \mathrm{~g}, 90 \%) . \mathrm{Rf}=$ $0.38\left(\mathrm{CH}_{2} \mathrm{Cl}_{2}: \mathrm{MeOH}=49: 1, \mathrm{v} / \mathrm{v}\right) ;{ }^{1} \mathrm{H}-\mathrm{NMR}\left(500 \mathrm{MHz}, \mathrm{CDCl}_{3}\right) \delta \mathrm{ppm} 3.83(\mathrm{t}, \mathrm{J}=4.0 \mathrm{~Hz}$, $4 \mathrm{H}), 4.23(\mathrm{t}, \mathrm{J}=4.0 \mathrm{~Hz}, 4 \mathrm{H}), 7.69(\mathrm{~m}, 4 \mathrm{H}), 7.74(\mathrm{~m}, 4 \mathrm{H}) ;{ }^{13} \mathrm{C}-\mathrm{NMR}\left(125 \mathrm{MHz}, \mathrm{CDCl}_{3}\right)$ $\delta$ ppm 69.73, 77.18, 123.66, 129.11, 134.64, 163.54 . 


\subsubsection{2,2'-diaminooxy diethyl ether}

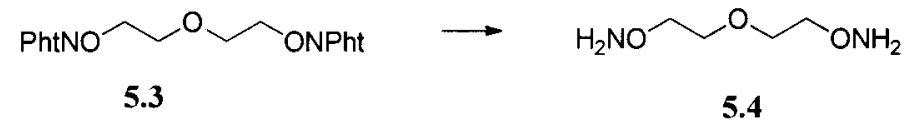

To a solution of compound $5.3(10.04 \mathrm{~g}, 25.3 \mathrm{mmol})$ in dichloromethane $(150 \mathrm{~mL})$ was added $\mathrm{N}_{2} \mathrm{H}_{4} \cdot \mathrm{H}_{2} \mathrm{O}(12.4 \mathrm{~mL}, 253 \mathrm{mmol})$. The reaction mixture was stirred at room temperature for $\sim 14$ hours. The percipetation was seperated and washed with dichloromethane $(20 \mathrm{~mL} \times 2)$ and then dissolved in water $(\sim 100 \mathrm{~mL})$. The aqueous buffer was extracted by dichloromethane $(50 \mathrm{~mL} \times 3)$. The combined organic solvent was concerated by rotary evaporation. The residual oil was filtered again and then purified by silica gel column chromatography $\left(\mathrm{CH}_{2} \mathrm{Cl}_{2}: \mathrm{MeOH}=10: 1, \mathrm{v} / \mathrm{v}\right)$ to give compound $5.4(3.00 \mathrm{~g}, 87 \%)$ as colorless oil. $\left(\mathrm{Rf}=0.30, \mathrm{CH}_{2} \mathrm{Cl}_{2}: \mathrm{MeOH}=9: 1, \mathrm{v} / \mathrm{v}\right)$; 1H-NMR (400 MHz, CDCl $) \delta$ ppm $3.68(\mathrm{~m}, 4 \mathrm{H}), 3.84(\mathrm{~m}, 4 \mathrm{H}), 5.55(\mathrm{br}, 4 \mathrm{H}) ;{ }^{13} \mathrm{C}-\mathrm{NMR}$ $\left(100 \mathrm{MHz}, \mathrm{CDCl}_{3}\right) \delta \mathrm{ppm} 69.69,74.92$. 


\subsection{4 tert-butyl 2-(2-(aminooxy)ethoxy)ethoxycarbamate}

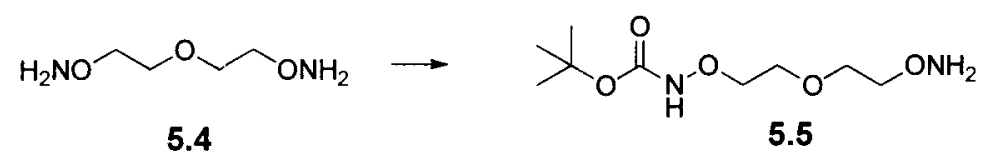

To the solution of compound $5.4(4.85 \mathrm{~g}, 35.6 \mathrm{mmol})$ in chloroform $(20 \mathrm{~mL})$ was slowly added di-tert-butyl dicarbonate $(1.55 \mathrm{~g}, 7.12 \mathrm{mmol})$ in chloroform $(50 \mathrm{~mL})$ at $0^{\circ} \mathrm{C}$. The reaction solution was then warmed up to room temperature and stirred for $\sim 14$ hours. The solvent was removed by rotary evaporation and the residual oil was purified by silica gel column chromatography $\left(\mathrm{CH}_{2} \mathrm{Cl}_{2}: \mathrm{MeOH}=19: 1, \mathrm{v} / \mathrm{v}\right)$ to afford compound $5.5\left(1.51 \mathrm{~g}, 90 \%\right.$, calculate from $\left.\mathrm{Boc}_{2} \mathrm{O}\right)$ as colorless oil. [Note: the unreacted compound 5.4 can be collected as late fraction.] $\mathrm{Rf}=0.30$ $\left(\mathrm{CH}_{2} \mathrm{Cl}_{2}: \mathrm{MeOH}=19: 1, \mathrm{v} / \mathrm{v}\right) ;{ }^{1} \mathrm{H}-\mathrm{NMR}\left(500 \mathrm{MHz}, \mathrm{CDCl}_{3}\right) \delta \mathrm{ppm} 1.38(\mathrm{~s}, 9 \mathrm{H}), 3.59(\mathrm{t}, \mathrm{J}=$ $5.0 \mathrm{~Hz}, 2 \mathrm{H}), 3.62(\mathrm{t}, \mathrm{J}=5.0 \mathrm{~Hz}, 2 \mathrm{H}), 3.75(\mathrm{t}, \mathrm{J}=5.0 \mathrm{~Hz}, 2 \mathrm{H}), 3.93(\mathrm{t}, \mathrm{J}=5.0 \mathrm{~Hz}, 2 \mathrm{H})$, $5.52(\mathrm{br}, 2 \mathrm{H}), 7.91(\mathrm{~s}, 1 \mathrm{H}) ;{ }^{13} \mathrm{C}-\mathrm{NMR}\left(125 \mathrm{MHz}, \mathrm{CDCl}_{3}\right) \delta \mathrm{ppm} 28.36,69.11,69.57$, $74.67,75.32,81.52,157.00$. 


\subsubsection{2,3,4,6-tetra-O-acetyl- $\beta$-D-Glucopyranosyl-(1 $\rightarrow 4)-2,3,5,6$-tetraacetate}

\section{- $\beta$-D-glucose $\{7-[(9 \mathrm{H}-9-$ tert-butoxycarbonyl)amino]-1,4,7-trioxaheptyimine}

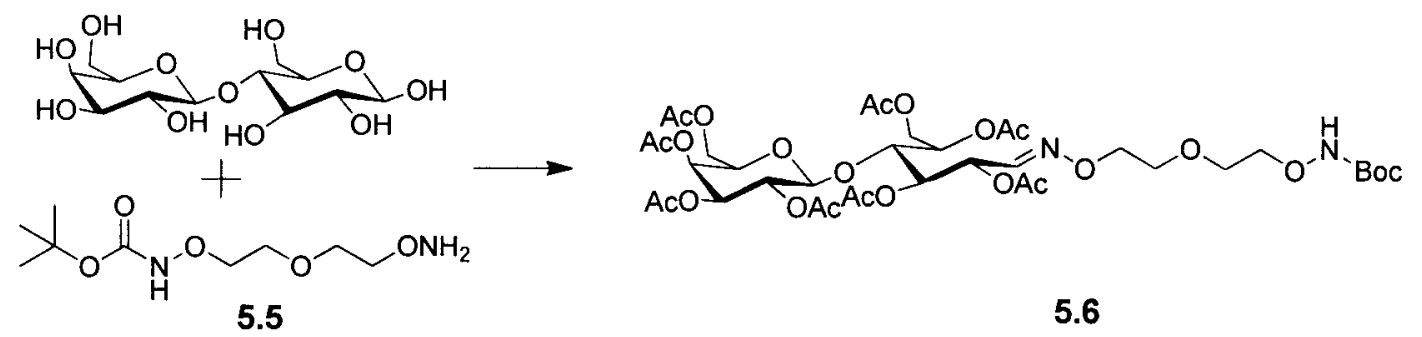

To a solution of linker $5.5(1.23 \mathrm{~g}, 5.20 \mathrm{mmol})$, lactose monohydrate $(1.78 \mathrm{~g}, 4.95$ $\mathrm{mmol})$ in pyridine $(20 \mathrm{~mL})$ was added Amberlyst-15 resin $(0.20 \mathrm{~g})$. After stirred for $12 \mathrm{~h}$ at $65^{\circ} \mathrm{C}$, the reaction mixture was cooled to $0^{\circ} \mathrm{C}$ and acetic anhydride $(20 \mathrm{~mL})$ was added dropwise. The reaction mixture was allowed to warm to room temperature and then stirred for $12 \mathrm{~h}$. The reaction mixture was diluted with ethyl acetate $(200 \mathrm{~mL})$ and washed successively with sat'd aq. $\mathrm{NaHCO}_{3}(3 X 200 \mathrm{~mL})$, sat'd aq. CuSO 4 (3X 200 $\mathrm{mL})$, Brine $(200 \mathrm{~mL})$ and dried $\left(\mathrm{Na}_{2} \mathrm{SO}_{4}\right)$. The solvent was removed by rotary evaporation. The residue was purified by column chromatography $\left(\mathrm{SiO}_{2}\right)$ using ethyl acetate in hexanes $(40 \%$ to $70 \%)$ to afford compound $(2.89 \mathrm{~g}, 65 \%)$ as a white foam; $\operatorname{TLC}\left(R_{\mathrm{f}}=0.1\right.$, ethyl acetate: hexanes $\left.=1: 1\right) ;{ }^{1} \mathrm{H}-\mathrm{NMR}\left(400 \mathrm{MHz}, \mathrm{CDCl}_{3}\right) \delta \mathrm{ppm} 1.41$ (s, $9 \mathrm{H}), 1.91-2.11(\mathrm{~m}, 24 \mathrm{H}), 3.66(\mathrm{~m}, 4 \mathrm{H}), 3.87-4.03(\mathrm{~m}, 4 \mathrm{H}), 4.10-4.18(\mathrm{~m}, 5 \mathrm{H}), 4.45(\mathrm{dd}$, $J=12,2.4 \mathrm{~Hz}, 1 \mathrm{H}), 4.59(\mathrm{~d}, \mathrm{~J}=7.6 \mathrm{~Hz}, 1 \mathrm{H}), 4.94(\mathrm{dd}, \mathrm{J}=10.4,3.2 \mathrm{~Hz}, 1 \mathrm{H}), 5.04(\mathrm{~m}$, 1H), $5.12(\mathrm{dd}, \mathrm{J}=10.0,8.0 \mathrm{~Hz}, 1 \mathrm{H}$ ), $5.30(\mathrm{~d}, \mathrm{~J}=3.2 \mathrm{~Hz}, 1 \mathrm{H}$ ), 5.47 (dd, J = 8.4, $2.4 \mathrm{~Hz}$, 1H), 5.72 (dd, J = 8.4, $5.2 \mathrm{~Hz}, 1 \mathrm{H}), 7.40(\mathrm{~d}, \mathrm{~J}=4.4 \mathrm{~Hz}, 1 \mathrm{H}), 7.59(\mathrm{~s}, 1 \mathrm{H}) ;{ }^{13} \mathrm{C}-\mathrm{NMR}$ (100 MHz, $\mathrm{CDCl}_{3}$ ) $\delta$ ppm 19.5-19.8 (6 signals), 27.2, 60.5, 60.9, 66.0, 67.9, 68.0 (2 signals), $68.4,68.5,68.6,70.0$ ( 2 signals) $72.5,74.4,75.2,80.6,100.4,144.7,155.8$, 168.2, 168.6, 168.7, 168.8, 169.0, 169.2, 169.4,169.6. HRMS (ESI) calculated for $\mathrm{C}_{37} \mathrm{H}_{56} \mathrm{~N}_{2} \mathrm{NaO}_{23}{ }^{+}\left[\mathrm{M}+\mathrm{Na}^{+}\right]:$919.3166, found: 919.3169 . 


\subsubsection{2,3,4,6-tetra-O-acetyl- $\beta$-D-Glucopyranosyl-(1 $\rightarrow 4)-2$,}

\section{3,5,6-tetraacetate- $\beta$-D-glucose(7-amino-1,4,7-trioxaheptyl)imine}

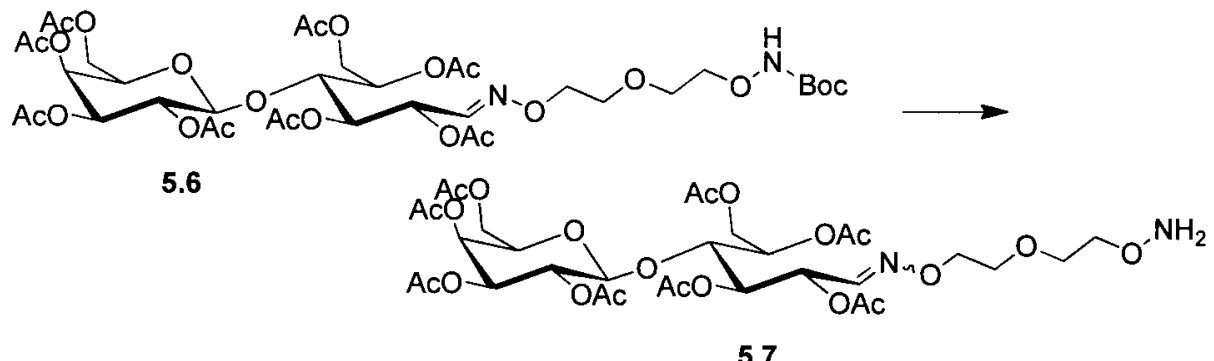

To a solution of compound $5.6(2.68 \mathrm{~g}, 2.99 \mathrm{mmol})$ in $\mathrm{CH}_{2} \mathrm{Cl}_{2}(42 \mathrm{~mL})$ at $0^{\circ} \mathrm{C}$ was added water $(3 \mathrm{~mL})$ and TFA (15 mL). After the reaction mixture was stirred for $\sim 12 \mathrm{~h}$, $\mathrm{CH}_{2} \mathrm{Cl}_{2}(260 \mathrm{~mL})$ was added. The reaction mixture was washed successively with sat'd $\mathrm{NaHCO}_{3}(2 \times 300 \mathrm{~mL})$, Brine $(300 \mathrm{~mL})$, and dried $\left(\mathrm{Na}_{2} \mathrm{SO}_{4}\right)$. After concentrated by rotary evaporation, the residue was purified by column chromatography $\left(\mathrm{SiO}_{2}\right)$ using $1.5-4 \% \mathrm{MeOH}$ in $\mathrm{CH}_{2} \mathrm{Cl}_{2}$ to afford compound $5.7(1.98 \mathrm{~g}, 83 \%)$ as a foam; [Note: the $c$ and $Z$ isomers can be elucidated on $T L C]) \operatorname{Rf}(E)=0.52, \operatorname{Rf}(Z)=0.43$, double elution in $\mathrm{MeOH}: \mathrm{CH}_{2} \mathrm{Cl}_{2}=1: 33 ;{ }^{1} \mathrm{H}-\mathrm{NMR}\left(400 \mathrm{MHz}, \mathrm{CDCl}_{3}\right) \delta \mathrm{ppm}$ 1.98-2.18 (m, 24H), 3.67-3.73 (m, 4H), $3.83(t, J=4.4 \mathrm{~Hz}, 2 \mathrm{H}), 3.95(\mathrm{~m}, 1 \mathrm{H}), 4.06-4.30(\mathrm{~m}, 6 \mathrm{H}), 4.41-4.53$ $(\mathrm{m}, 1 \mathrm{H}), 4.62(\mathrm{dd}, \mathrm{J}=17.2,8.0 \mathrm{~Hz}, 1 \mathrm{H}), 5.00(\mathrm{~m}, 1 \mathrm{H}), 5.08-5.20(\mathrm{~m}, 2 \mathrm{H}), 5.37(\mathrm{~s}, 1 \mathrm{H})$, 5.52-5.60 (m, 2H), $5.79(\mathrm{dd}, \mathrm{J}=8.0,5.2 \mathrm{~Hz}, 0.57 \mathrm{H}), 6.00(\mathrm{t}, \mathrm{J}=4.4 \mathrm{~Hz}, 0.43 \mathrm{H}), 6.51(\mathrm{~d}$, $\mathrm{J}=4.8 \mathrm{~Hz}, 0.43 \mathrm{H}), 7.47(\mathrm{~d}, \mathrm{~J}=5.2 \mathrm{~Hz}, 0.57 \mathrm{H}) ;{ }^{13} \mathrm{C}-\mathrm{NMR}(100 \mathrm{MHz}, \mathrm{CDCl} 3) \delta \mathrm{ppm}$ 20.5-21.0 (9 signals), 61.2, 61.6, 61.7, 62.0, 66.7, 67.0 (2 signals), 69.0-69.7 (8 signals), 70.9-71.2 (5 signals), 73.7,74.3, 74.9 (2 signals), 76.4, 101.6 (2 signals), 145.8, 147.1, 169.3-170.7 (14 signals); HRMS (ESI) calcd. for $\mathrm{C}_{32} \mathrm{H}_{48} \mathrm{~N}_{2} \mathrm{NaO}_{21}{ }^{+}$ $\left[\mathrm{M}+\mathrm{Na}^{+}\right]: 819.2642$, found: 819.2641 . 


\subsection{7 $\beta$-D-Glucopyranosyl-(1 $\rightarrow 4)-\beta$-D-glucose(7-amino-1,4,7-trioxaheptyl)imine}

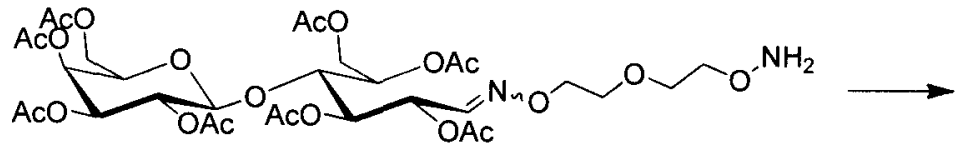

5.7

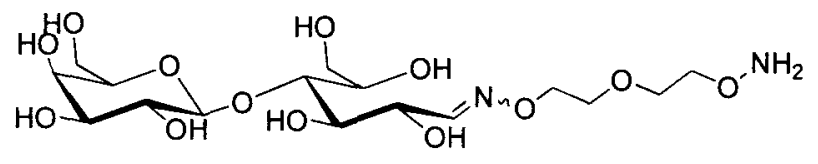

5.2

To a solution of $\mathrm{MeOH}(10 \mathrm{~mL})$ was added a piece of $\mathrm{Na}(\sim 20 \mathrm{mg})$ under Argon. After reaction done (no more gas come out), $2.5 \mathrm{~mL}$ of above $\mathrm{MeONa} / \mathrm{MeOH}$ solution was added to the solution of compound $5.7(1.55 \mathrm{~g}, 1.95 \mathrm{mmol})$ in $\mathrm{MeOH}(5 \mathrm{~mL})$. The reaction mixture was stirred $\sim 12 \mathrm{~h}$ and then added DOWEX 50WX8-200 ion-exchange resin $(0.25 \mathrm{~g})$ which is pre-washed by $30 \mathrm{~mL} \mathrm{MeOH}$. [ note: do NOT use too much of resin, it do absorb the product.] After stirred $1 \mathrm{~h}$ in room temperature, the reaction mixture was filtered. The solvent was removed by rotary evaporation and finally dried by oil pump to afford compound $5.2\left(0.863 \mathrm{~g}, 96 \%\right.$ ) as white foam. ${ }^{1} \mathrm{H}-\mathrm{NMR}$ (400 $\left.\mathrm{MHz}, \mathrm{CD}_{3} \mathrm{OD}\right) \delta \mathrm{ppm} 3.53-4.20(\mathrm{~m}, 18 \mathrm{H}), 4.19-4.20(\mathrm{~m}, 2 \mathrm{H}), 4.44-4.52(\mathrm{~m}, 2 \mathrm{H})$, 4.85-4.96 (m, 3H), $6.87(\mathrm{~d}, \mathrm{~J}=5.2 \mathrm{~Hz}, 0.27 \mathrm{H}), 7.55(\mathrm{~d}, \mathrm{~J}=6.0 \mathrm{~Hz}, 0.73 \mathrm{H}) ;{ }^{13} \mathrm{C}-\mathrm{NMR}$ (100 MHz, $\mathrm{CD}_{3} \mathrm{OD}$ ) $\delta \mathrm{ppm} 62.4,63.5,63.7,70.1,70.5$ (2 signals), 70.6, 70.8, 72.4, $72.8,72.9,73.0,73.3,74.0,74.4,74.7,75.7,76.8,76.9,81.3,105.4,105.9,152.6$, 154.9; HRMS (ESI) calcd. for $\mathrm{C}_{16} \mathrm{H}_{32} \mathrm{~N}_{2} \mathrm{NaO}_{13}{ }^{+}\left[\mathrm{M}+\mathrm{Na}^{+}\right]$]: 483.1797 , found: 483.1797 . 


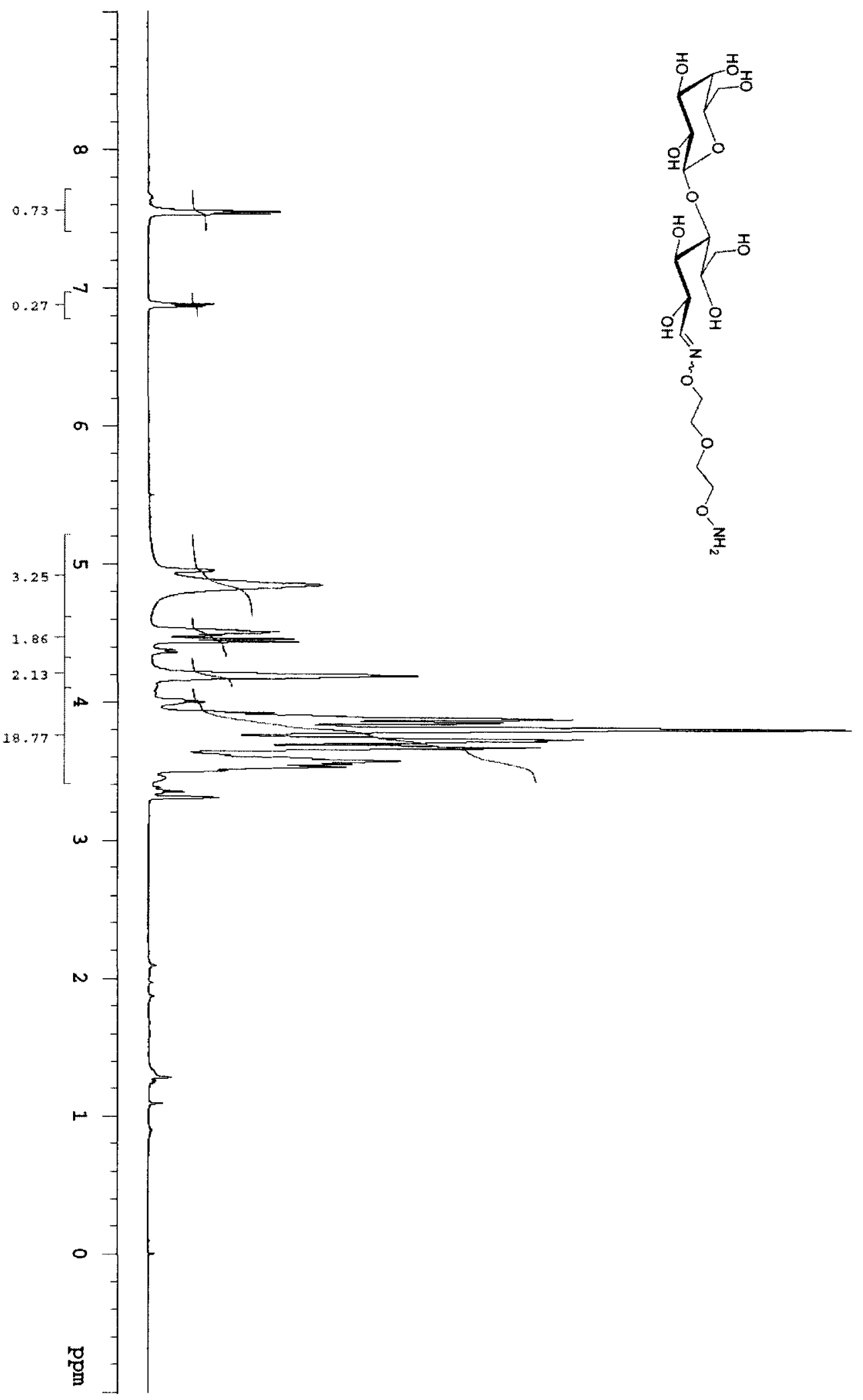

${ }^{1} \mathrm{H}$ NMR spectrum of compound 5.2 


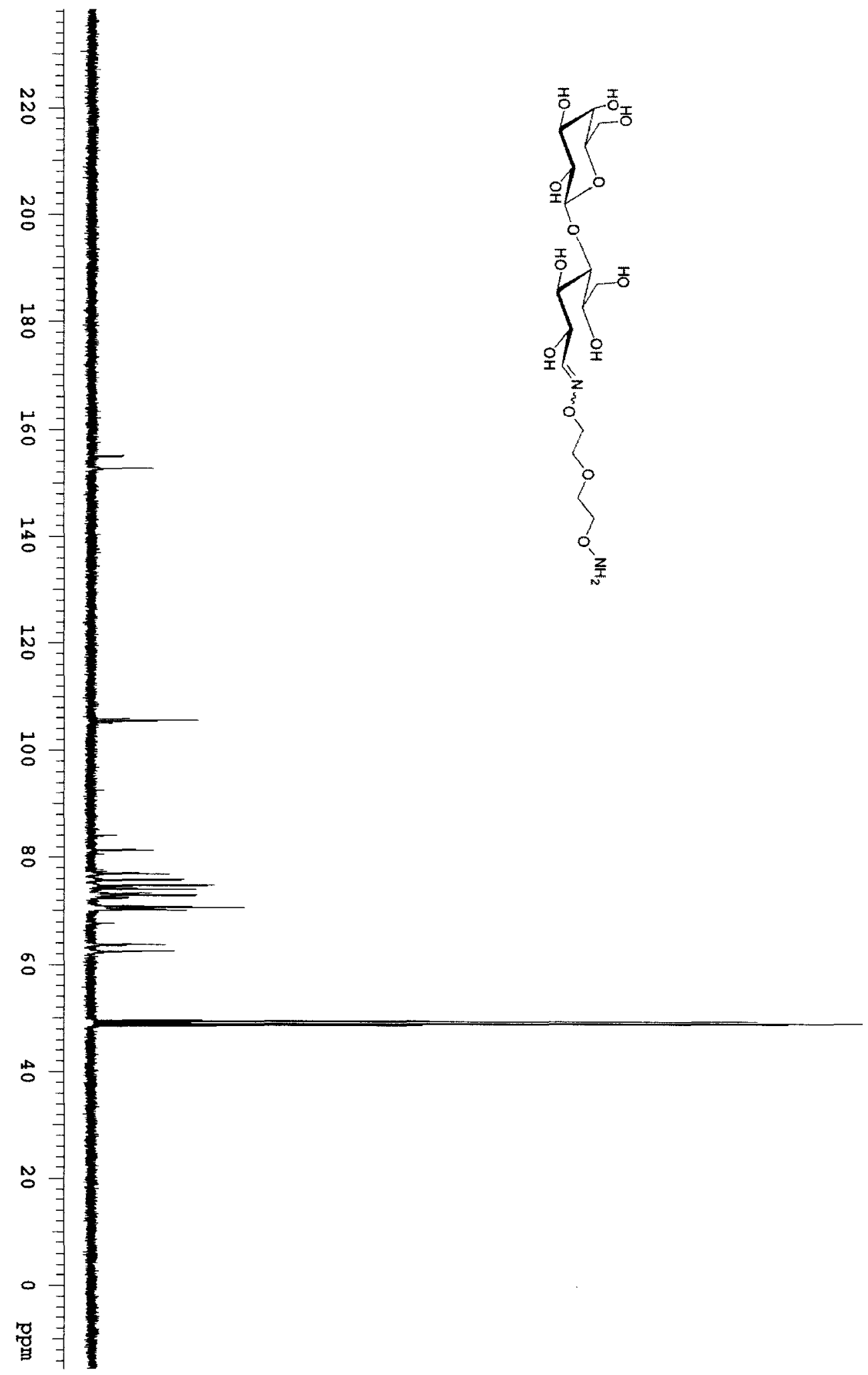

${ }^{13} \mathrm{C}$ NMR spectrum of compound 5.2 


\section{REFERENCES}

(1) Bangham, A. D.; Standish, M. M.; Watkins, J. C. Diffusion of univalent ions across the lamellae of swollen phospholipids. Journal of Molecular Biology 1965, 13, 238-252.

(2) http://www.ncbi.nlm.nih.gov/pubmed/ seach key word liposome.

(3) Mintzer, M. A.; Simanek, E. E. Nonviral vectors for gene delivery. Chemical Reviews 2008, 109, 259-302.

(4) Torchilin, V. P. Recent advances with liposomes as pharmaceutical carriers. Nature Reviews Drug Discovery 2005, 4, 145-160.

(5) Drulis-Kawa, Z.; Dorotkiewicz-Jach, A. Liposomes as delivery systems for antibiotics. International Journal of Pharmaceutics 2010, 387, 187-198.

(6) Cukierman, E.; Khan, D. R. The benefits and challenges associated with the use of drug delivery systems in cancer therapy. Biochem. Pharmacol. 2010, 80, 762-770.

(7) Rädler, J. O.; Koltover, I.; Salditt, T.; Safinya, C. R. Structure of DNA-cationic liposome complexes: DNA intercalation in multilamellar membranes in distinct interhelical packing regimes. Science 1997, 275, 810-814.

(8) Elouahabi, A.; Ruysschaert, J.-M. Formation and intracellular trafficking of lipoplexes and polyplexes. Molecular Therapy 2005, 11, 336-347.

(9) Riaz, M. Liposomes preparation methods. Pakistan journal of Pharmaceutical sciences 1996, 19, 65-77.

(10) Lasic, D. D. The mechanism of vesicle formation. Biochemical Journal 1988, 256, $1-11$

(11) Seow, Y.; Wood, M. J. Biological gene delivery vehicles: beyond viral vectors. Molecular Therapy 2009, 17, 767-777. 
(12) Human genome project information: Gene therapy http://www.ornl.gov/sci/techresources/Human_Genome/medicine/genetherapy.shtml

(13) Layzer, J. M.; Mccaffrey, A. P.; Tanner, A. K.; Huang, Z.; Kay, M. A.; Sullenger, B. A. In vivo activity of nuclease-resistant siRNAs. RNA 2004, 10, 766-771.

(14) Yang, J. P.; Huang, L. Direct gene transfer to mouse melanoma by intratumor injection of free DNA. Gene Therapy 1996, 3, 542-548.

(15) Ferber, D. Safer and Virus-Free? Science 2001, 294, 1638-1642.

(16) Felgner, P. L.; Gadek, T. R.; Holm, M.; Roman, R.; Chan, H. W.; Wenz, M.; Northrop, J. P.; Ringold, G. M.; Danielsen, M. Lipofection: a highly efficient, lipid-mediated DNA-transfection procedure. Proceedings of the National Academy of Sciences $1987,84,7413-7417$.

(17) Li, S.; Gao, X.; Son, K.; Sorgi, F.; Hofland, H.; Huang, L. DC-Chol lipid system in gene transfer. Journal of Controlled Release 1996, 39, 373-381.

(18) Kostarelos, K.; Miller, A. D. What role can chemistry play in cationic liposome-based gene therapy research today? Advances in Genetics 2005, Volume 53, 69-118.

(19) Rajesh, M.; Sen, J.; Srujan, M.; Mukherjee, K.; Sreedhar, B.; Chaudhuri, A. Dramatic influence of the orientation of linker between hydrophilic and hydrophobic lipid moiety in liposomal gene delivery. Journal of the American Chemical Society 2007, 129, $11408-11420$.

(20) Ghosh, Y. K.; Visweswariah, S. S.; Bhattacharya, S. Advantage of the ether linkage between the positive charge and the cholesteryl skeleton in cholesterol-based amphiphiles as vectors for gene delivery. Bioconjugate Chemistry 2002, 13, 378-384.

(21) Furuta, T.; Mochizuki, M.; Ito, M.; Takahashi, T.; Suzuki, T.; Kan, T. Versatile synthesis of head group functionalized phospholipids via oxime bond formation. Organic Letters 2008, 10, 4847-4850.

(22) Xu, Y.; Szoka, F. C. Mechanism of DNA release from cationic liposome/DNA complexes used in cell transfection. Biochemistry 1996, 35, 5616-5623. 
(23) Tseng, Y.-C.; Mozumdar, S.; Huang, L. Lipid-based systemic delivery of siRNA. Advanced Drug Delivery Reviews 2009, 61, 721-731.

(24) Tandia, B.-M.; Vandenbranden, M.; Wattiez, R.; Lakhdar, Z.; Ruysschaert, J.-M.; Elouahabi, A. Identification of human plasma proteins that bind to cationic Lipid/DNA complex and analysis of their effects on transfection efficiency: implications for intravenous gene transfer. Molecular Therapy 2003, 8, 264-273.

(25) Chen, C.; Han, D.; Cai, C.; Tang, X. An overview of liposome lyophilization and its future potential. Journal of Controlled Release 2010, 142, 299-311.

(26) Zhang, L.; Granick, S. How to stabilize phospholipid liposomes (using nanoparticles). Nano Letters 2006, 6, 694-698.

(27) Fujimoto, K.; Toyoda, T.; Fukui, Y. Preparation of bionanocapsules by the Layer-by-Layer deposition of polypeptides onto a liposome. Macromolecules 2007, $40,5122-5128$.

(28) Ruysschaert, T.; Sonnen, A. F. P.; Haefele, T.; Meier, W.; Winterhalter, M.; Fournier, D. Hybrid nanocapsules: 7 Interactions of ABA block copolymers with liposomes. Journal of the American Chemical Society 2005, 127, 6242-6247.

(29) Lee, S.-M.; Chen, H.; Dettmer, C. M.; O'Halloran, T. V.; Nguyen, S. T. Polymer-caged lipsomes: $7 \mathrm{~A}$ pH-responsive delivery system with high stability. Journal of the American Chemical Society 2007, 129, 15096-15097.

(30) Tanaka, T.; Yamazaki, M. Membrane fusion of giant unilamellar vesicles of neutral phospholipid membranes induced by $\mathrm{La}^{3+}$. Langmuir 2004, 20, 5160-5164.

(31) Di Biasio, A.; Bordi, F.; Cametti, C. Salt-induced aggregation in cationic liposome suspensions. Trends in colloid and interface science XVI 2004, 123, 78-82.

(32) Decher, G. Fuzzy nanoassemblies: toward layered polymeric multicomposites. Science 1997, 277, 1232-1237.

(33) Fukui, Y.; Fujimoto, K. The preparation of sugar polymer-coated nanocapsules by the Layer-by-Layer deposition on the liposome. Langmuir 2009, 25, 10020-10025.

(34) Mu, X.; Zhong, Z. Preparation and properties of poly(vinyl alcohol)-stabilized liposomes. International Journal of Pharmaceutics 2006, 318, 55-61. 
(35) Takeuchi, H.; Kojima, H.; Yamamoto, H.; Kawashima, Y. Polymer coating of liposomes with a modified polyvinyl alcohol and their systemic circulation and RES uptake in rats. Journal of Controlled Release 2000, 68, 195-205.

(36) Holland, J. W.; Hui, C.; Cullis, P. R.; Madden, T. D. Poly(ethylene glycol)-lipid conjugates regulate the calcium-induced fusion of liposomes composed of phosphatidylethanolamine and phosphatidylserine. Biochemistry 1996, 35 , 2618-2624.

(37) Yu, W.; Pirollo, K. F.; Rait, A.; Yu, B.; Xiang, L. M.; Huang, W. Q.; Zhou, Q.; Ertem, G.; Chang, E. H. A sterically stabilized immunolipoplex for systemic administration of a therapeutic gene. Gene Therapy 2004, 11, 1434-1440.

(38) Kreuter, J. Nanoparticulate systems for brain delivery of drugs. Advanced Drug Delivery Reviews 2001, 47, 65-81.

(39) Huang, Y.; Rao, Y.; Chen, J.; Yang, V. C.; Liang, W. Polysorbate cationic synthetic vesicle for gene delivery. Journal of Biomedical Materials Research Part A 2011, 96A, 513-519.

(40) Guo, J.; Ping, Q.; Jiang, G.; Huang, L.; Tong, Y. Chitosan-coated liposomes: characterization and interaction with leuprolide. International Journal of Pharmaceutics 2003, 260, 167-173.

(41) Azzam, T.; Raskin, A.; Makovitzki, A.; Brem, H.; Vierling, P.; Lineal, M.; Domb, A. J. Cationic polysaccharides for gene delivery. Macromolecules 2002, 35, 9947-9953.

(42) Eliyahu, H.; Makovitzki, A.; Azzam, T.; Zlotkin, A.; Joseph, A.; Gazit, D.; Barenholz, Y.; Domb, A. J. Novel dextran-spermine conjugates as transfecting agents: comparing water-soluble and micellar polymers. Gene Therapy 2004, 12, 494-503.

(43) Nicholas, A. R.; Scott, M. J.; Kennedy, N. I.; Jones, M. N. Effect of grafted polyethylene glycol (PEG) on the size, encapsulation efficiency and permeability of vesicles. Biochimica et Biophysica Acta (BBA) - Biomembranes 2000, 1463, 167-178.

(44) Perouzel, E.; Jorgensen, M. R.; Keller, M.; Miller, A. D. Synthesis and formulation of neoglycolipids for the functionalization of liposomes and lipoplexes. Bioconjugate Chemistry 2003, 14, 884-898. 
(45) Fenske, D. B.; Palmer, L. R.; Chen, T.; Wong, K. F.; Cullis, P. R. Cationic poly(ethyleneglycol) lipids incorporated into pre-formed vesicles enhance binding and uptake to BHK cells. Biochimica et Biophysica Acta (BBA) - Biomembranes 2001, $1512,259-272$.

(46) Zhang, H.; Ma, Y.; Sun, X.-L. Chemically-selective surface glyco-functionalization of liposomes through Staudinger ligation. Chemical Communications 2009, 3032-3034.

(47) Said Hassane, F.; Frisch, B.; Schuber, F. Targeted liposomes: convenient coupling of ligands to preformed vesicles using "click chemistry". Bioconjugate Chemistry 2006, 17, 849-854.

(48) Bourel-Bonnet, L.; Pécheur, E.-I.; Grandjean, C.; Blanpain, A.; Baust, T.; Melnyk, O.; Hoflack, B.; Gras-Masse, H. Anchorage of synthetic peptides onto liposomes via hydrazone and $\alpha$-oxo hydrazone bonds. preliminary functional investigations. Bioconjugate Chemistry 2005, 16, 450-457.

(49) Nakano, Y.; Mori, M.; Nishinohara, S.; Takita, Y.; Naito, S.; Kato, H.; Taneichi, M.; Komuro, K.; Uchida, T. Surface-linked liposomal antigen induces IgE-selective unresponsiveness regardless of the lipid components of liposomes. Bioconjugate Chemistry 2001, 12, 391-395.

(50) Schelté, P.; Boeckler, C.; Frisch, B.; Schuber, F. Differential reactivity of maleimide and bromoacetyl functions with thiols: application to the rreparation of liposomal diepitope constructs. Bioconjugate Chemistry 1999, 11, 118-123.

(51) Kirby, C.; Clarke, J.; Gregoriadis, G. Effect of the cholesterol content of small unilamellar liposomes on their stability in vivo and in vitro. . Biochemical Journal 1980, 186, 591-598.

(52) Kostarelos, K.; Tadros, T. F.; Luckham, P. F. Physical conjugation of (tri-) block copolymers to liposomes toward the construction of sterically stabilized vesicle systems. Langmuir 1998, 15, 369-376.

(53) Mueller, A.; O'Brien, D. F. Supramolecular materials via polymerization of mesophases of hydrated amphiphiles. Chemical Reviews 2002, 102, 727-758.

(54) Bennett, M. J.; Aberle, A. M.; Balasubramaniam, R. P.; Malone, J. G.; Malone, R. W.; Nantz, M. H. Cationic Lipid-Mediated Gene Delivery to Murine Lung: $\square$ Correlation of 
Lipid Hydration with in Vivo Transfection Activity. Journal of Medicinal Chemistry 1997, 40, 4069-4078.

(55)Wu, J.; Lizarzaburu, M. E.; Kurth, M. J.; Liu, L.; Wege, H.; Zern, M. A.; Nantz, M. H. Cationic lipid polymerization as a novel approach for constructing new DNA delivery agents. Bioconjugate Chemistry 2001, 12, 251-257.

(56) Ruysschaert, T.; Paquereau, L.; Winterhalter, M.; Fournier, D. Stabilization of liposomes through enzymatic polymerization of DNA. Nano Letters 2006, 6, 2755-2757.

(57) Lee, S.-M.; O'Halloran, T. V.; Nguyen, S. T. Polymer-caged nanobins for synergistic cisplatin-doxorubicin combination chemotherapy. Journal of the American Chemical Society 2010, 132, 17130-17138.

(58) Lee, S.-M.; Ahn, R. W.; Chen, F.; Fought, A. J.; O'Halloran, T. V.; Cryns, V. L.; Nguyen, S. T. Biological evaluation of $\mathrm{pH}$-responsive polymer-caged nanobins for breast cancer therapy. ACS Nano 2010, 4, 4971-4978.

(59) Kolb, H. C.; Finn, M. G.; Sharpless, K. B. Click chemistry: diverse chemical function from a few good reactions. Angewandte Chemie International Edition 2001, 40, 2004-2021.

(60) Hecker, J. G.; Berger, G. O.; Scarfo, K. A.; Zou, S.; Nantz, M. H. A flexible method for the conjugation of aminooxy ligands to preformed complexes of nucleic acids and lipids. ChemMedChem 2008, 3, 1356-1361.

(61) Biswas, S.; Huang, X.; Badger, W. R.; Nantz, M. H. Nucleophilic cationization reagents. Tetrahedron Letters $2010,51,1727-1729$.

(62) Antal, M.; Šimkovic, I.; Ebringerová, A.; Micko, M. M. New aspects in cationization of lignocellulose materials. IV. Modification of aspen wood meal with quarternary ammonium groups. Journal of Applied Polymer Science 1986, 31, 621-625.

(63) Haack, V.; Heinze, T.; Oelmeyer, G.; Kulicke, W.-M. Starch derivatives of high degree of functionalization, 8 . synthesis and flocculation behavior of cationic starch polyelectrolytes. Macromolecular Materials and Engineering 2002, 287, 495-502.

(64) Hebeish, A.; Hashem, M.; Abdel-Rahman, A.; El-Hilw, Z. H. Improving easy care nonformaldehyde finishing performance using polycarboxylic acids via 
precationization of cotton fabric. Journal of Applied Polymer Science 2006, 100, 2697-2704.

(65)Wang, C.; Fang, K.; Ji, W. Superfine pigment dyeing of silk fabric by exhaust process. Fibers and Polymers 2007, 8, 225-229.

(66) Futami, J.; Kitazoe, M.; Murata, H.; Yamada, H. Exploiting protein cationization techniques in future drug development. Expert Opinion on Drug Discovery 2007, 2, 261-269.

(67) Hashem, M. M. Development of a one-stage process for pretreatment and cationisation of cotton fabric. Coloration Technology 2006, 122, 135-144.

(68) El-Sakhawy, M.; Milichovsky, M. Oxycellulose modification. Polymer International $2000,49,839-844$.

(69) Hashem, M.; Hauser, P.; Smith, B. Reaction efficiency for cellulose cationization using 3-chloro-2- hydroxypropyl trimethyl ammonium chloride. Textile Research Journal 2003, 73, 1017-1023.

(70) Hyde, K.; Dong, H.; Hinestroza, J. Effect of surface cationization on the conformal deposition of polyelectrolytes over cotton fibers. Cellulose 2007, 14, 615-623.

(71) Okazaki, K.; Imoto, T.; Yamada, H. A convenient protein substrate for the determination of protease specificity: Reduced and S-3-(trimethylated amino)propylated lysozyme. Analytical Biochemistry 1985, 145, 87-90.

(72) Ott, G.; Schempp, W.; Krause, T. Kationisierung von Zellstoff unter homogenen reaktionsbedingungen. Die Angewandte Makromolekulare Chemie 1989, 173, 213-218.

(73) Grochowski, E.; Jurczak, J. A new synthesis of O-alkylhydroxylamines. Synthesis 1976, 1976, 682,684.

(74) Jones, D. S.; Hammaker, J. R.; Tedder, M. E. A convenient synthesis of $\mathrm{N}$-(tert-butyloxycarbonyl)aminooxy ethers. Tetrahedron Letters 2000, 41, 1531-1533.

(75) Berger, G. O. Liposome polymerization and applications using novel aminooxy and carbonyl lipids. University of California in Davis Thesis 2004. 
(76) Lovett, E. G. Zwitterionic quaternary ammonium alkoxides: organic strong bases. The Journal of Organic Chemistry 1991, 56, 2755-2758.

(77) Biswas, S.; Gordon, L. E.; Clark, G. J.; Nantz, M. H. Click assembly of magnetic nanovectors for gene delivery. Biomaterials 2011, 32, 2683-2688.

(78) Felgner, J. H.; Kumar, R.; Sridhar, C. N.; Wheeler, C. J.; Tsai, Y. J.; Border, R.; Ramsey, P.; Martin, M.; Felgner, P. L. Enhanced gene delivery and mechanism studies with a novel series of cationic lipid formulations. Journal of Biological Chemistry 1994, 269, 2550-2561.

(79) Regen, S. L.; Czech, B.; Singh, A. Polymerized vesicles. Journal of the American Chemical Society 1980, 102, 6638-6640.

(80) Sadownik, A.; Stefely, J.; Regen, S. L. Polymerized liposomes formed under extremely mild conditions. Journal of the American Chemical Society 1986, 108, 7789-7791.

(81) Andreana, P. R.; Xie, W.; Cheng, H. N.; Qiao, L.; Murphy, D. J.; Gu, Q.-M.; Wang, P. G. In situ preparation of $\beta$-d-1-O-hydroxylamino carbohydrate polymers mediated by galactose oxidase. Organic Letters 2002, 4, 1863-1866.

(82) Lee, Y.-G.; Koyama, Y.; Yonekawa, M.; Takata, T. New click chemistry: polymerization based on 1,3-dipolar cycloaddition of a homo ditopic nitrile $\mathrm{N}$-Oxide and transformation of the resulting polymers into reactive polymers. Macromolecules $2009,42,7709-7717$.

(83) Binder, W. H.; Sachsenhofer, R. 'Click' chemistry in polymer and materials science. Macromolecular Rapid Communications 2007, 28, 15-54.

(84) Cordes, E. H.; Bull, H. G. Mechanism and catalysis for hydrolysis of acetals, ketals, and ortho esters. Chemical Reviews 1974, 74, 581-603.

(85) Gerasimov, O. V.; Schwan, A.; Thompson, D. H. Acid-catalyzed plasmenylcholine hydrolysis and its effect on bilayer permeability: a quantitative study. Biochimica et Biophysica Acta (BBA) - Biomembranes 1997, 1324, 200-214.

(86) Thompson, D. H.; Gerasimov, O. V.; Wheeler, J. J.; Rui, Y.; Anderson, V. C. Triggerable plasmalogen liposomes: improvement of system efficiency. Biochimica et Biophysica Acta (BBA) - Biomembranes 1996, 1279, 25-34. 
(87) Anderson, V. C.; Thompson, D. H. Triggered release of hydrophilic agents from plasmologen liposomes using visible light or acid. Biochimica et Biophysica Acta (BBA) - Biomembranes 1992, 1109, 33-42.

(88) Shin, J.; Gerasimov, O.; Thompson, D. H. Facile synthesis of plasmalogens via Barbier-type reactions of vinyl dioxanes and vinyl dioxolanes with alkyl halides in LiDBB solution. The Journal of Organic Chemistry 2002, 67, 6503-6508.

(89) Shin, J.; Shum, P.; Thompson, D. H. Acid-triggered release via dePEGylation of DOPE liposomes containing acid-labile vinyl ether PEG-lipids. Journal of Controlled Release 2003, 91, 187-200.

(90) Boomer, J. A.; Qualls, M. M.; Inerowicz, H. D.; Haynes, R. H.; Patri, V. S.; Kim, J.-M.; Thompson, D. H. Cytoplasmic delivery of liposomal contents mediated by an acid-labile cholesterol-vinyl ether-PEG conjugate. Bioconjugate Chemistry 2008, 20, 47-59.

(91) Rui, Y.; Thompson, D. H. Efficient stereoselective synthesis of plasmenylcholines. Chemistry - A European Journal 1996, 2, 1505-1508.

(92) Shin, J.; Thompson, D. H. Direct synthesis of plasmenylcholine from allyl-substituted glycerols. The Journal of Organic Chemistry 2003, 68, 6760-6766.

(93) Van den Bossche, J.; Shin, J.; Thompson, D. H. Improved plasmalogen synthesis using organobarium intermediates. The Journal of Organic Chemistry 2007, 72, 5005-5007.

(94) Nordmann, G.; Buchwald, S. L. A domino copper-catalyzed C-O coupling-Claisen rearrangement process. Journal of the American Chemical Society 2003, 125, 4978-4979.

(95) Fujioka, H.; Sawama, Y.; Murata, N.; Okitsu, T.; Kubo, O.; Matsuda, S.; Kita, Y. Unexpected highly chemoselective deprotection of the acetals from aldehydes and not ketones: $\neg$ TESOTf-2,6-Lutidine combination. Journal of the American Chemical Society 2004, 126, 11800-11801.

(96) Fujioka, H.; Okitsu, T.; Sawama, Y.; Murata, N.; Li, R.; Kita, Y. Reaction of the acetals with TESOTf-base combination; speculation of the Intermediates and 
efficient mixed acetal formation. Journal of the American Chemical Society 2006, 128 , 5930-5938.

(97) Fyles, T. M.; Hu, C.-W.; Luong, H. Solid-phase synthesis of oligoester ion channels. The Journal of Organic Chemistry 2006, 71, 8545-8551.

(98) Badger, W. R. Synthesis of a cationic aminooxy lipid for pH-triggered lipoplex polymerization. University of Louisville undergraduate thesis 2009.

(99) Anelli, P. L.; Montanari, F.; Quici, S. A general synthetic method for the oxidation of primary alcohols to aldehydes (s)-(+)-2-methylbutanal. Organic Syntheses 1990, 69, 212-217.

(100) Lucio Anelli, P.; Biffi, C.; Montanari, F.; Quici, S. Fast and selective oxidation of primary alcohols to aldehydes or to carboxylic acids and of secondary alcohols to ketones mediated by oxoammonium salts under two-phase conditions. The Journal of Organic Chemistry 1987, 52, 2559-2562.

(101) Wang, M.-L.; Chang, S.-W. Synthesis of formaldehyde acetals by phase transfer catalysis. Bulletin of the Chemical Society of Japan 1993, 66, 2149-2155.

(102) Ward, W. J.; McEwen, W. E. In The Journal of Organic Chemistry; American Chemical Society, 1990; Vol. 55.

(103) Maryanoff, B. E.; Reitz, A. B.; Duhl-Emswiler, B. A. Stereochemistry of the Wittig reaction. Effect of nucleophilic groups in the phosphonium ylide. Journal of the American Chemical Society 1985, 107, 217-226.

(104) Furuta, T.; Mochizuki, M.; Ito, M.; Takahashi, T.; Suzuki, T.; Kan, T. Versatile aynthesis of head group functionalized phospholipids via oxime bond formationt. Organic Letters 2008, 10, 4847-4850.

(105) Bauer, L.; Suresh, K. S. S-[i-(aminoöxy)alkyl]isothiuronium salts, I,I'-bis(aminoöxy)alkanes and related compounds1. The Journal of Organic Chemistry 1963, 28, 1604-1608.

(106) Johnson, J. E.; Springfield, J. R.; Hwang, J. S.; Hayes, L. J.; Cunningham, W. C.; McClaugherty, D. L. Alkylation of benzohydroxamic acid. The Journal of Organic Chemistry 1971, 36, 284-294. 
(107) Amlaiky, N.; Leclerc, G.; Carpy, A. Unusual reaction of N-hydroxyphthalimido ethers leading to oxygen-nitrogen heterocycles. The Journal of Organic Chemistry $1982,47,517-523$.

(108) Rudolph, J.; Theis, H.; Hanke, R.; Endermann, R.; Johannsen, L.; Geschke, F.-U. seco-Cyclothialidines: $\neg$ new concise synthesis, inhibitory activity toward bacterial and human DNA topoisomerases, and antibacterial properties. Journal of Medicinal Chemistry 2001, 44, 619-626.

(109) Sisson, T. M.; Lamparski, H. G.; Kölchens, S.; Elayadi, A.; O'Brien, D. F. Cross-linking polymerizations in two-dimensional assemblies. Macromolecules 1996, 29, 8321-8329.

(110) Richard, A.; Barras, A.; Younes, A. B.; Monfilliette-Dupont, N.; Melnyk, P. Minimal chemical modification of reductive end of dextran to produce an amphiphilic polysaccharide able to incorporate onto lipid nanocapsules. Bioconjugate Chemistry 2008, 19, 1491-1495.

(111) Casadei, M. A.; Pitarresi, G.; Calabrese, R.; Paolicelli, P.; Giammona, G. Biodegradable and $\mathrm{pH}$-sensitive hydrogels for potential colon-specific drug delivery: characterization and In vitro release studies. Biomacromolecules 2007, 9, 43-49.

(112) Sigma-Aldrich Dextran and related polysaccharides. BioFiles 2008, 3, 17.

(113) Zhao, H.; Heindel, N. Determination of degree of substitution of formyl groups in polyaldehyde dextran by the hydroxylamine hydrochloride method. Pharmaceutical Research 1991, 8, 400-402.

(114) http://chemgroups.ucdavis.edu/ land/research_techniques/ATR.php.

(115) Sagrista, M. L.; Mora, M.; Madariaga, M. A. d. Surface modified liposomes by coating with charged hydrophilic molecules. Cellular \& Molecular Biology Letters 2000, 5, 19-33.

(116) Shi, G.; Guo, W.; Stephenson, S. M.; Lee, R. J. Efficient intracellular drug and gene delivery using folate receptor-targeted $\mathrm{pH}$-sensitive liposomes composed of cationic/anionic lipid combinations. Journal of Controlled Release 2002, 80, 309-319. 
(117) Franssen, O.; Vos, O. P.; Hennink, W. E. Delayed release of a model protein from enzymatically-degrading dextran hydrogels. Journal of Controlled Release 1997, 44, 237-245.

(118) Pitarresi, G.; Casadei, M. A.; Mandracchia, D.; Paolicelli, P.; Palumbo, F. S.; Giammona, G. Photocrosslinking of dextran and polyaspartamide derivatives: A combination suitable for colon-specific drug delivery. Journal of Controlled Release 2007, 119, 328-338.

(119) Annesini, M. C.; Braguglia, C. M.; Memoli, A.; Palermiti, L. G.; Di Sario, S. Surfactant as modulating agent of enzyme-loaded liposome activity. Biotechnology and Bioengineering 1997, 55, 261-266.

(120) Yoshimoto, M.; Wang, S.; Fukunaga, K.; Treyer, M.; Walde, P.; Kuboi, R.; Nakao, K. Enhancement of apparent substrate selectivity of proteinase $K$ encapsulated in liposomes through a cholate-induced alteration of the bilayer permeability. Biotechnology and Bioengineering 2004, 85, 222-233.

(121) Aill, D.; Mager, M.; Roche, D.; Stevens, M. M. Hybrid nanoparticle-liposome detection of phospholipase activity. Nano Letters 2010, 11, 1401-1405.

(122) Banerjee, J.; Hanson, A. J.; Nyren-Erickson, E. K.; Ganguli, B.; Wagh, A.; Muhonen, W. W.; Law, B.; Shabb, J. B.; Srivastava, D. K.; Mallik, S. Liposome-mediated amplified detection of cell-secreted matrix metalloproteinase-9. Chemical Communications 2010, 46, 3209-3211.

(123) Kim, C.-K.; Lim, S.-J. Liposome immunoassays using phospholipase $\mathrm{C}$ or alkaline phosphatase. Methods in Enzymology 2003, Volume 373, 260-277.

(124) Qu, B.; Guo, L.; Chu, X.; Wu, D.-H.; Shen, G.-L.; Yu, R.-Q. An electrochemical immunosensor based on enzyme-encapsulated liposomes and biocatalytic metal deposition. Analytica Chimica Acta 2010, 663, 147-152.

(125) Boeggeman, E.; Ramakrishnan, B.; Pasek, M.; Manzoni, M.; Puri, A.; Loomis, K. H.; Waybright, T. J.; Qasba, P. K. Site specific conjugation of fluoroprobes to the remodeled $\mathrm{Fc} \mathrm{N}$-glycans of monoclonal antibodies using mutant glycosyltransferases: application for cell surface antigen detection. Bioconjugate Chemistry 2009, 20, 1228-1236. 
(126) Nguyen, T. H.; Ferry, N. Liver gene therapy: advances and hurdles. Gene Therapy 2004, 11, S76-S84.

(127) Atta., H. M. Gene therapy for liver regeneration: Experimental studies and prospects for clinical trials. World Journal of Gastroenterology 2010, 16, 4019-4030.

(128) Warmann, S. W.; Fuchs, J.; Bitzer, M.; Lauer, U. M. Emerging gene-directed anti-tumor strategies against human hepatoblastoma. Expert Opinion on Biological Therapy 2009, 9, 1155-1161.

(129) Li, s.; Huang, L. In vivo gene transfer via intravenous administration of cationic lipid-protamine-DNA (LPD) complexes. Gene Therapy 1997, 4, 891-900.

(130) Ashwell, G.; Harford, J. Carbohydrate-specific receptors of the liver. Annual Review of Biochemistry 1982, 51, 531-554.

(131) Yao, T.; Degli Esposti, S.; Huang, L.; Arnon, R.; Spangenberger, A.; Zern, M. A. Inhibition of carbon tetrachloride-induced liver injury by liposomes containing vitamin E. American Journal of Physiology - Gastrointestinal and Liver Physiology 1994, 267, G476-G484.

(132) Arangoa, M. A.; Duzgunes, N.; Tros de llarduya, C. Increased receptor-mediated gene delivery to the liver by protamine-enhanced-asialofetuin-lipoplexes. Gene Therapy 2003, 10, 5-14.

(133) Kawakami, S.; Yamashita, F.; Nishikawa, M.; Takakura, Y.; Hashida, M. Asialoglycoprotein receptor-mediated gene transfer using novel galactosylated cationic liposomes. Biochemical and Biophysical Research Communications 1998, $252,78-83$.

(134) Zanta, M.-A.; Boussif, O.; Adib, A.; Behr, J.-P. In vitro gene delivery to hepatocytes with galactosylated polyethylenimine. Bioconjugate Chemistry 1997, 8, 839-844.

(135) Nishikawa M, Y. M., Morimoto K, Ishida E, Takakura Y, Hashida M. Hepatocyte-targeted in vivo gene expression by intravenous injection of plasmid DNA complexed with synthetic multi-functional gene delivery system. Gene Therapy 2000, 7, 548-555. 
(136) Bettinger, T.; Remy, J.-S.; Erbacher, P. Size reduction of galactosylated PEI/DNA complexes improves lectin-mediated gene transfer into hepatocytes. Bioconjugate Chemistry 1999, 10, 558-561.

(137) Wang, W.; Zhao, X.; Hu, H.; Chen, D.; Gu, J.; Deng, Y.; Sun, J. Galactosylated solid lipid nanoparticles with cucurbitacin B improves the liver targetability. Drug Delivery 2010, 17, 114-122.

(138) Wang, S.; Xu, H.; Xu, J.; Zhang, Y.; Liu, Y.; Deng, Y.-h.; Chen, D. Sustained liver targeting and improved antiproliferative effect of doxorubicin liposomes modified with galactosylated lipid and PEG-lipid. AAPS PharmSciTech 2010, 11, 870-877.

(139) Managit, C.; Kawakami, S.; Yamashita, F.; Hashida, M. Effect of galactose density on asialoglycoprotein receptor-mediated uptake of galactosylated liposomes. Journal of Pharmaceutical Sciences 2005, 94, 2266-2275.

(140) Ishida, T.; Iden, D. L.; Allen, T. M. A combinatorial approach to producing sterically stabilized (Stealth) immunoliposomal drugs. FEBS Letters 1999, 460, 129-133.

(141) Cervigni, S. E.; Dumy, P.; Mutter, M. Synthesis of glycopeptides and lipopeptides by chemoselective ligation. Angewandte Chemie International Edition in English 1996, 35, 1230-1232.

(142) Kubler-Kielb, J.; Pozsgay, V. A New method for conjugation of carbohydrates to proteins using an aminooxy-thiol heterobifunctional linker. The Journal of Organic Chemistry 2005, 70, 6987-6990.

(143) Gur'eva, L. Y.; Budanova, U. A.; Sebyakin, Y. L. Synthesis of neoglycolipids based on D-lactose. Russian Journal of Organic Chemistry 2009, 45, 173-177.

(144) Moon, K.-S.; Yang, Y.-K.; Ji, S.; Tae, J. Aminoxy-linked rhodamine hydroxamate as fluorescent chemosensor for $\mathrm{Fe}^{3+}$ in aqueous media. Tetrahedron Letters 2010, 51 , 3290-3293.

(145) Meng, F.; Zhong, Z.; Feijen, J. Stimuli-responsive polymersomes for programmed drug delivery. Biomacromolecules 2009, 10, 197-209.

(146) Onaca, O.; Enea, R.; Hughes, D. W.; Meier, W. Stimuli-responsive polymersomes as nanocarriers for drug and gene delivery. Macromolecular Bioscience 2009, 9, 129-139. 
(147) Rijcken, C. J. F.; Soga, O.; Hennink, W. E.; Nostrum, C. F. V. Triggered destabilisation of polymeric micelles and vesicles by changing polymers polarity: An attractive tool for drug delivery. Journal of Controlled Release 2007, 120, 131-148.

(148) Wang, W.; Li, R.; Gokel, G. W. "Aplosspan:" a bilayer-length, ion-selective ionophore that functions in phospholipid bilayers. Chemical Communications 2009, 911-913. 


\section{APPENDIX}

\section{LIST OF ABBREVIATIONS}

AcOH: acetic acid

BOC: N-tert-butoxycarbonyl

DBN: 1,5-Diazabicyclo[4.3.0]non-5-ene

DCC: N,N'-Dicyclohexylcarbodiimide

DCM: Dichloromethane

DIAD: Diisopropyl azodicarboxylate

DMAP: 4-Dimethylaminopyridine

DMSO: Dimethylsulfonyl oxide

DOPE: Dioleoylphosphatidylethanolamine

DOTAP: $N$-[1-(2,3-dioleoyloxy)propyl]- $N, N, N$-trimethylammonium chloride DOTMA: $N$-[1-(2,3-dioleyloxy)propyl]-N,N,N-trimethylammonium chloride DPA: Dextran polyaldehyde

eq.: equivalent

GVs: Giant Vesicles

h: Hour

HPLC: High performance liquid chromatography

HRMS: High resolution mass spectroscopy

Hz: Hertz

IR: Infrared

kbp: Kilo base pair

kD: kilo dalton

KHMDS: Potassium bis(trimethylsilyl)amide 
LBL: Layer by layer

LDA: Lithium diisopropylamide

LiMDS: Lithium bis(trimethylsilyl)amide

LUVs: Large unilamellar vesicles

mg: milligram

mL: milliliter

MLVs: Multilamellar vesicles

mmol: millimole

MW: Molecular weight

NMR: Nuclear magnetic resonance spectroscopy

pDNA: Plasmid DNA

p-TSOH: $p$-toluenesulfonic acid

PEG: Poly(ethylene glycol)

Pht: Phthaloyl

PG: Protection group

ppm: Parts per million

RF: Relative fraction

RNAi: RNA interference

rt.: Room temperature

SUVs: Small unilamellar vesicles

TBAF: Tetra- $n$-butylammonium fluoride

TBAI: Tetra- $n$-butylammonium iodide

TBS: tert-Butyldimethylsilyl

tert: tertiary

TESOTf: Triethylsilyltriflate

TFA: Trifluoroacetic acid

THF: Tetrahydrofuran

TLC: Thin layer chromatography

TMSOTf: Trimethylsilyltriflate

w/v: weight/volumn 


\title{
CURRICULUM VITAE
}

\author{
Xuan Huang
}

Lab address:

Department of Chemistry

University of Louisville

2320 South Brook St.

Louisville, KY 40292
Home address:

14310 Wedgewood $\mathrm{Ct}$

Apt 102

Tampa, FL 33613

E-mail: nushuangxuan@gmail.com

Phone: $\quad 502-210-8658$ (c)

\section{Academic Profile:}

Postdoc Research Fellow 2011 - Present

Imaging Department, Moffitt Cancer Center

Synthesis radiotracers for PET imaging

Doctoral Candidate in Chemistry, 2006 - Present

Department of Chemistry, University of Louisville, KY, USA

Cationic aminooxy lipids: synthesis, liposome stabilization and applications.

Graduate Study in Chemical Biology 2002 - 2006

Department of Chemistry, National University of Singapore, Singapore

Activity based proteomics \& microarray

Master of Science in Inorganic Chemistry, 1999 - 2002

Shanghai Institute of Nuclear Research (Current Shanhai Institute of Applied Physics), Chinese Academy of Sciences, Shanghai, China

Preparation of radioactive titanium dioxide nanoparticles and its biological properties.

Bachelor of Science in chemistry, 1995 - 1999

Wuhan University, Wuhan, China

Preparation of $\mathrm{SnO}_{2}$ powder by rheological phase-precursor reaction method. 


\section{Publications}

1. Nucleophilic cationization reagents. Tetrahedron Lett. 2010, 51, 1727-1729. Biswas, S.; Huang, X.; Badger, W. R.; Nantz, M. H

2. 'Click' Stabilized Liposomes. Huang, X. Nantz, M. H. will be submitted

3. Synthesis of aminooxy-functionalized lactose. Huang, X. Nantz, M. H. will be submitted

4. Synthesis of hydrophobic part of enol ether lipids. Huang, X. Nantz, M. H. will be submitted

5. Activity-based fingerprinting of proteases. ChemBioChem, 2006, 7, 32-36 Srinivasan, R.; Huang, X.; Ng, S.L.; Yao, S.Q.

6. Nanodroplet profiling of enzymatic activities in a microarray. Bioorg. Med. Chem. Lett. 2005, 15, 2135-2139. Uttamchandani, M.; Huang, X.; Chen, G.Y.J.; Yao, S.Q.

7. Microarrays of tagged combinatorial triazine libraries in the discovery of small molecule ligands of Human IgG. J. Comb. Chem. 2004, 6, 862-868. Uttamchandani, M.; Walsh, D.P.; Khersonsky, S.M.; Huang, X.; Yao, S.Q.; Chang, Y.T.

8. Developing photo-active affinity probes for proteomic profiling - hydroxamate-based probes for metalloproteases. J. Am. Chem. Soc. 2004, 126, 14435-14446. Chan, E.W.S.; Chattopadhaya, S.; Panicker, R.C.; Huang, X.; Yao, S.Q.

9. Recent advances in peptide-based microarray technologies. Comb. Chem. High throughput Screening 2004, 7, 547-556. Panicker, R.C.; Huang, X.; Yao, S.Q.

10. Recent Advances in Gel-Based Proteome Profiling Techniques. Mol. Biotechnol. 2004, 28, 63-76. Hu, Y.; Huang, X.; Chen, G.Y.J.; Yao, S.Q.

11. Application of microarrays in high-throughput enzyme profiling. Mol. Biotechnol. 2004, 28, 227-240. Uttamchandani, M.; Huang, X.; Chen, G.Y.J.; Tan, L.P.; Yao, S.Q.

12. Design and synthesis of fluorogenic substrates that target protein phosphatases. Tetrahedron Lett. 2004, 45, 707-710. Zhu, Q.; Huang, X.; Chen, G.Y.J.; Yao, S.Q.

13. Enzyme-targeting small molecule probes for proteomics applications. Appl. Genomics Proteomics. 2003, 2, 225-239. Huang, X.; Tan, E.L.P.; Chen, G.Y.J.; Yao, S.Q.

14. Activity-based fluorescent probes that targets phosphatases. Tetrahedron Lett. 2003 44, 2669-2672. Zhu, Q.; Huang, X.; Chen, G.Y.J.; Yao, S.Q.

15. Preparation of ${ }^{67} \mathrm{Ga}-\mathrm{C}_{60}(\mathrm{OH})_{x}$ and its biodistribution. Journal of Radioanalytical and Nuclear Chemistry 2005 265, 127-131. Li Y.; Huang X.; Liu R.; Li Q.; Zhang X.; Li W. 
16. The study of the filling behaviour of carbon nanotubes using the radioactive-trace technique. Nanotech. 2003 14, 1203-1207 Wu, S.; Guo, J.; Li, Y; Huang; X. Li, W.

17. The preparation of $\left({ }^{110 \mathrm{~m}} \mathrm{Ag}\right) \mathrm{Ag} / \mathrm{TiO} \mathrm{O}_{2}$ radioactive nano-particles. Nuclear Tech. 2003, 26, 229-232, (Chinese) Huang X.; Li Q.; Li Y.; Liu R.; Wu, S.; Li W.

18. Biodistribution of ${ }^{67} \mathrm{Ga}-\mathrm{C}_{60}(\mathrm{OH})_{\mathrm{x}}$ in mices. Nuclear Techniques 2003, 26,5, (Chinese) Li Y., Huang $X$.; Zhang $X$.; Liu R.; Zhang Y.; Li, W.

19. The study on the rasioiodination of nanometer-sized TiO2 particles. HUAXUE TONGBAO (Chemistry online) (Chinese)http://hxtb.icas.ac.cn/col/2002/c02062.htm 2002, 8. Huang X.; Li, Y.; Gao, F.; Li, Q.; Wu, S.; Li W.

20. The study on the preparation of ${ }^{67} \mathrm{Ga}-\mathrm{C}_{60}(\mathrm{OH})_{\mathrm{X}}$ J. of Nucl. Radiochem. 2002, 24, 161, (Chinese) Li, Y.; Li, Q.; Zhang, Y.; Huang, X.; Li, W.

21. Radiolabeling of fullerene derivatives and their biodistribution study. Chinese Science Abstracts 2001, 7, 919-921, (Chinese) Li, Q.; Li, Y.; Zhang, X.; Huang X.; Li W.

22. Preparation of $\mathrm{SnO}_{2}$ power by rheological phase-precursor reaction method $\mathrm{J}$. Wuhan $U$. 2000, 46, 232-233, (Chinese) Zhang, K.; Zhang, Y.; Huang X.; Yuan, L.; Sun J.

\section{CONFERENCES}

23. Chemical probes for fingerprinting of protease activity in gel- and microarray-based poteomics and their potential application in dynamic imaging of protease activity in-vivo. (Poster) Dec. 2005, Singapore. Fourth Singapore intentional chemical conference.

24. Pull down phosphatease by activity-based probe. (Poster) Dec. 2003, Singapore. Third Singapore intentional chemical conference.

25. Radiolabeling nanometer sized $\mathrm{TiO}_{2}$ and its biodistribution. (Oral) Dec. 2001, Xiamen, China. Eighth conferences on radiopharmaceutics and radiolabeling compound. 